


\section{Friends for Life \\ New partners in support of protected areas}

Edited by Jeffrey A. McNeely 



\section{Friends for Life \\ New partners in support of protected areas}

Edited by Jeffrey A. McNeely 
The designation of geographical entities in this book, and the presentation of the material, do not imply the expression of any opinion whatsoever on the part of IUCN, the Global Environment Facility (GEF) and UNEP concerning the legal status of any country, territory, or area, or of its authorities, or concerning the delimitation of its frontiers or boundaries.

The views expressed in this publication do not necessarily reflect those of IUCN or of the other funding organizations.

This publication has been made possible in part by funding from GTZ-Deutsche Gesellschaft für Technische Zusammenarbeit GmbH, GEF and UNEP.

Published by:

IUCN, Gland, Switzerland and Cambridge, UK

Copyright:

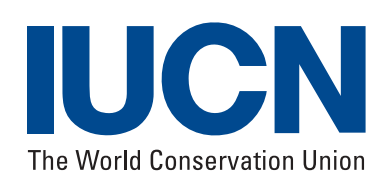

(C) 2005 International Union for Conservation of Nature and Natural Resources

Reproduction of this publication for educational or other non-commercial purposes is authorized without prior written permission from the copyright holder provided the source is fully acknowledged.

Reproduction of this publication for resale or other commercial purposes is prohibited without prior written permission of the copyright holder.

Citation:

Edited by McNeely, Jeffrey A. (2005). Friends for Life: New partners in support of protected areas. IUCN, Gland, Switzerland and Cambridge, UK. ix + 232pp.

ISBN-10:

$2-8317-0834-6$

ISBN-13:

978-2-8317-0834-8

Cover design by:

McHale Ward Associates

Cover photos:

(C) Jim Thorsell, Russell A. Mittermeier/Conservation International, Haroldo Castro/Conservation International, Thomas O. McShane (see inside back cover for details)

Layout by:

McHale Ward Associates

Produced by:

IUCN Publications Services Unit

Printed by:

Thanet Press Ltd, Margate, UK

Available from:

IUCN Publications Services Unit

219c Huntingdon Road, Cambridge CB3 0DL

United Kingdom

Tel: +44 1223277894

Fax: +44 1223277175

E-mail: books@iucn.org

www.iucn.org/bookstore

A catalogue of IUCN publications is also available.

The text of this book is printed on Fineblade Smooth 115gsm made from low chlorine pulp. 


\section{Table of contents}

\begin{tabular}{|c|c|c|}
\hline & $\begin{array}{l}\text { Foreword } \\
\text { Kenton Miller }\end{array}$ & vii \\
\hline & $\begin{array}{l}\text { Preface } \\
\text { Jeffrey A. McNeely }\end{array}$ & ix \\
\hline & $\begin{array}{l}\text { Introduction: building broader support for protected areas } \\
\text { Jeffrey A. McNeely }\end{array}$ & 1 \\
\hline 1 & $\begin{array}{l}\text { A taxonomy of support: how and why new constituencies are supporting protected areas } \\
\text { Jeffrey A. McNeely, Kent H. Redford and Assheton Stewart Carter }\end{array}$ & 11 \\
\hline 2 & $\begin{array}{l}\text { Extractive industries as a new constituency for protected areas } \\
\text { Assheton Stewart Carter }\end{array}$ & 21 \\
\hline 3 & $\begin{array}{l}\text { Urban dwellers and protected areas: natural allies } \\
\text { Ted Tryzna }\end{array}$ & 35 \\
\hline 4 & $\begin{array}{l}\text { The role of hunting in promoting protected areas } \\
\text { Kent H. Redford and Miranda Mockrin }\end{array}$ & 49 \\
\hline 5 & $\begin{array}{l}\text { Building support for protected areas using a "one health" perspective } \\
\text { Steven A. Osofsky, Richard A. Kock, Michael D. Kock, Gladys Kalema-Zikusoka, Richard Grahn, Tim Leyland } \\
\text { and William B. Karesh }\end{array}$ & 65 \\
\hline 6 & $\begin{array}{l}\text { Protected areas and the security community } \\
\text { Anne Hammill }\end{array}$ & 81 \\
\hline 7 & $\begin{array}{l}\text { Protected areas and development assistance agencies: at the intersection of conservation } \\
\text { and development } \\
\text { Thomas } O \text {. McShane }\end{array}$ & 91 \\
\hline 8 & $\begin{array}{l}\text { Protected areas and local and indigenous communities } \\
\text { Lea M. Scherl }\end{array}$ & 101 \\
\hline 9 & $\begin{array}{l}\text { Protected areas and indigenous peoples: the Durban contributions to reconciliation and equity } \\
\text { Peter Bille Larsen and Gonzalo Oviedo }\end{array}$ & 113 \\
\hline 10 & $\begin{array}{l}\text { Building cultural support for protected areas through sacred natural sites } \\
\text { Allen Putney }\end{array}$ & 129 \\
\hline 11 & $\begin{array}{l}\text { Building support for protected areas through tourism } \\
\text { Robyn Bushell }\end{array}$ & 141 \\
\hline 12 & $\begin{array}{l}\text { Making connections: the tactics, art and science of building political support for protected } \\
\text { natural areas } \\
\text { David Ostergren }\end{array}$ & 155 \\
\hline 13 & $\begin{array}{l}\text { Contribution of the World Heritage Convention to building support for the global protected } \\
\text { area system } \\
\text { Jim Thorsell }\end{array}$ & 169 \\
\hline 14 & $\begin{array}{l}\text { Communication as a means of building support for protected areas } \\
\text { Wendy Goldstein and Elisabeth Auchincloss }\end{array}$ & 177 \\
\hline \multirow[t]{4}{*}{15} & $\begin{array}{l}\text { Some conclusions and ways ahead } \\
\text { Jeffrey A. McNeely }\end{array}$ & 191 \\
\hline & Acronyms & 197 \\
\hline & List of contributors & 198 \\
\hline & References & 201 \\
\hline
\end{tabular}





\section{Foreword}

Protected areas have become part and parcel of global debates on such issues as security, human rights, genetic resources, foods and medicines, access to land and resources, social and cultural values and human heritage. Yet, while there are growing efforts to secure these areas, protected areas are also experiencing direct and indirect threats to their very survival. What must be done to protect these precious and often unique places has been debated over the past several decades since the earliest World Parks Conference in 1962. In the meantime, however, accelerating forces of change are bringing greater challenges to the protected areas management enterprise at local, national, and global levels. Climate change, rising sea levels, invasive species, changing habitats and expanding human settlements have direct impacts on existing protected areas. Current and proposed sites are facing new policies related to governance, finance and access to resources. Growing populations with increasing demands for water, food, energy and fibre, and with changing food preferences and employment needs, are creating pressures around the periphery of existing sites, resulting in what Norman Myers called "the salami treatment" where small but significant slices of protected areas are removed in favour of agriculture, forestry, mineral extraction and human settlements.

The authors of these chapters are a microcosm of the participants at the $5^{\text {th }}$ World Parks Congress who debated three pioneering and controversial issues: the rapidly evolving vision of protected areas; the kinds of integrative thinking and practice that will be needed in the coming decades; and the imperative of cooperation and agreement among protected area constituents, as well as between them and society at large, if we are to achieve secure human communities that benefit from and enjoy nature and natural resources.

The evolving vision of protected areas encompasses not only individual parks, but also areas which protect agricultural and settled landscapes and reach across national boundaries. In the past, idealistic values sufficed to justify the establishment of protected areas. Increasingly, however, well managed systems of protected areas are recognised as requirements for human wellbeing and survival, through protecting biological diversity and providing vital ecosystem

\section{by Kenton Miller}

services e.g. fresh air and water, soil, moderating climates, and buffering impacts from severe weather. Rather than being elective luxuries which only rich societies can afford, protected areas are essential components of the human enterprise in societies at all stages of development and degrees of affluence. The body of policies that lies behind this evolving vision includes the premise that achieving human security depends upon guaranteeing the security of nature itself.

Planning and managing protected areas in the 21st century will require forms of integrative thinking and practice that reach "outside of the box". For example, new social and economic thinking and practice include a focus upon the Millennium Development Goals, the Convention on Biological Diversity, the World Heritage Convention, and the Wetlands Convention (among other international agreements). These instruments now provide goals and objectives for action and investment, into which work on protected areas must be integrated. As some would say, "that is where the action is".

Integrative thinking and practice in the 21st century calls for consideration of the rights of all people, with particular concern at the present time for indigenous and local communities. Several authors have stressed that planning decisions must be based upon economic and ecological principles as well, and include corridors amongst individual areas and their surrounding landscapes. A basic concern that continues to warrant careful analysis is how to equitably share the costs and the economic, social, cultural, spiritual and other benefits derived from the "use" of protected areas. The authors stress the need for continuing research and sharing of experience on this issue.

Finally, perhaps the most profound issue emanating from the Congress is the recognition that little progress will be made in coming decades without agreements being forged on fundamental issues amongst critical constituencies. These same individuals and groups must establish new and effective ways to cooperate in taking decisions, formulating and implementing standards, evaluating progress, and deducing and sharing "lessons learned".

All of the aforementioned issues are further complicated by the growing trend towards decentralizing 
the management of protected areas, one implication of which is the challenge of sharing and disseminating effective strategies. Similarly, science and practice are generating new knowledge, yet little is being shared where it is most needed.
This book brings together, like no other, the experience and wisdom of the leading thinkers and practitioners of protected area planning and management. Jeff McNeely has long been an effective instigator of new ideas and debate related to protected areas; in this book, he successfully integrates the disparate and often complex literature and debate regarding protected areas, deducing the "lessons learned" by so many researchers, managers, teachers and local communities.

Kenton Miller (retired)

(recently, Chair, IUCN/WCPA, and Vice-President, Conservation and Sustainable Development, World Resources Institute) 


\section{Preface}

Every ten years since 1962, IUCN has worked with various partners to convene a major international conference bringing together those individuals who are working on protected areas. The first two, held in Seattle (1962) and Yellowstone and Grand Teton national parks (1972), dealt primarily with national parks. Starting in 1982, as the concept of protected areas began to spread well beyond national parks of the Yellowstone model, the Congresses have been held in developing countries. In 1982, the Congress met in Bali, Indonesia; in 1992, the Congress was convened in Caracas, Venezuela; and in 2003, the Congress gathered in Durban, South Africa (the latter was postponed for a year because of a scheduling conflict with the World Summit on Sustainable Development, also held in South Africa). Over the years, the Congresses have grown steadily, from a few dozen participants in 1962, to a few hundred in 1972, over 500 in 1982, about 2000 in 1992, and over 3000 in 2003. This growth reflects the growing international interest in protected areas and parallels the growth in numbers and extent of protected areas themselves.

As the numbers grew, so did the complexity of the meetings. The first two Congresses each produced a single volume (Adams, 1962; Elliott, 1974); the Bali meeting produced a major proceedings volume (McNeely and Miller, 1984), plus two technical volumes (MacKinnon et al., 1984; Salm and Clark, 1984), and the Caracas meeting produced a proceedings volume (McNeely, 1993), plus numerous additional volumes (McNeely, 1994; Barzetti, 1993; Amend and Amend, 1995; Harmon, 1994; Lewis, 1996; Thorsell, 1992; Kemf, 1993; Saunier and Meganck, 1995; McNeely, Harrison and Dingwall, 1994).

The Durban Congress undoubtedly will lead to even more useful products for the protected areas community, of which this book is one. It is the result of a stream of workshops held at the Congress on the broad topic of building support for protected areas. The papers each present a synthesis of considerable additional work that was reported in each of the respective workshops. The book also enlisted a contribution from a separate set of workshops, dealing

\section{by Jeffrey A. McNeely}

with communicating the benefits of protected areas, as a means of providing a more coherent picture. All of this work has also contributed to the Durban Action Plan, the Durban Accord, the recommendations of the Congress and other products (IUCN, 2005).

As one contribution among many, this book certainly does not attempt to cover all of the critical issues facing protected areas. Other volumes are expected to deal with topics such as effective management, protected areas and urban environments, economics of protected areas, completing the system of protected areas, communications (Auchincloss and Goldstein, 2004), tourism in protected areas, links to local people (Scherl et al., 2004) and building links to the numerous international conventions that are relevant to protected areas. We hope that this book will provide support to all of that work as well.

The workshops that led to this synthesis would not have been possible without the support of numerous individuals and institutions. Funding for this series of workshops came from numerous donors, led by the government of Germany through GTZ and the Global Environment Facility through the UNEP Division for GEF coordination. Shell International also contributed. Thanks also go to Conservation International and the Wildlife Conservation Society for their significant contributions. Workshop organizers included David Ostergren, Allen Putney, Ana Puyol, Kent Redford, Lea Scherl, Uday Sharma, Jason Switzer and Ted Tryzna. Secretarial support was provided by Elise Jueni and Wendy Price, and Frederik Schutyser provided administrative support to organizing the workshops. Thanks also are due to the IUCN Protected Areas Programme, including David Sheppard, Peter Shadie and Pedro Rosabal Gonzales, who were responsible for organizing the overall World Parks Congress. Sue Mainka and John Waugh provided helpful comments on the introductory chapter. Thanks also go to all the workshop contributors and participants for many fruitful meetings and discussions. Elaine Shaughnessy and Tiina Rajamets oversaw the production of the volume and helped us catch the inevitable typographical errors. To all of them we owe a great vote of gratitude. 
Government-declared protected areas have a long history. In the year $252 \mathrm{BC}$ the Emperor Asoka of India passed an edict for the protection of animals, fish, and forests, the earliest documented establishment of what we today call a protected area (Gadgil, 1989). The first nature reserve in Indonesia was established in $684 \mathrm{AD}$ by order of the king of Srivijaya, on the island of Sumatra (Schnitger, 1964). Babar, the first Moghul Emperor of India, is said to have hunted rhinos in special reserves established for that purpose in the floodplains of the Punjab during the 15th century (Gadgil, 1989). Forest reserves covering some $20 \%$ of the island were established on Tobago as early as 1764, designated as "reserved in wood for rains"; rain reserves still exist today as the oldest reserves of their kind in the world (Grove, 1992).

The modern protected area movement is generally considered to have begun with the establishment of Yellowstone National Park in the US State of Wyoming 1872, though in fact Yosemite in California was declared by the US Congress in 1864 as a nationally-recognised area of outstanding interest to the general public. Prior to Yellowstone, or even
Yosemite, colonial powers established various forms of control over resource use in South Africa, India, and other parts of their colonial empires. Protected areas grew slowly until after World War II, but postwar reconstruction, accelerating development, and rapid population increase began to put greater pressure on resources. Governments recognised that pre-war forms of conservation were inadequate, and that stronger measures were required to prevent environmental degradation. In order to meet national needs for an appropriate balance among economic growth, resource exploitation, and conservation of nature, governments over the past three or four decades have invested heavily in planning and establishing formal protected areas (Figure 1). These sites have also extended government influence into the most remote areas.

The early protected area networks grew in an ad hoc fashion, focusing on remote areas with beautiful scenery or plentiful wildlife but little value for other forms of development, or building upon the hunting or forest reserves established by local rulers or colonial administrators. More recently, as the impact of development on natural habitats has become more

\section{Figure 1}

\section{Growth of protected areas}

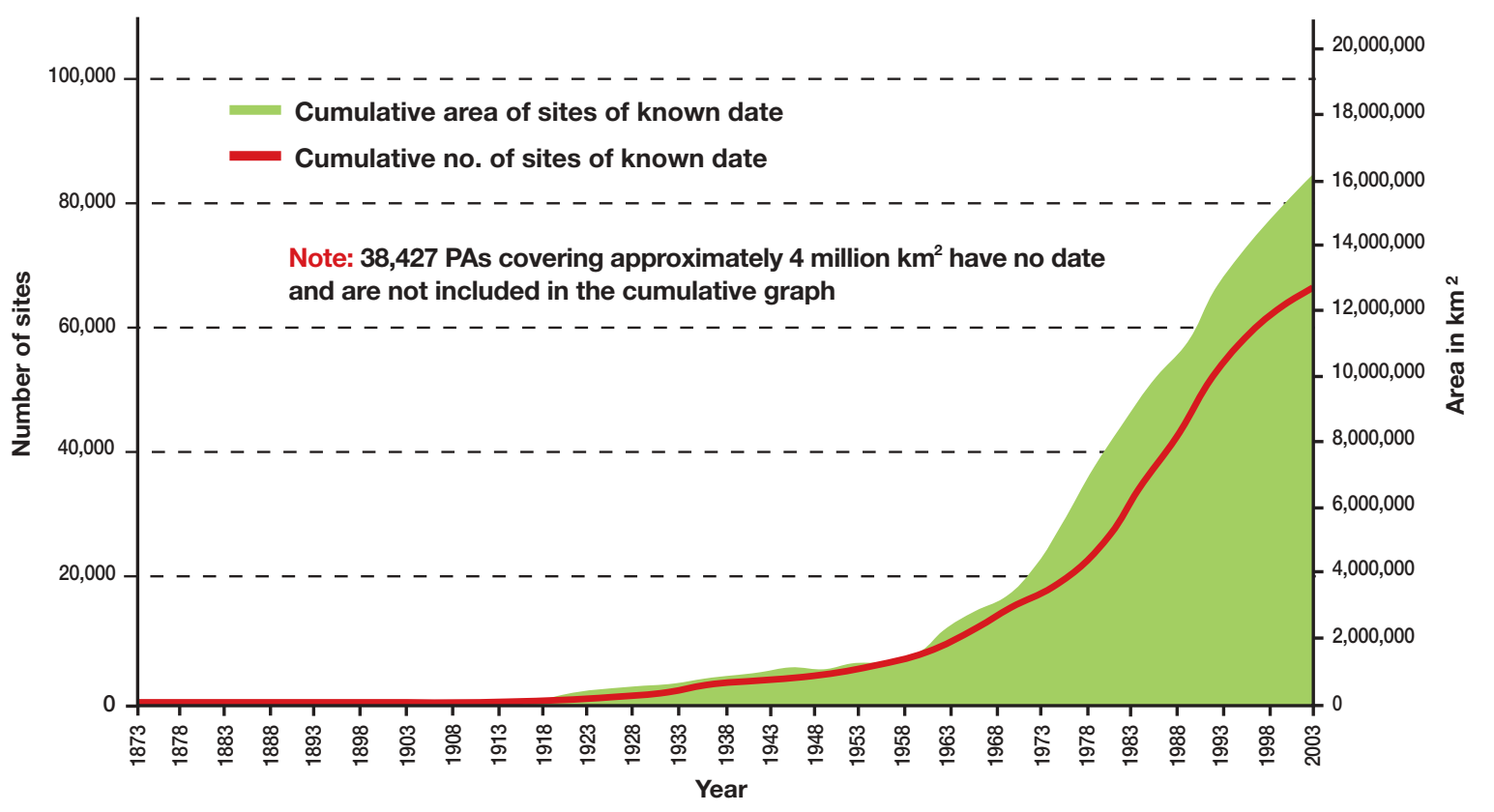


apparent, many countries have designed and established extensive protected area networks to conserve representative samples of the country's biodiversity. Indonesia, for example, established a national goal in the early 1980s of having 18 million ha protected as protected areas and 30 million ha as protection forests, to offset the 65 million ha to be used as production forest (Sudarsono and Suhartono, 1992). Now governments are looking increasingly to protected areas to provide economic opportunities both to local communities and to the nation as a whole (McNeely, 1993; CBD, 2004).

However, governments have many competing demands on their limited supplies of funds, expertise, and political capital. Meeting their national conservation objectives and obligations under international law (such as the World Heritage Convention, Wetlands Convention, and Convention on Biological Diversity) is encouraging governments to mobilize more support from more sources. This book will suggest approaches for doing so, in ways that contribute to the national interest.

A fundamental point is that protected areas are not "set aside", but rather are designated to provide or support a wide range of ecosystem services that benefit various interest groups. This introductory chapter highlights some of the development benefits of protected areas, demonstrating that this form of land use can make important contributions to human welfare (and the national economy) and describing some policy measures for delivering those benefits to various parts of society. It will provide a foundation for the main part of the book, which will provide examples of how "non-traditional" sectors - those not usually considered part of the community of protected areas supporters - are already supporting protected areas and can be encouraged to be even stronger partners in the future.

\section{The benefits of protected areas}

As defined by the Convention on Biological Diversity, "protected areas" are geographically defined areas which are designated or regulated and managed to achieve specific conservation objectives. Several other definitions are also widely used, including that of IUCN (1994): "Areas of land and/or sea especially dedicated to the protection and maintenance of biological diversity, and of natural and associated cultural resources, and managed through legal or other effective means." Protecting natural areas is no longer seen as a process of eliminating people from the land, but rather of integrating conservation objectives and human activities in an appropriate manner that assures the future of both people and the rest of nature. While some areas are so fragile or important that human influences must be minimized or excluded completely, many others achieve conservation objectives while enabling appropriate uses by people, ranging from tourism to sustainable use of some renewable resources.

Protected areas are of crucial, and growing, importance because they help to maintain the diversity of ecosystems, species, genetic varieties and ecological processes (including the regulation of water flow and climate) which are essential for supporting all life on Earth and for improving human social and economic conditions. They do this by protecting genetic varieties and species which are vital in meeting human needs, for example in agriculture and medicine, and providing the basis for human social and cultural adaptation in an uncertain and changing world. In some countries, protected areas also are home to communities of people with traditional cultures and irreplaceable knowledge of nature.

In short, well-designed and managed protected areas can provide major direct and indirect benefits to local and national economies (McNeely, 1994; Terborgh et al., 2002).

Protected areas are needed in order to safeguard biological diversity and other ecological services in their own right and as assets for the future. Indeed, they are potentially the most effective form of land use in many settings, in economic as well as ecological terms. The fact that virtually all countries have established protected areas indicates government commitment to ensuring that this generation passes on to future generations a world that is at least as diverse and productive as the one we enjoy today. 
Recognising the need for a range of approaches to protected areas, from strict protection to sustainable use, IUCN (1994 and 2004) has devised a system of protected area categories based on objectives for management (Box 1). Although national parks by definition need to be protected against resource harvesting on a commercial scale, other categories of protected areas - such as species management areas, protected landscapes, and managed resource protected areas - can be established around the strictly protected areas to prevent them from becoming biologically impoverished islands, or can stand by themselves to make important contributions to systems of land management. Several of these categories of protected area can include sustainable utilization of renewable resources as a management objective, to conserve biological diversity, provide sustainable benefits to local human communities from the use of those resources, and maintain significant cultural relationships between people and the rest of nature. For example, IUCN Category V and Category VI can be used for protecting traditional forms of agriculture, as an integral part of a national protected area system. A critical point here is for each protected area to have a management plan that defines "sustainable use" - whether consumptive or nonconsumptive - in practical terms relevant to the particular site.

\section{Box 1}

\section{The IUCN system of protected area categories}

I. Strict Nature Reserve/Wilderness Area. Areas of land and/or sea possessing outstanding or representative ecosystems, geological or physiological features and/or species, available primarily for scientific research and/or environmental monitoring; or large areas of unmodified or slightly modified land, and/or sea, retaining their natural character and influence, without permanent or significant habitation, which are protected and managed so as to preserve their natural condition.

II. National Park: Protected Areas Managed Mainly for Ecosystem Conservation and Recreation. Natural areas of land and/or sea, designated to (a) protect the ecological integrity of one or more ecosystems for this and future generations, (b) exclude exploitation or occupation inimical to the purposes of designation of the area, and (c) provide a foundation for spiritual, scientific, educational, recreational and visitor opportunities, all of which must be environmentally and culturally compatible.

III.Natural Monument: Protected Areas Managed Mainly for Conservation of Specific Features. Areas containing one or more specific natural or natural/cultural feature which is of outstanding or unique value because of its inherent rarity, representative or aesthetic qualities or cultural significance.
IV. Habitat/Species Management Area: Protected Areas Managed Mainly for Conservation Through Management Intervention. Areas of land and/or sea subject to active intervention for management purposes so as to ensure the maintenance of habitats and/or to meet the requirements of specific species.

V. Protected Landscape/Seascape: Protected Areas Managed Mainly for Landscape/ Seascape Conservation and Recreation. Areas of land, with coast and sea as appropriate, where the interaction of people and nature over time has produced an area of distinct character with significant aesthetic, cultural and/or ecological value, and often with high biological diversity. Safeguarding the integrity of this traditional interaction is vital to the protection, maintenance and evolution of such an area.

VI.Managed Resource Protected Area: Protected Areas Managed Mainly for the Sustainable Use of Natural Ecosystems. Areas containing predominantly unmodified natural systems, managed to ensure long term protection and maintenance of biological diversity, while providing at the same time a sustainable flow of natural products and services to meet community needs. 


\section{Ecosystem services from protected areas}

Protected areas provide significant ecological services to local communities, the nation, and the international community. A list of some of these services and the functions they carry out is presented in Box 2 . Particularly important services at the community level include soil regeneration, nutrient cycling, pollination, recreation, regulation of disease (Osofsky et al., this volume), provision of pure water, and maintenance of the functioning ecosystem which yields harvestable resources, and cultural services such as a sense of place (MEA, 2003). Such benefits are often difficult to quantify, and even local people may take them for granted. Ecological services do not normally appear in corporate or national accounting systems, but they far outweigh direct values when they are computed; one review estimated that coastal ecosystems provide services worth over US $\$ 4,000$ per ha per year, while per hectare annual values of tropical forests are placed at US $\$ 3,000$, wetlands at nearly US $\$ 15,000$, and lakes and rivers at US\$8,500 (Costanza et al., 1997).
While virtually all ecosystems provide at least some of the listed services, protected areas where biologically diverse ecosystems remain intact are likely to be particularly valuable (e.g., Tilman et al., 1997; Hooper and Vitousek, 1997; MEA, 2003).

One of the most important ecosystem services, especially in view of the major investments in water resource management, is the stabilizing of hydrological functions. As an example of economic costs of poorly-managed watersheds, in the USA, about 880 million tons of agricultural soils are deposited into reservoirs and aquatic systems each year, reducing their flood-control benefits, increasing operating costs of water treatment facilities, clogging waterways, and shortening the lives of dams. The annual damages to water storage facilities from sediments carried by water erosion in the US amounts to US\$841 billion per year, with another $\$ 683$ billion in damage to navigable waterways, \$2 billion in damage to recreational facilities, and \$1 billion for other in-stream uses (Pimentel et al., 1995). Watersheds whose functions are stabilized by protected areas could greatly reduce such damages and provide significant economic benefits.

\title{
Box 2
}

\section{Ecosystem services: The benefits people obtain from ecosystems}

\begin{tabular}{|c|c|c|}
\hline Provisioning & Regulating & Cultural \\
\hline $\begin{array}{l}\text { Goods produced or } \\
\text { provided by ecosystems }\end{array}$ & $\begin{array}{l}\text { Benefits obtained from } \\
\text { regulation of ecosystem processes }\end{array}$ & $\begin{array}{l}\text { Non-material benefits } \\
\text { from ecosystems }\end{array}$ \\
\hline $\begin{array}{c}\text { food } \\
\text { fresh water } \\
\text { fuelwood } \\
\text { genetic resources } \\
\text { biochemicals }\end{array}$ & $\begin{array}{l}\text { climate regulation } \\
\text { disease regulation } \\
\text { flood regulation } \\
\text { water purification } \\
\text { pollination }\end{array}$ & $\begin{array}{c}\text { spiritual } \\
\text { recreational } \\
\text { aesthetic } \\
\text { inspirational } \\
\text { educational } \\
\text { cultural heritage }\end{array}$ \\
\hline
\end{tabular}

\section{Supporting}

Services necessary for production of other ecosystem services

\author{
Soil formation \\ Nutrient cycling \\ Primary production
}




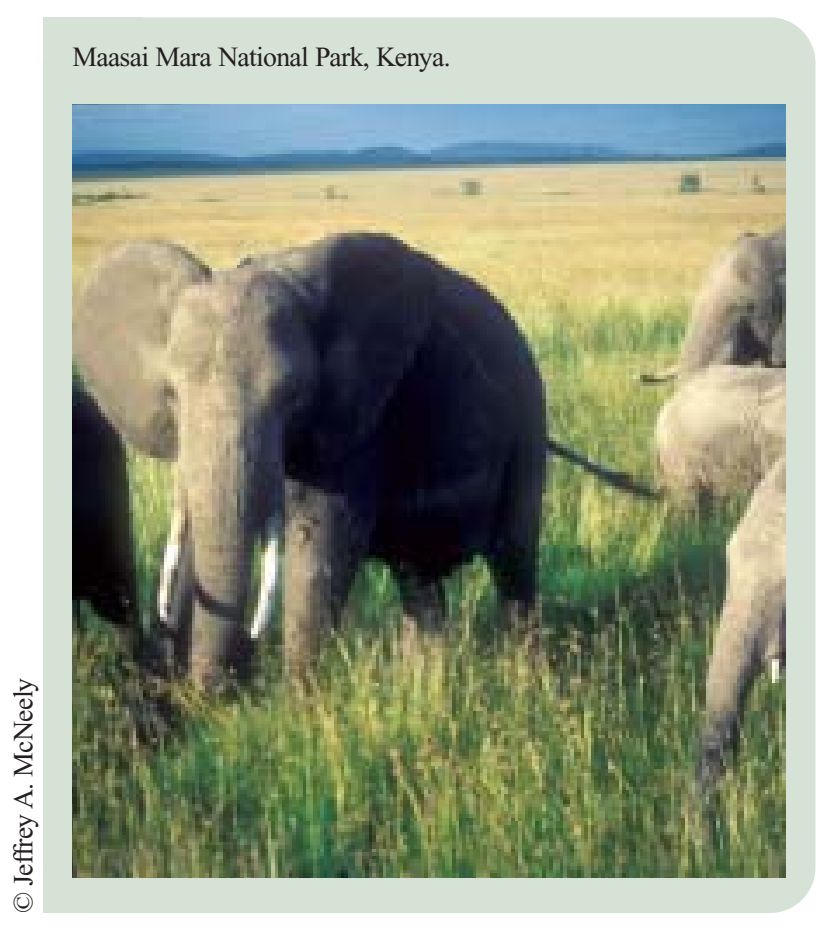

Experience from various parts of the world demonstrates that protected areas are a cost-effective management option for maintaining healthy watersheds that produce a steady and reliable source of water. For example, 7600 ha of cloud forest in the La Tigra National Park in Honduras provide the capital city of Tegucigalpa with $40 \%$ of its drinking water at a cost of about 5\% of its second largest source; Guatopo National Park in Venezuela provides 20,000 litres per second of high-quality water to Caracas, justifying an expenditure of over US $\$ 15$ million to buy out timber and farming interests in the area; and the value of the hydroelectricity produced by Venezuela's Canaima National Park (3 million ha) is equivalent to 144 million barrels of oil per year, about US\$7.2 billion at the current price (Garcia, 1984).

Allocating protected areas can bring significant changes in the remote areas where many such areas are designated. The people living in those areas have long depended on the natural resources that are available there. Experience and logic indicate that local communities are likely to support protected areas to the extent that such areas continue to provide benefits to them, especially in the form of continued availability of the resources such areas produce (in other words, emphasising the provisioning service of protected areas). Commodities such as animal skins, bamboo, beeswax, construction materials, dyes, fibres, firewood, fish, fodder, fruits, game meat, gums, honey, medicinal plants, mushrooms, ornamentals, resins, and timber have been harvested sustainably for thousands of years. The local people have often developed mechanisms for managing these resources and allocating the benefits among the community, though history shows that some resources were over-exploited to the detriment of the community (Diamond, 2005; Edgerton, 1992; Le Blanc, 1999).

Tourism, which can be seen as a cultural service, is undoubtedly the most well-known economic value of protected areas, providing a source of cash income to numerous stakeholders at local, national, and international levels (Bushell, this volume). A particular challenge is involving local communities, who quite accurately view visitors as often having very different cultures, lifestyles, and perspectives than their own, and may disrupt the local economy. Many local communities may have their own perspectives on the kinds of activities that may be appropriate for visitors, while many visitors remain oblivious to these perspectives (Scherl, this volume; Larsen and Oviedo, this volume).

Tourism from protected areas can bring considerable income, without threatening the natural resource base (if properly managed). In Kenya, tourism is one of the largest export industries, earning over US $\$ 400$ million per year; thousands of jobs exist because of the tourists visiting Kenya's magnificent coast and wildlife parks. Divers spend about \$30 million per year at the Bonaire Marine Park in the Netherlands Antilles, \$14 million in protected areas in the British Virgin Islands, over \$53 million per year in marine protected areas in the Cayman Islands, and \$23 million in Virgin Islands National Park in St. John's (OAS/NPS, 1988).

Tourists are willing to pay for the benefits they receive from protected areas. For example, the US National Park Service has reported that despite a doubling in admission fees at many of its facilities, to $\$ 10$ for a carload from $\$ 5$ in 1996, 112 million people visited the 374 federal parks, monuments and historic sites during the first six months of 1997 - an increase of $4.7 \%$ over the same period in 1996. A recent study of selected protected areas in Australia showed 
tourism revenues of $\mathrm{A} \$ 2$ billion, as compared to a management budget of A $\$ 60$ million (Driml, 1994). While these examples are from industrialized countries, visitation rates in many parts of the developing world are similarly high (see Bushell, this volume, for a further discussion).

\section{A word of caution}

Economic assessments of the full range of the ecosystem services protected areas provide are part of the global move toward a market economy. This economic valuation is broadly endorsed by governments, but it can have negative impacts on the way that resources are managed. By transforming non-monetary values into monetary ones, land, labour, and nature become commodities rather than part of the cultural heritage that binds the members of the community to one another (Alcorn, 1997). Overreliance on economic valuation, without considering the broader social, cultural, and ethical justifications of protected areas, can be very misleading. As Leopold (1949) has pointed out, "A system of conservation based solely on economic self-interest is hopelessly lopsided. It tends to ignore, and thus eventually eliminate, many elements in the land that lack commercial value but that are essential to its healthy functioning. It assumes that the economic parts of the biotic clock will function without the uneconomic parts". Protected areas are essential to keep the biotic clock ticking.

\section{Involving local people}

A particularly dramatic new force at the 2003 World Parks Congress was the new-found assertiveness of the people who are living in and around protected areas. The indigenous and local groups represented at Durban pledged support for protected areas and expressed their wish to be considered as stewards of the land (see Putney, this volume; Scherl, this volume; Larsen and Oviedo, this volume).

Some people remain pessimistic about gaining local support for protected areas, at least in the early stages of establishment. This holds for both the wealthy industrialized countries and the rest of the world as well. For example, Terborgh et al. (2002) conclude that, "Experience shows that parks become cherished national treasures only after they have existed long enough to acquire popular constituencies. In the formative stages, nearly all parks are established against fierce local opposition". They also contend that the survival of nature "almost uniquely in parks is inevitable where there are no firm mechanisms in place to prevent unprotected wild lands from being converted to human use".

A common way of trying to earn support from local people is to link development projects to the protected areas, in what are often called "integrated conservation and development projects." But these have not been as successful as hoped (McShane, this volume). And even when a new protected area is successful in generating economic benefits, other problems may arise, for example, through attracting people from other parts of the country to settle in and around the protected area. For example, Ericson et al. (1999) found that rapid population growth, primarily attributed to a dramatic rate of in-migration, threatens the long-term viability of the Calakmul Biosphere Reserve in Yucatan, Mexico.

Providing economic benefits to local people may seem to be an obvious solution to conflicts, but the solution is often somewhat problematic, due at least partly to the vagaries of politics and economics. In most situations, only a relatively small proportion of the neighbouring community derives financial benefits from tourism or other revenue-earning activities, and the income per capita is relatively low. Thus conservation efforts based solely on material benefits are often highly uncertain.

Although nature and people have co-existed for thousands of years, the increasing population, more sophisticated technology, and changing social, economic and political structures of today have removed most traditional controls on how resources are harvested. If sustainable benefits are to be provided to local communities (a primary objective of development) and to the nation at large, more effective controls may be required to ensure that populations of plants and animals are maintained at productive levels. The means of doing this will vary from place to place, but the foundations must be built on sound economic and ecological principles. Establishing 


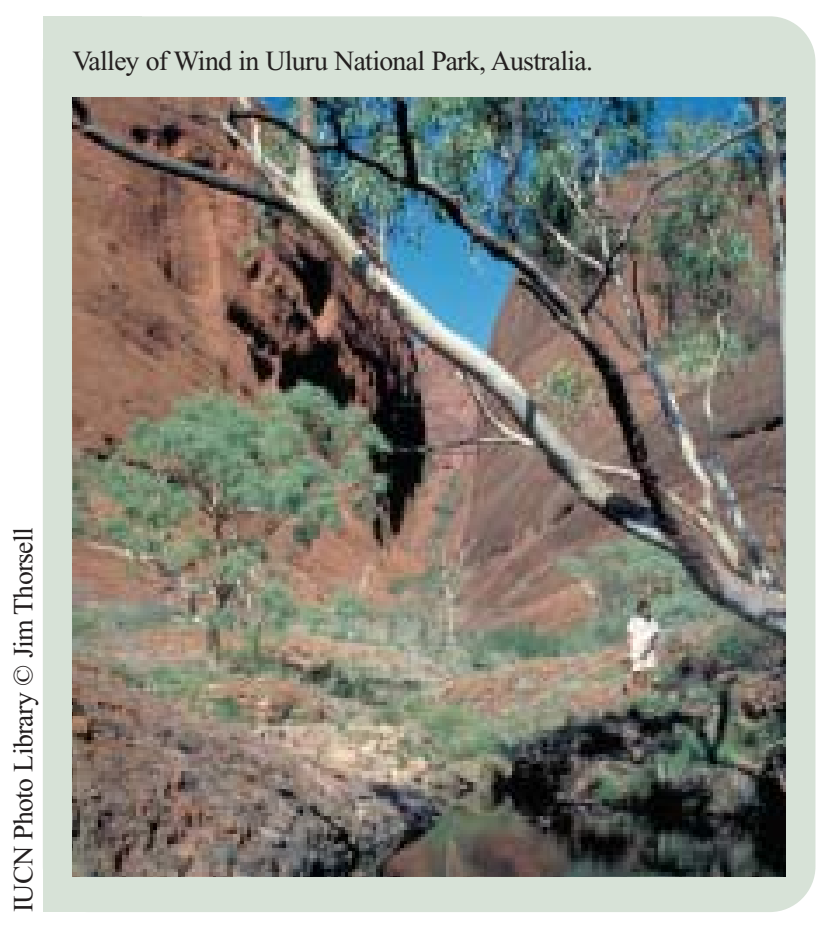

well-managed protected areas may provide new approaches to resource management based on sustainable use, thereby restoring at least part of the balance that has enabled human populations to survive.

\section{The current forces affecting protected areas}

As expressions of social and political choices about land use, protected areas are subject to the multiple forces affecting the relationship between people and resources. These forces can be positive or negative, or both simultaneously. Typically, the provisioning service has had the greatest influence on convincing decision makers to take an active interest in conservation. But abundant evidence has now demonstrated the close links between the conservation of healthy terrestrial and marine ecosystems and the delivery of regulating, cultural, and supporting services. Some local communities and urban dwellers show willingness to pay for such ecosystem services and to adopt land use and crop production systems that can support the protected areas; others are indifferent, or would prefer protected areas to be converted to "more productive" uses.

Even today, as security concerns dominate social and political agendas (Hammill, this volume), many countries are still creating new protected areas and seeking innovative ways to address protected area problems. The latest compilation of global protected areas indicates that the area of terrestrial protected areas has now almost reached the $12 \%$ aspired to by the 1987 report of the World Commission on Sustainable Development (Brundtland, 1987). But significant management challenges remain, as many of the newly-established protected areas remain "paper parks", little more than lines drawn on a map without a supporting management capacity, and many are found in remote mountain areas with few alternative uses while biologically important lowland areas remain unprotected. Positive forces of change include the implementation plan from the 2002 World Summit on Sustainable Development, which defined targets in key areas that re-commit the world community to the earlier Agenda 21 promises of the Earth Summit and the Millennium Development Goals (MDGs). Perhaps more important is the renewed commitment to stop biodiversity loss and to support the role of protected areas in doing so, through various governmental, intergovernmental, private sector, and non-governmental organizations. The approval by the Convention on Biological Diversity's 2004 Conference of Parties of a detailed Programme of Work on Protected Areas is especially notable in this regard.

The increased recognition of protected areas as potential tools for economic development is another reason why more are being established. But this also means that more protected areas are competing for limited funds, as both official development assistance (ODA) and tourism income remain stagnant, if not declining in many countries. Poverty may push people to invade protected areas to use wild products, possibly unsustainably, while greater wealth may lead to even more exploitation of natural resources. Is wealth or poverty the greater negative impact?

Demographics remain a driving force affecting protected areas, with nearly 80 million people being added to our planet each year, mostly in developing countries. Migration and urbanization are particular challenges (see Tryzna, this volume). Today, about half of the world's 6.3 billion people live in cities, well insulated from the realities of nature (except, of course, from the climate). But one arguably positive result of expanding population is that tourism to 
protected areas continues to grow. China alone welcomes one billion visitors annually to its protected area system, and countries such as Australia, Botswana, Canada, Costa Rica, Ecuador, Kenya, Nepal, South Africa, and Tanzania, have made naturebased tourism an important part of their national economies, and recognise the role of protected areas in supporting this industry.

Civil society is accelerating its contributions to protected areas. Non-governmental conservation organizations have become multinationals in their own right. Fauna and Flora International, WWF, The Nature Conservancy, Conservation International, BirdLife International, Wetlands International, the Wildlife Conservation Society, and numerous others, are together spending hundreds of millions of dollars annually in both developed and developing countries in support of protected areas. At the national level, numerous other civil society organizations are also having significant influences on protected areas, reflecting the interests of local people, indigenous groups, urban dwellers, farmers, students, and many others.

The private sector continues to contribute to protected areas, running concessions, providing financial support, and seeking forms of sustainable development that will contribute to both conservation and corporate profits; other activities of the private sector may threaten protected areas. Even though the world economy is struggling, new developments in information technology (IT) offer interesting potentials for protected areas. First, an enhanced and less expensive internet is strengthening knowledge and access to it, which in turn is contributing to building awareness and skills. Second, IT is promoting action by civil society, providing benefits to protected areas by way of support to co-management, political mobilization, and independent monitoring. Finally, some of the wealth generated by the IT sector is finding its way into various foundations which may also provide funding for protected areas. On the negative side, virtual reality has begun to replace nature as the source of experience; watching a flock of flamingos take wing from the floor of Ngorongoro Crater is very different from doing so vicariously through the miracles of modern IT.
Climate change remains a significant threat, and not only for island and coastal systems projected for flooding as icecaps and glaciers melt. Based on the projections prepared by the Intergovernmental Panel on Climate Change, many of the major vegetation types in various parts of the world are predicted to undergo significant biogeographical changes as they shift to follow patterns of rainfall and temperature. This is likely to be particularly dramatic in mountain areas and in highly distinctive but geographically restricted vegetation types, such as South Africa's Succulent Karoo and Fynbos.

Thus the current social, economic, political, and environmental forces affecting protected areas, of which the above is a small sample, are a complex combination of positive and negative influences, providing rewards with one hand while punishing with the other, handing out benefits to some and costs to others. The overall picture is one of increasing demands for the goods and services of protected areas, against growing threats to the ecosystems which provide those goods and services on a sustainable basis. All of this is coupled with the pressure on many governments to expand their protected area systems at a time when many rural people are clamouring for their rights to occupy these same lands, often with considerable historical justification. Oil, gas, and mining companies also seek to harvest certain resources while minimizing their impact on others (Carter, this volume). It is against this complex background of chaos, change, and challenge that this book has sought to identify a stronger constituency for protected areas. 
Friends for Life: New partners in support of protected areas 


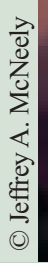 \\ A taxonomy of support: how and why new constituencies are supporting protected areas}

\section{by Jeffrey A. McNeely, Kent H. Redford and Assheton Stewart Carter}

\section{Editor's introduction}

A balanced approach to protected area management requires many institutional players to participate in strengthening a nation's network of protected areas, so that it can deliver benefits at levels from local to global. Strengths of a balanced approach include a fully-represented set of stakeholders, a clear set of agreed-upon goals and strategies, and more effective management of protected areas. Dangers to be avoided include governments abandoning their responsibility for the system's management under the guise of privatization; reduced protection of core areas in the forlorn hope that buffer zone management and local development will reduce threats to strictly protected core zones; and inappropriate levels of local control over nationally or internationally important resources. This paper introduces many of the issues that will be considered in further detail in subsequent chapters. 


\section{Introduction}

Protected areas represent one of the most important tools in the toolbox of sustainable living. From their early start as sacred groves and hunting gardens through their modern appearance as national parks, such areas allow humans to ensure the long-term survival of large portions of the natural world and provide numerous benefits to society. Despite, or perhaps because of, their importance, the long-term success of protected areas cannot be taken for granted. Though it is complicated to establish protected areas, establishment has proven substantially easier than ensuring that they are well managed, strongly endorsed, and sustainably financed.

Protected areas are spaces identified and declared through a political process and their success requires the on-going support of a broad range of social actors (Redford et al., 1998). Decades of experience across all continents, involving thousands of sites, have shown that a key component to achieving the longterm success of protected areas is involving a broad range of institutions and interest groups (McNeely, 1995). To date the support base for protected areas has been too narrow and instead of broadening this base, many potential allies have been alienated. As the world becomes increasingly integrated economically and increasingly dominated by humans, it is essential to build alliances and involve the constituencies who can agree on the critical values of protected areas and ensure that these values are maintained. In order to accelerate the process this book will present synthesis papers that show how various social and economic sectors can contribute to protected areas involving a set of potential allies.

Important efforts around the world are seeking to incorporate these different constituencies and some preliminary results are available to assess the robustness of the new alliances across ecological and political settings. As the protected area estate continues to expand faster than protected area budgets, new partners are required to enable countries to achieve their biodiversity conservation objectives. Such new constituencies will often imply trade-offs that require careful consideration. This book will discuss options for new partnerships, especially with the private sector, leading to guidelines for enhancing support to protected areas from new partners.

\section{Involving the private commercial sector}

The private commercial sector can make numerous contributions to protected areas. The most obvious is financial support, but the private sector can also ensure that its activities around protected areas are consistent with the objectives of the protected area, provide management expertise, lobby governments in support of protected areas that are providing important goods and services to the respective enterprise (for example, clean water or tourist destinations), and contribute to broader public support.

Attracting private sector support for protected areas will be facilitated by identifying and prioritizing specific investment opportunities that can be targeted for private sector financing. Efforts should be made to create biodiversity investment opportunities that will appeal directly to the financial instincts of the various interests within the private sector, ranging from tourism to energy to genetic resources. If suitable incentives can be provided to enterprises to assume a certain degree of financial risk, a wide range of private investments could be secured by protected area managers. Encouraging investment will require an accessible framework for providing information, structuring negotiations, and ensuring project security. While the market itself may be able to regulate financially-viable investments, for high-risk investments some sort of claim certification must be provided; one possibility might be a national environmental foundation or trust that could provide this sort of secure framework (Sitanon and Markopoulos, 1996).

While the market system is already providing a range of benefits, it is also leading to over-exploitation in many cases and considerable challenges face those who are seeking to achieve sustainable use. Thus expanding the role of the private commercial sector in protected areas carries some risks, including inappropriate commercialization, lack of long-term commitment, and quality control.

The critical factor in enabling the private commercial sector to contribute more effectively to protected areas is for governments to devise policy 
frameworks appropriate to their country that will allow consistent and realistic goals to be developed and met, with a clear distribution of costs and benefits; for example, tax breaks or other economic incentives for contributions to protected areas could generate greater private sector support. Because countries are highly diverse in size, complexity, ideology, and economic orientation, region-wide policies may tend to be very general. As pointed out by the Convention on Biological Diversity, each government needs to determine for itself how best to carry out the broad objectives for which protected areas have been established, and how it wishes to involve the private sector. But it is clear that such policies must be based on an integrated view of the economy, society, and the environment, incorporating good science and assessment of risk and an appropriate balance of ecological, economic, and social objectives.

\section{Genetic resources}

Protected areas potentially can provide benefits in the form of genetic resources to the pharmaceutical, biotechnology, agrochemical, seed, horticulture, cosmetic, and phyto-medical markets, but these different markets give rise to a wide range of approaches to benefit-sharing. Creating expensive bureaucratic regulatory systems, for example to implement the genetic resources provisions of the Convention on Biological Diversity (Articles 15 and 16), could act as a disincentive to investment by the industries that have the greatest potential interest in the biological resources held by protected areas. One approach is through the use of intermediaries, including botanic gardens, universities, research institutions, NGOs, and even commercial brokers who will collect, identify, and guarantee re-supply of promising materials, acquire government approval for collections, broker benefit-sharing agreements, and

\footnotetext{
Weyerhaeuser Company tree farm in the Pacific Northwest, USA near the Mount Saint Helens National Park. Weyerhaeuser plants more than 100,000,000 tree seedlings each year around the world.
}

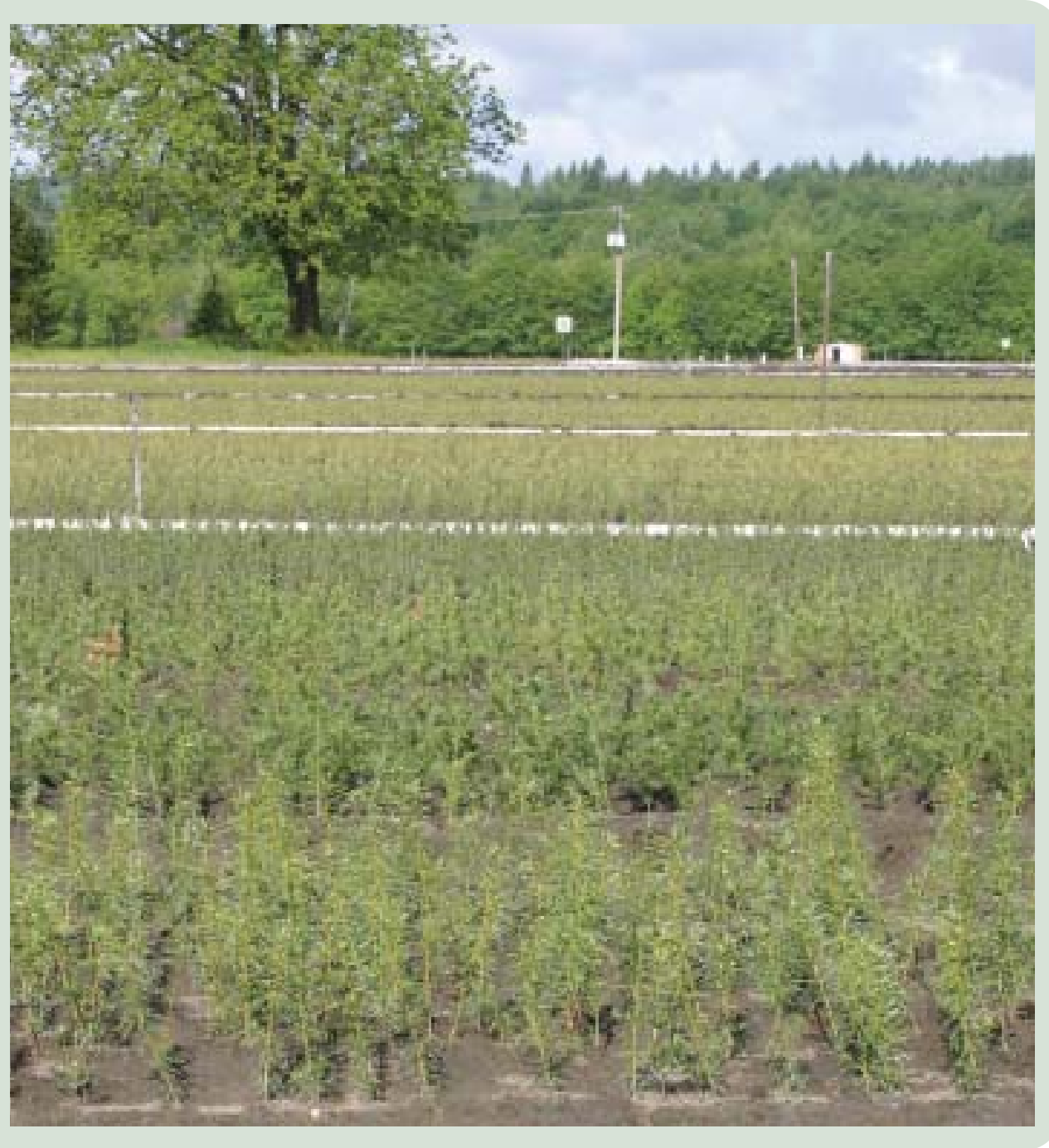


ensure that any benefits arising are shared fairly and equitably in the source country. Benefits are likely to be maximized when the governments create incentives for new, varied and equitable partnerships based on the use of biological resources. One advantage of modern biotechnology is that only modest amounts of living materials, sometimes only a few grams, are required to capture the genes necessary for research and development, ensuring a negligible impact on the protected areas where such collecting is permitted (Prescott-Allen and Prescott-Allen, 1984).

\section{Oil, gas and minerals}

As global demand grows for energy and minerals, mining, oil and gas exploration is expanding into some of the world's most fragile ecosystems within or near to the boundaries of protected areas (Rössler, 2000). This trend, while promising significant economic opportunities for both companies and host governments, brings with it risks to important biodiversity. Energy and mining companies are often economic pioneers in relatively undeveloped areas and their presence can lead to further economic and social activities, including migration, spontaneous settlement, agricultural conversion and infrastructure development that put additional pressure on natural resources and can cause even more harm to biodiversity.

Technological advances have led to a vast improvement in environmental management at mining and oil and gas projects and many potential environmental impacts can now be overcome. Companies do have limits to their ability to manage impacts outside of their concessions, and forming partnerships with conservation organizations can help them expand their scope for benefiting biodiversity.

Governments and NGOs concerned about biodiversity conservation, development opportunities for local communities, and rights of indigenous people are paying greater attention to companies choosing to operate in or near protected areas. In 2000, the IUCN World Conservation Congress recommended that 'IUCN's State members .... Prohibit by law, all exploration and extraction of mineral resources in protected areas corresponding to IUCN Protected Area Management Categories I-IV'.
This pressure can result in access to reserves being denied or restricted and opposition from local communities constraining production operations. For example, Shell production in Nigeria was cut to $40 \%$ of capacity due to opposition and sabotage from local communities (Austin and Sauer, 2002).

As both the protected area system and mineral exploration continue to expand, areas of potential conflict are also likely to increase and the case for the conservation community to engage the extractive industries becomes more compelling.

The long-term nature of oil, gas, and mineral development projects presents an opportunity for companies and civil society organizations to work in partnership to mobilize resources and together direct their efforts towards conservation within an appropriate time scale. Socially responsible energy and mining companies can demonstrate their commitment to support protected areas by catalysing the involvement of government agencies, conservation and development organizations, and communities to stem the decline of biodiversity through systematic planning at a regional scale. Careful planning can accommodate both the biodiversity values of protected areas and the need for economic development from mineral extraction. Because hydrocarbon and mineral development projects have a life of many decades, it is possible for much of the initial harm done to biodiversity to be ameliorated. In some cases, benefits to biodiversity may even be enhanced; for example, companies can manage their concession as de facto protected areas. Moreover, conservation efforts initiated or championed by a company can benefit from a sustainable flow of funding and political support.

\section{Hunting/fishing}

The luxury market for consumptive use of certain charismatic mammals, birds and fish is increasing. Trophy and sport hunters and fishers are willing to pay large sums to be able to obtain a lion, mountain sheep, ocellated turkey, tarpon, or steelhead trout. Often the animal population from which the hunted/fished individual is obtained is found in or near a protected area and all too often none of the money paid by the hunter returns to help ensure the 
protection of the source population. The same pattern is true for local communities whose cooperation is often essential to maintain the wildlife populations. In both cases, hunting and fishing organizations are important new constituencies in ensuring both sustainable businesses and conservation, in protected area categories where such use is permitted (Categories IV, V and VI) (Lewis and Alpert, 1997).

\section{Forestry}

In many parts of the world, protected areas are surrounded by forest lands designated for logging or being logged. In most of these forests the practices used by forestry companies are actively detrimental to the conservation values of the neighbouring protected area, either through interruption of ecological processes such as waterflow and stream pollution, direct loss of animal species through hunting, or cutting and/or destroying of trees essential for feeding and nesting of animals with essential resources located beyond park boundaries (Putz et al., 2000). With the rise of forest certification, logging companies may have the incentives to modify their practices so as to lessen threats to neighbouring protected areas (Rametsteiner and Simula, 2001)

\section{Tourism}

Tourism is arguably the world's largest industry, generating more than $\$ 4$ trillion per year and providing employment for nearly 250 million people worldwide. While all segments of the industry are rapidly expanding, nature-based tourism in areas with significant levels of biodiversity in or near protected areas is increasing at a much faster rate than the industry as a whole. This rapid expansion represents both a threat to fragile ecosystems and an opportunity to harness resources for biodiversity conservation and community development.

Large-scale tourism development involves the construction of major infrastructure, increased demands for water, energy and waste disposal, and an influx of new people, ideas and cultures into an area (Tour Operators Initiative and Conservation International, 2002). This increased activity can lead to widespread habitat conversion, pollution and resource degradation. However, when planned and
Chitwan National Park, Nepal.

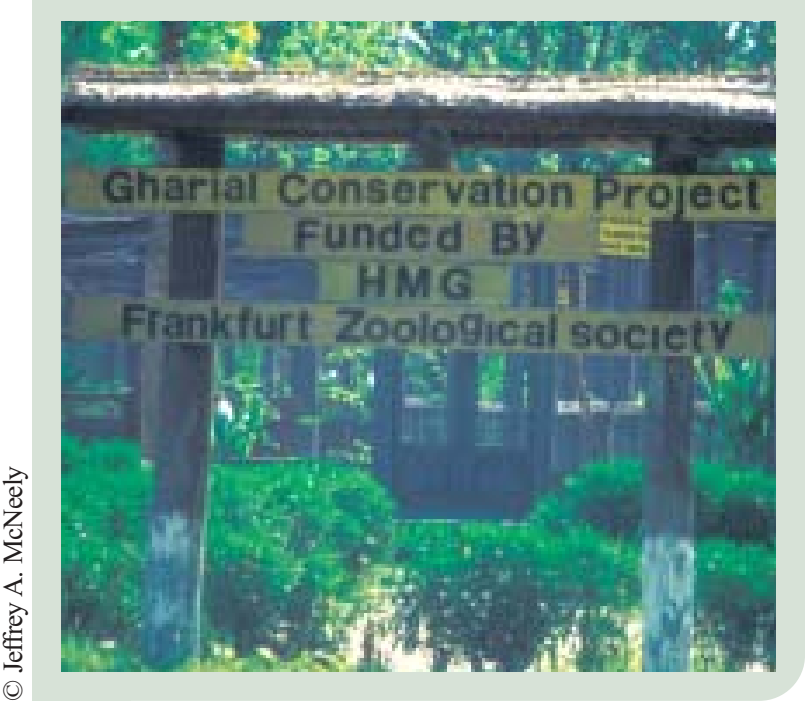

managed effectively, tourism development can have minimal negative impact on natural environments and can act as a catalyst for social development and biodiversity conservation.

Perhaps more than any other industry, the tourism sector has a vested interest in protecting the natural and cultural resources of the areas in which they operate. These resources are often what attract travellers to a destination in the first place. In an area blessed with rich biodiversity, it is even more likely that tourists are seeking natural and cultural attractions (Sweeting and Wayne, 2003).

\section{Involving public utilities}

One of the most important ecological services provided by protected areas is the stabilizing of hydrological functions. This is particularly important in view of the major investments in water resource management being made in much of the world. As an example of the economic costs of poorly-managed watersheds, about 880 million tons of agricultural soils are deposited into reservoirs and aquatic systems each year in the USA alone. This reduces their floodcontrol benefits, increasing operating costs of water treatment facilities, and shortening the effective lives of dams (Pimentel et al., 1995). Watersheds stabilized 
by protected areas could greatly reduce such damages and provide significant economic benefits to those operating the dams.

Water scarcity, water-based poverty, and the equitable allocation of water, are some of the key challenges facing global development. Although considerable spending is required in the water sector if the freshwater crisis is to be averted (The "Framework for Action" of the Second World Water Forum [2000] estimated that total investments in the water sector need to increase to US\$180b a year), decision makers have been reluctant to attach sufficient importance to water and treat it as a priority for investment. One of the reasons is that decision makers are receiving distorted signals from different people who give different values to water, including environmental values, social values, public health values, economic values, production and product use values, political values and gender values. For water to receive the investment it needs, these different values need to be more effectively communicated between stakeholders and unambiguous messages directed to decision makers. In particular, ways need to be found to bridge the divide between the economic perspective held by the commercial private sector, and the 'in situ' value attributed to water by conservationists. One of the most effective ways to achieve this is through dialogue and voluntary arrangements set in place through the shared adherence to common value perspectives.

Experience from various parts of the world demonstrates that protected areas are a cost-effective management option for maintaining healthy watersheds that produce a steady and reliable source of water. Many cities in both developed and developing countries depend on drinking water produced by protected areas. Natural vegetational cover on watersheds also regulates and stabilizes water run-off. Deep penetration by tree roots or other vegetation makes the soil more permeable to rainwater so that run-off is slower and more uniform than on cleared land. As a consequence, streams in forested regions continue to flow in dry weather and floods are minimized in rainy weather. Protected wetlands also have substantial ecological values, especially through their role in flood control (Ewel, 1997). Floodplain forests and salt marshes slow the flow of flood waters and allow sediments to be deposited within the floodplain rather than washed into downstream bays, oceans, or reservoirs. Isolated wetland protected areas may serve as detention areas during times of high rainfall, delaying saturation of upland soils and overland flows into rivers, thereby damping peak flows. Retaining the integrity of these wetlands by protecting vegetation, soils, and natural water regimes can reduce the severity and duration of flooding along rivers, thereby contributing to the irrigated agriculture which is so important in many parts of the world.

\section{Involving non-governmental organizations}

NGOs, both national and international, have been major contributors to protected areas in virtually all countries, providing funds and expertise, building public support, promoting training, taking action, and advocating conservation interests (Redford et al., 2003). While NGOs can provide very practical support to protected areas, their contributions are likely to be most useful when a clear understanding has been reached between the NGO and the protected area management authority. NGOs can diversify efforts and approaches to management of protected areas, sometimes using methods very different from those adopted by government agencies. Locally-based NGOs can often use their familiarity with local issues and resources to operate effectively where government agencies or national NGOs have difficulties.

NGOs also have their limitations. It is often difficult to provide oversight of their activities; their funding is often uncertain, making them dependent on changeable donor priorities that can limit their longterm commitment to a project; and they often are dependent on one or a few charismatic leaders. National NGO leaders are not typically associated socially, economically, and culturally with the rural communities they seek to empower, because of difficulties in finding appropriate leadership skills among the very poor, often illiterate, rural people who live closest to protected areas. Grassroots NGOs do not suffer as much from this problem, but may have difficulties in reaching those in authority. Many 
government officials view environmental NGOs particularly those that engage in advocacy work - as foes of economic development and unwelcome monitors of environmental and human rights abuses.

At the same time, some government agencies have found it useful to cooperate with NGOs in designing and implementing conservation projects since government agencies often have less relevant experience and operational flexibility. NGOs at the national level can better target the services they provide with personal knowledge of their clientele, and many donors have found the NGO sector to be more flexible, easier to monitor, more responsive to their needs, and less encumbered with politics than the public sector (Meyer, 1997).

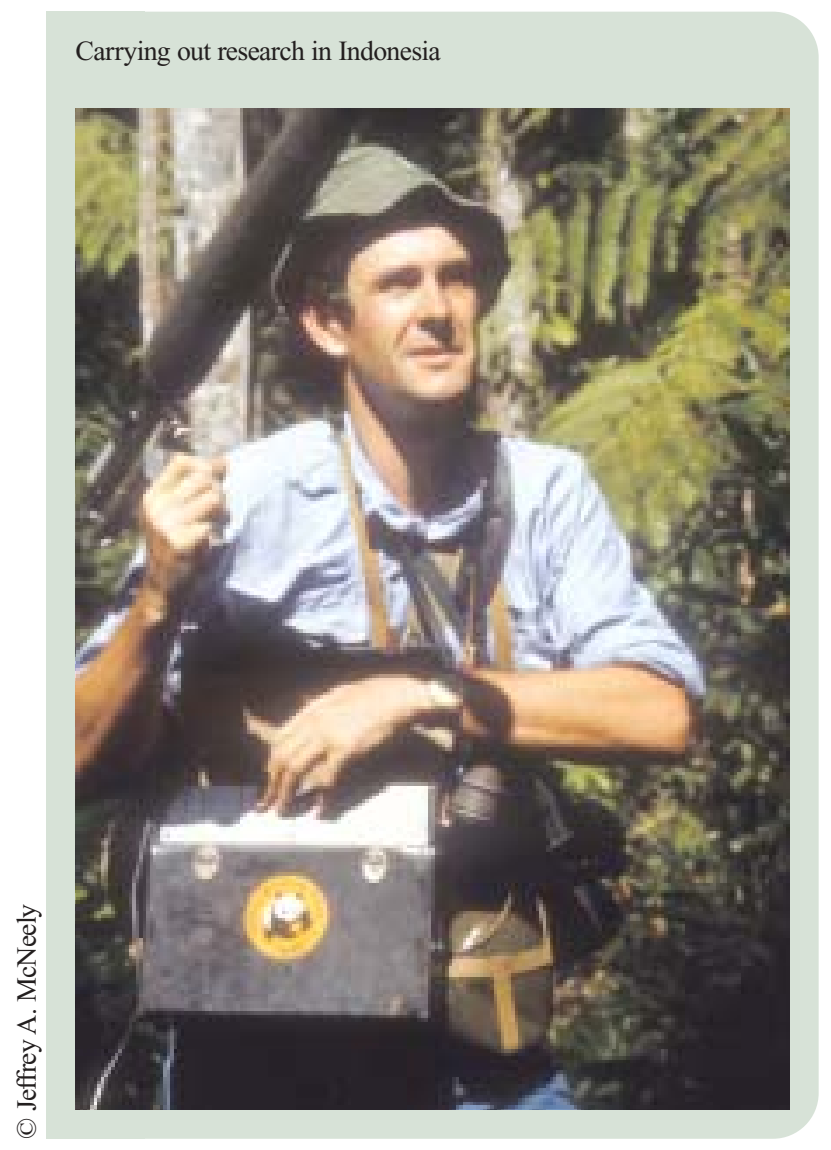

The contributions of NGOs will need to expand to meet growing demands. They especially need to find ways of working in partnership with many other interest groups, especially the private sector (as sources of funds, influence, and expertise), local communities (as those with the most immediate interests being affected), and governments (as those holding sovereignty over land and resources). For example, NGOs could become more effective by strengthening their capacity for working with the private sector through establishing partnerships with private sector actors with a proven track record in tourism, genetic resources, and small-scale sustainable enterprise, both national and international.

NGOs are important stakeholders in protected area discussions, but do not provide the single ultimate answer. In order to enhance their contribution, many NGOs need help in strengthening their capacity in project administration and management, as well as in the kinds of expertise relevant to modern protected areas. Numerous examples of NGO support are available to provide lessons to learn, adapt, and replicate, but our book is emphasising "new" or under-utilized constituencies so the NGO sector is not given as high a profile as it might deserve.

\section{Involving universities and research institutions}

Research and monitoring are critical parts of protected area management. Successful policy making requires continuous feedback from field-level resource management activities, through monitoring ecosystem structures and processes and various indicators of human welfare so that the results of management actions can be compared against expectations of the plans that led to the actions. Results from monitoring programmes must be made available to planners, managers, policy makers, and scientists so that they can adjust plans, management actions, policies and research programmes, thereby creating a loop, called "adaptive management", between implementing field actions, monitoring the affected ecosystems and human responses, comparing the results against expectations, and adjusting future actions, with each reiteration of activity based on past experience (Holling, 1978).

Universities and research institutions have been conducting research in protected areas for many years, and their work has been especially important in identifying sites worthy of inclusion within national systems of protected areas. Their research in agriculture, botany, forestry, geology, biogeography, animal behaviour, ecology, rural development, 
anthropology, and related subjects has provided important guidance to protected area managers, and to economic development in general. Protected area managers have benefited greatly from scientific research, because protected area management is at least partly dependent on the knowledge and wisdom that comes from science (McKerchar and Dingwall, 1984). However, increasing pressures on protected areas call for a concerted effort to mobilize additional research in support of protected area management. The basic principle for protected areas should be to provide conditions by which research can be encouraged rather than discouraged. Such research could be significantly increased if greater efforts were made to facilitate collaboration, for example through accelerating granting of permits and identifying suitable local counterparts.

It might be sensible for at least some countries to develop a biodiversity research centre that is oriented toward applications in protected areas and the surrounding buffer zones, focusing on problems of sustainable use and the economic development of renewable resources. Such a centre - perhaps located on a university campus - could also carry out the essential monitoring of status and trends of key species and ecosystems. For regions with limited scientific capacity, such as the Pacific, regional research programmes might be more sensible, involving universities and the protected area management agency.

\section{Involving indigenous and local communities}

Detailed knowledge of the people whose lives are affected by the establishment and management of protected areas is at least as important to protected area managers as information about the plant and animal species to be conserved. The cultural, socioeconomic, and demographic characteristics of local people - including the age and gender divisions of labour - form the basis for measures to promote the

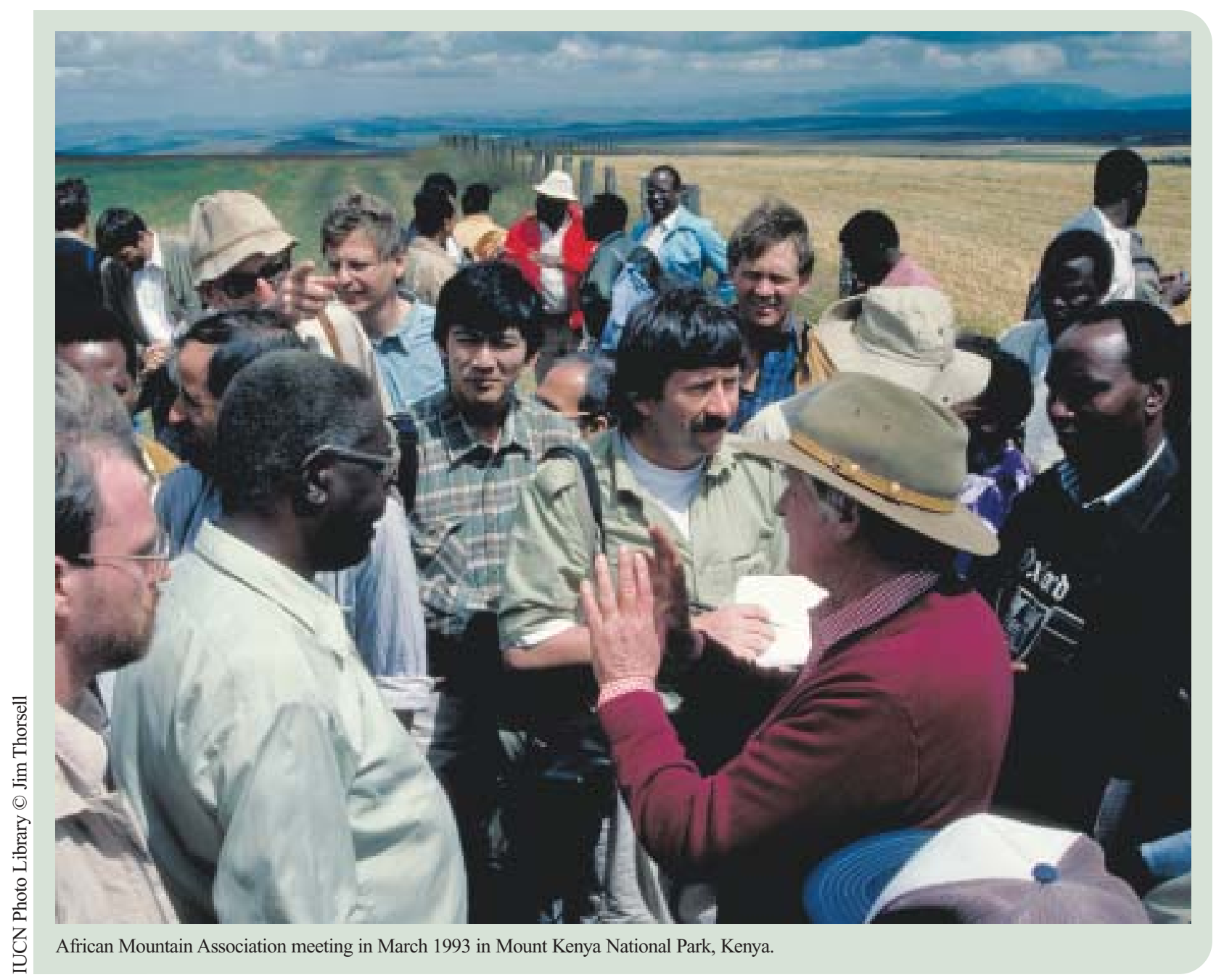


sustainable use of natural resources, alleviate poverty, improve the quality of human life, and create support for protected areas.

The history of relationships between protected areas and local communities generally has been a rather negative one. Local peoples need to be seen not simply as threats to conservation efforts but as one of the "new constituencies" whose involvement is essential for sustainable protected area management. It is now widely accepted that local communities have a legitimate right to participate in at least some aspects of protected area management in most places. Indeed, because of a range of economic and social factors, the supply of biologically-rich areas that could become protected areas is doomed never to meet the needs of a comprehensive protected area system without a concerted effort by the world community to make conservation an attractive option to the rural people who have practical jurisdiction over the resources (McNeely and Guruswamy, 1998).

As the human population continues to grow and more economic pressures are put on forests, wetlands, coral reefs, and other natural habitats, it is even more important to recognise and implement locally-instituted mechanisms to control access to resources, to ensure appropriate participation in decision-making processes, and to develop procedures for resolving conflicts. In many cases, the indigenous approaches to these mechanisms are more effective than those imposed from outside, and can complement protected areas.

At a minimum, local communities need to be deeply involved in buffer zone development activities, and should be consulted on any decisions that affect them. In many cases, giving the local people preferential treatment in terms of employment within the protected area, providing economic incentives to establish tourism or other income-generating activities in the buffer zone, and ensuring an appropriate flow of benefits from the protected areas to the surrounding lands can help to build a positive relationship between protected areas and local communities. This positive relationship will hopefully lead to greater support for the protected area - a proposition that is essential to test. This considerable challenge is being addressed in various ways in many parts of the world.

\section{Involving the military}

In many countries, national military forces have jurisdiction over substantial areas. In some cases these areas are bases used for training and weapons development while in other cases the area is considered of importance for national security particularly in border regions. But in most cases access to the land and its resources are tightly controlled and therefore the impact of human use is considerably less than in surrounding areas. In a variety of settings, national militaries have begun to be sensitized to the conservation importance of the land under their control and in some cases taken measures to ensure that these conservation values are maintained (McNeely, 2003). At least some of these are adjacent to protected areas and can help contribute to making their wildlife populations ecologically viable.

\section{Involving the global community}

It is increasingly being recognised that the global community is an important constituency in protected areas. The "global importance" value of certain places has long been recognised, and a great deal of international money has been spent on such areas. But the formalization of the global community as a stakeholder in decisions about protected areas is a complicated issue involving concerns of national sovereignty, local values, and accountability. It is clear, though, that if international funds are to continue to flow to protected areas and if the global community is to be seen as a legitimate "new constituency", then rules and procedures need to be formalized. Many of these issues are discussed in Ostergren (this volume).

\section{Institutions to support protected areas}

A protected area system needs wide diversity in institutional approaches and varied and complementary constituencies that together map onto the threats to conservation and the strategies necessary to alleviate these threats. Many biological processes operate at small scales that vary dramatically in climate, elevation, structure, and importance from one setting to the next. There is often a "mismatch" between institutional and ecological scales, and an 
over-emphasis on large-scale institutional arrangements, such as centralized protected area agencies, can undermine institutional mechanisms at smaller scales, such as traditional approaches to conservation (Folke et al., 1998, Pritchard et al., 2000). Local knowledge about specific complex interactions and concerns about natural capital can be applied in daily life, especially at the smaller scales. This clearly is not an either-or situation, but instead calls for creating complex, nested systems of complementary governance for protected areas, with different institutions having different responsibilities at different scales (Ostrom, 1998). Simply stated, large-scale, centralized governance units do not, and cannot, have the variety of response capabilities - and the incentives to use them - that complex, polycentric, multi-layered governance systems can have. This implies finding many ways of enlisting new constituencies for protected areas.

In general, the success of a protected area is enhanced when organizations that have a vested interest in maintaining the protected area are strong and effective, and thus are able to prevent unacceptable uses of the protected area. Well-designed protected areas require:

- clearly defined conservation targets for each protected area;

- clearly defined boundaries;

- zones of management which allow for management activities to ensure that all targets can be maintained;

- an understanding of the threats to the conservation targets and the strategies necessary to alleviate these threats;

- specific regulations on how much, where, when, and how different goods and services can be used from within the protected area;

- involvement of all the relevant stakeholders in decisions that affect the protected area;

- a system of monitoring the use of resources;

- sanctions on those who violate regulations;

- inexpensive local mechanisms for resolving conflict among stakeholders;

- the rights of the stakeholders to devise their own institutions; and

- a way of organizing these activities in multiple layers, with clearly-differentiated responsibilities at each layer.
Which institutional arrangement is most logical or successful will vary according to the national objectives that have been established for the protected area system and the specific objectives determined for each individual site. Because protected areas do not come in just one size or habitat, neither should their arrangements for management. A greater diversity of institutional approaches helps to stimulate creativity, enabling different kinds of institutions to take rather different kinds of approaches. Different kinds of protected areas demand different kinds of management and involve different sets of interest groups, so no single institution can meet the full range of requirements. However, it is essential that the central government establishes national objectives for the protected area system, ensures that the various approaches to protected area management are contributing to the national system, supports the interests of protected areas in the face of alternative land uses, establishes means for exchanging lessons learned from the participation of the various interest groups, and provides an appropriate regulatory framework to ensure quality control. But all of these steps will fail without a well knit, properly managed set of constituencies who can collectively ensure the long-term success of individual protected areas and portfolios of protected areas.

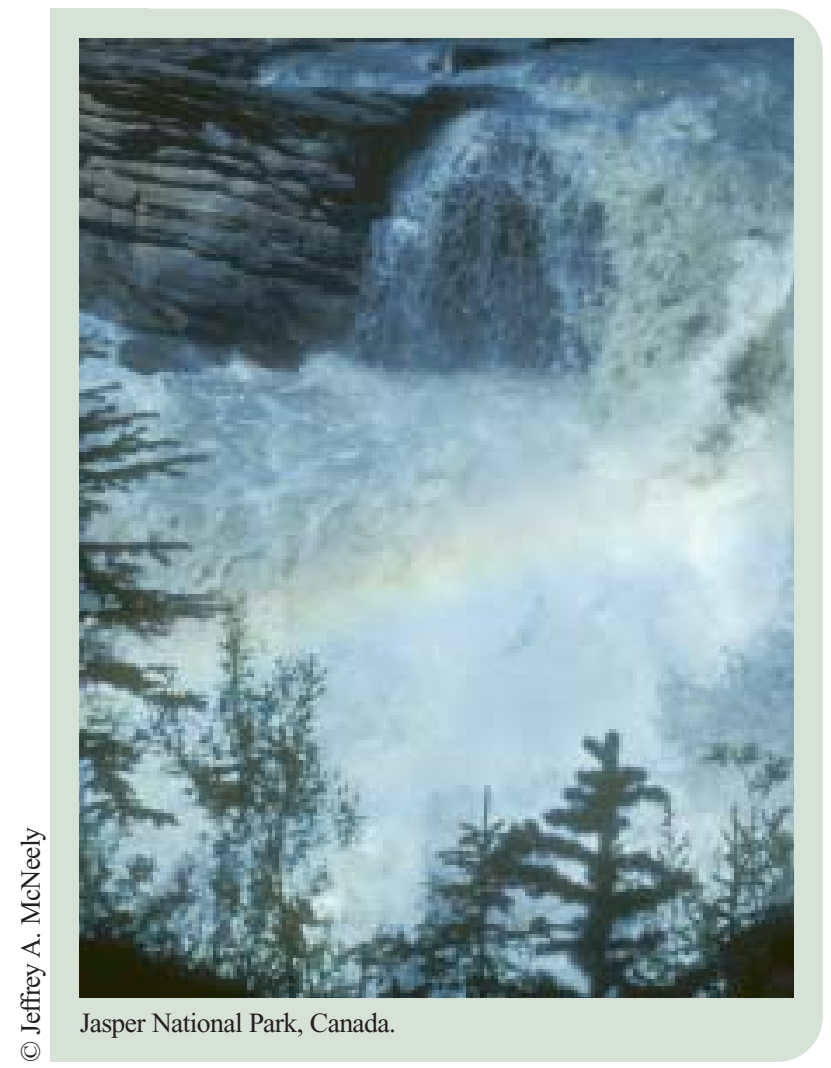




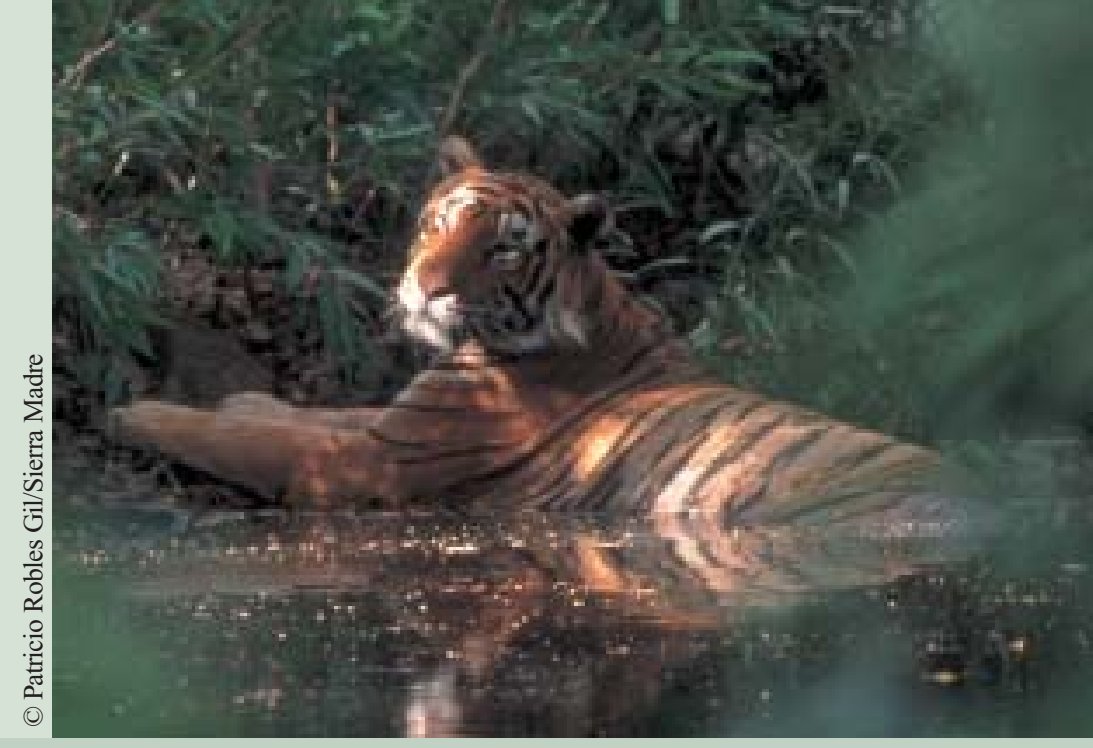

\section{Extractive industries as a new constituency for protected areas}

\section{by Assheton Stewart Carter}

\section{Editor's introduction}

One of the major threats to protected areas in many parts of the world is mining, either within the protected area or sufficiently close to it that the protected area is substantially affected by pollution associated with the mining, or by activities by miners. IUCN has called for its State Parties to pass legislation banning any mining from protected area categories I-IV. On the other hand, modern societies are heavily dependent on minerals, and as the protected area estate continues to expand, the interests of miners and conservationists will increasingly overlap in at least a geographical sense. This is a situation that could easily lead to conflict. As a response, many forward-thinking companies in the mining and energy sectors have recognised their responsibility to ensure that their activities do not have adverse effects on protected areas. BP, for example, has recognised the IUCN category system, and Shell has pledged not to operate in any natural World Heritage sites. Assheton Stewart Carter, drawing from many years of experience in working with extractive industries, identifies the interests of the extractive sector in protected areas and the recent measures that they have undertaken to be partners of protected area managers rather than opponents. Beyond the financial contributions that extractive industries may provide (and undoubtedly would provide more if government policies were more supportive of their doing so), the extractive industries also contribute to environmental planning and management, carry out important research that is relevant to protected areas, and contribute to building stronger public support for protected areas. One critical element is a commitment by the extractive companies to be explicit about their impact on biodiversity and protected areas, and to design and implement management measures to minimize any negative impacts and - in the best case - to provide net benefits to the protected area system of a country.

Photo: The Bengal tiger (Panthera tigris tigris) of India, Nepal, Sikkim, Bhutan, and Bangladesh, was the first recognised tiger subspecies. Kaziranga National Park in northeastern India, an alluvial plain grassland, is known to hold the highest adult tiger density - almost 17 tigers per $100 \mathrm{~km}^{2}$ - evidence that tiger densities can still be high in optimal habitats. Himalaya hotspot. 


\section{Introduction}

Mining for minerals and drilling for oil and gas takes place in or near many protected areas (Rosenfeld et al., 1997, Rosenfeld Sweeting A. and Clark A., 2000; Miranda et al., 2003; Austin and Sauer, 2003; Energy and Biodiversity Initiative, 2003; Farrell et al., 2004). As both the number of protected areas and mineral exploration projects continue to expand, areas of overlap, and potential conflict, between conservation interests and oil and gas development are likely to increase (Energy and Biodiversity Initiative, 2003).

Foreign multinationals, especially those engaged in the development of oil, gas and mineral resources, operating in developing countries have a poor environmental record (Warhurst, 1992) and a turbulent history in regard to the relationships with their workforce and local communities (Stewart Carter, 1999). The physical impacts of the extractive industries can be dramatic. Mining operations clear large areas of surface vegetation, scoop off the soil like icing from a cake, blast through naked rock to expose and mine the mineral vein, and leave monuments made from mining 'waste' that can leak pollutants into soil and watercourses. Developing an oil or gas field is more precise - like a root canal operation - but the seismic survey methods can leave a matrix of access routes over a large area that are visible by satellite. In Alberta Province in Canada, $80 \%$ of the seismic lines that cut through the vast boreal forest region to prospect for oil sands have failed to regenerate (Creasey and Fischer, 2004). Oil transmitted by pipelines or transported by seagoing tankers can spill with devastating effects on wildlife, as the world witnessed when in 2001 the fuel tanker Jessica grounded at the entrance of Wreck Bay in the Galapagos spilling much of the 240,000 gallons of fuel oil it was carrying (Lougheed, Edgar and Snell, 2002). Energy and mining development attracts people looking to improve their circumstances who can exert further pressure on forests surrounding projects through deforestation or hunting (Thibauls and Blaney, 2003).

The grave environmental and social risks associated with the activities of the extractive industries imply that mining and oil and gas development is incompatible with the protection of biodiversity. There are, and always will be, places where development and the conservation of the natural features valued by so many can not coexist. Some environmental challenges have no 'technical fix'. Yet, the oil and gas and mining industries have made significant progress in applying their capacity for technical and management innovation to environmental challenges. Many of the devastating impacts on the environment that have occurred in the past can now be avoided or considerably reduced. Furthermore, companies that have the will to recognise their potential impact, and the capacity to overcome damaging our natural world, have financial, strategic planning, business, scientific, and political resources that can, are, and should be mobilized to assist in the establishment and more effective management of protected areas. If we are to achieve the biodiversity conservation goals needed to secure the healthy functioning of our ecological, economic and social systems, new alliances, among them partnerships with the extractive industries sector, are required to support the expansion and effective management of the global protected area system (McNeely, Redford and Stewart Carter this volume).

\section{The extractive industries sector}

This chapter looks at the contributions that extractive industries can make to protected areas. Here the extractive industries sector is a description of the businesses that are involved in the exploration and development of oil, gas and mineral resources - the energy and mining industries. Other chapters in this book are concerned with industries that are often grouped under the general descriptive 'extractive', including logging, forestry, and fishing. Yet, combining the energy and mining industry sectors under this general rubric risks hiding some important differences between the two.

Both industries are of considerable importance to many national economies. For example, 34 countries depend on mineral exports for more than $25 \%$ of total exports, and many of these are significantly more reliant on mining. For instance, Zambia's exports in ores and metals account for $66 \%$ of total exports, Niger $67 \%$, and Guinea $71 \%$. Nevertheless, in the global context, the mining industry is relatively small, and is dwarfed by the energy sector. The top 150 
international mineral companies have a combined market capitalization of US\$224 billion (MMSD, 2002), while the single largest private sector oil company, ExxonMobil, exceeds that with a market capitalization of US\$289 billion.

Moreover, oil and gas production is not only important for the economies of producing nations, but a critical strategic issue in international relations. For those regions that will increasingly depend on nondomestic supply of hydrocarbons to meet their demand for energy, North America, Europe, China and Japan, continued energy security is essential to assure the health of their diversified economies. Governments in these regions will promote exploration and development of oil and gas reserves in countries endowed with hydrocarbon resources,

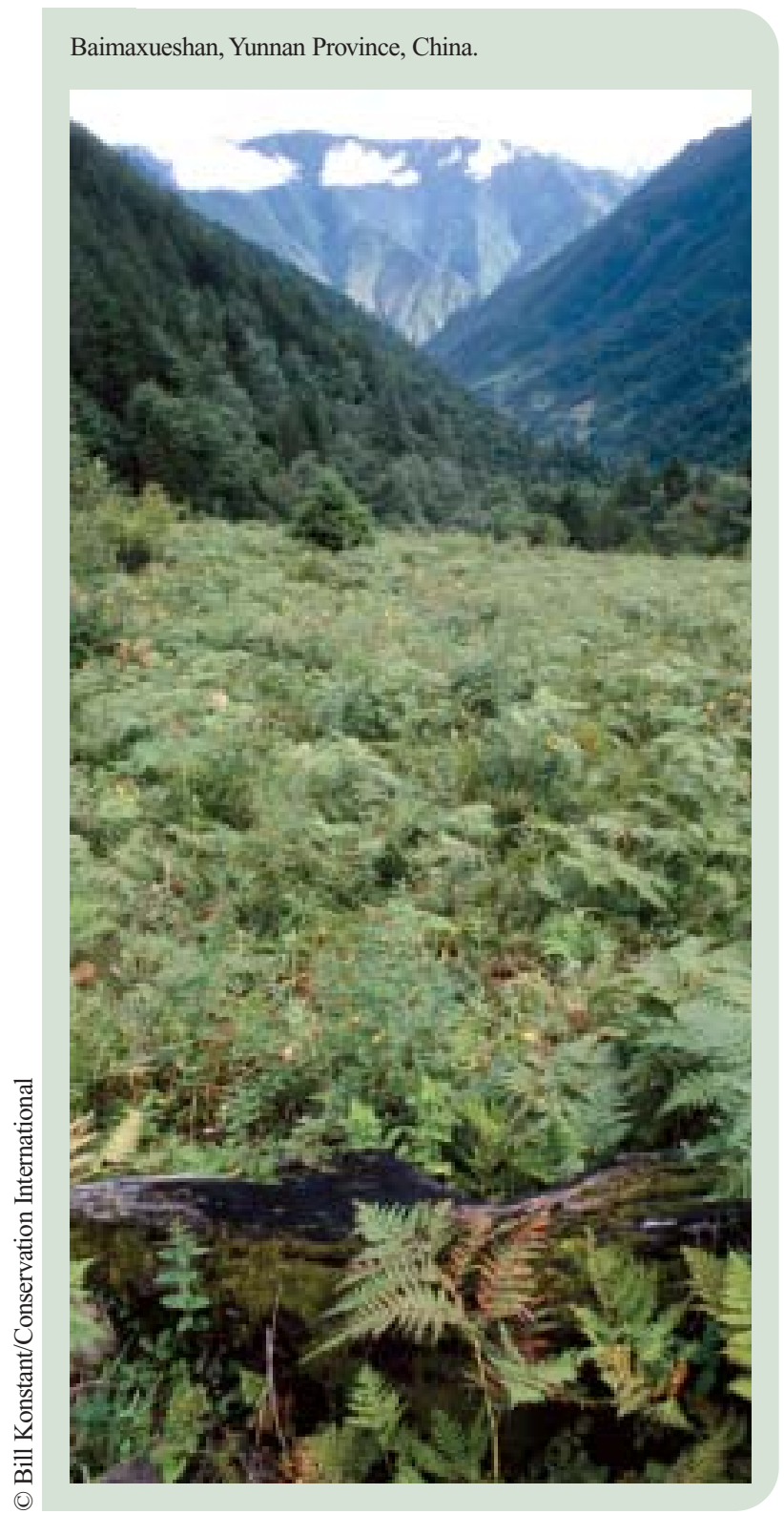

encourage their national companies to secure assets abroad, and seek to ensure that oil and gas energy products flow onto the international market through lending their support to the construction of transboundary pipelines and the establishment of new shipping routes.

Despite these differences in size and importance to international affairs, the energy and mining industries have some similar characteristics. A few very large companies, known as 'super majors' or 'majors', dominate both industries. Some have recognisable brands: Alcoa, Alcan, AngloAmerican, Barrick, BG Group, BHP Billiton, BP, ExxonMobil, ChevronTexaco, ConocoPhillips, Newmont, RioTinto, Shell, and Total. Other companies in this size category are state-owned enterprises the names of which are less well known: CVRD and Petrobras in Brazil; Codelco in Chile; Petronas in Malaysia; PetroChina and Sinopec in China; PetroEcuador and PetroPeru in the Andean countries; Saudi Aramco of Saudi Arabia; Statoil in Norway; Pertamina in Indonesia; and Sonangol of Angola. These national companies often control the industry in their home countries and have significant market shares in exploration and production globally. These 'super majors' are usually integrated across commodities, in the mining industry, and vertically in the energy industry, with businesses in exploration and production, transport, and retail. They operate, are joint venture partners, or have interests in a large number of operations worldwide.

At the other end of the size spectrum, small companies, known as 'juniors' or 'independents', take high risks in pursuit of profits. In the mining industry, their business is to explore and discover new resources and negotiate an interest in operating the mine with a larger company. In the oil industry, the 'independents' specialize in finding and developing fields that are of little interest to the larger companies that are searching for a larger 'prize'. The agent binding all businesses in the sector is the desire to win access to land to explore for oil, gas or minerals and replace reserves - a measure of a company's market value. Often, the land the sector covets is in the very same places that are cherished by conservationists for their natural features. 


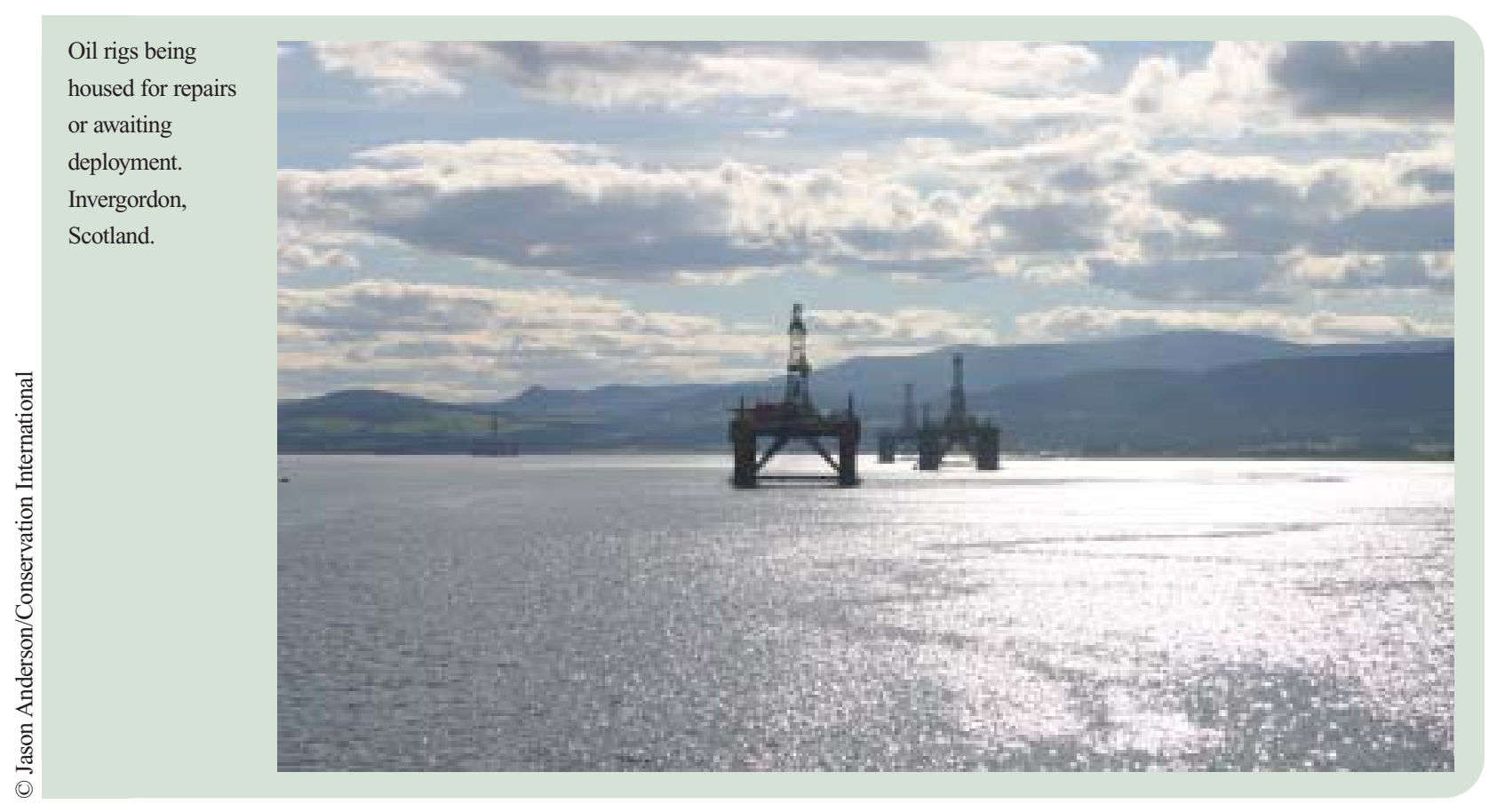

\section{The interests of the extractive industries in protected areas}

Place a global map showing areas known for their biodiversity value over a map showing the world's known mineral and hydrocarbon reserves and you will notice a high degree of coincidence. A similar exercise comparing the location of known existing and planned mineral and oil and gas development projects with boundaries of protected areas also reveals a marked correlation. This spatial relationship has not gone unnoticed by the conservation community. UNESCO (2004) records that one quarter of World Heritage Sites listed for natural value have mining or oil and gas development in or near their borders. The World Resources Institute reports that one-quarter of active mines and exploration sites overlap with or are within a $10 \mathrm{~km}$ radius of protected areas categorized as I-IV under the IUCN system (Miranda, 2003). And there are good reasons to believe that this close association between mining and oil and gas development and protected areas will strengthen.

Global demand for oil, gas, minerals and metals is expected to grow over at least the next thirty to fifty years. To supply the world's refineries and smelters, extractive companies will intensify their prospecting and production efforts into remote and hitherto unexplored areas, many of which are currently protected or candidates for protection. This is particularly evident when looking at the future of oil and gas supply. As traditional oil-producing regions mature and yield progressively less oil, the industry is exploring in new areas, and for new products such as natural gas. Production is already taking place or is planned in regions known for their biodiversity richness, for example the Caspian, Indonesia, West Africa and offshore Venezuela and Trinidad. Getting the oil and liquefied natural gas to the customer requires maritime transportation and construction of pipelines (Jaffe and Victor, 2004) that will cross vast wildernesses and conflict with both terrestrial and marine protected areas. For example the Baku-TbilisiCeyhan oil pipeline in the important Caspian region crosses a National Park, the Chad-Cameroon pipeline encroaches on indigenous territories, and the WestEast pipeline in China crosses six state and provincial protected nature reserves, twelve locations in the Great Wall of China (a UNESCO Cultural World Heritage site), and passes close to four important state-protected cultural heritage sites (Seymour, 2003).

At the same time, the dramatic upward trend in the number of protected areas over the last forty years is likely to continue over the next ten. Protected areas have increased tenfold since 1962 to more than 100,000 today, though many species (Rodrigues et al., 2004) and ecosystems are not yet represented in (Driver et al., 2003) the global system. Delegates at 
the Vth World Parks Congress called on the global conservation and development community to set new targets to enlarge and improve the effectiveness of the global protected areas system (IUCN, 2003), a recommendation that is reflected in the programme of work adopted by governments at the seventh Conference of the Parties to the Convention on Biological Diversity (2004). As both the protected area system and mineral exploration continue to expand, areas of potential conflict are also likely to increase and the case for the conservation community to engage the extractive industries becomes more compelling.

Although it is easy to assume that the extraction of hydrocarbons and minerals in protected areas would be legally excluded, the reality is far from simple. Legislation varies enormously from country to country. Some governments do not allow mining or oil and gas development in some of their protected areas, while others issue exploration permits in protected areas (Dudley and Stolton, 2003). Despite these legal differences, environmental campaign groups, and more recently the investment community (ten Kate, 2003; Miller, 2003), are invoking the recommendation made by IUCN members at the 2000 World Conservation Congress in Amman, Jordan to challenge energy and mining companies to make a voluntary commitment not to enter any IUCN category I-IV protected areas.

The "No Go" campaign has heightened the risk to companies of access to reserves being denied, restricted, or kept in limbo, and of opposition from local communities constraining production or increasing the cost of operating in or near to protected areas (ten Kate, 2003; Sykes, 2003). One study on the subject concludes that companies that have assets in or near existing or planned protected areas could see a loss of more than $3 \%$ of shareholder value (Austin and Sauer, 2002). Pressure on the industry has resulted in voluntary restrictions. In 2003, fifteen international mining companies, that make up the membership of the International Council for Mining and Metals, declared a policy not to operate in existing UNESCO World Heritage Sites (International Council for Mining and Metals, 2003) a commitment also made by Shell, an Anglo-Dutch oil company (Shell, 2003).
Yet, if successful, the campaign to force a voluntary commitment from energy and mining companies not to explore or produce in or near to protected areas runs the risk of a Pyhrric victory for conservation. Governments have to make tough decisions to balance economic development and environmental protection. Especially in the developing world, sovereign states will be reluctant to forego potential revenue from developing their natural resources and may resist calls to expand their protected areas system into areas that have the potential to hold mineral or hydrocarbon reserves, or choose to delineate boundaries to exclude mineralized zones.

Furthermore, a strategy that seeks only to oppose the commercial sector risks losing sight of the benefits for conservation that can be made available through collaboration. Companies in the extractive industries sector own or control many resources that, if harnessed, can be used to expand and strengthen the protected area estate. The remainder of this chapter gives examples of energy and mining companies that have provided financial, human, management and planning, scientific, and political resources for the support of protected areas.

\section{Examples of contributions to protected areas from the extractive industries sector}

\section{Financial contributions}

Budgets for protected areas have not risen commensurately with the rapid growth in their number. Recent studies estimate that an additional US $\$ 2.3$ billion each year is required simply to make management adequate in the existing protected area network (James et al., cited in Lapham and Livermore, 2003). Financial resources necessary to create and manage a broadly representative and effective global system of protected areas are upwards of US\$20 billion annually (Balmford et al., cited in Lapham and Livermore, 2003). Because the project life cycles of oil, gas, and mineral development projects span many years, or even decades, there is a tremendous opportunity for companies to provide a sustainable flow of funding to protected areas over the long term. 


\section{Box 2.1}

\section{The Chiquitano Forest Conservation Foundation}

The Chiquitano Forest Conservation Foundation (FCBC in Spanish) was created in September 1999 and marks an agreement between two energy companies (Enron and Shell) and four conservation organizations, of which two are Bolivian (Fundacion Amigos de la Naturaleza and Fundacion Amigos del Museo de Historia Natural Noel Kempff Mercado) and two American (Wildlife Conservation Society and Missouri Botanical Garden).

The founding members have committed US $\$ 30$ million over 15 years to the FCBC. The companies will each contribute US\$2 million annually over the first five years and will then match funds raised by the environmental groups up to a further US\$10 million. Establishment of the FCBC has proved instrumental in mobilizing funds from other sources. In 2002 the FCBC accepted US $\$ 320,000$ in contributions from external sources and a further $\$ 500,000$ in 2003.

The FCBC supports the long-term funding objectives of the conservation plan for a region of more than 8 million hectares in eastern Bolivia. The area includes the Chiquitano Dry Forest, the Cerrado and the Bolivian Pantanal ecoregions. In its relatively short history, the FCBC has enabled the creation of the 242,000ha Tucavaca Municipal Wildlife Reserve, provided incentives for implementation of a land-use plan that integrates sustainable-use and private reserves over $260,000 \mathrm{ha}$, and facilitated the awarding of land titles for 34 indigenous groups.

The FCBC is governed by a Board of Directors which oversees and approves the yearly work plan and budgets. Each of the four conservation organizations is represented on the board and there is one representative for the two energy companies. A stakeholder committee, which aims to represent $90 \%$ of the regional actors, including agrarian and forestry superintendents, municipalities, cattle ranchers associations and indigenous organizations, also exists.

Sources: Laine Powell (2003) and Justiniano (2003).
Madidi National Park, Bolivian Amazon, Bolivia.

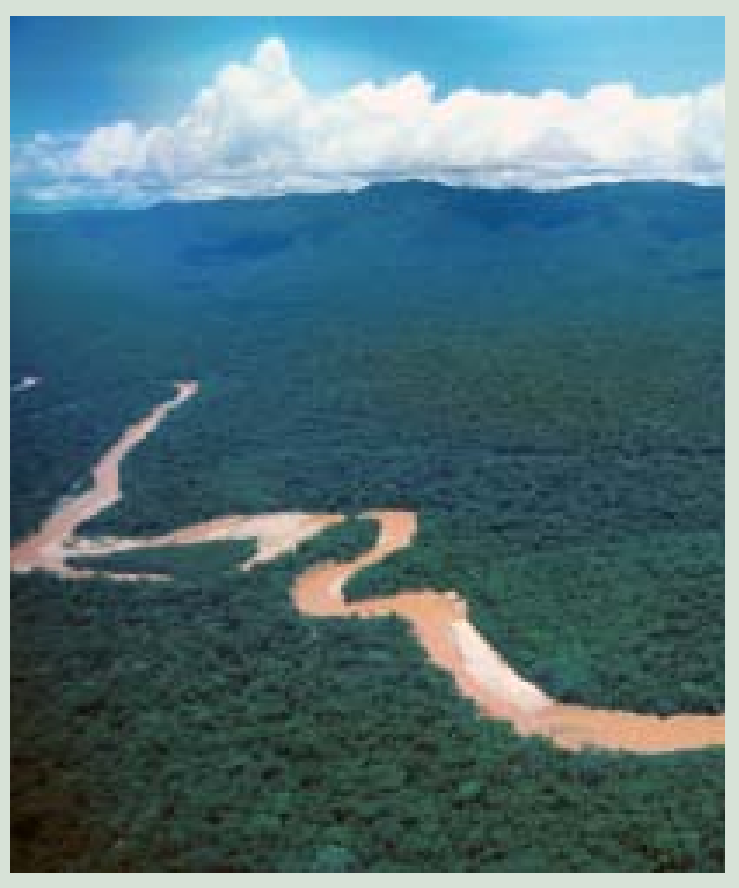

In the last five years there has been a marked change in the nature of corporate giving, however. Companies have reduced the size of their philanthropic budgets, winnowed out from portfolios gifts to organizations the work of which is unrelated to their business, and have aligned giving strategies with the core mission and values of the firm. In other words, a trend is towards 'strategic philanthropy' (Barktus et al., 2002; Saiia et al., 2003).

Yet, this trend may well favour conservation. Although corporate giving is declining, the share of the philanthropic pie destined for biodiversity will get larger. Biodiversity, and protected areas in particular, is a strategic issue for companies in the extractive industries, and thus is among the top candidates to receive funding from 'strategic' philanthropic budgets (Stewart Carter, 2003a). For example, RioTinto, an Anglo-Australian mining company, in the late 1990s supported over 80 charities and programmes. Today, the company has consolidated its annual contributions of $\$ 50$ million into 12 partnerships - nine of which are with conservation organizations (Richards, 2003). Moreover, because companies most acutely feel the business risks associated with operating in biodiversity rich and protected areas at the site level, it is at the project level that the growth in voluntary donations will most likely be seen. Collectively, 
budgets for external contributions at the project level are judged to be larger than corporate-level philanthropic budgets, especially in developing countries (Rondinelli, 2002).

The institutional arrangements to make these financial contributions vary, but an increasingly popular model is the Trust Fund or Corporate Foundation (Warhurst, Stewart Carter and Mohan, 2001). Endowments provided by companies can amount to several millions of dollars, especially in the oil and gas industry. For example BP donated US\$14 million to be disbursed over ten years to the Scottish Forest Alliance, a partnership established to regenerate the Caledonian Forest in protected lands in the Scottish Highlands (Herlugson, 2003). Meanwhile Enron and Shell will donate US\$10 million over a five-year period to the Chiquitano Forest Conservation Foundation that supports the creation of protected areas in eastern Bolivia (see Box 2.1). A consortium of companies (EnCana, Repsol, Pecom Energia, Occidental Petroleum, ENI-AGIP, Techint, and Pernco), that sponsored the construction of a pipeline in Ecuador that stretches from the country's Amazon rain forest to the Pacific coast, known as the OCP (Oleoducto de Crudos Pesados), created the Ecological Fund with a multi-year capital funding commitment of US\$16,930,000. The Fund will target biologically important zones along the route of the pipeline and invest in the strengthening of protected areas.

Although companies often describe funds as voluntary donations over and above environmental compliance, such agreements are more often arrived at through a process of gentle negotiation. In the example of the FCBC (Box 2.1), the companies agreed to discuss plans for the foundation in response to strongly voiced concerns from international NGOs about the $660 \mathrm{~km}$ Bolivia-Cuiaba natural gas pipeline that passes through areas important for biodiversity and traditional lands of indigenous peoples. As the companies had already met all their legal obligations set out by the government, the FCBC was never intended to be a compensation or mitigation fund. Rather, the commitment came about through a balanced process of pressure and respectful and constructive discussions on the issues between local and international NGOs and the consortium. The result was the companies' awakening to the potential long-term negative effects that infrastructure would have on biodiversity in this very special area and the need for a fully funded regional plan to avoid irreversible damage (Justiniano, 2003).

A compelling argument for involving companies in financing protected areas is the prospect of leveraging additional conservation funds. Some privately managed funds, for example the Global Conservation Fund and the Critical Ecosystems Partnership Fund, actively seek matching funds from other sources (Stone, 2003), as do public donors such as USAID. In 2000, Conservation International entered into an alliance with RioTinto Mining and Exploration and Production to undertake biological surveys in the Pic de Fon, a protected area in the Upper Guinean Forest of West Africa. The success of the collaboration encouraged USAID and Ecologie Guinea, a local NGO, to enter into an agreement with RioTinto and Conservation International to form the Alliance for Forest Guinea (AFG) that has a mandate to develop a conservation strategy for the region. The Alliance was able to apply for funds from USAID through its Global Development Alliance grant that requires matching funds from partners in the commercial sector. Together, the AFG has leveraged a total of US $\$ 1.8$ million for biodiversity protection over a three-year period (Gill, 2003; Stewart Carter, 2003a; Stewart Carter, 2003b).

Companies also provide very effective 'in-kind' support to ease the financial burden of protected area management. It is not uncommon for companies to cover the cost of salaries, donate equipment, provide office space, support education and awareness building projects, and run employee volunteer programmes. Shell El Salvador has supported SalvaNatura and the running of the El Imposible National Park since 1995. The company has covered the salaries of two park rangers through the 'Adopt a Ranger Scheme', donated petrol vouchers for use at the company's gas stations, matched funds to finance advertising projects for the park, promoted fund raising drives at gas stations, covered the costs for publishing a series of four bird books and Park guides, and sponsored television commercials for the park (Alvarez, 2003). 


\section{Environmental management and planning}

Providing much needed, long-term financial support to protected areas is not compensation or a substitute for avoiding harming protected ecosystems, habitats and species. In many cases, careful planning can accommodate both the biodiversity values of protected areas and the need for economic development from mineral extraction. Much of the initial harm done to biodiversity from the activities of extractive companies can be ameliorated over the life of the project. In some cases, benefits to biodiversity can even be enhanced; for example, companies can manage their concession as de facto protected areas.

Technologies and management techniques for mitigating many of the impacts of mining and oil and gas development are well known and documented in the industry literature. Roads through forests to access projects sites can be replaced by helicopter transport, seismic lines can be cut to less than $4 \mathrm{~m}$ in width, oil pipelines can be buried, canopy bridges built across 'rights of way', disturbed areas filled as extraction takes place and revegetated at closure, project sites managed to prevent pollution and made safe for wildlife, and the risk of marine oil spills can be reduced by transporting oil products in double-hulled tankers. Not all companies apply these practices at all of their facilities, however. Immutable damage is still done by irresponsible and careless operators in every size company, some of which operate illegally in protected areas (see Box 2.2).

Moreover, no 'technical fix' can manage all risks to biodiversity from exploration and production. There are some areas that will suffer even when the best available technology and management practices are applied. If the biodiversity values of these areas are to persist, projects have to be planned to avoid areas that are not able to withstand the pressure from development activities. For Alcoa, operating in the naturally bountiful land of Western Australia, the answer was to forego its legal right to operate in $15 \%$ of its lease in the protected jarrah forests (see Box 2.3). In the oil and gas industry, pipelines can be routed to skirt vitally important areas, or innovative drilling technology can avoid damage by accessing an area from a distance.

\section{Box 2.2}

\section{Destruction of tiger habitat in India: The plight of the Jamwa Ramgarh Wildlife Sanctuary}

A stark reminder of the negative impacts of mining can be witnessed inside the Jamwa Ramgarh Wildlife Sanctuary in Rajasthan, India. At $300 \mathrm{~km}^{2}$, Jamwa Ramgarh wildlife sanctuary is a vital forest corridor contiguous to Sariska Tiger Reserve. Large tracts were declared Reserve Forest in 1961 under the Rajasthan Forest Act of 1953 and additional areas were added to create the wildlife sanctuary in 1982 under the Wildlife Protection Act of 1972. The sanctuary holds resident populations of tigers and leopards and is a vital overspill area for the young tigers of Sariska and for transient individuals. The importance of the Jamwa Ramgarh sanctuary has been recognised by the central government whose director for Project Tiger has taken areas of the sanctuary under the administration of his office. Although the Ministry of Environment and Forests has prohibited the granting of new mining leases and ordered the cessation of existing mining operations in wildlife sanctuaries and areas under the jurisdiction of Project Tiger, significant areas of the Jamwa Ramgarh have been deeply scarred by commercial soapstone and marble mining operations. The mining continues to add to the pressures and stresses on the already threatened wildlife sanctuary and some empirical evidence is now emerging: the water table has dropped and streams have dried up, tigers have been disturbed and migratory routes for wildlife blocked, abandoned quarries have not been reclaimed, revegetated, or made safe for people or wild animals.

Source: Environmental Investigation Agency (2003),

Undermined: Destruction of Tiger Habitat in India,

www.eia-international.org 
For twenty years BP has been operating at Wytch Farm on the coastline of southern England. Wytch Farm is the largest onshore oilfield in Western Europe and is expected to yield some 460 million barrels of oil over the next twenty years. It is situated in an area that is designated as an Area of Outstanding Natural Beauty the features of which include a Site of Special Scientific Interest, Special Protection Areas, Ramsar sites, National Trust Land, Heritage Coastline and National Nature Reserves. To avoid intruding into these zones, BP used extended reach drilling, a technology that has enabled wells to reach more than $10 \mathrm{~km}$ horizontally from the wellhead (IPIECA, 2004a). BP has demonstrated how investment in technological innovation, although incurring a short-term cost, can reduce the trade-off between economic development and environmental protection in the long term.

As necessary as they are, efforts to respect the boundaries of protected areas are not sufficient. Conservation action is also necessary at a much larger scale in order to maintain the ecological and evolutionary processes on which species depend (Sanderson et al., cited in Mittermeier and Brooks, 2004). This means ways will have to be found to protect much more of the landscape; in some areas, such as South Africa, as much as 50\% is required (Driver et al., 2003). The demand for land renders impossible fencing-off the vast areas that this conclusion implies, and conservation planners have responded with the notion of 'living landscapes' or 'conservation corridors' - the linking of formal conservation reserves within a multiple land-use matrix. Oil, gas and mineral development projects are one of the many land uses that must now be considered alongside areas managed for conservation objectives.

A conservation project in the Succulent Karoo in South Africa provides an example of a collaborative approach to conservation at the landscape level. The Succulent Karoo is the only semi-arid biodiversity hotspot and is home to 6,356 plant species, $40 \%$ of which are endemic. Yet only $3 \%$ of its $116,000 \mathrm{~km}^{2}$ is protected. Anglo Base Metals operates a zinc mine in one of the most biologically important, yet unprotected, areas in the Karoo and has plans to begin operation of a second. With the intention of minimizing the damage of its activities on

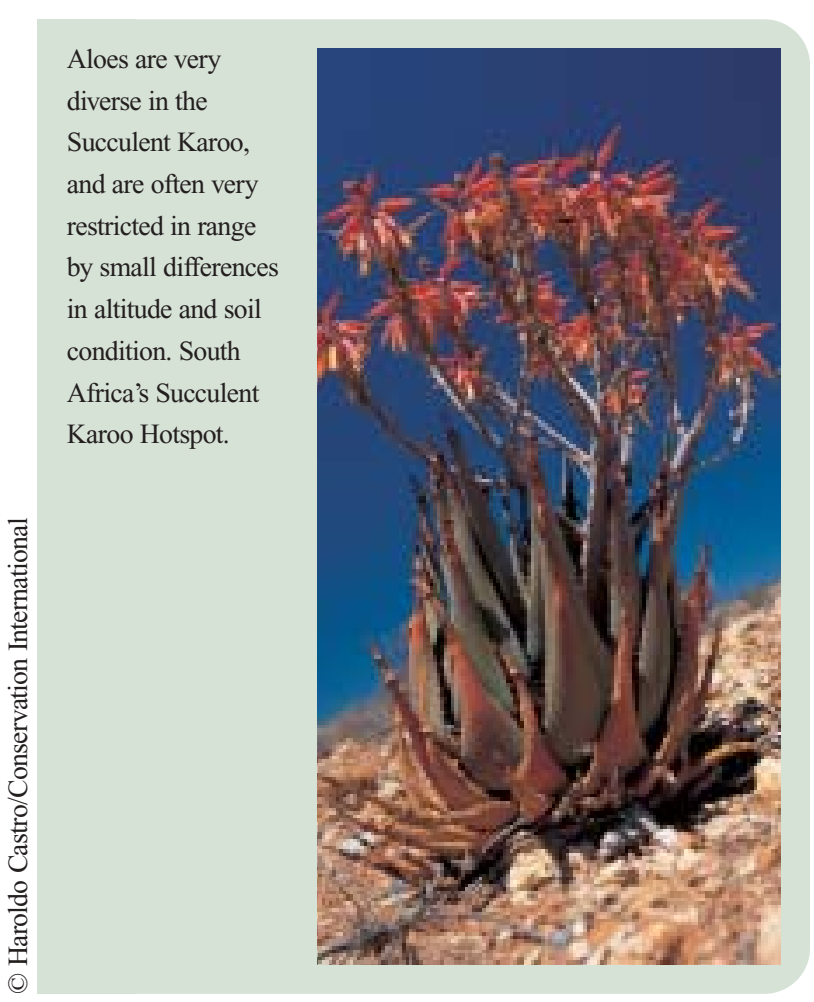

biodiversity, the company joined with conservation groups, communities, farmers, tourist operators and government agencies in a landscape-scale conservation planning process. The approach, Systematic Conservation Planning, identifies conservation outcomes based on identifying a set of options for meeting scientifically set conservation targets (Maze, 2003; Driver, 2003).

An outcome of the study is a proposal to establish a protected area that will be nested within a much larger multi-use landscape with other parts being managed extensively for grazing and a third area being allocated for more intensive development activities, including mining. A feature of the protected areas is that multiple landowners, including the mining company, control the land. The landowners will enter voluntary contractual management arrangements with a conservation agency. In the case of Anglo American, this means managing some of their concession land as a protected area. Where options exist for meeting conservation targets, mining impacts can be offset by contributing to meeting biodiversity conservation targets off the mining property and provides the window for the company to contribute to biodiversity conservation, not simply by reducing its impact but also in terms of making a measurable positive contribution to the protection of biodiversity (Maze, 2003). 


\section{Box 2.3}

\section{Bauxite mining in the protected jarrah forests, South-west Australia}

Alcoa has been mining bauxite in the biologically unique jarrah (Eucalyptus marginata) forests of Western Australia since 1963. The mining company's lease that runs until 2044 covers just less than 713,000 hectares and coexists alongside designated areas that are managed for conservation objectives. Although Alcoa was not operating in protected areas under the original agreement, since it commenced operation a series of assessments of the biodiversity and reviews of the state's conservation strategy resulted in the establishing of protected areas within the original lease area. Alcoa's operations are now restricted to multiple-use jarrah forests and the company has made a commitment not to access conservation reserves. In all, Alcoa has relinquished $15 \%$ of its bauxite reserves for biodiversity.

To ensure that its operating standards are consistent with the objectives of the protected area system, each year Alcoa submits a rolling five-year mine plan to a multi-agency committee, as well as 25 -year indicative mine plans on a regular basis. These mine plans detail further policy commitments that Alcoa has made to avoid entering important areas within the multi-use areas and protecting biodiversity. For example, the company has made a commitment not to disturb forests within $50 \mathrm{~m}$ of granite outcrops as these are areas of high plant species richness and are also sites of significance for indigenous peoples; not to disturb areas of old growth forest that remain outside formal reserves; and the company has established a special procedure for seeking approval to enter a series of 'informal' conservation reserves in the multi-use forest.

Bauxite mining is an intensive process that destroys all aspects of the ecosystem. Alcoa has had some considerable success in rehabilitating mined land, however. Alcoa's rehabilitation goal is to return the land to a "self-sustaining jarrah forest that maintains the water, timber, conservation, recreation, and other values of the pre-mining forest". Currently, about 550ha are mined and rehabilitated annually, and since the commencement of mining, 12,560ha have been cleared and 10,600ha have been rehabilitated. Monitoring and research programmes carried out in the rehabilitated areas show that mine sites rehabilitated in the past are becoming more like the surrounding, un-mined forest.

To be successful in its reforestation efforts, Alcoa has had to face a pervasive threat to the forest ecosystem from the root pathogen Phytopthera cinnamomi that causes the 'dieback' disease that can kill jarrah trees. Because the disease is easily spread throughout the forest by human activities, Alcoa put in place the Dieback Management Strategy (DMS). The DMS uses aerial photography and GIS to produce dieback hygiene maps of affected areas in the mining lease at least 10 years ahead of mining operations to effectively minimize the spread of dieback from mining activities and protect the adjacent forests from infection or intensification of the disease. Machinery operations are subject to strict quarantine and hygiene procedures that include careful routing of access roads, vehicle wash down facilities, and the timing of soil and vehicle movements to periods of low infection risk. A detailed monitoring programme put in place to assess the effectiveness of the DMS found that the spread of the disease that could be attributable to mining was very low, corresponding to $0.005 \mathrm{ha}$ infected for every hectare cleared for mining. Critical information about the pathogen has come from research funded by Alcoa and from the company's own R\&D programme on the 'dieback'. Alcoa scientists contributed to data on the likely presence of the pathogen, while field operators had the practical knowledge on transporting soil and altering drainage patterns. Alcoa has also supported joint research projects on dieback with government agencies and universities over that time. One research programme is attempting to identify and clone seedlings that are resistant to the fungus. Field tests show that jarrah can be replanted in areas affected by the fungus. Over its 44-year history in the area, Alcoa through careful planning has avoided many impacts on protected areas and made considerable contributions to the body of applied scientific knowledge that has been used to improve conservation management. 


\section{Contributions to conservation science}

Equal in importance to winning support for the establishment of protected areas and securing funds for their management is the generation of scientific knowledge about the species within their boundaries. Scientists have recognised only a fraction, maybe less than $10 \%$, of the world's species, and know the biology of only a handful of these (Novotny et al., 2002). Without this knowledge it is difficult, if not impossible, to craft strategies for biodiversity protection and establish a representative protected area system.

Either because they are legally required or because they are acting to comply with their own corporate environmental policies, energy and mining companies carry out, commission, or support a great number of environmental studies in the locality of their projects. Throughout the project cycle, biological data is gathered for base line studies, scientific analysis completed for inclusion in environmental impact assessments, and monitoring programmes put in place to track changes in the physical environment at various scales, from the project site to the regional land or seascape.

QIT Madagascar Minerals S.A. (QMM) has been exploring the feasibility to mine ilmenite in southeastern Madagascar from the mineral sands found beneath the fragile ecology of a littoral forest system. The company hired sixty of its own experts and worked with leading Malagasy and international specialists to undertake extensive, in-depth environmental and social studies over a ten-year period. QMM established partnerships with several leading research institutions, including Missouri Botanical Gardens, Oxford University, Hamburg University, Royal Botanic Gardens at Kew, the Institute of Development Studies at Sussex University and the Smithsonian Institution. Arrangements with academic institutions have enabled 105 Malagasy and international students to complete studies for professional, masters, and doctorate degrees.

The range of taxonomic groups and species studied is impressive. More than fifty volumes contain information on lemur species, invertebrates and pedofauna, small mammals, birds, reptiles, amphibians, fish, shrimps, mussels, algae, multiple flora species and plants, and mycorhiza and rhizobium. To date, 18 papers have been published in scientific publications (Vincelett, 2004, pers. comm.). As a result, there is now available some of the best scientific knowledge possible in regard to the dynamics of the littoral forest ecosystem and specific faunal species. These data and analyses are the bedrock of the biodiversity monitoring programme for the area that is of international importance (Porter et al., 2001).

Data and analysis generated by energy and mining companies can be an important resource for managing protected areas, as the example in Box 2.3 of Alcoa in south-western Australia shows in the control of the deadly dieback disease that threatens the unique jarrah forest (Gardner, 2001; Gardner and Stoneman, 2003). As well, the findings of scientific studies carried out to explore increasingly geologically complex areas can be of equal importance for conservation efforts when used to gather information on species and delineate protected areas. Nowhere is this more the case than in the marine biome, the frontier for both conservation efforts and oil and gas exploration.

Statoil, the Norwegian national oil company, found the first coral reef in Norway at $70^{\circ} \mathrm{N}$ in 1982 using multibeam sonar, a technology used for seismic exploration activities and for routing sub-marine pipelines to avoid sensitive biodiversity. Sonar and echo sounder technologies, combined with new technologies for visualization, and video recording cameras on remotely operated vehicles are increasingly popular tools for mapping coral reefs and their associated macrofauna. Since then the company has been working with scientists at the Norwegian Institute of Marine Research in a collaboration that has led to the protection of the Sulia Reef, one of the largest coral reefs in Norway, and the designation of an inshore coral reef in the Trondheim fjord as a marine nature reserve (IPIECA, 2004b).

\section{Public support for protected areas}

Finally, the extractive industries sector can be an advocate for the global protected area system. Large international energy and mining companies are not without influence. They have an audience with 
Convened by CELB, the EBI includes four energy companies and five NGOs.

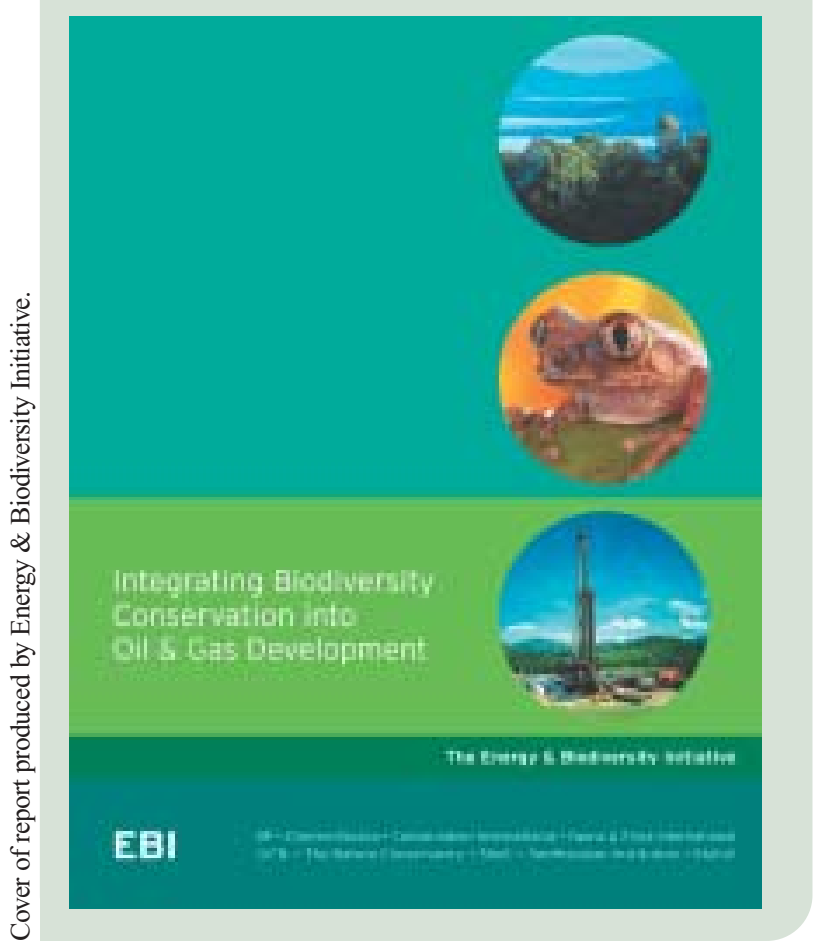

national governments, multilateral development agencies, international financial institutions, development agencies, and industry bodies. Many people concerned about the state of the environment and the behaviour of big business see a universal front standing in opposition to any perceived barrier to companies advancing into areas to explore for minerals, oil, and gas. They perceive companies as seeking to have protected areas degazzetted and the boundaries redrawn. Companies articulating publicly their support for the protected area system can help both to dispel this negative image and contribute to efforts to promote the fundamental importance of protected areas for global conservation (ten Kate, 2003).

The announcements made by Shell and the International Council of Mining and Metals not to operate in existing World Heritage Sites in 2003 is a progressive step (Shell, 2003; International Council on Mining and Metals, 2003). So too is BP's public statement that it recognises the importance of and supports the protected area system. The four company members of the Energy and Biodiversity Initiative (EBI) - Statoil, ChevronTexaco, Shell and BP subscribe to the recommendation in the EBI report that all energy companies "should respect the integrity of protected areas" (Energy and Biodiversity Initiative, 2003). These public acknowledgements of the importance of protected areas help to communicate the importance of and the need for a representative system of protected areas worldwide.

\section{Conclusions}

\section{Public policy, conservation and the extractive industries sector}

The examples given in this chapter of the contributions companies in the extractive industries sector have made in support of protected areas are only a toe in the water of the steady flow of benefits that can be channelled to conservation. This chapter sought only to synthesise the discussions and cases on the subject presented at the Vth World Parks Congress in Durban, not provide an exhaustive survey of such collaborations. Mostly, these successful collaborations and outcomes rely on the voluntary actions of companies and the initiative of protected area professionals. To harness the potential for this new constituency to support protected areas, more formal arrangements need to be put in place.

The establishing by national governments of land-use planning systems that include spatial objectives for conservation and protected areas alongside other economic and social needs, including mineral and oil and gas development (see World Parks Congress Recommendation 5.09, IUCN, 2003), would make it possible for the protected area system to work constructively with the extractive industries. In the absence of clear and equitable planning procedures the combative relations that have embittered the dialogue between the energy and mining companies and conservation organizations will surely continue, and the potential for alliances with the sector will be harder to realize. A review of the IUCN protected area categories recommended at the Vth World Parks Congress (Recommendation 5.19, IUCN, 2003) and its proper use by governments will help build better relations between the two sectors.

The difficulty of building effective integrated planning processes should not be underestimated. There have been successes, however (Koziel and 
Omosa, 2003). In Manitoba Province, Canada, for example, the process for identifying candidate protected areas involves the mineral exploration industry, the Government of Manitoba, Parks and Natural Areas Branch of the Department of Conservation, Geological Survey and Mines Branch, and representatives from the Canadian Nature Federation and the World Wildlife Fund. A systematic, government-led process such as this that draws in conservationists, landowners and other stakeholders to share their knowledge and goals stands a better chance of arriving at sustainable land-use choices, than do decisions based on incomplete information.

Ensuring that biodiversity conservation is taken into full account by sponsors and operators of extractive projects can ease pressure on protected areas (see World Parks Congress Recommendation 5.28, IUCN, 2003). Unfortunately, international standards relating to biodiversity are poorly represented in regulations for mining and oil and gas development. This is especially the case with environmental impact assessments. There are guidelines published by industry and conservation groups on how best to integrate biodiversity issues with mineral and oil and gas development (for example the Energy and Biodiversity Initiative [EBI 2003] and the IUCN ICMM Mining and Biodiversity Dialogue [IUCN 2004]). These guidelines could be used by government agencies to develop contractual 'best practice' and technical conditions and be attached to exploration and production permits.
This burden should not fall solely on the creaking resource base of government agencies but also with the better-endowed multilateral agencies. The World Bank Group's safeguard policies and Natural Habitats policy are the de facto standard for the industry sector. In response to the Extractive Industries Review (2003) the World Bank could set the bar internationally by reviewing its environmental policies and ensure that they are truly world standard, enforceable, and practised. To this end the World Bank could establish a facility that would draw on the expertise in the conservation community and provide technical assistance for evaluating the environmental feasibility of mining, oil and gas development projects.

Finally, governments could provide incentives for companies to direct funds to conservation and protected areas (see World Parks Congress Recommendation 5.08, IUCN). This could be achieved through allowing part of royalties or taxes due to the central exchequer to be offset by both inkind and financial resources used to benefit land-based conservation projects. And bilateral and multilateral lending agencies, for too long the primary international provider of conservation funds, need to recognise the deep well of financial resources that can and should be tapped through strategic alliances with the extractive industries. USAID's GDA programme is a fine example of a public-private alliance (Gill, 2003) that should be bolstered, more generally demonstrated, and news of its effectiveness broadcast widely.
Community meeting with local village chiefs with Guinea Ecology representative, Conservation International representative and Alcoa representative. In the photo they are looking at a biodiversity priority setting map for the region. Alcoa is planning on sourcing an aluminum refinery in the region and is examining biodiversity and socio-economic

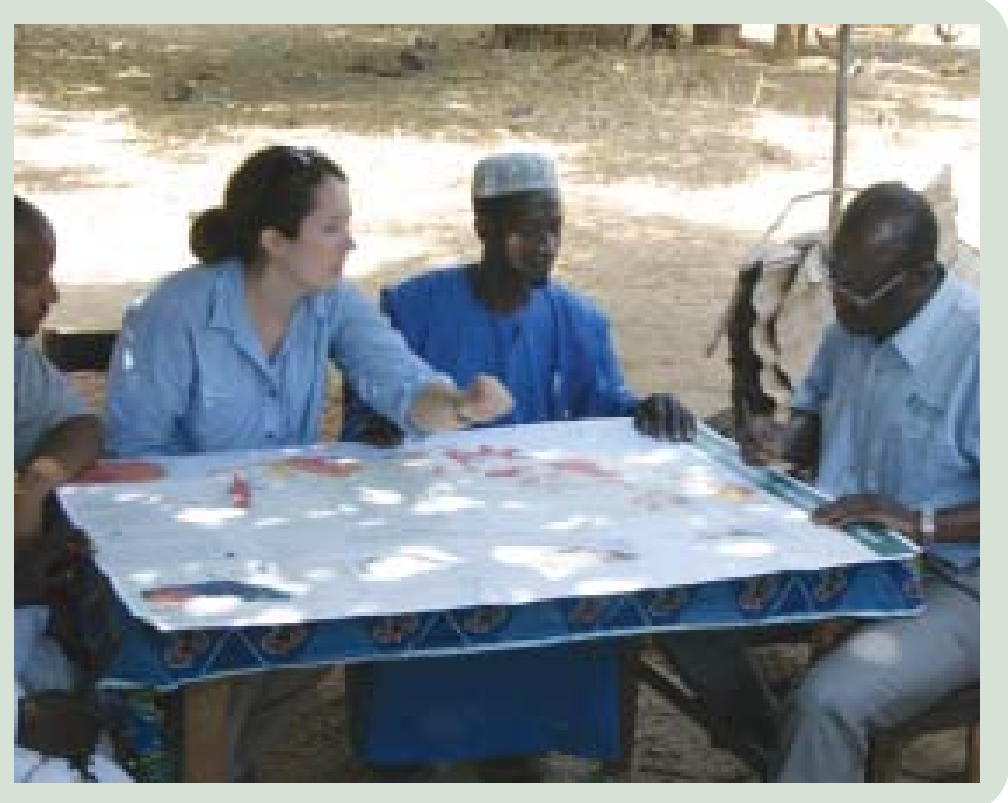




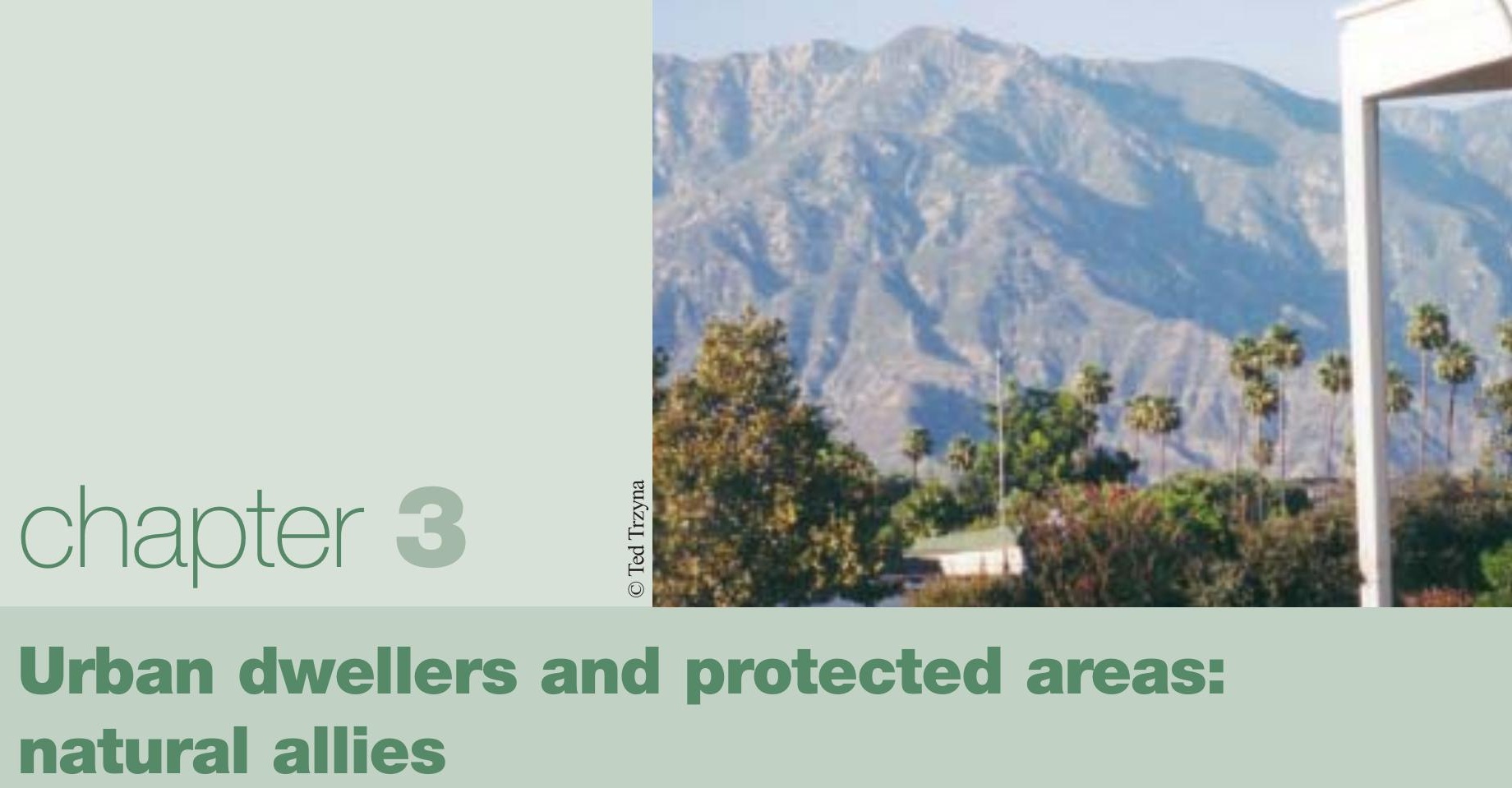

by Ted Trzyna

\section{Editor's introduction}

Protected areas may seem to be the opposite of cities, with the former celebrating nature while the latter are essentially human-made environments. Yet in this chapter, Ted Trzyna shows that people living in cities are both highly dependent on protected areas (for example, protected areas provide water to cities and make substantial contributions to social welfare), and protected areas depend on urban people, for political support, economic support, and the biodiversity conserved in urban settings. This chapter contains numerous examples of cities that are working to enhance the relationship between urban people and protected areas, through providing opportunities for the urban poor to visit protected areas, establishing partnerships with students and the interested public, and establishing protected areas within cities. When cities adopt an ecosystem approach to management, they can make significant contributions to national strategies for conserving biodiversity, and this in turn will greatly benefit protected areas if a real commitment is made to enable urban people to experience nature. Bringing together those working on urban problems with those working on conservation problems can provide multiple benefits, not least in building a stronger political constituency that can yield significant support for sustainable livelihoods and yield a better quality of life for urban people. 


\section{Introduction}

Cities have had a bad name in many quarters of the conservation community, even though most conservationists live in cities and depend on urban people for political and financial support. Conversely, the conservation movement has had a bad name among many who work on urban problems, even though protected areas safeguard the larger ecosystems on which cities depend.

The truth is that protecting nature and improving city life are interdependent goals. Conservation and urban leaders are natural allies. The challenge is in making the right connections.

\section{A rapidly urbanizing world}

The distribution of the world's population between rural and urban areas is changing fast. Globally, the proportion of people living in cities rose from about $30 \%$ in 1950 to $47 \%$ in 2000 , and is projected to reach $50 \%$ in 2007 and $61 \%$ by 2030 . Contrary to a commonly held belief, the proportion of people living in "megacities" (urban agglomerations of 10 million inhabitants or more) is small, less than $4 \%$. In fact, most urban dwellers live in settlements with fewer than half a million inhabitants, and some of the fastest growing cities have relatively small populations.

The world regions show marked differences in the level and pace of urbanization. In the Americas, Europe, and Oceania, the proportion of people living in urban areas is already over $70 \%$. Although the figures for Africa and Asia are currently much lower, $38 \%$ and $37 \%$, respectively, many cities in those regions are projected to double their populations in the next 15 years (UN, 2004).

Almost all the global population increase expected during 2000-2030 will be absorbed by the urban areas of the less developed regions. Based on current trends, most of these new urban dwellers will live in overcrowded slums, often situated on marginal and dangerous land, without sanitation or easily accessible access to clean water. According to the Cities Alliance, a World Bank-based partnership of official development agencies and global associations of local authorities, "ignoring this policy challenge risks condemning hundreds of millions of people to an urban future of misery, insecurity, and environmental degradation on a truly awesome scale" (CA, 2004).

These trends have important implications for the conservation community.

\section{Cities depend on protected areas}

Protected areas provide important benefits to city dwellers, ranging from education and healthy recreation to watershed protection, biodiversity conservation, food and fuel, and income from tourism. However, these benefits have rarely been catalogued or presented in clear terms and urban residents generally have a poor understanding of them. Research documenting such benefits can be very useful in demonstrating the value of protected areas to decision makers, as is shown by the following examples.

\section{Documenting water supply in the world's largest cities}

Over a third of the world's hundred largest cities draw a substantial proportion of their drinking water from protected forests. The agencies responsible for protecting these areas range from national park services to municipal water departments. Forested watersheds almost always result in purer water than alternative land uses. In a world in which an estimated one billion city dwellers lack clean water, this is a powerful argument for preserving and restoring forests (Dudley and Stolton, 2005). Protected areas are an important means for doing so.

\section{Demonstrating social benefits}

The idea that protected areas provide substantial health and other social benefits to urban people is not a new one. The American landscape architect Fredrick Law Olmsted wrote in 1870 that nature "operates by unconscious processes to relax and relieve tensions created by the artificial surroundings of urban life" (Maller et al., 2002). However, only recently have these benefits started to be examined critically and systematically. One important such initiative is sponsored by the park agency of the Australian state 
of Victoria as part of a programme called Healthy Parks, Healthy People. About $75 \%$ of Victoria's 4.5 million population is concentrated in metropolitan Melbourne. Parks Victoria wanted to encourage wider use of open spaces and build support for protecting them. It compiled strong scientific evidence showing that access to nature in urban settings can reduce crime, foster psychological well-being, reduce stress, boost immunity, enhance productivity, and aid community cohesion and identity (Senior and Townsend, 2005).

\section{Measuring economic benefits}

Several conservation agencies are working to measure the economic benefits urban residents derive from protected areas. For example, in Durban, South Africa (population 3 million), the environmental management staff of the municipal government is examining the economic value of ecosystem goods and services from the city's extensive open space system. This is in response to a need to realign environmental planning with new development goals emphasising poverty alleviation and economic opportunity. Although many people saw the open space system as elitist, initial research shows that it is a significant provider of "free" goods and services such as water supply, flood protection, fishing, fuel wood, plants for traditional medicine, climate regulation, and waste treatment (Roberts et al., 2005).

The environment agency of the Australian state of New South Wales, whose population is concentrated in metropolitan Sydney (population 4.2 million), is developing quantitative indicators to assess the contribution of protected areas to the quality of life in an urban community. However, this information is seen as only a first step that will have limited utility unless it is "part of a broader approach to influencing communities and decision-makers to support protected areas and conservation," an approach that includes promoting natural and cultural values (Conner, 2005).

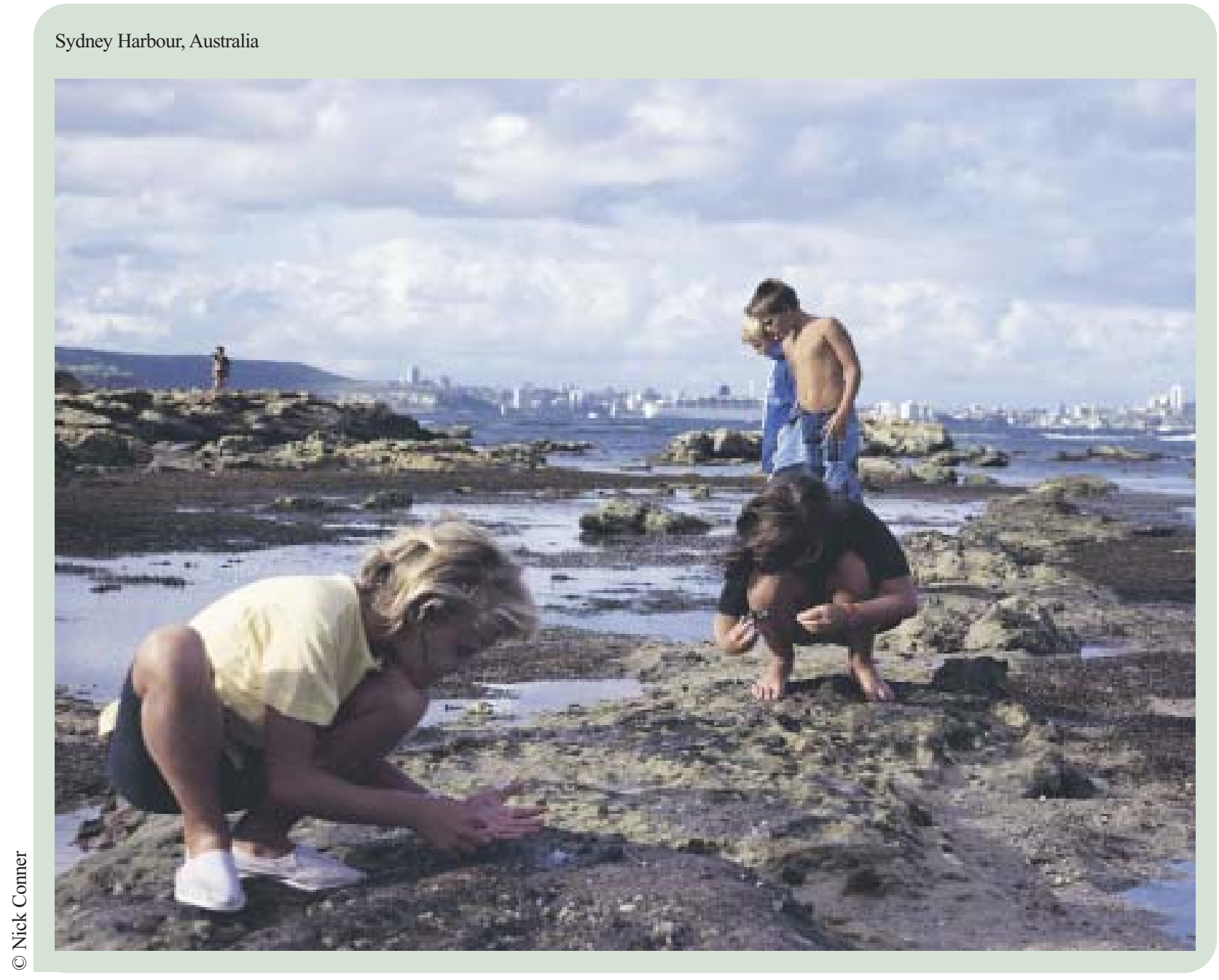




\section{Protected areas depend on urban people}

As cities depend on protected areas, urban dwellers are essential to building broader support for protected areas. Throughout the world, political power, opinion makers, and communications media are concentrated in major cities. It follows that protected area agencies need a presence in those cities. A former director of Tijuca National Park in Rio de Janeiro has made the point eloquently: "The fight for the conservation of the Amazon will not be won in the depths of the Amazon forest. It can only be won in Rio de Janeiro, São Paolo, Brasilia, and the other large Brazilian metropolises. In democracies, no matter how obvious management decisions are, they must always be decided by the will of the citizens, and citizens will not decide or care about the unfamiliar" (Cunha e Menezes, 2005).

City dwellers gain appreciation for nature less through conventional education than through outdoor experiences. In fact, without direct experience of nature early in life, teaching about environmental issues can actually breed cynicism about the environment (Finger, 1994; Schultz, 2000; Schultz, 2002). Growing scientific evidence indicates that direct experience of nature early in life is essential for healthy intellectual, emotional, and even moral development (Kahn and Kellert, 2002).

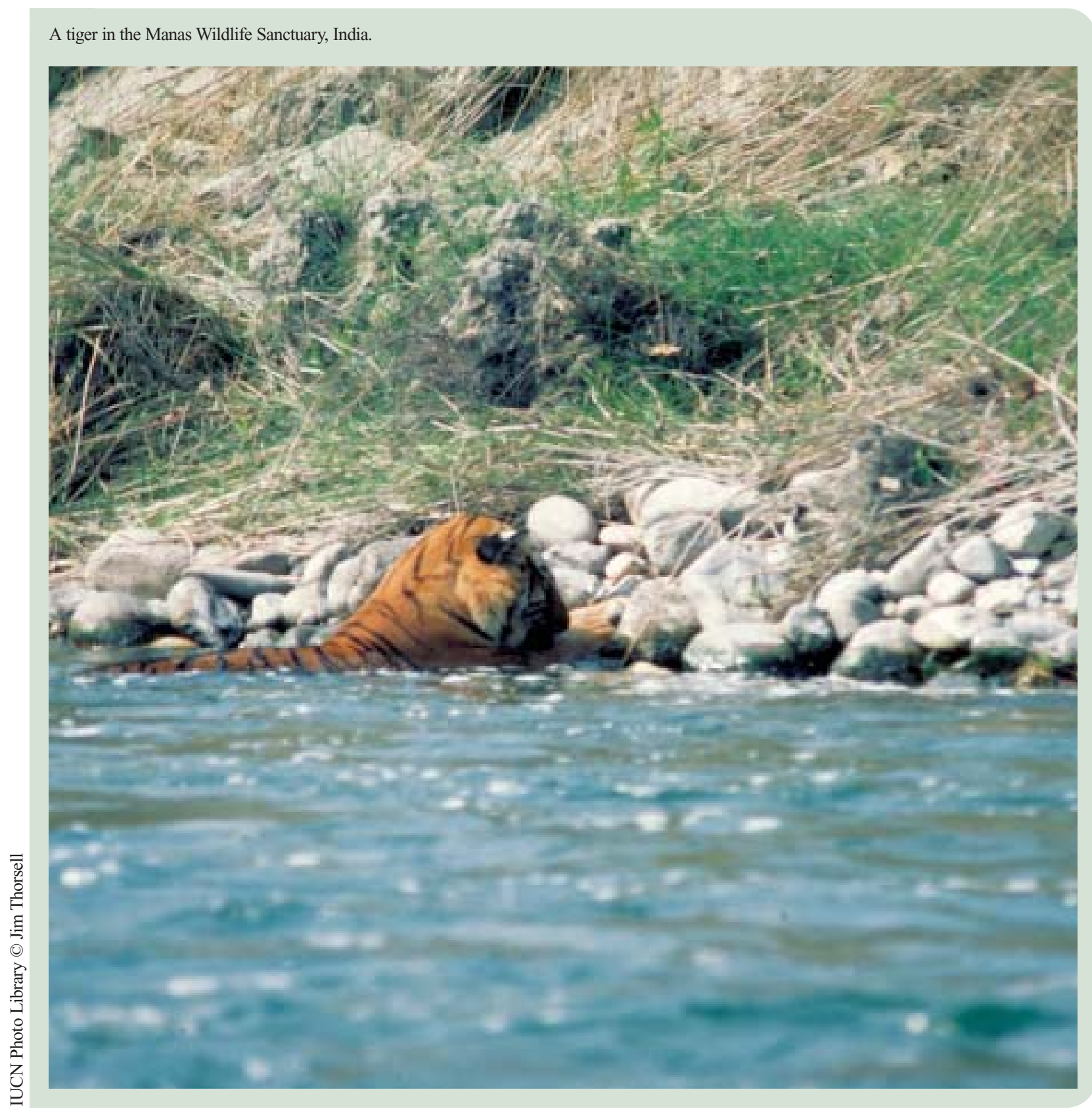


Unfortunately, people in cities tend to be less and less familiar with nature and the benefits of natural resources. This phenomenon cuts across social groups. The urban poor often have no access to nature. The more affluent are experiencing what Bob Pyle calls "the rise of the virtual in place of the real," as television, computer games, the Internet and "other forms of second-hand entertainment have come to occupy an ever more enormous portion of childhood's hours" (Pyle, 2002). As a consequence, not only does the quality of urban dwellers' lives suffer, they may behave irresponsibly toward the environment, albeit unknowingly, and over the long run be less inclined to provide political support for conservation.

Agencies responsible for protected areas can serve urban residents through conventional activities such as preserving, restoring, and interpreting natural areas in and near cities, but also through less conventional roles such as reaching out to disadvantaged people, working to bridge social divisions through shared experiences in nature, and helping to "green" and promote sustainable development in cities. Following are several examples of successful initiatives by conservation agencies and their partners to reach out to urban populations.

\section{Reaching large numbers of children: India's Kids for Tigers}

Kids for Tigers was launched in 2001 by the publisher of India's leading wildlife magazines, with support from a major business corporation and the involvement of Project Tiger, part of the Government of India ministry responsible for protected areas. In keeping with Project Tiger's philosophy, the tiger is a symbol for all of nature. Kids for Tigers aims at turning large numbers of urban children, and through them their parents, into "proactive defenders of protected areas." As its founder Bittu Sahgal puts it, "Our story was simple and direct and children understood it easily: 'We cannot save the tiger unless we save its forests. If we save its forests we wind up saving the subcontinent's most precious water sources. And if we save our water sources, we save ourselves." The programme reaches over a million children a year through hundreds of schools in 13 cities, including Mumbai and Delhi (which have populations, respectively, of 18.4 and 17.5 million). Children with exceptional potential are chosen to participate in a nature camp at a tiger reserve (Sahgal, 2005).

\section{Greening cities: Examples from Los Angeles and London}

The global movement to "green" cities ranges from planting street trees and creating urban farms on one hand to protecting and restoring natural areas on the other. These are usually seen as quite separate activities, but they actually reinforce each other. In poor areas, for example, neighbourhood gardens can be important stepping stones to understanding nature and visiting more distant protected areas; broader support for conservation can result.

Greening initiatives and responsibility for them vary greatly among cities, but at least two questions are probably relevant everywhere: What are possible roles in urban greening for traditional national (and state or provincial) protected area agencies? What can these agencies learn from local initiatives, and vice versa?

First, an example from a traditional, although unusual, protected area agency. In metropolitan Los Angeles (population 16 million), the Santa Monica Mountains Conservancy, a unit of the California state government, is creating "natural parks" in poor innercity neighbourhoods. This is an exceptional step for an agency such as SMMC, which was originally set up in 1979 to protect remaining natural areas in a mountain range that bisects the city and includes some of the most expensive real estate in the world.

During its first two decades, SMMC reached out to inner-city residents by providing free outings for school and neighbourhood groups in its mountain parks. In the mid-1990s, SMMC's Executive Director, Joe Edmiston, was challenged by a city council member representing a poor district in South Los Angeles to do something for her constituents. In fact, Edmiston had long been bothered by the inaccessibility of nature experiences to people living in the inner city. The result was the 3.5ha Augustus F. Hawkins Natural Park, opened in December 2000. The park lies on a busy street surrounded by recycling businesses and run-down houses. Designed as a portal to the natural protected areas nearby, it has samples of 


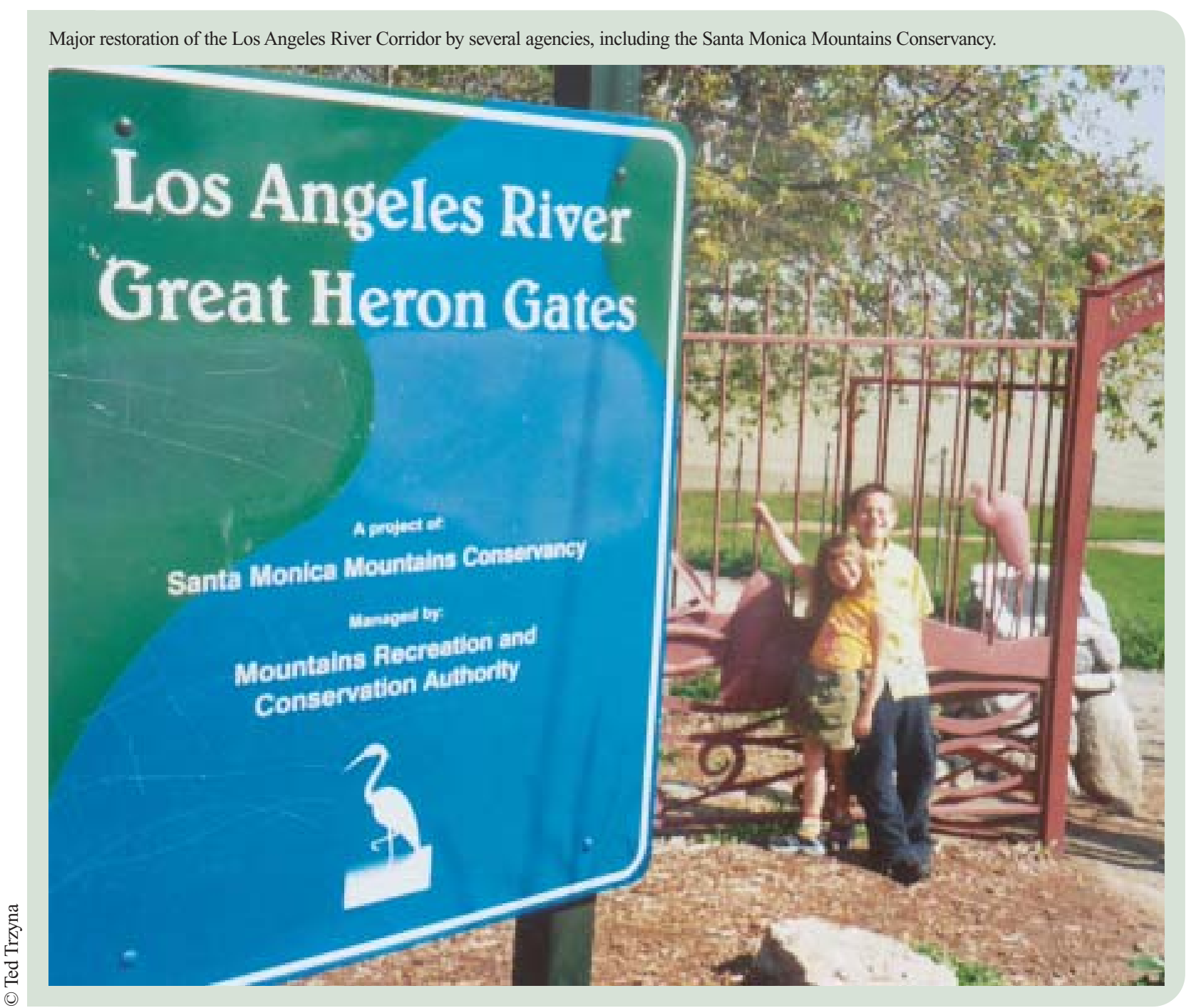

seven ecosystems, including chaparral and freshwater marsh. The visitor centre and other structures conform to the high design standards the conservancy applies to all its projects. A ranger resides on site, supporting a junior ranger programme and organizing trips to the conservancy's mountain parks.

The conservancy's landscape architect, Stephanie Landregan, who shepherded the project, notes that initially "there were lots of naysayers who said 'why are you giving that to those people?"' However, the park is now seen as a great success and there are plans to replicate it elsewhere in Los Angeles. The most innovative of these plans is for a four-hectare natural park on the grounds of a new high school. The school will be divided into several specialized "academies," of which one will likely be a "Conservancy Academy" devoted to education in natural resource management (Trzyna, 2001a; Sorvig, 2002).
Second, an example from local government. In Greater London (population 11.9 million), the Mayor adopted a Biodiversity Strategy in 2002 that aims to "protect and enhance London's natural areas and their associated species and make it possible for Londoners to have greater contact with nature in their everyday lives." According to David Goode, Head of Environment in the Mayor's office and a longtime leader in urban conservation, under this Strategy, "New approaches with a strong social dimension, that may at first have seemed a radical departure from traditional nature conservation, have now been adopted as an integral part of city management." For example, access to nature for people living in disadvantaged or heavily built-up parts of London is often given priority even where sites are of relatively low ecological quality. Areas where residents lack accessible wildlife sites "within reasonable proximity" are being mapped to guide future habitat enhancement or creation and even landscaping. Other 
goals are ensuring that more people know the location of their local green space and can get there easily, and helping people understand and enjoy contact with nature.

Another key element of London's Biodiversity Strategy is a system for protecting important wildlife habitats. Over 1500 sites are listed for protection under the local planning process. These represent about one fifth of the area of Greater London. In addition, wildlife habitat is being created by enhancing public parks and open spaces and "mainstreaming biodiversity as an element of urban design."

The Strategy evolved out of work that began in 1982 in the public sector and was continued for many years by an officially sanctioned NGO called the London Ecology Unit. One of the unit's main objectives was building nature conservation into the strategic planning process in London. It produced a long series of handbooks, starting with Ecology and Conservation in London (1984), and included such titles as Nature Areas for City People (1990) and Building Green: A Guide to Using Plants on Roofs, Walls, and Pavements (1993). These handbooks were widely distributed and were crucial to gaining public and political support for urban conservation in London. They were also influential internationally.

The Biodiversity Strategy is one of eight strategies the Mayor is required to adopt by statute. (The others relate to air quality, culture, economic development, noise, transport, spatial development, and waste.) Together, they set out an integrated social, economic, and environmental framework for the development of London (Goode, 2005; London, 2002).

\section{Bridging divisions in urban society: Examples from South Africa and the United Kingdom}

Urban populations are often located along economic and ethnic lines. Protected area agencies and their allies need to reach out to these different groups. In addition, they can help build bridges across divisions in society through shared experiences in nature.

Within the boundaries of metropolitan Cape Town (population 3.5 million) is an extraordinary array of remnant natural areas that contain 1400 indigenous plant species, including 131 rare or endangered species of which 76 are narrow endemics. These plants are part of ecosystems that support a rich diversity of birds, reptiles, and other animals. Many of the most threatened natural areas are on the Cape Flats, once an interesting mosaic of dunes and wetlands, now largely developed. Part of this development is housing built under programmes to relocate and segregate non-white people during South Africa's era of apartheid, a race-based separatist system that existed from 1948 until the early 1990s. Then, when the apartheid controls ended, informal settlements sprang up on the flats to house an influx of job-seekers from rural areas. These informal settlements lack proper supplies of water, electricity, or sanitation. Up to three-quarters of their residents live below the country's poverty line of US $\$ 45$ per adult per month. Many earn much less.

To put this in context, the poorest $40 \%$ of the population of Cape Town as a whole earns less than $4 \%$ of the total income generated in the city, while the wealthiest $20 \%$ commands $70 \%$ of this amount. Divisions in Cape Town society coincide largely with ethnic and racial boundaries, and are exacerbated by nearly half a century of apartheid.

A project called Cape Flats Nature: Mainstreaming Biodiversity for the People addresses "this paradox of biodiversity wealth and human poverty on the Cape Flats in a positive way." Cape Flats Nature is a partnership of the City of Cape Town, conservation NGOs, local community groups, and the National Botanical Institute (a parastatal conservation and research agency). It works by "engaging with people rather than by erecting fences." Initially it focused on four pilot sites of high biodiversity value where local communities were willing to become involved. The programme is being expanded and adjusted as lessons are learned. Activities are quite varied. For example, a garden has been created to demonstrate indigenous plants of direct value to people, including those used by traditional medical practitioners. A prime coastal natural area is being reclaimed from criminal activity. Bird-banding sessions are held to expose disadvantaged youth to scientific methods. Community members are trained in fire-fighting to 
prepare for volunteer emergency work. These and other activities are beginning to build support for biodiversity conservation among Cape Flats residents (Davis, 2005; CFN, 2004).

In the United Kingdom, two NGOs set up the Mosaic project in 2002 to enable members of ethnic minority groups in England and Wales to "access everything that national parks have to offer." The NGOs are the Black Environment Network and the Council for National Parks. BEN "works across diverse sectors for ethnic environmental participation." (It "uses the word 'black' symbolically, recognizing that the black communities are the most visible of all ethnic groups [in Britain]. We work with white, black, and other ethnic communities"). CNP "promotes the conservation, enhancement, quiet enjoyment, and understanding of the national parks of England and Wales" (BEN 2004; CNP 2004).

Mosaic was inspired by an address by Judy Ling Wong, BEN's director, to a 1999 conference marking the fiftieth anniversary of the act that made possible the creation of national parks in England and Wales. She noted that although British society was increasingly diverse, members of minority ethnic groups were rarely seen in national parks. "People cannot care about what they have not experienced," she said. "Neither will they have much interest in paying the taxes or providing the political support which is necessary to maintain viable national parks for the next fifty years" (Memon, 2005).

In 2001, Mosaic was set up as a three-year project to experiment with methods and develop a model for enabling national parks to "gain the awareness and skills to work effectively with ethnic groups and to enable ethnic groups to enjoy national parks and to represent their interests and concerns." Mosaic first concentrated on organizing group visits of people from urban ethnic minority communities to eight national parks in the countryside. One series of visits, for example, was for separate groups of Muslim women, Sikhs, older Chinese, and Afro-Caribbean youth. These experiences were carefully evaluated. Later, Mosaic focused on involving ethnic groups in planning park activities. The final year of the project is being devoted to reviewing lessons learned, "paving the way for all national parks to put into place and resource their own initiatives to take forward the work of establishing links with ethnic communities into the future" (Memon, 2005; CNP, 2004).

Since January 2005, the new Mosaic Partnership has continued its work amongst the British minority ethnic communities, strengthening communications and relationships between their representatives and the Park Authorities, the Youth Hostel Association and the Council for National Parks.

(The term "ethnic minority" is accepted in the UK, although it is considered inappropriate in some other places, for example South Africa, where a minority oppressed the majority under apartheid; and California, which no longer has an ethnic or racial majority.)

\section{"Changing places, changing lives": Groundwork in the United Kingdom}

In rural areas, especially in developing countries, conservationists routinely work to improve the circumstances of local people. This started mainly because it was understood that helping people would motivate them to cooperate in protecting wildlife and protected areas. Eventually, in many cases, it was done because it was the right thing to do.

As protected area agencies and their allies become more involved in cities, they soon realize that environmental, social, and economic issues are intertwined. One question they face is how far to go in meeting the needs of poor people in the neighbourhoods where they work.

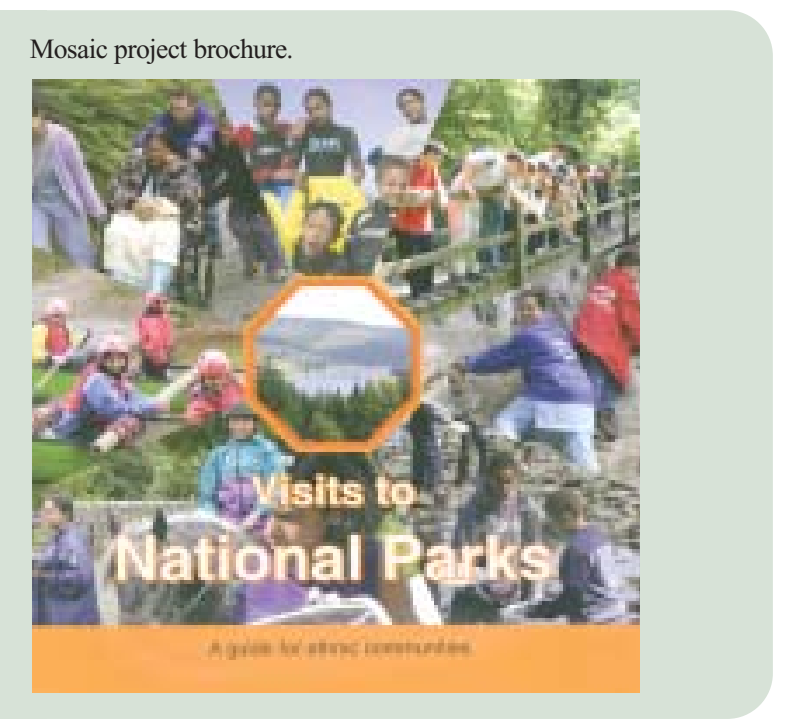


In the United Kingdom, the agency responsible for national parks and countryside management was asked by the government in the early 1980 s to do something about abandoned industrial sites and played-out quarries in the urban fringe areas of the economically depressed Northwest of England. Conventional top-down approaches didn't work, so it was decided to take a more flexible approach. An "environmental partnership" NGO called Groundwork was set up to bring the public, business, and voluntary sectors together in clearly defined geographic areas to clean up contaminated sites, create parks and green corridors, build hiking and biking trails, and convert abandoned buildings to offices and housing.

Groundwork has been a great success. Almost fifty local Groundwork "trusts," as the local organizations are called, exist in the UK. They include more than a quarter of the country's population. The areas in which they operate now span inner city and countryside, as well as urban fringe, but they are still places where the quality of life is poor owing to a combination of economic, social, and environmental problems. Overall, Groundwork has an annual budget of some US\$100 million and over a thousand employees. It is involved in over 3000 projects at any given time.

Groundwork's motto is "changing places, changing lives." Its purpose is to "build sustainable communities through joint environmental action." Although many of its projects still relate to parks, open space, and outdoor recreation, it is also heavily involved in such areas as environmental education and advising small businesses on compliance with environmental regulations. One programme aims to reduce crime among teenagers by involving them in hands-on environmental improvement projects. Another programme trains unemployed people for new "green collar" jobs in such fields as recycling.

The main ingredient of Groundwork's success is engagement with local communities and serving their expressed needs. John Davidson, co-founder and former chief executive of Groundwork UK, explains that "We had to get into a dialogue with people. For there to be sustained regeneration, we had to invent incentives." Such "participatory planning" is much more demanding than the conventional kind, but much more likely to produce results, he believes. The key is to "achieve social and economic benefits at the same time as achieving conservation benefits" (Trzyna, 2001b; Groundwork, 2004).

\section{The key role of partnerships}

Partnerships are essential to connecting protected area agencies with urban institutions. All of the programmes described above rely on such partnerships. For example, Kids for Tigers works through schools. California's Santa Monica Mountains Conservancy has representatives of local authorities, other state government agencies, and national agencies on its governing board. South Africa's Cape Flats Nature is a multi-partner project.

However, two special kinds of partnership organizations can be particularly useful to protected area agencies in connecting with city people: urban cooperating associations; and metropolitan umbrella organizations. A third model, urban biosphere reserves, approaches the problem from a different perspective.

\section{Urban cooperating associations}

Cooperating associations are NGOs dedicated to serving the needs of one or more protected areas. A good example of a cooperating association in an urban area is the Golden Gate National Parks Conservancy. The Golden Gate National Recreation Area, known informally as the Golden Gate National Parks, contains natural, cultural, and historic units of the US National Park Service covering 30,000 hectares in California's San Francisco Bay Area (population 7.3 million). Its NGO partner, the conservancy, was established in 1981 to increase awareness of the Golden Gate parks and their value; provide avenues for public engagement to bring more resources to the parks; and preserve the parks over time by building long-term constituencies. The conservancy "leverages" the role of its public partner. It raises substantial amounts of money for projects such as visitor centres, youth programmes, and restoration of natural areas, and engages over 110,000 volunteers annually in the parks. 
According to the parks' General Superintendent Brian O'Neill and the conservancy's Executive Director Greg Moore, the key to the conservancy's success is community awareness. It "has worked to make the parks as well-known and well-loved as other cherished public assets." Its goal is to "elevate parks to the same level of community importance as other civic assets: as basic as schools; as essential as libraries; as necessary as hospitals; as valuable as clean air and water; as culturally important as symphony halls, opera houses, and museums. The conservancy has achieved this goal with a welldeveloped strategy of research, opinion sampling, marketing, branding, and public opinion-making" (O’Neill and Moore, 2005).

\section{Metropolitan umbrella organizations}

A good example of an umbrella organization that promotes cooperation systematically in an urban region is Chicago Wilderness, a consortium of over 170 organizations in greater Chicago (population 9.4 million). Members include local, state, and national agencies; museums and botanic gardens; colleges and universities; and NGOs ranging from branches of major national associations to small neighbourhood groups. Four teams develop and carry out collaborative activities in science, land management, education and communication, and sustainability. The "wilderness" is a mosaic of natural areas covering some 100,000 hectares of protected lands and waters, as well as many that are unprotected. These areas have a high concentration of globally significant natural communities, including tallgrass prairie and oak savannah.

The ingredients for the consortium's success are a critical mass of people eager to make it succeed; sharing of expertise and resources across organizational boundaries; and early and highly visible accomplishments. A year after the consortium was formally launched in 1996, it published an attractive atlas of biodiversity in the region; more than 50,000 copies have been distributed. Another early accomplishment was agreement on a regional biodiversity recovery plan that still serves as the guide for the work of Chicago Wilderness. A further reason for the consortium's success is a "conscious decision to define it not as an entity unto itself, but rather as a

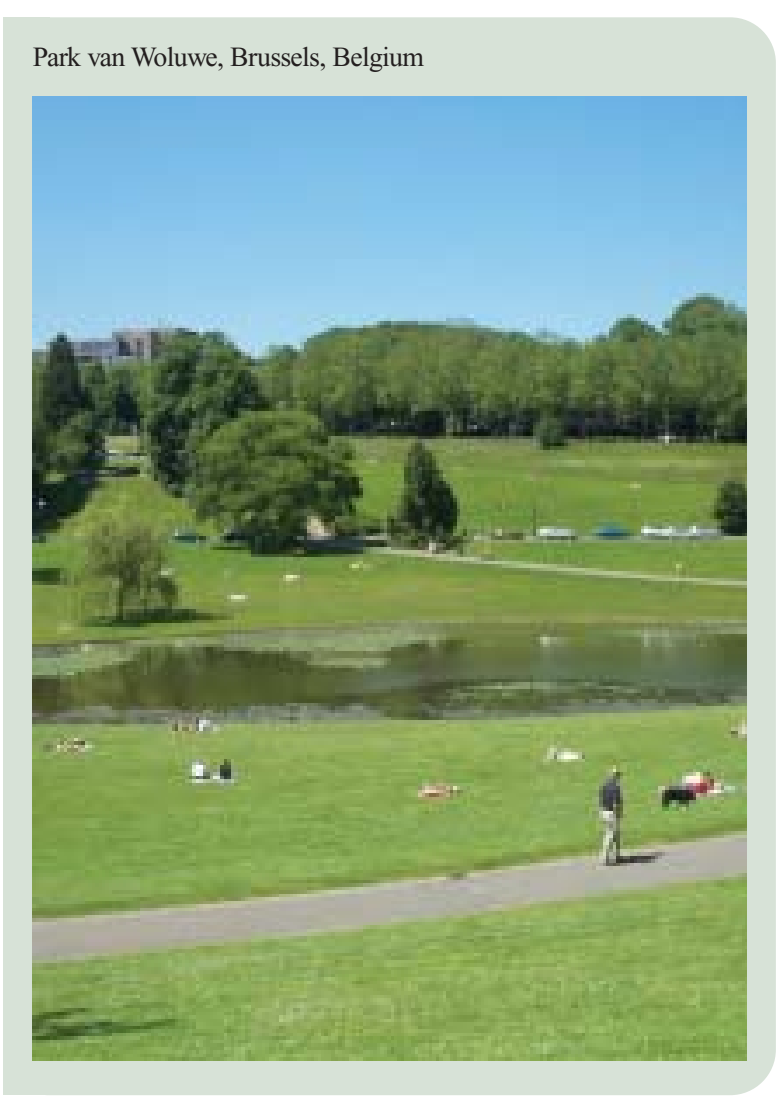

loose network of partners." Its sole purpose is to facilitate collaboration among its members. Its small staff is housed within member organizations, rather than centrally located (Hutcherson, 2005).

\section{Urban biosphere reserves}

Yet another approach to partnerships is the urban biosphere reserve. Biosphere reserves are areas that are internationally recognised within the framework of UNESCO's Man and the Biosphere programme. They consist of a core protected area, or cluster of such areas, a buffer zone, and an outer transition area. Groups in several countries are taking the biosphere reserve concept, typically used in rural areas, and applying it to urban settings. Under UNESCO guidelines, each biosphere reserve is intended to fulfill three complementary functions: (1) conservation of landscapes, ecosystems, species, and genetic variation; (2) local economic development that is culturally, socially, and ecologically sustainable; and (3) research, monitoring, education, and information exchange related to local, national, and global issues of conservation and development. Biosphere reserves bring together stakeholders ranging from conservation agencies and scientists to economic interests and local authorities. In addition, 
one of their main purposes is to foster international exchange of information and experience. UNESCO has set up a network of committees for this purpose (UNESCO, 2004).

Although several biosphere reserves exist in urban areas, their role has generally been limited to coordinating conservation activities. The idea of a distinct category of urban biosphere reserve is being considered in several countries. In October 2003, an international conference was held by Columbia University and UNESCO in New York to discuss the concept (CUBES, 2004). Proposals for urban biosphere reserves are most advanced in Cape Town, New York, and Seoul. The Cape Town Urban Biosphere Group has suggested that guidelines for such areas provide for cultural, as well as natural, cores; include protection of human and cultural, as well as natural, diversity; and allow for applying the zoning system (core, buffer, transition) "in a functional way, and not necessarily spatially specific as with traditional rural biosphere reserves" (CUBES CT, 2003; Stanvliet et al., 2004).

The proponents of the new category of urban biosphere reserve are a lively and creative group. They offer a different perspective on the people-city-nature triad. Their ideas and energy could also help to invigorate the biosphere reserve concept, a good idea that has yet to reach its potential.

\section{Local authorities and international conservation}

Although most organizations active in international conservation are based in large cities, few of them make connections between their international work and urban conservation in their own cities. And it is rare for local governments to become involved in international environmental matters, except in cases where transboundary issues affect them directly.

London is an unusual exception. One of the fourteen policies in its Biodiversity Strategy, discussed above, states that "The Mayor will promote London as a world centre for biodiversity conservation, working with London's world-class organizations for greater influence globally and to learn from experience at home and abroad."
This is elaborated as follows: "The Mayor will foster working links and exchanges with international bodies and organizations in other major cities, to give a lead in urban greening and biodiversity conservation. The Mayor will support enterprising new flagship projects for urban nature conservation and people's enjoyment of the natural world, which may further London's reputation as a World City. The Mayor will encourage the formation of a partnership for excellence in global biodiversity conservation, harnessing the skills and expertise of London's centres of excellence."

This partnership includes the Greater London Authority, the London Zoo, the Natural History Museum, the Royal Botanic Gardens at Kew, the Wildfowl and Wetlands Trust, and the UK Environment Agency (London, 2002).

Other major cities might well follow London's example.

\section{Needed policies}

Two fundamental policy changes are needed to meet the needs of city dwellers and build stronger urban constituencies for nature conservation. These are adopting an ecosystem approach to managing cities and their surroundings, and making a serious commitment to provide ways for urban people to gain access to nature.

\section{Adopting an ecosystem approach to managing cities and their surroundings}

The disconnections between cities and protected area systems are part of a bigger problem. What is needed first and foremost is an ecosystem approach to policy making and policy implementation that recognises the interdependence of cities and the larger environment. An ecosystem approach to natural resource management treats a region as a system of interrelated parts - environmental, social, economic - and embraces the major governmental and other interests affected. In some places, the larger environment is simply the local watershed. In other places, cities reach much farther afield. Los Angeles, for example, receives its water supply from protected areas many hundreds of kilometres away. 
The barriers to ecosystem management are mainly political. Responsibility for environmental matters is fragmented among levels of government and singlepurpose agencies. Each agency acts within its own framework of laws, purposes, constituencies, and organizational culture. Highly effective tools are now available to support integrated decision making. These include sophisticated methods of collaborative problem-solving, as well as geographic information systems that show the interrelationships in a region as never before possible (CIPA, 2001). None of these methods will work, however, without the political will to change, and this depends on an informed public.

\section{Making a serious commitment to provide urban dwellers with access to nature}

All levels of government need to make a serious commitment to providing urban dwellers with access to nature, with particular attention to serving the needs of disadvantaged people. This commitment should be formalized in legislation and plans. An excellent example is the London Mayor's Biodiversity Strategy, which is as much a social as an environmental document.

Many kinds of public agencies can contribute to this goal, ranging from traditional protected area and wildlife agencies to municipal park departments and schools. Much of this work can be done most effectively in partnership with NGOs. In addition, many activities can be carried out by NGOs on their own initiative. The private sector can also contribute, for example, in the way businesses landscape and provide access to their lands.

Many examples of ways of providing access to nature are given in this paper; they and others are discussed in more detail in Trzyna (2005).

\section{Actions required in the coming decade}

\section{Educating the conservation community}

Interest in cities is not widespread in the conservation community. One reason for this is that many people are attracted to conservation careers because they want to spend their lives in the countryside. Another reason is a feeling that involvement in cities detracts from what is perceived as the main task of conservation, protecting biodiversity, even though research in many parts of the world shows that urban and periurban areas are exceptionally rich in indigenous species, and that threats to such species are usually higher in these places. Another important barrier to getting conservationists more interested in cities may be resistance to becoming involved with urban social issues for which they are unprepared.

The conservation community needs to be educated about the "why" and "how" of links with urban institutions and city dwellers. This can be done most effectively by those who are succeeding in making those links. Some prominent examples are mentioned in this paper.

\section{Bringing urban and conservation actors together}

With few exceptions, separate sets of people and institutions work on urban issues and on conservation. At local, national, and international levels each side would benefit from better understanding of the concerns of the other. Both would benefit from identifying common goals and working toward them together.

A good place to start is dialogue at international and local levels between conservationists on one hand and urban officials, managers, and planners on the other. At the global level, international conservation organizations such as IUCN could invite prominent mayors and leaders of the major associations of local authorities, city planners, and related professions to major events such the World Conservation Congress. Conservation organizations could arrange for speakers and panels at conferences of such cityoriented associations. These international activities should be complemented by meetings of local leaders from both sides of the conservation-urban equation, beginning with experiments in a few carefully chosen cities. All these discussions should be aimed at setting up and reinforcing partnerships.

In addition, IUCN, whose membership is dominated by traditional conservation organizations, should follow a recommendation of the World Parks 
Congress (see below) that it "recruit as members organizations engaged in urban environmental issues, and invite prominent leaders and experts in urban management to participate in the work of IUCN."

\section{Training leaders}

Leadership development is critical. This should include an international short course for leaders with high potential, as well as leadership forums in individual cities. In both cases, participants should come from urban institutions as well as conservation organizations. They would learn from local and international speakers, share experiences, and build networks of people and institutions.

\section{Assembling a toolkit}

A toolkit is needed for practitioners responsible for linking conservation and urban issues, and for instructors training those who want to engage in such activities. Toolkits typically include case studies and guidelines drawn from them, along with other material about specific methods.

Case studies and guidelines are widely accepted models for international sharing of experience among conservationists. They are usually very helpful to practitioners and educators. However, it often helps if the case studies are written by people who have not participated in the cases being described, which is rarely so.

A toolkit for linking urban dwellers to protected areas, and promoting the larger concept of managing cities as parts of larger ecosystems, should also include advice on such methods as collaborative decisionmaking and use of such technical resources as satellite imagery and geographic information systems.

\section{Conducting exchanges, study tours, and technical assistance}

Toolkits are useful, but they are not a substitute for direct sharing of experience through exchanges, study tours, workshops, and technical assistance. Such sharing can be among cities within a country or world region, or by theme or language. An initiative on cities and conservation in the world's five Mediterraneantype ecosystems is already underway (CIPA, 2004).
Cities are particularly suited to international cooperation because they often have more in common with each other than with their hinterlands. Cities in industrialized countries have much to learn from those in developing countries, as well as vice versa. Examples of this are India's Kids for Tigers and South Africa's Cape Flats Nature project.

\section{Reaching political leaders}

More must be done to reach elected and senior appointed government officials with the conservation message. First of all, a better case must be made for connecting urban dwellers with nature. Those who decide on budgets increasingly want measurable objectives against which results can be evaluated.

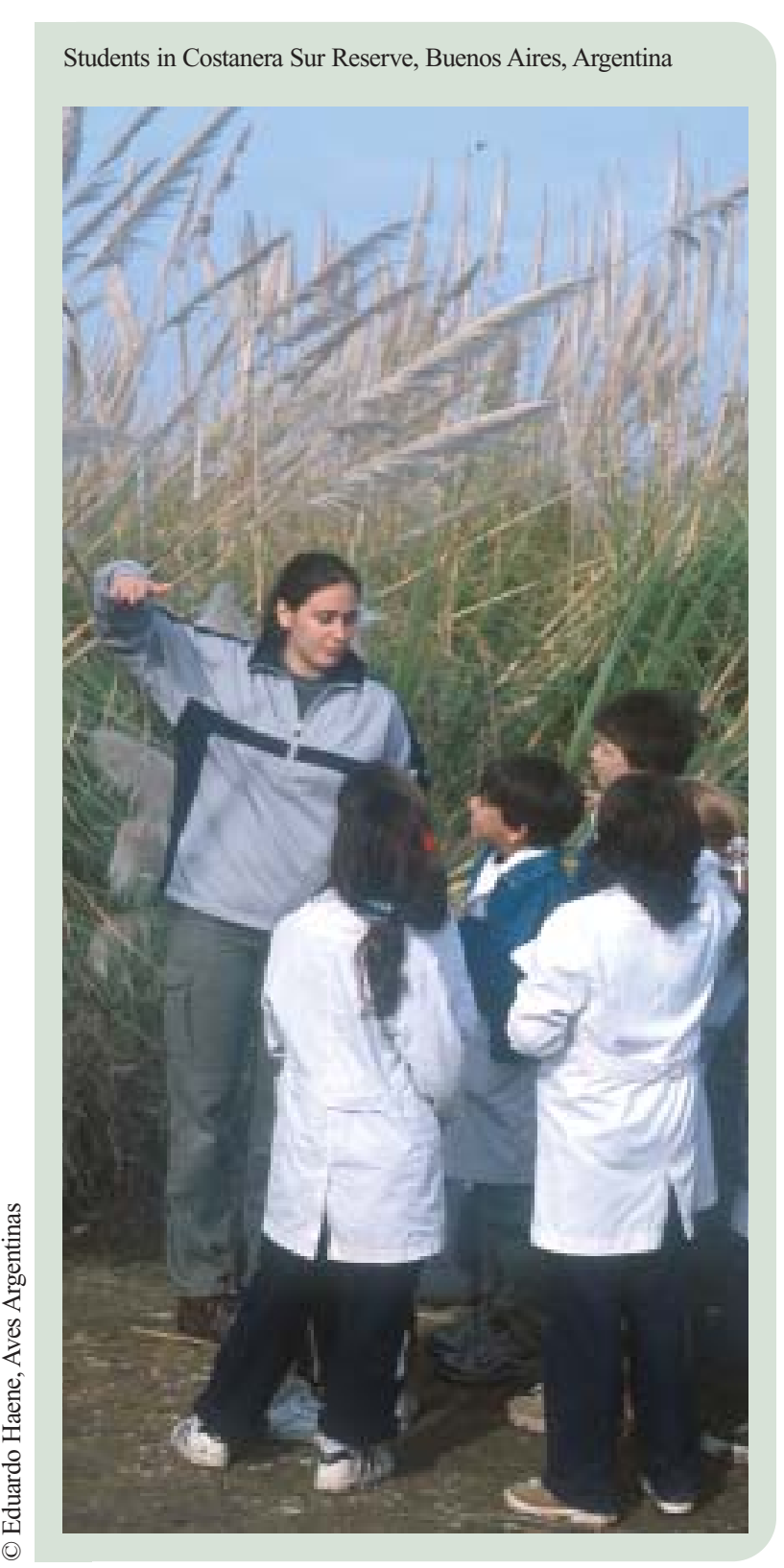


Such evaluation is difficult in this instance, because results take place over time and have to do with changing persons' values. A substantial body of scientific evidence supports the value of nature programmes in cities, but it is compartmented in different disciplines. This research should be synthesised and translated into points easily understood by busy decision makers.

Second, it is important for conservationists to talk face-to-face with senior officials and show them how things work on the ground. Visiting places like the nature reserves on the Cape Flats in South Africa, or the Hawkins Natural Park in inner-city Los Angeles can be mind-changing experiences. For particularly important political figures, study tours in which they meet with counterparts in other countries and see what is being accomplished on the ground can be especially valuable.

\section{A role for IUCN}

At the global level, IUCN is well-positioned as a forum for discussing ways to improve urban dwellers' access to nature and to promote an ecosystem approach to managing cities and their surroundings. IUCN leaders started to look seriously at the connections between cities and nature in the mid1990s (McNeely, 1999). In 2001, a special number of IUCN's Parks journal on "Cities and Parks" (McNeely, 2001) drew attention to the subject. This led to the workshop on "The Urban Imperative" at the Vth World Parks Congress in 2003. The workshop resulted in a Congress recommendation on "Cities and Protected Areas" (WCPA, 2003) calling on conservation agencies, NGOs, local authorities, and local communities to give more attention to the importance of protected areas and green spaces to people living in cities, and recognise the interdependence of cities and protected areas. It also called for incorporating an urban dimension in IUCN's own activities. To follow up this recommendation, the World Commission on Protected Areas has created a Task Force on Cities and Protected Areas (WCPA, 2004).

\section{Conclusion}

An urbanizing world poses new challenges for protected areas, but also new opportunities. Building broad support among urban dwellers may be the most important goal conservationists can adopt to preserve and expand protected areas everywhere. However, building such support means paying more attention to the needs of city people and the places where they live.

For individual conservationists, this requires changing long-established attitudes - without compromising core values - and acquiring new skills. For conservation organizations, it requires adopting an enlarged, but not radically different, perspective.

Urban pioneers in the conservation movement, including those mentioned above, have strived toward this goal for many years. A new generation of leaders can move us much closer. Those more seasoned in this exciting new arena must do all they can to help them do so.

The Urban Imperative. Published by California Institute of Public Affairs.

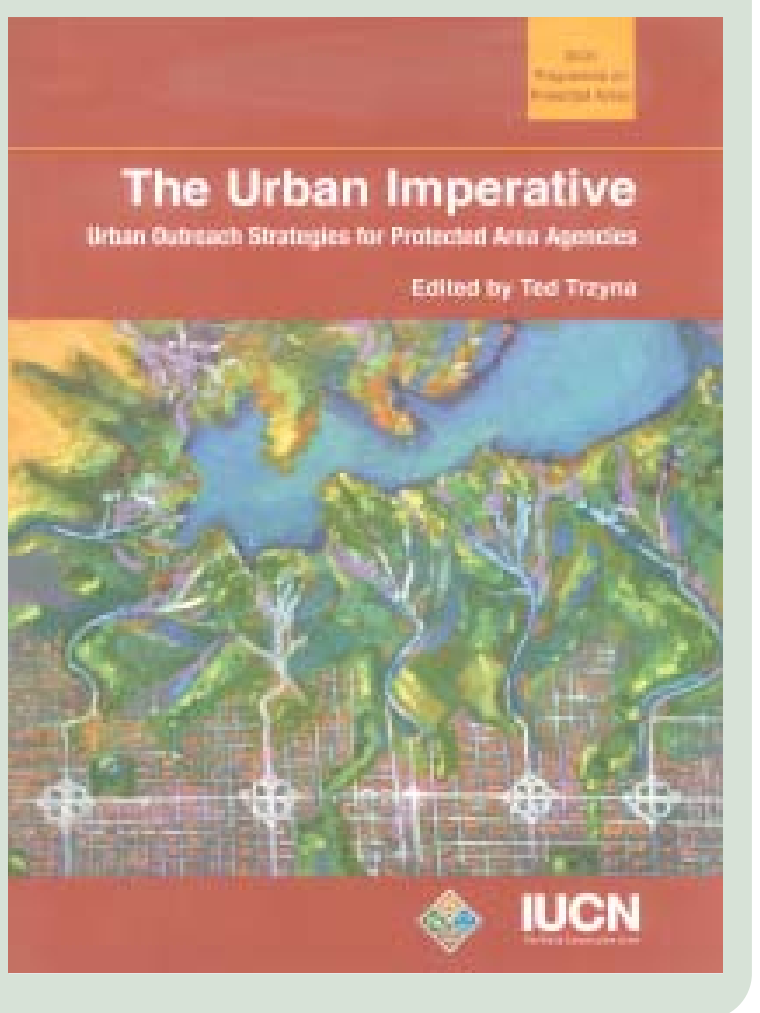




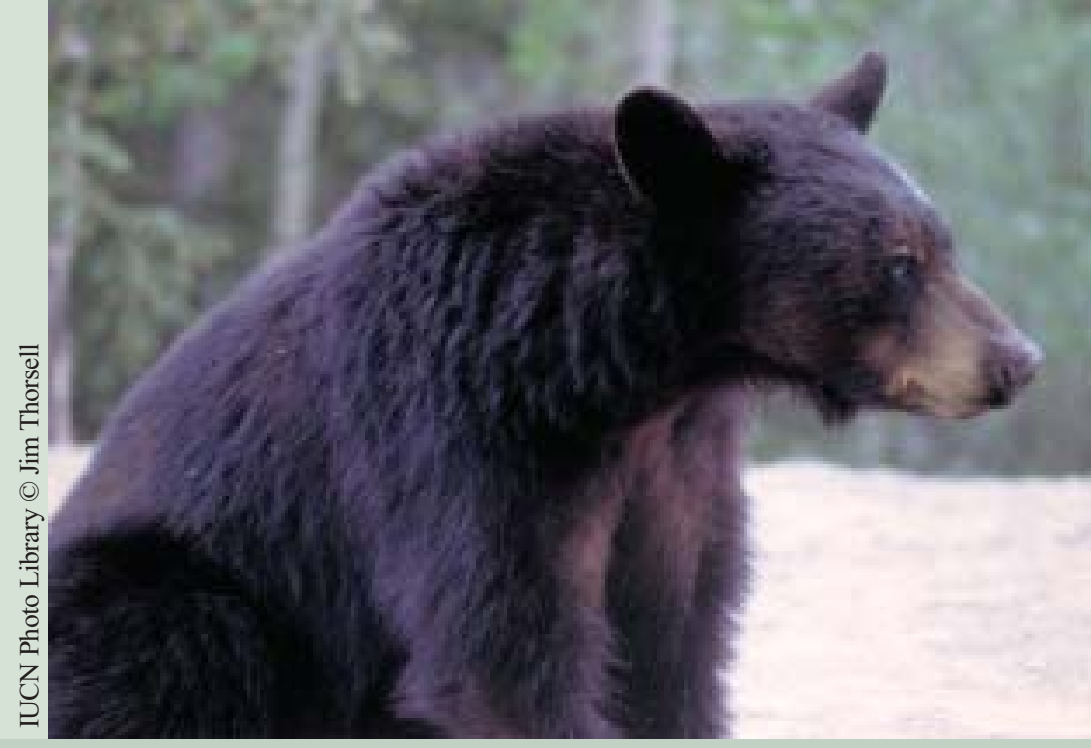

\section{The role of hunting in promoting protected areas}

\section{by Kent H. Redford and Miranda Mockrin}

\section{Editor's introduction}

For many people, the idea of protected areas is associated especially with protection of animals from hunting. But throughout history, hunters have shown a capacity for managing their game animals in a sustainable manner, provided the necessary cultural and social controls are effectively in place. For many categories of protected areas, hunting is a permissible activity. For example, category I wilderness areas may permit indigenous hunting, and many category IV areas are managed especially as game reserves. Kent Redford and Miranda Mockrin provide a historical overview of hunting and explain the many ways that hunters support protected areas, and often deliver direct financial benefits to the local communities involved. Hunters also contribute to managing the habitat, monitoring wildlife and managing the offtake, providing considerable knowledge about wildlife that may be useful to managers, helping to enforce regulations and controlling pest species. While hunting is not permitted in all protected areas, in those areas where controlled hunting is a management objective, protected area managers can gain substantial benefits by working closely with hunting associations, safari operators, and local hunters. 


\section{Introduction}

For millennia humans have realized that their actions were capable of exhausting natural resources on which they relied. Though actions were not always taken on these realizations, in a broad variety of cultures, times, and geographies human societies did put into place institutions designed to prevent resource exhaustion. Such institutions have focused first on those resources most susceptible to overexploitation.

Until the last century or two, the resource that has arguably been most susceptible to human overuse is vertebrate species. It is then no surprise that humans have created a variety of institutions designed to manage this resource and prevent overexploitation. In some traditional forest-dwelling or fishing societies these institutions have focused on taboos and spatial patterns of management In other, more agrarian societies, management institutions have often involved monopolization of hunting rights by elites. Such systems usually involved exerting control over areas of land and limiting harvest of certain species of animals on that land. Though this was usually associated with killing of "royal animals" the same system was applied to capturing of elephants for domestication in India (Rangarajan, 2001).

The custom of allocating areas for hunting often involved enclosing areas of natural habitat and restoring or enhancing populations of game animals (Redford, 2000). For example, in Assyria in the $8^{\text {th }}$ century BC King Saragon II was reported to have stocked royal hunting grounds with wild bulls, lions, ostriches and apes (van Zuylen, 1995). Often however, these reserves were just habitat protected from hunting by commoners. Such systems were widespread from Venice in the $8^{\text {th }}$ century AD (Allin, 1990), to Mughal India (Rangarajan, 2001), to Java in the $17^{\text {th }}$ century (Boomgaard, 2001). The rulers of England, as elsewhere in Europe (Cartmill, 1993), designated large areas as "royal forests" where only the King and chosen guests were allowed to hunt. In fact the "forest" was defined as "... a certain territory of woody grounds and fruitful pastures, privileged for wild beasts and fowls of forest, chase and warren, to rest and abide in, in the safe protection of the king, for his princely delight and pleasure..." (Manwood, 1665 in Whitehead 1950).
In all of these cases, the purpose of the institution was to prevent the elimination of animals so that they could continue to be harvested. This seems to have most frequently have been accomplished by identifying and demarcating areas and limiting use within these areas. These "protected areas" were often called "parks" as in "deer parks" (Whitehead, 1950) and the English word park comes from the prehistoric German word for 'enclosed place' (Oxford English Dictionary). In the American tradition a park became associated with preserving wilderness, but even here the association with animals was maintained as Williams (1989) states that etymologically, "wilderness" comes from "the place of wild beasts."

In its modern usage, the term park encompasses a much broader meaning being subsumed under the umbrella term "protected area". IUCN defines a protected area as "an area of land and/or sea especially dedicated to the protection and maintenance of biological diversity, and of natural and associated cultural resources, and managed through legal or other effective means" (IUCN, 2004). Some categories of protected areas are strictly protected while others allow specified types of use or protect anthropogenic features. Increasing understanding of the ubiquity of human influence worldwide has created a climate where increasingly controlled human use is considered acceptable if it provides support for protection of many other, non-targeted components and attributes of biodiversity (Redford and Richter, 1999). Hunting is a recognised use of protected areas worldwide (Rosabel, 1997; Freese, 1998), and legal code for protected areas and hunting is increasingly integrated (Cirelli, 2002). But it is important to note that even in the absence of other impacts, hunting has been shown to affect genetic, species, and ecosystem components of biodiversity (Freese) so areas where hunting takes place do not achieve the same biodiversity objectives as areas with no hunting (Redford and Richter, 1999).

It is important to highlight the fact that the relationship between hunting and protected areas is not a simple one. Hunting itself has been responsible for many extinctions, and left uncontrolled, is one of the most prevalent threats to huntable species worldwide. The ability of hunting to be useful as a tool 
in support of a given protected area will depend on how the ecological, political, historical and social context shape the nature of the interactions. For example, while trophy hunting seems to offer promise as a means of generating significant money for some protected areas, it is much less feasible in tropical forest areas with no animals of interest to trophy hunters. Additionally, some species do not have the biological characteristics to allow hunting to be sustainable in any economically significant fashion. Likewise, where laws prohibit all types of resource extraction, hunting could not become a conservation tool.

\section{Description of the interest group}

Humans have hunted since before they became human and hunting remains of interest and importance to many human populations around the world. Animals have been, and are, valued by humans for a broad variety of reasons (Redford and Robinson, 1991; Redford et al., 1995) ranging from food to religion. Arguably, the most important value humans place on animals is for food both for subsistence and commercial purposes. Wild animals are also used for other subsistence purposes including clothing, tools, medicine and material for handicrafts and ritual. Many of these animal products have acquired commercial value in local, national and international markets - particularly for luxury uses such as furs, ivory and meat, or for traditional Chinese medicine. Wild animals have other values that are nonconsumptive in nature. These include religious and spiritual values, values due to the willingness of tourists to pay to see them, and value as components of function of ecosystems (e.g. seed dispersal, predation, nutrient cycling). Though usually valued positively, animals can have negative values in some contexts such as when feeding in gardens, preying on livestock or humans, or transmitting diseases.

Although hunting is very common, it has often been controlled by social factors. In different settings hunting is limited by season, by sex, by bag limit, and by type of hunter. Control of hunting has often been done by those in power, wishing to control the harvesting by others. This association between hunting and power is part and parcel of the European experience (Cartmill, 1993) and was carried by Europeans to their colonies, colouring the way both hunting and park establishment were conducted (Mackenzie, 1997). For example, the British occupiers of India, wishing to hunt tigers and lions, treated with favours those Indian princes who could offer big game hunts in hunting preserves (Rangarajan, 2001).

Control of hunting by those in power inevitably results, and has always resulted, in the extinguishing of harvest rights by those less powerful. Rights to hunt have been taken and either kept or reassigned in nontraditional patterns. This fact is part and parcel of all consideration of hunters as collaborators in park establishment and management. In many settings outside of Europe and the United States hunting is among the most contentious of topics for people living in and near protected areas and wishing to continue their cultural practices of hunting (c.f. Oilwatch and World Rainforest Movement, 2004). In this piece we do not specifically address the issues of traditional rights and legality of the hunting, but these are vital issues for all practitioners engaging hunters as a new constituency for protected areas.

Kayapó young woman with hummingbird, Brazil.

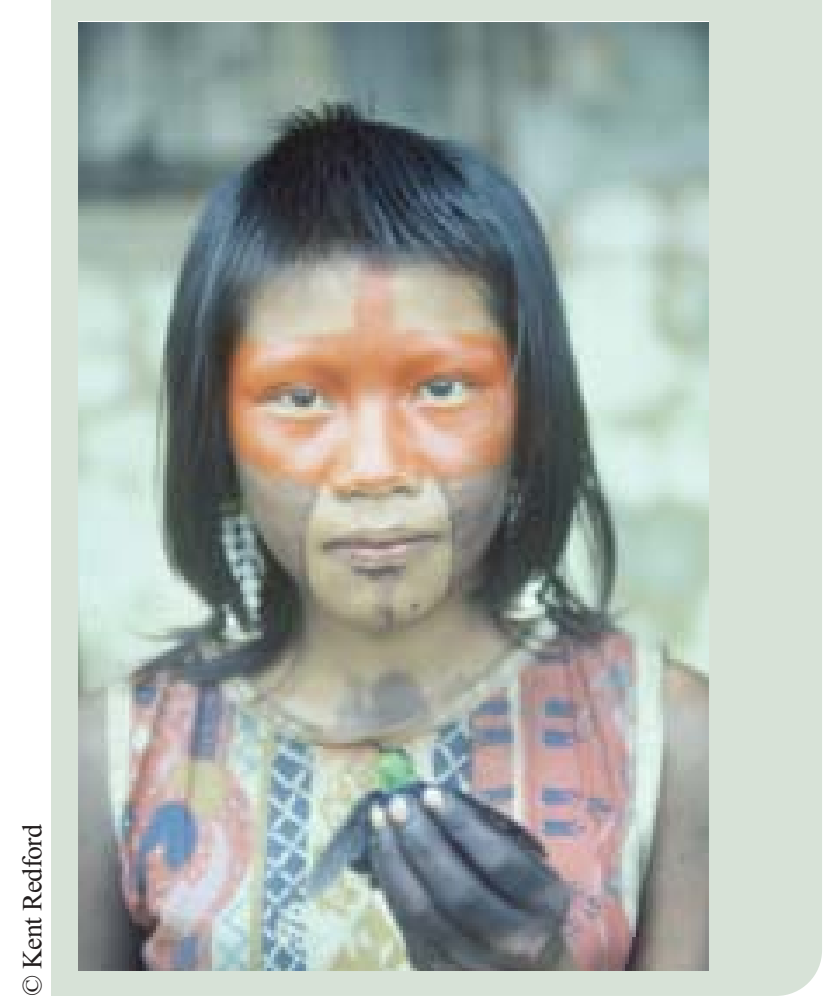




\section{Description of the interests of hunters in protected areas}

Hunting plays an important role in promoting protected areas, both through the designation of protected areas to be used for sport or subsistence hunting, and through the creation of protected areas to serve as harvest refugia that protect game populations within their borders and supply dispersing animals to areas beyond the refugia.

\section{Hunting in protected areas}

Hunting in protected areas can be broadly described as motivated by three main factors: hunting for recreation, hunting for subsistence, and hunting to manage invasive or overabundant species. These motivations are not mutually exclusive: recreational hunting may provide valuable game meat (Freese, 1998) and is often used to accomplish management goals of reducing numbers of overabundant or nonnative species. Finally, hunting may have cultural significance as well. In the following section, we will focus on the recreational and subsistence hunting that occurs in protected areas. Hunting for management purposes will be discussed in the next section, under management.

Sport and subsistence hunting may be further separated, occurring in different types of protected areas, although there are exceptions. Where sport hunting occurs, hunting is often the primary use of the protected area. Hunters are often foreign tourists, although they can be nationals as well. Local inhabitants may be prohibited from residing or hunting for subsistence in these parks.

However, within the past decade, protected areas that explicitly include subsistence hunting and human habitation have become more common (IUCN, 1994). Local people are increasingly involved in natural resource management, including parks, and the management of wildlife hunting (Adams and Hulme, 2001). Some parks controlled by communities, such as wildlife management areas in Botswana, allow both subsistence and tourist hunting (Arntzen, 2002).
Parks that allow hunting make significant contributions towards the total area of land protected, on local, regional, and global scales. This increase is due, in part, to the increase in community-based wildlife management. Areas reserved for sport hunting and areas designated for subsistence hunting are discussed separately below.

\section{Sport hunting}

Providing sport hunting opportunities may result in significant amounts of land being contained in protected areas. On a local level, Cameroon's Northern Province includes 28 hunting zones, which combine with three national parks to make up $44 \%$ of the province's land surface (Jell and Machado, 2002).

Countries in eastern and southern Africa that allow sport hunting may devote very high percentages of national territory to sport hunting, leading to a significant amount of land protected on a regional scale. For example, Tanzania and Botswana have some of the highest percentages of land included in protected areas worldwide, with $27 \%$ of mainland Tanzania and $30 \%$ of Botswana set aside in protected areas.

In Tanzania, $80 \%$ of these protected areas allow hunting. In total, protected areas that allow hunting include 43 Game Controlled Areas and 23 Game Reserves, which combine to make up $22 \%$ of mainland Tanzania, or $207,919 \mathrm{~km}^{2}$ (Leader-Williams, 2000). The Selous Game Reserve alone is the largest protected area in Africa, comprising $43,000 \mathrm{~km}^{2}$, and holds $35 \%$ of Tanzania's hunting blocks, with hunting blocks an average of $955 \mathrm{~km}^{2}$ (Creel and Creel, 1997).

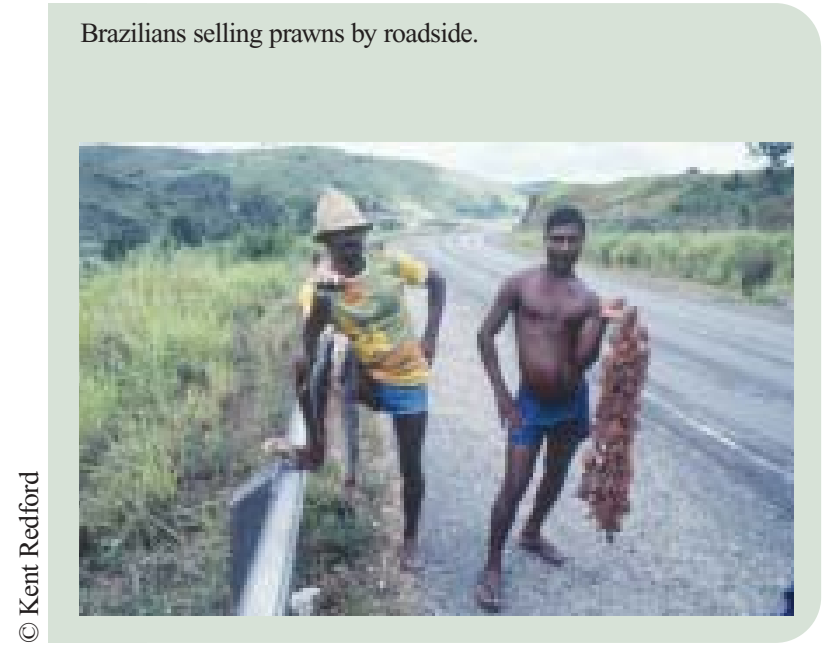


In Botswana, $24 \%$ of national territory, or $139,680 \mathrm{~km}^{2}$, is zoned as Wildlife Management Areas (WMAs), and an additional $18 \%$ of national territory is reserved in protected areas where no hunting occurs (Rozemeijer, 2003). WMAs are subdivided into Controlled Hunting Areas, the units used by the Department of Wildlife and National Parks to administer hunting licences. Communities may apply to manage Controlled Hunting Areas, for both subsistence and sport hunting, and sport hunting also occurs on privately owned game ranches (Barnes, 2001). In Zambia, hunting occurs on 34 Game Management Areas, covering more than $140,000 \mathrm{~km}^{2}$, or $20 \%$ of the country. In Zimbabwe, protected areas with hunting make up $17,360 \mathrm{~km}^{2}, 34 \%$ of Zimbabwe's parks and wildlife estate, and $4.5 \%$ of the country (Martin, 1996; Price Waterhouse, 1996).

Privately-owned and communally-owned lands that allow sport hunting are also increasingly common in southern Africa, when law allows private or community wildlife ownership of wildlife and individuals and communities can reap the financial rewards of sport hunting (Child and Chitsike, 2000). An estimated $75 \%$ of Namibia's wildlife is found outside governmental protected areas, mostly on commercial farming operations (Jones and Murphree, 2001). In South Africa, the majority of sport hunting takes place on private property, with over 8,000 private game ranches or farms in 1992 (Price Waterhouse, 1996).

In the United States, hunting is allowed on the majority of the National Wildlife Refuge system, and on other state and federally controlled land. In total, the National Wildlife Refuge system includes 542 refuges and more than 3,000 small areas for waterfowl breeding and nesting, comprising more than $388,000 \mathrm{~km}^{2}$. More than 300 refuges allow hunting (http://refuges.fws.gov/). However, the vast majority of hunting (more than $80 \%$ ) takes place on private land (U.S. Department of the Interior et al., 2002). Similarly, hunting in Europe is often conducted on private lands, managed through communal hunting associations (Cirelli, 2002; Schwenk, 1991; Ruzicka, 1995).

\section{Subsistence hunting}

Many kinds of protected areas allow subsistence hunting, and some have been created with the express purpose of maintaining traditional human cultures. Subsistence hunting is a recognised part of traditional culture (Ross, 1994). For example, the Bolshoi Arkticheskiy State Nature Reserve in Russia is inhabited by 4,000 indigenous people who hunt, fish, and herd reindeer over $42,000 \mathrm{~km}^{2}$. The reserve is classified as a Wilderness Area (Category Ib under IUCN designation) (IUCN, 1994).

In South America, the Kaa-Iya del Gran Chaco National Park of Bolivia, and the Tamhiyacu-Tahuayo Communal Reserve of Peru both allow the exploitation of wildlife for the benefit of local communities. Both reserves rely upon a pattern of zoning that designates central protected areas where no hunting occurs, and surrounding buffer zones that allow for extraction of resources, with human habitation removed one more layer beyond (Bodmer, 1994; Taber et al., 1997; Noss and Cuellar, 2001). This multiple-use module design is also used in Man and the Biosphere (MAB) reserves, which may allow subsistence hunting. MAB reserves focus on human-inhabited areas by definition, and work towards the sustainable use of resources and the conservation of biodiversity.

In Amazonia, legally-recognised reserves for indigenous people make up 248 of 459 officially recognised conservation areas, or $52 \%$ of protected areas. In the Brazilian Amazon, the total size of these parks is $1,000,000 \mathrm{~km}^{2}$ (Zimmerman et al., 2001). In Africa, the Lobéké Reserve of Cameroon has been proposed as a similar multiple use reserve (Jell and Machado, 2002), and legal codes in West and Central Africa allow the creation of reserves for subsistence hunting in Guinea, Burkina Faso, Mauritania and Cameroon (Cirelli, 2002). In Southern Africa, community controlled conservancies and wildlife management areas may allow subsistence hunting, but in some instances, sport hunting precludes the use of wildlife resources by local inhabitants. For example, in Tanzania, although national residents can purchase licences for sport hunting, the requirement to purchase a licence for each animal effectively precludes any local residents of wildlife management areas from hunting for subsistence (Leader-Williams, 2000). 


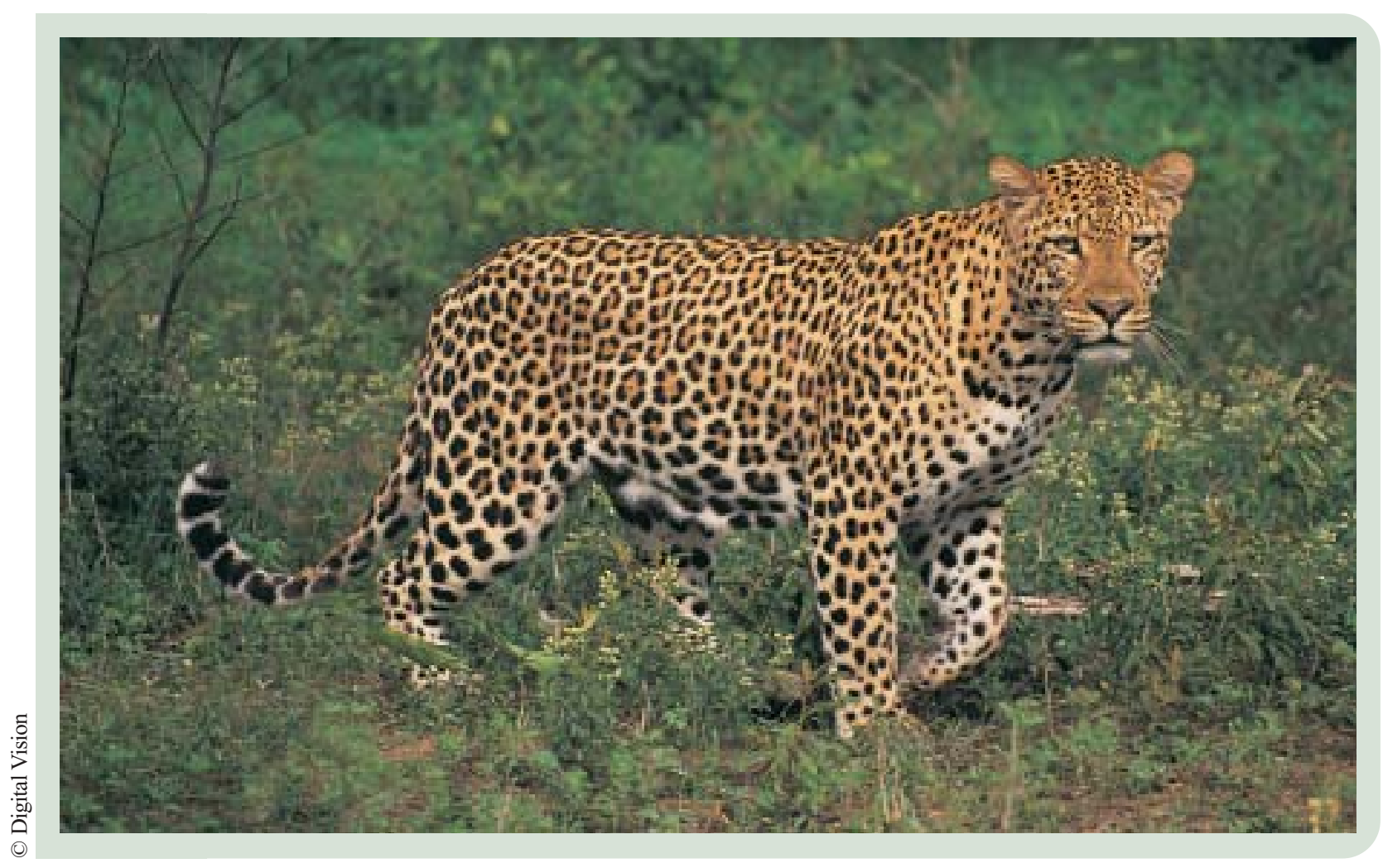

\section{Hunting "from" protected areas (sink/source etc.)}

Hunters also benefit from protected areas that do not allow hunting, and use these areas as a form of hunting management. Termed harvest refugia, these areas are purposefully protected from hunting to increase the sustainability or yield available from hunting. Hunting refugia prevent local extinctions of species, and they provide a steady supply of wildlife that can disperse into hunting areas (Joshi and Gadgil, 1991; McCullough, 1996). As a result, higher offtake can be sustained in hunting regions. Human hunting pressure therefore creates a "sink" sustained by dispersing animals from the protected "source" or harvest refugia (sensu Pulliam, 1988). The dispersal behaviour of organisms varies between species and among individuals of the same species, but source populations may sustain both nearby and far away sink populations.

Similar to protected areas dedicated to hunting, protected areas designated as hunting refuges can attain significant size and conserve important habitat for wildlife populations. Because hunting grounds may be placed immediately outside the hunting refuge, hunting and non-hunting areas combine to form sizeable complexes on a landscape.
The use of harvest refugia is not a novel concept in wildlife management. Harvest refugia have been used in traditional societies in marine and terrestrial settings (Joshi and Gadgil, 1991; Colding and Folke, 2001) and were advocated by Aldo Leopold (1933) at the advent of modern wildlife management. In the United States, harvest refugia were often established after overhunting, to allow formerly abundant species a chance to recover (McCullough, 1996). Harvest refugia may be a valuable management strategy in remote areas where the level and distribution of hunting is difficult to control (Leopold, 1933; Novaro et al., 2000).

Today, harvest refugia are used in a wide variety of ecosystems, in developing and developed countries. Harvest refugia may be established in multiple use reserves, in the form of a core protected area that will prevent total overharvest and allow animals to disperse into hunting areas (e.g., the TamhiyacuTahuayo Communal Reserve (Bodmer and Puertas, 2000). In Burkina Faso, the law allows for "local refuges" to be reserved by local authorities to facilitate the reproduction and exploitation of wildlife, and law in both Albania and Portugal envisions "repopulation zones" (Cirelli, 2002). In France, an estimated 5\% of the national territory, over 12,000 reserves, covering $25,300 \mathrm{~km}^{2}$ is included in harvest refugia, with 
communal hunting associations also setting aside $10 \%$ of their hunting grounds. These harvest refugia have been credited for supplying dispersing organisms to nearby and distant hunting grounds in significant numbers (Trouvilliez, 1997).

The placement of harvest refugia often focuses on high-quality habitat or breeding grounds to ensure the enhanced reproduction and eventual dispersal of animals to hunting areas. This function is well demonstrated in waterfowl. In North America, pothole wetlands produce half of North America's waterfowl, earning the title "North America's duck factories" (Abell et al., 2000). These wetlands are purposefully conserved as national wildlife refuges (USFWS, 2003).

Hunting areas may also be arranged around a protected area, allowing them to capitalize on dispersal of animals from protected areas. Both recreational hunting managed by the state and informal hunting activities may concentrate on the outskirts of protected areas (e.g., Mathevet and Tamisier, 2002). Sport hunting positioned outside a no-hunting area in Tanzania allows hunting outfitters to use habitat in relatively good condition, in a region with low human occupation, so that "the ideal safari hunting situation is in an area surrounding a national park" (Hurt and Ravn, 2000). However, the motivation for arranging hunting areas outside nohunting protected areas may not always be to capitalize on wildlife dispersal. This spatial arrangement could follow from the practice of establishing protected areas in remote regions with little human habitation. Human uses such as hunting may then be relegated to more accessible regions surrounding parks, as is the case with ibex hunting in the French alps (Skonhoft et al., 2002). In southern Africa, hunting areas may be positioned as buffers to protect national parks from human encroachment from more heavily populated areas (Price Waterhouse, 1996).

It should be noted that game refugia will not increase harvests of absolutely every species, but will depend upon population structure, behaviour, and dynamics of individual species, as well as the size, placement, and habitat of hunting and no-hunting areas. For example, elk (Cervus elaphus) in Rocky
Mountain National Park are thought to be inhibited from moving outside the park because they can not easily switch social groups (Lubow et al., 2002). Hunting on the periphery of parks can also have effects on populations and social structures that extend within parks. Populations that are not fully contained in no-hunting protected areas, but extend into hunting areas, may be vulnerable to overharvest. For example, none of the wolf packs that utilize Bieszczady National Park in Poland are confined to the park boundaries, a factor which must be included in management plans to prevent overharvest (Smietana and Wajda, 1997). In the Serengeti, harvest of male lions outside protected areas attracts males from the park and distorts sex ratios within the protected area (Sinclair, 1995).

\section{Box 4.1}

\section{Regulation of puma hunting by designating hunting and no-hunting zones}

Laudré and Clark (2003) proposed regulating puma (Puma concolor) hunting over an $18,600 \mathrm{~km}^{2}$ landscape in the Idaho/Nevada/Utah region through the creation of hunting and no-hunting areas. Location, size, and arrangement of hunting and nohunting areas proposed were dependent on biological data: they identified natural biological sinks (mountain ranges less than $100 \mathrm{~km}^{2}$ ) and used radiotelemetry data to determine dispersal distances. Creation of hunting and no-hunting zones was seen as a good policy option, buffering puma populations from politically-motivated and biologically unsustainable changes in state hunting regulations, while also allowing ample opportunities for harvesting. Laudré and Clark (2003) are of the opinion that traditional quota hunting is endangering puma populations, and they have turned to spatial management as a way to safeguard populations. However, authors stress that dispersal is critical to the function of the proposed systems; if dispersal capabilities are altered through land use changes, the genetic structure and population structure will be altered.

Source: Laudré and Clark (2003). 


\section{Marine parks and fishing}

Harvesting refugia are also used in marine ecosystems as a management technique to safeguard or improve the offtake of aquatic protein. Marine parks benefit commercial, subsistence, and recreational fishers. Marine parks are used for fisheries management by prohibiting harvesting within the reserve. Marine protected areas generally prohibit all fishing, so no protected areas are specially designated to fishing, as some terrestrial protected areas are dedicated to hunting. In some cases, marine protected areas may not completely halt fishing, but rather implement restrictions on fishing gear, or the nature of the fishing (recreational, and not commercial, for example) (Rosenberg, 2001). When harvesting is halted, populations increase inside the protected area, allowing "spillover" of adults and juveniles beyond park boundaries, and increasing the number of the export of larvae outside the reserve. Fish inside park boundaries will also tend to be older and bigger, with a concordant increase in reproductive potential, or ability to export eggs and larvae (Gell and Roberts, 2003).

Commercial and subsistence fishers will therefore benefit as fish populations inside reserves increase. Recreational fishers also benefit as populations increase, because more fish are available to catch, and the fish may be of a better quality. Recreational fishers are often interested in harvesting large individuals as trophies. Because marine protected areas allow individuals within to achieve large sizes, the areas outside marine protected areas yield larger fish. For example, the Merritt Island National Wildlife Refuge in Florida has been closed to fishing pressure since the establishment of the Kennedy Space Center in 1962. Recreational fisheries adjacent to the reserve have produced exceptional numbers of world-record-size fish, with most of the fish size records from Florida originating from around the reserve (Gell and Roberts, 2003).

Similar to terrestrial hunting refugia, spatial techniques have also long been used by traditional people to regulate fisheries, for example, in Pacific islands (Colding and Folke, 2001). Fishers utilizing inland waters have similar traditional customs of prohibiting harvesting in certain areas for part or all of

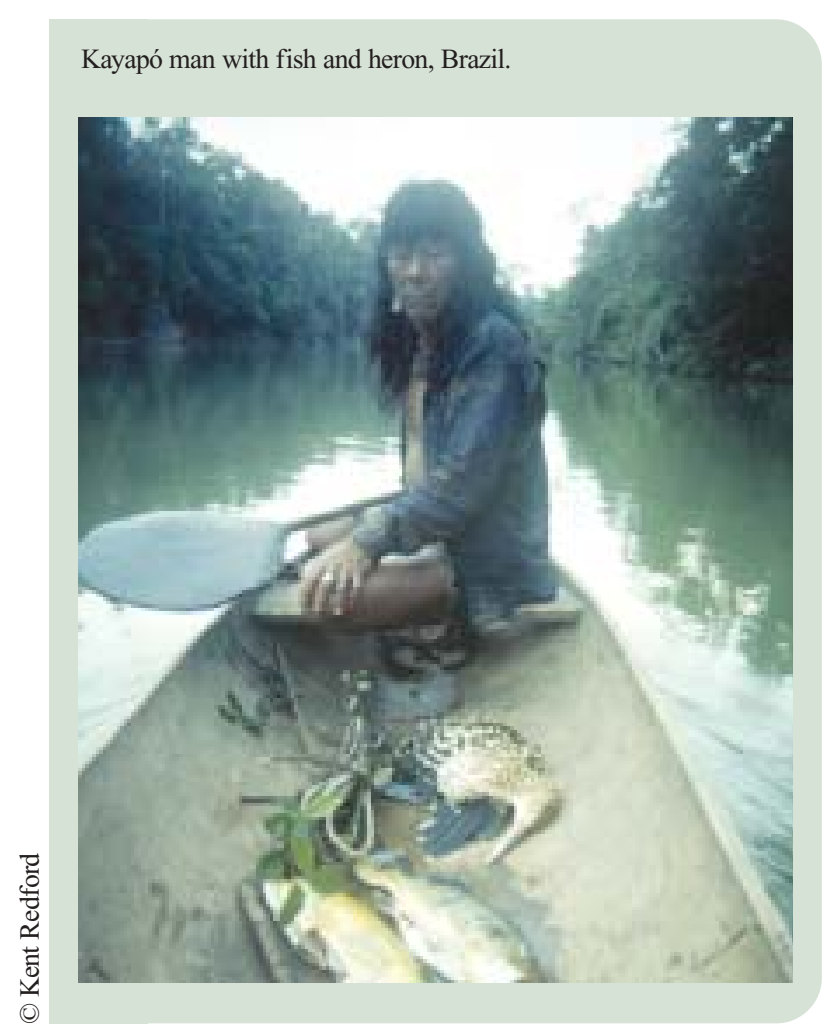

the year (Welcomme, 2001). In contrast, marine protected areas have been discussed in fisheries science over the last 40 years, but only recently have many been enacted (National Research Council, 2001).

The effects of marine protected areas on fish stocks are still being researched, and studies postulating benefits have often relied on theoretical simulations (Sladek Nowlis and Roberts, 1999; Sumaila et al., 2000; Gerber et al., 2002). However, the ability of harvesting restrictions to increase biomass within park boundaries is now generally accepted (Halpern, 2003; Russ and Alcala, 2003). In addition, the benefits of marine protected areas for fish stocks and harvesting outside the protected area are increasingly recognised (Gell and Roberts, 2003). The benefit of marine protected areas to fishers depends on the amount of spillover and larval export achieved by protected areas, which is in turn heavily dependent upon reserve placement, duration of harvesting prohibition, and species' life histories and ecologies. For example, fish overspill can range from a few hundred metres to a few kilometres in coral reef habitats, but more mobile species in estuaries, continental shelves and rocky reefs can travel distances of tens to hundreds of kilometres (Gell and Roberts, 2003). Significant 
larval dispersal outside reserves has also been noted for invertebrates, which are less mobile and may spend their entire lives inside reserve boundaries. Larval dispersal need not be long-distance; new evidence suggests dispersal may leave larvae near reserves (Gell and Roberts, 2003).

Marine protected areas therefore share a number of similarities to terrestrial harvest refugia. In both realms, no-take refugia are a traditional system of management, and benefit resource users by making harvesting more sustainable and of a higher quality. In both settings, placement of reserve, duration of protection, and species' life histories are likely to determine the types of benefits enjoyed by resource users (Gell and Roberts, 2003; Milner-Gulland et al., 2003). One important different between the two types of harvesting is that recreational fishing is often conducted on a catch and release basis, with no analogous terrestrial hunting activity. Because catch and release fishing is non-consumptive, some feel that it should be allowed in marine protected areas. For ecologically sensitive areas, however, the presence of catch and release fishing may still cause degradation (National Research Council, 2001).

\section{How hunters contribute to protected areas}

People who hunt in protected areas, or who derive hunting benefits because of game refugia, have an incentive to support protected areas and hunt sustainably. The significant revenue generated by sport hunting is an example: hunters must manage wildlife resources wisely to yield a continued source of revenue (Salvatori et al., 2002). These benefits are not limited to income but can also include food, recreation, medicine, and the maintenance of sociocultural systems (Freeman, 2001).

Hunters contribute to protected areas through a multitude of actions. The most direct may be funding: hunting generates a great deal of revenue that can then be used for protected area management. Hunters also directly participate in protected area management, including habitat management, monitoring wildlife populations, limiting access to hunting, and controlling pest species. Hunters also provide ecological knowledge on which protected area management depends. Finally, hunters provide political support for protected areas, both domestically and internationally.

\section{Funding for protected areas}

Sport hunting is capable of generating substantial revenue, which can then be used to support national parks. Funds may directly pay for park maintenance, management, and acquisition, or may be returned to local people, which increases support for protected areas.

\section{Amount and methods of generating revenue through hunting}

Revenue from hunting is generated in a variety of ways, either through direct payments to governments, or through taxes levied by the government. In Africa, hunters must pay a variety of fees which can include hunting licences and fees, trophy fees, conservation fees, observer fees, weapons import fees, and sometimes fees to communities, in addition to payments to hunting operators and expenditures towards transport, hotels, trophy processing. Hunting outfitters also pay the government a concession fee in order to have exclusive access to a hunting area.

In total, hunters from North America and Europe are willing to pay from US\$14,000-\$60,000 or more for a 10-21 day safari to hunt African trophy species, including elephant, buffalo, lion, and eland (Wilkie and Carpenter, 1999b). The availability of elephant can substantially increase the revenue generated from a safari. A single African hunting concession without elephants can generate $\$ 150,000$ in government revenue through trophy fees, each year, while a concession with elephants can generate $\$ 340,000$ (Wilkie and Carpenter, 1999b).

Significant earnings accrue to national governments. In 2000, Botswana generated gross revenue of US\$12.5 million through the recreational hunting sector (Arntzen, 2002). In 2000, the trophy hunting industry in Namibia hosted 3,640 trophy hunters for a total of 15,450 hunter-days, and 13,310 game animals were hunted (Humavindu and Barnes, 2003). Trophy hunting generated at least US\$19.6 million in direct 
expenditures, or gross output. In total, trophy hunting makes up at least $14 \%$ of the total tourism sector and is a significant component of the Namibian economy. Some $24 \%$ of the income earned in the trophy hunting industry accrues to poor segments of society in the form of wages and rentals/royalties. About $21 \%$ of income generated is captured by the government, through fees and taxes. Trophy hunting is considered an important contributor to development.

Sport hunting therefore has the ability to generate a significant portion of funds needed for management of protected areas (hunting and non-hunting) and conservation programmes. For example, approximately 180 safari hunters visit Northern Cameroon each year. The state receives US\$650,000 dollars per year from hunting activities (Mayaka, 2001 ), or an estimated $34 \%$ of annual management costs for protected areas (Wilkie and Carpenter, 1999a).

One final advantage of revenues generated from sport hunting is that they may be more reliably and evenly distributed than revenues generated from wildlife viewing. In Tanzania, tourist hunting is dispersed over a wider range of protected areas than wildlife viewing, which concentrates on a few wellknown national parks (Leader-Williams, 2000). Hunters may be more willing to "rough it" and travel to areas with minimal amenities and infrastructure (Wilkie and Carpenter, 1999a). Hunting revenue is also considered more resistant to recessions and civil strife than revenue from wildlife viewing (Ndolanga, 1996). During Zimbabwe's civil war from 1970 to 1980 the sport hunting industry continued largely unabated (Martin, 1996).

\section{Hunting revenue benefits protected areas}

Hunting revenue benefits protected areas by providing governments with funds for protected area management and expansion, and through programmes that disperse funds to communities adjacent to parks. For hunting revenue to benefit protected areas by either of these means, it is essential that funding return from the central treasury to protected areas and their environs. The flow of revenue generated from hunting is often contentious and may be revised frequently. The resultant distribution schedules can be complex and may vary between different types of protected areas, and even between individual protected areas (Leader-Williams, 2000). Problems with financial oversight and leakages can also occur, complicating the flow of funds back to protected areas and local people. For example, revenue from sport hunting in Cameroon is required to be split between the national treasury $(70 \%)$ and a special fund for conservation (30\%) (Mayaka, 2001), but Wilkie and Carpenter report that the conservation fund has experienced problems with accounting and transparency.

When used by governmental authorities, revenue derived from hunters can pay for acquiring new land as protected areas. In the United States, $11,000 \mathrm{~km}^{2}$ or approximately $3 \%$ of National Wildlife Refuges, have been acquired using funds raised from hunting, including import duties on firearms and ammunition, refuge entrance fees, and migratory bird hunting and conservation stamps, also known as duck stamps ( $90 \%$ of stamps are purchased by hunters) (USFWS, viewed February 20, 2004). Revenue can also pay for management, research and staffing needs of protected areas.

In developing countries there has been increasing impetus to return revenue to communities managing, occupying, or living adjacent to protected areas (Adams and Hulme, 2001). Because of their proximity to parks, these communities have reduced access to natural resources for food and building materials, and suffer an increased risk of crop and property damage. Therefore, profit-sharing from hunting revenue is predicted to increase community support for wildlife and national parks, resulting in better management, and increase the effectiveness of parks. Revenue-sharing can take the form of increased social infrastructure and efforts to improve a community's standard of living, as well as increased opportunities for employment.

Communities are now receiving far more of the profits from hunting than they were in the past, which in turn benefits protected areas. At one point in the 1980s in Zambia less than 1\% of safari hunting revenue was returned to local village economies. Local attitudes towards safari hunting were negative 


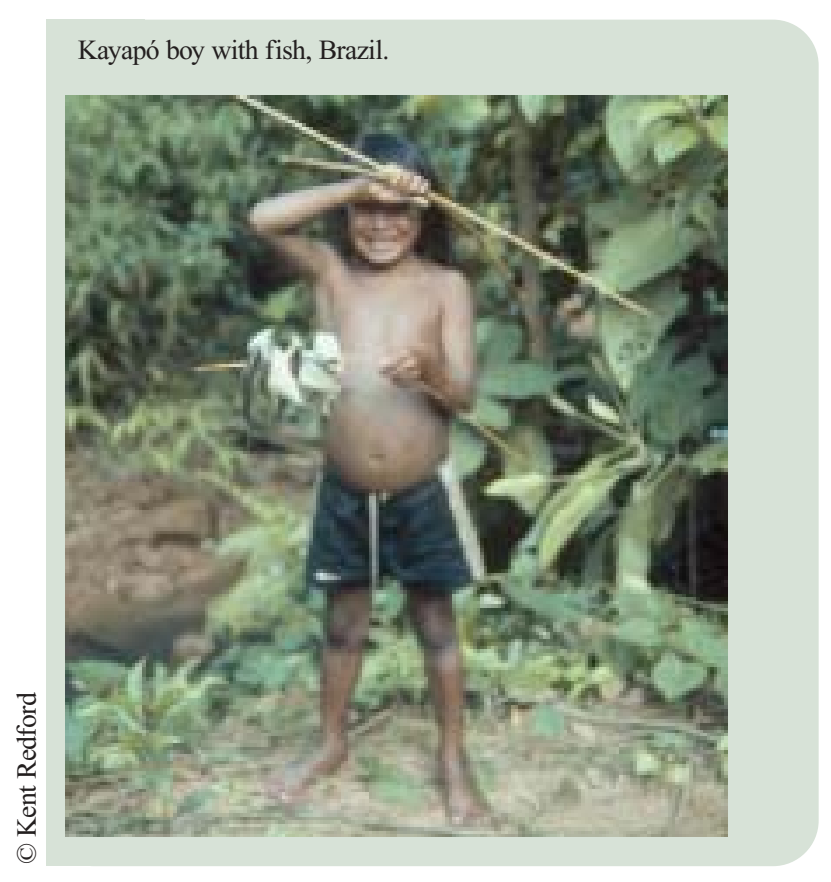

(Lewis et al., 1990). By 1994, communities received $67 \%$ of the total government revenue from hunting, and approximately $20 \%$ of hunting-industry receipts from hunting in GMAs (Lewis and Alpert, 1997).

The increased funding to local communities is beneficial for protected areas because some of this funding has paid for community game guards, and because community attitudes towards wildlife conservation have improved (Lewis and Alpert, 1997). The ability of revenue-sharing projects to improve biodiversity conservation in national parks depends upon their ability to meet livelihood needs and generate real income and subsistence products. Community-level projects may encounter difficulties achieving these benefits across individuals and households (Emerton, 2001). However, small communities can receive substantial benefits from sport hunting revenues. Tiburón Island in Mexico contains a community of approximately 800 people who share the profits from bighorn sheep hunting, with permits raising $\$ 100,000$ per trophy sheep (Medellin, 2003). When less resources are available per individual, funds that provide subsistence hunters with alternative sources of livelihood can have a substantial impact on wildlife conservation within parks. Reducing subsistence hunting also makes more animals available for sport hunting. Annual revenue saved from animals not illegally hunted exceeds $\$ 300,000$ (Lewis, 2003).

\section{Hunting and protected area management}

Hunters play significant roles in protected area management. In both protected areas dedicated to sport hunting and protected areas dedicated to subsistence hunting, sport hunting outfitters and hunters may engage in a variety of management practices, including habitat management and restoration, monitoring wildlife and managing hunting offtake, and protecting the area from poaching or hunting by outsiders (Mayaka, 2001). Hunters also contribute ecological knowledge which can be utilized by protected area management. If hunting areas are located outside no-hunting protected areas, enforcement and maintenance in hunting areas will also benefit no-hunting protected areas (Pasanisi, 1996). Within protected areas, recreational hunting may be used to control pest species.

\section{Habitat management}

Habitat management and restoration are some of the more profound alterations of the environment that may be undertaken to improve or maintain hunting.

The manipulation of habitat to increase hunting has a long history, and was present in 19th century Germany and England (Schwenk, 1991; Leopold, 1933). Habitat alterations may be motivated by a desire to maintain a single species (e.g., heather Calluna vulgaris moorlands managed for red grouse Lagopus lagopus), to maintain a suite of related species (e.g., increasing wetlands to maintain migratory ducks), or to maintain a diverse array of species. Management alterations may be carried out by governmental agencies or hunting outfitters in protected areas in order to maintain hunting opportunities.

In western Zimbabwe and northeastern Botswana, habitat management in sport hunting protected areas is undertaken to "provide the wildlife community with a diversity of habitats and waterpoints, and provide the high paying hunting client with access to a diverse community of trophy quality game and an exclusive wilderness experience" (Hunter, 1996). Management actions include controlled burns, bush clearing, water provisioning (through pumping or damming seasonal rivers), annual cutting, and occasional planting of 
native grasses. Because hunting protected areas in this region make up more than $13,000 \mathrm{~km}^{2}$, management activities undertaken by hunters have the potential to significantly influence the region's biodiversity.

Habitat restoration has received the most attention in the restoration of wetlands for waterfowl hunting. In the United States, wetlands restoration and conservation projects in protected areas may be carried out under the North American Wetlands Conservation Act (NAWCA), a partnership-based programme using public-private partnerships to protect, restore, and manage wetland habitat for migratory birds and other wildlife. Ducks Unlimited, a hunting advocacy organization in the United States, currently receives $\$ 6.8$ million in federal funding to work with governmental, NGO, and private partners and carry out wetlands restoration and conservation projects in North America (Ducks Unlimited, accessed April 19, 2004).

Subsistence hunters manage other natural resources at the same time as they pursue hunting, for example by using a combination of agroforestry, swidden rice cultivation, and hunting to procure food. Some of this habitat management may be purposefully undertaken to increase or maintain game populations. For

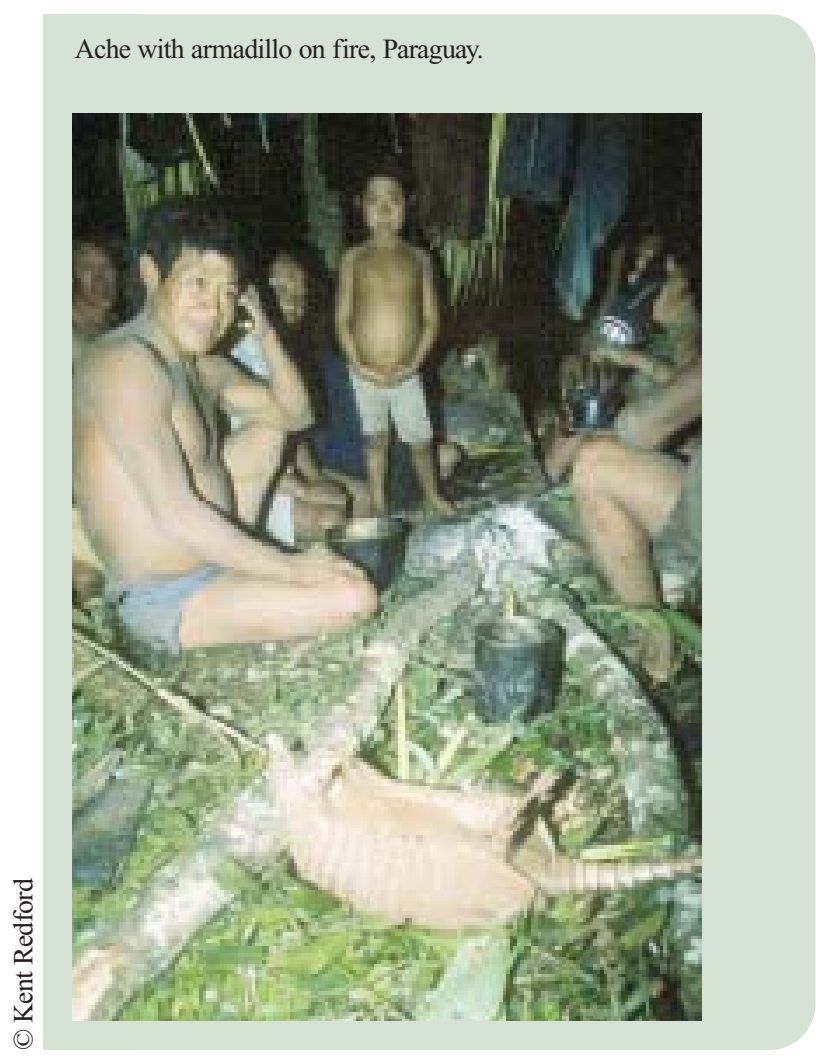

example, specific fruit trees may be planted in managed forest areas for game species, and plant species not utilized by people may be maintained or planted if they are an important resource for a valued game species (Wadley et al., 1997). Protected areas established to maintain traditional lifestyles will allow these game management practices to continue, along with other traditional uses of natural resources.

Potential habitat alteration, together with the introduction of non-native species and the artificial provisioning of food may comprise some of the more significant alterations hunters can make to hunted landscapes. The use of these management interventions in protected areas may have varying effects on biodiversity in the system, and need to be carefully investigated.

\section{Monitoring wildlife and managing offtake}

Where reserves allow continued subsistence hunting by residents, communities may play an integral role in monitoring harvest and managing wildlife, working in cooperation with government agencies, NGO extension workers, and researchers (Bodmer and Puertas, 2000). For example, in the TamshiyacoTahuayo Communal Reserve, hunting offtake is monitored through collection of skulls from hunters and their families, working with extension agents. Decisions regarding resource use are made by democratic voting processes at community meetings (Bodmer and Puertas, 2000). Data from recreational hunters, such as species harvested, effort expended, and spatial distribution of the harvest, also contribute to governmental efforts to monitor wildlife populations and regulate harvests.

In a sport hunting context, participatory on-theground animal counts can be combined with additional census data, a safari operator's perception of population levels or measurement of catch and effort, and community perceptions about hunting levels and wildlife populations (Taylor, 2001). The use of participatory monitoring techniques may encourage higher levels of stewardship and greater involvement in conservation. Collecting data from hunters in the Tamshiyacu-Tahuayo Communal Reserve provides not only a valuable source of 
biological data for monitoring, but also an opportunity for broader education and discussion between residents and wildlife extension workers (Bodmer and Puertas, 2000).

\section{Hunters as sources of knowledge}

Indigenous knowledge of wildlife and local ecology is considerable and is important for the management of protected areas and hunting. Local people can contribute knowledge likely to be important to hunting management, including habitat use and reproductive cycles (Jell and Machado, 2002). For example, Inuit hunters in northern Canada are aware of denning areas used by polar bear females, and prevent land use predicted to negatively affect areas important for denning (Freeman, 2001).

In many cases, hunting-related knowledge has positively contributed towards research and conservation in protected areas. For example, in Central Africa, indigenous net hunting techniques have been used to conduct scientific research (Hart, 2000) and proposed as a possible management tool to be used by local people (Noss, 1999). Skills acquired from hunting also enable local people to work as research assistants and make valuable contributions towards scientific research and management (Marks, 1996; Hill et al., 2003).

Finally, maintaining strong indigenous culture and knowledge may strengthen support for protected areas and conservation because indigenous culture may bestow values upon wildlife and provide incentives to preserve it (Freeman, 2001). Although indigenous culture benefits conservation efforts, these cultures and knowledge are maintained through the use of the environment, including wildlife hunting. Therefore, the maintenance of local hunting may be intimately linked to stores of ecological knowledge; one will not long survive without the other.

\section{Enforcement}

In some cases, the presence of safari hunting in a region may dissuade poaching. In other cases, safari operators have started benefits-sharing and policing programmes with communities in an attempt to lessen illegal hunting in the area (Tanzania Game Tracker Safaris and Robin Hurt Safaris, 1996; Hurt and Ravn,
2000). In protected areas where subsistence hunting is allowed, hunters often work to maintain community access to protected areas while excluding outsiders from utilizing natural resources. For example, the impetus for creating the Tamshiyacu-Tahuayo Reserve originated when community members organized a system of controls to prevent outsiders from commercially hunting meat, fishing, and extracting timber (Bodmer and Puertas, 2000).

\section{Hunting to control pest species}

Hunters benefit protected areas by hunting within them to control non-native and overabundant species (Rosabel, 1997). For example, a number of exotic ungulates were originally introduced into New Zealand for hunting, but are now regarded as pests. Recreational hunting remains the main method of control (Davys et al., 1999). The ability of species to self-regulate population densities, without carnivores in historic abundances, is controversial (Shafer, 2000). However, replacing natural carnivore offtake with human predation is one motivation for allowing human hunting in protected areas, and can be considered as part of efforts to restore and maintain biologically diverse systems (Berger et al., 2001).

\section{Tenure and management}

Uncertainty about concession tenure, however, may decrease motivation to invest in management. Tenure is often not secure in sports hunting areas. In Tanzania, hunting blocks are allocated for periods of five years (Hurt and Ravn, 2000), and in Botswana, communities are awarded management of Controlled Hunting Units for six years (Rozemeijer, 2003). These short time spans do not allow outfitters or communities to achieve long-term goals, such as effectively managing elephant populations for a trophy-sized male. Even over the short term, investment in management may be lacking. In Cameroon, safari hunters generally do not maintain a year-round presence. This investment may not be worthwhile because concession tenure may be uncertain from year to year, or because it will not yield worthwhile results - subsistence hunters generally target non-trophy species, and increased protection of hunting concessions may not increase revenues (Wilkie and Carpenter, 1999b). 


\section{Box 4.2}

\section{Ability of hunters to conserve large carnivores in the Carpathian Mountains}

Poland, Slovakia, Ukraine, and Romania contain over $90 \%$ of the Carpathian Mountains, and harbour the greatest populations of large carnivores found in Europe. Brown bear (Ursus arctos), wolf (Canis lupus), and lynx (Lynx lynx) populations in the Carpathians are estimated to represent 14\%, 35\% and $30 \%$ respectively of the total European populations. More than $80 \%$ of forested areas in these states belong to the government, but are divided into hunting management units, or hunting grounds, which range in size from $25 \mathrm{~km}^{2}$ to $100 \mathrm{~km}^{2}$. Hunting grounds are generally regulated by non-governmental bodies, often hunting clubs (Table 4.1). Hunting ground managers are responsible for setting and enforcing quotas each year, and only in Romania and Slovakia are quotas submitted to a central governmental authority for approval. Hunting may be conducted by local people or foreigners, and the trophy fee from foreign hunters goes to hunting ground managers. Therefore, these large forested areas remain largely under local control, often the control of hunters, and the local people who manage the environment and wildlife can gain benefits from trophy hunting. Hunting works effectively to conserve game populations found here. In addition, due to their similar political histories, these countries have remarkably similar mechanisms for regulating hunting, and also display similarities in opinion towards large carnivores, in addition to a shared cultural tradition of hunting. Working with hunting ground managers would therefore offer an excellent opportunity to promote the conservation of large carnivores.

\section{Table 4.1}

\section{Management of hunting grounds in the Carpathians}

\begin{tabular}{l|l}
\hline Country & $\begin{array}{l}\text { Management of } \\
\text { hunting grounds }\end{array}$ \\
\hline Slovakia & $\begin{array}{l}86 \% \text { non-governmental } \\
\text { (church, municipality, hunting club) } \\
14 \% \text { Ministry of Agriculture }\end{array}$ \\
\hline Poland & $\begin{array}{l}92 \% \text { hunting clubs } \\
7 \% \text { State Forest Administration } \\
1 \% \text { research institute }\end{array}$ \\
\hline Ukraine & $\begin{array}{l}\text { 13.9\% State Forest Administration } \\
3.9 \% \text { research institutions } \\
2.7 \% \text { Ministry of Defence }\end{array}$ \\
\hline Romania & $\begin{array}{l}72 \% \text { hunting clubs } \\
26 \% \text { State Forest Administration } \\
2 \% \text { Research Institutes }\end{array}$ \\
\hline
\end{tabular}

Source: Salvatori et al. (2002).

\section{Political support for protected areas}

In West Africa, recruiting the support of hunters is seen as a way to garner domestic support for national parks. In traditional cultures in West Africa, hunting skills were linked to war and defence, a tradition that has existed at least since medieval empires. During colonialism, hunters' brotherhood associations became important organizations for mobilization against the French (Leach, 2000). These brotherhood associations are identified by initiation, apprenticeship networks, and shared ceremonies. In Guinea, hunters brotherhood associations have been tapped to play a key role in management and protection of national parks (Leach, 2000).

Hunters have been recruited for this role because they are seen as possessing valuable ecological knowledge. The brotherhood associations have been used to form an environmental programme that attempts to reinvigorate traditional systems for managing hunting, and use hunters to spread goals of new environmental education and management programmes. In some cases, hunters are being used as park guards, or work with local hunters' associations is undertaken to reduce hunting and therefore eliminate the need to have park guards. Alliances 
between conservation organizations and members of hunters' brotherhood associations are also formed with the goal of enabling hunters' organizations to prevent outside or commercial hunters from harvesting resources. Hunters outside of these associations may lack experience, cultural knowledge, and the formal initiation that members of hunters' associations possess, although commercial meat hunting still earns them a good income (Leach, 2000).

\section{Policies needed to support the interests of hunters}

Listed below are policies needed to maximize the contributions of hunters towards protected areas and conserving biodiversity. Putting these policies into place should be the priority actions in the coming ten years.

1. First and foremost, hunting affects biodiversity at the genetic, species, and ecosystem levels. Therefore, conserving all components of biodiversity requires significant areas protected from all consumptive use.

2. Not all areas are suitable for hunting or would provide the economic or cultural returns to satisfy potential hunters. For example, in Botswana, only an estimated one-sixth of the country is thought to be suitable for sport hunting with another sixth suitable for wildlife viewing. The wildlife viewing areas are higher quality, and can earn more revenue than hunting. The recommended sport hunting areas are slightly lower in quality (areas where animals disperse in the wet season). Sport hunting is the best use of this land in terms of generating revenue, but can not profitably be expanded throughout the country (Barnes, 2001).

3. IUCN should develop an integrated "learning portfolio" consisting of a global set of protected areas where hunters are thought to be a significant force for conservation. This portfolio could be used to test assumptions about the relationship between use and conservation.

4. IUCN should work to develop social and biological monitoring systems to provide tools for testing the impact of hunting and the trade-offs generated as a resulting of hunting in protected areas.
5. Conservation managers should work with hunters to implement management practices that optimize the conservation of all components and attributes of biodiversity, not just increase quantities of game to be harvested.

6. Hunting management by hunting associations or in hunting areas should be coordinated with national park management (for example, habitat manipulation or assessment of abundance, or behavioural effects on harvested animals).

7. Tender for hunting areas should be distributed in a fair, transparent process, to maintain consumer confidence and a stable trophy-hunting market.

8. Systems should be put in place to ensure that an agreed-upon portion of trophy hunting fees is returned to local human communities (e.g. "green bullet" certification (Lewis)).

9. Hunting fees for sport hunting should take an animal's ecosystem services into consideration, and be set after examining other prices in the region.

10. Hunting fees should go to support protected areas and conservation on hunting areas. Strict oversight and diligence are necessary to ensure equitable disbursement of funds.

11. Hunting can have significant benefits by providing incentives to return wildlife to private land, conserve wildlife on communally owned or managed land, and generating revenue for government. To promote hunting in these situations, the legal rights of people to own or manage wildlife and land must be ensured.

12. In the context of subsistence hunting, comanagement of hunting between state and communities may be appropriate when the efforts of individuals, communities or the state will not be effective in controlling over-hunting (Jell and Machado, 2002).

13. Hunting management should incorporate the traditional ecological knowledge of local people and skills of local people should be utilized in carrying out management and monitoring. The role of hunting in developing and maintaining ecological knowledge and support for conservation should be acknowledged. 
$4 \quad$ Friends for Life: New partners in support of protected areas 


\section{Introduction}

In 1933, Aldo Leopold observed that "the role of disease in wildlife conservation has probably been radically underestimated" (Leopold, 1933). Despite this recognition early in the 20th century, conservation efforts worldwide are still being hampered because of their failure to recognise the critical role that health plays in animal population dynamics, species survival, and follow-on impacts on the human condition. Improving the health of people and their domestic animals is not only a key step to raising living standards and improving livelihood security, it is the single most effective way to reduce the incidence of disease transmission to highly susceptible wildlife populations (WCS FVP, 2003c), including those that live within or utilize protected areas.

Throughout the world, domestic and wild animals are coming into ever more intimate contact. Without adequate scientific knowledge and planning, the consequences can be detrimental on one or both sides of the proverbial fence. But with the right mix of expertise armed with the tools that the animal health sciences provide, conservation and development objectives have a much greater chance of being realized, particularly at the critical wildlife/livestock interface where conservation and agricultural interests meet head-on.

Infectious diseases are increasingly being recognised as important "emerging issues" by health specialists, disease ecologists, conservation biologists, wildlife managers, and protected area planners (Meffe, 1999; Deem et al., 2002; Lafferty and Gerber, 2002; Aguirre et al., 2002; Daszak and Cunningham, 2002; Graczyk, 2002; WCS FVP, 2003b; KalemaZikusoka, 2005; World Parks Congress Outputs 2003; Osofsky et al., 2005). Examples of emerging diseases that have impacts on human health and biodiversity include:

- from 2001-2003 the Ebola virus killed dozens of people and wiped out hundreds of gorillas in central Africa (WCS FVP, 2003a) and remains of major concern;

- West Nile virus has afflicted a wide range of domestic and wild animals and people in North America ( Marfin et al., 2001);
- bovine tuberculosis (BTB) is now known to occur in buffalo, lion, and a range of other species in Kruger National Park (Clifton-Hadley et al., 2001; Bengis, 2005; Michel, 2005);

- brucellosis is compromising bison populations in North America in terms of management implications (Bienen, 2002; Gillin et al., 2002); and

- foot and mouth disease outbreaks in southern Africa affect livestock and wildlife as well as land-use policies over vast areas (Thomson et al., 2003).

It is clear from these examples that the issues of health and disease need to be brought into the conservation mainstream (Osofsky et al., 2000; Deem et al., 2001; WCS FVP, 2003a).

\section{Box 5.1}

\section{The AHEAD Initiative}

The $\boldsymbol{A H E A D}$ (Animal $\boldsymbol{H}$ ealth for the Environment $\boldsymbol{A}$ nd $\boldsymbol{D}$ evelopment) initiative, led by the Wildlife Conservation Society and partners, focuses on several themes of critical importance to the future of livestock, wildlife, and, of course, people: competition over grazing and water resources; disease mitigation; local and global food security; zoonoses (diseases transmitted between animals and people); and other potential sources of conflict related to the overall challenges of land-use planning and the pervasive reality of resource constraints. Prior to this initiative, neither non-governmental organizations, nor aid agencies, nor academia have holistically addressed the landscape-level nexus represented by the wildlife health/domestic animal health/human health triangle, especially as it relates to protected areas.

www.wcs-ahead.org

Impacts from interactions between livestock, wildlife and people (and habitat) are profound in many parts of the world. The issues at this interface represent an unfortunately all-too-often neglected sector of critical importance to the long-term ecological and sociopolitical security of protected areas and grazing lands worldwide. Whether the issue is the ongoing bovine tuberculosis crisis in and around South Africa's Kruger National Park, or Yellowstone 


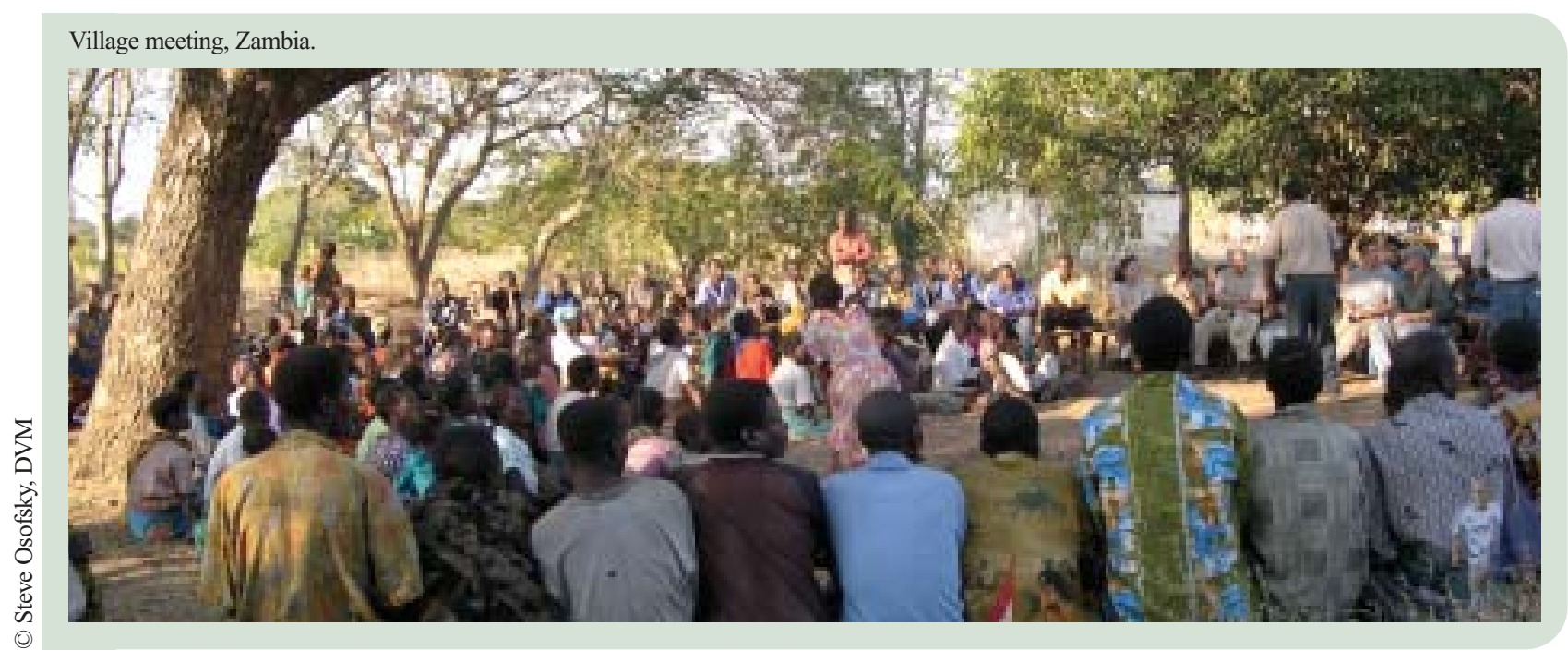

National Park's ongoing brucellosis saga costing U.S. authorities millions of dollars to manage, these issues merit more proactive attention than they have received to date. It is important to note that many of the diseases of concern to landscapes of conservation importance are essentially invasive alien species, and are either already negatively affecting biodiversity or have the potential to do so. As people and their domestic animals penetrate once pristine areas and expand their range and intensity of activities, the risk of transmitting serious diseases to wildlife increases significantly. Diseases of people, domestic animals and wildlife are now being recognised as an increasing challenge to biodiversity conservation, as well as to efforts to improve the quality of life for people. Although endemic (i.e., native) wildlife diseases play important ecological roles, human activities in many cases have disrupted ecosystems, leading to both gradual and catastrophic losses of wildlife populations. A "One Health" approach is not about interfering with nature - it is about trying to help systems already perturbed by pathogens that may or may not "belong" within them to re-establish a state wherein disease does not threaten vital conservation and development objectives. Many factors affecting health and the basic epidemiology of multi-host diseases are still poorly understood, and conservation and wildlife management decisions are often made without complete information. The critical edge where the health of wildlife, domestic animals, and people meld together and are best addressed as "One Health" - exists at the borders of most protected areas of the world.

\section{The "One Health" paradigm: some basic concepts}

People and the natural resources from which they derive their livelihoods are integral parts of their given ecosystem - a dynamic complex of plant, animal and micro-organism communities and the nonliving environment interacting as a functional unit. The World Health Organization (WHO) defines health as a state of complete physical, mental and social wellbeing and not just the absence of disease and infirmity (Deem et al., 2001; Last, 1983), and this definition implies a link between human health and ecosystem integrity. Ecosystems provide vital services to human and animal communities, for example, by providing natural filtering systems, sources of food and fibre, and clean water (Rapport, 1998). Disruption of some of these natural services, these ecosystem "products," will have impacts on air, water, and other renewable resources and thus health.

The concept of "One Health" - the interface between human health and that of the environment is not new. During the 1960s and 1970s visionary attempts were made to construct a bridge between, for example, medicine and agriculture. Discussions on medical ecology and zoology, animal monitors of the environment, and comparative biology and medicine were the precursors to a more holistic approach to animal and human health (Schwabe, 1974). This concept has been further developed through programmes such as Envirovet (Beasley, 1993) and the development of ecosystem health as an integrative science (Rapport et al., 1998). 


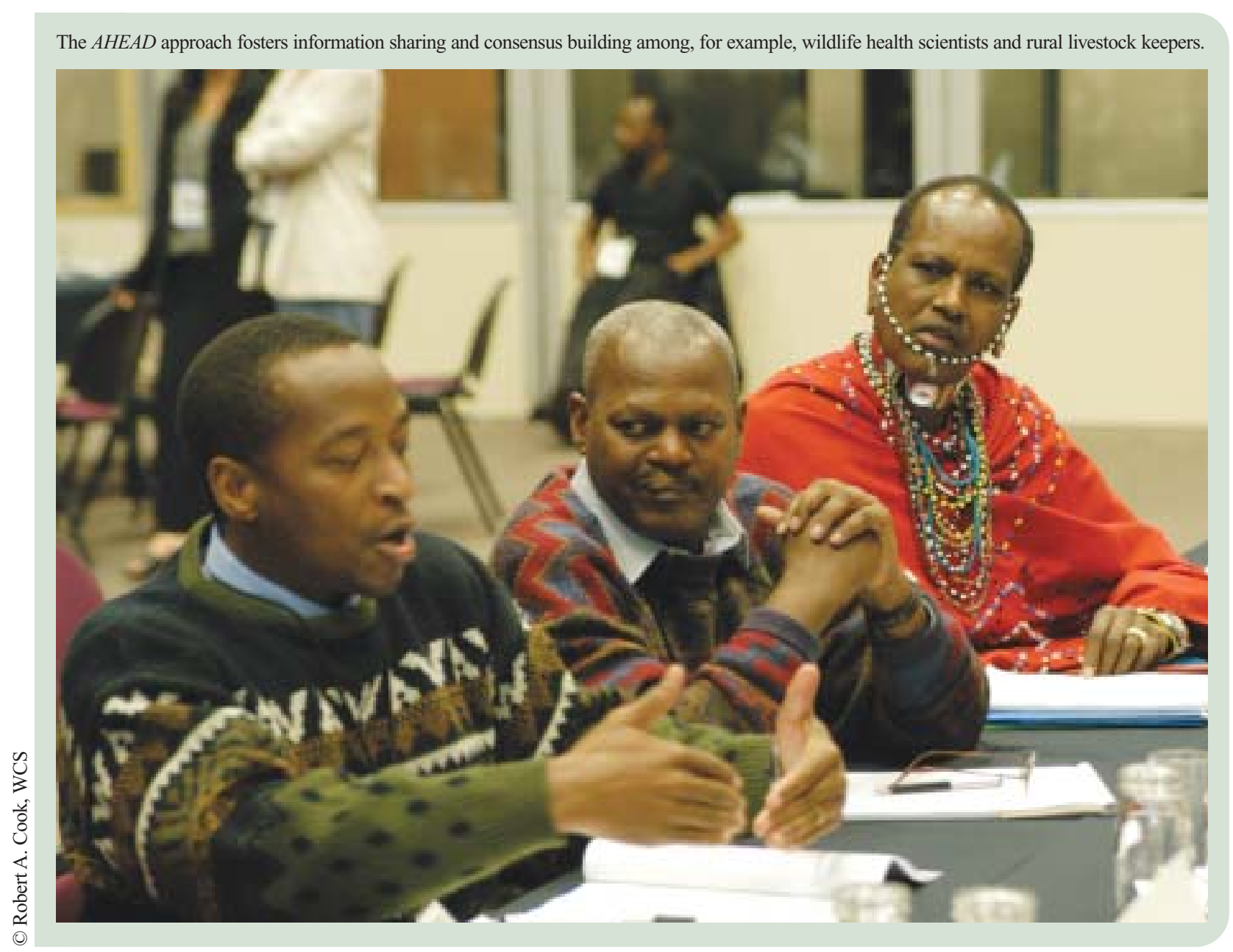

The "One Health" concept takes conservation medicine a step further by broadening an ecological definition of health (Kock, 1996), while acknowledging that conservation medicine's primary goal is the pursuit of ecological health - the health of ecosystems and the species that live within these systems (Else and Pokras, 2002; Tabor, 2002). Conservation medicine attempts to bring together many disciplines, including human and public health, epidemiology, veterinary medicine, toxicology, ecology, and conservation biology (Meffe, 1999). Adopting an ecosystem approach to health issues related to protected areas and the communities that live close to or in these areas represents an attempt to bridge the gaps that exist between the different disciplines and create an enabling environment for expanding benefits to both protected areas and local people. Conservation medicine indeed encourages practitioners to look both upstream and downstream for potential environmental impacts of land uses and activities (Tabor, 2002). A “One Health” approach can be attractive to a broader constituency, as it can be viewed with equal clarity through a conservation, development, or public health lens. Powerful biomedical tools are fortunately available to address these complex issues and develop preventive approaches.

The state of health of an ecosystem can be judged by criteria very similar to those used for evaluating the health of a person or animal, namely, homeostasis (having balance between system components), absence of disease, diversity and complexity, stability and resiliency, and vigour and scope for growth. An ecosystem can be viewed as a patient (Rapport, 1998) and can be evaluated in terms of objective standards that relate to the system's capacity for organization, vigour, and resilience. Identification and diagnosis of problems and the application of solutions along with biodiversity assessment and monitoring represent a basic approach to ecosystem health care. In biomedical terms this would be achieved through detection, diagnostics, prognostics, treatment, and prevention. In the case of ecosystem health, the precautionary principle supports an approach based on the tenets of preventive medicine - anticipatory 
action to protect the environment from possible or irreversible harm (Calver, 2000). The "ecosystem as patient" metaphor can also help shape our overall approach to conservation: "Critical clinical problems mandate a rigorous diagnostic plan, a multifaceted therapeutic plan, clear communication, and short- as well as long-term monitoring. Critical conservation problems deserve no less." (Osofsky, 1997). In addition, a preventive medicine approach allows for action to be taken with a causal relationship being reasonably suspected if not proven, thus lessening the risks of uncertainty.

The development of ecological indicators can yield powerful tools that can generate scientific information on the status or trends of important ecosystem health parameters (Sayre et al., 2000). In parallel, epidemiological tools such as disease surveillance and monitoring can be linked to various indicators in terms of disease and health trends. The use of indicators will help simplify data for decision makers, and provide a focal point for strategic planning, policy formulation, resource allocation, and specific management actions (Boyce, 2003).

\section{The wildlife-livestock disease interface in Africa}

The wildlife-livestock interface means different things to different people. The many facets of the interface, such as health, conservation, environment, culture, and economics, have been issues since livestock became an integral part of the landscape. The interface has positive and negative aspects and it has been a source of conflict in many areas, often as a result of misunderstanding and polarization of opinion between ecocentric and anthropocentric forces in society (Boyd et al., 1999). Attention here is given to those elements relevant to the health of the large mammal communities in Africa, where it is urgent to find solutions to the problems of abject poverty, poor health status for people and animals, and threats to the environment and biodiversity.

In Africa's dry-land pastoral systems, livestock and people share resources with the most diverse array of wild ungulates on earth (R. Kock et al., 2002). With improvements in human health care, the population is growing exponentially but the economies of most countries are not keeping pace correspondingly. Poverty is both acute and widespread, with significant portions of the continent's people living on less than US\$1 per day (FAO/UNEP/CGIAR, 2004). Communities are often food insecure, especially where land degradation is prevalent and social systems have broken down, which often happens during times of war or other unrest. Consequently, there is considerable international pressure to accelerate development and alleviate poverty (Thrupp and Megateli, 1999). With rapid economic development, environmental change and loss of biodiversity can be expected; indeed, this has been the experience in many countries, where one form of poverty is thus replaced by another.

Eighty percent of Africa's population is rural and 70 million people are wholly dependent on livestock with no alternative source of food or wealth (AU/IBAR, 2002). Yet Africa accounts for only $2 \%$ of the total value of world trade in livestock and livestock products and imports twice as much as it exports, with the net imports increasing at $4 \%$ per year (Thambi, 2003). The single most important constraint on the African livestock export trade is the "Sanitary and Phytosanitary Measures" of the World Trade Organization (WTO) (OIE, 2003). The status of endemic livestock disease(s) in many African countries limits exports of meat, serving as a barrier to trade that is a key concern of policy makers. However, the impact of these trade-sensitive diseases is minimal within Africa, especially among pastoral livestock and poor farmers (Perry et al., 2002). As the maintenance of these extensive livestock systems, and to some extent the close association between wildlife and livestock, is the main reason for the current disease status, pressure is building among certain political elements in Africa for changes that may threaten both traditional pastoral society and also wildlife resources (R. Kock et al., 2002). These WTO rules are set up by the developed nations, essentially in their own selfinterest, and African nations have not been able to influence changes in these regulations to their own advantage (Thambi, 2003).

Some feel that the international community's desire to conserve Africa's wildlife as a global environmental 
good underpins its reluctance to support livestock development based on the belief that livestock is a major factor in land degradation and loss of wildlife (Bourn and Blench, 1999). However, positive environmental benefits can be attributed to wellmanaged livestock systems as much as poor management can lead to negative impacts (Mace, 1991). Often, livestock are only part of the picture in terms of the trend towards a general fragmentation of habitats and disruption of natural ecosystems, including the disappearance of large mammal species across much of their historic range, increases in agriculture and settlement, and disruptions to traditional systems of transhumance and mobility. Recent studies have shown that pastoralists' strategies are optimal for sustaining communities and resources, and that they are a force in conserving the environment to the benefit of wild species (Roth, 1996; Scoones, 1994).

The improved understanding of the role of livestock in dry lands is accompanied by an increasing awareness of a new potential value of the wildlife resource through community-based management. Ecotourism and other forms of utilization (both consumptive and non-consumptive) are becoming increasingly important in the economies of at least some African countries (Chardonnet et al., 2002;
Jansen et al., 1992; Cumming and Bond, 1991). To further support this, studies of mixed systems indicate considerable environmental benefits as well as economic ones in some settings (Western, 1994). It can be argued that one of Africa's main advantages (perhaps the only one in economic terms) over the rest of the world is its extensive and diverse wildlife resource, which is so attractive to tourists. This is not to say that livestock are not important on the continent but, to put it into context, Chile and Argentina taken together currently have a larger livestock industry than all the countries of Africa combined (FAO, 2003). So to sacrifice wildlife in favour of developing a competitive commercial livestock sector has little justification, but to develop both wildlife and livestock resources together (not necessarily defaulting to one or the other exclusively) is a key to efficient utilization of available resources.

Given the economic benefits of wildlife, health issues are an increasing concern in this field especially where epidemics and chronic disease problems occur as a result of introduced (alien) disease. A review of the co-existence of livestock and wildlife (Bourn and Blench, 1999) reported that wildlife disease was not a constraint, but lack of information on diseases in the field makes this a risky conclusion. Other studies have found that disease can

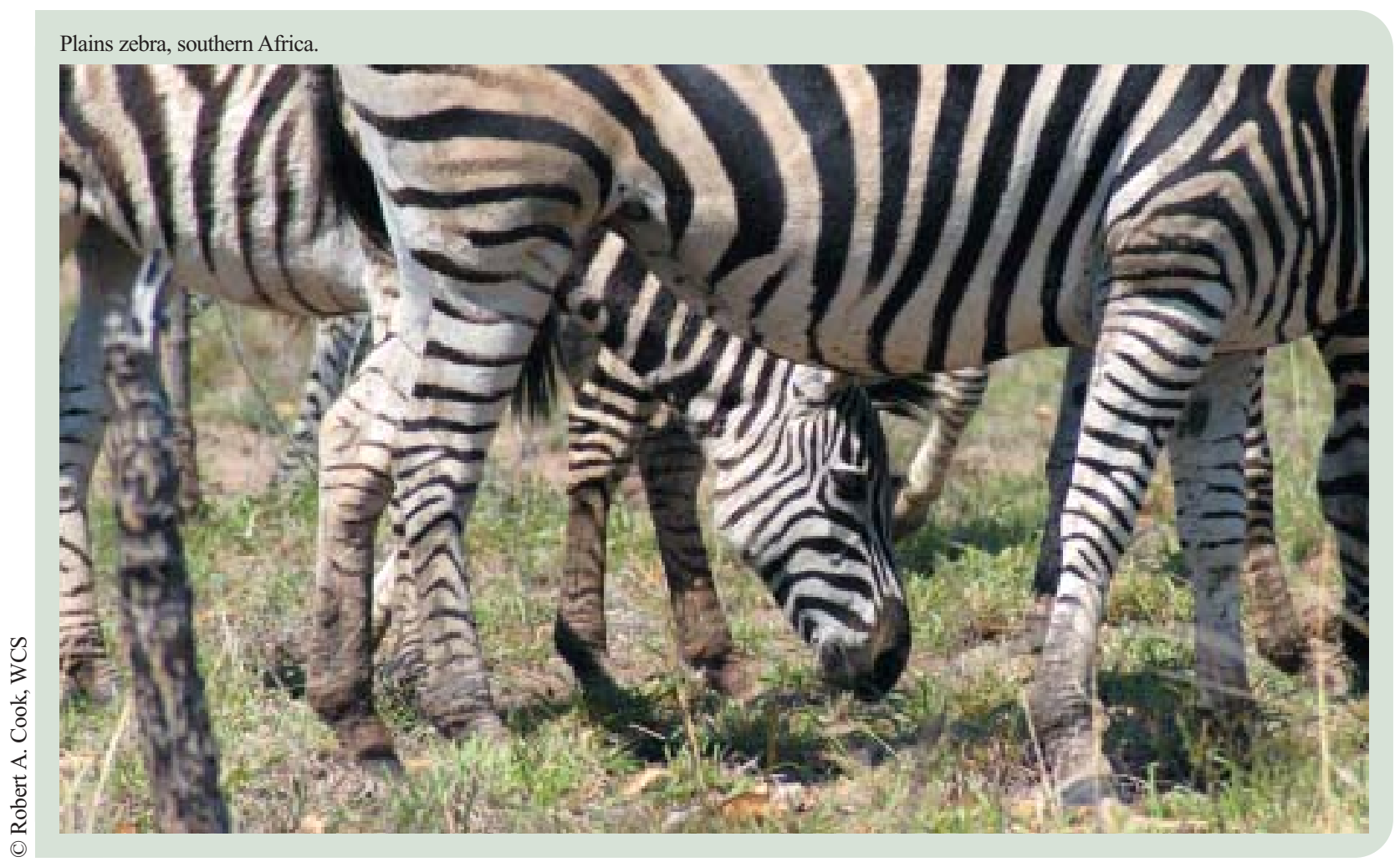


adversely affect wild animal population dynamics in the short and long term (Hudson and Dobson, 1989; Rodwell et al., 2001; Jolles, 2003; Lankester, 2003; Hwang, 2003) and increases the risk of the extinction of rare species (Andanje, 2002). The initial impacts of exotic disease can be devastating and depress population growth for decades (Mack, 1970; Plowright, 1982; Kock et al., 1999); conversely, control or eradication of these pathogens can lead to dramatic recovery of populations (Sinclair, 1970). The more subtle effects of disease are to make the population more susceptible to other impacts, such as predation, and effectively depress numbers well below limitations related to food resource available (Joly, 2003). The decision on what to accept as a natural or an acceptable disease dynamic within a biological system may well in the end be a value judgement, but in terms of resource use, consumptive or otherwise, depressed populations will limit the options.

The emergence of wildlife and livestock disease in many parts of the world is partly a result of the expansion of human and livestock populations into wildlife areas, with dramatically disturbed habitats and novel interactions, but may also reflect increased awareness and monitoring of diseases. The trend towards establishing larger and more integrated wildlife systems is also evident in Africa, e.g., through transfrontier parks (Gelderblom et al., 1996) and extension of wildlife management areas into communities, conservancies, and wildlife corridors (IIED, 1994; Hulme and Murphree, 1999). Clearly, conserving wildlife requires a more integrated approach that will incur costs. These initiatives will inevitably be a compromise with other land use practices, and will result in complex disease phenomena (Rosenzweig, 2003) that will need novel solutions and interventions - ideally proactive ones. This is the contemporary challenge to the veterinary community, disease biologists, development specialists, and protected area managers alike. It is vital that the interests of livestock keepers living around protected areas are taken into account in the management of the wider wildlife systems.

Conditions have changed significantly over the past century, with many examples of transcontinental disease introductions (rinderpest, BTB) causing persistent problems in wildlife and livestock populations. The wild species had not been exposed to these agents for millennia, so no co-evolution of host and disease agent had developed, with serious and persistent consequences (Bengis et al., 2002; de Lisle et al., 2002). Besides these initial introductions of major diseases through importation of livestock to the continent, the co-existence of people and their livestock with wildlife is not governed by "natural" mechanisms; at best they are only partially integrated, especially in pastoral systems when contact may occur seasonally or only in drought years. Thus endemism of disease organisms is disturbed and this is another reason the interface deserves close attention.

Countries where extensive wildlife populations are integrated with pastoral systems have no possibility of effective separation. In these locations the proposed solution is the creation of small export zones from which wildlife is excluded. Effectively, this means the creation of 'protected areas' for livestock, where foot and mouth disease, for example, can be controlled. This approach could resolve the conflict and provide the opportunity for commercial livestock development without much affecting the important wildlife resources in these parts of Africa. This would also support the culture and traditions of pastoral peoples. The concept does not exclude the opportunity for links between pastoral communities and the export zones, although a system of quarantine and the mechanisms for this would need to be explored. A fundamental issue relates to product quality and market preferences, and it will be interesting to see if some improved penetration into markets can be achieved for range or pastoral cattle (Thomson et al., 2004). As the loss of key grazing resources has been a factor in the decline of pastoralism, this potential reconnection with mainstream livestock economics and what would amount to fattening areas could strengthen the overall livestock economy and reduce pressure on protected areas, which are frequently used for this purpose. This will also enable traditional peoples to benefit from a mixed-species system and develop wildlife-related livelihoods in addition to their livestock, while bypassing the veterinary restrictions that have been a constraint to market access. 


\section{The "One Health" paradigm and protected areas}

In balancing the needs and expectations of Africa's rural inhabitants with those of wildlife conservationists, including protected area managers, it is necessary to consider how disease interactions influence human, livestock, and wildlife health (WCS, FVP, 2003a, 2003b; Kalema-Zikusoka, 2005; Kock, 2005b; Bengis, 2005) while keeping in mind that the role of wildlife health in conservation goes beyond the presence or absence of disease (Mainka, 2001; Deem et al., 2001). Wildlife health, in the broadest sense, is a holistic concept with a focus on populations and the environments in which they live. This focus must of course include human populations and livelihood needs, especially at the wildlifelivestock interface. While some caution is merited to prevent making too simplistic a linkage between "ecosystem health" and "human health," potentially at the expense of wildlife and conservation funding (Osofsky et al., 2000), it is clear that a paradigm shift in Africa is needed. Health is the key linkage that can contribute to human well-being and, therefore, serve as a logical entry point to promote environmental stewardship and healthy ecosystems (Margoluis et al., 2001).

In many instances, both historically and currently in Africa (Kock et al., 2002), disease control methods that have been adopted by veterinary and health authorities have been drastic, have had a significant negative impact on ecosystem health and biodiversity, and have rarely considered the broader issues surrounding and influencing health. Classic disease control methods include vaccination, test and slaughter, blanket slaughter, vector control, and movement controls including fencing. Many of these require "out-of-the-box" thinking by traditional veterinary and animal health authorities, including the promotion and legalization of community-based animal health systems. The indiscriminate use of fencing to control disease transmission between livestock and wildlife without considering connectivity and vital linkages between ecosystems is an example of a cause for concern (Albertson, 1998; Keene-Young, 1999; Scott Wilson and EDG, 2000; Thomson et al., 2003; Kock et al., 2002; Martin, 2005).

Historically, African protected areas have been managed without due concern for the communities that live nearby. This "hard edge" approach has done little to foster support for conservation and environmental issues and this legacy can be seen in the lukewarm response that the wildlife industry receives from politicians and other decision makers in many parts of postcolonial Africa (Kock, 2005a). In southern Africa, the adoption of community-based approaches to resource management, such as CAMPFIRE (Communal Areas Management Program For Indigenous Resources) in Zimbabwe, softened the hard edge and allowed communities to benefit from protected areas, be they national parks, game reserves, safari areas, or private conservation initiatives (Child, 1995). Other Community-Based Natural Resource Management (CBNRM) programmes continue to be developed and evaluated

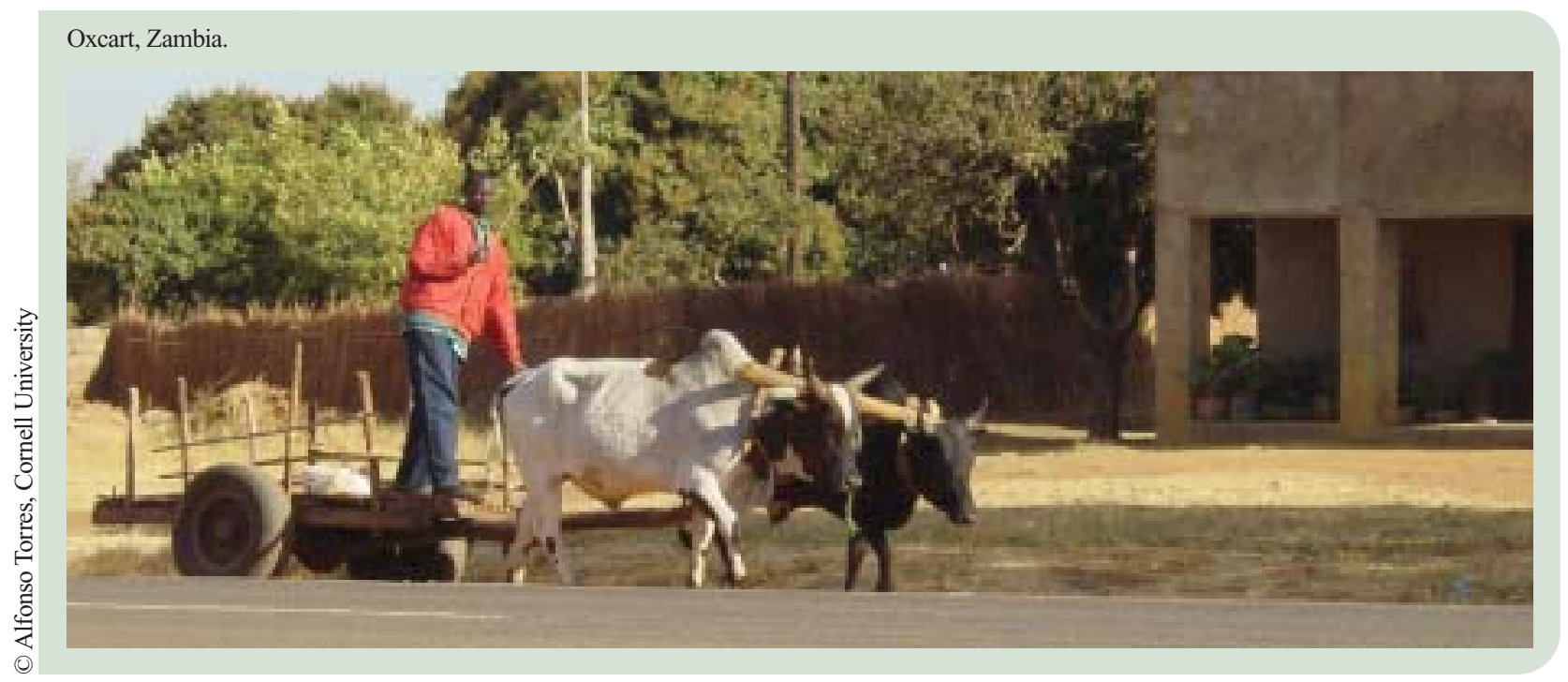


in East and southern Africa (Murphree, 2000; DFID, 2002; Weaver and Skyer, 2005; Murphree, 2005; Lewis, 2005) including the DFID-funded Mpomiba project with 19 villages close to the Ruaha National Park in Tanzania and the Deutsche Gesellschaft für Technische Zusammenarbeit (GTZ)-funded project with forty villages adjacent to the Selous Game Reserve. In Namibia, the National Community Wildlife Conservancy Programme has led to the registration of significant numbers of communityowned conservancies, many of which have entered into joint ventures with the private sector.

In general, pastoralist communities are likely to perceive the main CBNRM benefits to be the managed and more sustainable cropping of bush meat; increased revenues gained from consumptive tourism (hunting) and nonconsumptive tourism (wildlife viewing), or enterprise and employment opportunities in the tourism sector; as well as access to grazing and water resources for their own animals. Indirect gains come from investments in wildliferelated tourism, which lead to improved infrastructure such as roads, water mains, electricity and communications.

To ensure that these protected areas are able to provide the resource base for these benefits to communities, addressing disease issues should be an integral part of protected area planning and management and should involve veterinary and other health authorities. This is crucial as the impact of emerging and resurging diseases on the health of people, their livestock, and wildlife is likely to constrain the maintenance and development of protected areas and compromise conservation initiatives into the future. The potential for spread of bovine tuberculosis from Kruger National Park to surrounding human communities (Michel, 2005) is a case in point. In the 21 st century, management of protected areas needs to go beyond just concern for improved relationships with communities through benefits such as cash returns related to CBNRM. It must consider the health of the overall ecosystem, including people, their livestock, and the flora and fauna that are part of the larger community.

\section{Box 5.2}

\section{Transboundary management of natural resources and the importance of a "One Health" approach}

The transboundary management of natural resources, particularly of water and wildlife, and the associated development of transfrontier conservation areas (TFCAs) has been a major focus of attention over the last few years in southern Africa. Twenty potential and existing TFCAs have been identified in the Southern African Development Community (SADC) region, involving 12 continental African member states. The TFCAs include many national parks, neighbouring game reserves, hunting areas and conservancies, mostly occurring within a matrix of land under traditional communal tenure. Altogether the proposed TFCAs cover about 120 million hectares.

Transboundary natural resource management and TFCA development have also been closely linked to emerging Spatial Development Initiatives (SDIs) and corridors within southern Africa. A key economic driver linking these conservation and infrastructure development initiatives is wildlife-based tourism that seeks to maximize returns from marginal lands in a sector where southern Africa enjoys a global comparative advantage. However, the management of wildlife and livestock diseases within the envisaged larger transboundary landscapes remains unresolved and an issue of major concern to other economic sectors in the region. The interactions at the interface between animal health, ecosystem services, and human health and well-being are also poorly understood, with the result that policy development is compromised by a lack of appropriate information and understanding of the complex systems and issues involved.

Whatever the potential of wildlife-based tourism to generate wealth in such areas, the current reality is that small-scale agro-pastoralists living in the adjacent communal lands depend greatly on livestock for their livelihoods. The need to balance their livelihoods and environmental security with the development of alternative land uses and opportunities gives rise to a very 


\section{Box 5.2 (cont.)}

complex set of development issues. A central focus of these issues, and one that provides a unifying theme across sectors and disciplines, is that of animal, human and environmental health - "One Health". Innovative and integrated approaches to disease and natural resource management based on sound knowledge and understanding are urgently needed. An integrated, interdisciplinary approach offers the most promising route forward in tackling these issues.

With the ongoing philosophical and practical expansion of the transfrontier conservation area concept, the needs of communities living in and near these areas must be addressed, as transfrontier conservation areas have the potential to have both positive as well as negative impacts on sustainable livelihoods. In particular, disease issues are a significant concern when contact between wild animals and domestic stock increases with changes in land-use patterns. Corridors themselves, designed to (re)connect protected areas, can serve not only as biological bridges for wildlife, but also for vectors and their pathogens - so thorough assessments of disease risks should be made before areas with potentially different pathogen or parasite loads are joined.

Livestock will remain critically important culturally and economically - and of course as a vital source of sustenance - in much of the region. However, when it comes to animal health programmes and policies in transboundary landscapes, where domestic as well as wild animals have opportunities to cross international borders, making the right decisions becomes even more critical.
There is probably no region on earth where animal health policies have had as tangible an effect upon the biotic landscape as in Africa. In many parts of the world, land-use choices are often driven by government (domestic and/or foreign) incentives or subsidies that can favour unsustainable agricultural practices over more ecologically sound resource management schemes. And the most obvious beneficiaries of more holistic management are small landholders and pastoralists: people who derive much of their subsistence directly from livestock, people who are almost always marginalized in African economies and political systems.

Wildlife and livestock disease issues will likely have a significant impact on the future development of sustainable land uses, transboundary natural resource management, biodiversity conservation, and human livelihoods in the marginal lands of southern Africa. Some $65 \%$ of southern Africa is semi-arid to arid where extensive livestock and wildlife production systems are the most suitable and potentially sustainable forms of land use. The need to arrest desertification and enhance the capacity of these marginal areas to generate wealth and sustain improved human livelihoods is of paramount importance to the region. There does not appear to be an existing formal policy on animal health and disease control for the TFCAs being developed, and this must be addressed sooner rather than later. Source: Adapted from Cumming et al., 2004 and Osofsky et al., 2005. 


\section{Protected areas, human livelihoods, and healthy animals: how to improve conservation and development interventions}

Disease is becoming increasingly recognised as a threat to wildlife conservation, especially for endangered species (Werikhe et al., 1998). The relative risk is often increased by diseases that can be transmitted between closely related species, such as people and primates or cattle and buffalo. Transmission of such diseases at the interface of protected areas with human settlements can be exacerbated by mixing of people, wildlife, and domestic animals, for example, when wild animals leave the park boundaries, when domestic animals graze illegally within the park (Bengis et al., 2002), and when tourists, researchers, and field staff enter protected areas to view primates (Macfie, 1992; Woodford et al., 2002).

\section{Protected areas and diseases}

Disease transmission is of particular concern for local communities around protected areas, which in developing countries tend to be surrounded by some of the poorest of the population (Balmford and Whitten, 2003). Problem animals threaten these people's lives and property (Karanth and Madhusudan, 2002), in some cases reducing the value of land around protected areas. In Uganda, with a gross domestic product (GDP) per capita-purchasing power parity of $\$ 1200$ (CIA, 2003), those community and rural settings have very limited basic health care because most people have no transportation and live at least $30 \mathrm{~km}$ from the nearest health centre (Ministry of Planning and Economic Development, 1997; Homsey, 1999). This marginalized group also has very little access to information on zoonotic disease prevention because very little content has been developed for local education (Grant, 2002). Even when people manage to get to health centres, many centres are not adequately equipped to diagnose and treat diseases. This has resulted in a persistence of preventable diseases such as tuberculosis (TB) and scabies that can be transmitted between people, wildlife, and domestic animals.
Although there are relatively few documented cases of disease transmission between people and wild primates, the number of cases of suspected disease transmission is growing. A disease for which transmission from primates to people has been proven is Ebola, from a chimpanzee in Cote d'Ivoire (Formenty et al., 1999) and, more recently, in outbreaks involving western lowland gorillas and chimpanzees (Leroy et al., 2004). The origins of HIV in chimpanzees are of course now well-known (Gao et al., 1999).

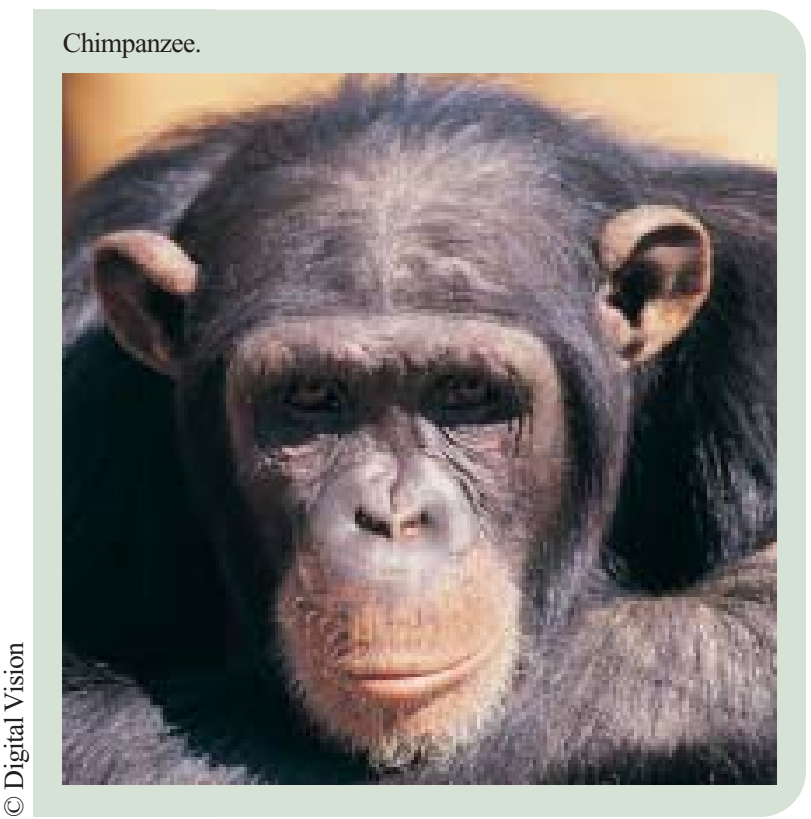

Diseases that have reportedly been transmitted between domestic cattle and Cape buffalo (Syncerus caffer) in Africa include BTB (Woodford, 1982; De Vos et al., 2001), rinderpest (Plowright, 1968; Kock, 1999), and foot and mouth disease (Dawe et al., 1994; Chilonda et al., 1999; Sutmoller et al., 2000). Examples of disease transmission between species that are only distantly related include mongooses (Mungos mungo) in Botswana and suricates (Suricata suricatta) in South Africa that have contracted human TB (Mycobacterium tuberculosis) from rubbish heaps outside tourist lodges visited by someone with a chronic cough (Alexander et al., 2002). A particularly dramatic example of disease transmission from people to wildlife is the outbreak of scabies - a skin affliction caused by mites - affecting mountain gorillas in southwestern Uganda's Bwindi Impenetrable National Park (BINP) in 1996 (KalemaZikusoka et al., 2002). This outbreak is thought to have been associated with scabies in the local human community. 


\section{Box 5.3}

\section{Case Study - Mountain Gorillas in Bwindi and the Virungas}

Mountain gorillas and people are very closely related and are therefore potentially at risk of transmitting pathogens to each other (Ott-Joslin, 1993; Wallis and Rick, 1999). Approximately 300 of the estimated 655 mountain gorillas (Gorilla gorilla beringei) live in the 33,100ha of Uganda's Bwindi Impenetrable National Park (BINP). A small forest remnant in Sarambwe, Democratic Republic of Congo (DRC), is contiguous with BINP. The remaining individuals of this highly endangered species are found in Rwanda, DRC and Mgahinga National Park in Uganda (McNeilage et al., 2001). The area surrounding Bwindi and the Virungas has one of the densest human populations in Africa, with an estimated 200-300 people per $\mathrm{km}^{2}$ (UWA, 2001). The establishment of BINP in 1991 restricted people's access to the forest to controlled activities such as tourism and research, while allowing multiple-use access for products such as medicinal plants, basket-weaving materials, and honey (UWA, 2001).

Bwindi gorillas have close contact with tourists and researchers (Macfie, 1992) and with local farmers when crop raiding (Madden, 1998) or foraging on community land. In addition to receiving inadequate health services and information, the local communities lack hygienic amenities such as clean water and pit latrines (Ministry of Planning and Economic Development, 1997; Homsey, 1999). These factors have resulted in a large percentage of people suffering from preventable diseases that can spread to gorillas. These include scabies, diarrhoeal diseases, measles, and TB (WHO, 2002). TB is exacerbated by a greater than $35 \%$ co-infection with HIV/AIDS (Kibuga, 2001) of which Uganda, Rwanda, and DRC are among the highest prevalence nations in the world (Castro, 1995) and are among the 22 countries contributing to $80 \%$ of the global TB burden (WHO, 2002).

Uganda Wildlife Authority (UWA), a national conservation authority, has developed an ecotourism programme in BINP. Sustainable ecotourism is dependent on maintaining gorilla health, improving the welfare of local communities through tourism, and promoting the national economy. The welfare of local communities in BINP has been improved through tourism revenue (via sharing of funds), development of incomegenerating activities (selling crafts, food, and lodging), and employment in restaurants and lodging facilities (Kamugisha et al., 1997; Ratter, 1997). The national economy is enhanced by the funds generated by mountain gorilla tourism, which amount to up to $50 \%$ of the overall income of the Uganda National Park System in some years (McNeilage et al., 2001). However, successful management of gorilla health is undermined by an unhealthy buffer zone surrounding the gorilla habitat. According to the district medical personnel surrounding BINP, the most commonly treated diseases in people are malaria, respiratory tract infections, diarrhoeal diseases, scabies, ringworm, intestinal parasites, tropical ulcers, and eye infections, including river blindness (Robert Sajjabi and Benon Nkomejo, personal communication, 2001).

The first reported scabies outbreak in mountain gorillas occurred in 1996 in a tourist-habituated group of four gorillas adjacent to the Buhoma tourist site in BINP (Kalema-Zikusoka et al., 2002). The source of the scabies was never determined, although people were suspected for two reasons: scabies is common in the local communities; and the gorillas' severe reaction to the disease indicated a lack of prior exposure to this mite from a closely related host. Four years later, a scabies outbreak occurred in another group of gorillas being habituated for tourism in Nteko parish, also in BINP, resulting in morbidity of some of the group. They, too, recovered with ivermectin treatment (Graczyk et al., 2001). While the ivermectin treatment was successful, interventions addressing the public health situation around BINP were needed to prevent further outbreaks. In early to mid-2000, UWA conducted health education workshops with local communities to improve the situation. Over 1000 people in five of 19 parishes 


\section{Box 5.3 (cont.)}

surrounding BINP participated in the community outreach, which included eight villages. During these participatory rural appraisal workshops, the team presented lectures in the local language to introduce diseases common in the BINP area that can be transmitted between gorillas and people. Prevention strategies were also discussed.

Protected area managers were initially concerned that the local community would believe the park authorities valued gorillas more than people. However, those communities that had directly benefited from the creation of the national park were actually very receptive to these ideas, and gave more recommendations than those communities that had received fewer benefits from the creation of Bwindi Impenetrable National Park. Recommendations from the communities were divided into three categories: medical, non-medical, and hygiene. Responsibility for implementation of improved practices was shared among government and local communities.

Having a multidisciplinary team of community conservation, wildlife health, human health, and education personnel appears to have been helpful. Additionally, the target communities seem to realize that healthy gorillas can generate income to support villages, which have already become trading centres as a result of ecotourism. Encouragingly, communities that received conservation education appear to have a greater understanding of the need to protect mountain gorillas both for conservation and a sustainable income (Kalema-Zikusoka et al., 2001). By contrast, one community in DRC that had received very little conservation education and virtually no tourism or gorilla research benefits did not trust the participatory rural appraisal team enough to admit that they had seen gorillas.

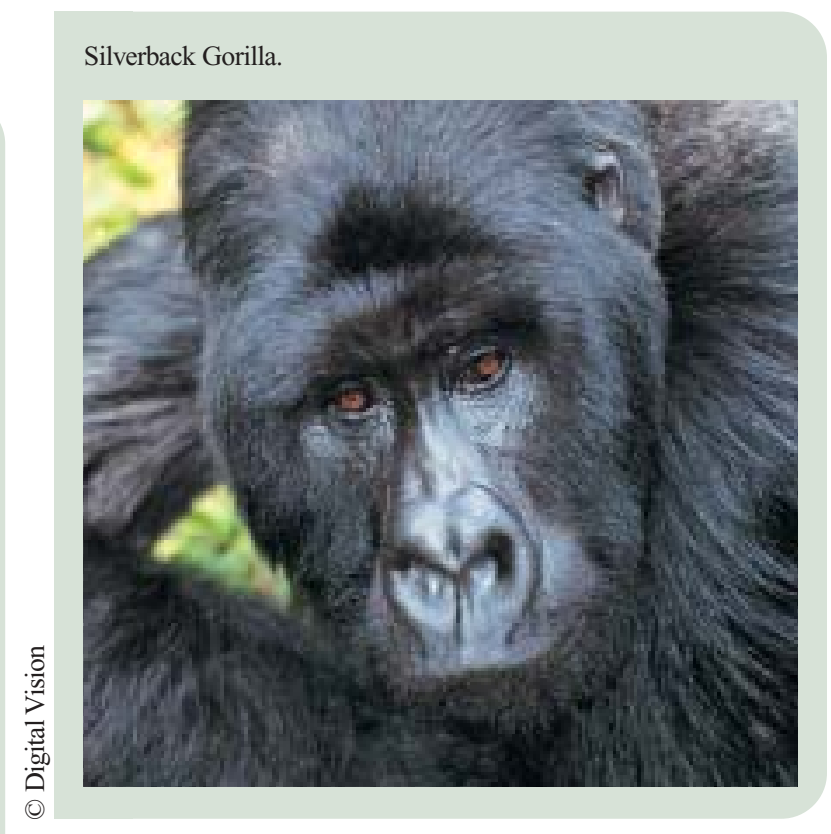

Health education appears to be a conservation tool that can bring the public health, wildlife conservation, and ecotourism sectors together. Local communities that received mountain gorilla ecotourism benefits recognised that they could protect mountain gorillas from human diseases by doing things like digging better pit latrines and covering rubbish heaps. However, some recommendations were beyond the communities' control, such as improving access to better health services or safer water. The lack of access to clean water not only contributes to a range of gastro-intestinal illnesses but also undermines efforts to control scabies, as the mites survive on dirty clothes that can be handled by curious wild animals, such as mountain gorillas (Fossey, 1983).

\section{Improving conservation and development interventions}

An integrated approach to controlling disease transmission between wildlife, people and domestic animals in a given area needs to be developed by a full range of stakeholders. This could start with dialogue among the affected communities and professionals from the wildlife, human health, veterinary, agriculture, education, media, and communication technology sectors, and could lead to sharing of knowledge using print, radio broadcasts, video, CDROM, handheld computers, databases, or the internet to play a supportive role in improving education and enhancing access to health information and services (Grant, 2002). 
Multidisciplinary teams from these sectors could be established to carry out joint education, health training, and research programmes while helping to maximize the use of limited resources. Close collaboration among governments, non-governmental organizations, the private sector, universities, and schools is needed to develop effective and efficient programmes, focusing specifically on interrelated human and animal diseases such as (for example) TB, scabies, brucellosis, rabies, Ebola, avian influenza, West Nile virus and HIV/AIDS. Local involvement in designing these programmes is crucial for long-term success. These grassroots programmes would benefit from input from all key stakeholders to ensure that the materials developed would be relevant to the local situation and available in local languages. Participatory rural appraisal techniques can also help to promote local community ownership of the recommendations put forward.

Joint training programmes could involve medical and veterinary technicians carrying out laboratory work together; and could help wildlife personnel, veterinarians, medical doctors, and other health workers to carry out integrated education campaigns on interrelated wildlife conservation and public health issues. In addition to promoting collaboration, local community involvement could be encouraged through "training of trainers" to educate others.

Research on interrelated wildlife conservation and public health issues should be encouraged to increase understanding of these links, and results should be shared with policy makers. Such research could help to identify the most common diseases that pose a threat to public health, wildlife conservation, animal agriculture, and ecotourism in a given area. Other research studies could help to evaluate local community attitudes and behaviour that facilitate disease transmission at the interface. Because public health is dependent on people's behaviour, evaluation of programmes integrating wildlife conservation and public health should focus on how people's behaviour is changing (or not) over time. Studies to determine how poor wildlife conservation and public health practices are affecting socio-economic development would be useful. Furthermore, research could explore models for sustainability for integrated conservation and public health programmes.

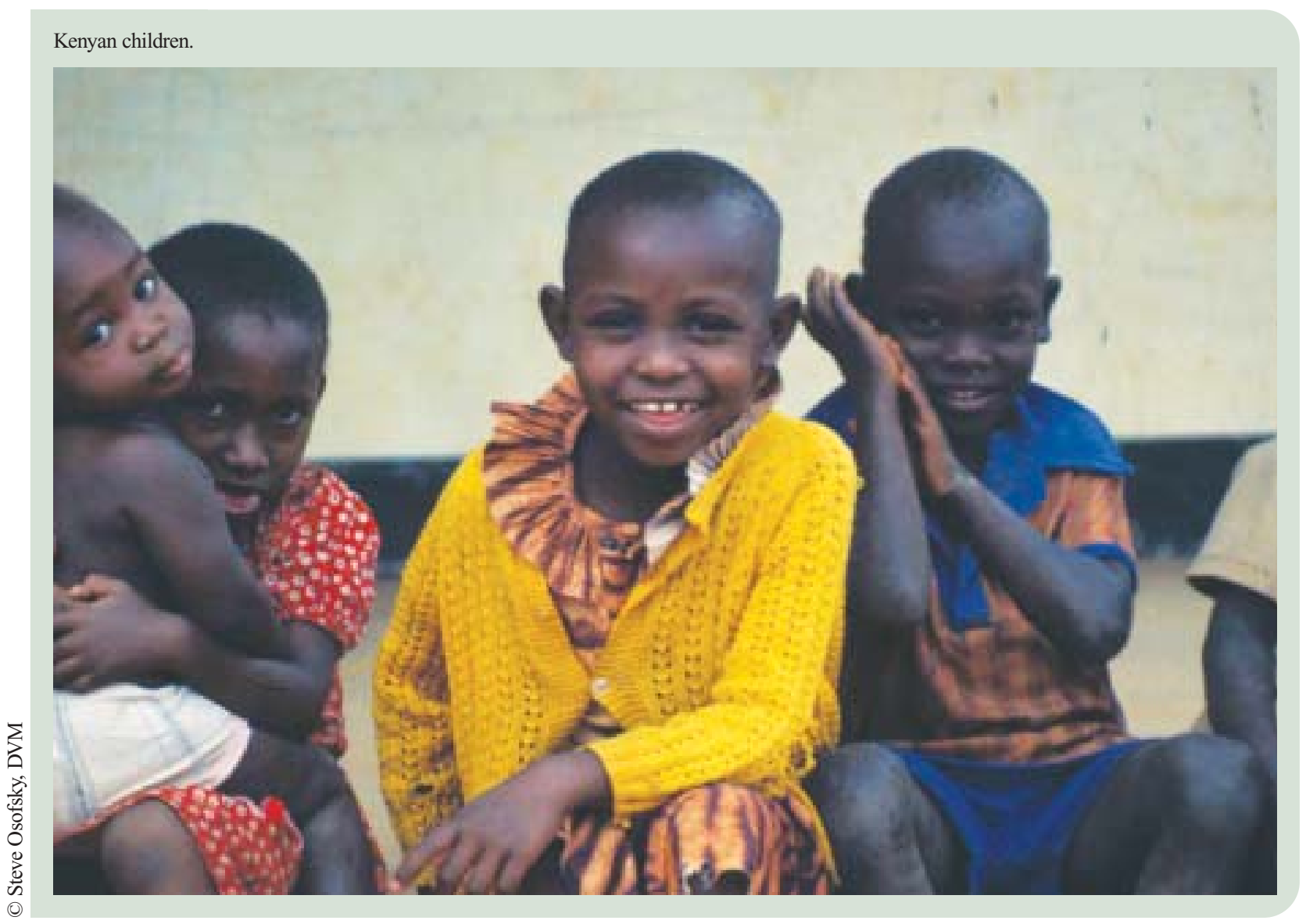


Developing "multiple use" health care and diagnostic services and facilities can potentially be more effective in preventing diseases that spread between people, domestic animals, and wildlife because information can be shared more easily. Sharing facilities and services could also save costs. Many places with wildlife have poorly developed infrastructure and few resources for transporting needed goods to the population. Tour operators and wildlife managers with access to good vehicles could help by transporting free medication, such as TB medication (WHO, 2002), to the people who need it. Such a programme has been carried out via the Healthy Community Initiative of the Kayapo Health Project in Brazil, where researchers bring malaria medication to people residing next to the forest (Margoluis et al., 2001). Joint domestic and wild animal laboratories at the interface of protected areas and human settlements could help to facilitate information sharing and better control of disease outbreaks, as could functional community-based animal health systems made up of trained community members, under the supervision of veterinarians, who can provide services to the animals of fellow community members as well as assist in disease surveillance.

Finally, an integrated approach to wildlife conservation and public health can maximize the limited resources available to control disease transmission between wildlife, people and domestic animals at the interface. Funds from wildlife conservation could be allocated to public health, where it directly affects conservation, such as the case of scabies in the Bwindi mountain gorillas. Similarly, donor funds earmarked for health improvement could be allocated to wildlife conservation where it directly affects public health, such as the situation of people contracting Ebola from eating gorillas or chimpanzees (Leroy et al., 2004). Beyond reducing the risks of disease transmission across the human-wildlifedomestic animal interface, a favourable outcome of improving the health status of local communities living around protected areas and of the domestic animals on which they depend is the potential to cultivate a more positive attitude towards wildlife conservation and public health. Developing new constituencies for conservation, especially local ones, is certainly worthwhile.

\section{Conclusions}

Disease is becoming an important issue in conflicts between protected area authorities and adjacent communities. These frequently poor communities increasingly perceive wildlife negatively, especially where they have no stake in the management or use of that wildlife resource. Under these circumstances disease outbreaks can trigger conflict, and historically, politics have dictated that interventions by public health and (agriculturally oriented) state veterinary services take priority: this usually has negative impacts on the wildlife resource. On the other hand, those same poor communities and livestock are seen as a threat to many protected areas as they compete with wildlife for resources and also because of a history of disease introductions. This situation is counterproductive for all concerned and cannot lead to better decisions being made for healthier ecosystems or human environments.

To reduce this conflict, as well as the risks and impacts of disease, in particular at the interface between wildlife and livestock but also at the interface with people, a "One Health" approach is required. Public education, training and awareness-raising regarding human, domestic animal, and wildlife health issues are crucial. In addition, more research on land-use and disease management at the interface is needed, as are new philosophies, attitudes, and approaches to livelihoods and resource use. New practical measures, such as multiple-use diagnostic centres, should be introduced in order to improve both animal and human health. This will be beneficial to community development and biodiversity conservation alike.

By raising the profile of the management, development, and research implications of the impacts of infectious diseases on the ecological and socio-political security of protected areas, especially in (but not by any means limited to) Africa, this chapter has sought to sensitize the reader to the critical importance of these issues. As socio-economic progress demands sustained improvements in health for people, their domestic animals, and the environment, the value of moving towards a "One Health" perspective is hopefully clear. 


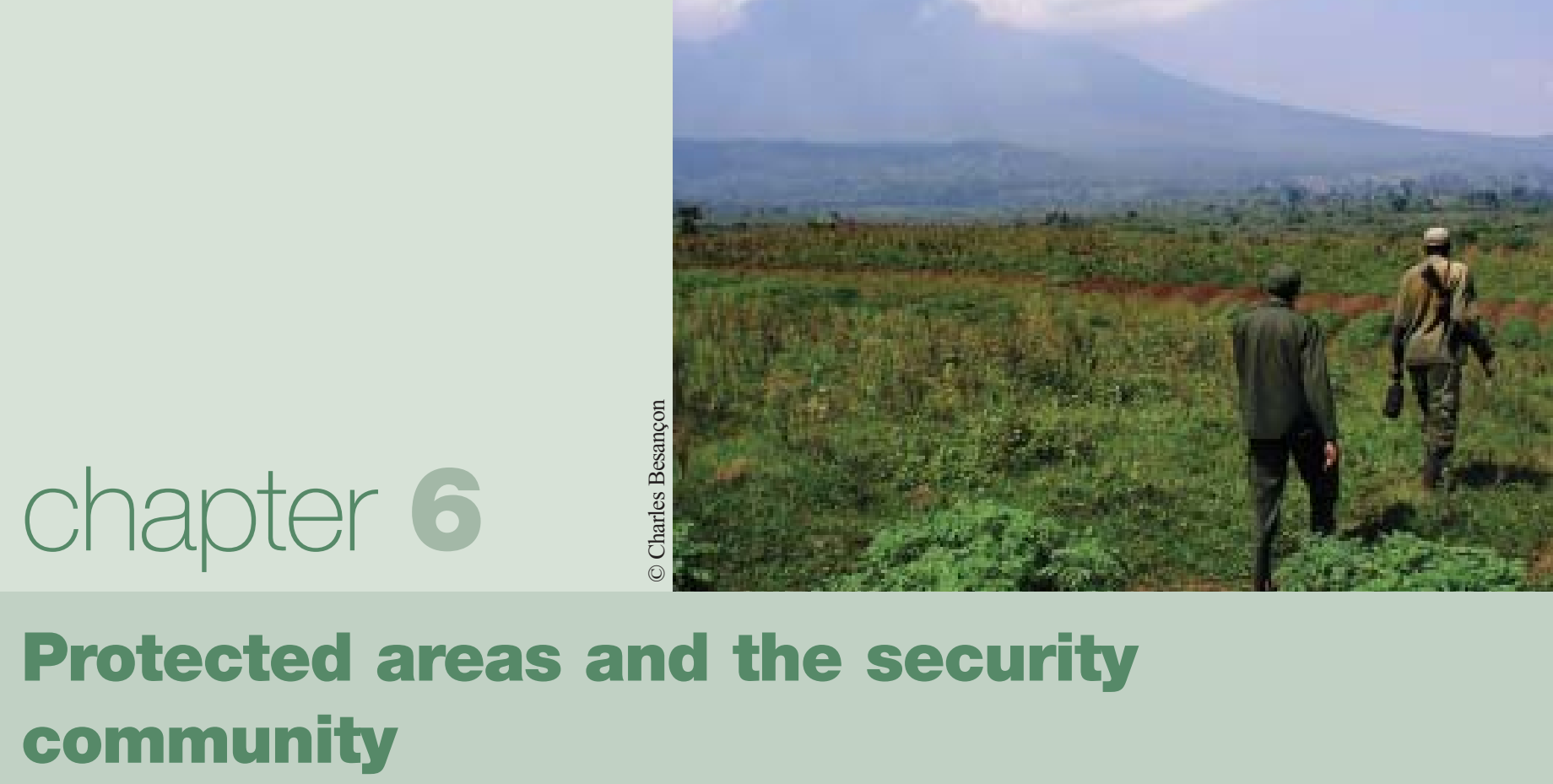

by Anne Hammill

\section{Editor's introduction}

Protected areas are often located in remote areas that are subject to conflict, but they can also make important contributions to peace. The security community includes the military, peace and development agencies, and governing bodies that are formulating and enforcing policies related to conflict and peacebuilding. This community increasingly is recognising that protected areas represent numerous strategic interests and are often located in volatile socio-political settings. Anne Hammill has shown the close relationship between protected areas and security, and suggests appropriate roles for the various parts of the security community. The military can help provide assets for biodiversity protection, and engage in practices that are not harmful to protected areas. Peace and development agencies can help to build the capacity of protected area staff in conflict analysis, help integrate conflict sensitivity into protected area design and management, offer support in conflict management and resolution processes, and integrate protected area activities into post-conflict reconstruction and peacebuilding. The relevant government decision makers can ensure that appropriate measures are taken to avoid conflict in protected areas, ensure that financial and technical assistance continues to be provided to protected areas during times of social unrest and conflict and encourage the appropriate use of protected areas in demobilization, disarmament and re-integration policies in post-conflict situations. The complex links between protected areas, human security and conflict deserve much greater attention, leading to benefits for both biodiversity and rural people. 


\section{Introduction: the links between protected areas and security}

Issues related to the design, establishment and management of protected areas (PAs) have traditionally been the purview of conservationists, resource managers, and with the advent of community-based conservation, community development practitioners. But with a growing body of research showing that environmental degradation, access to natural resources, and targeted conservation strategies - including the management of PAs - are contributing to and affected by conflict and security, the range of groups interested in PA issues is expanding to include security actors.

The links between PA and security are complex. Protected areas are inherently political, as they are mechanisms of resource control and power, with a wide range of interests seeking access to PA resources. In fact, protected areas represent different things to different interests. For conservationists, they are an effective measure for protecting biodiversity; for private tourism companies, a basis for tourism development; for pharmaceutical companies, a source of genetic information for drug development; for oil and mining companies, an unexplored potential supply of revenue; for the military, a refuge and strategic target during times of violent conflict; and for surrounding local communities, PAs can signify restricted access to livelihood resources, forced relocation, opportunities for income generation through tourism revenues, or a source of ecosystem services. With so many (sometimes conflicting) political and economic understandings of the role of PAs, it comes as no surprise that they can present risks of conflict.

In addition to the multiplicity of interests surrounding PAs, it is important to remember that they exist within complex social and political contexts where issues such as poverty, inequity, contested resource rights, corruption, and ethnic tensions factors that traditionally contribute to conflict - can further politicize PA policies, creating grievances that, when left unaddressed, can escalate into more open forms of conflict. PAs can also become embroiled in ongoing military conflicts, through their use as strategic bases for combatants or refugee camps in

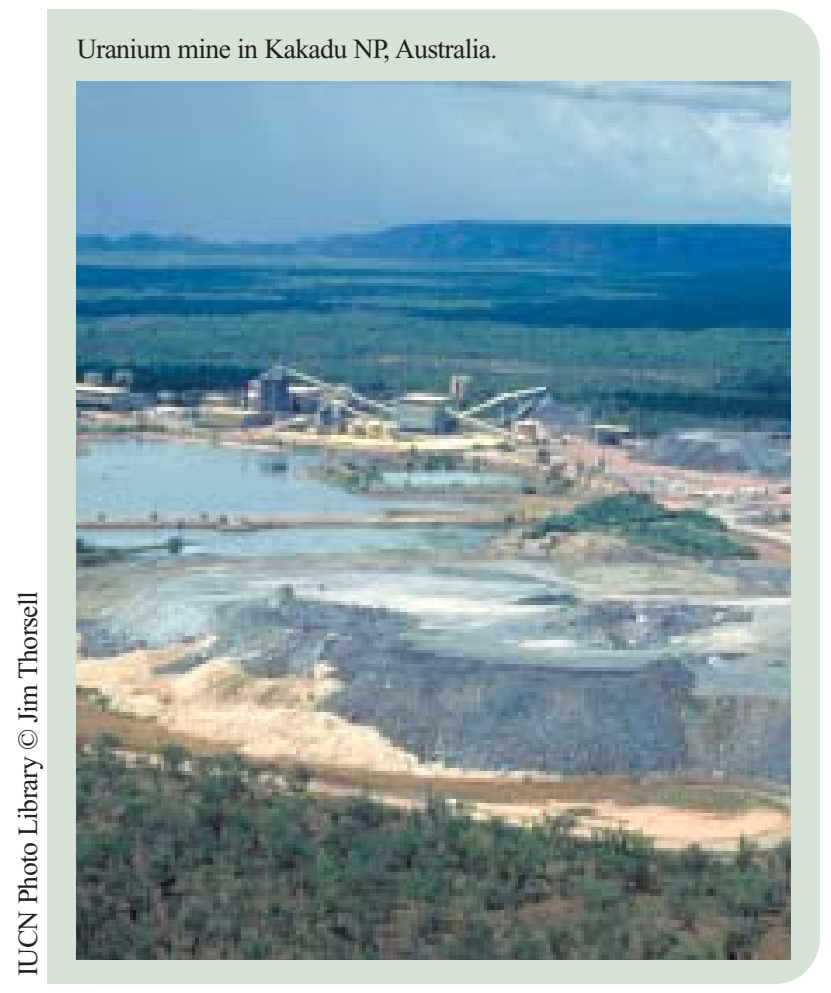

post-conflict settings. Thus, the (mis)management of PAs can be both a cause and symptom of insecurity.

This chapter will elaborate on why the security community (defined below) has a vested interest in the design and management of protected areas, and how their interests can be best strengthened and translated into mutually supportive policies that contribute to conservation and peace-building goals. It will start with a brief discussion on the links between environment and security, which will set the stage for a more in-depth look at the links between specific environmental concerns (i.e. biodiversity and ecosystem conservation) and certain security interests (i.e. social disruption, violent conflict and peacebuilding). Attention will then be turned to how the security community can contribute to the effective establishment and management of PAs.

\section{Background: the environment as a security issue}

Understanding the mutual interest in the relationship between PA and security communities requires an understanding of the broader links between environment and security. The body of work that has analysed and sought to address these links has included academic and conceptual, scientific, policyoriented and even very practical applications. While at 
times confusing and even contradictory, these different approaches to addressing environment and security linkages have brought together researchers, policy makers and practitioners from two seemingly disparate communities to work on new ways of reconciling environmental sustainability with socioeconomic issues.

The current interest in environment and security issues can be attributed to two significant political developments at the end of the 1980s/beginning of the 1990s: the end of the Cold War and the resurgence of the environmental movement. The absence of a sharply defined East vs. West political standoff to govern international relations, coupled with mounting concerns over the state of the Earth's environment, left researchers and policy makers contemplating a changing security landscape, prompting some to rethink the definition of 'security' and the forces that threaten it. Research yielding sobering evidence of tropical deforestation, species extinction, ozone depletion, global warming, and air and water pollution, demonstrated that environmental degradation and resource depletion could threaten human well-being - and even survival - just as much or even more than the threat of external military aggression. As Najam (2003) states, "indeed, one could argue that the wrong end of a smoke stack can be as much of a security concern to humans as a barrel of a gun".

\section{The ensuing research and discourse on environment and security consisted of several distinct approaches:}

- Conceptual debates over the need to expand or redefine the concept of 'security' to include nonconventional or non-military threats, such as environmental degradation and resource scarcity (Ullman, 1983; Mathews, 1989; Myers, 1993 and Sooros, 1997);

- Empirical case studies explaining how resource scarcity/resource dependence contributes to violent conflict - a more tangible and testable condition than 'security' (Baechler and Spillman, 1996; Collier, 2000; Collier et al., 2004; Homer-Dixon, 1994 and 1999; Homer-Dixon and Blitt, 1998); and
- Research on how environmental cooperation - such as international river basin commissions or transboundary protected areas - contributes to peacemaking (Conca and Dabelko, 2002).

In recent years there has been a move towards focusing on environment and 'human security', which focuses on the sub-state or intrastate level, understands the relationship between individual/community security and state security to be a two-way street (i.e., just as secure states can mean secure people, insecure communities can challenge or undermine state security), and recognises that manifestations of 'insecurity' are not limited to violent conflict, but include social disruptions (Najam, 2003). Where does the environment fit into the human security approach? Environmental degradation and resource scarcity is both a cause and symptom of insecurity, ultimately having profound impacts on humans by affecting the availability of and access to resources that are necessary to their health and well-being. Without these crucial environmental resources and services, communities can become further impoverished and more vulnerable to shocks and disruptions such as disease, famine, climate-related disasters, market collapse and war. In some instances, such protracted conditions of vulnerability and insecurity can become grounds for insecurity in the more traditional sense open violent conflict. Thus, while not entirely shunning matters of state sovereignty or violent conflict, the more people-centred approach of human security, which prioritizes the immediate needs of the most vulnerable and disadvantaged segments of the world's population, provides a more nuanced understanding of the relationship between environment, poverty and social stability.

For conservationists, the links between environment and security are relevant in several important ways. First, as over a decade of research has revealed, environmental mismanagement is a contributor to human insecurity. It follows then that through their work, conservationists may play a role in achieving and sustaining human security. Similarly, conservation is essentially a mechanism of resource control and management, which has implications for a number of stakeholders including resourcedependent communities. Because their work can be intricately linked to the welfare of vulnerable 
livelihoods, misguided conservation activities can also play a role in undermining conditions of social stability and peace. It would do conservationists well to be cognizant of the broader socio-political implications of their work, as instability and conflict are ultimately detrimental to biodiversity protection. And finally, conservationists are increasingly called upon to work in areas experiencing potential or open conflict, not only to sustain conservation activities (for example, gorilla protection in war-torn Congo) but to participate in post-conflict assessments and reconstruction. Understanding the links between environment and security issues will ensure that their contributions are integrated into the broader social and economic development agendas.

Thus, whether linking environment and security concerns has been the result of Cold War players looking for "new threats to justify old institutions" (Barnett, 2001), or environmentalists seeking to raise the political status of environmental issues by using a 'power word' such as security, there has been a growing consensus that the links do exist and that they warrant further attention. As traditional members of the 'environmental community', conservationists have a role to play in analysing and addressing the links. One particular approach to biodiversity conservation that is relevant to the security debate, and which will be the focus of the rest of this paper, is the establishment and management of protected areas (PAs). While central to conservation strategies at global, national, and local levels, PAs are also becoming increasingly relevant to 'security' issues both in traditional (state-centred, conflict-focused) and expanded (human-centred) understandings of 'security.'

\section{Who is the 'security community'?}

Before going on to explain how the establishment and (mis)management of protected areas are linked to security issues, it is useful first to say a few words about the 'security community,' to whom this chapter frequently refers and is largely directed. To many people, the security community consists of those actors and decision makers responsible for protecting their constituents - and interests - from violence and unrest. Members of this community are usually from the national and international military establishment (army, navy, and UN peacekeepers), domestic security forces (i.e. police forces, coast guard), intelligence services (such as the CIA, Interpol, and MI6), and people in government ministries or departments (i.e. defence, foreign affairs, etc.). Yet the expansion of the security agenda to include non-traditional or nonmilitary threats has conceivably translated into the expansion of the security community to include actors such as international development practitioners, natural resource managers, and health experts.

Nonetheless, for the purposes of this discussion the 'security community' refers to three types of actors working on various aspects of conflict issues - i.e. the prevention, management, and resolution of potential or open conflicts, as well as associated recovery efforts. Members tend to include people working in the following sectors:

a) Military establishment: Individuals and groups involved with the support, training and deployment of combat personnel, ranging from high level decision makers, to technical support staff, to ground troops. These individuals and groups can be associated with international military forces (UN peacekeepers, NATO forces, etc.), national militaries, and informal or underground armed groups (rebels or insurgents, terrorist networks, etc.)

b) Peace and development agencies: These actors are concerned with unarmed or 'soft' approaches to conflict prevention, management and resolution. They include civil society groups, NGOs, departments in bilateral assistance agencies, UN agencies, and regional organizations. As Anderson et al. (2003) describe, their goals are twofold, "both to end war and to build just, sustainable societies that resolve conflicts nonviolently". Activities range from education and training in conflict analysis and mediation, dispatching civilian peace monitors to conflict zones, and designing conflict-sensitive reconstruction and development programmes, to convening informal negotiations between communities or governments. 


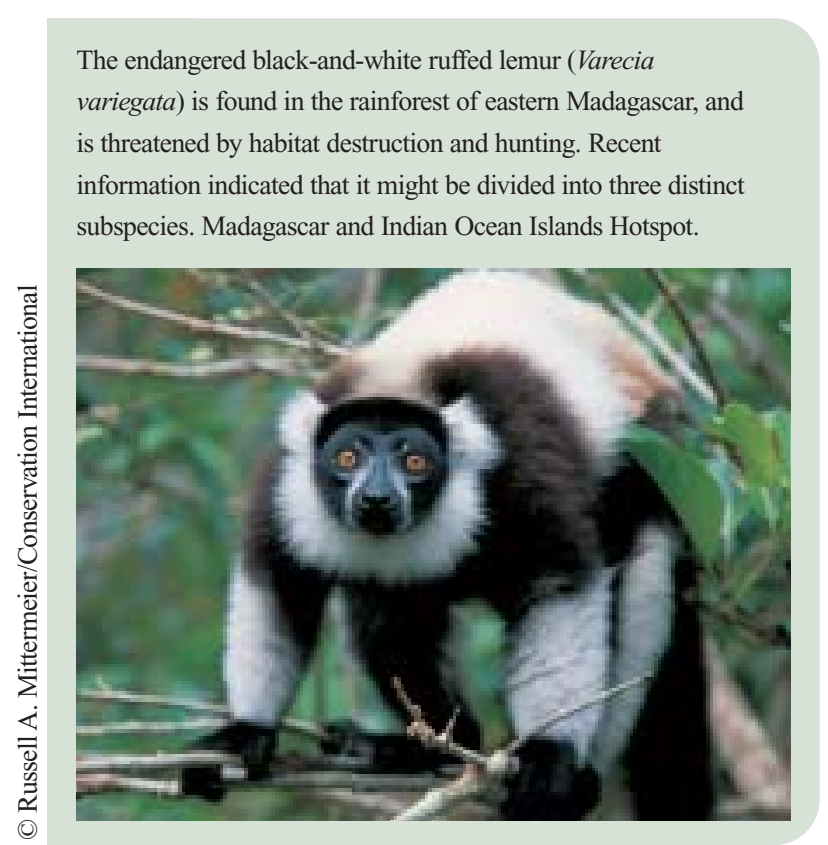

c) Government and decision makers: Members of local, regional, national and international governing bodies who formulate and enforce policies related to conflict and peacebuilding. These policies can range from decisions on where and when to take military action, to how to resolve different types of conflict (mediation, economic sanctions, use of armed force, etc.) and guidelines for reconstruction efforts.

Although their specific mandates, policies and practices may differ, each of these members of the security community has strategic interests associated with protected areas. The first step in engaging these members in protected areas issues is to outline the links between PAs and peace/conflict.

\section{Description of the security community's interest in protected areas}

The security community's interest in protected areas lies in both the challenges and opportunities they present for peacebuilding. This is not to overstate the role of PAs in preventing violent conflict or brokering peace deals. Obviously the forces and conditions that shape local and regional security dynamics are much broader and more complex than the need to conserve biodiversity and sustainably manage natural resources. But in some parts of the world, PAs can contribute or help sustain conflict situations, or conversely, play a role in promoting peace, cooperation and sustainability in post-conflict reconstruction processes.

Geography plays an important role in determining the relevance of protected areas to security interests, as not all regions in the world are equally endowed with biodiversity. In some parts of the world, namely developing countries, protected areas and nature conservation can be highly politicized endeavours that feed into broader social justice problems. As Brechin et al. (2002) observe:

"...most areas considered to be high-priority "hot spots" are also social and political 'hotbeds.' These rural areas in countries such as Colombia, Brazil, Madagascar, Tanzania, Malaysia, Indonesia and the Ivory Coast often feature high levels of poverty, insecure land tenure and landlessness, unstable and/or undemocratic political systems, and histories of state-sponsored repression."

Moreover, because PAs are zones with a relatively high concentration of economically-valuable natural resources (timber, wildlife, and plant genetic resources) and are often situated in frontier regions at the fringes of state control, they attract a wide range of interests and stakeholders, such as tourism agencies, oil and mining companies, guerrilla groups, pharmaceutical companies, the military, and development banks. With so many strategic interests represented in geographically defined areas and embedded in complex and sometimes volatile sociopolitical settings, it is hardly surprising then that protected areas should garner the attention of the security community.

\section{Protected areas and conflict}

The role of PAs in creating and sustaining conflict can take various forms. As instruments of resource control, they can be a direct cause of social instability, which can sometimes lead to violence. For surrounding rural communities, the establishment of a protected area often signifies restricted access to livelihood resources or even forced relocation, which can undermine economic security and socio-cultural identify. According to Brechin et al., (2002), "For outsiders looking in, such as resource-dependent 
agrarian communities, protected areas are not necessarily understood as a means of providing ecological and economic services but rather as territorial control strategies." Even where provisions are made to allow for limited local resource access or to financially compensate communities, crop damage from wild animals, unequal distribution of benefits, conflicting resource rights regimes (statutory vs. customary) and exclusionary and/or non-transparent decision-making processes can continue to fuel tensions.

The perceived imposition of unjust policies associated with the establishment of PAs can become catalysts for violent conflict. In areas with ethnic tensions, widespread poverty, unemployment, land shortages, and/or recent histories of violent conflict, the impacts of PA strategies may mobilize group identities and serve as a rallying point for resistance and opposition against government authorities. Where the implementation of conservation interventions brings up memories of elite control and colonial power dynamics, protected areas can symbolise legacies of imperial domination. Thus it is important to recognise that:

“...the conservation community...contributes heavily to shifts in power dynamics in rural areas that are already highly politicized. This is a result of [the community's] relative wealth and influence compared to most local actors. In short, conservation practices are not benign. They alter the local playing field, sometimes drastically" (Brechin et al., 2002).

Apart from directly contributing to emergence, escalation and incidence of conflict, PAs can also play a strategic role in sustaining ongoing military conflicts. The remote and relatively inaccessible location of some PAs can make them refuges for military groups, as they offer physical protection, food, water, fuel and medicine. The high concentration of wildlife can provide a ready supply of bushmeat for armies. Guerrilla groups in Colombia, Sierra Leone, Burundi, India and Nepal, for example, have established bases in protected areas, sometimes costing parks staff their lives (Austin and Bruch, 2003; McNeely, 2000). As a result, protected areas can become strategic targets in military operations. Some groups may deliberately contaminate water supplies and defoliate or burn forests in order to deprive opposing forces of shelter and resources. In 1991 the Rwandan army cut $50-100 \mathrm{~m}$ wide swathes of bamboo forest that link the Virunga volcanoes in order to minimize the risk of rebel ambushes (Kalpers, 2001).

In addition to providing physical support to military groups, resources in protected areas help to finance military operations. Wildlife, timber, oil or minerals can be plundered and sold to local and foreign markets in order to pay troops and purchase weapons. For example, the Angolan rebel group UNITA (National Union for the Total Independence of Angola) reportedly financed their military campaign through sales of ivory, teak, oil and diamonds (Austin and Bruch, 2003). Similarly, in Mozambique, elephant poaching and the ivory trade helped finance insurgent activities, while Charles Taylor's coup in Liberia was made possible through revenues from timber and valuable minerals (Boutwell and Klare, 2000). Moreover, the consequences of financing wars with natural resources from protected areas extend further than immediate biodiversity loss or ecosystem degradation. According to Austin and Bruch (2003),

"Aside from depriving a country of capital that is desperately needed for development or social programs, financing wars with natural resources prolongs the misery of war and often wreaks greater environmental harm, as constraints and mitigation requirements that may be placed on resource extraction during peacetime are ignored in the urgency of conflict. The emphasis of short-term gains over long-term sustainability drains national resources and makes it more difficult to return to peaceful life after the conflict."

In fact, post-conflict settings give rise to new security concerns associated with protected areas. Refugees, internally displaced people (IDP) and demobilized troops may move into protected areas, as they contain unsettled lands and livelihood resources. In some instances, resettlement in PAs has been encouraged by governments when no other land is available and the overarching priority is to establish peace, address immediate humanitarian needs and create some semblance of order. Following the 


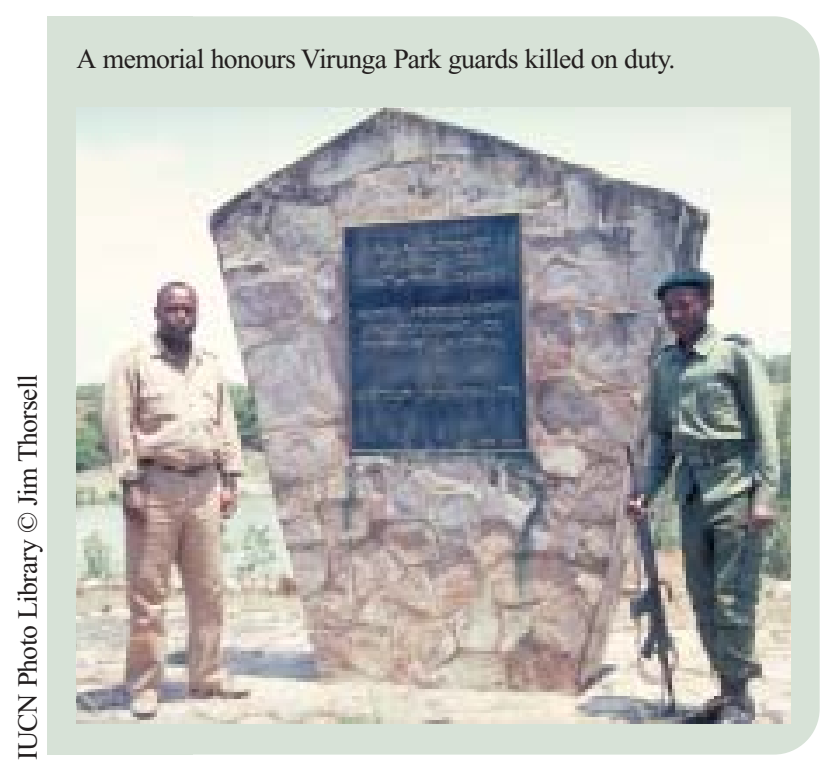

Rwandan genocide in 1994, $50 \%$ of the country's population was estimated to be displaced or temporarily settled. Hundreds of thousands of refugees crossed the border into the Democratic Republic of Congo and settled in and around Virunga National Park (Lanjouw, 2003), while the Rwandan government opened portions of Akagara National Park to resettlement and considered proposals for degazetting $5 \%$ of Volcanoes National Park to accommodate IDPs. The acute need for land, shelter and resources that leads displaced and demobilized populations to PAs (and their immediate surroundings) has the potential for fuelling further tensions and conflict. When host communities, who are also dealing with the social and environmental consequences of war, are faced with competition for livelihood resources from refugees and displaced people (sometimes of different or previously opposing ethnic groups), tensions can rise and conflicts can (re)ignite. When considered against a background of widespread arms circulation, demobilization, and general disorder and confusion in post-conflict settings, the gathering of different groups in refugee camps or settlements around relatively resource-rich protected areas can become a flashpoint of conflict.

\section{Protected areas in post-conflict reconstruction and peacebuilding}

While the discussion above has outlined some of the potential security threats associated with protected areas, it is important to note that they can also play a positive role in post-conflict reconstruction and peacebuilding. Among the most prominent examples of this potential are transboundary protected areas (TBPAs). TBPAs are being established at a remarkable rate: In 1998 there were a total of 59 transboundary complexes involved 136 areas; by 2001, the number had jumped to over 169 complexes involving over 666 areas. This recent proliferation of TBPAs is generally welcomed as a sign of good will and cooperation, particularly in areas with relatively recent histories of conflict. In fact, TBPAs represent the confluence of several seemingly mutually reinforcing interests, namely those of biodiversity conservation, economic development, cultural integrity and regional peace and security. The possibilities are impressive: large, contiguous ecological habitats that simultaneously protect biodiversity, create widespread opportunities for tourism development, alleviate poverty, reunite previously separated ethnic groups, and promote good political relations between neighbouring states.

This latter point has led some TBPAs to be called 'Peace Parks', although their actual peacebuilding potential and impact is rarely evaluated systematically. Cooperation and peacebuilding is an assumed outcome of bringing together different - sometimes previously opposing - stakeholders for the common purpose of managing biodiversity and protecting livelihoods. This assumption is drawn from a broader literature on 'environmental peacemaking', which claims that environmental cooperation can have positive spin-offs for peace. As Conca and Dableko (2002) explain:

"The basis for this [environmental peacemaking] claim lies partly in the general conditions understood to facilitate cooperation, partly in the issue characteristics common to many environmental problems, and partly in the kinds of social relations that are engendered by ecological interdependencies."

They go on to describe two ways in which environmental cooperation may occur:

1. "Changing the strategic climate": Exploiting environmental problems as opportunities in conflictual situations. That is, using discussions 
over environmental issues as a means to create at least minimum levels of trust, cooperation, and transparency between actors, thereby improving the 'contractual environment' in the bargaining process; and

2. "Strengthening post-Westphalian governance": Looking outside of formal, state-sanctioned negotiations to broader social dynamics - i.e. using environmental concerns to deepen transsocietal linkages, strengthen regional identities, and transform state institutions to become more open, democratic and accountable.

TBPAs have the potential to promote environmental cooperation along both pathways. For example, the technical cooperation needed to establish and manage PAs across borders could serve as an opening to other forms of cross-border cooperation, while the opening of borders to allow for animal migrations and personnel exchanges may deepen trans-national relations and regional identities, thereby lessening the incentives for conflict. TBPAs may therefore prove to be one of the more viable opportunities for peacebuilding in a post-conflict setting.

Related to but not exclusive to TBPAs are the economic opportunities associated with PAs and their role in promoting social stability and peace. Although the establishment and management of PAs is a highly politicized process, particularly in conflict-prone regions, when done right PAs can offer opportunities to resource-dependent communities to diversify their livelihood options and generate supplemental incomes, namely through tourism revenues and other community development benefits. For example, tourism operations in PAs can offer employment opportunities to local community members, mostly to work as park rangers or general labourers; create or enhance the market for locally-produced goods (food, handicrafts, etc.); improve local infrastructure such as roads and water supplies; and fund community institutions such as schools and churches through revenue-sharing schemes. The benefits of PAs can therefore increase human security for surrounding PA communities, addressing some of the root causes of violent conflict and promoting peace.

\section{How can the security} community contribute to protected areas?

Having outlined how PAs can contribute to both peace and conflict, how can the security community contribute to PAs? Just as decades of lessons in conservation and development can inform our understanding of 'security' and the forces that threaten it, the security community can play a role in the design, management and protection of PAs, particularly for those located in conflict zones. Below are some suggestions of how the different members of the security community can contribute to PAs.

Roles for the military. Because military actors are political and by definition linked to armed conflict, involving them in PA activities can be a sensitive topic - i.e. there is a fear of militarizing protected areas, which is not only counter-intuitive but detrimental to their conservation mandates. That said, the military establishment can contribute to PAs in a few relatively benign ways:

\section{Share or donate assets for biodiversity} protection: Many protected areas continue to be underfinanced and insufficiently equipped to monitor and evaluate ecological conditions. Access to assets such as satellite imaging and communications technology would certainly fill this gap. Satellite imaging could assist with monitoring land use changes, while communications equipment would help staff members working in large PAs, such as TBPAs,

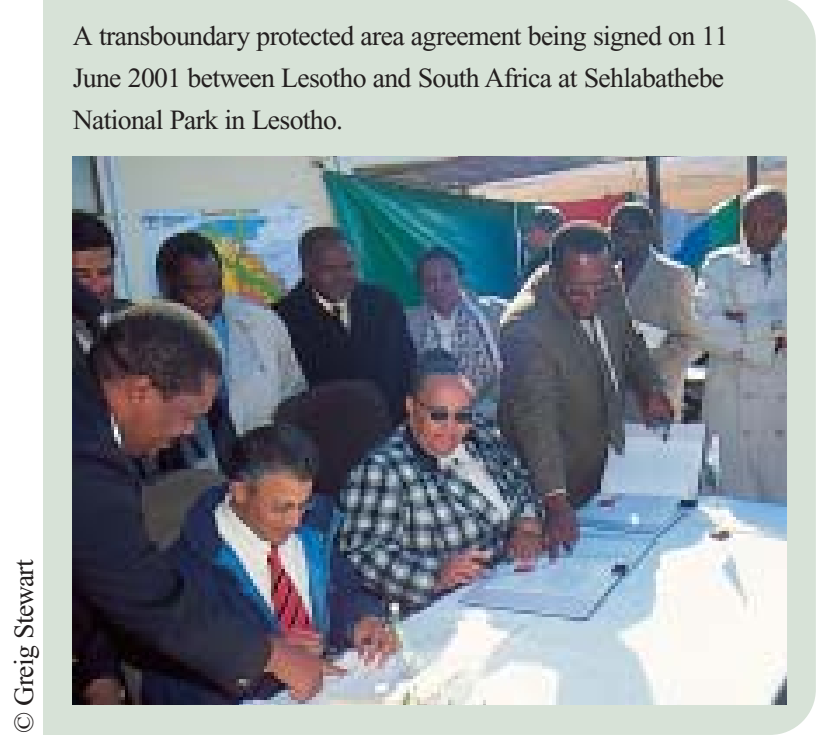


to maintain regular contact and inform each other of important developments (poaching activities, disease outbreaks, rebel movements, etc.).

\section{Green military practices: Although} environmental protection is not a priority for military actors (in fact, environmental destruction may be part of a military strategy), efforts can still be made to raise awareness of and provide alternatives to PA destruction in armed conflicts. Declaring PAs (especially World Heritage Sites) as 'no-go' zones, or heightening security around PAs to prevent incursions are two simple (simplistic?) options, as are policies against poaching, water contamination, and clearcutting.

Roles for peace and development agencies. Because PA managers and staff members are finding themselves working in areas of potential or open conflict, there is an increasing need to build their understanding of conflict situations and adapt their work accordingly. Peace and development practitioners can help conservationists assess and redesign their operations so that security risks are minimized; conflict-sensitivity is integrated into PArelated activities and opportunities for peacebuilding are maximized. This type of support can take a number of shapes:

\section{Build capacity of PA managers/staff in conflict}

analysis: PA managers and staff usually have technical and scientific backgrounds in natural resource management/ecosystem management. Moreover, they operate under mandates which generally require them to measure the impact of their work according to biologically or environmentally-defined criteria. While this is not to underestimate the intimate knowledge that local PA managers and staff have of the social and political forces that affect their work, those working in conflict zones should be trained to understand the conflict setting and how their work is directly and indirectly linked with the root causes of conflict. The security community can certainly offer insights and tools for analysing such relationships, such as conflict analysis/assessment frameworks, checklists, indicators, etc.

\section{Help to integrate conflict sensitivity into PA} design and management plans: Building on the point above, PA authorities can reflect their understanding of the links between PAs and peace/conflict dynamics by integrating conflictsensitivity into their work. In other words, they must assess and adapt their work to ensure that, at the very least, PA-related activities do not exacerbate tensions or contribute to conflict, and ideally that they strengthen human security and peacebuilding. Again, the security community can facilitate this process and use examples from the humanitarian, development and business sector to highlight how conflict-sensitivity can be achieved.

\section{Offer support in conflict management and} resolution processes: Because PA managers and staff can become directly or indirectly involved with local and regional conflicts, they can find themselves in positions of trying to manage or resolve conflicts. While conservationists have developed some guidelines for addressing PArelated conflicts (Lewis, 1996), a continued dialogue with the security community on the development and use of different and emerging conflict management and resolution strategies would strengthen their position.

\section{Integrate PA activities into post-conflict reconstruction and peacebuilding} programmes: Natural resource and environmental services are closely tied to the livelihoods and human security of many vulnerable communities in conflict zones, and yet environmental considerations are usually overlooked in post-conflict settings when more immediate needs take priority. As such, conservation activities should become central components of at least some reconstruction and peacebuilding programmes. Engaging communities in activities within and around PAs - either in (re)building park infrastructure, monitoring poaching activities, carrying out ecosystem assessments, developing the tourism plans, etc. - may present some win-win options. 
Roles for government decision makers. Finally, for government decision makers, the biggest contribution they could make to PAs is to establish a policy environment and regulatory framework that enables the implementation of the recommendations above. This might include developing or strengthening policies that:

1. Ensure that all measures will be taken to avoid conflict in and damage to PAs, particularly World Heritage Sites. For example, further developing and adopting IUCN's Draft Convention on the Prohibition of Hostile Military Activity in Protected Areas.

\section{Provide for continued financial and technical} assistance in PAs during times of social unrest and conflict. Environmental protection is often perceived as a luxury during times of crisis, leading authorities to divert funds from conservation activities such as PA management. Recognising the complex links that exist between PAs, human security and conflict, and maintaining a minimal amount of support and training for PA managers and staff during times of escalating or open conflict can prove to be an investment in conflict resolution and post-conflict reconstruction.

\section{Promote Peace and Conflict Impact} Assessments (PCIAs) of PAs. Just as government policies require Environmental and/or Social Impact Assessments (EIA or SIA) of development projects/programmes, there should be a requirement for PCIAs for PAs situated in conflict zones. The process would raise awareness of the different links between PA activities and peace/conflict dynamics, and force PA managers to rethink activities so that conflict risks are minimized, and peacebuilding opportunities are maximized.
4. Encourage the use of PAs in demobilization, disarmament and reintegration policies in post-conflict situations. Where appropriate, the restoration, management and operation of PAs should be integrated into post-conflict policies so that the parallel and complementary goals of biodiversity protection and peace-building can be simultaneously met. This can include guidelines for offering PA-related employment opportunities and training to demobilized soldiers or including PA eco-tourism and community development schemes as part of reintegration programmes.

\section{Conclusion}

The links between protected areas, human security and conflict are complex. This chapter has attempted to summarise some of them, highlighting both the positive and negative impacts PAs may have on security dynamics. Much of this is not new to conservationists - they have long searched for an optimal resolution to people vs. nature conflicts, where biodiversity protection goals are not met at the expense of social and cultural concerns. Similarly, in the wake of rising levels of local and regional violent conflicts, conservationists have been developing guidelines and management strategies for maintaining basic levels of biodiversity protection in times of conflict (Shambaugh et al., 2001). These efforts have been met with varying degrees of success. Bringing in the security community to buttress these efforts could be an effective way of addressing the gaps, helping PA authorities to maximize the peacebuilding opportunities and minimize the conflict risks associated with their work. 


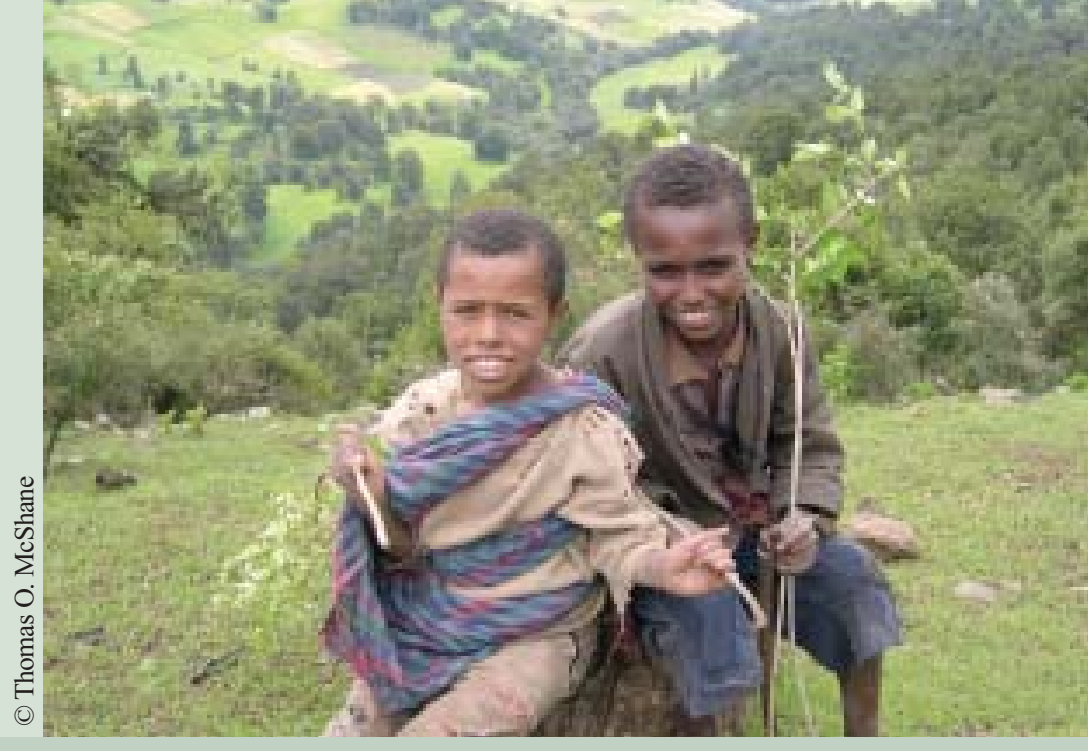

\section{Protected areas and development assistance agencies: at the intersection of conservation and development}

\section{by Thomas 0 . McShane}

\section{Editor's introduction}

While development assistance agencies are hardly a "new constituency" for protected areas, much has been learned over the past decade about the relationship between protected areas and the development assistance agencies. Early enthusiasm for so-called integrated conservation and development projects (ICDP) has been tempered by experience and many important lessons have been learned about how to design protected area projects so that they can be relevant to the objectives of development assistance. In summarising this work, Tom McShane has emphasised the importance of linking protected areas to larger contexts, acknowledging trade-offs between conservation and development, and identifying incentives for protected area conservation. Maintaining the development assistance agencies as important supporters of protected areas in the coming decade will require clarity about goals and objectives, an improved understanding of the constraints of project structures, an expanded scale of intervention that often extends to the landscape level, a component of policy change that accompanies site-level intervention, developing appropriate local institutions that can support improved relations between local people and protected areas, clear acknowledgement of trade-offs between conservation and development objectives, an improved understanding of poverty, and adaptive management that enables an active process of learning from experience and then modifying interventions. As other papers in this book demonstrate, protected areas have much to offer to human welfare, and are therefore worthy of investments from development assistance agencies. 


\section{Introduction}

Even though protected areas now cover $11.6 \%$ of the world's land area (Chape et al., 2003), conservationists argue that protected areas are not enough; that even if all of the ecological systems contained in protected areas remained intact, this would still be woefully insufficient for humanity's future needs. Protected areas face a myriad of threats to their integrity and few are adequately managed, especially in the tropics where biodiversity is concentrated (WWF, 2004). There is now a broad consensus that most protected areas will have limited future prospects without the cooperation and support of the people living around them. This has been a key doctrine of international conservation efforts for at least two decades. Putting this doctrine into practice has proven frustratingly difficult, however, especially in developing countries (cf. McShane and Wells, 2004).

Park management has often prioritized keeping local people out, following the view that human activities are incompatible with ecosystem conservation. Many protected area residents and neighbours have lost their homes and their livelihoods as a result. Having alienated their primary users while failing to build political support, most national conservation agencies have also shown neither the capacity nor the resources to manage the protected area estate under their jurisdiction. Growing pressure on protected areas from increasing populations, persistent poverty and the penetration of the market economy have all compounded the futility of trying to manage parks by isolating them from human activities.

Conservation organizations responded during the 1980s by pioneering new approaches to protected area management that promised to build support among local constituents by sharing social and economic benefits from protected areas. The goals of these initiatives included compensating local people for lack of access to protected areas and providing alternative income sources that would allow people to benefit economically from conservation while refraining from environmentally-destructive practices.

Numerous terms have been used to describe these efforts to reconcile protected area management with local needs and aspirations. Although none of these labels has proven entirely satisfactory, experience suggests that Integrated Conservation and Development Project or Programme (ICDP) continues to be a viable collective description for site-based conservation with social or economic development goals, including community-based conservation, ecodevelopment and other terms (Wells and Brandon, 1992).

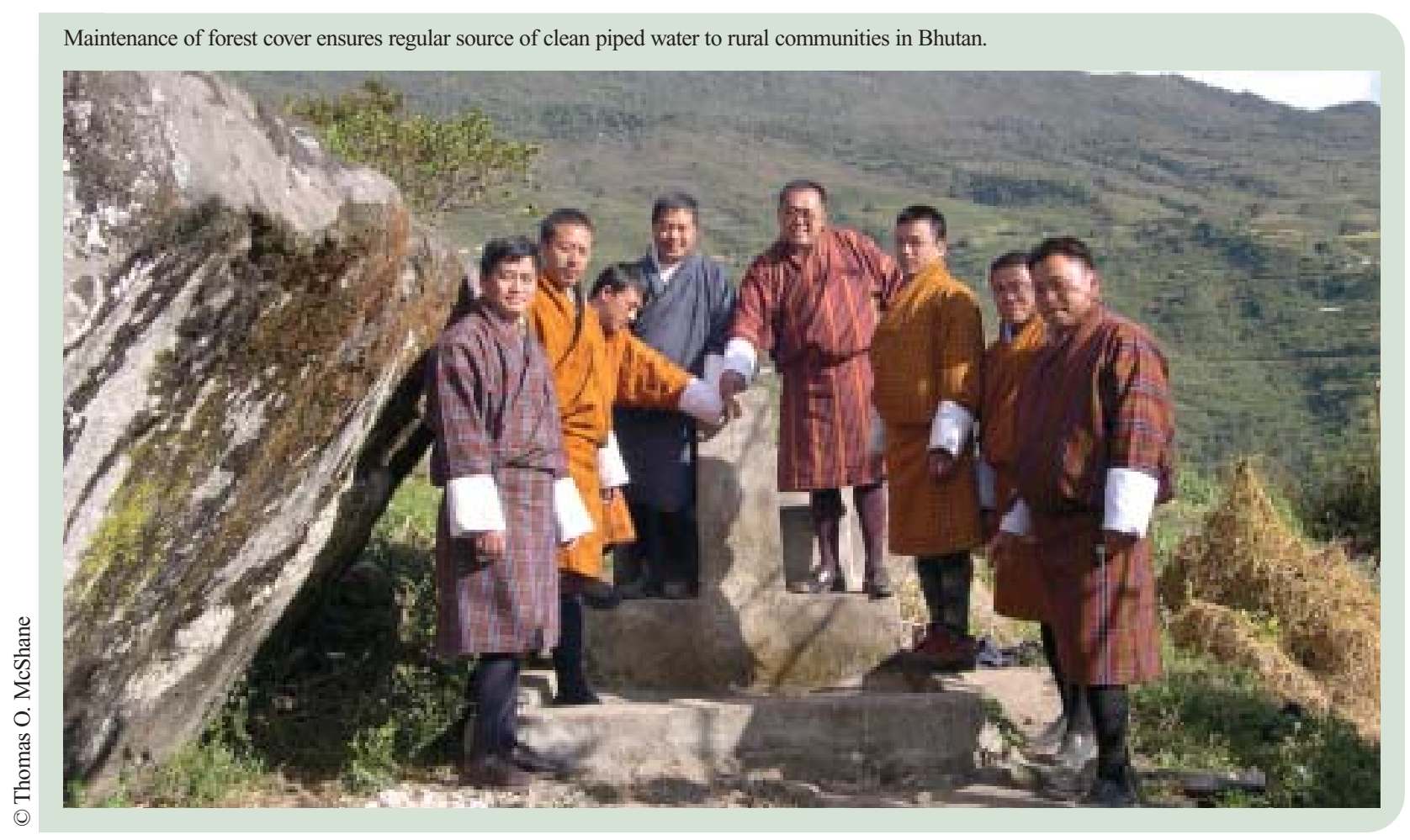


ICDPs initially offered the attractive prospect of contributing to three of the most sought-after goals on the international sustainable development agenda: more effective biodiversity conservation; increased local community participation in conservation and development; and economic development for the rural poor. Such an approach found an enthusiastic audience among the international development assistance agencies that had just added environmental conservation to their mission of stimulating economic growth. Support from these agencies provided financial resources for biodiversity conservation on an unprecedented scale during the 1990s. The result was a proliferation of conservation projects supporting development activities amongst poor, rural communities around protected areas, to such an extent that a conservation project without a major emphasis on local people's welfare would have been almost unthinkable.

\section{Development assistance agencies and their goals}

Bilateral official development assistance (ODA) agencies are government agencies set up to channel assistance to other countries - typically this assistance goes directly to the government. The largest such agencies are in North America, Europe and Japan. Some examples are the Canadian International Development Agency (CIDA), the Department for International Development (DFID) of the United Kingdom and the Japan International Cooperation Agency (JICA). The European Commission's ODA agencies are considered bilateral agencies in that they provide assistance to other countries, not to the European Union members.

Multilateral ODA agencies are composed of member's governments that agree by international treaty or convention to establish them. These agencies have a wide variety of objectives and interests. Multilateral agencies providing official development assistance include many parts of the United Nations such as the United Nations Development Programme (UNDP), United Nations Environment Programme (UNEP), United Nations Educational, Scientific and Cultural Organization (UNESCO), the UN Food and Agriculture Organization (FAO), World Health Organization (WHO) and others.
Although technically part of the United Nations system, the World Bank and International Monetary Fund (IMF) are governed in a different manner than other parts of the UN - according to weighted shares held by member states. They are sometimes called the Bretton Woods institutions or, together with regional development banks (such as the Inter-American Development Bank, African Development Bank, and Asian Development Bank), the International Financial Institutions. While the World Bank and regional development banks provide loans and technical assistance for development purposes, the IMF is not directly involved in development - rather its purpose is to promote international monetary cooperation.

Perhaps the most important multilateral institution when it comes to financing biodiversity conservation and protected areas is the Global Environment Facility (GEF), an independent financial organization that provides grants to developing countries for projects that benefit the global environment and promote sustainable livelihoods in local communities. GEF projects are managed by three implementing agencies: UNEP, UNDP, and the World Bank. GEF projects address six complex global environmental issues: biodiversity, climate change, international waters, land degradation, the ozone layer, and persistent organic pollutants. Since 1991, the GEF has provided US $\$ 4.5$ billion in grants and generated $\$ 14.5$ billion in co-financing from other partners for projects in developing countries and countries with economies in transition. GEF funds are contributed by donor countries. In 2002, 32 donor countries pledged \$3 billion to fund operations between 2002 and 2006 (GEF, 2004).

The Organisation for Economic Co-operation and Development's (OECD) Development Assistance Committee (DAC) groups the world's principal aid donors. The DAC brings together development assistance agencies from OECD governments (bilateral donors) as well as representatives of the World Bank, the IMF and the UNDP (multilateral donors). The OECD groups thirty member countries that generally share a commitment to democratic government and the market economy. The DAC is the principal body through which the OECD deals with issues related to co-operation with developing countries. 
The Millennium Development Goals and targets come from the UN Millennium Declaration signed by 189 countries, including 147 Heads of State, in September 2000 (World Bank, 2002). The Millennium Development Goals are used by development assistance agencies as a common framework to guide their policies and programmes and to assess effectiveness of the development aid being provided worldwide (see Box 7.1).

\section{Box 7.1}

\section{Millennium Development Goals}

1. Eradicate extreme poverty and hunger

2. Achieve universal primary education

3. Promote gender equity and empower women

4. Reduce child mortality

5. Improve maternal health

6. Combat HIV/AIDS, malaria and other diseases

7. Ensure environmental sustainability

8. Develop a global partnership for development

The eight Millennium Development Goals aim for a world free of poverty and free of the misery that poverty breeds. The goals and targets are seen as interrelated and represent a partnership between developed and developing countries determined, as the Declaration states, "to create an environment - at the national and global levels alike - which is conducive to development and the elimination of poverty." The environment is one of eight goals and the targets of the environmental sustainability goal are:

- Integrating the principles of sustainable development into country policies and programmes and reversing the loss of environmental resources.

- Reducing by half the proportion of people without access to safe drinking water by 2015 .

- Achieving significant improvement in the lives of at least 100 million slum dwellers by 2020 .

None of the targets explicitly address protected areas, though one of MDG 7's indicators for progress is "land area protected to maintain biological diversity".

\section{Integrating conservation and} development

\section{The implementation response}

The investment in protected areas has taken place in the shadow of a broader debate about the compatibility of environmental conservation and economic development. This argument, which continues today, is about whether biodiversity conservation can co-exist with economic development. ICDP proponents have generally argued that biodiversity conservation goals could be achieved through the means of economic development by using an approach that balances the two, while opponents argued that such an approach would be disastrous for biodiversity. This argument has been particularly vitriolic in cases where indigenous people's interests were concerned (Christensen, 2004; Wilkie, Redford and McShane, in press).

The conservation response to this debate has been mixed. Some conservation NGOs have started to question or even reject protected area approaches targeting local people. The increasing focus of development assistance agencies on poverty reduction and the Millennium Development Goals has started to limit the funding available for biodiversity, while the steadily increasing pressure to demonstrate quantifiable and early successes from projects seems to be reducing the appeal of ICDPs within these agencies (Hulme and Murphree, 2001). Perhaps to counteract these signs of donor agency disenchantment, some conservationists have vigorously renewed their calls for protected areas to make even greater contributions to poverty reduction (IUCN, 2003; Christensen, 2004; Roe and Elliott, 2004).

It is clear that any framework for a "new" approach to protected area management emphasising poverty reduction must be informed by a careful analysis of the ICDP experience. The basic rationale that led to the popularity of ICDPs remains unchanged. Demonstrating constructive ways of involving local stakeholders in the conservation and sustainable use of biodiversity in and around the most significant protected areas remains one of the most important challenges and priorities for nature conservation at the beginning of the $21^{\text {st }}$ century. 
Many ICDPs have been built on precarious assumptions. ICDPs often began with the assumption that farming and hunting by poor people were the major threat to protected areas, and targeted their responses accordingly (McShane and Newby, 2004). But the activities of local people are often less of a threat to biodiversity than mining, roads, dams, irrigation schemes, resettlement programmes, plantations and commercial logging and hunting, often backed by rich and powerful interests operating well outside the influence of park managers or shortterm projects. Compounding this problem, many park managers are disconnected from the land use and economic development planning processes that are critical to parks (Brandon, Redford and Sanderson, 1998; Wells et al., 1999).

Considerable efforts are usually invested in encouraging local people to participate in, or at least not to oppose, ICDP activities. However, projects seriously interested in fostering local participation may need to spend many years, if not a decade or more, helping build the capacity of local institutions, even assuming that local and national laws, customs and tenure arrangements permit and support such an approach. While local people are usually intended beneficiaries of ICDPs, the original decision to launch an ICDP is rarely theirs and few projects cede significant decision making to local stakeholders despite much rhetoric to the contrary. This means that ICDPs remain outside local systems and any gains they may achieve are unlikely to persist beyond the project life.

Most ICDPs tend to ally themselves with a single major stakeholder, usually either the protected area management agency or an environmental NGO. As such the project automatically becomes (or at least is perceived as) biased towards this stakeholder's interests. As a result, other stakeholders then lack incentives to engage with the project and its goals.

Projects tend to focus on activities (social programmes and income creation through alternative livelihoods) rather than impacts (on biodiversity). ICDPs usually emphasise community-level social and economic development activities as an indirect step towards more effective conservation in the long-term future. When the linkage between the eventual goal and the activities selected seems distant or vague, as has often been the case with ICDPs, attention inevitably becomes focused on the project activities themselves rather than the impacts of these activities. This often leads to an excessive focus on getting activities completed (on the part of the project implementer) or getting as much as possible out of the project (on the part of the intended beneficiaries). This disconnect between development activities and desired conservation impacts within ICDPs has often led to a divergence between the benefits obtainable from biodiversity conservation and the benefits obtainable from the project. Many projects start by emphasising the former but end up concentrating almost entirely on the latter.

One might feel at this point that the "pathology of projects" is so fundamental that other approaches should be found. But the reality is that the overwhelming majority of external funding for biodiversity conservation in developing countries either originates from or passes through international development agencies. While these agencies do have non-project financing models, the dominant method of financing in the environmental sector, and especially in biodiversity conservation, continues to be through projects. There is no sign that they are about to decline in importance (Sayer and Wells, 2004).

Working with non-traditional constituencies such as the Scouting movement offers opportunities to raise awareness and improve community involvement in both conservation and development.

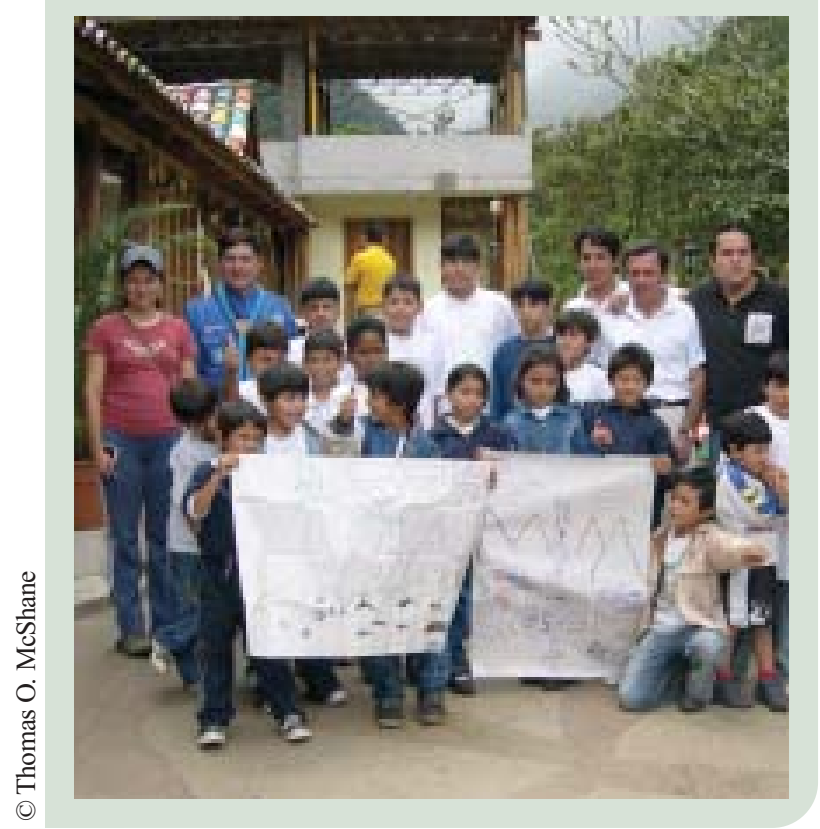




\section{The development assistance response}

Many development assistance agencies today focus their support for biodiversity conservation and protected areas at the macro policy level through the Convention on Biological Diversity (CBD). The CBD was one of several major initiatives stemming from the Earth Summit in Rio de Janeiro in 1992, which together form an international agreement on sustainable development. The Convention now has 188 Parties, which reflects a worldwide recognition that human activities are changing and destroying habitats and natural ecosystems on an increasing scale, with unprecedented loss of species. Parties recognise that action must be taken to halt this global loss of animal and plant species and genetic resources and that each country has the primary responsibility to conserve and enhance biodiversity within its own jurisdiction. At the same time, they agree to develop national strategies, plans and programmes for the conservation and sustainable use of biological diversity, and to share resources to help implement such programmes.

The most recent manifestation of support was the adoption of an ambitious programme of work on protected areas by the Parties to the CBD in February 2004. This programme of work is one of the most significant documents adopted by the CBD. It sets clear targets, including the establishment of a global network of comprehensive, representative and effectively managed protected area systems. Emphasis is also placed on strengthening the management of protected areas and ensuring that the costs and benefits of protected areas are equitably shared. Time will now tell if development assistance will be available to support this bold programme of work.

However, the move by development assistance agencies to focus their work on poverty reduction as their primary goal, and sustainable development as a broad strategy to meet this, has meant that protected areas are not a high priority for funding. In fact, a number of development assistance agencies no longer have units within their structure to specifically deal with biodiversity conservation. This cutting of their own institutional support network for conservation activities is a clear indication of where development assistance agencies have set their priorities.
While governments are well aware of the three pillars of sustainable development, the market economy has taken priority over social development and environmental concerns in recent decades. The market economy is seen as the primary force for poverty reduction and attention to the environment and natural resources is primarily utilitarian. References to natural resources now concern their provision for use by society and that of the environment to quality issues related to health.

In the early years of development assistance it was common for aid funds to be invested in 'institutional support' for government agencies in developing countries. International advisers were sent to work within the host institutions. Later the drive for accountability and the need for international donors to be able to target their support more precisely led to the emergence of the 'development project' as the main delivery mechanism. This meant that donors worked with their national counterparts to define discrete, time-bound packages of development assistance. These packages have allowed donors to apply their own accountability mechanisms and allowed development to be reduced to bite-sized components for which donors can assume responsibility and take credit (Sayer and Wells, 2004).

This trend away from institutional support and towards projects has been reflected in international development agency support for biodiversity conservation. Early aid programmes supported game rangers, wardens, researchers and others working within national protected area programmes. As international donor support for biodiversity conservation has been significantly reduced over the last five years, protected areas often have been at the top of the list when it comes to cutting expenditures as governments aim to balance their budgets and meet other development objectives. The external funds available for protected areas continue to shrink despite ever-increasing demands on these areas to provide clean air and water, tourism and recreational opportunities, in addition to the protection of biodiversity and the ecosystem processes that support it. Against this backdrop, protected area managers have no choice but to master the language of values and benefits that protected areas represent and adopt 


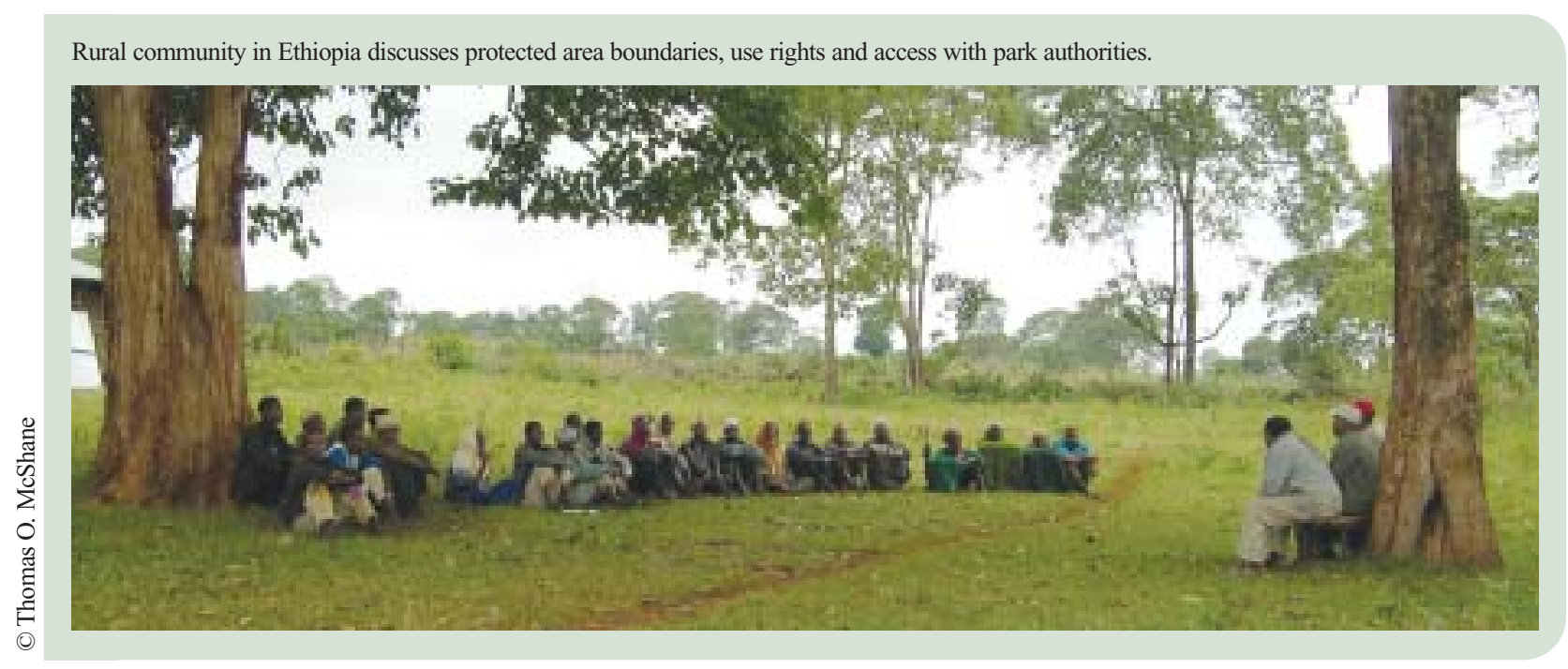

more business-like approaches, including developing business plans and generating income to supplement ever-decreasing funding allocations.

Alternative, non-project financing models have recently grown in importance within at least some international development agencies. For example, more than half of the World Bank's lending is now in the form of programmatic support linked to structural adjustment, sector-wide investment programmes and social action funds.

\section{Influencing development assistance agencies}

\section{Linking to broader contexts}

Understanding of the root causes of biodiversity loss, and environmental degradation in general, has become more sophisticated. It is clear that many of the most important threats to biodiversity originate far from protected area boundaries and involve issues and institutions well outside the traditional realm of conservationists. What does this mean for project identification and design? Site-specific efforts will always be necessary. However, these need to be nested within broader-based land use strategies supportive of biodiversity conservation and more ecologically friendly forms of economic development. Interventions must occur at different scales. Policy change is as important as field-level intervention. These two should ideally go hand-in-hand with local action helping people to influence the policies that affect their lives. Too many of the interventions of conservation and development agencies address local symptoms while ignoring underlying policy constraints or deal with macro-level issues while ignoring local realities.

More effective protected area management requires local-scale interventions to be complemented by stronger law enforcement within protected areas, more effective environmental screening of nearby development projects and more aggressive policy interventions in support of biodiversity conservation. It is often necessary to support or build partnerships to pursue these objectives, sometimes with those who are not traditional allies of conservation. The use of diverse field- and policy-oriented approaches must be vertically integrated, ensuring that site-based interventions are directly supported by policy-level actions both nationally and internationally.

\section{Acknowledging trade-offs between conservation and development}

Experience shows that site-specific biodiversity conservation is rarely compatible with unfettered development, income generation or livelihood interests. In practice, there will be winners and losers. So better techniques are needed to identify and understand the goals and interests of the major stakeholders in and around parks. Once these different interests have been identified and understood, the opportunities for negotiation and trade-offs can be explored. Until recently, there have been few systematic attempts to help stakeholders identify and then make rational choices between competing scenarios in conservation or development, partly because of the persistence of the "win-win" myth. 
More recently, however, applied researchers have begun to develop and test tools that may prove extremely useful in helping diverse groups of stakeholders understand each other's viewpoints and make informed and appropriate choices (Brown, 2004). One of the more exciting aspects of this work has been to dispel the conventional wisdom that outsiders can simplistically predict the outcome of such choices.

\section{Identifying incentives for protected areas}

Are there alternative ways of providing adequate conservation incentives at the site level, particularly where conflicting stakeholder interests do not appear resolvable through a project intervention? One possibility would simply be to pay cash in return for biodiversity protection (Ferrero and Kiss, 2002). Selected local or national government entities, NGOs or communities would receive payments, to use as they see fit, in exchange for park management and conservation commitments. Payment schedules over extended periods would then be subject to independent performance reviews. The funding for such arrangements could originate from international sources or from the government budget.

Governments could consider inviting tenders for the management of individual protected areas. For example, a government would commit to taking whatever steps necessary to protect a particular park, say for 25 years, while allowing independent monitoring. Interested parties (development assistance agencies, NGOs, even private sector organizations) would then bid the amount they would be prepared to pay to secure this protected area, payable over the full term of the agreement as long as the government continued to live up to their protection commitment. If adequate offers of international funds were not forthcoming, the government could then decide whether to finance conservation activities domestically (perhaps based on an assessment of watershed protection, tourism potential, or other national economic benefits) or to turn the protected area over to other uses. Such an approach could also help sharpen the discussion concerning the level of financial resources that should be transferred to developing countries to support biodiversity conservation (Wells et al., 1999).
Paying directly for conservation performance may be simpler and more effective than the ICDP approach in certain specific cases. This type of conservation contracting can simplify the achievement of conservation goals and strengthen the links between individual actions and habitat conservation, thus creating a local stake in ecosystem protection (Ferrero, 2001; Ferrero and Kiss, 2002). Although conservation contracting does seem to offer considerable promise in North America and Europe, its success depends on governance arrangements and an institutional framework that provides clarity over land use and access rights as well as the consistent enforceability of legal contracts. These are still lacking in many developing countries.

Finally, the assumption implicit in the discussion above, that protected areas will only survive if they receive external donor support in some form, is simply not true. Many protected areas in developing countries can themselves be profitable through user fees, environmental taxes and other charges. For example, Botswana raised its national park entry fees for foreigners by $900 \%$, leading to a dramatic increase in total revenues that effectively eliminated the subsidy being provided by the central government to game reserves and national parks (Barnes, 1998). During this time, the number of visitors actually rose by $49 \%$ in the first two years after the fees were increased. The Pacific island republic of Palau requires each of the 80,000 foreign divers who visit annually to pay a USD 15 fee, which generates around USD 1 million a year for conserving Palau's marine protected areas (Spergel, 2002). The key to financial autonomy is supportive government policies that allow protected areas to retain the fees they take in and the requirement that these funds be invested back into the protected area. For example, Ecuador's "Special Law for the Galápagos" requires that $90 \%$ of the USD 100 park entry fee be used to protect and maintain the Galápagos' natural environment. Nepal allows individual protected areas to keep 50\% or more of the entry fees that they collect (Spergel, 2002). 


\section{Actions required in the coming ten years}

Integrated conservation and development is intuitively appealing. It offers something for everyone. It promises to defuse the major threats to biodiversity, create better opportunities for people to earn a decent living and gain access to basic services, and equitably address the rights and interests of everyone who uses land and resources in and around protected areas. It is not a surprise that the integration of conservation and development has been so easy to sell to a broad range of interests, from park managers and conservation organizations, to local communities, governments and development assistance agencies.

The problem is that the myth of "win-win" solutions has created a culture in which overly ambitious projects have proliferated based on weak assumptions and little evidence. There is no doubt that poverty reduction and conservation of biodiversity must work hand-in-hand in today's world. However, some tradeoffs must be recognised, and mistakes need to be avoided for integrated conservation and development to work in the future. The following features are key to this success in the coming ten years (adapted from McShane and Wells, 2004):

1. Clarity about goals and objectives. Biodiversity goals are often in partial opposition to development goals and this is rarely explicitly acknowledged and addressed from the start.

2. Constraints of project structures. The constraints imposed by the project structures of many conservation and development agencies are still inhibiting real engagement with local stakeholders and preventing the integrated management of natural resource systems.

3. The scale of intervention. Too many of the interventions of conservation and development agencies are scale-specific, often addressing local symptoms but ignoring underlying policy constraints or dealing with macro-level issues while ignoring local realities.

Culture plays an important role in linking conservation and development. Traditional land use practices around Punakha Dzong in Bhutan ensures the maintenance of riverside habitat for endangered species such as the white-bellied heron.

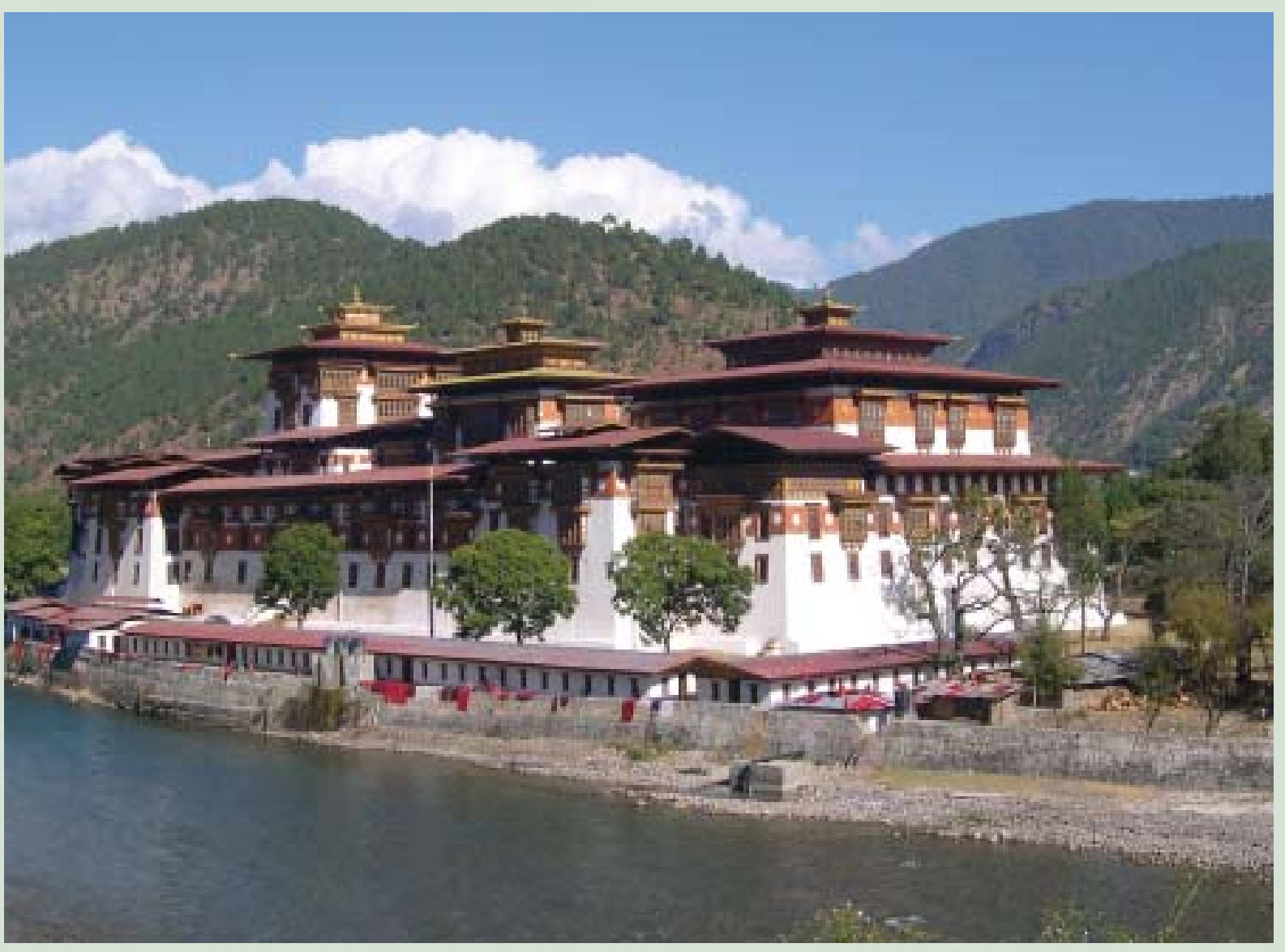


4. Policy change. Field-level intervention and policy change should ideally go hand-in-hand and local action should help people to influence the policies that affect their lives.

5. Institutions. Community-based development requires strong local institutions and legal frameworks. Defensible land tenure and access rights are vital and securing these rarely receives enough attention in conservation and development programmes. Many otherwise excellent concepts for reconciling conservation and development founder because they are not supported by the institutional and political structures concerned.

6. Trade-offs. Acknowledge and address trade-offs between conservation and development objectives. Too many programmes have raised funds on the basis of false claims about potential win-win outcomes.

7. Understanding of poverty. Poverty reduction is indeed linked to environmental deterioration, but many conservation and development programmes proceed on the basis of very simple and incorrect assumptions about the nature of relationships between poor local people and natural resource systems.

8. Adaptive management. Learning from experience, and then modifying interventions, is often preached but rarely practised. This requires constant monitoring of design and management and the systematic testing of assumptions and adaptation of activities.
Protected areas simply are not practical if people's needs and aspirations are not taken into account. To succeed in the future, integrated conservation and development will need to be based on explicit testable assumptions, clearly stated objectives, and measurable conservation targets. It should promote simple and adaptive conservation and development initiatives that are consistent with strengthening protected areas. Integrated conservation and development needs to identify and address diverse stakeholder interests, and it must work in partnerships to address larger problems that defy local solutions. To effectively address these issues will require a vertically integrated mix of site-based programmes, policy initiatives and campaign action. The appropriate positioning of integrated conservation and development relative to these other complementary conservation activities operating on a variety of spatial and temporal scales will be one of the major challenges of the emerging landscape- or ecoregion-scale conservation approaches. Development assistance agencies will continue to be a key actor in this process of learning, change and adaptation. 


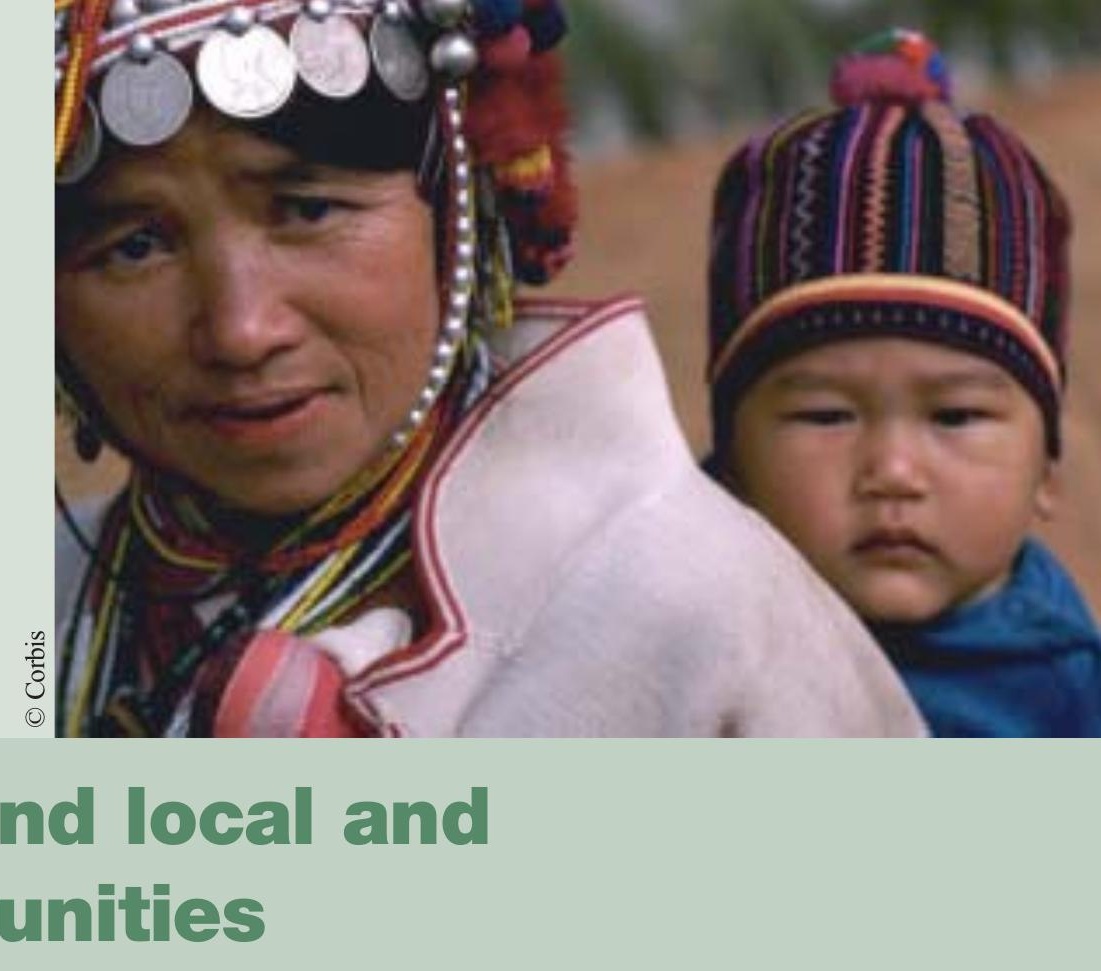

by Lea M. Scherl

\section{Editor's introduction}

As the first of three chapters dealing broadly with protected areas and local people, this one provides a synthesis of the workshop organized by IUCN's InterCommission Task Force on Indigenous and Local Communities, Equity and Protected Areas (TILCEPA) at the World Parks Congress. The people living in and around protected areas may seem to be the primary beneficiaries from conserving the ecosystem services provided by protected areas, but in fact they often feel disenfranchised and are denied access to resources that they consider rightfully belong to them. Lea Scherl summarises the various grievances and suggests ways for moving ahead. While noting the view that an exclusionary approach to protected areas is favoured by many conservationists, this chapter argues that the continuing dichotomy between human and environmental interests prevents significant collaboration that could provide important support for protected areas on a sustainable basis. Focussing on the themes of poverty and sustainable development, rights and equitable sharing of costs and benefits, and empowerment and governance, this chapter seeks to promote social justice in conservation as a means of building support for protected areas. A fundamental issue is the lack social impact assessments when protected areas are being established, along with appropriate measures to address any negative impacts identified. Part of this social justice is to ensure that globalization does not make communities living in and around protected areas any worse off than they already are; even better would be to find ways to ensure that they are able to gain from participation in the global economy if they choose to do so. This chapter also raises the important idea that community conserved areas can make a significant contribution to national efforts to conserve biodiversity, and thus provide an important complement to protected areas. The chapter concludes with a set of policies and actions that will go a long way toward building support for protected areas among indigenous and local communities. 


\section{Introduction}

Protected areas cannot survive as islands, sheltered from the broader physical, social, cultural and economic context within which they are located. Dudley et al. (1999), in addressing challenges for protected areas in the $21^{\text {st }}$ century, note that protected areas need to expand in size, in concept, in the number of partners involved, in vision from islands to a system where the parks connect to each other, to the wider landscape, to society, to the economy and to other countries. The progressive shift towards a more integrated context highlights the fact that a much broader constituency of actors needs to be empowered to manage protected areas in order to ensure their survival.

This chapter will analyse the link between protected areas and the wider context from the perspective of local, traditional and indigenous communities that are residents of these areas or neighbours to them. Conserving biological and cultural diversity within and around protected areas, while maintaining and promoting sustainable livelihoods of local and indigenous communities, is at the core of understanding this linkage. Local, traditional and indigenous communities have been extremely important to the support, management and maintenance of protected areas in many parts of the world. However, much debate still rages about the role that local and indigenous communities can play and the power and the rights they may have with respect to establishing and managing protected areas. "The single most important missed opportunity for conservation today may well be the misunderstanding, neglect and disaffection of civil societies - and of indigenous and local communities in particular" (Policy Matters 12, editorial). The following discussion reflects the evolution of the protected area management paradigm towards being more people focused, less centralized in management and looking for better balances between conservation and social, economic and cultural objectives (Phillips, 2003).

\section{The relationship between local and indigenous communities and protected areas}

Professionals in the field of protected area management are moving away from the notion that the interests and rights of local and indigenous communities (which also includes the concept of mobile peoples) are in conflict with the objectives of protected areas. However, some continue to believe that a weaker interface with local and indigenous communities will be better for protected areas. The promotion of a dichotomy between human and environmental interests will not lead us towards supporting and sustaining protected areas into the future. Conflicts surrounding establishment and management of protected areas are, nevertheless, more the norm than the exception. However, the existence of conflict implies that protected areas contain something of value to a variety of groups, and it is the understanding and promotion of these values and their harmonization that need to be emphasised.

The effective management of the relationship between local and indigenous communities and protected areas is of paramount importance for their survival in the long term. First, because numerous issues permeate such relationships that need to be addressed. These include:

- Inequality with respect to the distribution of costs and benefits of protected areas;

- Loss of control by local and indigenous groups over natural resources;

- Governance systems for protected area management that still largely exclude local and indigenous groups from effective participation/power sharing;

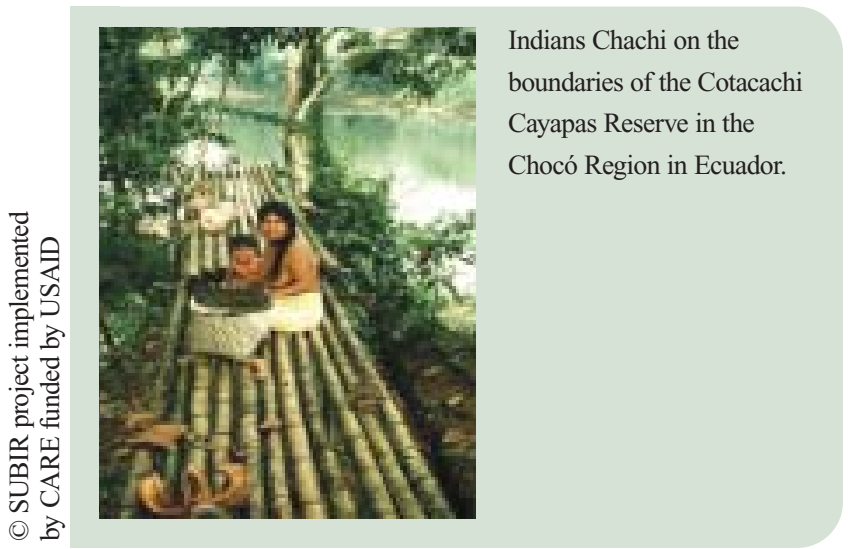


- Rights and knowledge of indigenous/traditional populations with respect to protected areas that are not yet fully recognised;

- Unsustainable poaching and illegal harvesting inside protected areas that are still taking place, with policies for sustainable harvesting lacking in many places;

- Lack of compensation for loss of livelihood opportunities, land and resource rights; and

- Lack of effective mechanisms for payment for environmental services.

And second, because of the special nature of the relationship that local and indigenous community have with protected areas, being so dependent on them for their social, cultural and economic survival

\section{Addressing the relationship between local and indigenous communities and protected areas}

The emphasis throughout this chapter on the term relationship reflects the reality that one cannot understand the contributions of local and indigenous communities to protected areas in isolation from an analysis of the factors and conditions that may hinder or promote such contributions. The relationship between local and indigenous communities and

\section{Figure 8.1}

\section{Dimensions for addressing the relationship between local and indigenous communities and protected areas}

Social Justice in Conservation

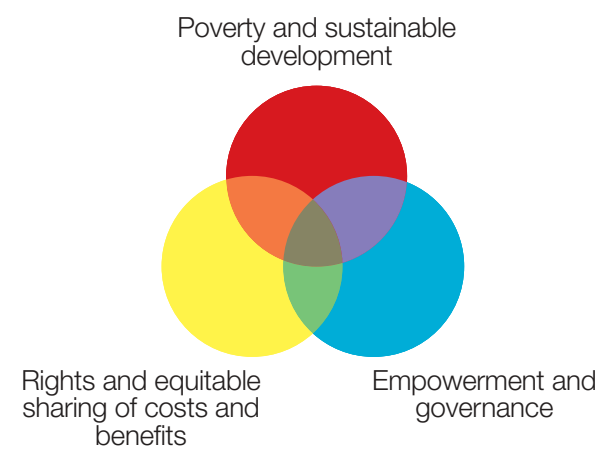

\section{Box 8.1}

\section{Facets of the relationship between local and indigenous communities and protected areas}

Livelihood security: opportunities for local and indigenous communities to: obtain food, clean water, construction materials, medicinal plants; to maintain genetic resources, pollinators, cycling of nutrients and natural chemicals that are important to sustaining agriculture, livestock and fisheries; maintain wild food supply in times of scarcity; reduce vulnerability to natural hazards and environmental change; and access infrastructure put in place to manage protected areas.

Economic: opportunities for local and indigenous communities to obtain: direct economic benefits through employment in the management of protected areas (e.g. park rangers, tourist guides) and payment for the conservation of environmental services; and indirect economic benefits through an increase in visitors that can help to promote and sustain a myriad of small businesses.

Cultural and spiritual: maintenance of cultural integrity through the protection of important places of identity, including sacred sites that hold symbolic meaning of spiritual importance, and by the provision of materials for traditional indigenous arts and utensils.

Psychological well-being and recreation: a sense of identity and belongingness from feeling secure with the existence of place, from being able to maintain and enjoy the knowledge that areas will remain protected and relatively unchanged, thus preserving landscapes, geological features and species diversity.

Educational: opportunities to learn about nature and from nature, to transmit traditional values and customs, and for reciprocal learning amongst different groups on how to most effectively manage protected areas.

Governance: opportunities to empower local and indigenous communities to participate in decisionmaking processes along other groups of actors and to be partners in conservation. 
protected areas can be seen from many perspectives, of which three are particularly important. They are related to: poverty and sustainable development; rights and equitable sharing of costs and benefits; and empowerment and governance. This chapter will provide an overview of these themes. Other chapters in this volume address specific aspects related to the themes (e.g. Putney, this volume; Larsen and Oviedo, this volume; McShane, this volume). Figure 8.1. presents graphically the themes that will be discussed below and their linkages.

\section{Poverty and sustainable development}

Poverty is an overarching issue that needs to be considered in the relationship between local and indigenous groups and protected areas. Many of the residents and neighbours of protected areas are poor and highly dependent on the environmental resources and services provided by protected areas to meet their daily survival needs. The $\mathrm{V}^{\text {th }}$ World Parks Congress emphasised the need to promote discussion on all aspects and levels, including ethical, moral and practical issues, related to protected areas, local and indigenous communities and poverty (Fisher, 2003; Gichere, 2003; Roe and Elliot, 2003; Scherl, 2003). Poverty is a multi-dimensional concept that incorporates assets and income, vulnerability, voice, empowerment, and capacity (World Development Report, 2000/2001). Where poverty is endemic, the linkages between management of protected areas and poverty alleviation need to be addressed for the very survival of protected areas. However, through what mechanisms this can be achieved, and whether protected areas should be considered as a means to alleviate poverty, still remains a vast area for expanding understanding, analysis and exploration (Scherl et al., 2004). A better understanding of the negative impacts that the establishment and management of protected areas have had on many local and indigenous communities can help address the issue of poverty with respect to protected areas. Many protected areas have been established and are still managed at the expense of the poor, often local and indigenous communities. The traditional approach to conservation has frequently had a negative impact on the livelihoods of local communities through their loss of rights over resources, loss of control to influence what happens to the environment, lack of participation in decision making related to management, and lack of appreciation and fair reward for their stewardship role (e.g. Brechin et al., 2003; Ghimire and Pimbert, 1997; Nelson and Hossack, 2003). An ethical consideration that is increasingly being voiced relates to displacement, and the poverty and dispossession (including a sense of place) that the establishment of protected areas can create (Geisler, 2003a and 2003b; Cernea and Schmidt-Soltau, 2003).

Geisler (2003a) refers to these victims of planned human intervention as "conservation refugees", advocating that the establishment of protected areas is akin to any form of major development. Even when such linkages and dependency on protected areas by local and indigenous communities are fully acknowledged, much still needs to be done to properly understand and manage them. A global study on wildlife-poverty linkages (also covering protected areas) came to the conclusion that despite the fact that poor people in many parts of the world depend on wildlife for food security and livelihood, this dependence is not reflected in policy documents and the public goods value of wildlife is still 'paid for' by the poor (Roe and Elliot, 2003). A major issue is the lack of proper social impact assessments of protected areas that recognise that the social relevance of protected areas includes issues of rights, cultural importance, economic opportunities, compensation for loss of access, and empowerment and participation. The lack of such assessments makes it difficult to put in place associated mitigating and compensatory mechanisms.

In summary, the main overall messages reflected in the recommendation adopted at the WPC on 'Poverty and Protected Areas' (IUCN, 2003) include:

1. Poverty, displacement, hunger and land degradation have a profound impact on biodiversity and protected areas and pose a very serious threat to their survival;

2. Biodiversity should be conserved both for its value as a local livelihoods resource and as a national and global public good;

3. Protected areas should strive to contribute to poverty reduction at the local level (either directly 


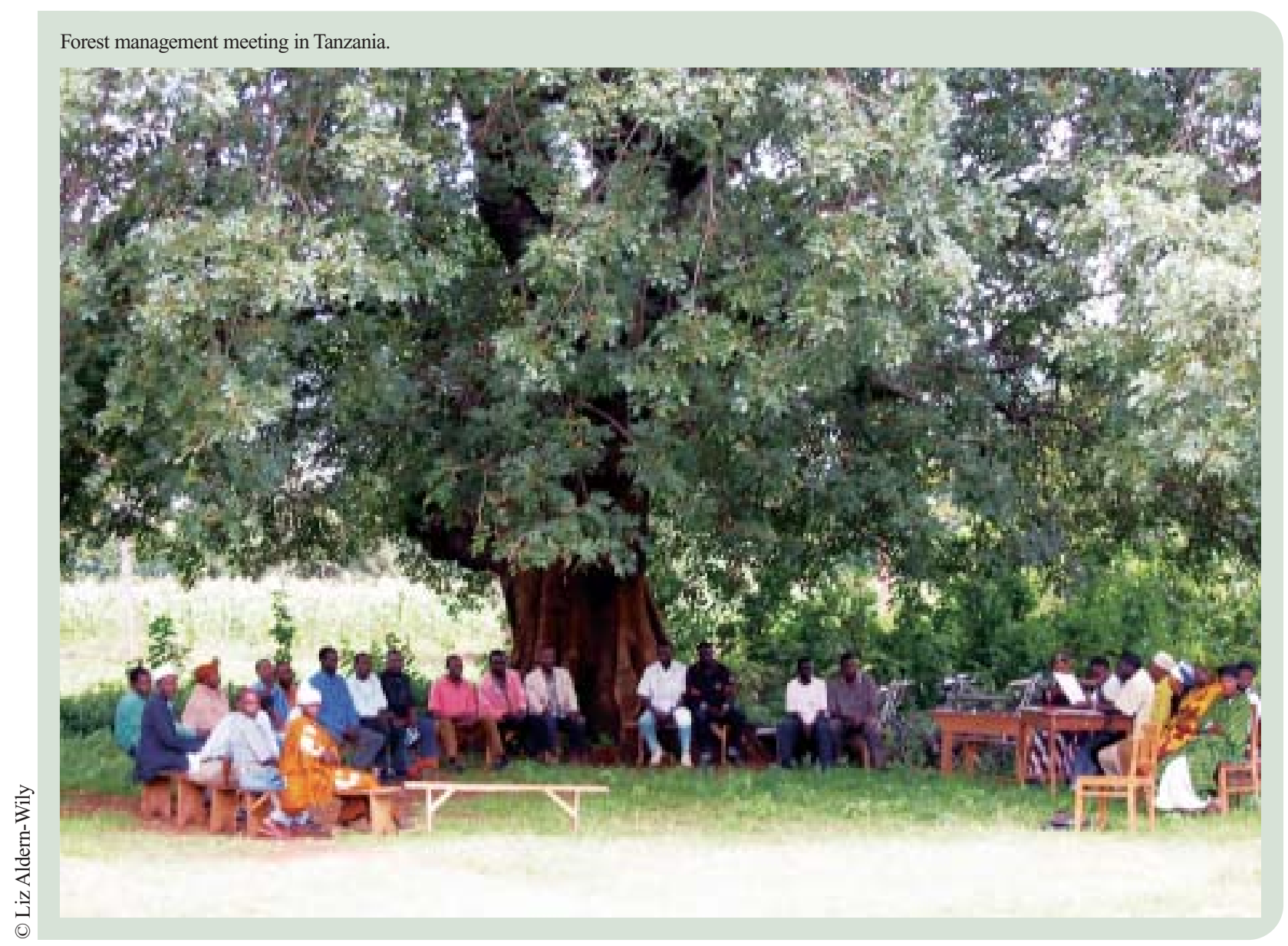

or indirectly), and at the very minimum not create, contribute to, or exacerbate poverty;

4. In order to achieve their potential both to conserve biodiversity and to assist in reducing poverty, protected areas should be integrated within a broad sustainable development system; and

5. Knowledge about the linkage between protected areas and poverty needs to be improved.

Debate on this theme is increasingly placing the relationship between local and indigenous communities and protected areas into a broader context. It is becoming more imperative to understand the role of protected areas within larger ecosystems, landscapes and seascapes (e.g. Maginnis et al., 2003; Redford et al., 2003), all of which contain biophysical and social-cultural characteristics. Contributing to this broader level of discussion are many years of practical experience with approaches that aim to integrate conservation and development (see McShane, this volume) which were also analysed during the WPC (Barrow, 2003; Franks, 2003;
McShane, 2003; Namarra, 2003; Scherl and Morales, 2003; Wells, 2003).

\section{Rights and equitable sharing of costs and benefits}

Principles and guidelines (Beltran and Phillips, 2000) provide understanding of the rights of indigenous and traditional communities with respect to protected areas. However, these guidelines are yet to be fully embraced (e.g. Nelson and Hossack, 2003).

Land tenure. The rights of indigenous communities, in particular, are more thoroughly addressed by Oviedo (this volume). I will highlight here one particular set of rights - land tenure. This topic is critical to efforts towards integrating the management of protected areas with the needs and aspirations of local and indigenous communities, particularly with respect to sustaining livelihoods and promoting empowerment. What was revealed with respect to analysis of land-tenure in the context of protected areas for Africa and Latin America (Wily, 2003; and Morales, 2003, respectively) is the following: 
- Recognition is increasing of the importance of land-tenure rights in the conservation and management of protected areas and as a key factor to sustainability of conservation practices.

- Protected areas often overlap with indigenous territories, or are established in areas already occupied by indigenous and local community groups, where land-tenure issues and rights of access then become central to any conservation efforts.

- Recognition of these rights is highly diverse; communal rights are also being recognised and multiple tenure regimes are becoming more common, demanding new ways to manage protected areas. These different tenure arrangements may require different management responses and governance models.

- Land tenure security is a very important step in rights recognition but is not sufficient to guarantee control over resources and decisions; local empowerment is also necessary, supported by enabling and inclusive governance.

Case studies illustrate that tenure is essential for more effective land management and poverty reduction (Masoud and Wild, 2003), is of critical importance for biodiversity conservation within protected areas (Tongson, 2003), and how land ownership is critical within larger eco-developments (Dutt, 2003).

All in all, land tenure, as one set of rights, is increasingly becoming a critical issue that needs to be addressed in the relationship between local and indigenous communities and protected areas.

Equitable sharing of costs and benefits. Another critical issue is the perceived need to fully understand the costs and benefits of protected areas, beyond simply management costs, as much of the hidden cost is borne by communities. The unbalanced distribution of these costs and benefits (with most opportunity costs incurred at the local level, while benefits accrue elsewhere) is noted as a deterrent to conservation efforts from the part of local and indigenous communities. Important questions then arise. Why

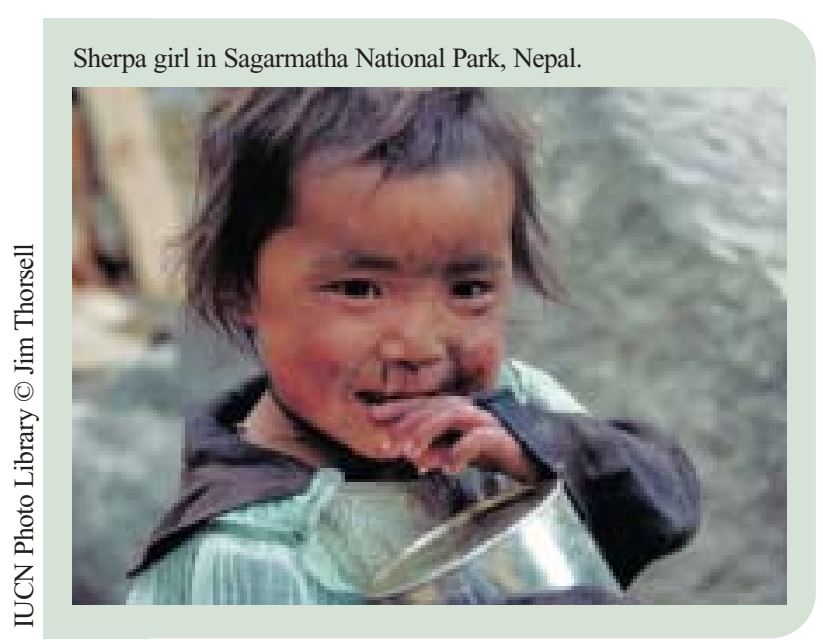

should local and indigenous communities subsidise the cost of protected areas? What are the rights of poor local and indigenous communities to benefit financially for stewardship of global public goods?

Many approaches are available to ensure that local and indigenous communities benefit (in an economic sense) from protected areas. Analysis of numerous case studies across the Asia-Pacific region confirmed that enterprise-based approaches could lead to conservation, but only under specific conditions. They are best employed where a major threat to biodiversity is local people's need for cash and where a viable enterprise is possible. Moreover, they should be supported with other strategies such as education and awareness or direct protection (Salafsky, 2003). One very promising mechanism to bring biodiversity into the marketplace is payment for ecosystem services, such as carbon sequestration, watershed protection, landscape amenity, and biodiversity conservation. But market-based approaches require information on benefits, establishing and enforcing rights and responsibilities, and relieving policy constraints and disincentives (Bishop, 2003). A review of payments for environmental services related to water catchment services (Pagiolo, 2003) reveals the following:

1. Payments for environmental services are not poverty reduction programmes, while trying to make them so can undermine their utility;

2. Payments for environmental services can help to maximize positive impacts/minimize adverse impacts on poverty, as many natural resource users are poor and payments can improve their welfare; 
3. The extent to which payments for environmental services affect the poor and their livelihoods is still an empirical issue and is likely to be casespecific;

4. Appropriate contract design and support for effective participation of the poor are required; and

5. How markets for environmental services can affect the tenure situation or leave those with tenure insecurity (often the most poor) even more vulnerable remains a concern.

An interesting case study by Child (2003) showed how governance models can affect the distribution of benefits and incentives. Bottom-up approaches (second generation community-based natural resource management projects) were found to be much more effective in distributing benefits than representational democracies (more top-down), not only at the household level but also with respect to benefits that go to public objectives. However, the literature shows that in only a few cases have payments actually gone to local communities and benefited poor people. Benefits have stayed, by and large, with the private or public sector that manages the protected area (Pagiola et al., 2002).

Some of the overall conclusions from discussions at the WPC related to incentives for conservation and fair reward for stewardship were:

- Conservation-based enterprises have great potential to generate incentives for conservation, but it is important to recognise that non-cash benefits may be as important as cash benefits.

- The effectiveness of revenue-based incentives depends crucially on the mechanism for distributing benefits at the community level.

- Payments for environmental services have the potential to generate local benefits, but need further exploration.

Understanding incentives for conservation and equitable ways of allocating costs and benefits is of paramount importance for protected area management. However, much still needs to be done to highlight the obligations of national and international agencies supporting conservation of protected areas to ensure that this occurs. Moreover, inequalities in the distribution of costs and benefits should be addressed at all levels, local, national and international, and the linkages between these levels should be more clearly understood. We need better understanding of the impacts that trade-offs that benefit international, regional and national levels can have at the local level.

\section{Empowerment and governance}

Central to establishing and promoting effective relationships between local and indigenous communities and protected areas is empowering community members to actively participate in the management of these areas. Empowerment needs to begin prior to the establishment phase. Empowerment means not only giving local and indigenous communities the opportunity to voice and represent their interests during decision-making processes, but also engaging them as partners, creating incentives for them to mobilize resources, and recognising the value of giving community members real rights and ownership of resources (e.g. Brandon et al., 1998; Jeanrenaud, 1999; Kothari et al., 2000; McNeely, 1999; Pimbert and Pretty, 1995; Jaireth and Smyth, 2003; Policy Matters, 2003; Wells and Brandon, 1992; West and Brechin, 1991). Empowerment of local and indigenous communities is essential for a number of reasons: to mobilize close allies for protected areas; to ameliorate the negative impacts caused by the establishment of many protected areas (displacement and denial of a range of rights); to provide a critical element that addresses the linkages between protected areas and sustainable livelihoods; to take advantage of local and ancestral knowledge for the management of protected areas; to permit better integration of the objectives of protected areas with other land-uses

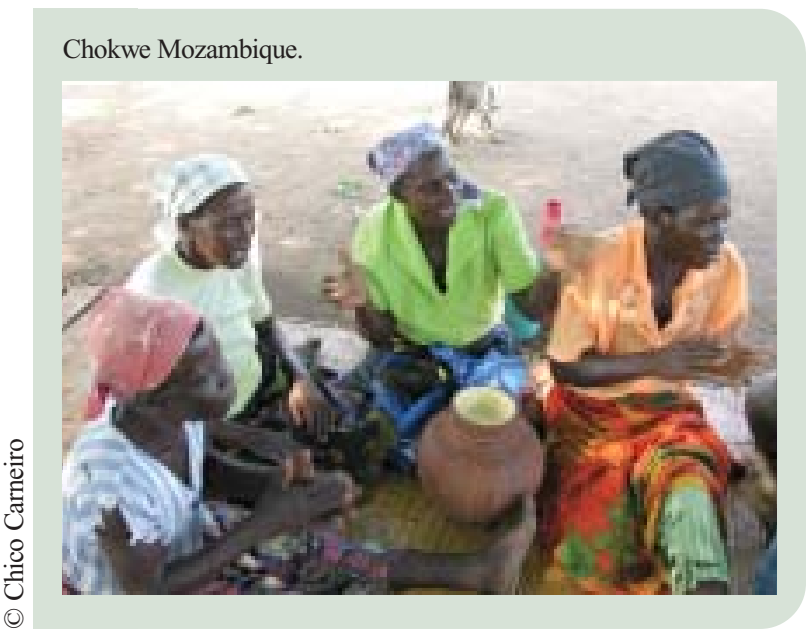


adjacent to those areas; and to provide an important element for a more eclectic and inclusive system of governance for protected areas that benefits from diversity.

However, this will not be accomplished easily and many barriers exist. These barriers may include a lack of capacity within local and indigenous communities to participate in decision-making processes and on the part of management agencies to deal effectively with the participation of local and indigenous groups. Other barriers may include models of participation which are not sensitive to cultural needs, the organizational structures of local and indigenous communities that concentrate power within certain groups and lack of willingness to relinquish power on the part of managers. "Empowering indigenous and local communities in conservation may require a difficult sharing of authority and responsibility, but conservation can no longer afford to consume its precious resources fighting its most promising allies" (Policy Matters 12, editorial). The WPC provided further support for empowering indigenous and local communities by endorsing a recommendation on ' $\mathrm{Co}$ Management of Protected Areas' that defines comanaged protected areas (CMPAs) as those "where management authority, responsibility and accountability are shared among two or more stakeholders, including government bodies and agencies at various levels, indigenous and local communities, non-government organizations and private operators, or even among different state governments as in the case of transboundary protected areas" (IUCN, 2003).

The empowerment of local and indigenous communities requires governance systems that are inclusive and flexible, and embrace in an equitable way the diversity of perspectives from different interest groups. Within this, gender considerations should also be taken into account (e.g., Aguilar et al., 2002; Flintan, 2003). Governance is considered to be of central importance to the effectiveness and survival of protected areas within larger political, economic and social contexts (e.g., Borrini-Feyerabend, 2003). The recommendation from the WPC on "Good Governance" promoted better understanding of this concept. It recognised that governance of protected areas "should reflect and address relevant social, ecological, cultural, historical and economic factors, and what constitutes 'good governance' in any area needs to be considered in light of local circumstances, traditions and knowledge systems" (IUCN, 2003).

Governance issues with respect to protected areas should not be addressed only at the local level, but also at national, regional and international levels. Establishing linkages among all these levels is crucial for multi-scale governance systems, all of which affect local and indigenous communities on the ground.

\section{Social justice and human rights in conservation: An ethical consideration for future policies and actions}

Globalization, with its economic decision making and governance structures that are far removed from the local protected area context, has further contributed to the alienation and deterioration of living conditions of local and indigenous communities in many places. This concern needs to be addressed and, at a minimum, protected area conservation and management should not make communities living in and around them worse off than they are already. The re-distribution of benefits (particularly from global, regional and national levels to the local level) needs to take place for this to occur. Governance mechanisms need to be flexible and inclusive, and policies and planning frameworks need to be supportive and address the linkage between conservation and the needs and aspirations of local and indigenous communities. Moreover, the relationship between local and indigenous communities and protected areas must be viewed within a broader context of sustainable development and poverty reduction efforts which nowadays dominate many such policy and planning frameworks.

It is time to recognise that we need to foster a better connection between biodiversity conservation and social justice. The concept of social and environmental justice (i.e., the equitable achievement of human and environmental rights) is evolving and is articulated in partnerships between environmental and development NGOs (CARE-WWF Social and Environmental Justice Initiative, 2002; Brechin et al., 
2003). This approach does not detract from the main and central goal of protected areas, to conserve nature, but it does promote the goal of social justice to a higher level comparable to the one of protecting genes, species and habitats. It is also an approach that purposefully seeks to position the role of protected areas more broadly within the sustainable development agenda. Much remains to be understood about practising social justice and addressing human rights in conservation. This is no doubt an ethical consideration with practical implications that will increasingly permeate debates surrounding nature conservation.

\section{Policies and actions needed to support the relationship between local and indigenous communities and protected areas over the coming ten years}

\section{Protected areas within sustainable development}

Policies

- Protected areas are integrated within a broad sustainable development planning agenda.

- Conservation strategies and poverty reduction and policy frameworks are integrated and oriented towards common goals.

- Protected areas are integrated within larger multiple land-use and marine systems.

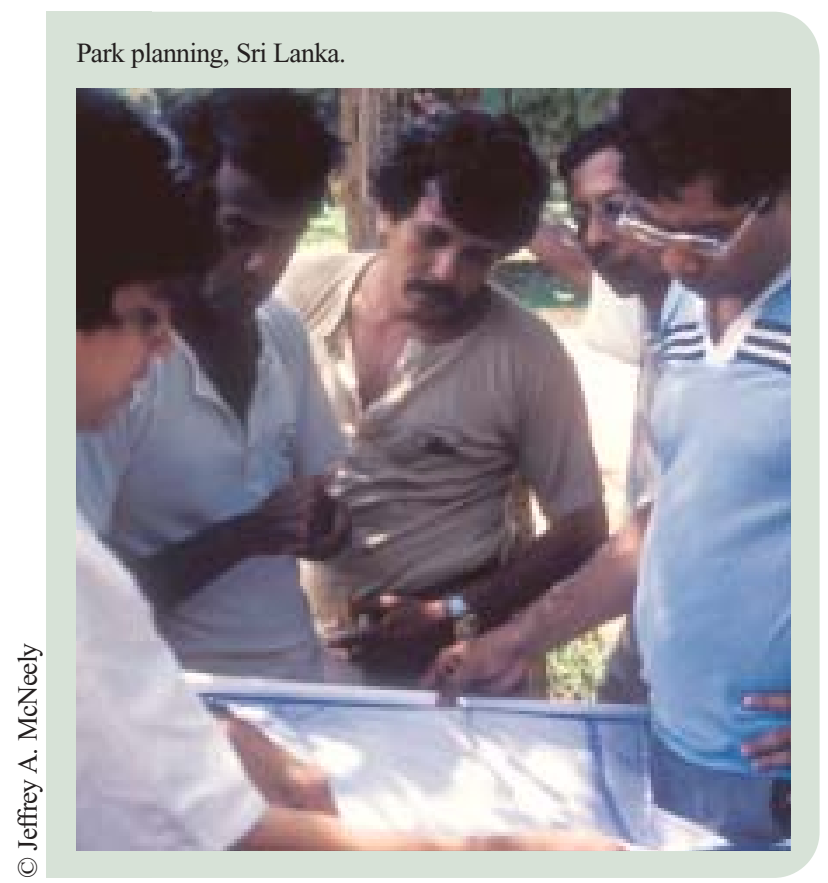

\section{Actions}

- Understand the linkages between protected areas (their functions and governance systems) and poverty (reduction or exacerbation) nationally and globally.

- Incorporate protected areas in National Poverty Reduction Strategy Papers (PRSPs) and in the Millennium Development Goals (not just for MDG7 - Environmental sustainability).

- Develop mechanisms to integrate the livelihood security needs of local and indigenous communities with conservation goals for protected areas.

- Form partnerships, oriented towards common and integrated goals, among conservation and development organizations.

- Encourage active participation of environmental groups in the development of PRSPs at the national level, highlighting the role of protected areas in these strategies in particular.

- Include assessment of the linkages between protected areas and poverty within the programme of work of the Convention on Biological Diversity.

- Undertake routine social impact assessments (that includes poverty impact assessment) for establishment, and throughout on-going management, of protected areas.

- Recognise the services that ecosystems conserved through protected areas provide and the role of these in livelihood protection for local and indigenous communities.

- Highlight the nature of these services in national poverty reduction strategies and the MDGs.

- Highlight the role of protected areas among other land-use types, and the complementarity they provide.

- Promote involvement, inclusiveness and transparency in the process of assigning protected area categories between government agencies and other stakeholders in order to better position protected areas within larger land-use planning contexts. 


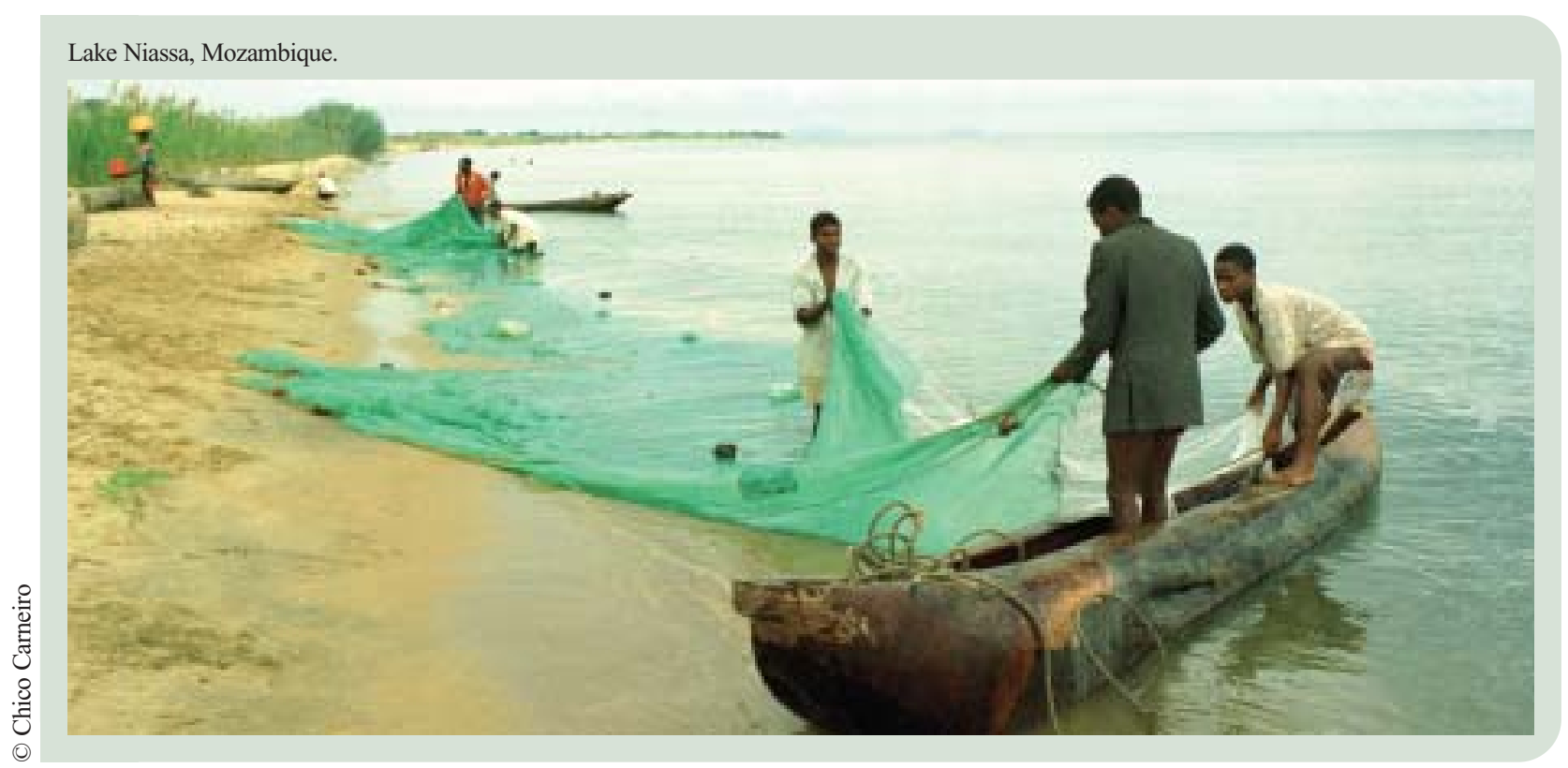

\section{Human rights and sharing of costs and benefits}

Policies

- Respect and recognise customary ownership, use and access rights for local, indigenous and traditional people in protected area establishment and management.

- Incorporate traditional knowledge into protected area management.

- Incorporate mechanisms to reward environmental stewardships, including payments for environmental services, as part of management strategies for protected areas.

- Include mechanisms to compensate for losses incurred as part of establishment and management of protected areas.

\section{Actions}

- Promote the implementation of indigenous and traditional peoples and protected area guidelines, and monitor and assess their implementation.

- Provide secure tenure for local and indigenous communities, particularly in areas essential for livelihood resources and cultural identity.

- Continue to understand and apply traditional knowledge to protected area management.

- Document and acknowledge communities' own efforts to manage protected areas.

- Promote the notion that, beyond state-owned protected areas, community conserved areas (CCAs) are important efforts to conserve biodiversity and that a wider concept of protected areas should prevail.
Develop, strengthen and promote the adoption of legislation and policies that create the conditions for recognising and respecting indigenous and traditional knowledge in protected area management.

Continue to develop and apply mechanisms to provide fair compensation for losses incurred by local and indigenous communities as a result of restricted access to protected areas and from displacement and decreased environmental services.

- Continue to develop and apply mechanisms for equitable distribution of benefits from protected areas.

Document and assess the effectiveness of mechanisms to provide for compensation and to reward stewardship.

Ensure informed consent for equitable compensation for any resource use restrictions, total displacement and for equitable benefit sharing.

Develop more comprehensive costs and benefit analyses for protected areas.

Extend the principle of equitable sharing of benefits to include all components of biological diversity within the Convention on Biological Diversity.

Develop, strengthen and promote the adoption of legislation and policies that create the conditions for fair reward for stewardship and compensation for loss of access rights. 


\section{Empowerment and governance}

Policies

- Empower local and indigenous communities to manage protected areas.

- Local and indigenous communities are crucial partners for the management of protected areas.

- Inclusive and flexible governance is an important component of management mechanisms of protected areas.

\section{Actions}

- Develop and promote inclusive and flexible governance systems for protected area management that are site-specific and culturally sensitive, and provide legitimacy of voice, empowerment, transparency, fairness, accountability and appropriate mechanisms to deal with conflict.

Ensure that within inclusive and flexible governance systems for protected areas there are mechanisms to clarify rights, roles and responsibilities.

- Promote capacity building for protected area managers and the range of stakeholders, particularly indigenous and community groups, for the effective implementation of inclusive and flexible governance systems.

- Build partnerships with local and indigenous communities as actors and stakeholders in conservation and management of protected areas.

- Develop mechanisms to deal with inequities in protected area establishment and management (such as those related to gender, economic status, ethnicity, religious affiliation).

- Incorporate a gender perspective that encompasses the different roles of women and men, and their respective knowledge and use of biodiversity in protected areas.

-Describe and document protected areas worldwide by their governance systems, assessing the empowerment of local and indigenous communities within such systems.

- Develop, strengthen and promote the adoption of legislation and policies that empower local and indigenous communities to contribute to the management of protected areas.

\section{Social justice in conservation}

Policies

- Promote respect for human rights as a premise upon which protected areas are established and managed for the conservation of biodiversity.

\section{Actions}

- Promote the concept of social justice in conservation to the range of protected area stakeholders.

- Develop mechanisms to better articulate and reconcile conservation objectives and respect for human rights.

- Develop guidelines for the practice of social justice in conservation.

\section{Acknowledgements}

The Workshop from which this paper draws also included significant contributions from: Maria Fernanda Espinosa, Phil Franks, Alison Johnson, Jennifer Jones, Tom McShane and Robert Wild. Their contributions are gratefully acknowledged. 


\section{Introduction}

Durban served as a unique meeting point, where representatives from indigenous peoples, more numerous than in any previous World Parks Congress WPC, and protected area professionals, jointly took important steps forward in recognising their common concerns and interests and achieved real progress on indigenous involvement in protected area design and management, based on addressing and redressing the past wrongs. On the one hand, the protected area community recognised the legitimate interests of indigenous peoples in conservation matters, and the need to overcome the heavy legacy of insensitive protected area policy and practice towards indigenous peoples. Good practice of recent years and policy advancement on the links between protected areas and people, further consolidated by the CBD programme of work on protected areas adopted by COP7 in February 2004, were reviewed and discussed in Durban, and prompted initiatives that included qualitative benchmarks for protected area performance in the areas of indigenous rights, more diverse governance options and equitable cost and benefit-sharing as part of a broader reconciliation effort.

On the other hand, indigenous representatives conveyed their commitment and interest in protected areas, confirming their share of responsibilities in reaching biodiversity conservation objectives.

The outputs of the Congress testify to this window of opportunity. The Durban Accord urges commitment to a wide range of indigenous concerns. The Durban Action Plan lists recognition and guarantee of indigenous rights in relation to natural resource management and biodiversity as one of ten major outcomes. Further, the importance of taking into account indigenous rights, interests and aspirations and their full involvement and participation runs through other major outcomes and suggested activities of the Action Plan.

Of the 32 Congress recommendations, six have major sections on indigenous concerns. Another 15 mention indigenous peoples in their problem analysis or recommendations, and nine more relate to indigenous issues, in the context of broader equity, community and poverty-oriented language.
Altogether, the Durban outputs represent an impressive set of achievements in relation to the views and interests of indigenous peoples on protected areas (all are available at www.iucn.org/wcpa/).

The process of building mutual support and trust between conservation organizations and indigenous peoples has a long history, albeit often dominated by polarized positions, conflicts and lack of dialogue. In the past decade, a wide range of international and national policy efforts have sought to overcome these differences, stimulated by increasing dialogue between indigenous peoples and conservation actors. These have included the Seventh Conference of the Parties to the Ramsar Convention, which adopted "Guidelines to establish and strengthen participation of local communities and indigenous peoples in the management of wetlands". The Intergovernmental Panel on Forests, the Intergovernmental Forum on Forests and the United Nations Forum on Forests have all made strong recommendations on matters related to indigenous peoples and protected forest areas. The World Heritage Convention has been increasingly addressing indigenous peoples issues, especially in the context of the protection of cultural landscapes. The CBD is the environmental agreement with most relevance to indigenous peoples, and its recently adopted Programme of Work on Protected Areas mentions the role of local and indigenous peoples. Among nongovernmental conservation organizations, WWF issued a Statement of Principles on Indigenous Peoples and Conservation in 1996. The IUCN World Conservation Congress has adopted several resolutions on indigenous peoples and conservation, such as 1.53 on Indigenous Peoples and Protected Areas; and the joint IUCN-WWF Principles and Guidelines on Indigenous and Traditional Peoples and Protected Areas were adopted in 1999. A range of policy statements and decisions of conservation organizations and fora exist on the matter. For a review of these processes, see Oviedo (2003a) and Castelo and Schielmann (2001).

Many problems remain, however, at the government and national implementation level. Protected area legislation and policy have slowly changed in some countries on matters relevant to indigenous peoples; in other countries, changes are yet to be seen. In the field, despite policy progress, examples of conflicts and inequities still abound. 


\section{Box 9.1}

\section{Durban outputs relating to indigenous concerns}

\begin{tabular}{|c|c|c|}
\hline Durban Accord & Action Plan & Major recommendations \\
\hline $\begin{array}{l}\text { We urge commitment to... } \\
\text { - the integral relationship of people with } \\
\text { protected areas, fully incorporating } \\
\text { the rights, interests and aspirations of } \\
\text { both women and men. } \\
\text { - involve local communities, indigenous } \\
\text { and mobile peoples in the creation, } \\
\text { proclamation and management of } \\
\text { protected areas. } \\
\text { - ensure that people who benefit from } \\
\text { or are impacted by protected areas } \\
\text { have the opportunity to participate in } \\
\text { relevant decision-making on a fair and } \\
\text { equitable basis in full respect of their } \\
\text { human and social rights. } \\
\text { - protected area management that } \\
\text { strives to reduce, and in no way } \\
\text { exacerbates, poverty. } \\
\text { - protected area management that } \\
\text { shares benefits with indigenous } \\
\text { peoples and local communities. } \\
\text { - innovation in protected area } \\
\text { management including adaptive, } \\
\text { collaborative and co-management } \\
\text { strategies. } \\
\text { - recognise, strengthen, protect and } \\
\text { support community conservation areas. } \\
\text { - value and use all knowledge systems } \\
\text { on protected areas, both scientific } \\
\text { and traditionally based. }\end{array}$ & $\begin{array}{l}\text { Outcome 5: } \\
\text { The Rights of Indigenous Peoples, } \\
\text { Mobile peoples and Local Communities } \\
\text { Recognised and Guaranteed in Relation } \\
\text { to Natural Resources and Biodiversity } \\
\text { Conservation } \\
\text { Key Target 8: } \\
\text { All existing and future protected areas } \\
\text { shall be managed and established in full } \\
\text { compliance with the rights of } \\
\text { indigenous peoples, mobile peoples } \\
\text { and local communities by the time of } \\
\text { the next IUCN WPC. } \\
\text { Key Target 9: } \\
\text { Protected areas shall have } \\
\text { representatives chosen by indigenous } \\
\text { peoples and local communities in their } \\
\text { management proportionate to their } \\
\text { rights and interests by the time of the } \\
\text { next IUCN WPC. } \\
\text { Key Target 10: } \\
\text { Participatory mechanisms for the } \\
\text { restitution of indigenous peoples' } \\
\text { traditional lands and territories that were } \\
\text { incorporated in protected areas without } \\
\text { their free and informed consent } \\
\text { established and implemented by the } \\
\text { time of the next IUCN WPC. }\end{array}$ & $\begin{array}{l}\text { V.13 Cultural and spiritual values of } \\
\text { protected areas } \\
\text { V.17 Recognising and supporting a } \\
\text { diversity of governance types } \\
\text { V.24 Indigenous peoples and } \\
\text { protected areas } \\
\text { V.25 Co-management of protected } \\
\text { areas } \\
\text { V.26 Community Conserved Areas } \\
\text { V.27 Mobile indigenous peoples and } \\
\text { conservation }\end{array}$ \\
\hline
\end{tabular}

In this light, Durban outcomes are even more important. They acknowledge a history of neglect and continuous problems such as indigenous peoples often "bearing most of the costs and receiving few of the benefits", yet also put forward a new vision in which such costs and benefits are equitably shared, while promoting new governance approaches to protected areas overlapping with indigenous lands and waters. A strong ethical foundation for addressing indigenous peoples issues became a major achievement of the Durban Congress. Furthermore, participants at the event recognised that such approaches would not only benefit indigenous peoples, but would also help in filling remaining protection gaps and strengthening protected area effectiveness.
The CBD programme of work on protected areas built on the Durban outputs and confirmed the global importance of these approaches. The adoption of the programme of work demonstrates global political commitment to the new protected area vision, with legal obligations for signatory countries - and moral obligations for the few that remain outside of the global consensus. This chapter seeks to contribute to the identification and implementation of the steps necessary to effectively respond to the Durban and the CBD consensus on indigenous peoples and protected areas, thereby solidifying and enhancing lasting reconciliation and bringing indigenous peoples strongly into the protected areas constituency. 


\section{Box 9.2}

\section{Indigenous peoples - who are they?}

Global estimates list between 300 and 400 million people worldwide with substantial historical, cultural, social and economic differences which, together with a range of internationally defined standards, identify them as indigenous and tribal peoples and distinguish them from other population groups.

According to the ILO Convention 169 on Indigenous and Tribal Peoples in Independent Countries, indigenous and tribal peoples are:

1. (a) Tribal peoples in independent countries whose social, cultural and economic conditions distinguish them from other sections of the national community, and whose status is regulated wholly or partially by their own customs or traditions or by special laws or regulations;

(b) Peoples in independent countries who are regarded as indigenous on account of their descent from the populations which inhabited the country, or a geographical region to which the country belongs, at the time of conquest or colonisation or the establishment of present State boundaries and who, irrespective of their legal status, retain some or all of their own social, economic, cultural and political institutions.

2. The Convention states that self-identification as indigenous or tribal shall be regarded as a fundamental criterion for determining the groups to which the provisions of this Convention apply.

Conservation principles and practices are also relevant to other categories such as 'traditional peoples' and 'mobile peoples'. The different terms may appear overlapping or confusing, yet represent an effort to identify, address and develop appropriate policies for groups of people with particular conservation interests and rights, deriving from their history, culture and forms of natural resource use.

\section{Indigenous peoples and protected areas}

"Why have ancestral domains of indigenous and traditional peoples, in so many cases, been considered valuable enough to deserve their designation as protected areas? Isn't it because their resources, biodiversity in particular, have been conserved and maintained in better condition than those in areas outside their ancestral domains? If that is the case, isn't it possible that traditional institutions - from customary tenure to control systems and authorities have played an important role in conserving lands and resources? If the answers to these questions were affirmative, then the conclusion could be that conventional approaches to protected areas overlapping with ancestral domains of indigenous and traditional peoples have been fundamentally flawed in having promoted the eviction of traditional peoples from their territories as a pre-condition for long-term biodiversity conservation, since in doing so they have lost an ally and an asset, and have gained instead conflicts and discredit" (Oviedo, 2002).

Many existing, as well as potential, protected areas overlap considerably with the ancestral territories of indigenous peoples. This common history and interest in the same areas has not been without problems or conflict. Although no systematic data exist (Oviedo, 2002), several regional and global studies (Oviedo et al., 2000) have revealed considerable overlaps in major eco-regions of the world. Oviedo (2002) lists $50 \%$ as a reasonable global estimate. This does not mean that all indigenous peoples engage in conservation, nor that all protected areas concern indigenous territories. It rather reflects customary presence, use and ownership structures, which have often been overruled by exclusionary protected area practices.

"The declaration of protected areas on indigenous territories without our consent and engagement has resulted in our dispossession and resettlement, the violation of our rights, the displacement of our peoples, the loss of our sacred sites and the slow but continuous loss of our cultures, as well as impoverishment". (Closing plenary indigenous statement in Durban) 


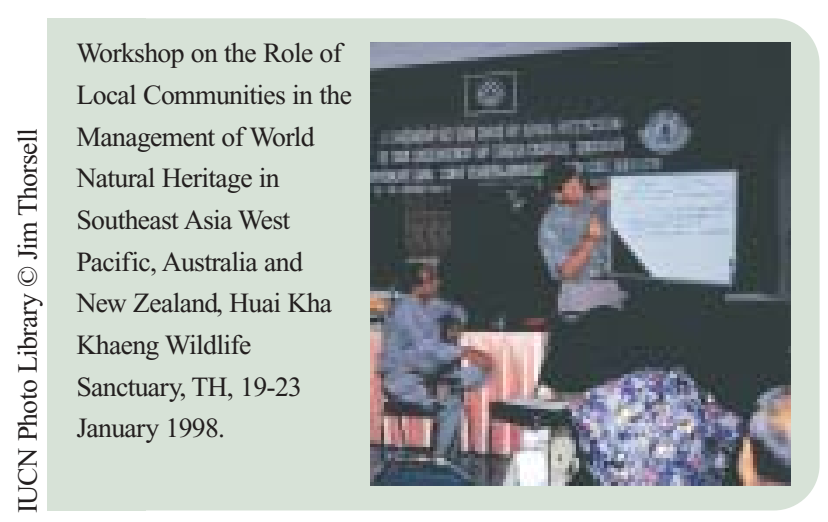

The negative impacts of exclusionary protected area practices on indigenous peoples have now been widely documented and include:

- Denial of indigenous rights

- Forced displacement and resettlement

- Lack of participation in protected area design and management

- Socio-economic and cultural disintegration

- Loss or restriction of livelihoods and lack of sharing in the benefits of conservation

Indigenous priorities involve addressing the legacy of protected areas (e.g. MacKay, 2002). Indigenous representatives at Durban welcomed "the recognition and guarantee in the Durban Action Plan, in particular Outcome 5, on the rights of Indigenous Peoples, mobile peoples and local communities in the relation to natural resources and biodiversity conservation" and expressed their hopes that "Key Target 10, which aspires to implement participatory mechanisms for the restitution of indigenous peoples' traditional lands and territories taken as protected areas without the free, prior consent of indigenous peoples will be realized". (Closing plenary indigenous statement in Durban)

The common interest of conservation actors and indigenous peoples in these territories under the new paradigm, however, also build on a number of shared objectives. Generally, conservation matters for indigenous peoples. Indigenous communities of the world have many interests for the protection of the territories and resources that they own, occupy or use; although the perspectives and views on protection may differ from those of protected area professionals and agencies, most of the interests of such communities significantly concur with protected area objectives. Among them:
Indigenous values of biodiversity. Biodiversity plays a fundamental role in many indigenous livelihood, economic development and food security strategies. Biodiversity may also be imbued with particular cultural and spiritual significance.

The significance of ecological services. The ecological services provided by protected areas are fundamental for indigenous peoples, who often, more than other segments of society, rely on healthy environments for their well-being.

The importance of protection of the territories and resources. Protection of areas of land and water is not new to indigenous peoples. Various forms of traditional protected areas and mechanisms have been documented (e.g. Borrini-Feyerabend, 2003). Furthermore, territorial protection has become in many cases a central element of indigenous strategies in their efforts to effectively manage their customary lands and waters, in the presence of diverse threats emerging from national societies and competition for lands and resources. In this context, indigenous peoples perceive protected areas as a useful tool to solidify and strengthen their territorial control and management.

Indigenous knowledge: from past to the future. Long-term presence, ancestral attachments to customary territories, understanding of the present and active management of ecological change have led to an accumulation of traditional ecological knowledge and conservation practices integrated with broader livelihood strategies. This does not make them, as is frequently misunderstood, sustainable per se; rather it involves direct or indirect knowledge and efforts to identify comprehensive (in contrast to 'narrow') conservation solutions.

Indigenous land and seascape visions. Based on customary cultural attachments to broader land and seascapes, indigenous visions of territorial management typically emphasise linkages between productive zones, conservation areas, and sustainable resource use, as well as broader processes including local development planning, political reform processes and education systems. Such visions provide local "frameworks" for protected area strategies to ground the sustainable development 
efforts. More than in Western approaches to protected areas, conservation and protection of lands and resources in indigenous communities is a vital and integral part of cultural strategies for survival.

Conservation as part of indigenous rights. Indigenous peoples often emphasise conservation and natural resource management as an integral part of a broader set of territorial rights connected to selfdetermination. In Australia, designation of protected areas by indigenous peoples in their lands has been advocated as an expression of self-determination "self-declaration for self-determination" as coined by Szabo (1996) and others. Durban outputs recognised the right of indigenous peoples to freely consent to activities affecting them, setting a new benchmark for how conservation agencies go about design and management planning for protected areas in indigenous lands and territories, and implicitly recognising the self-determination dimension of indigenous peoples' involvement in decision making on these matters.

Interests in management. Indigenous conservation interests go beyond the "substantive" issues, and also relate to process and cultural questions: how to effectively participate in protected area design and management and what mechanisms are or should be at their disposal for that. Indigenous peoples have long emphasised the role of their customary institutions (such as common property regimes), practices (e.g. conflict resolution) and representative organizations in these processes.

Such a list of indigenous conservation interests does not minimize the importance of real conflicts between conservation actors and indigenous peoples. Such conflicts are often significant in areas with considerable cultural change, strong external pressures, population growth and increasing market demands. Some indigenous groups or individuals practice unsustainable use of natural resources. There are cases where they are involved in 'poaching', overexploiting or harvesting species close to extinction. Others may support non-conservation friendly land use priorities or be in favour of expanding extractive industries. As in other segments of society, indigenous peoples harbour a vast diversity of relationships to the environment, values attributed to conservation and the priority given to (un)sustainable development.

However, the presence of diverging priorities, in particular cases, does not remove the particular conservation interests of indigenous peoples, and the fact that vast portions of their lands and resources overlap with protected areas and with areas of high conservation value. Rather, this provides an important basis for indigenous peoples and conservation agencies to re-establish common ground for moving towards new ways of addressing such conflicts. If protected areas are to strengthen their relevance to such internal debates and discussions, it is fundamental that their relevance is consolidated through real and tangible contributions to indigenous conservation interests. This is already happening in many countries, where indigenous peoples are actively involved in and promoting protected area establishment reflecting their rights and concerns. Durban showcased several examples of indigenous peoples establishing their own protected areas both within and beyond the formal protected area system, and explicitly integrating protected area management objectives in their self-development strategies.

Durban emphasised the need to "fill the gaps" in protected areas coverage and effective protection through comprehensive systems in order to fulfil the 2010 target to reduce the rate of biodiversity loss. Recognising the wide presence of indigenous peoples

A char fish caught by an Inuit in the Northwest Territories Province, Canada.

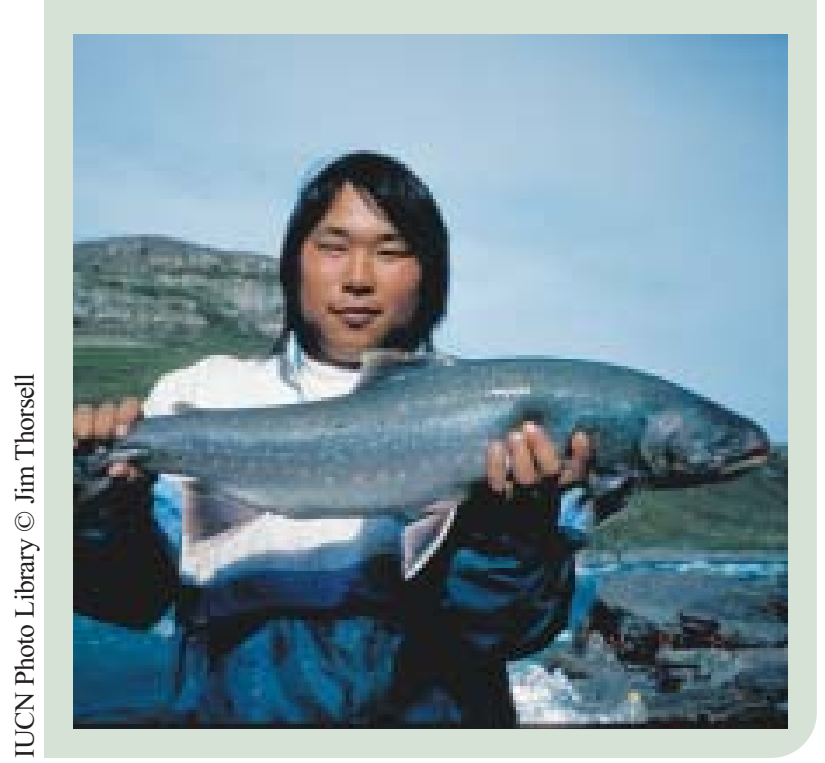


in priority conservation regions, it seems reasonable to build on the existing conservation interest and practices of indigenous and local communities. This will only be possible if a reconciliation agenda is further consolidated through a common agenda on key policy elements.

\section{Key policy elements for IP-PA reconciliation}

One of the major outputs of the WPC was the high profile given to alternative and innovative ways of working with indigenous peoples in protected area planning and management as a way of building support from this "old", but often neglected, protected area constituency. This new consensus was driven by equity concerns (conservation should be based on a fair sharing of costs and benefits and build upon rights) and effectiveness concerns (conservation will not happen without the commitment of local stewards). It was further underlined by a new conservation vision situating and specifying the role of protected areas at the ecosystem level including through providing a more accurate valuation of the biodiversity and broader ecosystem values they provide. The consolidated "Durban vision" emphasises the importance of:

- The rights of indigenous peoples, mobile peoples and local communities in relation to natural resources and biodiversity as a building block rather than an obstacle to effective protected areas;

- Protected areas' critical role in global biodiversity conservation;

- Protected areas' fundamental role in sustainable development and poverty alleviation;

- Consolidating the contribution of protected areas to broader Millennium Development Goals through an emphasis on equitable cost and benefit-sharing, "do no harm" approaches and poverty-oriented protection strategies;

- Reconciling past and present conflicts and grievances suffered by indigenous and local communities;

- Broadening protection objectives to cover biological, economic, social and cultural values;

- Strengthening scientific approaches to protected area design and management;
- Improving protected area governance, recognising the role of traditional forms of land management and innovative approaches linking protected areas to surrounding landscapes and seascapes;

- Improved quality, effectiveness and reporting of protected area management.

This vision was accompanied by a range of policy options and suggested approaches.

\section{Indigenous rights as building blocks for protected areas}

"We want to stress our insistence for the recognition and respect of the rights of indigenous peoples in existing and proposed protected areas and to prioritize the recognition of indigenous-owned and communityowned territories and areas as a sound basis for conservation. We also reiterate indigenous peoples' vital role in the achievement of sustainable development and to recognize that indigenous peoples have their own concepts of protected areas and conservation that are based upon their customary laws, traditional knowledge and profound connection with their lands, territories and resources." (Closing plenary indigenous statement in Durban)

Under Key Target 12, to achieve further support from major stakeholder constituencies, the Durban Action Plan recommends national governments and local authorities to "demarcate and recognise indigenous peoples' territories in support of community conservation". Such approaches form part of the Durban consensus to establish clear legal frameworks recognising the rights and concerns of indigenous peoples and thus creating further certainty when establishing protected areas. Furthermore, Key target 8 aims for "all existing and future protected areas" to be "managed and established in full compliance with the rights of indigenous peoples, mobile communities and local communities". An important difference between the Durban Action Plan and the CBD Programme of Work on Protected Areas is the inclusion in the former of a target to establish and implement "participatory mechanisms for the restitution of indigenous peoples' traditional lands and territories that were incorporated in protected areas without their free and informed consent" by 2008 . This target could be pursued as part of the broader 
mechanisms for equitable sharing of costs and benefits. For protected area agencies, the critical question is how to engage in restitution, while ensuring viable protection efforts. Experiences in countries, such as Australia, which have combined restitution efforts with protected area agreement building, provide relevant lessons in this respect. In Canada, protected areas are a major component of comprehensive land claim agreements with indigenous peoples. However, even where rights remain unresolved, mechanisms are in place to continue collaboration on shared conservation objectives. For example, in the Gwaii Haanas National Park Reserve, covering 149,500ha, Haida and Parks Canada have agreed to disagree on land-ownership matters, yet continue to collaborate on common conservation objectives (Gladu et al., 2003). This is a salient feature of the four-step process of negotiating land claims with First Nations in Canada (Oviedo, 2002).

\section{Comprehensive protected area systems: the need to build on the role of indigenous peoples and their territories}

The Durban Action Plan specifically notes the potential of "community conservation areas, community managed areas, and private and indigenous reserves". Further, indigenous commitment to all protected area types affecting their lands and waters, under conditions of respect for indigenous rights and interests, should also be mentioned. This entails a double approach of strengthening the establishment and recognition of new types of protected area management, along with a revision of the status of existing protected areas so as to ensure full indigenous participation and mechanisms to guarantee equitable cost and benefit-sharing. It particularly involves linking indigenous protection efforts to the overall system design and planning, to fully recognise the conservation value of indigenous territories in key biodiversity areas. In the Indian Himalayas, for example, research has revealed how community conserved areas can fill major gaps between officially protected areas (Kothari, 2003). In the Russian Arctic, indigenous natural sacred sites, an integral part of the customary land and water management mosaic, form a cultural basis for linking protected areas to surrounding landscapes (Raipon and Caff, 2004). In the Brazilian Amazon, indigenous territories not only fill many existing protected area gaps, but often provide more effective protection

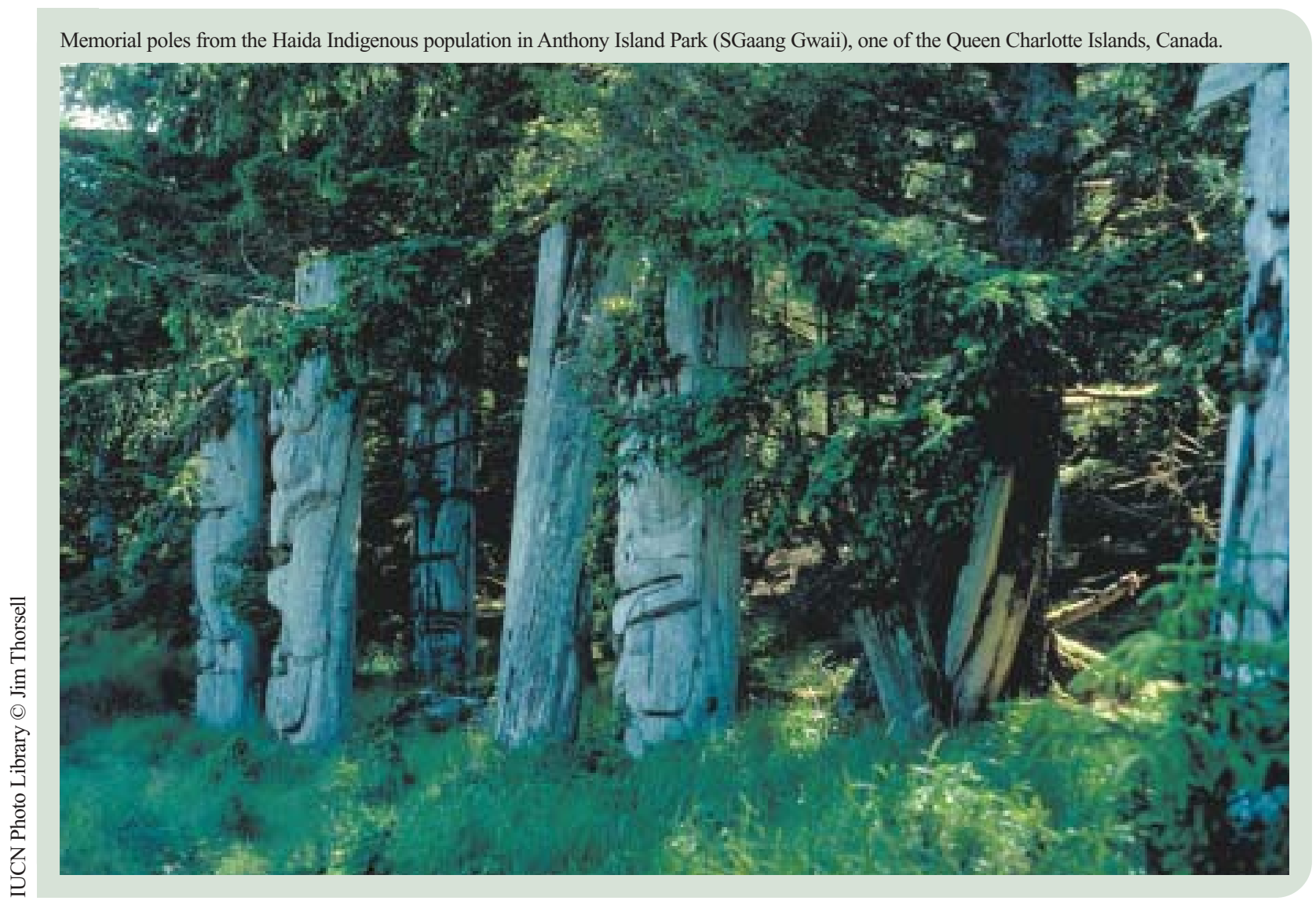


measures compared to conventional protected areas (Maretti, 2002). Often, however, such conservation contributions are not fully recognised and fully linked up with protected area systems.

\section{Protected areas should contribute to sustainable development, equity and poverty alleviation}

Effective sustainable development approaches are essential to build indigenous support for protected areas, especially considering that in many places indigenous communities belong to the poorest segments of society. Unless recognition of indigenous involvement in design and management is accompanied by comprehensive development strategies to ensure local and tangible benefits, conservation support has proven difficult to sustain. The CBD call for equitable sharing of conservation costs and benefits cemented this approach as a fundamental objective rather than a stand-alone activity. A critical element emphasised in the Durban Action Plan is the need for action to ensure that protected areas strive to alleviate poverty and in no case to exacerbate it (Key Target 3); this would include strictly eliminating forced resettlement of indigenous peoples and local communities and the involuntary sedenterization of mobile peoples, as such actions usually have led to impoverishment of the affected communities. Key developments to address such challenges involve indigenous contributions to zoning arrangements and regulation regimes, which support customary livelihoods such as grazing, hunting and harvesting of wild species along with conservation objectives. Such efforts need to be situated in a revised approach to protected area objectives.

\section{An array of biological, economic, social and cultural objectives should replace conventional protection objectives, and recognise the value of indigenous conservation visions}

The conventional view involving governmentdesignated and government-run areas with protection objectives defined as a strictly national or regional concern is being challenged by increasingly sophisticated approaches addressing the specific contexts and objectives of protected areas in their surrounding landscapes. Scientists have challenged the biodiversity value of political compromise-based protected area design (Mulongoy and Chape, 2004) calling for the establishment of specific, representative and viable biodiversity and ecosystem service goals. Furthermore, the Durban vision established the necessity to integrate socio-cultural and sustainable development objectives as integral elements of protected areas. The CBD Programme of Work on Protected Areas responded to this vision by emphasising the need to establish "mechanisms for the equitable sharing of costs and benefits". This responds to a major claim by indigenous peoples: the need to address their conservation interests as part of a broader vision for the ancestral lands and waters explicitly including their cultural, customary use and livelihood security objectives, rather than limiting conservation to "narrow" ecological objectives. In Colombia, for example, the Alto Fragua-Indiwasi National Park created in 2002 is in the management hands of the Ingano people as part of their Life Plan, a broader long-term vision for the entirety of their territory and the region (Oviedo, 2002). In many other cases, promoting equity and benefit-sharing presents a profound challenge as well as opportunity for the protected area community.

\section{Strengthening scientific approaches: harmonizing natural and social sciences}

Durban emphasised that only an adequate understanding of the patterns of distribution of species, habitats, ecosystems and ecological processes across all scales would allow for truly systematic conservation plans and decision-support tools. The call for "biodiversity-based targets" in comprehensive systems clarifies goals at stake when engaging with indigenous peoples regarding concrete conservation planning on their lands and waters. A clear set of scientifically based objectives can then be discussed, complemented and weighed against indigenous conservation interests and use priorities. In conjunction, strengthened social science skills (e.g. Cernea and Schmidt-Soltau, 2003) and tools are fundamental to effectively reach an understanding of the costs and benefits at stake as well as identifying the range of potential management 
responses - in order to "implement sustainable development" and "equitable cost and benefit sharing" in protected areas. Scientific argumentation should, and will, remain a basic principle of protected area planning and management. Indeed, it can and should serve to fully recognise indigenous concerns through clear and transparent problem identification, impact assessment, strategy feasibility studies and effectiveness evaluations. Finally, indigenous knowledge is no longer seen as in contradiction to scientific approaches. Rather its value in identifying critical species, habitat and ecological linkages and processes is being strengthened as well as its role in identifying locally appropriate management responses.

The IUCN protected area category system can also help build conservation alliances with indigenous peoples, if properly understood and applied. For example, when identifying major protection gaps in Australian bioregions, many were found to overlap with aboriginal lands and waters. In response, efforts such as the establishment of an Indigenous Peoples
Protected Areas Program, sought to accommodate cultural priorities, while linking protection efforts to the National Reserve System. When establishing such Indigenous Protected Areas, aboriginal communities review and apply the IUCN Protected Area Categories. Nantawarrina, for example, established by the Nepabunna community, is a protected area declared under four IUCN Protected Area Management categories (II, IV, V and VI).

\section{Adopting new governance approaches including community-driven and co- managed protected areas}

Durban emphasised the growing presence and recognition of community-conserved areas and comanagement as effective management strategies in a renewed emphasis on good governance of protected areas. While such overall general typologies may make sense in some countries, most countries will require tailoring policy options to fully reflect particular governance characteristics. This typically requires

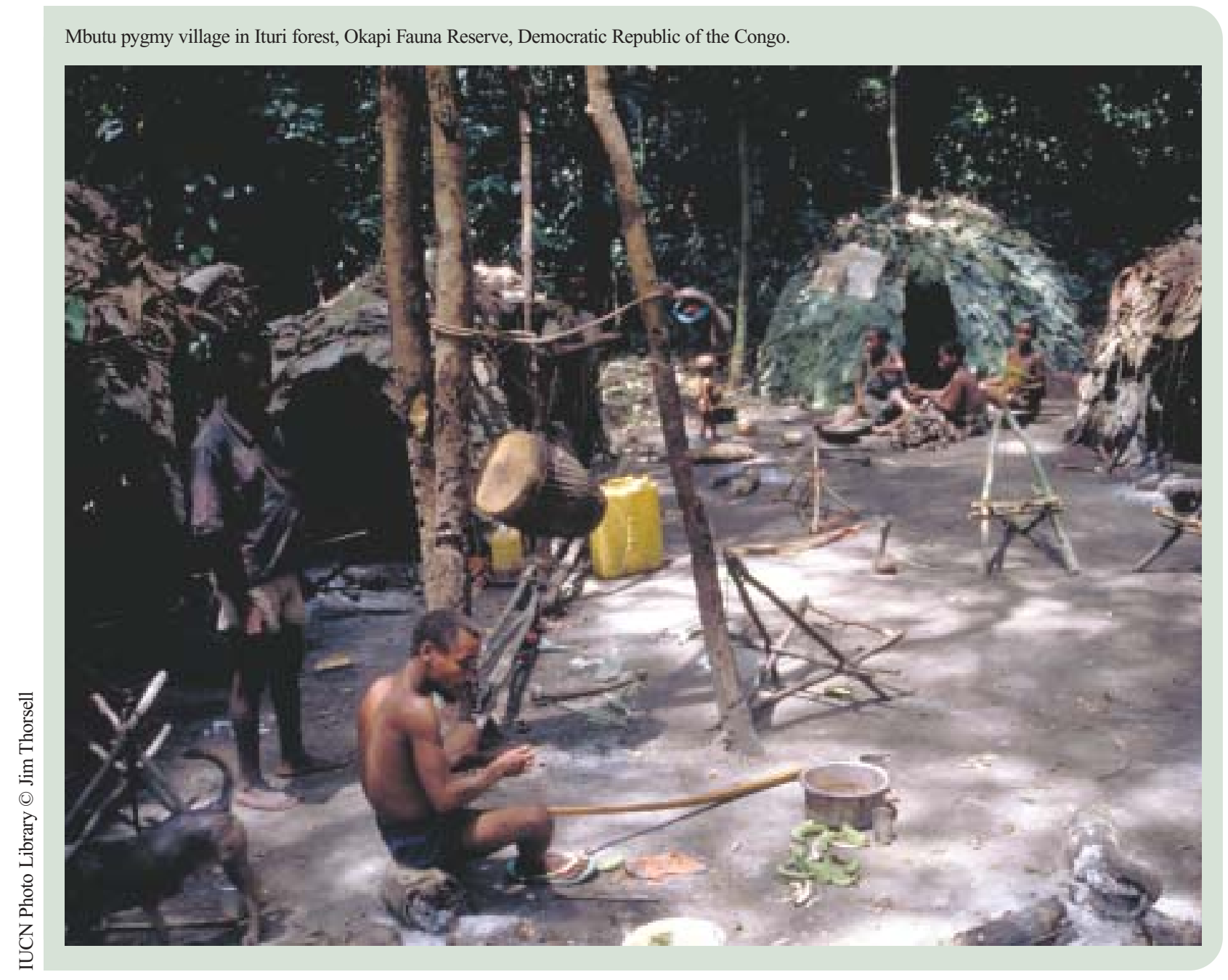


clarifying roles and responsibilities between national and subsidiary levels. Most countries will require the combination of several governance approaches e.g. through strengthening co-management mechanisms in existing government-managed areas, supporting indigenous peoples in establishing communityconserved areas and, importantly, establishing corridors between, and networks of, protected areas. In Colombia, for example, the Matavén Forest Indigenous Territory, covering 1,849,613 hectares, comprises 16 indigenous territories of six indigenous peoples, who collaborate on management issues through an association of traditional authorities, while relying on the central support of the government (Oviedo, 2002).

\section{Improving quality, effectiveness and reporting of protected area management}

Improving quality and effective delivery of protected area objectives serves as a major incentive for securing indigenous buy-in to protected area strategies. The Durban Action Plan emphasised the importance of ensuring "sufficient knowledge of trends in ecological, environmental, social, cultural and economic indicators" along with recognising the value of indigenous and traditional knowledge. This means emphasising the role of socio-economic and cultural objectives in assessing effectiveness. Are protected areas effective in reaching cultural objectives? Do they provide indigenous peoples the benefits agreed upon? The Durban CBD message highlighted the importance of socio-economic criteria for evaluating the performance of all protected areas. Even, and perhaps especially, strictly protected areas have socio-economic impacts, which need to be fully addressed when evaluating effectiveness.

\section{Four key steps and their benchmarks towards 2010/2012 targets}

A broad reconciliatory agenda is needed responding to the aforementioned policy objectives in the implementation of the Durban Action Plan and the CBD programme of work on protected areas. Such an agenda could be structured around the key elements of both instruments, with their targets guiding specific actions and serving to monitor and assess progress.
In order to avoid compartmentalized action, four key steps are proposed below to situate these policy elements in overall system design and implementation. As these targets are mainly 'procedural' involving the conduct of reviews, ensuring participation, and establishing mechanisms and systems, it is fundamental to qualify implementation through a number of benchmark indicators to review progress on the substantive issues at stake. Such indicative benchmark indicators are suggested below.

\section{STEP 1: Effective involvement of indigenous peoples in national and regional gap analyses, protected area reviews and system planning processes}

Goal 1.1, considered the 'overall purpose' of the CBD programme of work on protected areas, aims to establish and strengthen national and regional protected area systems by 2010 (terrestrially) and 2012 (marine). Suggested activities by Parties include gap analyses (1.1.5) and national reviews, by 2006, of "existing and potential forms of conservation" including "innovative types of governance" - with full and effective participation of indigenous and local communities (1.1.4). Furthermore, Parties are suggested to "encourage the establishment of protected areas that benefit indigenous and local communities" (1.1.7). These activities are all the more important given that the gap analyses will establish baseline data for the further establishment of new protected areas. The considerable overlap between areas of high biodiversity and those of cultural diversity (Oviedo et al., 2000) provide a fundamental reason for fully exploring effective conservation solutions with the indigenous peoples concerned. Second, it is fundamental that indigenous protected area strategies are effectively linked with, rather than separate from, national systems and approaches. Suggested activity 2.2.1 is clear on the necessity of participatory national reviews. It calls for protected area agencies to "Carry out participatory national reviews of the status, needs and context-specific mechanisms for involving stakeholders, ensuring gender and social equity, in protected areas policy and management, at the level of national policy, protected area systems and individual sites." In order for this to 
happen, it is essential that the following benchmarks are reached:

\section{Benchmarks 1}

i. System gap analyses identify overlaps with the lands and waters of indigenous peoples.

ii. National reviews fully reflect indigenous concerns, rights and responsibilities in relation to current policies, existing and potential conservation approaches including interim measures, alternative governance options to "fill the gaps" and address existing problems.

iii. National reviews document the costs and benefits of establishing and managing protected areas for indigenous and local communities.

iv. National reviews explore appropriate processes, the relevance of alternative governance options and suggest context-specific mechanisms and roadmaps for involving indigenous peoples building on their rights.

v. Goal 2.2 on full and effective participation is applied in the gap analyses and national review processes.

\section{STEP 2: Ensure full and effective participation of indigenous local communities in existing and new protected areas in full respect of their rights and recognition of their responsibilities by 2008}

Step 2 responds to goal 2.2 of the CBD programme of work on protected areas. Reaching this goal and the accompanying 2008 target will depend on the outcome of the review process outlined above. Such building blocks establish the necessary understanding and knowledge allowing Parties to craft appropriate policies, institutional reform and action plans.

In this context, it is also relevant to emphasise CBD goal 1.4 to "substantially improve site-based protected area planning and management ... using participatory and science-based site planning processes that incorporate clear biodiversity objectives, targets, management strategies and monitoring programmes". Activity 2.2.2 suggests that Parties:

"Implement specific plans and initiatives to effectively involve indigenous and local communities, with respect for their rights consistent with national legislation and applicable international obligations,

\section{Box 9.3}

\section{Relationship between the CBD programme of work on protected areas and the Durban Action Plan}

\section{CBD Programme Element 2}

\section{Programme Element 2:}

Governance, participation, equity and benefit sharing

Goal 2.1

To promote equity and benefit-sharing

Target: Establish by 2008 mechanisms for the equitable sharing of both costs and benefits arising from the establishment and management of protected areas

\section{Goal 2.2}

To enhance and secure involvement of indigenous and local communities and relevant stakeholders

Target: Full and effective participation by 2008, of indigenous and local communities, in full respect of their rights and recognition of their responsibilities, consistent with national law and applicable international obligations, and the participation of relevant stakeholders, in the management of existing, and the establishment and management of new, protected areas.

\section{Durban Action Plan}

\section{Outcome 5:}

The Rights of Indigenous Peoples, Mobile peoples and Local Communities Recognised and Guaranteed in Relation to Natural Resources and Biodiversity Conservation

\section{Key Target 8:}

All existing and future protected areas shall be managed and established in full compliance with the rights of indigenous peoples, mobile peoples and local communities by the time of the next IUCN WPC.

\section{Key Target 9:}

Protected areas shall have representatives chosen by indigenous peoples and local communities in their management proportionate to their rights and interests by the time of the next IUCN WPC.

\section{Key Target 10:}

Participatory mechanisms for the restitution of indigenous peoples' traditional lands and territories that were incorporated in protected areas without their free and informed consent established and implemented by the time of the next IUCN WPC. 


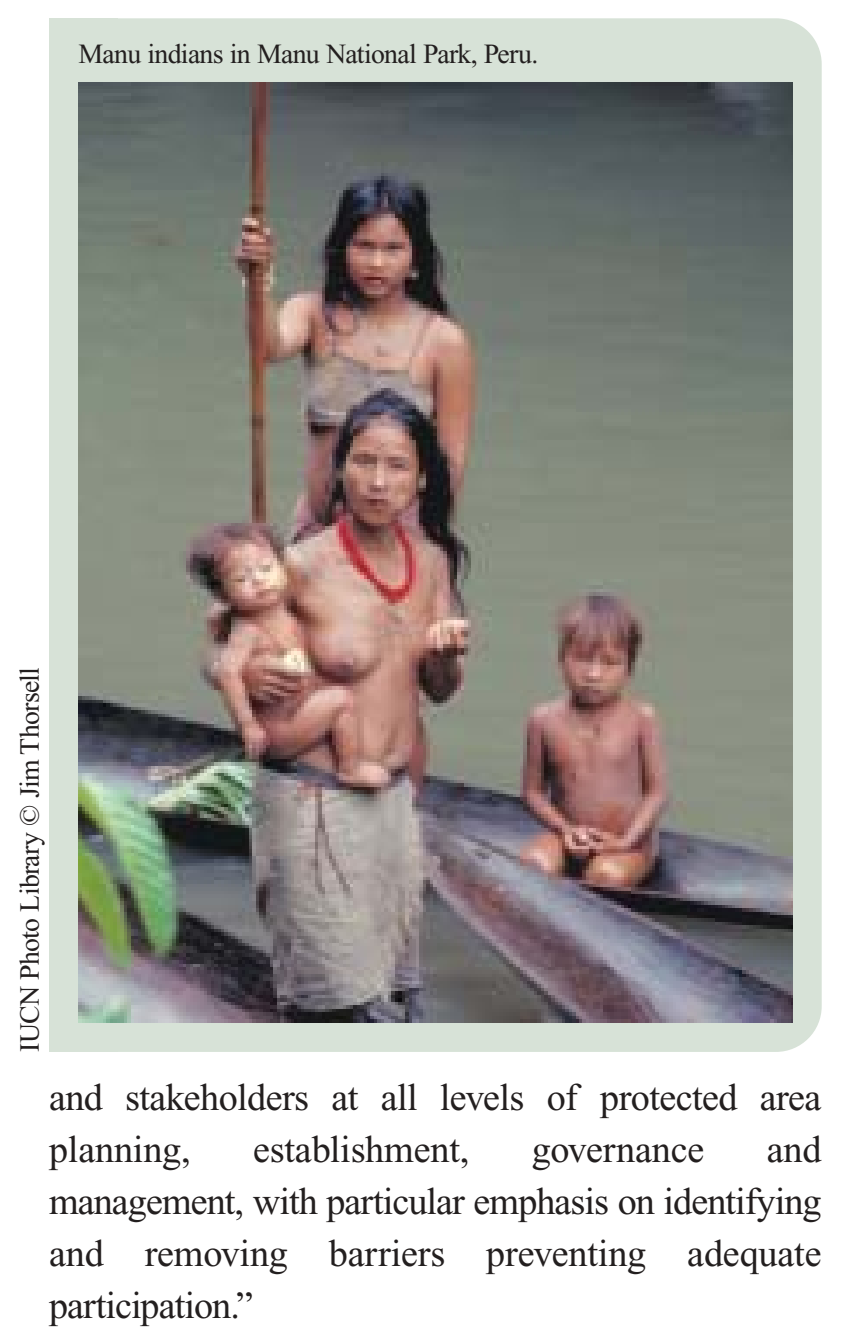

The key issue here involves joint action planning processes between indigenous peoples and protected area agencies. Activity 2.2.3 suggests to "support participatory assessment exercises to identify and harness the wealth of knowledge, skills, resources and institutions of importance for conservation" forming a natural starting point for action planning processes. A key element will also involve responding to national review processes and "promote an enabling environment (legislation, policies, capacities, and resources) for the involvement of indigenous and local communities in decision making, and the development of their capacities and opportunities to establish and manage protected areas, including community-conserved and private protected areas" (2.2.4). Most likely, this will require further work to tailor appropriate policy solutions, particularly on how to work in "full respect of indigenous rights and ... responsibilities". Finally, Parties are suggested to ensure that resettlement only takes place with the prior informed consent of indigenous peoples (2.2.5).

\section{Benchmarks 2}

i Policy and judicial reviews to clarify indigenous rights and responsibilities consistent with national law and international obligations.

ii. The identification of barriers preventing adequate participation at all levels of protected area planning, establishment, governance and management.

iii. Agreement on a joint action planning process.

iv. Agreement on joint protected area action plans, which address all levels of protected area planning, establishment, governance and management.

v. Existence of safeguard policies requiring the use of Prior Informed Consent if resettlement is proposed for the establishment and management of protected areas.

vi. Appropriate legislation, policies, capacities, and resources in place to facilitate appropriate participatory processes and the employment of governance alternatives such as comanagement, community-conserved areas and private protected areas.

\section{STEP 3: Establish mechanisms for the equitable sharing of costs and benefits arising from the establishment and management of protected areas by 2008}

What is needed to reach the 2008 target of having established mechanisms for the equitable sharing of costs and benefits arising from the establishment and management of protected areas? Given that an improved understanding of costs and benefits for indigenous peoples is achieved in the gap analysis and review process, the participatory action planning process outlined above should emphasise the establishment of such mechanisms.

This would include policy measures requiring new, as well as existing, protected areas to assess both economic and socio-cultural costs for indigenous communities. Such policies would need to be accompanied by sufficient financial and technical 
resources to conduct impact assessments and implement the necessary follow-up activities. Adopting a different governance approach to protected area management, such as the establishment of community-conserved areas rather than the introduction of a new authority, is one mechanism which can contribute to equitable cost and benefitsharing. If indigenous communities are found to bear the major burden of an existing protected area, are they involved in planning effective responses? If a protected area is identified as providing significant benefits to indigenous communities, are their governance solutions sufficiently engaged? Whether government, co-management or community-driven protected area approaches are chosen, such structures need to be enabled through sufficient resources and capacity to provide indigenous communities tangible benefits in response to opportunity costs. Such benefits can often partly be dealt with through appropriate design, zonation/demarcation practices and sustainable use approaches, yet may also involve various other forms of compensation.

\section{Benchmarks 3}

i. Protected area policies are adjusted to avoid and mitigate negative impacts through appropriate compensation measures and equitable sharing of benefits (2.1.1). ii. Protected area policies recognise and promote a broad set of governance options such as community-conserved areas, co-management and private reserves.

iii. Indigenous and local communities and relevant stakeholders are engaged in participatory planning and governance, recalling the principles of the ecosystem approach (2.1.5).

iv. Policies and joint planning followed up by concrete compensation measures for conservation costs and equitably shared benefits according to indigenous priorities.

v. Minimum standards and best practices for indigenous involvement in existing and new protected areas developed and adopted.

\section{STEP 4: National and regional protected area systems, recognising indigenous rights and responsibilities, established and strengthened by 2010 (terrestrial) and 2012 (marine).}

Will the first three steps get us closer to the Durban goal 'to fulfil protected areas' critical role in global biodiversity conservation" through filling the gaps and improving effectiveness? The goal of step 4 is to ensure the integration of indigenous rights,

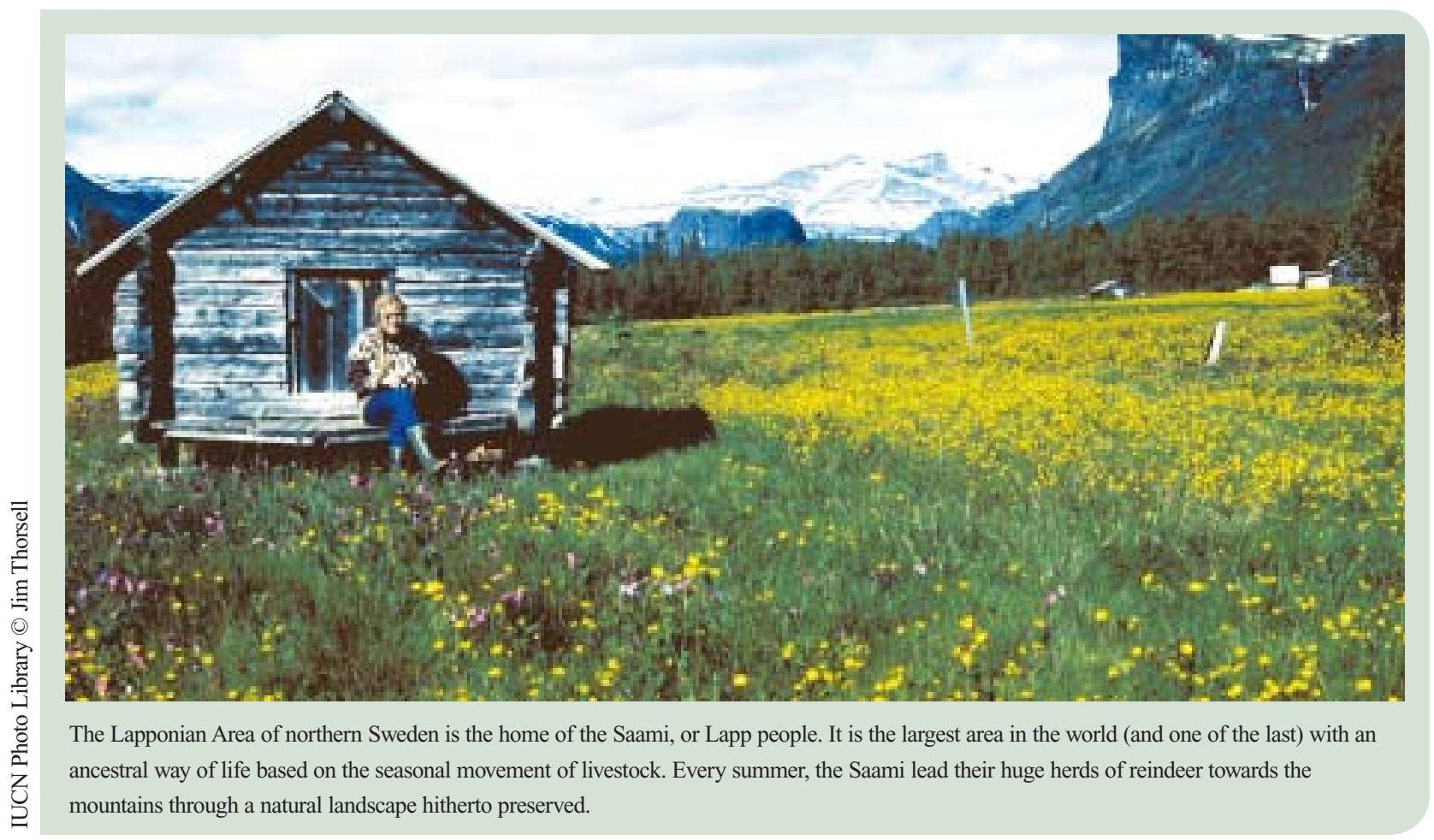


conservation priorities and responsibilities in the overall system building and maintenance process. Effective reconciliation can only happen if good practices and tools are established system-wide.

\section{Benchmarks 4}

i. System-wide capacity for the planning, establishment and management of protected areas on indigenous lands and waters.

ii. Sufficient financial, technical and other resources are available to meet the costs of effectively involving indigenous peoples throughout the system.

iii. Protected area gaps overlapping with indigenous territories filled through the employment of rights-based and culturally responsive management solutions such as community conserved areas.

iv. Effectiveness of protected areas overlapping with indigenous territories strengthened to address both biodiversity targets and other indigenous priorities.

v. National and regional monitoring systems address effectiveness in involving indigenous peoples and ensuring equitable cost and benefitsharing and sustainable development/MDG targets.

In summary, these four steps condense the policy objectives related to indigenous peoples in the broader Durban and CBD action plans to bridge existing protection gaps and build effective protection strategies. Different regions and countries may be more or less close to these benchmarks and, furthermore, apply diverse planning approaches. The four steps are not meant as a blueprint to replace the latter, but rather as a checklist to help ensure effective progress in relation to international commitments.

\section{Concluding remarks}

The reconciliation agenda with indigenous peoples developed in Durban is one of the elements of the new protected area paradigm with the most profound implications for design and management practices.
Policy reform aspects are wide-reaching. Further, the new paradigm consolidated by the CBD programme of work shifted emphasis from de facto recognition of indigenous concerns towards increasing de jure recognition of indigenous rights. This has led to a conceptual, political and legal shift in the protected areas paradigm concerning indigenous peoples that it was difficult to conceive of a few years ago. This goes as far as working with indigenous communities and their representative institutions in establishing and managing protected areas in their territories, much the same way government agencies are key actors in recognising and establishing protected areas in their national jurisdictions. The implications of the new protected areas paradigm for indigenous selfdetermination are evident and may be in some cases decisive to reformulate the relationships between indigenous communities and national governments regarding management of their lands.

The paradigm change repositions protected areas from being of general interest of society to one which recognises the value of specific social and cultural priorities. How can this be put in practice without fragmenting broader ecosystem priorities and thus undermining the basis for global and national conservation priorities? The considerable theoretical overlap between indigenous conservation interests and broader biodiversity priorities should facilitate integration rather than fragmentation. But still, considerable conflicts and differences over livelihood practices and land use priorities do exist, and they could expand as cultural change, particularly prompted by the expansion of market forces, affects land and resource management. Retaining the reconciliation agenda as an integral part of implementing the Durban Action Plan and the CBD programme of work on protected areas is fundamental to addressing such conflicts in a constructive manner.

The establishment of large-scale protected areas on ancestral lands requiring the reduction or even halt of certain customary livelihood activities may be deemed necessary for the preservation of particular species or ecosystems. In this sense, the new paradigm does not compromise on halting biodiversity loss. On the contrary, it retains the need for strong scientific priorities, but combines this with 


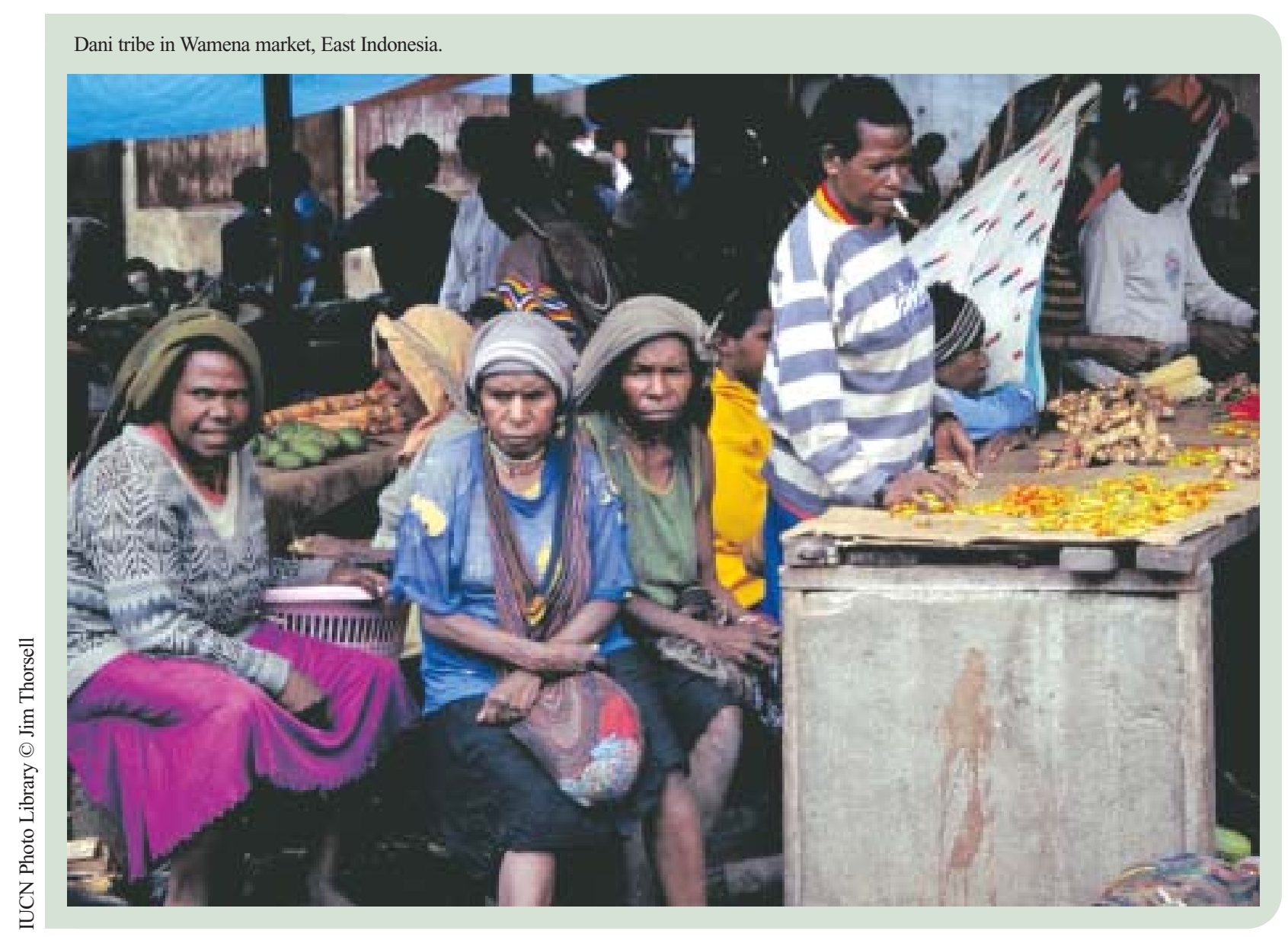

a new, rights-based, approach to establish equitable trade-offs and compromise solutions with the communities concerned. Customary livelihoods may need to undergo change, but how this takes place must be identified with the consent of indigenous communities - and equitably. The implications are enormous for the protected area world, not least in terms of revisiting the costs of protected area establishment.

Yet if protected areas are expected to contribute to sustainable development goals, as established in both Durban and the CBD, they must benefit, or at least do no harm, to indigenous and local communities. This may make protected areas more expensive, but also make them more relevant as viable solutions to governments struggling to reconcile social, economic and conservation priorities. The legacy of "paper parks" needs urgent attention. What is important is the need for the protected area community to integrate indigenous concerns in all levels of policy development and strategising. The four key steps and their accompanying benchmarks listed above intend to offer concrete advice in this respect. Although planning realities are seldom as rational and linear, these benchmarks are fundamental in bridging gaps through the full recognition and involvement of indigenous peoples.

Fully understanding the conservation concerns of indigenous peoples allows for a bottom-up construction of a common agenda of issues for strengthening protected areas and facilitating indigenous contributions. This cannot happen through compartmentalized micro-level interventions alone, but requires solid policy and system level developments, which recognise and build on indigenous rights and interests as much as on more objective, science-based, less emotional conservation frameworks. On the ground, creativity and efforts of concerned individuals and groups to reconcile the indigenous peoples vs. protected area dilemma can provide many useful lessons to enrich and feed into overall policy goals. In the end, it is protected area managers and community representatives, not distant policy makers, who have the knowledge and experience to make the paradigm shift work in practice. 
This volcanic archipelago, with its spectacular landscapes, is situated off the coast of the Hebrides and comprises the islands of Hirta, Dun, Soay and Boreray, Scotland, United Kingdom.

\section{Introduction}

The values associated with the world's protected areas (PAs) vary considerably from place to place and between interest groups. In most cases, however, nonmaterial values associated with PAs are as important as material values, or more so. While the material resources of protected areas contribute to the physical standard of living, the non-material values of PAs enrich the intellectual, psychological, emotional, spiritual, and/or creative aspects of human existence (WCPA, 2000).

People seem to have a basic need for a connection to the environment of their origin. The park establishment can use this need as an entry point for encouraging society to seek harmony with the environment and the rest of humanity. This potential role for PAs is only dimly perceived by most protected area managers and advocates, but in time could become a dominant one, reconnecting increasingly urbanized societies to nature and encouraging a reencounter with the knowing of oneness (Harmon and Putney, 2003).
Current discourse on PAs pays scant attention to the intangible, non-material values. It is as if scientific, technical and economic criteria were considered adequate for managing the intricate web of life (Posey 1999). This approach ignores the humanistic, cultural and spiritual criteria that are so important to an integrated approach to management, and to living.

In recognition of the importance of the non-material values of PAs, IUCN's World Commission on Protected Areas (WCPA) established a Task Force to assist park managers in defining, recognising and integrating non-material values into PA management. As pointed out by English and Lee (2003):

"protected area boundaries are overlain on environments that have a history of human presence and in many cases a recent or existing human use. This means they cannot be neatly excised from human memory or culturally defined ways of perceiving and valuing landscapes. Parks are embedded in social, economic, and political systems that ensure the values we place on them are linked to ongoing debates about our place in the world." 


\section{Typology of non-material values}

One of the first activities of the Task Force was to develop the following typology of non-material values related to PAs (Harmon and Putney, 2003):

1. Recreational values: Those intrinsic qualities of natural areas that interact with humans to restore, refresh, or create anew through stimulation and exercise of the mind, body and soul (i.e., re-creation).

2. Spiritual values: Those qualities of protected areas that inspire humans to relate with reverence to the sacredness of nature.

3. Cultural values: Those qualities, both positive and negative, ascribed to natural, cultural or mixed sites by different social groups, traditions, beliefs, or value systems that fulfil humankind's need to understand, and connect in meaningful ways, to the environment of its origin and the rest of nature.

4. Identity values: Those natural sites that link people to their landscape through myth, legend or history.

5. Existence values: The satisfaction, symbolic importance, and even willingness to pay, derived from knowing that outstanding natural and cultural landscapes have been protected and exist as physical and conceptual spaces where all forms of life and culture are valued and held sacred.

6. Artistic values: The qualities of nature that inspire human imagination in creative expression.

7. Aesthetic values: Appreciation of the harmony, beauty, and profound meaning found in nature.

8. Educational values: The qualities of nature that enlighten the careful observer with respect to the relationships of humans with the natural environment, and, by extension, the relationships between humans, thereby creating respect and understanding.

9. Research and monitoring values: The function of natural areas as refuges, benchmarks and baselines that provide scientists and interested individuals with relatively natural monitoring sites less influenced by human-induced change or conversion.

10. Peace values: The function of protected areas in fostering regional peace and stability through cooperative management across international land or sea boundaries (Transfrontier Conservation Areas); as 'intercultural spaces' for the development of understanding between traditional and modern societies, or between distinct cultures or age groups; or as refuges for nurturing internal peace and harmony for the individual.

11. Therapeutic values: The relationship between people and natural environments in protected areas that creates the potential for healing, and for enhancing physical and psychological well being.

\section{Sacred natural sites}

Early on, the Task Force chose to give particular attention to sacred natural sites (SNS) because of their cultural and spiritual importance to many societies, and their value for biodiversity conservation. Sacred natural sites are defined as "areas where nature, the divine and remembrances come together in special combinations that are particularly meaningful to a community, society or people. They can be the abode of deities, natural spirits and ancestors. They can be feared and secret places, and they can be benign areas for contemplation and meditation allowing also communication with the transcendental. Common to most sacred natural sites is that they are areas removed from everyday access and resource use" (Putney and Schaaf, 2003).

The SNS of indigenous and traditional peoples around the world frequently serve as communitybased conservation areas that fulfil functions similar to the PAs of western societies. They are also integral parts of ethnic identity and play a key role in indigenous and traditional peoples' culture and lifestyles. Because of the spiritual values ascribed to them, these sites (groves, mountains, forests, islands, desert oases, lakes, rivers, caves, etc., as well as entire landscapes) many times contain relatively unaltered ecosystems where human-induced impacts are minimal. They have been spared environmental degradation because their protection is embedded in local cultures and traditional belief systems. As a result, they frequently contain rare and endangered species, and serve as gene pools for species that can be reintroduced into surrounding degraded landscapes. However, in recent years the community 
controls that once served to protect SNS have become increasingly tenuous due to poverty, population pressures, insecure land tenure, and a lack of participation in decisions that affect them (Jeanrenaud, 2001).

NOTE: The location of SNS are secret in many indigenous and traditional societies, and can only be shared by spiritual leaders or the initiated. Thus all references to SNS in this chapter refer only to those that are willingly identified by their stewards.

\section{Description of the interest group and its relation to protected areas}

While potentially all PA interest groups relate to nonmaterial values in one way or another, the interest groups associated with SNS are much more limited. Two major groups can be discerned: (1) indigenous and traditional peoples (I\&T peoples), and (2) sympathetic groups within the globalized society.

I\&T peoples the world over are closely associated with, and dependent on, nature and the natural resources of their immediate environment. They often recognise sacred landscapes, SNS, and/or sacred species as essential components of their environment. This sacred geography provides a cultural and spiritual connection between the people, their surroundings and the universe, and plays an essential role in maintaining the vitality and survival of indigenous and traditional cultures (Otegui, 2003).

Within the more globalized society, which in general is disconnected from the natural environment, some small groups remain sympathetic to the worldview, lifestyle, and/or rights of I\&T peoples. Some of these groups are organized, such as environmental and human rights groups, but individuals in all sectors of society form part of this "sympathetic group", and can potentially be mobilized around specific issues or causes.

Historically, the interest of I\&T peoples in PAs has been reactive, usually in response to the incorporation, without consultation, of ancestral lands and/or sacred sites into PAs. In recent years, the opposite has been true in a few cases where I\&T peoples have sought to

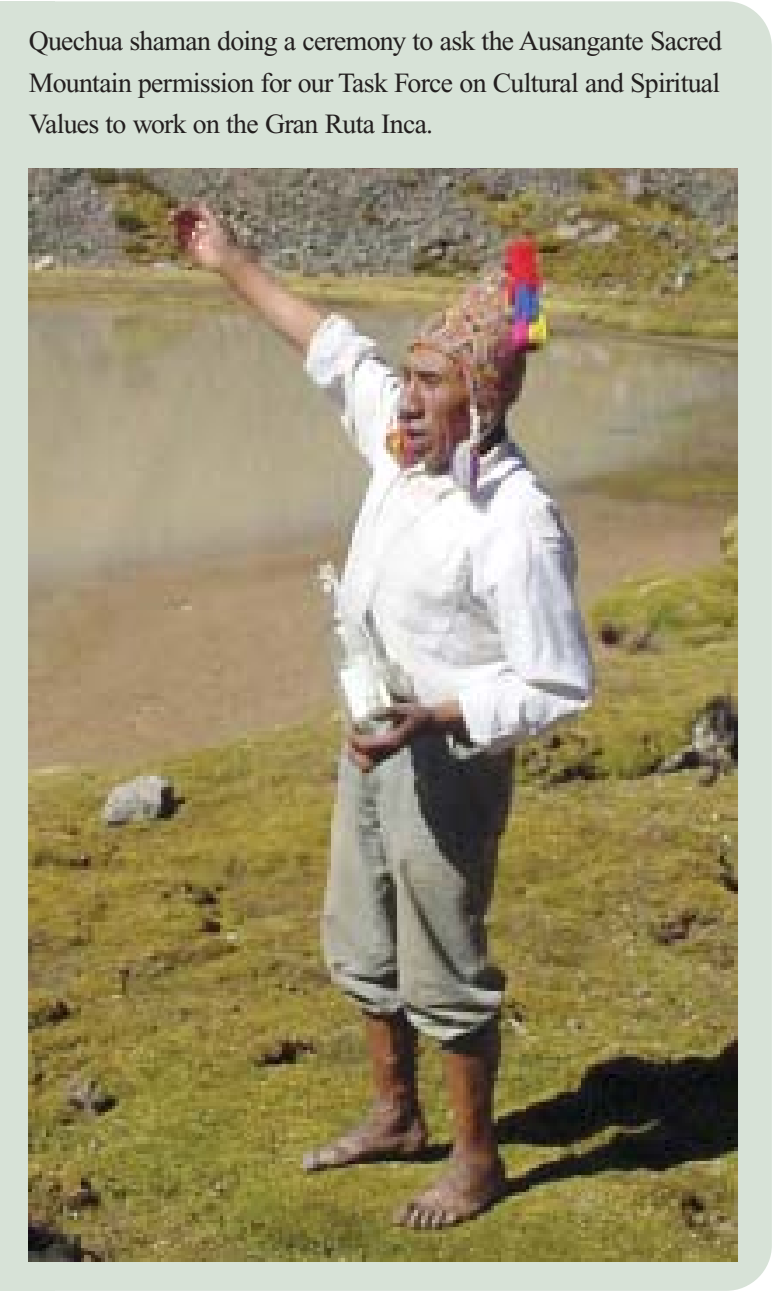

establish PAs in order to protect ancestral lands and/or specific SNS.

Where SNS have been incorporated into PAs without consultation, the reaction has often been to pursue the recognition of such sites within the PA, and to seek free access and the right to practice traditional rituals and ceremonies. In some cases, I\&T peoples have advocated closing general public access to these sites, either totally, or during specific periods when ceremonies are held. The official recognition of sacred sites within PAs has in exceptional cases led to the development of special institutional arrangements to guarantee the meaningful participation of the indigenous or traditional peoples in the management of the landscapes or sites that are sacred to them, and recognition of their cultural values and ecological knowledge.

The interests of those individuals and groups of the wider globalized society who are sympathetic to the belief systems and rights of I\&T peoples are often expressed through development of alliances on 
specific issues or conflicts, through the adoption of belief systems and/or through participation in, or imitation of, traditional practices, rituals and ceremonies. Though human rights and environmental groups have many times initiated alliances with I\&T peoples, the results have been mixed. Sometimes, as relationships evolve and interests are more clearly defined, it is found that the community of interest is not sufficient to warrant maintenance of the alliance over time.

\section{Examples of how indigenous and traditional peoples contribute to PAs}

I\&T peoples contribute to PAs, and to the conservation of biodiversity in general, in three main ways: sharing their traditional ecological knowledge; participating in the management of established protected areas; and maintaining biodiversity in sacred natural sites outside of legally protected areas. Modern groups sympathetic to I\&T peoples' worldviews, knowledge and rights contribute by recognising the importance and value of these cultural attributes, and advocating the integration of these cultural inputs into the practices of the wider society.

\section{Traditional environmental knowledge (TEK)}

I\&T peoples have gathered an intimate knowledge of their environments through thousands of years of interaction with their surroundings, trial and error management, and knowing, channelled from the spiritual level. They have co-evolved with their environment, modifying natural conditions, but actively maintaining it in a diverse and productive state, based on TEK, socio-cultural practices and/or spiritual beliefs (Ramakrishnan, 2003). This knowledge, and associated traditional management practices, can provide an important complement to the scientific knowing of modern society, and to its application to the management of specific environments in general, and PAs in particular.

TEK is particularly important because of the longterm perspective it provides on ecosystem dynamics based on ancestral interaction with habitats and species. I\&T peoples have also accumulated a vast knowledge about individual plants and species, their nutritional and medicinal properties, the use of their fibres, their function within the ecosystem, and their relationships to hydrological cycles. Many sophisticated classification systems of I\&T peoples have been documented, some indicating more complete taxonomies than western science (Oviedo, 2004).

Ramakrishnan (2003) notes that studies in India have shown that sacred species are often ecologically significant keystone species, thus linking the ecological and the social at the process level. $\mathrm{He}$ further notes that:

"such socially selected and ecologically important keystone species, by their very presence in the ecosystem, contribute to enhancing associated biodiversity at ecosystem and landscape levels. This interphase between ecological and social processes, which contributes to ecosystem integrity, represents a major gap in scientific knowledge that is understood through TEK" (Ramakrishnan, 2001).

Groups and individuals from modern society play an important role in accepting and applying TEK in their own lives and work. For scientists, the challenge is to decipher this knowledge, validate it and integrate it into the modern scientific and technical paradigm (Ramakrishnan, 2003). They can also be a catalytic force in promoting the recognition and application of this knowledge by natural resource management agencies, private landowners and businesses.

\section{Participation in management}

I\&T peoples can, and in many cases do, participate in a variety of ways to support the management of PAs. They can make significant contributions to the development of the information base, decision making, resource protection and management, public education, and as staff. Sympathetic modern groups can promote and facilitate the participation of I\&T peoples in management.

Development of the information base: Traditional environmental knowledge, management practices, and cultural perspectives of I\&T peoples can provide an important complement to the usual types of information that are developed for decision making for protected areas. However, as English and Lee (2003) point out: 
"If we wish to manage protected areas in a way that respects and sustains intangible values, we must do it collaboratively and be conscious of our thought processes and our cultural biases. In addition, often the way to elicit traditional knowledge or values is not at brainstorming sessions in meeting rooms or through scientific analysis. The landscape is the book in which the values are written, and being on and in the land is far more likely to elicit intangible values through experience, reminiscence, and storytelling. How to capture these values in such a way that respects their intangible nature but still allows them to be analyzed and understood and transmitted into management practices is the challenge. In many cases, the recording of place names and the associated stories can lead toward determining what management regimes or action would be appropriate. This is because the stories often carry implicit or explicit advice on how people should behave toward the land, the animals, plants, and each other."

Decision making: Participation of I\&T peoples in decision making can take a variety of forms, the most common of which are simple consultation, participation in stakeholder committees, and formal co-management. In the end, however, decision making in the context of PA management is about values, and no matter how park planners and managers personally perceive their roles, they function as 'arbiters of value'. Thus, it is their responsibility to make sure that all values are considered when making management decisions, defining park values broadly so that the interests of all stakeholders are considered (Tranel, 2003). In this context, the decision-making process is enhanced immeasurably when I\&T peoples participate directly in the decision-making processes affecting their ancestral lands, rather than having their interests and concerns interpreted through others.

\section{Resource protection and management: I\&T peoples} living within protected areas or in buffer zones must cooperate with, or actively assist, resource management if it is to be successful. The alternative is constant conflict and management failure. The example of Uluru-Kata Tjuta National Park in Australia is a case in point (see Box 10.1).

Public education: The worldviews, traditions and management practices of I\&T peoples can provide rich resource materials for public education programmes. Of particular importance are their beliefs and myths that convey an understanding of their oneness with nature and total dependence on it. These are the "voices of the earth", the "archaic whisper", that express with such directness and simplicity the need for harmony with nature. This is a truth that is corroborated extensively by modern science, yet is ignored by many of the actions in modern society.

Staffing: I\&T peoples can, and in many cases do, play a direct role in management by serving as staff members of the protected area agency. This provides a daily link between original peoples, non-I\&T staff, and the visiting public.

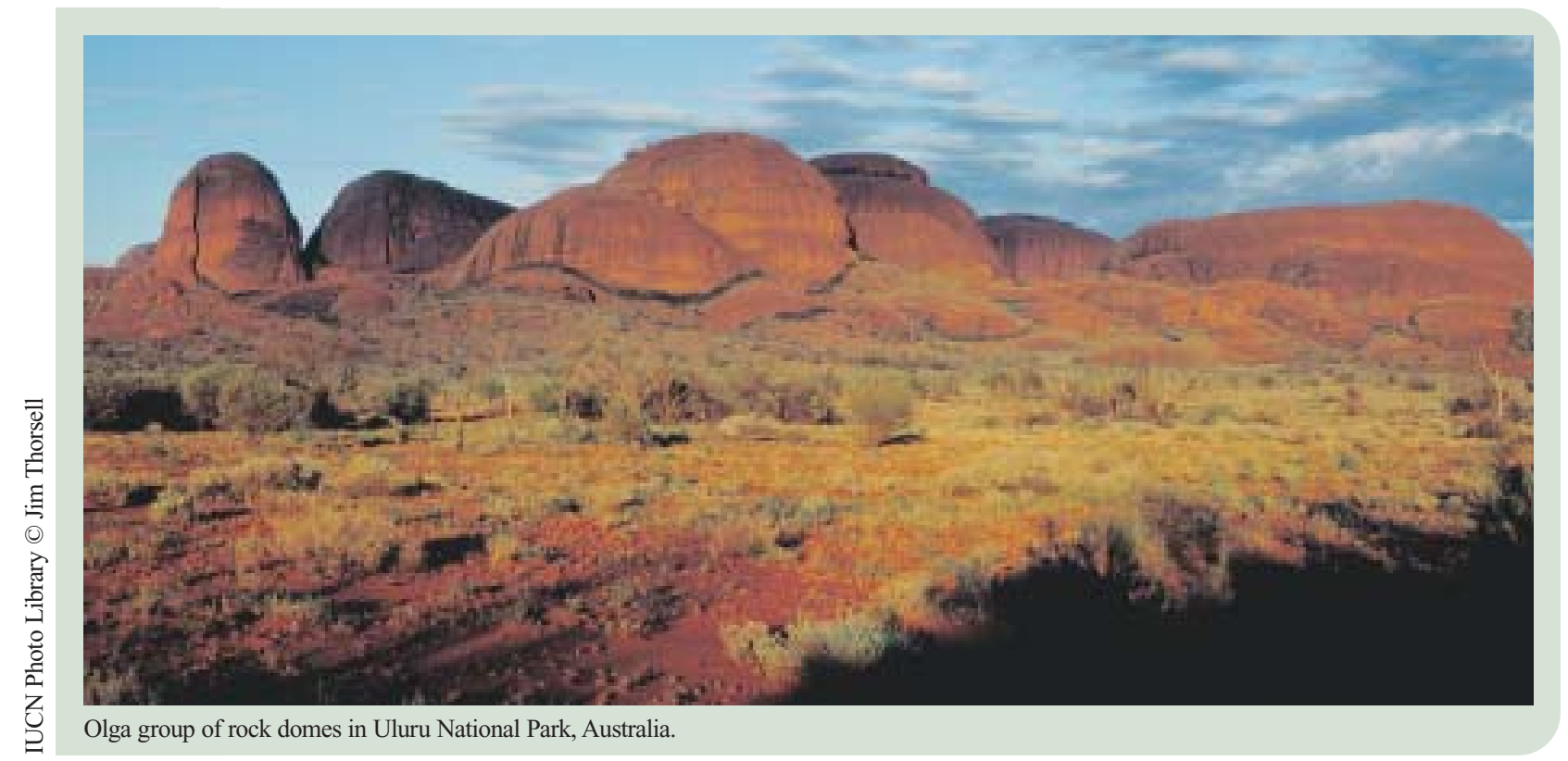




\section{Box 10.1}

\section{Traditional stewardship of Uluru-Kata Tjuta National Park}

Traditional stewards have been integrated into the management of protected areas in many sites and, in most cases, this has evolved over time. One of the more interesting examples that traces such an evolutionary path is that of Uluru-Kata Tjuta National Park in Australia (Beazley et al., 2001). The Park was established in 1977 on the ancestral land of the Aboriginal Anangu Peoples. They indicated their interest in the Park's management, including a request for protection of sacred sites and the right to build shelters for older people so that they could camp at Uluru to teach young people about Tjukurpa, the traditional law. In 1979 a claim was lodged under the Aboriginal Land Rights Act for an area of land that included the Park. While the Anangu were found to be the traditional owners, it was decided that the park land could not be returned to them because it was no longer unalienated Crown land. Title uncertainty and negotiation of joint management arrangements led to a decision in 1985 to grant the Anangu title to the land on the condition that it be simultaneously leased back to the Territorial Parks and Wildlife Department to be managed by a Board with an Anangu majority. At the same time, the Anangu were awarded a share of Park revenues as annual rental for use of their land as a Park. Difficulties in making these arrangements work led to the transfer of day to day management from the Territorial Parks and Wildlife Department to the Australian National Parks and Wildlife Service. Since 1985 the Anangu have played a strong role in park management, and in accordance with Tjukurpa, it is the prime responsibility of Parks Australia and the Anangu, to "look after the country" within the context of the joint management arrangements. Management practices aim to retain and protect both cultural and biodiversity values.

\section{Maintenance of biodiversity outside of PAs}

Ample documentary evidence shows that the sacred natural sites of I\&T peoples have played, and continue to play, an important role in preserving biodiversity outside of PAs by serving as refugia for vulnerable species and preserving ecosystem functions that have been lost in surrounding landscapes. Additional documentary evidence is provided by: Barrow (2003) on sacred groves worldwide; Bernbaum (2003) on sacred mountains worldwide; Malhotra, Gokhale and Bhutia (2003) on India; Secaira (2003) on Guatemala; Pei Shengji and Moseley (2003) on Southwestern China; Ntiamoa-Baidu (2003) on Africa; Todishev (2003) on Siberia; Amaya and Rodriguez (2003) on Colombia; LeBeau (2003) on California; Alem, de la Cruz and Robles (2003) (for Otegui, Torres and Luque) on Mexico; de la Torre (2003) for Ecuador; and Torres, Espinosa and Argumedo (2003) for Peru. These examples provide specific and convincing evidence on the extent and importance of SNS worldwide to biodiversity conservation.

One example provides a glimpse of just how extensive SNS may be worldwide. India, where considerable work has been done to document sacred groves, has an estimated 100,000 to 150,000 sacred groves nationwide (Chatterjee et al., undated).

\section{Policies needed to support the interests of indigenous and traditional peoples}

In order for I\&T peoples to be fully integrated into the management of PAs and continue to contribute to biodiversity conservation outside of PAs, policies are required to recognise traditional rights and support multicultural approaches to management. Modern groups sympathetic to the interests of I\&T peoples can play an important role by promoting and implementing the required policy framework.

\section{Recognition of traditional rights}

In those cases where PAs have been established on the ancestral lands of I\&T peoples, government policies need to recognise their right to have a voice and participate in the management of these lands, and to 
Aerial view of the Tronador Sacred Mountain in Nahuel Huapi National Park, Argentina. The peak in the far background is Osorno Volcano in Vicente Perez Rosales National Park, Chile.

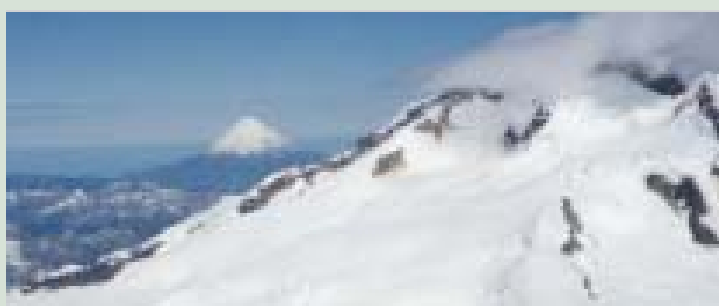

have free access and conduct traditional ceremonies related to SNS. Policies are also required for lands outside of PAs, so that as a minimum, SNS and related traditional practices are respected.

The WWF Statement of Principles on Indigenous Peoples and Conservation makes the point when noting that "without recognition of the rights of indigenous peoples, no constructive agreements can be drawn up between conservation organizations and indigenous peoples groups... WWF recognizes the right of indigenous peoples to exert control over their lands, territories, and resources, and establish on them the management and governance systems that best suit their cultures and social needs, while respecting national sovereignty, and conforming to national conservation and development objectives." (www.panda.org/about_wwf/what_we_do/policy/indi genous_people/rights.cfm).

The UN Draft Declaration on the Rights of Indigenous Peoples also gives full recognition to traditional rights (Posey, 1999). In part VI, Paragraphs 25-26 it states, "Indigenous peoples have the right to maintain and strengthen their distinctive spiritual and material relationship with the lands, territories, waters and coastal seas and other resources which they have traditionally occupied or used, and to uphold their responsibilities to future generations in this regard". Further, "Indigenous people have the right to own, develop, control and use the lands and territories, including the total environment of the lands, air, waters, coastal seas, sea-ice, flora and fauna and resources which they have traditionally owned or otherwise occupied or used. This includes the right to the full recognition of their laws, traditions and customs, land-tenure systems and institutions for the development and management of resources, and the right to effective measures by States to prevent any interference with, alienation of, or encroachment upon, these rights."

\section{Multicultural approach}

Policies are needed to recognise and implement a multicultural approach to PAs, and to biodiversity conservation outside of established PAs. At the system level, the most basic element of such a policy is the development of a multicultural system plan that sets the criteria for the development of the PA system from the science-based approach characteristic of western cultures, and the value-based approaches characteristic of I\&T peoples. A system plan of this type would also establish mechanisms to incorporate the management of SNS outside of the current PA system. This may entail the development of new management categories.

For example, Canada has followed a multicultural approach by seeking to include aboriginal cultural landscapes in their protected area system. An innovative process has been set up to identify, categorize and evaluate the significance of aboriginal cultural landscapes as a prelude to selecting those that will be integrated into the national, and in some cases regional, protected area systems (Lee, 2000). 
As part of the recognition of the first rights of I\&T peoples with respect to individual PAs already created on ancestral lands, policies are required to establish and implement a multicultural approach that guarantees I\&T peoples' participation in management, including development of the information base for management decisions, decision making and implementation. Participation in development of the information base for management decisions is an important starting point, because it allows I\&T peoples to identify those elements of the PA that are of particular importance to their culture and worldview. These elements can then be an integral part of the common information base that is used for decision making. A multicultural approach to decision making would guarantee that I\&T peoples participate in setting up the mechanisms for the decision-making process for PA management and for management itself on ancestral lands.

An example of such an approach is that which was adopted in New South Wales in Australia (English, 2000). In 1996, legislation was passed that allowed joint management of protected areas with aboriginal people where park values were considered to be of cultural significance. This policy was augmented in 1998 when a "Visions Symposium" recommended that traditional and contemporary associations with the land be recognised, and the "indivisibility of the environment's natural and cultural values should form the basis for working with Aboriginal people". As a follow-up, an Aboriginal People and Biodiversity Project was undertaken to enhance understanding on how this approach could be implemented, and a series of recommendations on practical approaches have been developed.

\section{Actions required in the coming ten years}

A strategic approach is required to catalyse the policies suggested above on a global level, and to promote the consequent implementation programmes that need to follow at the regional and national levels. The recognition, protection and management of SNS is part of the larger concern for multicultural approaches to PA management where relevant. A multi-faceted approach is recommended that would deal simultaneously with five major action themes: policy; planning; management programmes; capacity building; and technical and financial assistance. While there would be overlap among these action themes, this overlap would serve to inform and reinforce actions among the individual themes.

\section{Policy}

The development and implementation of the required policy framework could be catalysed by research, the synthesis of model policy statements and laws, and advocacy at both the international and national levels.

Research. Some of the needed policy elements outlined in the previous section have been developed and implemented in individual countries, or in states or provinces within a country. Research is needed to identify these specific policies, and to highlight the lessons that have been learned from their development, adoption and implementation.

Model policies. Once the policy research has been completed, model policy statements and a listing of related lessons learned can be developed and distributed internationally as a reference.

Advocacy. These model policies could be promoted through international treaty processes, such as the Convention on Biological Diversity, the World Heritage Convention, the Man and the Biosphere Programme and the Ramsar Convention; the IUCN-sponsored World Conservation Congresses; through United Nations agencies, such as UNDP, UNEP and FAO; international development banks; bilateral technical cooperation programmes; and the action programmes of major international non-governmental organizations such as IUCN, Fauna and Flora International, WWF, The Nature Conservancy, Conservation International, BirdLife International and the Wildlife Conservation Society.

In order for this advocacy to be effective, technical meetings would be required to present and discuss these policies and enlist the support of each of the potential advocate agencies. 


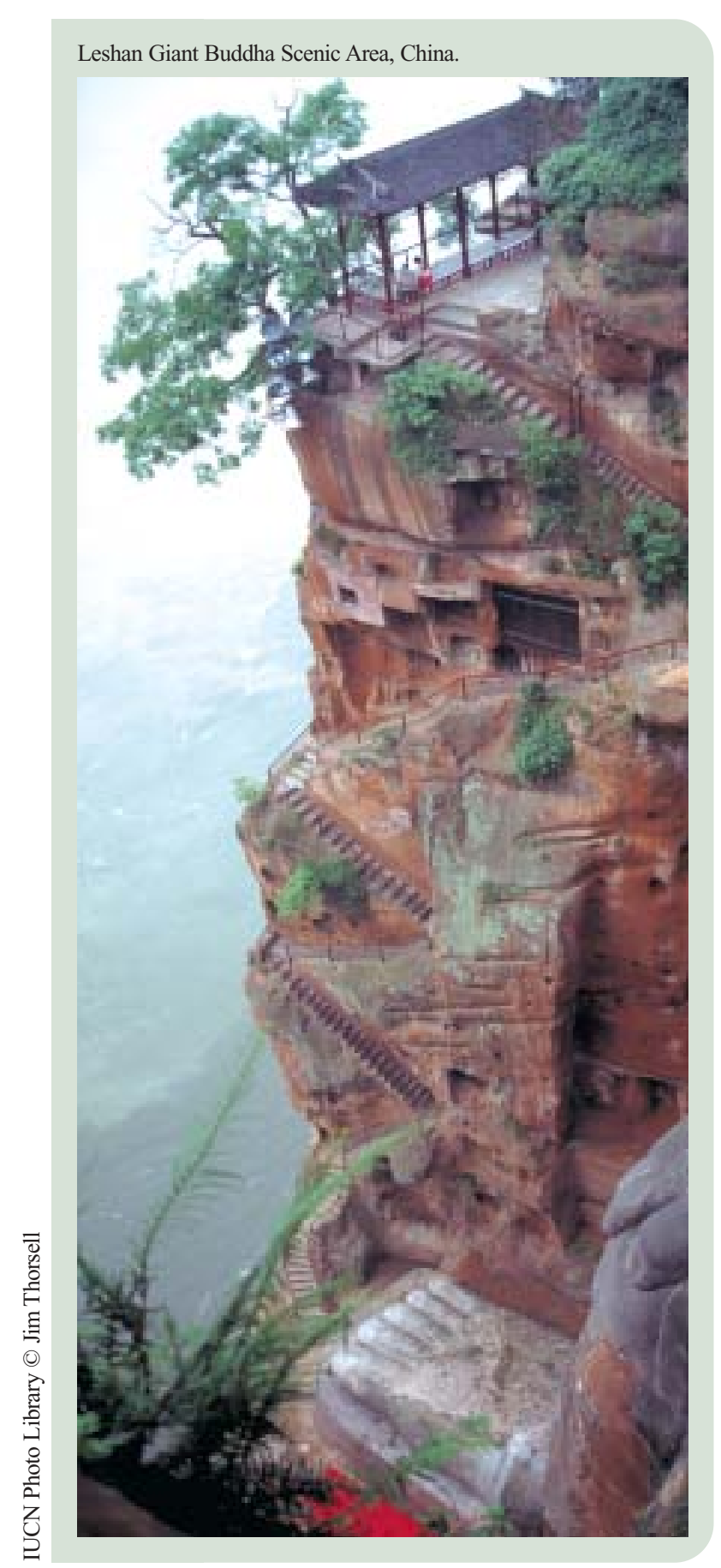

Elements for an International Programme:

1. Compilation of an international database of existing policies relating to SNS, and lessons learned in their application.

2. Synthesis and distribution of model policies based on experiences around the world.

3. Inclusion of model policies in the work programmes of major environmental conventions.

4. Promotion of resolutions at global meetings to support model policies.

5. Technical seminars at major world environmental meetings to promote model policies.

\section{Planning}

Formal planning methods have been established for most of the world's PA systems, and this is a sound entry point for the required action programmes. Of particular interest are effective I\&T peoples' participation in development of the information base, multicultural system plans, management plans for individual PAs, and detailed programme plans for individual PAs on ancestral lands seen as "intercultural spaces".

Information base. As indicated earlier, a multicultural approach to development of the information base is an extremely important starting point for management planning. At this point the perspectives, knowledge and interests of I\&T peoples can be put on the table and integrated into the scientific, geographical, contextual and situational information normally developed for management planning.

System plans. Perhaps the most important implication of a multicultural policy for PAs is the development of a multicultural system plan that includes criteria for the identification of areas that are considered of importance for protection by I\&T peoples, as well as the areas considered important from the perspective of the dominant culture. System plans also provide an opportunity to deal in a comprehensive way with the protection and management of SNS, both through the use of existing mechanisms or through the establishment of complementary mechanisms.

Multicultural Management Plans. Traditional environmental knowledge, traditional management practices evolved over thousands of years, and cultural perspectives of I\&T peoples represent the accumulation of human knowledge about specific landscapes. This information is extremely important for inclusion in the information base for management plans. The management planning process also provides I\&T peoples with the opportunity to make inputs and influence decisions on the objectives, zoning, management programmes, and budgetary and administrative arrangements for individual PAs. This is basic for the recognition, protection and management of SNS within the PA. 


\section{Elements for an International Programme:}

1. Development and distribution of case studies on multicultural approaches to PA planning that include the recognition, protection and management of SNS, and treatment of PAs on ancestral lands as "intercultural spaces".

2. Publication of addenda to the WCPA Best Practice Guidelines for system planning and for management planning of protected areas through multicultural approaches where relevant.

3. Publication of an addendum to the IUCN publication on PA categories to include guidelines and criteria with respect to the cultural and spiritual values of PAs, especially SNS.

4. Presentation of seminars at world and regional environmental meetings on the integration of SNS into PAs through multicultural approaches to planning.

\section{Implementation of management programmes}

Actions are needed to promote I\&T peoples' contributions to management programmes such as protection, resource management, and public use, which go beyond planning to include implementation, monitoring and evaluation.

Protection. Resource protection programmes will not be successful unless I\&T people in and around PAs are integrated into the management process. As a minimum I\&T peoples must understand and accept the protection programme, but the ideal is that I\&T peoples play a direct role in monitoring and enforcement. This can be particularly effective in portions of the PA that are recognised as SNS by their traditional stewards.

Resource management. Resource management programmes can be made more effective by incorporation of traditional stewards of SNS on management committees and/or by including them in implementation programmes. Often, special provision for resource management will be needed to regulate traditional uses.

Public use. Public use programmes can benefit enormously from the contributions of I\&T peoples. They can play a central role in developing culturally sensitive interpretation and education programmes that contrast I\&T peoples' and modern worldviews, and subsequent impacts on the environment. In most cases, the perspectives of I\&T cultures offer the opportunity for visitors to analyse their own attitudes to nature, and to encourage experiences of oneness. Interpretation and education programmes can also develop the notion of PAs as spaces where intercultural harmony is actively pursued.

Staffing is also important. If properly structured, participation of I\&T peoples as PA staff provides an opportunity for daily contact between I\&T staff, nonI\&T staff and the visiting public, and the development of mutual understanding and respect.

\section{Elements for an International Programme:}

1. Development and distribution guidelines, and an accompanying video, on the integration of I\&T peoples into the implementation of PA management programmes around the world, especially in relation to SNS.

2. Utilization of park-to-park exchange programmes to facilitate the sharing of experiences related to the integration of I\&T peoples into management programmes, especially in relation to SNS.

3. Compilation and distribution of model interpretation and education programmes that integrate cultural and spiritual values and seek to promote harmony between cultures, and harmony with nature.

\section{Capacity building}

Actions are needed to build capacities at the international, national and individual PA levels so that I\&T peoples can effectively contribute to PA management, especially as related to SNS. Capacity building will be a particularly important component for the development of multicultural system plans and bi-cultural management plans, as well as for the integration of I\&T peoples into PA agency staff positions.

Building on the example provided earlier for UluruKata Tjuta National Park in Australia, an interesting experiment in staff capacity building for that Park is worth noting. A "Kinship Project" is being carried out to evaluate whether the Aboriginal concept of kinship with the natural world can be respected by, and 
influence, the role of non-Aboriginal field staff (NSW National Parks and Wildlife Service, 2003). The central element of this evaluation has been to consider the possible effects, both positive and negative, of developing an experimental programme where Aboriginal elders and staff will work with nonAboriginal rangers in adopting aspects of the Aboriginal notion of kinship with nature as part of their work practice and identity.

\section{Elements for an International Programme:}

1. Development of course modules on multicultural approaches to PA management, giving prominent attention to SNSs.

2. Staging of mini-courses on multicultural approaches to PA management at international and regional environmental meetings attended by PA staff.

\section{Technical and financial assistance}

In many cases, countries interested in adopting and implementing the model policies and consequent actions may require technical and financial assistance. This assistance might be provided by the advocate agencies, especially if model policies and associated lessons learned are available, and a core of qualified consultants are identified and listings made available to, and promoted with, the advocate agencies.

\section{Elements for an International Programme:}

1. Development and funding of an international project on multicultural approaches to PA planning and management with pilot projects in the major regions of the world. A central component of the project would be an emphasis from the start on tracking lessons learned, developing case studies, and the use of video as a tool for sharing experiences.

2. Establishment of an international SNS Emergency fund to provide technical and financial assistance for SNS in danger.

3. Building of a database of PA practitioners with experience in multicultural approaches to PAs and the management of SNS. Dissemination of information regarding the database to potentially interested institutions and agencies.

\section{Conclusion}

Building broader support for protected areas through sacred natural sites is an approach to biodiversity conservation that is finally receiving increasing attention. It is an approach fraught with difficulty because of the legacy of conflict between I\&T peoples and PAs established on ancestral lands, and the general lack of recognition of, and respect for, SNS. Yet in many traditional societies, SNS have functioned as a community instrument for biodiversity conservation that has many commonalities with western society's PA approach.

The recognition and management of SNS is part of a wider need for policies and programmes to recognise and respect the rights of I\&T peoples and to adopt and implement a multicultural approach to PAs that would specifically address the formal recognition of and management of SNS. This would include both those within established PAs, and those that are currently outside of PA systems. It is a challenge faced in varying degrees by many countries around the world. If approached in an honest and forthright manner, and if accompanied by good will and perseverance, SNS could indeed play a significant role in catalysing broader cultural support for PAs. 


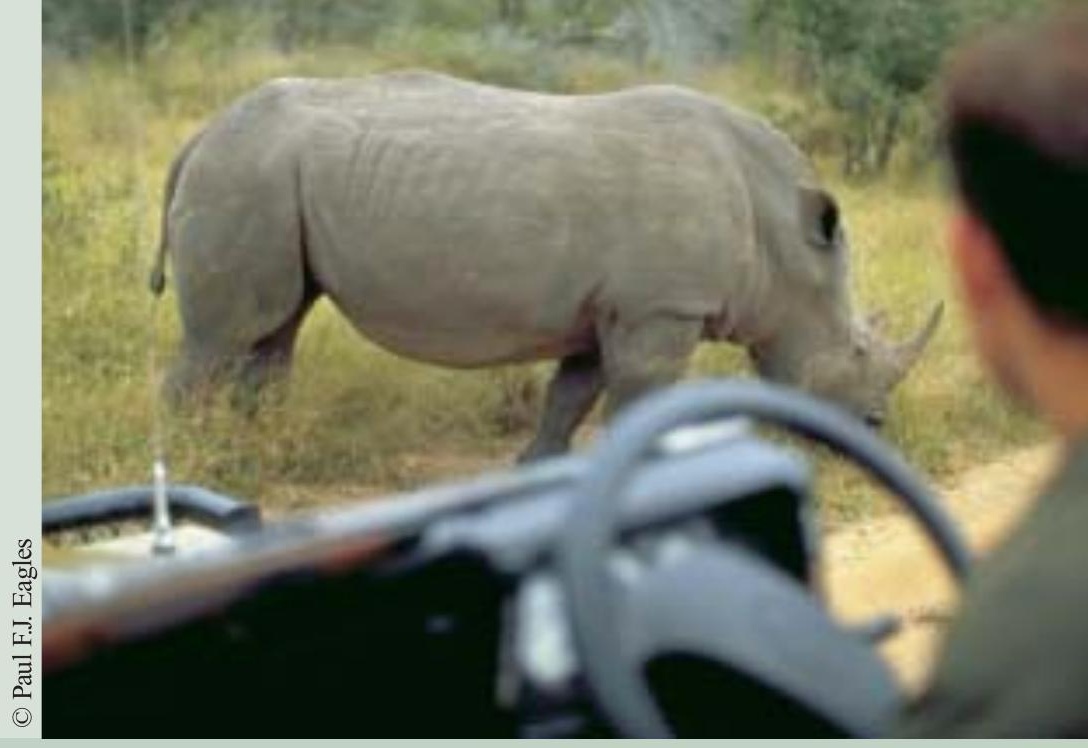

\section{Building support for protected areas through tourism}

\section{by Robyn Bushell}

\section{Editor's introduction}

Tourism has been a key partner of modern protected areas from the very early days, but the recent rapid expansion of both tourism and protected areas calls for a reassessment of the relationship between protected areas and tourism. Robyn Bushell reviews the major issues that need to be involved in developing and maintaining a productive relationship between protected areas and the tourism industry. Drawing on the work of the WCPA Task Force on Tourism and Protected Areas, this chapter highlights the many benefits of tourism for protected areas, including economic benefits, opportunities for communities to acquire land for community conserved areas, greater appreciation of cultural and natural heritage, and increased interest, understanding and commitment from the general public to the improved management of protected areas. But tourism also carries some dangers if it is poorly planned and managed, leading to undermining the very attractions that led to the establishment of the protected area. This chapter also includes numerous examples of private tourism operations that are either adjacent to protected areas and contribute to protected area objectives, or are well separated from protected areas but still make significant contributions to conserving biodiversity. The impact of tourism is certainly going to continue to expand, and mobilizing the tourism sector to help ensure the sustainability of protected areas as prime tourism destinations would seem a useful part of any overall strategy to maintain public support for nature. 


\section{Introduction}

Tourism is an increasingly important feature of protected area management, an opportunity for new conservation partnerships and a potential source of financing. It can also increase pressure on protected areas due to rapidly escalating interest in visitation and nature-based tourism. Tourism and visitation to protected areas is thus an important area that will gain prominence in conservation planning and management.

The relationship between tourism and natural heritage has become more prominent over the past decade. The industry, government agencies, academia and NGOs involved in research, policy and development have all embraced the concept of sustainable tourism due to the heightened awareness brought about by the 1992 Earth Summit. Strategies stressing the urgent need for policies and practices that ensure tourism is developed in line with principles of sustainable development have been recommended by a wide range of international organizations including the World Tourism Organization (WTO), the United Nations Environment Programme (UNEP), UNESCO, the United Nations Commission on Sustainable Development (CSD), regional UN commissions, and the international banks. In 2002 the International Year of Ecotourism brought together the largest gathering of stakeholders involved in or affected by ecotourism, and focussed much attention and interest on the ecological, social and cultural costs and benefits of tourism (UNEP and WTO, 2002). This same year the World Summit on Sustainable Development (WSSD) also focussed some of its attention on tourism and its potential to support the UN Millennium Development Goals.

Despite this progress and recognition of tourism impacts, the WTO sees the road to achieving the goals of sustainable tourism much longer than it was a decade ago, due to the unstoppable growth of tourism around the world, and the more liberal attitudes that most governments and peoples have adopted towards its development (Yunis, 2003). According to WTO statistics the number of international tourist arrivals reached nearly 700 million in 2000 , well over $10 \%$ of the world population. This represents a growth of $7.4 \%$ since 1999 . This is a much higher rate than expected and twice the $3.8 \%$ rate of $1998 / 99$. As demand for tourism, both international and domestic, continues to grow, particularly from the rapidly rising middle class of the Asian region, so too is commercial interest in the development of the most ecologically fragile, diverse, and aesthetically, culturally and spiritually rich locations. These natural and cultural heritage conservation hotspots are the drawcards for much tourism development both within and outside protected areas. The challenges and the opportunities this represents have never been so great. It will require the concerted and collaborative efforts of all interested parties to combine expertise, knowledge, resources and influence to ensure that this continued growth trajectory is managed within the guidelines of sound policy frameworks. Protecting the environment from the impacts of tourism will require proactive participation of tourism bodies and operators.

During the past decade, nature-based and adventure travel has emerged as one of the fastest growing segments of this vast industry. It is not all ecotourism nor sustainable tourism, though these labels are frequently used as marketing tools. From cruise ships plying the unspoiled waters and islands of the Indian Ocean, home to some of the rarest plants and animals on Earth, to Antarctic adventures and groups trekking the cloud rainforests of Costa Rica, increasing numbers of intrepid travellers are seeking out nature and indigenous people in remote places (Mittermeier, 2003).

Conservation International (CI) reports that biodiversity-rich places once covered more than $12 \%$ of the Earth's land surface. Nearly $90 \%$ of the original vegetation of these places has been lost with a mere $1.4 \%$ of these unique terrestrial environments remaining. Yet they are habitat for more than $44 \%$ of all plants and $35 \%$ of endemic species of mammals, birds, reptiles and amphibians found nowhere else. These same areas are home to more than one billion people, many of whom live in extreme poverty. These places are a crossroads where biodiversity conservation, survival of many indigenous groups and tourism meets (Mittermeier, 2003). Christ et al. (2003) show how tourism development in such areas has profound consequences to the future of biodiversity conservation and to the health and well- 


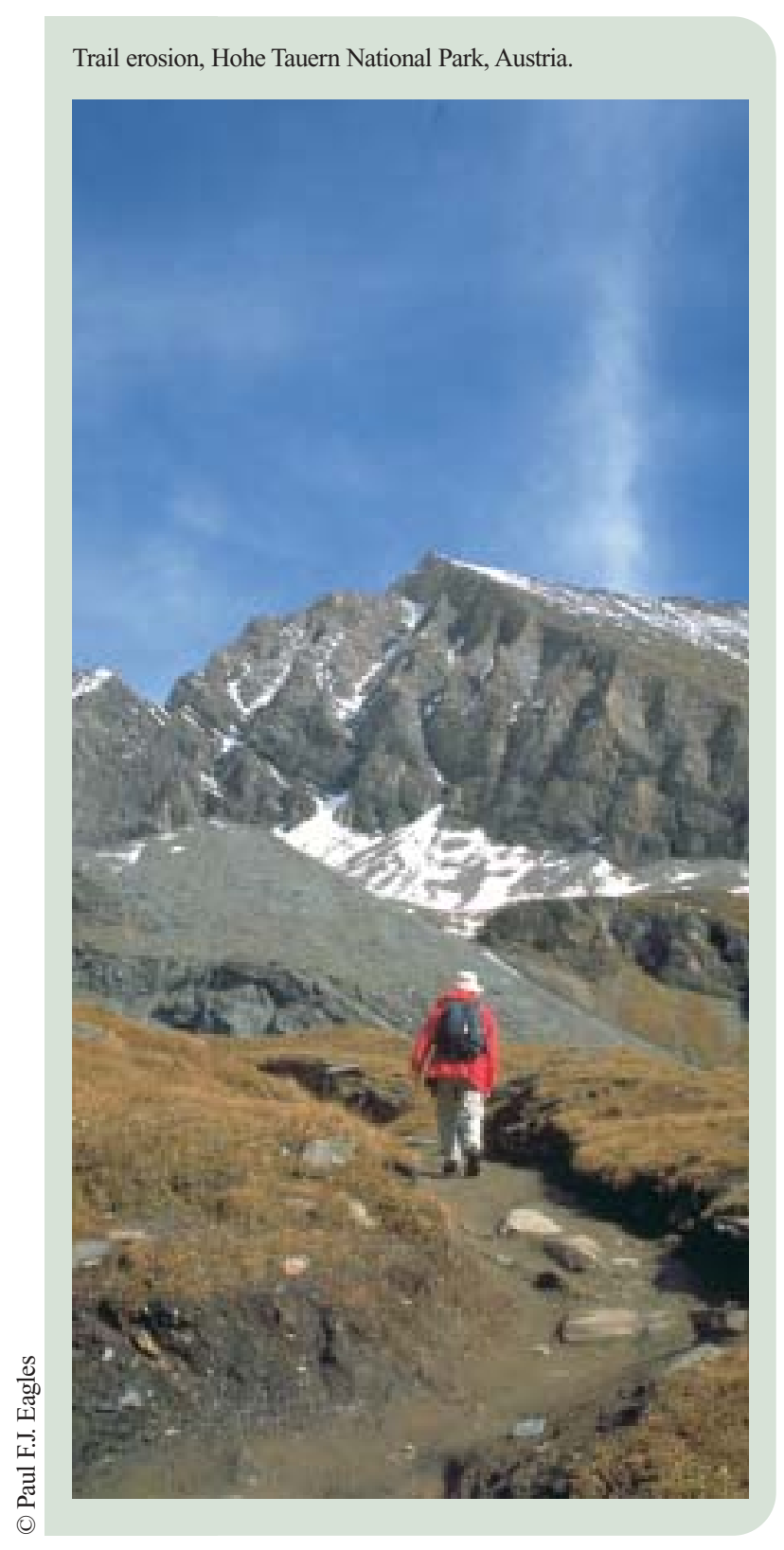

being of these local people. Biodiversity and human welfare are inextricably linked, not just for the people living in these biodiversity hotspots, but globally.

WSSD identified biodiversity conservation as one of the five priority areas. As tourism is one of the fastest growing sectors of the global economy, it is imperative it be strategically aligned with conservation. A number of highly ethical tourism operations lead the way and demonstrate that it is possible that tourism in partnership with conservation can work to benefit the health and well-being of local people at the same time as achieving conservation objectives and economic growth. The benefits are not confined to wealth creation alone. The protection and conservation of non-material values important to quality of life are essential if these people are to be given hope, and if they and their governments are to be expected to support both tourism and conservation (Putney, this volume).

The relevance of tourism to the role of IUCN and to the concept of 'benefits beyond boundaries' is in working together with key stakeholders to build support for conservation and ensure tourism policy and practice results in:

a) the protection of nature conservation areas from being loved to death by visitors or exploited by industry, as feared by many conservationists;

b) the potential of tourism being harnessed to help finance conservation;

c) support for local communities through nature based tourism; and

d) visitor services and interpretation strategies that foster a greater level of understanding of the many values of protected areas and wider support for conservation.

These objectives are best achieved through high level negotiation between key conservation and tourism bodies, together with on-the-ground partnerships between natural resource managers, local communities and tourism operators.

\section{The interest between tourism and protected areas}

One of the world's fastest growing and largest industries, tourism is the epitome of the globalized world. As such the world's tourism and recreation industries can potentially be highly influential on investors, on the travelling public and on nations who look to tourism for economic growth. It can also provide significant benefits to conservation and society. These can include: economic benefits; opportunities for communities to acquire land for community conserved areas; greater appreciation of cultural and natural heritage; greater knowledge of the interplay between humans and their environment; and increased interest, understanding and commitment from the general public to the conservation of places of significant natural and cultural value. Well planned and executed tourism can contribute to increased tolerance and respect for diversity of all sorts - 


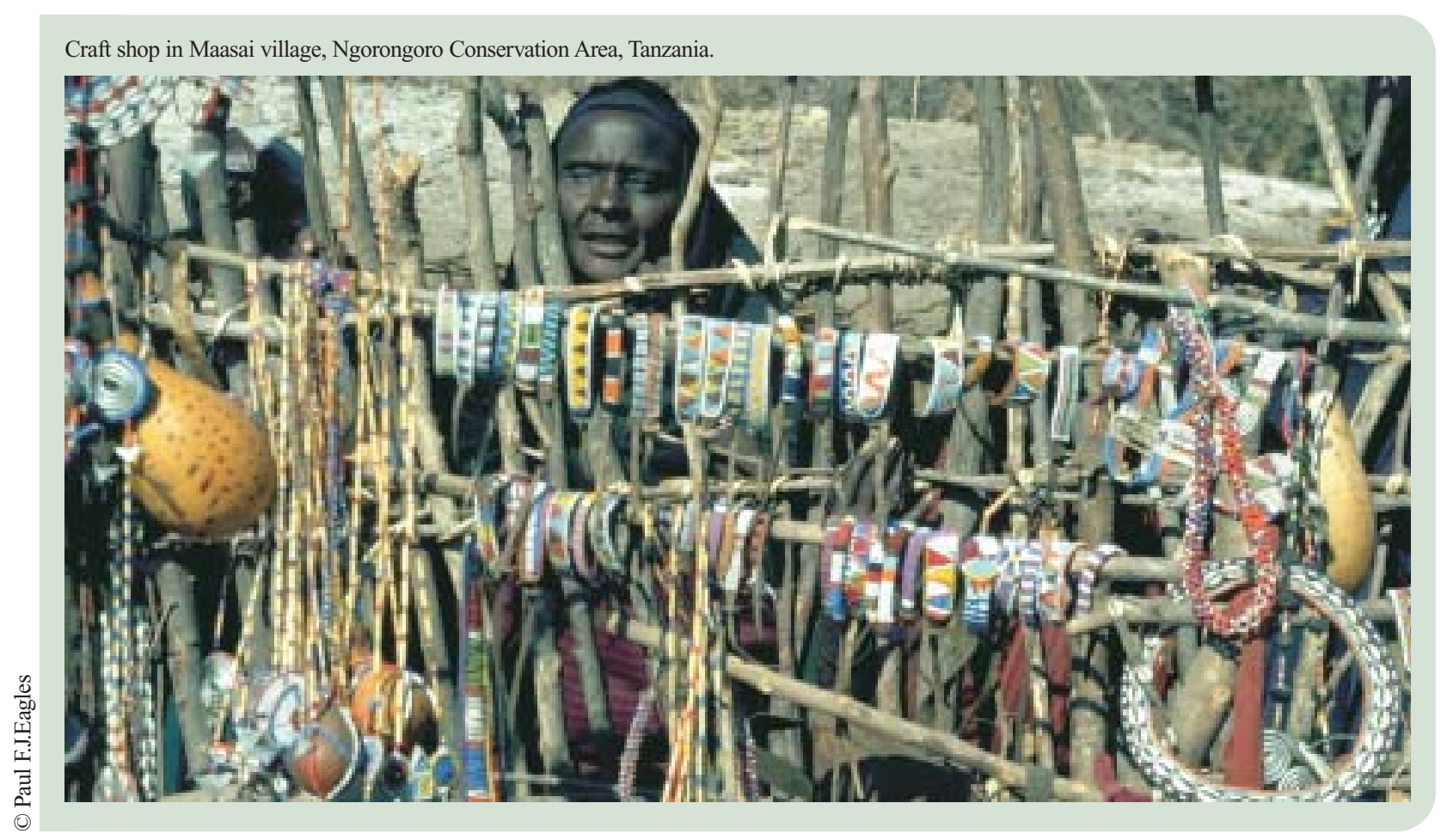

biological, cultural, religious and political - and provide incentives to support indigenous people's traditional customs and values; protect and respect sacred sites; and enhance the legitimacy of traditional knowledge. The tourism industry is therefore a critical component in fostering global support for heritage conservation, poverty alleviation and community well-being.

On the other hand, if poorly planned and managed, the ecological, social and cultural consequences of tourism can be considerable. Tourism development that does not aspire to the goals of sustainable development can contribute to the deterioration of cultural landscapes, threaten biodiversity, contribute to pollution and degradation of ecosystems, displace agricultural land and open spaces, diminish water and energy resources, and drive poverty deeper into local communities.

\section{Providing financial support for protected areas}

While national and local governments worldwide provide the base funding for protected areas, in recent times, many governments have reduced their funding support. Tourism is frequently viewed as an alternate and supplementary source of funding. Income from visitation and tourism in protected areas can be generated through donations, entrance and user fees, levies, concession fees and licences, taxes on retail purchases by visitors and increased general tax revenues from economic activity associated with tourism. Natural resource management agencies can run their own tourism operations, collecting fees for entrance, guided tours, camping, accommodation, sales in shops and cafes. They may also sell licences and permits to tour companies or contractors to provide any of these visitor services; provide longterm leases to tourism operators who develop infrastructure within protected areas, or have a range of partnerships, such as public-private transboundary conserved areas; or private funding of full-time park staff to run visitor services. The other model that is increasingly common is private reserves that use tourism to fund conservation activities on private land. Private safari parks in Africa, for example, often have a strong conservation mandate.

Unfortunately, the environmental costs of tourism development are typically externalized by operators and visitors wanting access to the resource, and often place unreasonable expectations on park agencies or are unaware of the primacy and high cost of conservation in these places and complain when asked to make modest financial contributions.

The need for external funding creates pressure for higher visitation and the granting of more concessions and licences. This demand raises a number of issues, 
including impact on protected area values from the increased visitation with negative consequences for biodiversity protection, cultural heritage and the visitor experience. The challenge is to derive economic benefit without unacceptable degradation of other values. The impetus to achieve this is considerable because the economic benefits of parkbased tourism can far exceed government expenditures to manage these sites (Driml and Common, 1995; Taskforce on Economic Benefits, 1998).

Many people are concerned that the more protected area managers rely on visitation-based funding, the more likely compromises will favour development and visitor activities rather than conservation priorities (Figgis, 1999). Setting appropriate and equitable fees is a complex task and fraught with contentious politics reflecting conflicting ideologies about protected areas. Park managers require greater training in visitor service management and ecotourism in order to maximize the benefits.

\section{Supporting sustainable use of natural and cultural heritage}

While revenue generated from touristic activities may be helpful in funding conservation, tourism development and activity may threaten the values for which protected areas are established.

The major causes of environmental impacts due to visitors in national parks vary according to the features of the site (soils, topography, aspect and vegetation), prevailing conditions (for example, temperature and precipitation), plus the specific behaviours in which visitors engage (Leung et al., 2001; Leung and Marion, 2000). Buckley and Pannell (1990) broadly summarise the types of impacts, suggesting systematic approaches to address the numerous, complex issues associated with visitor management (Gilligan and Allen, 2001). It is important to ensure the visitors have a good experience and develop a commitment to protecting nature - both in the park and in their own environments. This requires adequate and appropriate infrastructure, zoning, staffing, codes of conduct and good environmental interpretation.

\section{Linking practice to conventions and guidelines}

The growing demand for tourism in protected areas frequently challenges the capacity of management to meet this demand without unacceptably affecting the values for which protected areas exist. Protected area managers encounter difficulties when seeking to integrate the demands of conservation and visitors. Increasing visitation is a global phenomenon, and these challenges will increase, as worldwide, parks become major attractions for visitors (Worboys et al., 2001).

This requires expanding the knowledge of managers into visitor management; educating visitors and up-skilling the private tourism sector to better understand conservation priorities. In the short term, guideline documents such as minimum impact principles and codes of ethics are designed to reduce problems, though the relative success of these is questionable to date. Public access and private sector use of public lands, nature reserves and national parks is often uncontrolled and unmanaged due to lack of funds. The use of accreditation and on-site training schemes can help limit access to only appropriately qualified or well intentioned operators.

State tourism authorities and protected area agencies should collaborate on the development of nature-based tourism strategies. This can assist tourism businesses to translate national and international guidelines on biodiversity conservation into the local context and appropriate frameworks.

Meyer and Garbe (2001) and Foxlee (2003) reviewed existing charters, declarations and guidelines for sustainable tourism noting the emphasis on developing partnerships, minimal impact management, raising awareness, and the need for integrated and strategic tourism planning and management. Documents such as the Quebec Declaration on Ecotourism (2002) also acknowledge the need to share the task of conservation among all stakeholders. Conservation objectives are not the sole responsibility of protected area managers; tourism operations, visitors and the general public have equal responsibilities. 


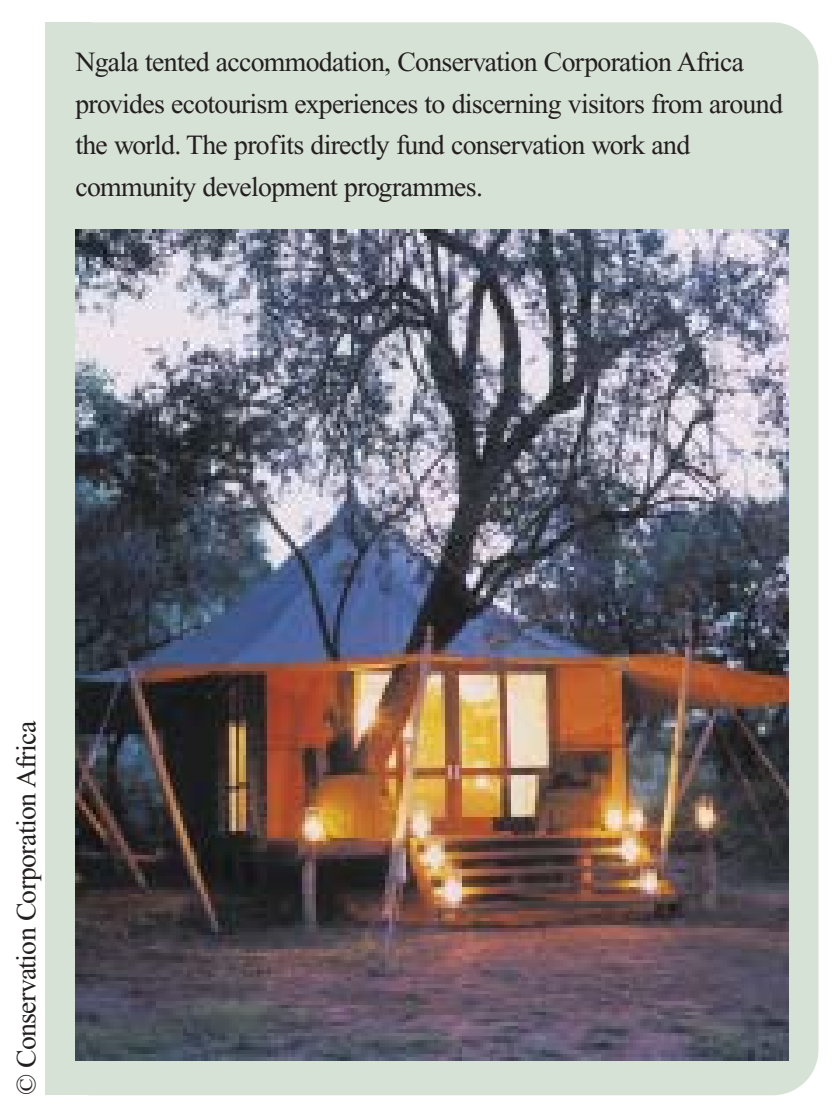

\section{Fostering attachment to heritage through visitation and effective conservation education}

Due to rapid urbanization, many citizens have little connection with nature. Consequently they are less aware of the benefits of natural areas, and may be less likely to support conservation (Tryzna, this volume).

Visitation to protected areas is valuable, not just in an economic sense, but also to take people back to nature, and to foster environmental awareness and a conservation ethic. The benefits associated with visitation to protected areas can be significant, ensuring more people enjoy and value nature.

Greater research is needed into the role and effectiveness of conservation education/interpretation, and the multicultural dimensions of these strategies. Comprehensive information on visitors (visitation numbers, source markets, demographic profile of visitors, patterns of visitation, motivation for visiting) is lacking for many protected areas. Little effort has gone into understanding the different ways people construct and relate to nature, and how this understanding should inform approaches to environmental education programmes (Staiff et al.,
2002) that are engaging and effective for visitors of different ethnicity, ages, interests and levels of literacy. An effective conservation message changes attitudes and behaviour. Considerable effort has gone into modes of delivery and communication techniques, including ecotour-guide training programmes and accreditation schemes, such as the Savannah Guides programme in Australia. Much less attention has been given to content of the message and how it translates into actions.

Tourism can be a powerful vehicle for conservation messages through guides, story telling, brochures, displays, souvenirs including books, games, products and performances, that all extend well 'beyond the boundaries' and can actively build support for conservation.

\section{Encouraging a stewardship ethic among the public}

Residents often hold large amounts of knowledge about their local area. Protected areas often hold spiritual or cultural significance to locals and visitors. Managers can exploit these interests through visitor programmes that develop sensitivities to the conservation mission of the area, and through management actions that acknowledge local interests and encourage involvement from all age groups in conservation initiatives, such as volunteers, guides and through environmentally aware actions at home.

\section{Working with local stakeholders and industry}

As the shortcomings of government policies and funding for protected area conservation become more apparent, increased support from non-government sources such as local communities, private landowners, landusers and NGOs become more important (McNeely, 1994). The tourism industry is included among these important stakeholders. Tourism in and around protected areas should lead to economic benefits to the local community such that they have incentives to support conservation and tourism. Other non-material values relating to aesthetics, recreation and health aspects of protected areas should not be underestimated in their influence on community attitudes (Putney, this volume). 


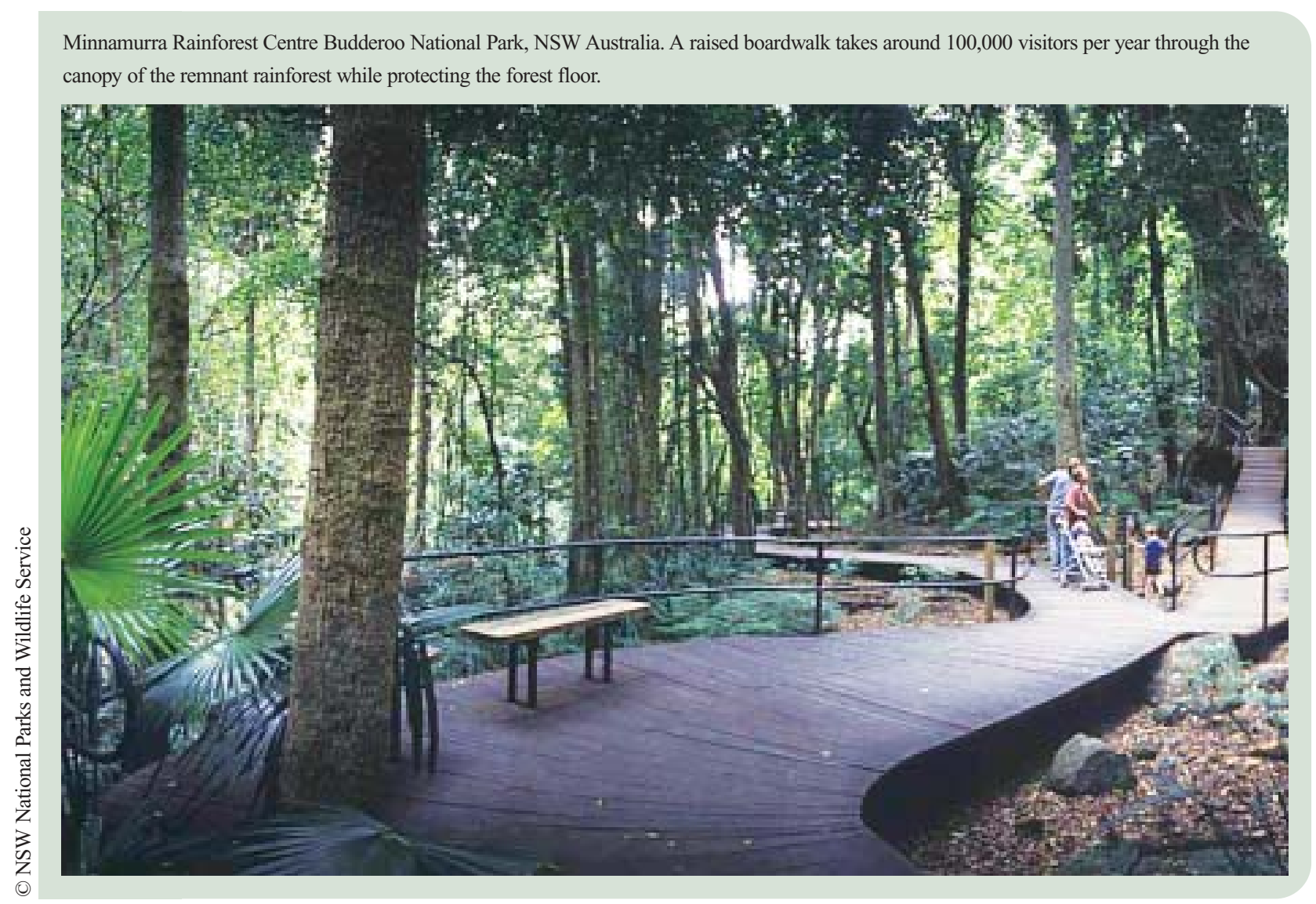

\section{Working to support local and indigenous community development, poverty alleviation, and co-management of protected areas}

The rights of indigenous peoples to access protected areas and the values they contain are complex, and at times, controversial (Scherl, this volume). Issues of traditional use of biological resources, land rights, and ownership, particularly for colonized peoples who have been dislocated, dominate much of the policy discourse in this arena.

The issues of indigenous people are often oversimplified and romanticized. The debates over appropriate use of protected areas and models of management have been linked to efforts to restore and address the land rights of indigenous peoples. A range of cultural and ethical issues surround the identification, evaluation and management of cultural landscapes, particularly those associated with the history of indigenous people and the associated issues of territory, dislocation, secret knowledge, lost language, and sacredness. Co-management of protected areas and the use of locally managed tourism to generate income for both the local community and the conservation work has been successful in a number of countries.

Protected area-based tourism is not without problems for traditional owners, especially if they are excluded or displaced. For example, Machu Picchu, a World Heritage Site, has outstanding cultural and agrarian values as a 500 year old Inca city. It is one of the most important tourist destinations in Latin America. For the poor people of this land, it is sacred, yet the system which declared it 'protected', removed them and then encouraged hundreds of thousands of visitors, generating vast income while the asset was degraded, both spiritually and ecologically, and they experienced loss of basic necessities of food and water (Andrade, 2000).

\section{Contributing to civil society, engendering respect for others and for our natural and cultural heritage}

The construction of nature varies in time across cultural, political and social beliefs and economic status. This influences the values placed on nature and what is regarded as priority for protection and what is acceptable use (Bushell, 1999; Staiff et al., 2002). 
Appreciating how different groups of people value nature is essential to making decisions about appropriate park-based tourism and visitor management.

Visitor use must be compatible with the overriding mission of a protected area. It occurs within a dynamic social, cultural, legal, institutional and geographic context. Compatibility among users is important to the financial success and effective management of a protected area. Incompatible user groups can lead to conflict, loss of support and wasted investment (FPATF, 2000). Overuse and misuse can lead to destruction of the asset. Tourism, recreation and visitation to protected areas must be designed to respect the ecological and social carrying capacity of any site, and with respect for the rights of others especially local people.

\section{How tourism contributes to protected areas}

\section{Providing financial support for protected areas}

An exemplar of private sector contribution is SabiSabi Private Game Reserve situated in the Mpumalanga province of South Africa, bordering the Kruger National Park. It is a 5000ha property that has been operating for 25 years. It has three separate lodges with a total of 46 luxury units, based on a model of high yield, low volume tourism.

SabiSabi espouses a philosophy that the only way for conservation to survive in Africa is by justifying itself economically. It epitomises the link between tourism, conservation and community, each supporting the other. The conservation is the tourism product, and the tourism provides the funds for the conservation work on the property. Together they support the local community. Through employment of 190 locals they provide economic benefit to over 1200 people.

SabiSabi is one of four properties in South Africa to receive the IUCN South Africa Fair Trade in Tourism South Africa trademark. It has earned this through working conditions, employment principles and conservation outcomes (Shorten, Harper and Loon, 2003).
A second example demonstrates how user fees and levies on the private sector help finance public conserved areas. The Great Barrier Reef Marine Park Authority (GBRMPA) requires commercial tour operators to pay an Environmental Management Charge (EMC). For most types of operations in 2002/2003 this was $\$ A 4.50$ per day for each tourist carried. The total income generated was \$A6.7 million, approximately $20 \%$ of the entire budget of the GBRMPA. The EMC is also applied to mariculture, vessel chartering, vending operations and sewage discharge, though insignificant in comparison $(0.3 \%$ of the budget). Other charges apply to the tourism industry, including permit application assessment fees. The EMC is a highly successful and equitable component of financing the GBRMP (Skeat and Skeat, 2003).

\section{Supporting sustainable use of natural and cultural heritage}

Conservation Corporation Africa (CC Africa) demonstrates private sector tourism supporting conservation and impoverished neighbouring communities. They integrate the needs of local people with their overall conservation and development objectives through very successful high yield tourism. This approach for the past 13 years has resulted in the development of 36 luxury camps and lodges in six African countries. Informed by their guiding principles of 'Care of the Land, Care of the Wildlife, Care of the People,' CC Africa's conservation model attracts discerning global travellers whose leisure expenditure funds the development of conservation, land-restoration and community empowerment.

Examples of the benefits to the natural environment include funding the conservation of 340,000ha of African wildlife land. CC Africa currently spends \$US3m annually directly on conservation, community empowerment, and national park gate fees and wilderness traversing rights. Their contribution towards the future prosperity and conservation of Africa through alliances and joint ventures is incalculable. At several of their properties they have transformed former hunting grounds employing a few people into sustainable ecotourism models providing employment for hundreds of people. 
On each property the benefits to wildlife conservation are significant, for example at Phinda, adjoining the St Lucia Wetlands, CC Africa pioneered the translocation of family herds of elephants. They also pioneered lion reintroduction. Twelve lions were initially introduced; currently 17 lions occupy the property and 45 have been relocated to approved reserves. Phinda was pivotal in restocking reserves with tuberculosis-free buffalo, providing the only TB quarantine facility in KwaZulu-Natal province. It is one of the most successful free-roaming cheetah-breeding reserves in the world. Less than 30 cheetah existed in the province's parks prior to Phinda. Fifteen cheetah were reintroduced; currently 18 are in residence, and 45 have been relocated. The initial reintroduction of 26 endangered white rhinos has grown to a current population of 60 .

In 1992 they established the Rural Investment Fund (RIF), now called Africa Foundation, as an independent not-for-profit rural development organization. The Foundation channels financial contributions received from guests and the corporate sector into education, health, water provision and other projects. The Foundation has committed approximately \$US 4 million to consultative community development projects in five African countries. This includes building more than 65 classrooms and 18 pre-schools, training 250 teachers and 4500 pupils in environmental awareness through conservation lessons; awarding university level scholarships to more than 150 students and building three health clinics. The Ololosokwan Clinic close to CC Africa's Klein's Camp in Tanzania now serves between 350 and 700 people a week with just one doctor in attendance. They employ more than 1300 local staff members, with some 13,000 dependants, and provide \$US 1.7 million in wages per year across Africa (Carlisle and Bagley, 2003).

\section{Linking practice to conventions and guidelines}

A major accreditation initiative for the NSW Camping and Caravan Industry Association (CCIA), Australia, uses the critical elements from a number of international guidelines on sustainable tourism including the UNEP, WTO and CBD guidelines. The Gumnut Award Programme demonstrates a commitment to continuous improvement in environmental sustainability and social responsibility. The caravan and camping sector is important in the context of outdoor tourism and recreation. It provides approximately $51 \%$ of the accommodation sector in Australia and has a growth rate of $15 \%$ per annum in visitation (Baillie, 2002). The majority of properties are situated in or near very sensitive coastal

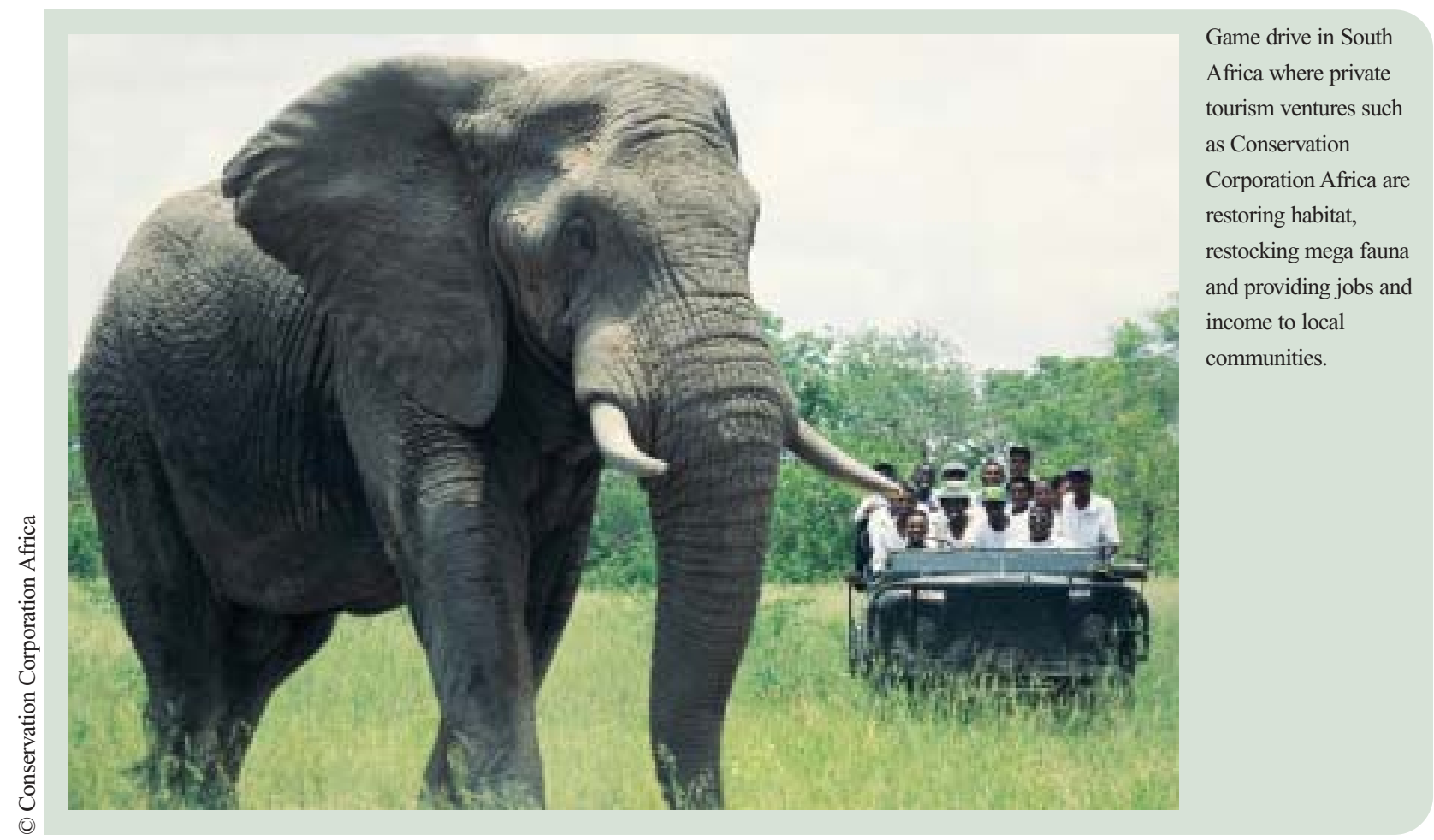


Phinda Forest Lodge: High yielding ecotourism at Conservation Corporation Africa properties throughout Africa provide world class luxury in low impact accommodation - Phinda Lodge adjoins the St Lucia World Heritage Area.

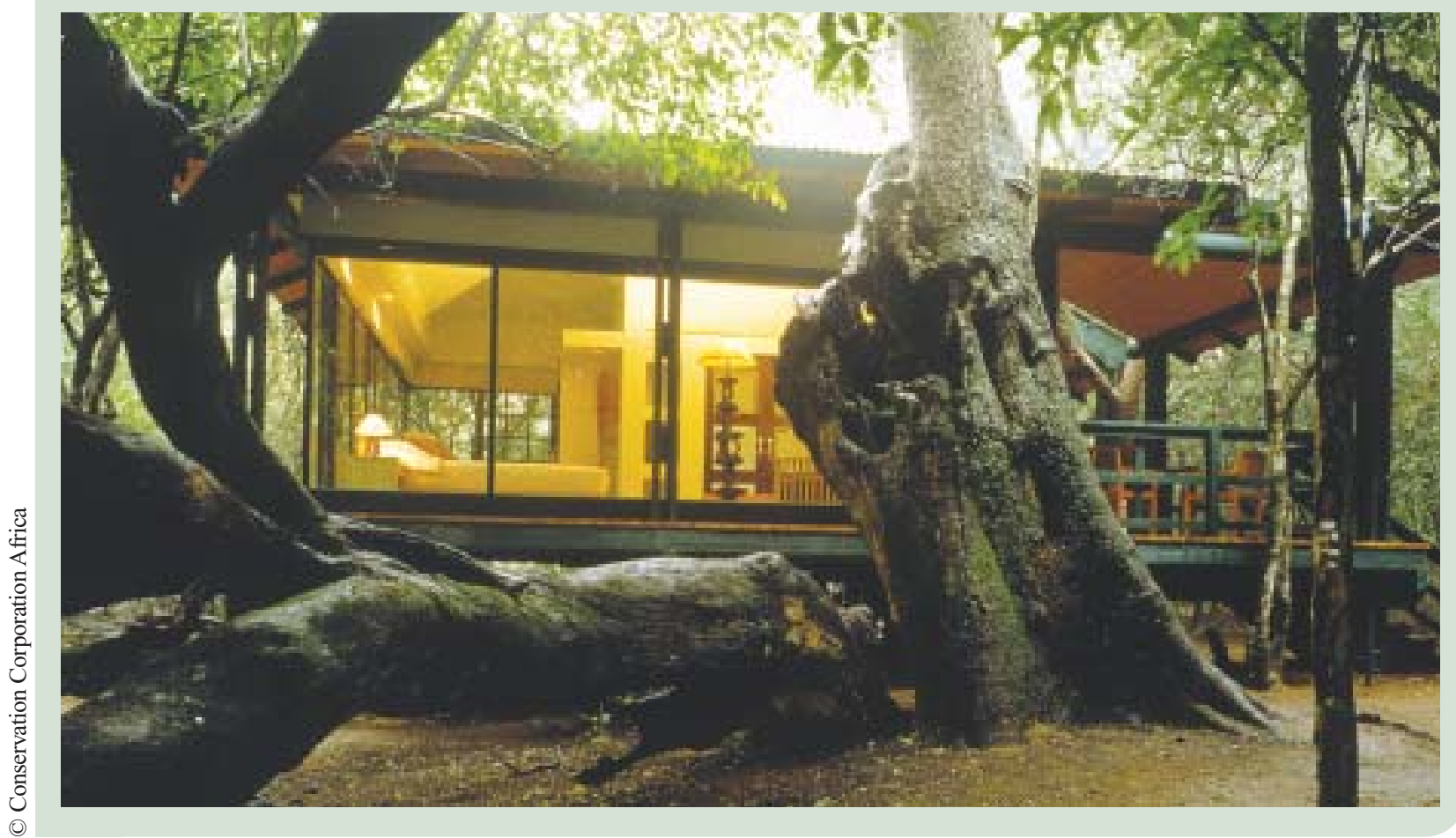

environments, with a significant number on crown land, adjoining national parks and nature reserves. CCIA recognises that these operations have significant social, cultural, ecological and economic impacts. The programme seeks to increase awareness and encourage the implementation of practices that foster responsible management and that meet the expectations of park visitors, staff and the general community. The programme is particularly distinguished by the inclusion of a training component in collaboration with the University of Western Sydney helping operators to develop their own integrated environmental management plan.

\section{Fostering attachment to heritage through visitation and effective conservation education and working with local stakeholders and industry}

The Minnamurra Rainforest, within Budderoo National Park, is a 401-hectare remnant of the onceextensive rainforests on the South Coast of NSW. The area comprises four types of rainforest and is the southern-most limit for many sub-tropical rainforest species. The site is a significant regional and state tourism facility receiving numerous state and national awards of excellence. Minnamurra is one of three rainforest education centres managed by the NSW National Parks and Wildlife Service (NPWS). It has a Visitor Information and Education Centre, 2.6km of elevated timber boardwalk and paved walking tracks that lead visitors along the gorge cliffs overlooking the rainforest canopy and onto viewing platforms at the lower and upper Minnamurra Falls. During peak visitation periods visitor numbers have reached 1200 visitors in a day. They currently receive over 20,500 primary and secondary school students on educational excursions each year.

The Minnamurra Rainforest Centre is a major component of the regional tourism product. A 1996 economic study showed the Centre contributes $\$ A 2$ to 4 million dollars per annum in business turnover to the regional economy; of this \$A 1 to 2 million in visitor expenditure in the Centre itself. Many marketing and promotional initiatives have been developed in partnership with tour operators and accommodation providers. An example of such a cooperative approach was the instigation of the 'Illawarra EduTourism Project' creating a successful co-operative of the region's major field based education, accommodation and transport providers catering for school groups. The site is also widely used as an 'icon' tourism destination in promotional campaigns by all four local 
government tourism associations in the region and Tourism NSW. Many small tour companies and accommodation providers include the Centre as a highlight to complement their individual product and marketing. Park staff work closely with the NSW Department of Education providing environmental education resources including CDs, a web site linked to the higher school certificate geography curriculum and teachers' kits for field trips (Kennedy, 2001).

They are also actively involved in environmental research with a number of universities. This has included numerous studies relating to the effectiveness of the interpretation at the site. Researchers have worked with the site manager to develop an educational mission for MRC "educating about rainforest conservation and its symbiotic relationship to cultural heritage conservation through a living experience of the forest. The fostering of an attachment to heritage is sought through the widest possible sense of experiential education..." (Staiff and Bushell, 2004). The site is seen as a keeper of stories and a story-telling place about connections to nature. These include ancient and contemporary indigenous relationships to the site, early European agriculture, including cedar logging and dairying responsible for the destruction and clearing of much of the forest, a place of romance, of family picnics and recreation in the cool forest and its scenic waterfalls, of poetry and spectacular photography, and as a place of meditation, particularly for a local Buddhist temple, and as a place of great interest to scientists, locals and tourists. The NPWS is actively engaged in this research to ensure the environmental message is more effective in enhancing visitor concern for conservation and their enjoyment of nature.

\section{Support local and indigenous community development and poverty alleviation through nature-based tourism}

Turtle Island is a 14 room five-star luxury resort located on a 200ha privately owned island (Nanuya Levu) in the Yasawas group of islands, Fiji. Purchased in 1972 by Richard Evanson, who remains as owner manager, the island was uninhabited and degraded after decades of neglect, overgrazing and clearing. Flora and fauna were depleted, soils eroded and the ecosystems, including mangroves, coral reefs and beaches, were damaged. Mr Evanson made a commitment to restore the island and help the local community. Tourism became the vehicle to achieve these goals. Turtle Island has implemented a range of innovative environmental and community-based programmes and activities to achieve these objectives. This includes planting over one million trees established from a nursery set up on the island. Vegetation cover has grown from around $10 \%$ to over $82 \%$ across the island, halting erosion and provided habitat for birds and wildlife that are again rich in diversity and number.

All solid waste is composted on the island. With no natural streams, several dams have been built to ensure abundant water supply. Some $90 \%$ of fresh fruit, vegetables and herbs are grown in the resort garden. Reforestation has provided timber for building works. Local staff have been retrained in environmental management and rehabilitation, market gardening, complex carpentry, and building, as well as work within the resort operations.

Due to the vision of the resort and the special visitor experience, philanthropic gestures are quite common. In 1992 the Yasawas Community Foundation was established to receive guest donations for special projects in the Turtle Island communities. Because the area has no secondary schools, they have been providing scholarships to assist local children to go to high school on another island. The Foundation recently committed $\$ 200,000$ to assist Turtle Island to build a secondary school. The school opened in 2002, and now has 38 students across three forms, with four teachers.

Turtle Island has been augmenting the quality of health care available through the provision of several health care resources. This includes responding to the endemic problem of blindness due to cataracts and diabetes. For the past 13 years, the resort closes for one week, and a team of medical professionals who have themselves been guests at the resort, donate their time on a pro-bono basis to set up a full eye clinic. In this time more than 11,000 Fijians have had their eyes tested, more than 9,000 pairs of glasses have been issued free of charge, over 1,000 operations have been performed (mostly cataracts, and 20 corneal implants). The clinics are now operating from Savu 
Savu. Turtle Island runs other health clinics including dermatology, women's health and dental clinics, providing specialist health services that would otherwise not be available.

Turtle Island has also provided interest-free funding under a social entrepreneurial programme, expending over \$A 1 million in the construction of three budget resorts. Turtle Island plays an active role in the governance, marketing and management of these resorts and a proactive role in skills transfer to assist local people to run these businesses. The Turtle Island private plane also services the needs of the budget resorts and the villagers, with Turtle Island guests heavily subsidising the service.

This example of privately conserved land and high yield nature-based tourism shows the mutual benefits to conservation and poverty alleviation through one small operation.

\section{How tourism can support indigenous people in the co-management of protected areas and contribute to civil society}

The concept of Aboriginal ownership and joint management of national parks in Australia has emerged as a response to increasing acknowledgement of Aboriginal rights to traditional lands and opportunities. Co-management involves the establishment of a legal partnership and management structure reflecting the rights, interests and obligations of the Aboriginal owners as well as the relevant government. In 1981, Gurig National Park northeast of Darwin, in the Northern Territory became the first co-managed park in Australia. Since then several others have emerged in the Northern Territory, Jervis Bay Territory, New South Wales and Queensland (Smyth, 2001).

The statutory Management Plan for each of these co-managed parks looks to tourism to generate significant income for the traditional owners/community and for conservation goals of the Park. Tourism is anticipated to be the key to eventual self sufficiency and provides the pathway for Park values to be communicated to the wider world.

The Australian government, through the Director of National Parks and the Department of Environment and Heritage, is the government agency responsible for the joint management of each park. The Director sits on the Board of Management of each park in conjunction with the traditional Aboriginal owners, and Ministerial appointments representing science, environment and tourism expertise plus other relevant stakeholders.

The cultural dimension is an extremely important feature of the tourism in these parks. These parks provide opportunities to care for land that is special to both the Indigenous people and others; opportunities for Indigenous people and others to work together and learn about one another, and a window on Indigenous Australian culture through park visitation.

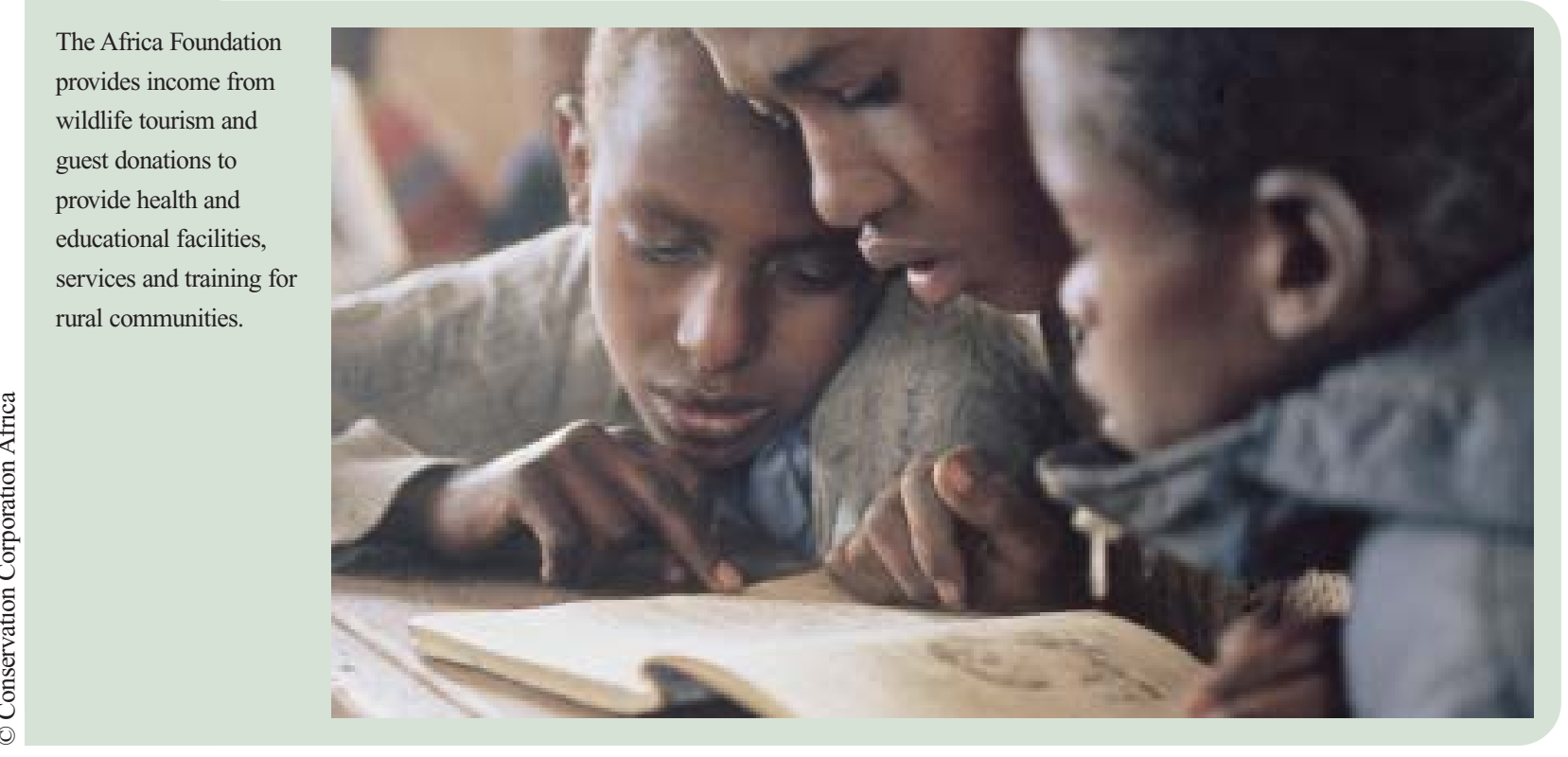


Kakadu National Park and World Heritage Area in the Northern Territory is jointly managed with the Bininj/Mungguy people. The Board of Management has 15 members, including ten elected from the region representing the different regions and language groups. Kakadu is a special cultural landscape. It was shaped by the spiritual ancestors of Aboriginal people during the Creation Time. These ancestors journeyed across the country creating landforms, plants, animals and Bininj/Mungguy (Aboriginal people). They brought with them laws to live by: ceremony, language, kinship and ecological knowledge. They taught Bininj/Mungguy how to live with the land and look after the country.

Kakadu National Park is visited by approximately 200,000 people each year, most of whom stay within the park for an average of three days. During 2003, commercial permits issued to tour operators included 575 for camping, 45 for photography and 30 for filming. There is a high level of visitor satisfaction (76\%) and plans to increase Aboriginal participation in visitor programmes, as a means of cultural heritage support, income generation for locals, increased visitor satisfaction and understanding of the Park's rich cultural history.

The Board of Management has developed an Action Plan for Cultural Heritage in conjunction with senior traditional owners. Over 5000 cultural sites have been registered and a Register of Oral History Audio and Video Material continues to be developed. This is an important aspect of the conservation work of the Park. It will be a valuable resource for the community and for interpretative material for the visitors.

The Plan of Management aims at capacity building of Bininj-Mungguy staff and support for their move into senior management positions. Almost half the staff at Kakadu National Park are local Aboriginal people.

These examples all demonstrate the success that can be achieved through partnerships between tourism and conservation, leading to effective outcomes in line with principles of sustainable and ethical development.

\section{Improving policies on tourism and protected areas}

Careful and strategic implementation of policy together with proactive and effective management of tourism is essential. For tourism to be an effective conservation tool also requires increased understanding of both its beneficial effects and its negative consequences. This requires considerable capacity building of park staff and communities if they are to ensure the desired outcomes. It also requires a much better level of understanding of park visitation patterns, numbers and trends; and much more sophisticated understanding of effective conservation awareness, education and interpretation strategies.

When used as a conservation tool, tourism is an essential component in raising awareness outside the conservation movement, and contributing to processes needed to implement the Convention on Biological Diversity, the CBD Guidelines on Sustainable Tourism in Vulnerable Ecosystems and many other Multilateral Environmental Agreements such as the Convention on Migratory Species of Wild Animals, CITES, World Heritage Convention (see Thorsell, this volume), the Ramsar Convention, along with many regional agreements. To achieve desired outcomes for conservation, local authorities, local people, the tourism industry, and visitors must all be involved and co-operate with natural resource management agencies, the scientific community, government bodies and international agencies concerned with biological and cultural heritage policy, and influence tourism planning.

One of the most notable omissions in many of the existing sustainable tourism declarations, charters and guidelines, in terms of protected areas, is that few documents make any clear reference to the conservation priorities of the authorities responsible for protected areas (Foxlee, 2003). There is a need for attitude change to see the opportunity of tourism as a tool for conservation, rather than viewing parks as a business opportunity and resource for tourism. More effective and equitable public-private partnerships involving tourism need greater guidance and shared learning on many management issues, such as policies on licensing, entry fees, concessions and permits. 


\section{Actions required in the next ten years}

To harness the potential of tourism as a tool for positive change, policy development should be driven by the international organizations with the greatest influence on national agendas and the tourism industry.

A key action arising from the Tourism Recommendation at the World Parks Congress (5.12) is strengthening the existing strategic alliances between IUCN-WCPA and key stakeholders, seeking a more sustainable partnership between tourism and protected areas. For example, the WCPA Task Force on Tourism and Protected Areas proposed to SBSTTA 9 in preparation for COP 7 in 2004 to extend the role of tourism beyond financing conservation to also include the roles of visitor education and awareness raising, capacity building, cultural heritage conservation and community empowerment.

The Task Force on Tourism and Protected Areas can continue to play a valuable role within the WCPA and with other IUCN Commissions, in particular the Commission on Education and Communication, the Species Survival Commission, the Ramsar programme and the IUCN Building Support for Protected Areas ten-year action plan.
To achieve the aims of 'Benefits Beyond Boundaries' and Building Support a number of key actions are necessary. The following are priorities:

- Seeking greater tourism industry involvement and sponsorship for conservation and Task Force initiatives;

- Development of an inventory of park tourism;

- The preparation of guidelines for park concessions, permits and licences;

- The training of current park managers in park/nature-based and ecotourism and strategic interpretation planning;

- Strategic alignment within the WCPA and other IUCN commissions on priority issues.

To further the implementation of the WPC Recommendation on Tourism, a joint application with UNESCO-WHC and WTO to the Rockefeller Foundation has been prepared to convene a meeting of UN agencies and funding bodies on 'Strategic global collaboration on tourism for heritage conservation, poverty alleviation and global wellbeing' leading to greater collaboration and sharing of knowledge, resources and joint funding of priority initiatives.

Tourism in and around protected areas must be a tool for conservation, building support and raising awareness of the many important values of protected areas including ecological, cultural, sacred, spiritual, aesthetic, recreational and economic.

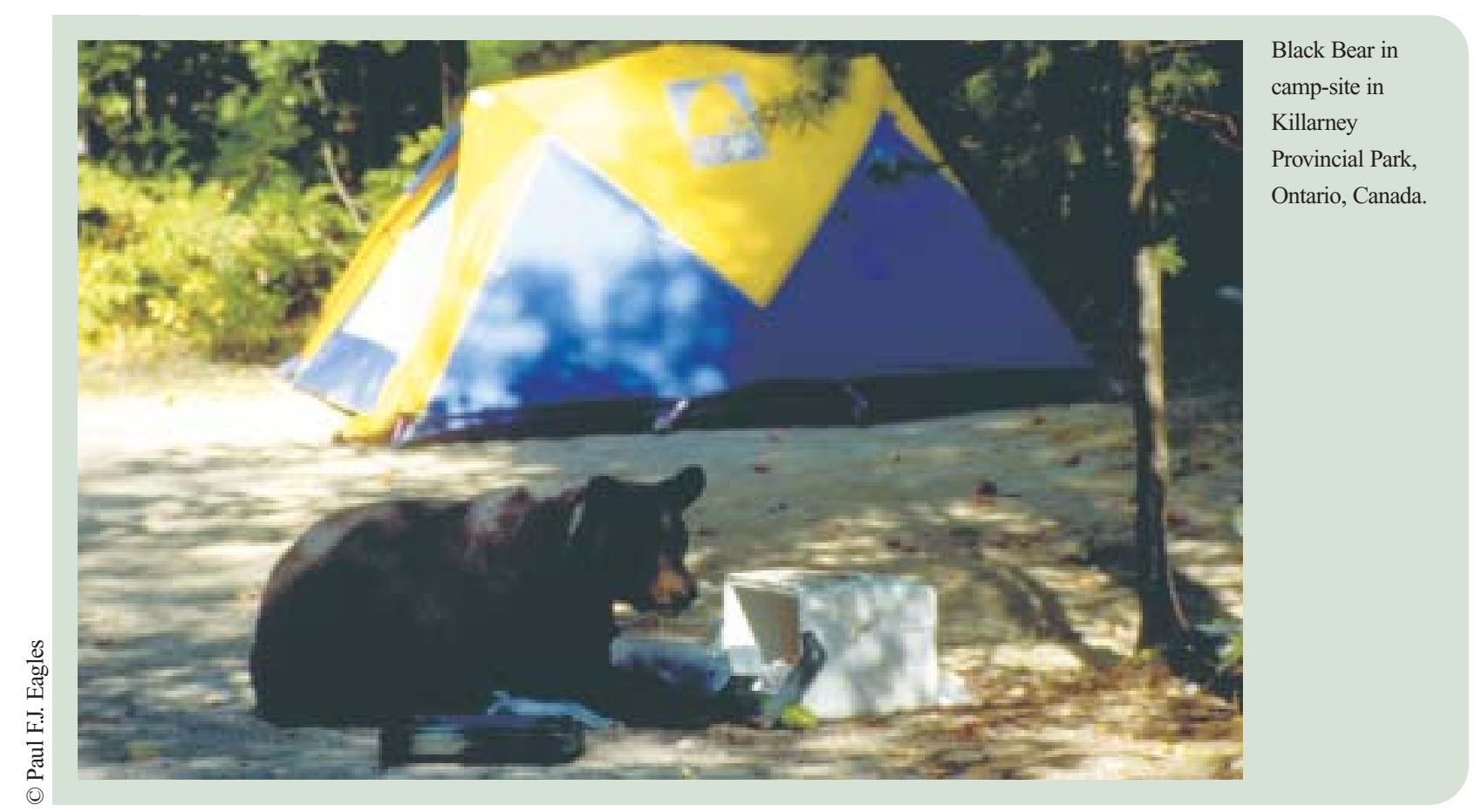




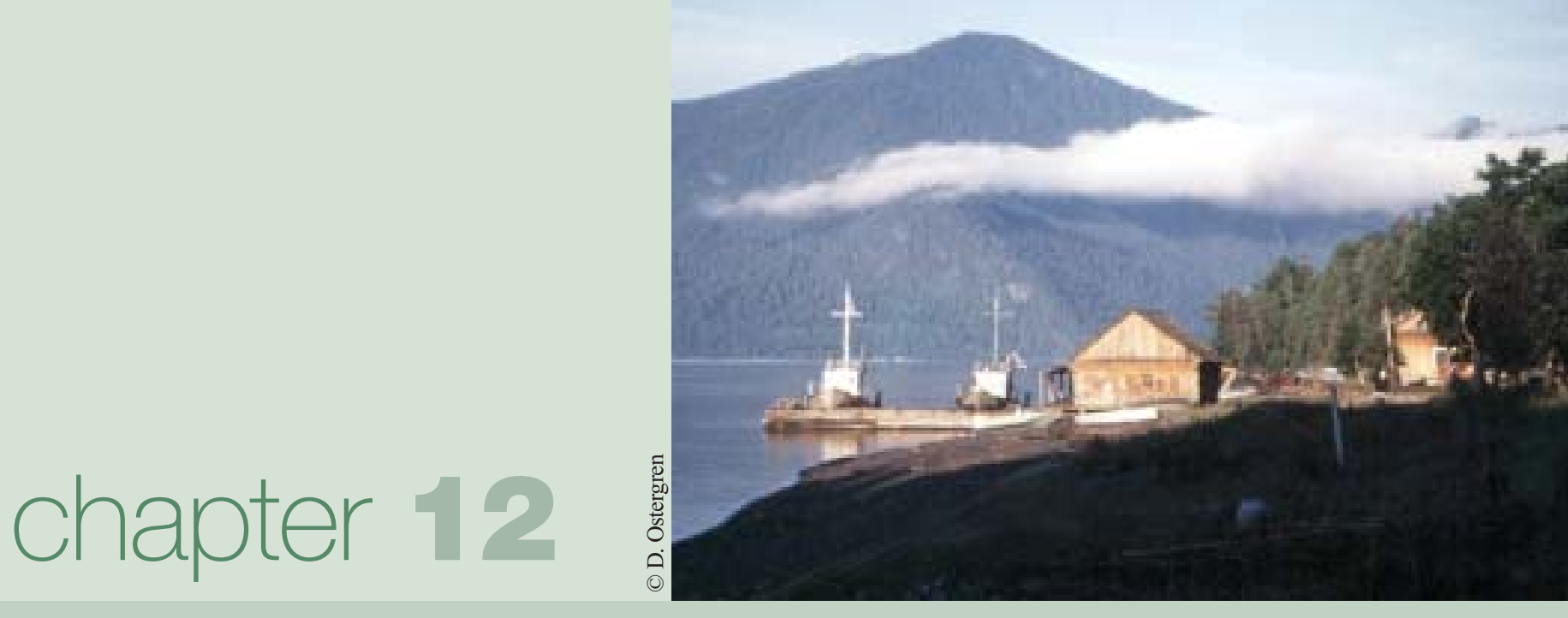

\section{Making connections: the tactics, art and science of building political support for protected natural areas}

\section{by David Ostergren}

\section{Editor's introduction}

In the context of protected areas, political support is essential to ensuring that the protected area receives the kind of support that is required. This often requires building a political constituency of supporters, broadly defined as those who have a significant interest in the effective management of the protected area. Historically, the early protected areas often were established by administrative fiat by kings or other powerful leaders, but beginning in the second half of the twentieth century, the establishment of protected areas became a much more democratic process that required more consultation with stakeholders, very much a political process. The political process, as David Ostergren points out in this chapter, also includes addressing the concerns of those who oppose the protected area, possibly over concerns about the possible negative impact on their own welfare. An essential element for those seeking to build political support for protected areas is a thorough understanding of the values that are delivered through managing the site in a particular way. This will enable the advocate to build a personal relationship with those who need to be a committed part of the constituency. While many will argue that all politics is local, international support can also play an important role in legitimizing the local interests, for example through listing under the World Heritage Convention. International agreements between governments, such as the Convention on Biological Diversity, the World Heritage Convention and the Ramsar Convention, offer the highest level of political support for protected areas, and help to guide international funding in support of protected areas in developing countries. At the national level, political support can start at the top, with a sympathetic government leader, as in Madagascar or Costa Rica. In other cases, national support can build on a broader grass roots movement, as in Brazil. The challenge is to ensure that political leaders are in fact able to earn the support of the voters for the policies they are advocating, and this in turn typically involves delivering benefits to the affected constituents. At the local level, indigenous and local peoples increasingly are being enlisted as partners in establishing protected areas, and in some cases are even given ownership of the site (as in some parts of Australia). Effective political support requires a combination of local, national and international measures, but the foundation is making a connection with the politicians and enabling them to provide benefits to their constituents through the establishment and effective management of protected areas. 


\section{Introduction}

Political support for protected natural areas is tightly interwoven with the larger economic and sociopolitical forces of any society. The strategies employed by individuals and organizations who support protected areas reflect their own political talents and resourcefulness as well as the larger context of a nation's culture and political character. This chapter investigates some of those strategies to build political support for protected areas, based on case studies. Though the most influential variable appears to be the national context, the case studies themselves are organized on the international, regional, national and local scales. The strategies presented here are but a small sample of the many tremendous efforts throughout the world. The consistent theme throughout is that building political support depends upon making connections - connections between institutions, nations, organizations, communities and people. Successful strategies involve people communicating with each other on a very personal level and adapting each set of protected area needs and unique values to the type of political support that will make the most of the larger socio-political circumstances.

Many texts and guidelines have been written to manage protected areas, including those that address the critical process of national planning strategies (see, for example, Davey, 1998; Eagles and McCool, 2002) but few dedicate more than passing remarks to political strategies. A concerted, deliberate effort to record and disseminate successful political strategies in support of protected areas throughout the world is urgently needed.

This chapter is part of the process of disseminating political strategies. In addition, readers may refer to the hundreds of case studies, IUCN guidelines, articles, books and analyses on protected areas. Many of these publications document cases of success which is ultimately political success. Examples include establishing or expanding a protected area; managers working across boundaries for the social or economic benefit of a neighbouring community; biological treatises revealing new aspects of natural phenomena; a species or landscape better protected; and protected areas focusing their mission to provide one or more of the many values.

One question that managers, politicians or PA advocates may ask is: "where and when do I adopt a particular strategy?" This chapter will not provide an easy answer, but many of the techniques discussed in this chapter may be transferred from one nation to another. The task for anyone successfully using these strategies is to be sensitive to the cultural context and make the necessary translations and adjustments. Ultimately, it is up to protected area advocates to rise to the tremendous challenge of making connections in a fluid, changing socio-political context.

\section{Background}

For centuries, protected natural areas served the personal desire of kings to hunt, ride or more rarely provide raw material for state needs such as timber for ships. The pattern was that political support was generated by the decree of an authoritarian ruler and similarly, by dictate of colonial powers as in game reserves established throughout Africa. By the late $19^{\text {th }}$ century, game reserves and restricted access forest lands existed in many cultures but not necessarily to protect nature nor serve the general public. Even in the democratic United States the first federal forest reserves and national monuments were established by presidential fiat. However, even as US Presidents, centralized governments and European monarchs were enacting policy from the top down, in the late $19^{\text {th }}$ and early $20^{\text {th }}$ centuries, protected natural areas started to reflect the emerging political variation and political realities of post-authoritarian rule.

Beginning with Yellowstone National Park (established 1872) in the USA, national parks were established in many nations and reflected a public desire to protect natural areas for recreation, aesthetics, and the economic benefits derived from tourism. These first areas emerged in early free market democracies such as the United States, Canada, New Zealand and Australia and reflected their unique national character as well as an extensive, intact, wild natural beauty (Butler and Boyd, 2002; Nash, 2001). Special interests such as the railroad industry undoubtedly played a role in the establishment of 


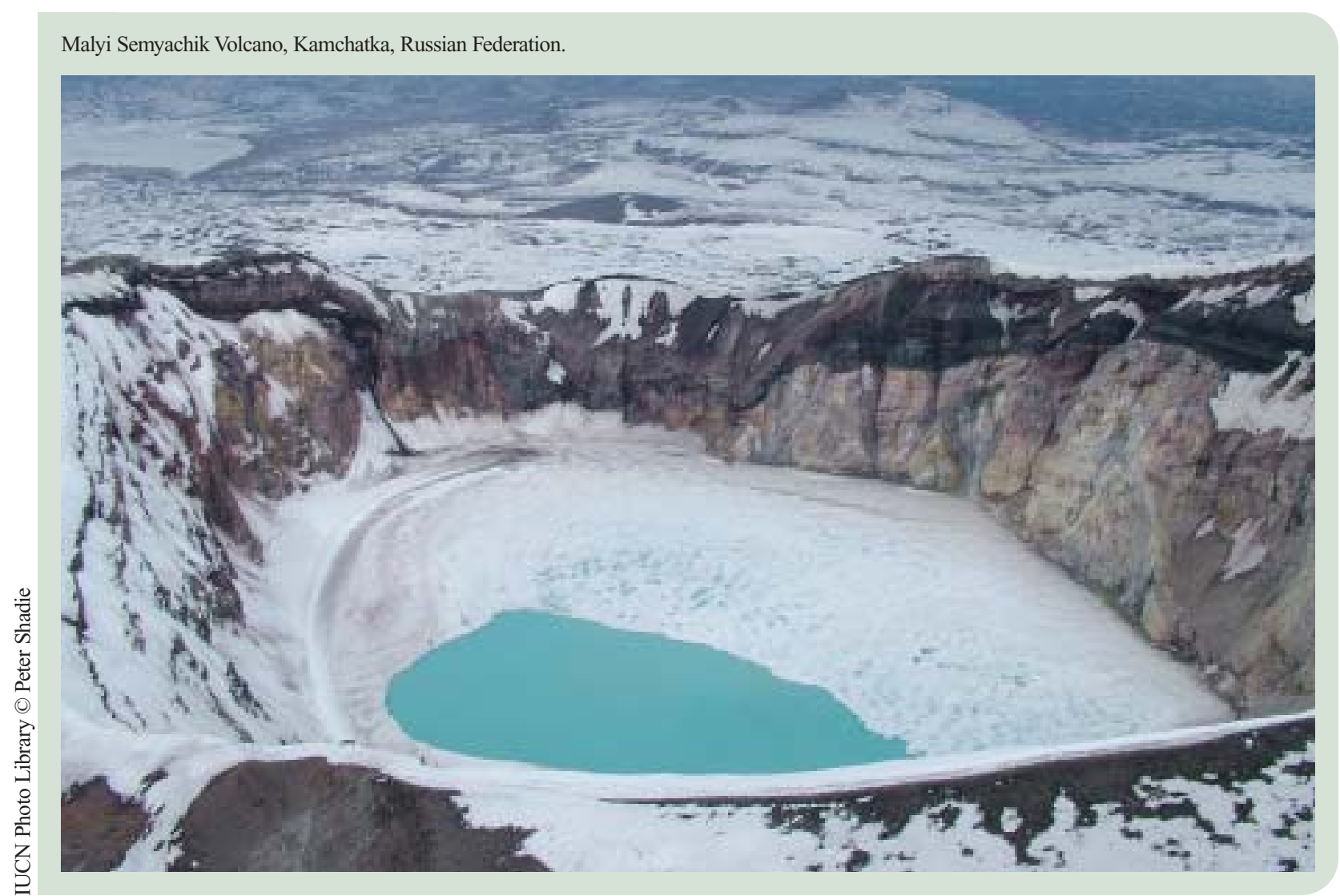

national parks but these areas were primarily designed for access by the general public rather than exploitation by commercial interest. The democratic notion that public lands were to be managed for the public, and remain accessible, was a reflection of the larger democratic practice.

Other nations with different socio-political systems established PAs with different goals and missions. Kruger National Park in South Africa (est. 1926) was designated to protect wildlife and allow for recreational access and aesthetic appreciation (Nash, 2001). However Kruger NP remained segregated as in the wider society until the destruction of apartheid in the 1990s. The South African parks have now become a focus for environmental justice and restitution (Cock and Fig, 2000). A comparison between the United States and the USSR serves to illustrate the influence of socio-political systems on protected area policy. In the early $20^{\text {th }}$ century the USSR had a very small, mobile leisure class, a political system dominated by a few elites, and a scientific community that held a much more significant social position than in the USA (Ostergren and Hollenhorst, 1999). Thus, the Soviet strict nature preserves established were off limits to the general public and reserved for an elite cadre of ecological scientists (Weiner, 1988). National parks in the US were tourism-based, geared toward attracting visitors, and incidentally (or intentionally) supported economic interests just outside park boundaries (Sellars, 1997). The difference between the Russian areas that excluded the public and the US areas that maximized public access persisted through the 1970s. National parks in Russia did not emerge until the 1980s and today include tourist zones, small logging zones and sometimes agricultural areas or communities as in Great Britain. One reason for the late emergence of national parks in Russia is that most of the land was under communal ownership and thus the need to reserve land for public access was, on the face of it, redundant (Gaava, 1984).

Several areas and systems reflect the trend from authoritarian control to public access and participation. Belgian King Leopold established Albert National Park in 1925 in the Congo as a place reserved for a small cadre of scientific experts (Nash, 2001). It was rededicated in 1969 as Parc National de Virunga, or Virunga National Park, and inscribed on the World Heritage List in 1979. This park has hosted millions of visitors from around the world and is part of the diminishing habitat for gorillas. National 
character is reflected in the name of a protected area as well as its goals. King George the Vth National Park was established by decree in Malaysia in 1938 and renamed Taman Negara (literally "National Park") after Malaysian independence in 1957. Japan's first national park created for primeval characteristics was in 1964 (Natori, 1997). By the mid-20 th century the trend to provide public access to nature affected private lands as well. The first national parks in Great Britain appeared in the 1950s and provide access to nature through hiking trails and walkways, though much of the land is in private ownership (Mair and Delafons, 2001).

The protected area concept was well entrenched by the 1940s and the post-WWII era allowed for an internationalization of the PA. The process of internationalization both prompted an increase in the amount of area protected and conversely, increased the complexity of designating protected natural areas. The political scene grew to include many (often competing) interests within nations and between nations. The list of goals and benefits from PAs has grown to include biodiversity, clean water, recreation, economic benefits from tourism, environmental education, clean air, pharmaceutical reserves, wilderness, food, scientific laboratories, cultural preservation, international symbols of peace, places to re-connect with nature, spiritual sites and historic interpretation. Though many goals are complementary, some are interpreted as mutually exclusive.

In 1948, the United Nations Educational, Scientific and Cultural Organization (UNESCO) established IUCN and charged it with preserving the world's biotic environment. Since that time 183 nations have established protected areas and by 2002, the United Nations List of Protected Areas listed 3881 national parks and 102,102 protected areas altogether (Chape et al., 2003). Significantly, protected areas have emerged under many political systems and some international designations have occurred under outright defiance of national leadership. Institutions have been developed at the international and national level to manage PAs and distribute resources in fluid and challenging political climates (McNeely, 1999).
Despite the spread and success of the global protected area network, managers, researchers, policy makers and citizens recognise a wide range of problems and shortcomings. The number of threatened species worldwide has increased over the last decades and the rate and extent of species extinction continues to expand (Harmon, 2002). Though trends show improved conditions over the last decades, indigenous and mobile peoples as well as the immediate neighbours of PAs have been ignored in the planning and management process for many areas throughout the world (Poirier and Ostergren, 2002; Brechin et al., 2003). As the total extent of wild areas decreases we may well ask, are protected areas nature's last great strongholds (Burton, 1991)? Never has the need been so great to expand and strengthen the world's protected area system, calling for effective political strategies utilizing the wide array of reasons for protecting natural areas. This chapter attempts to continue documenting progress and to present successful strategies to build political support for protected areas. Moving from the international scene to the local, the political landscape becomes immensely complicated, but in each case a protected area advocate makes a connection to build political support.

\section{Strategies for political support}

Essential to understanding how political support is generated is considering "who is asking for support, who is providing that support, and what does the support look like?" Paraphrasing Lasswell (1958), this is the study of who gets what, when, how. The political support that is generated to establish, expand or bolster protected areas may materialize as funding for equipment, research, or personnel allocations. Support may be legislation that creates or expands the mission, rights, roles and/or responsibilities of protected area staff and employees. Political support may include the creation or strengthening of PA institutions and agencies, or take the form of increased awareness of the ecological services or economic influence of protected areas within society. Support may originate locally, regionally, nationally or internationally. Each of the following examples may warrant an extended investigation, but these short vignettes provide a view of how broad and flexible the tool kit of political strategies is throughout the world. 


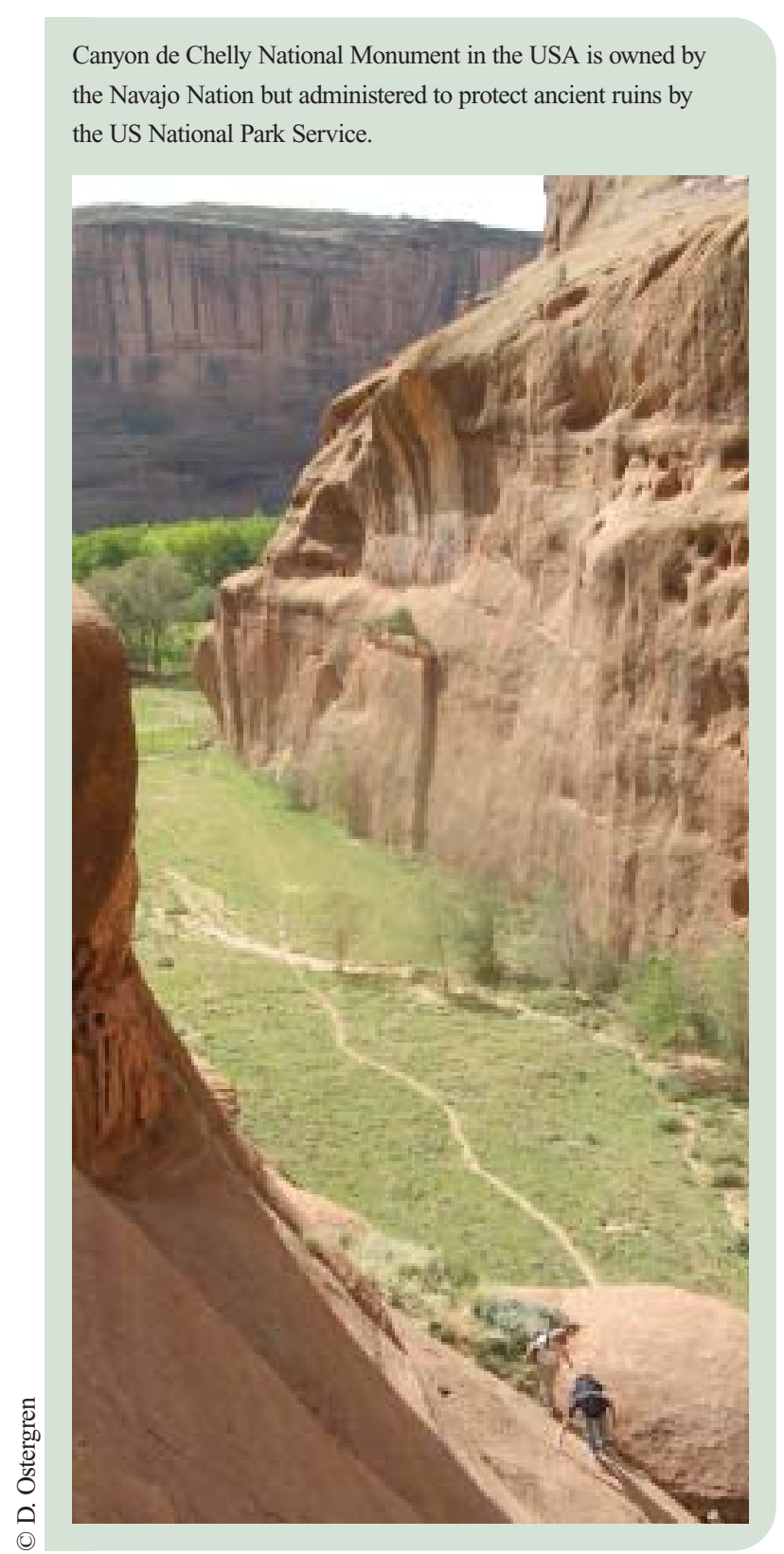

For the purposes of this chapter, protected area advocates form the constituency of those who are asking for support. An advocate is anyone seeking to establish, expand or support a protected area and may include managers, politicians, academics, researchers, neighbours, non-governmental organizations (NGOs), international bodies, experts, neighbouring communities, businesses, grassroots citizen organizations or, most significantly, individuals. Opponents to developing a protected area may include a similar list, and trade-offs are very much a part of the political process of establishing and managing a protected area. Management decisions are often fraught with disagreement, conflict and occasional physical opposition, but resolving conflict is addressed elsewhere in the literature (see for example,
Lewis, 1994). Advocates are faced with institutional or bureaucratic apathy, or the challenge of making connections with communities and individuals who see benefits from extraction and utilization rather than protection and preservation. These examples are directed to building political support by positive, proactive mechanisms.

Advocates seek to establish and support protected areas for many different values. To be effective they need to be aware of the wide range of potential values that may be in the PA as well as those values that are apparent and realized. Advocates need to be aware of the multiple sources of financial or administrative support, and the range of culturally unique strategies to garner support, and then they need to reach out and make connections with a broad, politically diverse audience. In sum, whether an advocate seeks political support from a politician, bureaucrat, business, international organization or community, success depends upon the advocate's knowledge of the PA values and the ability to communicate those values.

A central message is that managers and advocates will benefit by directing resources to build relationships. In other words, they need to answer the question, "who provides the support?" Protected area advocates also need to invest in meeting with, and connecting to, community members or politicians. Personal connections increase trust, increase cooperation and ultimately increase the political support for protected areas. Part of building those relationships depends upon politicians and community members hearing clear (direct) messages that convey how PAs serve the public good of local, regional and national communities.

Two broad perspectives answer the question: "what is the political support?" One perspective is for advocates and managers to realize that politicians (and civil servants) seek to garner and maintain political support from their constituents - most often by providing goods and jobs through relatively consistent, predictable policies. That is, the 'what' is more political support to politicians. Another point of view originates from the community perspective and tends to focus on concrete benefits such as jobs, water, clean air, plant and animal resources, existence value, wilderness, sacred places, or food. If a government 


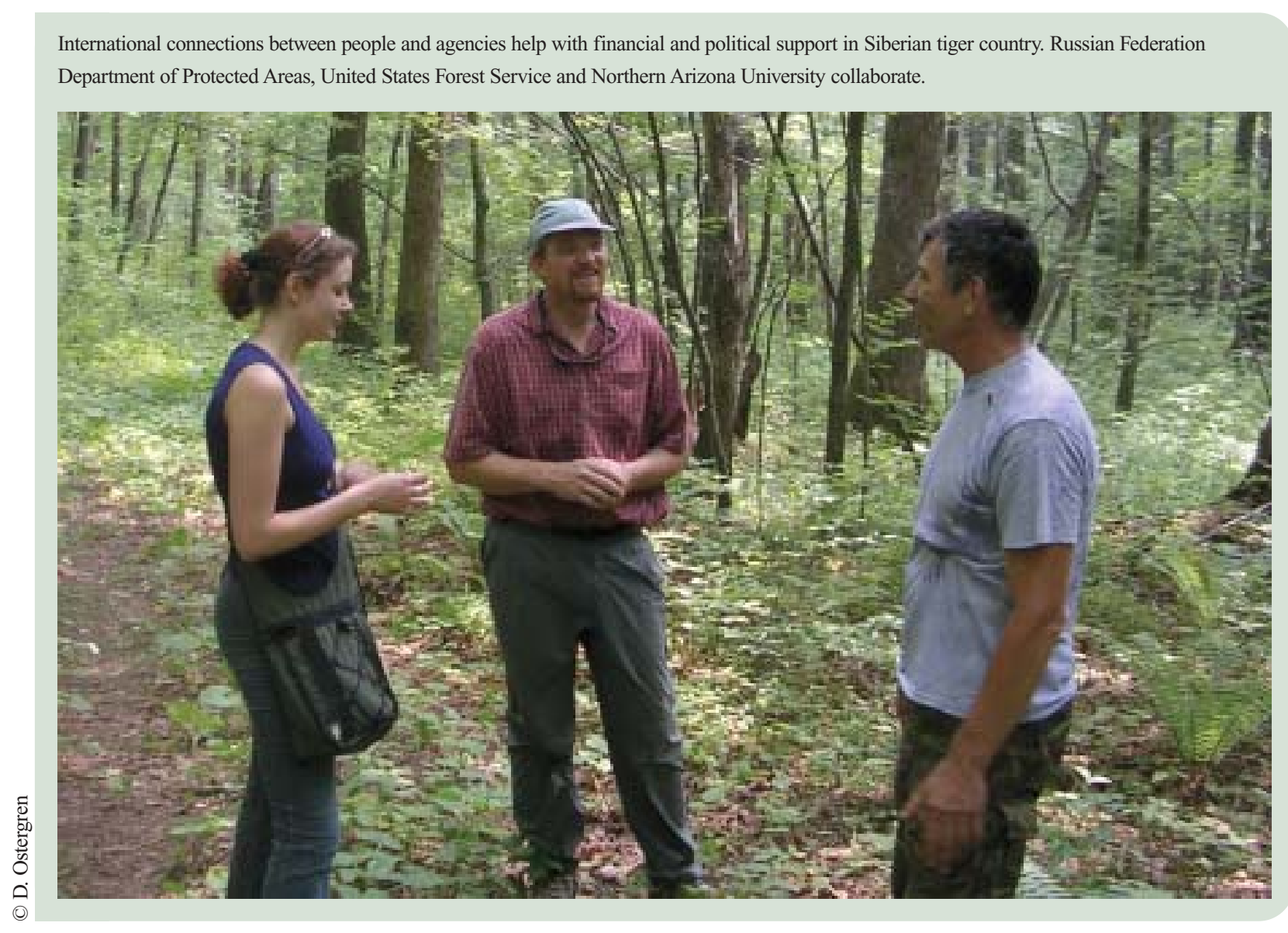

official or community can clearly see a benefit such as international recognition, the cooperation of funding institutions, clean water, tourism or other values, then subsequent actions will likely favour protected natural areas.

Building support within a local or regional community requires the insight that communities will act in their own best interest. Those actions may or may not be consistent with national or international interests. PA advocates need to employ a wide range of communication strategies to present a convincing case that a community's best interests may be served though PA values and benefits. Discussed elsewhere in this volume are constituencies such as indigenous and mobile people; the mining, oil and gas industries; advocates for protecting biodiverse ecosystems or wilderness; those who benefit as consumers or providers of ecotourism experiences; groups where the priority is to restore war-torn ecosystems or communities; and urban populations seeking avenues to connect to the natural world. Each constituency provides a unique set of challenges for PA advocates and a potential area of PA support.

\section{International support}

International institutions such as agreements, conventions and/or organizations have tremendous potential to contribute to the establishment or expansion of protected areas. Most often international institutions serve as sources of financial cooperation, administrative advice or information clearinghouses. The international community provides legitimacy to an advocate's position that protected natural areas benefit the entire society well beyond the PA boundaries. And, by definition, international institutions work across a range of political conditions and cultural perspectives to build the political support that often puts a protected area on the map.

International organizations and institutions offer support as a higher authority that can be harnessed to effect change. An important institution is the World Heritage Convention (WHC). As part of identifying and prioritizing sites for assistance, the WHC employs a "danger listing" for those sites most threatened by human activity. The danger listing launches several actions and mechanisms into play for existing and potential World Heritage Sites. The listing identifies 
specific threats, strengthens agency positions to protect an area, protects the area through international attention, encourages bilateral donors and prompts financial assistance from emergency funds or donor organizations. Though the UN can take action to prompt a State to address problems within a World Heritage Site, and the State can oppose those actions or denounce the process, the goal of the WHC is to build support through dialogue, funding and constructive measures rather than confrontation and delisting a site.

In areas such as Plitvice National Park, that was degraded by the Serbo-Croat war, the danger listing has allowed UN presence and an eventual recovery of the area and infrastructure. Organizing resources and administrative services to direct resources to Plitvice would have been much more difficult without international support and the credibility of the WHC. Triggering a "danger listing" may be a difficult process for a small NGO or community organization but because World Heritage sites are in the international system, a significant political process is in place. The task for a small organization is to learn how to connect to the WHC resources and the responsibility of World Heritage Centre, located at UNESCO, is to keep those resources and mechanisms accessible.

A direct, international but non-government response to the threat to World Heritage Sites is funding from the United Nations Foundation. Utilizing funds from a donation from Ted Turner, the UN Foundation partners with local organizations through UNESCO. Foundation funds will end in 2015 so an essential component of any agreement is that local organizations are leveraging their own time and effort with Foundation resources into long-term political and financial support. Foundation funds may support early efforts to organize, collect data, make political connections and get a study under way for potential World Heritage designation. The Foundation has worked in a variety of situations. Sometimes all parties are in agreement with World Heritage designation and the government endorses the process. In other situations, such as Manas NP in India, the government did not support designation and some conflict continues. In each case the UN Foundation proceeded with the understanding that the benefits to the world outweighed political obstacles.

An important and often overlooked source of PA support is the banking community. As any PA or advocate organization will report, the PA network is chronically short of finances. Regional banks such as the Asian Development Bank (ADB) may have a corporate commitment to supporting sustainable economic growth rather than boom and bust extractive activities. As part of the ADB process to make a loan, they may link PAs to strategic areas or resources such as watersheds. Reducing poverty depends upon clean water resources just as much as creating jobs. Tempering idealistic goals to protect natural areas is the reality that banks have limited ability to influence government actions and/or implement on-the-ground practices. However, if establishing or supporting a PA is part of the condition for a loan, the results of that loan have a much greater probability to improve environmental conditions rather than degrade a ecosystem.

A lending institution that has been under a great deal of international scrutiny from environmental NGOs and development organizations is the World Bank. The Bank's commitment to environmental quality merits a close look at its programmatic goals and mission. In recent years the climate has changed within the Bank and some reports suggest that this is in large part due to public pressure. The three pillars of the World Bank are quality of life, quality of the environment, and improving the standard of living for people. Historically, opponents to the World Bank lending policies have complained that the Bank lends without regard for the negative consequences for humans or the environment.

The World Bank has dedicated US\$3.2 billion to environmental issues between 1988 and 2003, with a third of that coming from the Global Environment Facility (GEF). One strategy to encourage politicians to take environmental initiatives more seriously is that the Bank requires a clear articulation of benefits to people that encompasses both economic considerations as well as ecosystem or environmental health. Establishing or supporting a PA is a relatively concrete step to protect ecosystem values and PAs 
serve as visible evidence of positive steps to improving quality of life. The World Bank has helped establish PAs in Madagascar, Brazil and Argentina as well as strengthened areas in Vietnam, Venezuela and Uganda. Improvements in the quality of life translate into political support for both politicians and PAs.

The World Bank has also supported tourism projects in southern Africa, coastal fisheries projects in Indonesia and watershed projects in several countries including Mexico, China, Kazakhstan, Uzbekistan and in the Andes, all with links to protected areas. The Bank can specifically help with new management models, new financing models, better economic analysis and integrating protected area values into mainstream development. In several new projects the Bank has improved community input, integrated PAs into the larger planning process, documented economic benefits from ecosystem services and from job production, and played a key role in water quality and quantity improvement in countries such as Belize and Columbia. Through their influence and expertise, international institutions have a tremendous potential to communicate the benefits beyond boundaries for PAs to society.

Perhaps the most significant international political support for protected areas comes from international conventions. Conventions may offer expert technology, advice, fora for international political support, international standards to measure success and determine priorities for assistance, and provide databases for reference and to identify possible collaborators or resources. However, conventions may need to be more consistent to be readily accessible to a broad public and work across multiple jurisdictions. A standard set of terms and a consistent message would help limit duplication or conflicting messages.

The Convention on Biological Diversity (CBD) entered into force in 1993 and now has 188 state parties (CBD, 2004). The CBD is one of the most important legally binding instruments addressing protected areas in a comprehensive manner. Article 8 addresses the role of protected areas and "in situ" protection of biological diversity. The $7^{\text {th }}$ Conference of the Parties in 2004 affirmed the role and detailed tasks for PAs, responsibilities of governments and projected goals. Traditional ecological knowledge and the participation of indigenous people and/or neighbours to PAs was specifically addressed. Tasks such as gap identification and coordinating multiinternational agency cooperation were among the many goals within the 2004 Conference of the Parties' decisions (CBD, 2004).

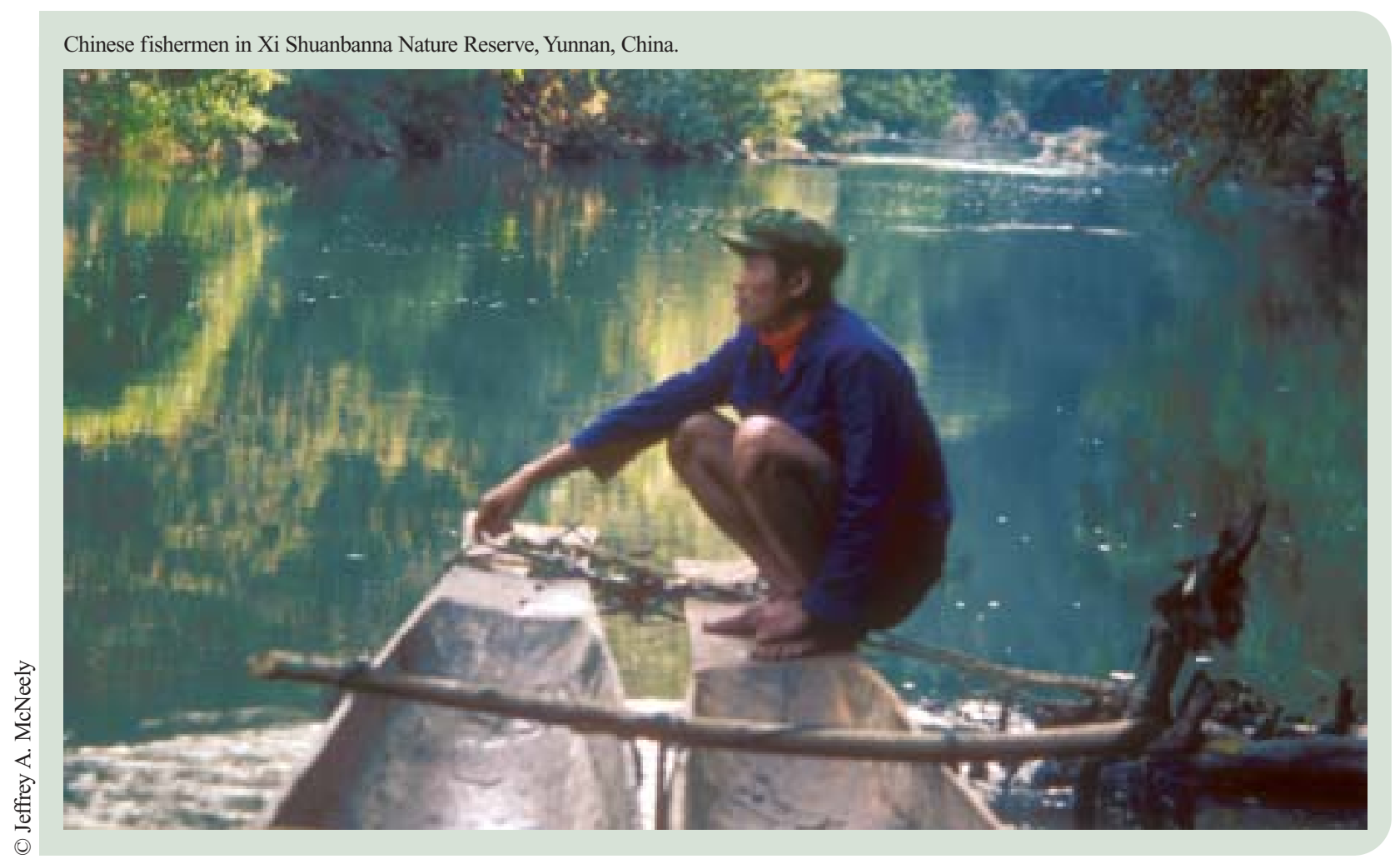


The CBD brings an international impetus and validity to protected area advocates working for the establishment or expansion of PAs. Within the CBD is a funding mechanism (the Global Environment Facility) and opportunities for international collaboration. For instance, although the USA is one of the very few countries that has not ratified the $\mathrm{CBD}$, it has donated nearly 1 billion dollars to the GEF which supports activities of the CBD. That financial support and mechanism is essential to holding meetings, creating databases, publishing results and, most important, directly supporting protected areas.

One area that international conventions facilitates is the process of inter-national learning, how countries exchange information to develop protected area strategies and learn from examples that have succeeded or failed to deliver promised ecological or economic goals. As nations look abroad for lessons in PA management and ratify international conventions or treaties, governments tend to both resist any hegemonic practice or philosophy sweeping the international community, and to embrace that very ideology to maximize support and financial opportunities. Harmonizing with international institutions works in two directions. Not only should international conventions be consistent in their message but as each country uses similar strategies and language, the international dialogue continues and creates a synergy that is difficult for governments to ignore.

Inter-national learning is the process of adopting those strategies that build support and adapt to changing political conditions while maintaining a sense of cultural integrity. Inter-national learning may be a process of years or decades as political boundaries ebb and flow. For instance as the USSR collapsed, the funding for the Russian zapovednik system (strict nature preserve, IUCN Category 1a) was reduced by $60-80 \%$ and crippled management and research capabilities. To build political support, since 1991 Russian Federation legislation has incorporated the strategies of environmental education and the prospect of ecotourism. A new practice on these strict nature preserves throughout Russia is to allow travel on limited portions of the preserves and maintain the traditional value of preserving these areas as 'etalons,' that is pristine natural areas as control areas to compare ecosystems that are developed or subjected to economic activities. In any nation the forces of international pressure should be voluntarily accepted or rejected while the valuable lessons are embraced within a cultural and traditional context that best fits the unique sociopolitical conditions.

A consistent theme for international institutions is that while advocates need to seek the institution's financial or administrative help through appropriate channels and within the institutional mission, the institutions themselves have an obligation to be accessible. At the most basic level international institutions ought to be reaching out to individuals in the field. Many protected areas are located where computer links, telephones and even electricity may be scarce. People living in and around PAs are often engaged in the day-to-day tasks of living and are oblivious to the benefits that international institutions have to offer. As impractical as it may be to have each large institution send representatives to remote areas, one obligation of institutions is to make information easy to translate to unique situations. Advocates who have access to international information need to be able to translate that information to on-the-ground action. Visiting the GEF, CBD, IUCN or UNESCO web sites should be a consistent experience that offers support. A great deal of useful information is available through publications and through the field offices or individuals who work with these institutions. But many people new to the protected area community may need straightforward answers to what, at first, appear to be simple questions. How does a small Bolivian community ensure that its watershed is protected as the nation seeks to harvest resources or build a hydroelectric power plant? How does a Lithuanian village promote itself as a protected area destination and resist the perceived negative forces of development? Who can those communities turn to for international support? The good news is that information and support through international institutions is increasing every year, but the challenge is to keep that information and support easy to understand and readily accessible. 


\section{National support}

At the national level, support is usually channelled through the institutions and agencies that have been established by enabling legislation, regulations or decrees. National laws allow protected areas to ask for finances, determine boundaries, enforce regulations and meet the goals to fulfil a national mission to protect areas of significance. Although the broad, ideological goals of protecting cultural or biological diversity may be articulated at the international level, advocates are most often working within very specific socio-political conditions that determine what pathway to take toward support. In countries with powerful presidencies and strong leadership, advocates must make their case at the very highest level. Nations with strong parliamentary or congressional rule may require advocates to convince a regional political leader that PAs offer quality of life benefits that will re-elect that official. Advocates living in countries where ministerial or bureaucratic politics dominate the political landscape will spend a great deal of time in administrative offices (assuming that enabling legislation exists). Finally, at times the path to influencing national politics is through local politicians and local politics so this section on national politics is closely linked to local politics.

As advocates seek political support, moments of opportunity surface and in some countries those moments entail enlisting the aid of a sympathetic president or high level politician. The first step is to engage the politician by presenting alternatives that serve his/her constituency (and take credit for that service) through job creation or the preservation of a traditional way of life. Past relationships may play a part in making a connection to politicians through school, work or family. Although this is often accidental it may also arise from years developing an immediate, on-the-ground connection to an individual. In many countries, national politicians emerge from local politics which requires that PA advocates think 5-10 years down the road. However, politicians may only think in terms of the election cycle or the very politician that PA advocates courted for support is replaced in the next election cycle.

National politics highlights a negative image that accompanies international PA advocates. As the cause to protect biodiversity in the 1970s and 1980s gained international notoriety, western environmental nongovernmental organizations (NGOs) were seen by some to invade 'nature rich' less developed nations to establish PAs. Accused of environmental imperialism, the NGOs may have overlooked or ignored the needs and rights of local people or the political realities of a national government. On the one hand, ignoring the needs of local people is an affront to their sovereignty, while on the other hand public participation in all decisions is not appropriate in all nations or all conditions. When international organizations support national efforts, that support ought to be invited, culturally appropriate and developed over long periods of time.

In contrast to the recommended slow approach for international advocates, nationally based advocates may need to move quickly, taking advantage of opportunities and marshalling international support to their advantage. In Columbia, President Alvaro Uribe Velez had demonstrated a history of environmental awareness. As part of his personal conviction and as Minister of Environment, he found areas to participate in the Parks for People programme. As Minister Uribe became President, the time to make a case for further PA development surfaced. Although the President has focused on more pressing needs, the opportunity should not be ignored. To illustrate where the presidency and government stand in relation to international standards, three NPs have been recently established for different reasons. One focuses on medicinal plants and two are transboundary parks. Unfortunately, these wild areas are also sites for conflict and often unsafe for international travellers. As discussed in Hammill (this volume), insecurity limits the opportunities for PA managers to work in this war torn region.

One concern in PA advocacy is recruiting and soliciting the support of national level politicians who are relatively uninformed about PA issues. The first and best strategy is a personal connection that allows for time to discuss and describe issues, terminology or broad concepts. In other cases the first contact is necessarily through printed material. In this instance the promotional material needs to clearly communicate the many values and benefits of PAs 
and be free of jargon. India has had success through written communication and a great deal of information can be digested by civil service, politicians, NGOs and religious leaders.

\section{Box 12.1}

\section{Protected areas in a time of political transition: the case of Russia}

The Russian Federation has a long history of protecting natural areas, with some efforts predating the Soviet era. Since 1991 and the fall of the USSR, Russia has enacted a series of laws that are designed to protect the environment. In 1995 the Law on Specially Protected Natural Areas set high standards and provided needed authority to managers for all protected areas. Currently, however, President Putin is perceived by many as apathetic toward the PA system. In 2000 the 100 zapovedniks (strict nature preserves), and 35 national parks were merged from two administrative agencies into one Department of Protected Areas and placed within the Ministry of Natural Resources (traditionally a development-oriented ministry). In Russia, one strategy is to appeal to national politicians and their need for publicity. The initial challenges to overcome are that historically zapovedniks have had little to do with local people and that most people in Russia assume protecting nature means a loss of economic resources. Thus, politicians need to promote an environmentally favourable image to voters, to communicate the values and benefits of protected natural areas. To develop political support in villages the traditionally isolated zapovedniks have initiated education programmes on-site as well as in local schools. Other services include zapovednik research staff monitoring environmental conditions within nearby communities or offering expert opinion on potential development projects. These strategies integrate the PA into the community which builds support and both short and long-term benefits.
Observers have variously characterized Russian politics as chaotic democracy where rules change yearly, or a delegative democracy where a single leader has unusual freedom to make decisions. Many nations experience political instability, so what message should be sent to national politicians? First on the list are the direct economic benefits to communities (such as selling indigenous crafts or providing tourism) and the broader economic values as outlined by the World Bank or IUCN (1998). In Russia, some national parks are zoned to allow limited forest management, fishing or hunting. Advocates create support and awareness of PA goals with school programmes that will hopefully translate into future political support. However even when national parks enjoy widespread popular support and notoriety as in the USA, budgets may not be fully funded. At the national level, support often depends upon the goals and aspirations of a particular administration. In some cases such as in countries in transition, the economy is such that no opportunity is available to wait for federal support and local managers need to act on their own.

Some PA systems benefit tremendously from a strong state. Cuba has a very solid system despite the fact that $90 \%$ of the land mass has been disturbed. The remaining $10 \%$ is unpopulated and the state is responsible to protect those areas. Protected areas in Cuba do not have high economic value. To earn support the ecological values are emphasised to the general public and then translated to the national level.

Building political support includes outreach to communities like this owner/operator of a bed and breakfast in the Altai Mountains near Katun Zapovednik (strict nature preserve IUCN category 1a).

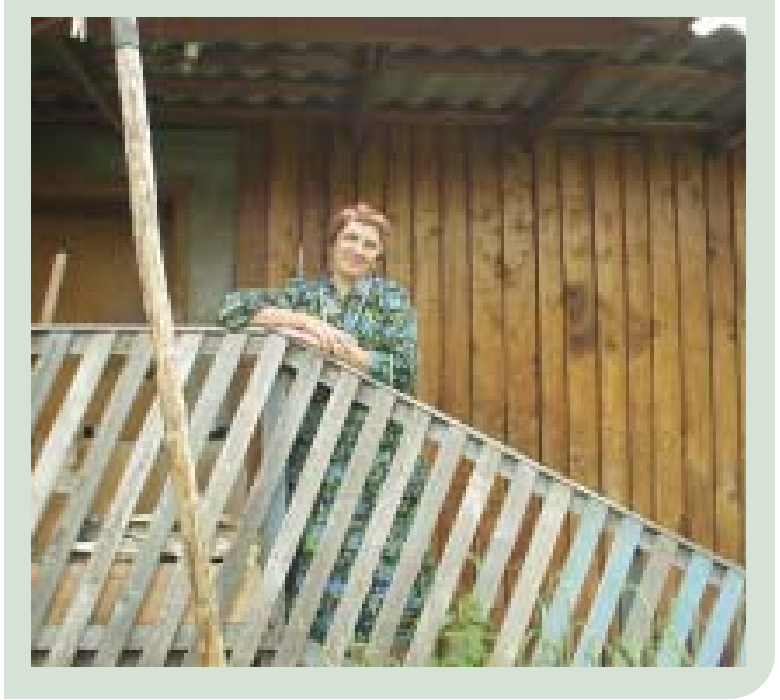




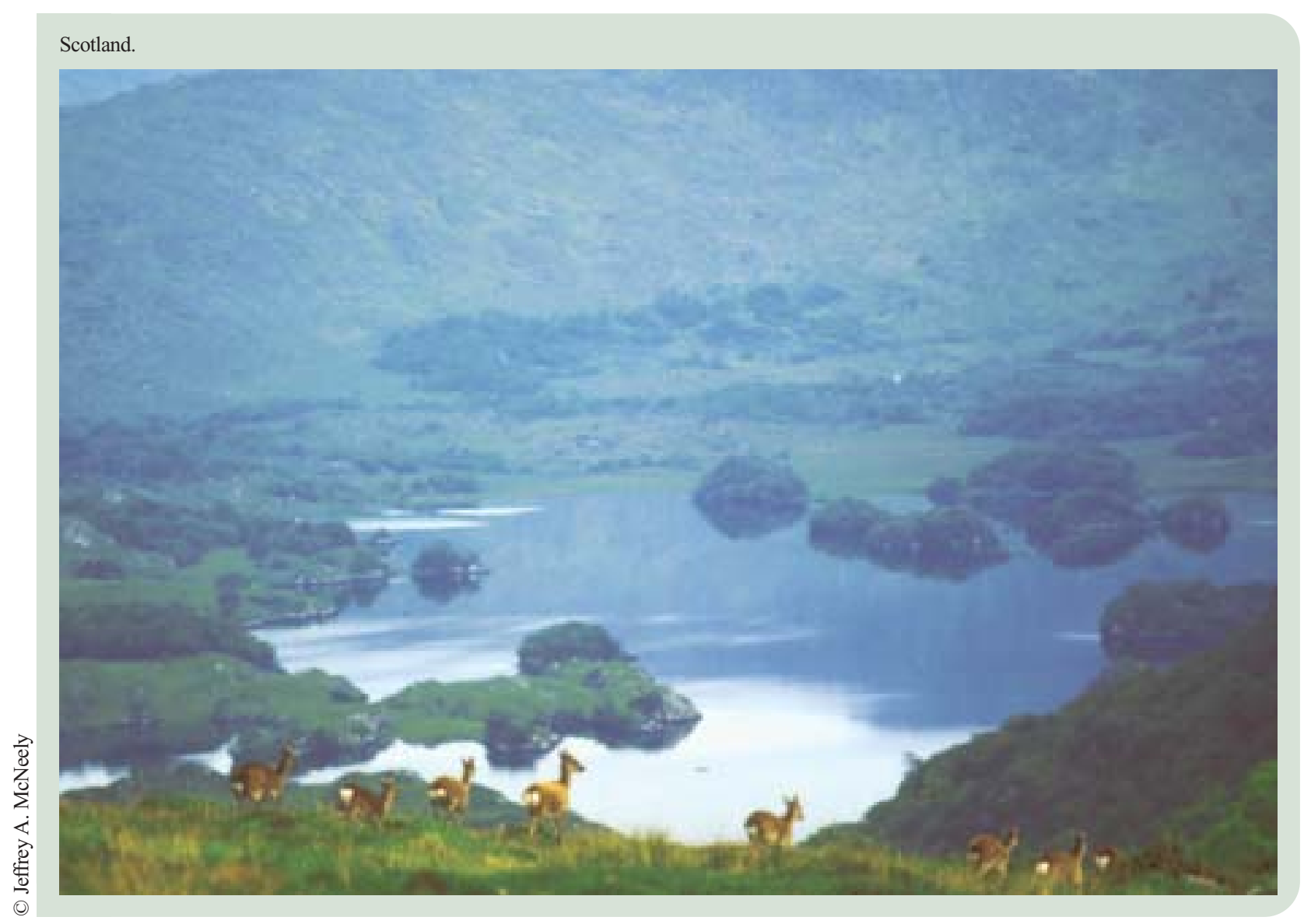

In Mexico a federal PA initiative may originate from NGOs, scientists, or a federal agency. However, to recruit support at the national level, the process needs to go through the people. Decisions and actions are strongly driven by economics and the perception is that PAs hinder people from meeting basic needs. However, where nations emphasise clean water, wild spaces or biological diversity in addition to jobs as contributing to the quality of life, PAs emerge as an essential contribution to society as well as the landscape. Currently PAs in Mexico have a small amount of political capital. Although virtually every ecosystem is represented, only eight protected areas are doing "most of the work."

Scotland and the Scottish National Heritage programme use a combination of strategies where private lands are designated and then the government pays for certain conservation behaviour. One designation unique to the United Kingdom including Scotland, that makes a significant contribution to the PA system but is not recognised by IUCN, are the Sites of Special Scientific Interest. In addition to the Scottish national parks, a recent initiative is the EU Natura 2000 that has identified many natural areas throughout Europe which are now integrated into the system and pay particular attention to marine conservation. This is an example of international pressure having a positive effect on national nature protection efforts. At first Natura 2000 had a pure science base with scientists deciding where and what to protect. As with many top-down decision making processes, this approach met some resistance and resentment, so the process has evolved to include more community participation.

\section{Local support}

Protected area neighbours, indigenous and mobile peoples, local politicians and communities can be both potential sources of great support and/or sources of tremendous conflict for PAs. Often when a PA is proposed, and most notably when it is a national park, local residents look to the promise of tourism dollars and improved infrastructure as their PA gets "on the map" and government support systems are activated. As parks expand or local communities strive for economic growth, the strategy for advocates is to communicate that those natural resources "locked up" 
in parks can be translated into non-extractive sources of income and wealth. Nations have had some great success with this strategy (see e.g. CeballosLascurain, 1996; Eagles and McCool, 2002; Machlis and Field, 2000; IUCN, 2000).

But in other cases the promise of tourism has failed to materialize and/or brought on more problems than anticipated (e.g. Hall and Lew, 1998; Honey, 1999; Boyd, 2000). When the people see the PA as an establishment that does not take into consideration their needs, wants and perspectives on the area and the resources therein, problems are likely to arise. If the community only sees economic values as a raw, extractable resource, or the PA staff and legislation only recognises one value such as biodiversity/habitat preservation, public support is difficult to earn. A better strategy for PA advocates to build local support is to communicate the full range of values in a PA. The wider range of non-tangible values needs to be recognised (Harmon and Putney, 2003) and many strategies to include those values into the PA philosophy and mission are available (e.g. Stolton and Dudley, 1999; Brechin et al., 2003). The rights and values of indigenous and mobile peoples are highlighted by Larsen and Oviedo (this volume).

Although official recognition is yet to come, in Tanzania the situation in the Tangi Region is ripe for PA development and residents are amenable to establishing a PA. The area can serve as a corridor between protected areas such as the Amani Nature Reserve and the Nilo Forest Reserve. In this corridor, 1500 people from eight villages use the resources for farming organic cardamom. The crop is a potential money earner while the area can remain mostly covered in natural vegetation and support a variety of species. The people support the creation and maintenance of this protected area because they care about the area and it is historically important to their livelihood and traditions. However, in this case the locals had relatively little information about the powers of their government. The IUCN Environmental Law Centre and Ministry of Lands have worked to build capacity not only to deal with the government, but to negotiate any possible ramifications of policy change. Capacity building may take many forms but sometimes it is as simple as clarifying goals of both the local entities and the national government. Appropriate capacity building also assumes that development need not be 'aid' but projects that fulfil multiple goals.

Australia is famous for extensive protected areas with a unique system of Aboriginal cooperative agreements. Portions of parks or entire parks are owned by Aboriginals and leased out to provincial governments. These cooperative agreements hold great promise to build and maintain wide support. However a great deal of biodiversity is on private land and the PA system has not necessarily captured all biological diversity. One recent initiative has been directed to working on private lands in South West Victoria, known as "Bush Tender".

After contact between the government and the private land owner, the government agency identifies many of the values that can be captured by the land (especially water which dilutes the salinity of aquifers). Then private land owners are contracted to protect their land by the government. The prices are calculated by combining the quality and quantity of the resource and the proposed level of protection. Part of the agreement is training for land owners in how to care for the land. One of the more rewarding benefits is a generational effect as land and values are passed down through time. The private landowners support protecting areas because they can see multiple benefits (e.g. income, nature protection). Some $85 \%$ of the participants are recent adherents to the programme and there has been an increase by $15 \%$ of protected area in South West Victoria. As community members learn to trust the Bush Tender programme, enthusiasm grows and once the politicians recognise a popular programme they affiliate with it and are more likely to support it with federal funding.

As an international NGO that has a long history of conservation work throughout the world, The Nature Conservancy 'Parks in Peril' programme has developed a slow but steady approach to working in Latin America. They build civil society by working with local NGOs that often have more flexibility and influence than PAs. TNC helps organizations work effectively with local NGOs by building in plans to develop personnel recruitment and a familiarity with 
national politics. The philosophy is to work well, and work long term. Financial stability and effective funding strategies are essential in training programmes and resource commitment. Key messages are the multiple PA benefits to society and local communities such as water quality or long-term preservation of biological hotspots.

In South Africa one successful strategy to connecting politicians with the local and national benefits of PAs is "Putting Politicians in the Wild." For decades black people (people who are now political leaders) were excluded from wild areas - "no go" areas. Advocates recruit leaders and politicians to take a four-day wilderness trip into one of the park wilderness areas. There is a fairly predictable and fairly significant transition as they personally experience the wild. The 250 participants, including 148 legislators, are in positions to make decisions. With this experience many of their decisions are much more attuned to the impact on environmental or park resources. The tremendous challenge in South Africa as in many developing nations is to include all of society in the benefits and costs of protecting nature. A high, national quality of life is not essential to establishing PAs but managing an area that works with locals and provides some economic benefits will certainly produce more political support than a strategy of isolation and unilateral actions.

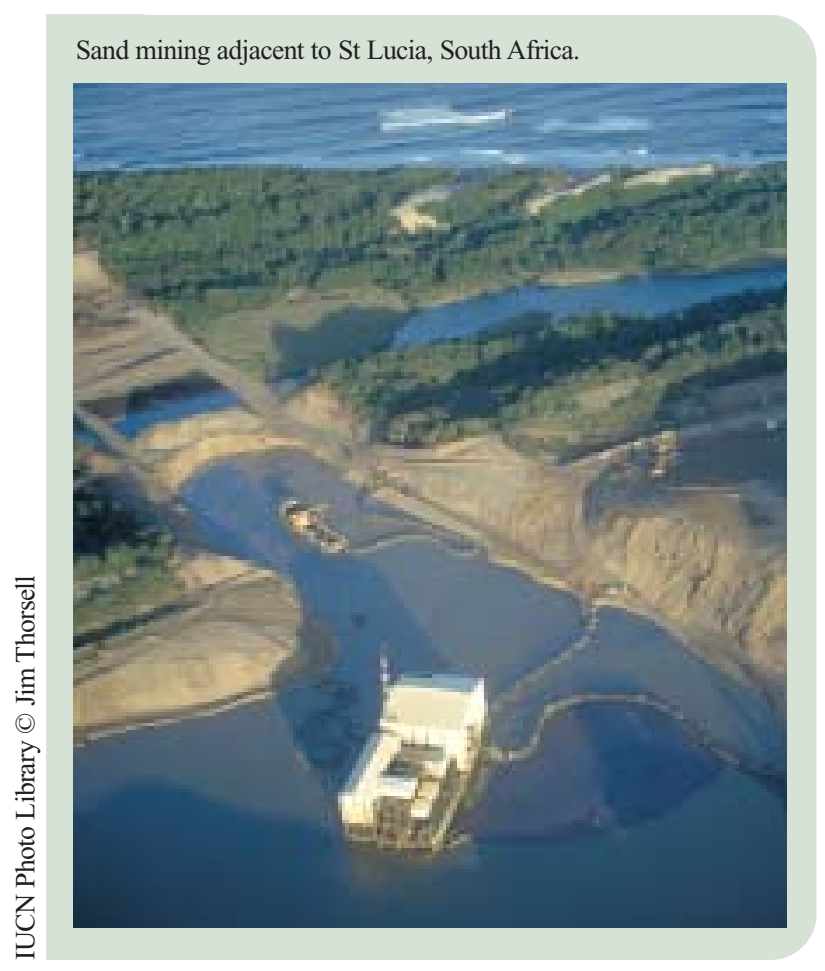

Establishing and maintaining PAs in some parts of the world will continue to be surrounded by conflict for decades to come. Local political strategies are no more a panacea than national or international strategies. Nonetheless, PAs are much more likely to succeed and flourish with a concentrated effort to connect local communities to PA goals, connect local communities to national strategies, and connect local problems to international support.

\section{Conclusion}

This is but a sampling of the many strategies to building political support. The most common theme that has emerged is for advocates to "make a connection." The examples include international institutions connecting to national agencies and local communities, conventions and agreements clarifying their message to connect to NGOs or individuals, nations connecting to other nations, and PA advocates taking the time to effectively connect on all levels. Indigenous people and local communities work to communicate with local or national politicians to make their own needs clear while private land owners connected with the goals of national programmes. Each PA needs to be placed into the political, economic and social context. Then protected area advocates can use these strategies to improve connections between multiple stakeholders but more important, make the essential connection between stakeholders and PAs themselves.

\section{Acknowledgements}

Pedro Araya, Bob Dobias, Bernd von Droste, Joseph Edmiston, Reinaldo Estrada Estrada, Robert Hoft, Steve Hollenhorst, Ian Jardine, Will Kennedy, Tom Kiernan, Kelly Levin, Kathy MacKinnon, Juan Mayr Maldonado, Nikolai Maleshin, Gavin Mathieson, Steve McCool, Rodrigo Medellin, Gwen Mhlangu, Kathryn Monk, Andrew Muir, Klemani Jo Mulongoy, Seema Paul, Alexander Shestakov, Pavel Sulyandziga, Floro Tunubala, Jorge Viana and Tomme Young contributed significantly to the discussions that resulted in this chapter. 


\section{Introduction}

As of the end of 2003, 172 protected areas have been inscribed on the prestigious World Heritage (WH) List as being of "outstanding universal value" for their natural features (including 23 which also satisfy cultural criteria). Together these sites cover an area of 1.7 million $\mathrm{km}^{2}$, approximately $9 \%$ of the global protected area network and $0.16 \%$ of the total number of the world's protected areas (IUCN Category I-VI sites). This may appear to be a small proportion of the total network but the WH Convention is only intended to apply to a select number of the world's most outstanding sites.

Although relatively few in comparison to the global total of protected areas, WH sites assume a disproportionate prominence in ways that other sites do not. For example, WH sites are part of a rigorously screened exclusive global network of "the best of the best", the "crème de la crème" or the "crown jewels" of this network. They fall under an international convention ratified by 176 countries that seeks not representativeness (which is the objective of UNESCO's Man and the Biosphere programme) and recognises that $\mathrm{WH}$ sites are at the zenith on our scale of natural resources.

Figure 13.1 provides a graphic view of World Heritage sites and how they fit in the spectrum of different types of protected areas. The figure illustrates that WH sites are limited in number and that there is a hierarchy of sites, all of which are important in conserving the earth's diversity.

One consequence of this "hall of fame" approach is that WH sites have attained a high level of public exposure and political support. For nature conservation they could be referred to as "political hotspots" - areas that have been proposed by governments and accepted by a committee made up of 21 countries as being of "Nobel prize" quality.

A second consequence of WH listing is that most sites (particularly those in non-OECD countries) are in a favoured position when it comes to financial support. Not only do tourism levels increase, bringing added economic benefits, but donors such as the UN Foundation and the Global Environment Facility
(GEF) give priority to funding projects in WH sites. Donors justify funding WH sites more easily as they have been designated under a UN convention, they have been screened for their global importance and ecological integrity and come with a national commitment for their protection (Paul, 2003). This donor preference has been recently reinforced through a significant Memorandum of Understanding between the World Heritage Centre, the Convention on Biological Diversity and the UNDP/GEF.

With this reinforced financial backing along with their "branding" and political support, WH sites have been called "Cadillac parks" and are expected to set the standards and be models of effective management for other sites in the protected areas system.

But along with these advantages, WH site status also carries greater responsibility and brings wider international exposure, particularly when a site's integrity is threatened. A reporting and monitoring system is in place which allows a site to be placed on the List of WH in Danger and eventually to be delisted if the values for which it was originally inscribed are lost. Though this latter step has never been taken, the prospect of it has been raised in several cases (e.g. Srebarna in Bulgaria and Ichkeul in Tunisia). This "state of conservation reporting" mechanism serves as an important means to ensure accountability of member countries and to maintain credibility for the system. It also helps marshall international support if needed (Von Droste and Ishwaran, 2003). The leverage value in reporting on threats to sites has been applied with great effect in many sites (Thorsell, 2003) and is another mechanism unique to this Convention.

Despite these distinguishing features, WH sites should not be viewed as above and apart from the global protected area network. Indeed, Article 5 of the Convention text as agreed in 1972 calls for each State Party to undertake a number of measures that apply generally to protection of the natural and cultural heritage. These include adoption of heritage policies that would be integrated into comprehensive planning programmes, establishing government departments to manage heritage sites, undertaking research and setting up training centres for staff. All of these 


\section{Figure 13.1}

\section{Schematic representation of the relationship of World Heritage Sites to other types of protected areas}

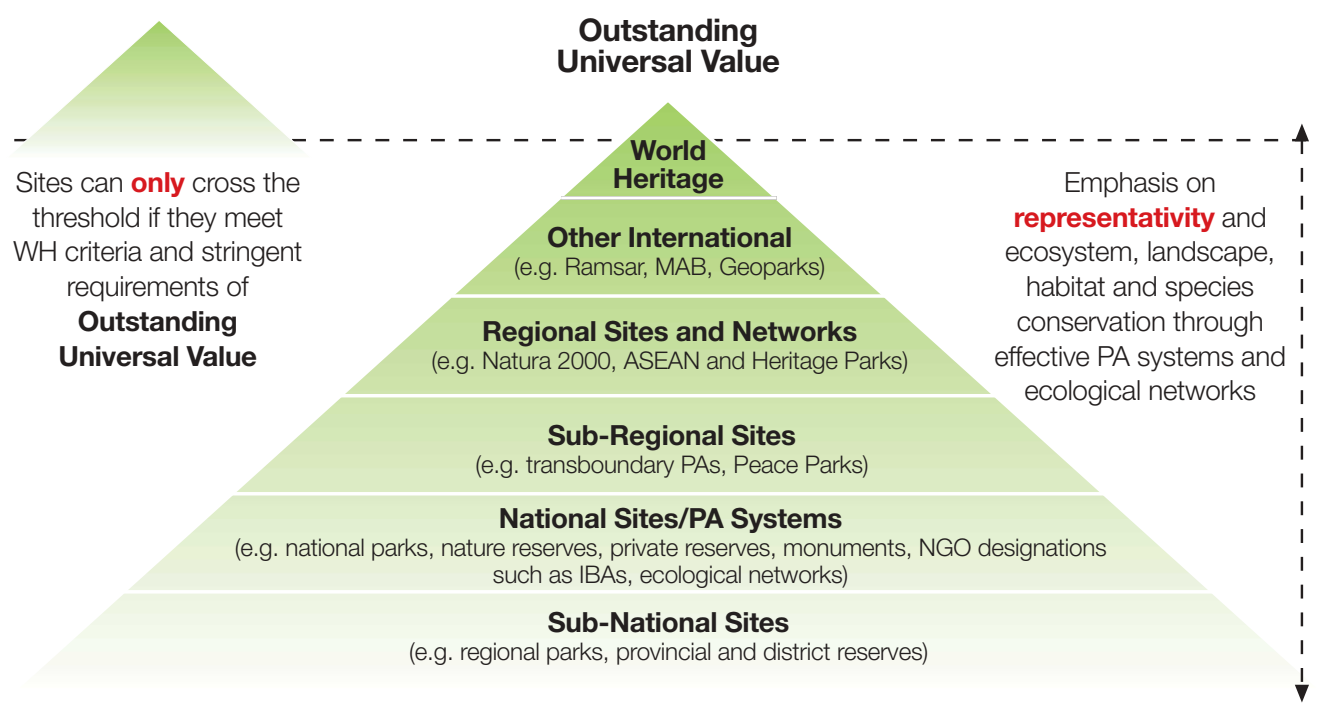

measures were foreseen by the drafters of the Convention as being essential elements that would make up a heritage protection framework for all countries.

Case studies presented during the preparatory workshop and at the World Parks Congress demonstrate that $\mathrm{WH}$ serves to contribute to protected area systems generally via two main directions: through raising the standards of management throughout the system; and by helping to develop new strategic thinking and policies about protected areas in general.

\section{How World Heritage can assist in raising standards of protected area management}

\section{World Heritage standards of management}

By definition, WH sites are those areas of "outstanding universal value" and it is expected that they will be models of "best practice", demonstrating the highest standards of management. Although there is no statement to this effect in the Convention text or in the Operational Guidelines for the Convention, WH sites are expected to play a leadership role and provide models of management that could be promoted and applied to other areas in the protected area system.

For example, it is a requirement that all WH sites have a management plan. Much effort by State Parties, often with support from the WH Fund, has gone towards preparing plans to ensure that this fundamental requirement of effective management is met. Many of these plans have broken new ground in terms of their scope and process (e.g. in the Central Eastern Rainforest Reserves of Australia and China's Three Parallel Gorges Protected Areas). Virtually all natural WH sites now have some form of management plan and/or management policy statement. In many cases the management planning exercise for a WH site was the first attempted in the country and has led to similar initiatives for other areas in the system.

At the broader bioregional planning scale some WH sites have led the way in system-wide planning. One of the first was the regional conservation plan for Fraser Island and the Great Sandy region of Australia which was complemented by regional plans for the Great Barrier Reef and the Wet Tropics. Similar regional conservation planning has been carried out in the Serengeti ecosystem in Tanzania, the Ruta Maya 


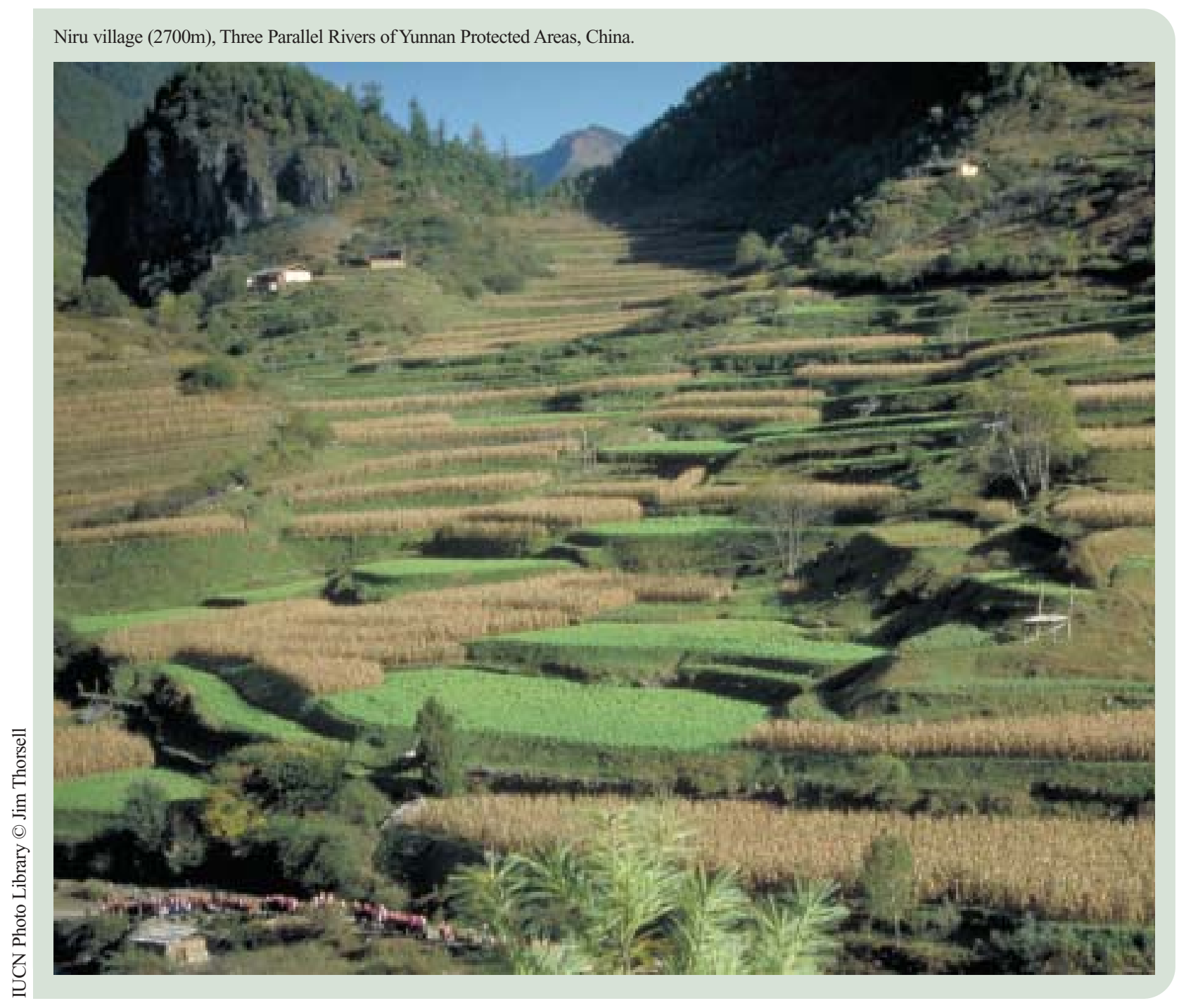

and Path of the Panther in Central America, the Inca Trail in the Andes and the Yellowstone to Yukon in Canada and the USA. WH sites form the core of many of these attempts to establish linkages and corridors between networks of protected areas which are essential to establishing long-term ecological viability for many species.

Several of the above examples involve transboundary agreements and peace parks which also serve to demonstrate the role of $\mathrm{WH}$ in fostering international cooperation. Examples in addition to the above are cooperative agreements signed between Brazil and Argentina on management of the Iguazu WH site, and similar transfrontier agreements between Zambia and Zimbabwe on Victoria Falls, Panama and Columbia on the Darien/Los Katios WH site, Belize and Mexico on the western Caribbean reef system and the current nomination of the Borneo rainforest reserves of Malaysia and Indonesia.
WH sites also perform another exemplary role for the rest of the system in terms of monitoring and reporting on trends and threats. This on-going periodic reporting activity is also required under the Operational Guidelines and has proved its worth in many cases in terms of taking corrective actions to mitigate or avert management deficiencies (specific examples are contained in Thorsell (2003) and Wilson and Wilson (2004)). It is not known how widely this "state of the parks" practice has been adopted but it has been applied with useful results in Canada and in some States in Australia.

One key issue that has been defined as a priority in many protected area fora is capacity building. Here there have been many spillover effects to other protected areas from using $\mathrm{WH}$ sites as focal points for training activities. As noted by Phillips (2003): “A case in point is the series of workshops held in and near WH sites as part of the UN Foundation-backed 
management effectiveness project, Enhancing our Heritage. The World Heritage Foundation also provides about US\$1.5million per year for natural and cultural heritage training activities proposed by State Parties and the Advisory Bodies, as well as a training programme for youth in World Heritage (e.g. the upcoming training course in Indonesia on marine conservation for young people of the region)." Related to these activities the WH Fund is a significant provider of scholarships to the regional training centres in Tanzania, Costa Rica and Cameroon which have supported over 100 students over the past two decades.

Additionally, many regional workshops have been held for WH site managers and others which have focused on key management concerns. One illustrative example of many focused on dealing with local communities was held in Thailand attended by representatives from 17 countries in the region. The proceedings of this workshop were published by the World Heritage Centre (Thulstrup, 1999) and are now widely used as a reference in the region.

A final example of where $\mathrm{WH}$ sites can act as models for management and where there are many beneficial secondary effects on the rest of the system is tourism management and marketing. As $\mathrm{WH}$ designation virtually always attracts increased visitation, bringing with it both positive and negative pressures, many efforts to better control tourism in WH sites have been undertaken. The WH Fund has, for example, provided assistance to the Galapagos for tourism planning and guide training which is viewed as one of the better models of its type. It has also provided funds to better manage natural $\mathrm{WH}$ sites in China where increases in visitation of 500\% have been experienced in some sites. Managing Tourism at WH Sites: A Practical Manual for WH Site Managers is a publication issued by the WH Centre which also attempts to assist in addressing the tourism issue that is a major concern in many protected areas (Pedersen, 2002 and Pedersen and Arellano, 2003 ).

Although the above initiatives are not always supported by hard data (this is currently the subject of a $\mathrm{Ph} . \mathrm{D}$. dissertation based on a questionnaire survey), it can be claimed that many WH sites do set standards which provide wider benefits to the rest of the protected area system. The challenge here is to ensure that WH sites do provide this leadership or else suffer a loss in credibility as standard setters. Unfortunately this is often the case in many sites. In a review of WH sites in the ASEAN region, for example, Mackinnon (2002) concludes that of the nine WH sites in the region only two (Gunung Mulu and Kinabalu in Malaysia) are adequately managed. Many other WH sites are known to have serious management deficiencies, particularly the 17 natural sites that are on the WH in Danger List. WH sites in Africa are predominant on this list and case studies detailing the difficulties faced in the five WH sites in danger in Congo are provided by Debonnet and Hillman-Smith (2003) and for Comoe in Cote d'Ivoire by Fischer et al. (2003).

Most protected areas in the world are facing serious management challenges and WH status does not grant immunity from threats. WH sites do, however, have an advantage over other types of protected areas in that they have an international profile and access to a wider array of funding sources including the $\mathrm{WH}$ emergency assistance fund. When funding becomes the problem (e.g. as was the case in Ngorongoro in Tanzania and Sangay in Ecuador) financial and technical assistance can be provided. However, where there are other barriers to management such as civil disturbance, response to climate change or lack of political commitment, WH sites are as vulnerable to losses in integrity as any other protected area.

\section{How World Heritage can assist in developing new strategic thinking and policies for protecting a nation's natural heritage}

The World Heritage Convention (as well as UNESCO's Man and the Biosphere Programme) has acted to stimulate many new approaches and policies to strengthen conservation at the global level. As noted above, the WH Convention text calls on countries to undertake a wide range of measures to protect their national heritage as well as internationally significant sites. Beyond these basic measures as defined in 1972, WH has advanced thinking on protected areas and conservation in a number of ways. 


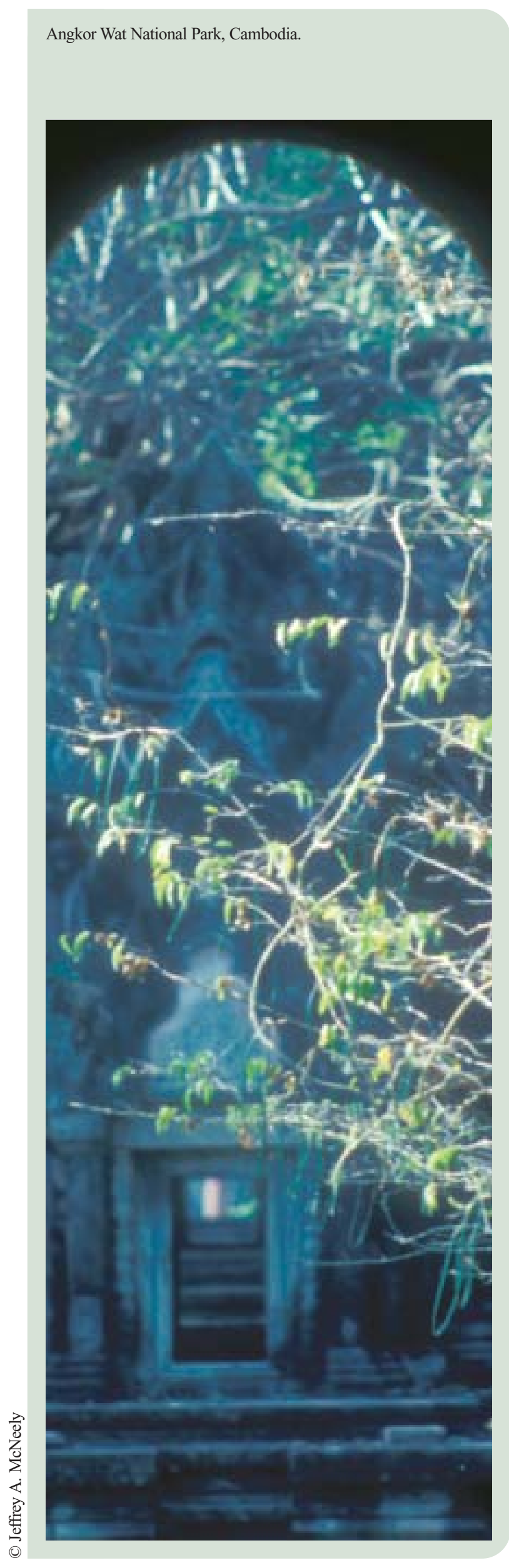

For instance, WH takes a much wider view of what should be identified and protected as part of the heritage of a nation. In addition to the customary emphasis on biological values, $\mathrm{WH}$ has expanded the range of interests in two additional directions. One is by bridging the gap between the cultural and natural heritage by introducing the concept of cultural landscapes in 1992. This initiative gives added weight to IUCN's efforts to promote the use of Category V Protected Landscapes which are inhabited working landscapes where significant conservation values also co-exist. This nexus between nature and culture is a difficult but key policy issue in many places. One of the better instances where it has been examined in some depth has been in the Laponia WH site in Sweden. Here, a decade of work has led to an improved understanding of the balance between nature protection and the role of the indigenous Saami reindeer herders, which has management implications throughout northern Scandinavia (Dahlstrom, 2003).

Another aspect of the cultural landscape approach is based on the premise that "...powerful beliefs, traditions and spiritual relationship of people with nature can contribute to global heritage conservation and add a new dimension in linking culture and nature" (Rössler, 2003). Since this effort to consider the intangible and non-material values of heritage, a number of innovations were introduced. For example, with the acceptance of traditional custodianship and customary land tenure, sites such as East Rennel in the Solomon Islands were entered on the WH List, which led to a surge of interest in alternate means for nature protection among other small island states in the South Pacific.

Growing appreciation (mostly by indigenous people) of the spiritual and cultural values of many WH sites (e.g. Tongariro in New Zealand, Taishan in China, Nanda Devi in India and the Hawaii Volcanoes) also led to a number of initiatives to promote greater recognition of the sacred aspects of heritage. The WH Fund has sponsored several meetings on this topic (for example, WH Centre, 2002) and is a part of the new "International Network on Sacred Sites for Biodiversity Conservation". This concept is rather poorly reflected in most national protected area systems and its explicit recognition 
through the WH Convention will hopefully encourage wider application.

Another uncommon and often overlooked aspect of heritage that has gained acceptance through $\mathrm{WH}$ is the recognition of geo-physical, geomorphological and fossil sites. A total of $46 \mathrm{WH}$ sites have been inscribed for these values, which has led to greater prominence of geological features as part of a nation's heritage. It has led to a proposal to establish a "Geoparks" initiative which would provide international recognition to the large number of sites that deserve protection for "geodiversity" reasons.

In addition to expanding the approach to considering what comprises "heritage", WH has been a leader in designing new concepts and approaches to management. For instance, WH has been active in fostering the concept of serial sites - the linking of a network of related places within and between countries. This has been a parallel development with "cluster sites" as promoted by UNESCO's MAB programme. The first of these (1988) was the Central Eastern Rainforest Reserves of Australia which set a benchmark for establishing a management framework over a widely dispersed series of remnant forests. Experience gained here was subsequently used as a model for protection of other forests along Brazil's Atlantic coast, Madagascar's wet forests, the boreal forests of Fennoscandia, the sacred forests of Cote d'Ivoire and the marine reserve network of the Belize Barrier Reef. Perhaps the boldest attempt at a serial site is the current project to prepare a nomination of 20 isolated atolls and islands belonging to six countries in the Central Pacific (WH Centre, 2003). All the above efforts complement the linkage and network initiatives proposed by conservation biology planners.

WH has been particularly active in addressing the difficult issue of mining and protected areas. Spurred by threats from mining activities to the $\mathrm{WH}$ sites of Lorentz in Indonesia, Kamchatka Volcanoes in Russia, Kahuzi-Biega and Okapi Wildlife Reserve in the DRC, Huascaran in Peru, Kakadu in Australia and others, the WH Committee established a working group which engaged the International Council on Metals and the Environment (ICME) to study the issue. Subsequent workshops led to a set of principles intended to guide mining activities in and adjacent to protected areas. This eventually led to a position statement on mining and protected areas endorsed by the IUCN Council in April 1999. In 2003, the members of the mining industries belonging to the ICME announced an agreement that they would not undertake mining activities in WH sites. By setting standards for mining and energy extraction near $\mathrm{WH}$ sites, and opening a partnership with the mining industry, new ground in this contentious area has been forged.

An even more complex and intractable issue for some protected areas has been what actions to take in times of civil unrest, warfare and political turmoil. The situation in the DRC which has seriously affected five WH sites there (Debonnet and HillmanSmith, 2003) as well as other lesser known conflicts in India's Manas WH site (Anon, 2003) and the Comoe WH site in Cote d'Ivoire (Fischer, 2003) were the subject of case studies at the World Parks Congress in 2003. Although normal management activities cannot be conducted under these conditions, some effective use of the WH label has been used to open dialogue with the military and rebel groups. Equipment and funds for training and monitoring have been provided in all cases. Crisis management and conflict resolution skills have been strengthened which will prove important in the recovery phase. Again, experience gained on some of the innovative approaches used by WH in crisis situations is of broader use for conservation agencies.

Finally, as suggested by Phillips (2003), the WH experience can be adapted to apply to other international conservation regimes such as Biosphere Reserves, Ramsar and regional agreements such as ASEAN Heritage sites. These lessons would include the value of having independent advisory bodies, the monitoring system that allows a measure of accountability and the opportunities for peacebuilding across international boundaries. With the recent Memorandum of Understanding with the Convention on Biological Diversity referred to above, a closer relationship with this powerful conservation instrument will also lead to stronger "benefits beyond WH boundaries". 


\section{Conclusions/actions}

As evident in Figure 13.1, there is a continuum in the range of the protected area spectrum of which WH is at the pinnacle but where all levels contribute to protecting a nation's patrimony. The contribution of the WH Convention has clearly made a difference through the many activities discussed above. The corollary of this is that individual WH sites should be seen and managed in the overall context of a country's protected area system. The potential benefits of WH to the rest of the system, however, will not occur automatically - they must be consciously pursued. The following actions are suggested:

- State Parties, recognising the multilateral approach of the Convention, need to strengthen transboundary cooperation to achieve more effective regional conservation.

- State Parties should complete the exercise of preparing Tentative Lists of potential natural $\mathrm{WH}$ sites which are now a requirement of the Operational Guidelines and which greatly assist in providing complete inventories of the nation's heritage.

- Coordination of activities between the relevant UN Agencies (UNESCO, FAO, UNDP, UNEP) as well as major donors such as the World Bank and GEF, and international organizations such as the ITTO and the World Tourism Organization, need to be further enhanced as do ties between the international and regional conservation conventions.

- Partnerships between WH and the resource industries (building on the model of the mining industry), particularly forestry, water resources and tourism should be pursued by the WH Centre and IUCN.

- Inasmuch as WH sites need to be models of "best practice", national protected area agencies should ensure that those sites where management deficiencies are apparent are given greater attention.

- Site managers themselves must take greater initiative in working closely with local residents and stakeholders, submitting requests for technical assistance, communicating the message of the role of $\mathrm{WH}$ and how it relates to other protected areas and what it means at the local level.

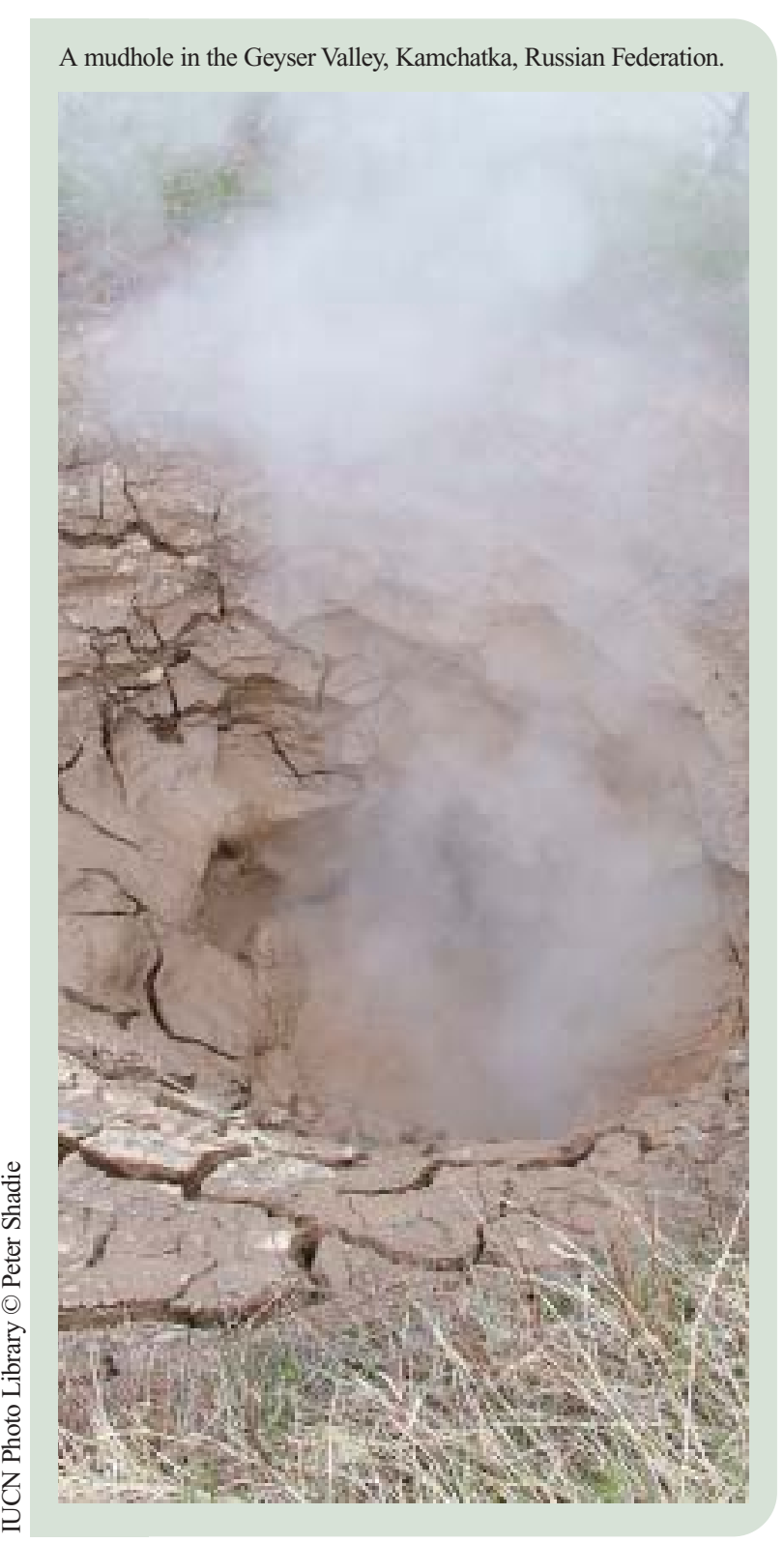




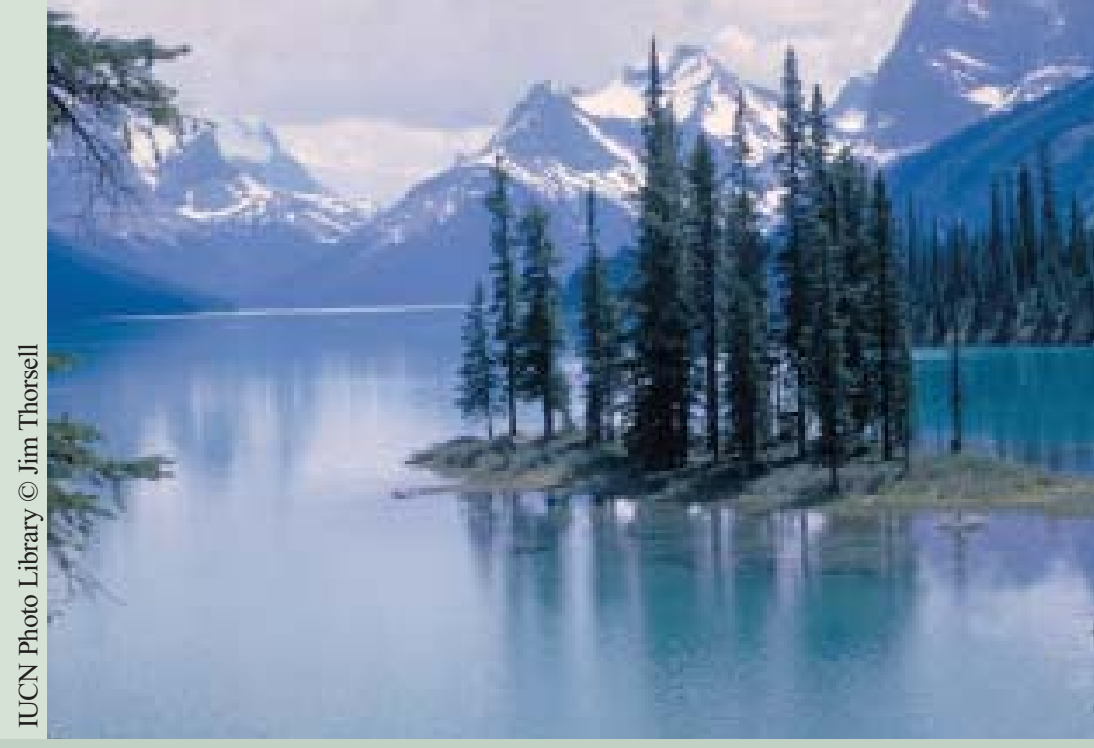

\section{Communication as a means of building support for protected areas}

\section{by Wendy Goldstein and Elisabeth Auchincloss}

\section{Editor's introduction}

People will support protected areas only if they receive information about these sites in a form that is meaningful to them. This requires excellent communication skills on the part of those who are seeking to expand support for protected areas. This paper draws on a series of workshops held under the auspices of IUCN's Commission on Education and Communication to provide advice on how to apply modern approaches to communication to protected areas. It starts by addressing some of the external threats to protected areas, often in the form of competition for resources. Drawing on practical experience in many parts of the world, Wendy Goldstein and Elisabeth Auchincloss share positive experiences on how to communicate with different audiences, with a particular emphasis on the communities in and around protected areas, considering these stakeholders to have particular legitimacy in being involved in decisions that affect them. They discuss instruments for communicating, including information, publicity, stakeholder dialogue, public relations, social marketing, education, and capacity development. Using these tools to package messages that are relevant to the various interest groups affecting protected areas seems to be an essential part of the protected area enterprise. All of the approaches to building broader support for protected areas that are described in this book depend fundamentally on communication. This chapter describes how to use communication as a strategic tool for achieving the broader support that this book is advocating. Rather than relying on technical solutions, it argues for treating external pressures especially as a problem of communication, requiring skills in relation development, negotiation and learning. Such communication skills are the essential foundation upon which building the broader constituency for protected areas can be built. This also requires building understanding about the reasons for current behaviours that may be contrary to the protected area management objectives. Case studies from South Africa, Botswana, the Philippines, Senegal, Mexico, Peru, Nepal and Canada demonstrate the wide variety of communication tools that are available to protected area managers and advocates. 


\section{Introduction}

Whether a protected area is managed by a small community-based organization, an international NGO, a local government, a national institution or intergovernmental agency, an integral component of protected area management is its interaction with people. For a successful interaction, communication must to be used strategically.

Actions conflicting with protected area conservation, promoted by other sectors and developers, present a recurrent challenge. Though it is recognised that environmental concerns are central to development, protected area agencies still have difficulties relating to other sectors. Addressing external pressures requires more than technical responses, suggesting that many protected area organizations need to change the way they work.

Another common issue is the inadequate participation of stakeholders in the planning and management of protected areas. Despite the almost universal recognition of the importance of stakeholder involvement, the inability to handle such processes successfully reflects a lack of capacity and at times will. Because sustainable development is ultimately about social change, it cannot be achieved without communication, education and learning unless it is imposed or coerced (Mefalopulos, 2003).

Often communication is perceived as being the oneway transmission of information, the "push" approach to communication, whereby conservation values are promoted as a means of changing behaviour. Generally this is insufficient in bringing about changes on its own, unless the required actions do not present much difficulty to people.

A two-way communication approach involving dialogue is more likely to be successful. Hamú (2003) refers to a "pull" strategy based on an understanding of the motivations, perceptions and interests of the stakeholder. In this approach people are "attracted" towards conservation action by working from their perceptions. Based on the premise that "perception is the only reality", this requires a different approach by conservationists, and one that acknowledges that conservationists are not "always right" and the rest of the population is wrong.
Communication is increasingly recognised as an important management and policy tool that must be used strategically to address objectives at each phase of the policy or management process. Strategic communication is based on research so that the communication problem is addressed, as distinct from the conservation problem. The communication problem relates to how people perceive the issue and the actions that they take. Strategic communication also plans who is to be addressed, what is to be said or negotiated and the appropriate means to do so.

In accordance with trends towards a broader-based landscape approach to protected area management (Hesselink, 2003), communication as an instrument in protected area management needs to transform, as do protected area managers. After all, their ability to function with the cooperation of society depends on an enabling environment for strategic communication (Van Boven, 2003). Making communications more professional will enable communication to be used strategically to address external challenges.

\section{Communication challenges facing protected area managers}

\section{External threats}

Protected areas are threatened by competition for natural resources. These threats are varied and may be intentional or inadvertent. The protected areas in Mexico, for example, face great pressure because they are not presented in any special way to development planners, so development activities often conflict with conservation objectives (Vidal, 2003). Likewise the Butrint National Park (World Heritage Site), Albania, faced challenges in overcoming resistance from the Ministry of Tourism as well as national and international developers. Weak planning controls, local greed and political interests related to tourism and construction development permitted small-scale constructions in the protected area (Santi, 2003). In the Philippines, local development preferences can counteract national biodiversity targets and affect protected areas. The loss of most of the forest cover during the $20^{\text {th }}$ century was due to logging and conversion of forest to agricultural areas, and "developers" - logging companies - continue to construct and use logging roads in protected areas without approval (Van Weerd, 2003). 
In Peru almost two decades of violence resulting from the drug trade and insurgency resulted in a reduction of the state apparatus for protected areas (Fernandez Davila, 2003). Parks Canada in the 1980s and 90 s faced changes brought about by immigration, multiculturalism and urbanization and the preoccupation of Canadians with social and economic issues such as the economy, health care and education diminished support for protected areas (Bronson, 2003).

In addition to activities driven by contradictory development plans, customary and/or traditional indigenous practices may also conflict with conservation objectives, as is the case in Mexico where unsustainable land-use practices, such as the slash-andburn system of maize production, "are based on deep cultural beliefs and have been transmitted by community elders to new generations" (Vidal, 2003). These examples indicate some of the difficulties faced in creating and managing protected areas.

Many protected area managers come from a technical background which typically provides little training on communication, stakeholder management or interactive policy making (Van Boven, 2003). This results in technical solutions being applied to external pressures, when in fact the problem is a people problem, requiring skills in relation development, negotiation and learning.

\section{Role of communication in protected area management}

Communication, as a tool of protected area management, can hardly be expected to bring about great change in the face of the many socio-economic issues confronted by protected area managers, unless combined with other instruments. The complexity of motivations and sources of changes which affect protected areas suggests the need for communication research that can clarify the change agents in the issue, the sources of influence, the appropriate means to work with people, and ways to break down the tasks into manageable steps.

While some actions conflicting with protected area objectives represent explicit opposition, others may be due to a lack of awareness or understanding of the conservation objectives, the absence of sufficient motivation, or no realistic capacity to act differently. Understanding these reasons for current behaviour is essential before planning a communication intervention for bringing about change.

Much conflict around protected areas has arisen from the failure to adequately involve stakeholders in decisions on protected area management. Indeed, in some cases communication with stakeholders may be so deficient that local people do not even know the protected area exists, why its biodiversity is important, or how it benefits the community (Davila, 2003). Similarly, the lack of clear definitions of protected area boundaries may result in conflicts and disputes over matters such as agricultural borders and practices.

In other cases stakeholders may be well aware of the protected areas, especially when they were established in top-down approaches, through enforcement and compulsory exclusion. These processes were characterized by conflict between the parks and neighbouring communities, mainly due to disrespect for local indigenous knowledge and traditional conservation practices, provoking attitudes against this model of conservation (Makwaeba, 2004; Viday, 2003).

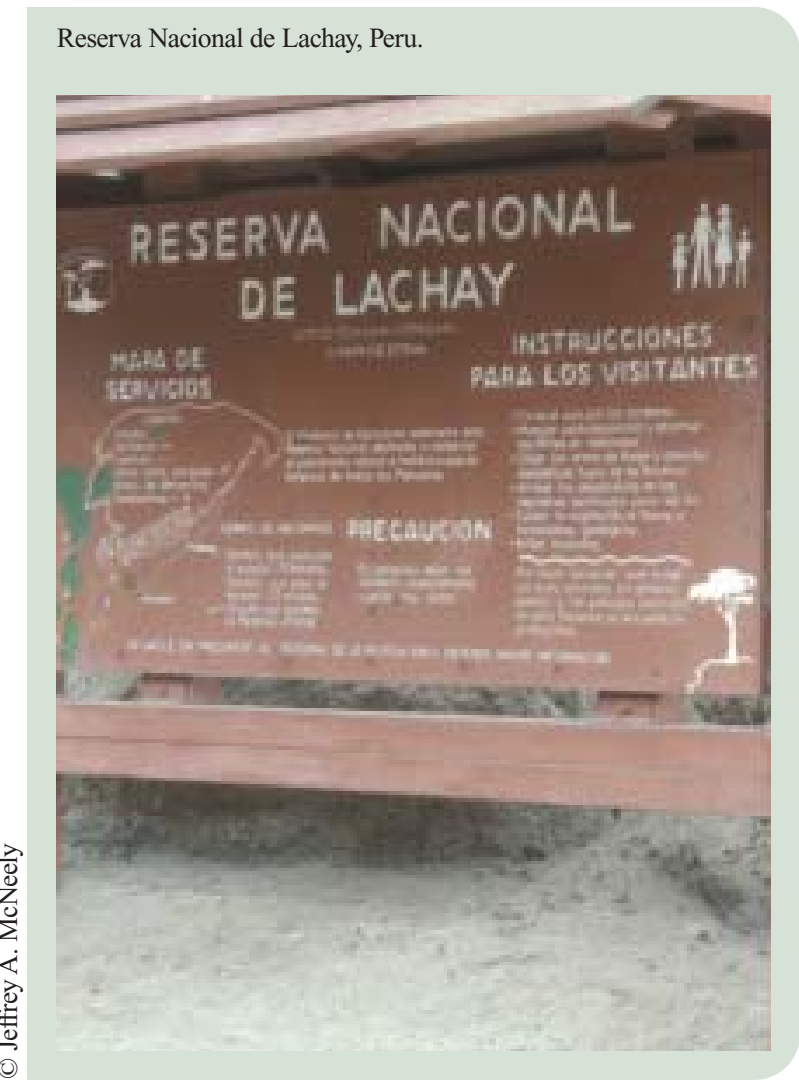


Stakeholders need to be involved in protected area management and trends are pointing in the direction of broader-based landscape approaches, comanagement and public participation (Van Boven, 2003). In the landscape approach, people are at the heart of the mission of a protected area. Therefore, managing protected areas is managing people - with emphasis on participation and not manipulation - and communication becomes increasingly important as a management tool (Van Boven, 2003; Hamú, 2003; Goldstein, 2003). Emphatically, Cavalcanti (2003) states that communication is "the strategic tool to work with people on different levels of the project, including them in decision-making processes".

Communication is the means to participation and is used to resolve diverse stakeholder expectations. Protected area managers need to use communication to build support for protected areas, while resolving and clarifying roles, responsibilities and equity in terms of benefits related to the protected area, developing a shared understanding and developing capacity to act.

Where knowledge of the protected area is lacking, communication is used to ensure stakeholders understand the benefits provided by the protected area, in terms of the long-term conservation of biological diversity, the economic values of protected areas (beyond employment), and their potential for sustainable development.

In South Africa, a "social ecology programme" is being implemented across the National Parks, focusing on the historically disadvantaged communities (those that have suffered from loss of land, loss of access to natural resources, and reduced economic opportunities) living around National Parks. The programme presents a shift to a more holistic, integrated conservation management approach, bringing vital participation of local people into conservation, better reflecting the new political, economic and social realities of South Africa. It aims to acknowledge cultural perspectives in the broadening of environmental interpretation and education, respecting local indigenous knowledge and conservation practices. Selected and trained retired indigenous game rangers/wise elders use the African oral tradition to communicate traditional knowledge about the environment and conservation to youth on four-day bush camps and trails. Local taxonomy, proverbs, beliefs, taboos, community law, indigenous games and workshops are used to increase environmental awareness and guide participants on future involvement in conservation. A follow-up course (6-9 months) with workbook, workshop, portfolio and a practical group project, further empowers participants, building their capacity to address environmental problems and opportunities and develop and implement action plans. Results of this participatory programme include the development of positive attitudes towards parks among disadvantaged communities and increased participation in conservation efforts (Makwaeba, 2004).

In Botswana, the Every River Has Its People project was implemented by the Kalahari Conservation Society and its partners to facilitate the participation of more than 3000 people living in the 25 communities around the Okavango delta. The Namibian government plans to build a pipeline to extract water from the river. The project aim was to give stakeholders a basic understanding of the dynamics of the river and enable communities to play a meaningful role in the management and decisionmaking processes about the delta, and improve communication between government, decision makers, local structures and the community. Using existing institutions and structures in the communities as the initial means for establishing rapport at the village and district level, a communication and education process included consultation meetings, socio-ecological surveys, feedback meetings, capacity building and information-sharing presentations and training workshops. It strengthened working relations and trust between NGOs, the project and government departments, the community and project.

The Haribon Foundation in the Philippines has a strategy of building local government and community support and generating public support towards the management of small marine protected areas appropriate for islands with fragmented habitats and populous poor communities. This NGO has facilitated the establishment and maintenance of about 15 


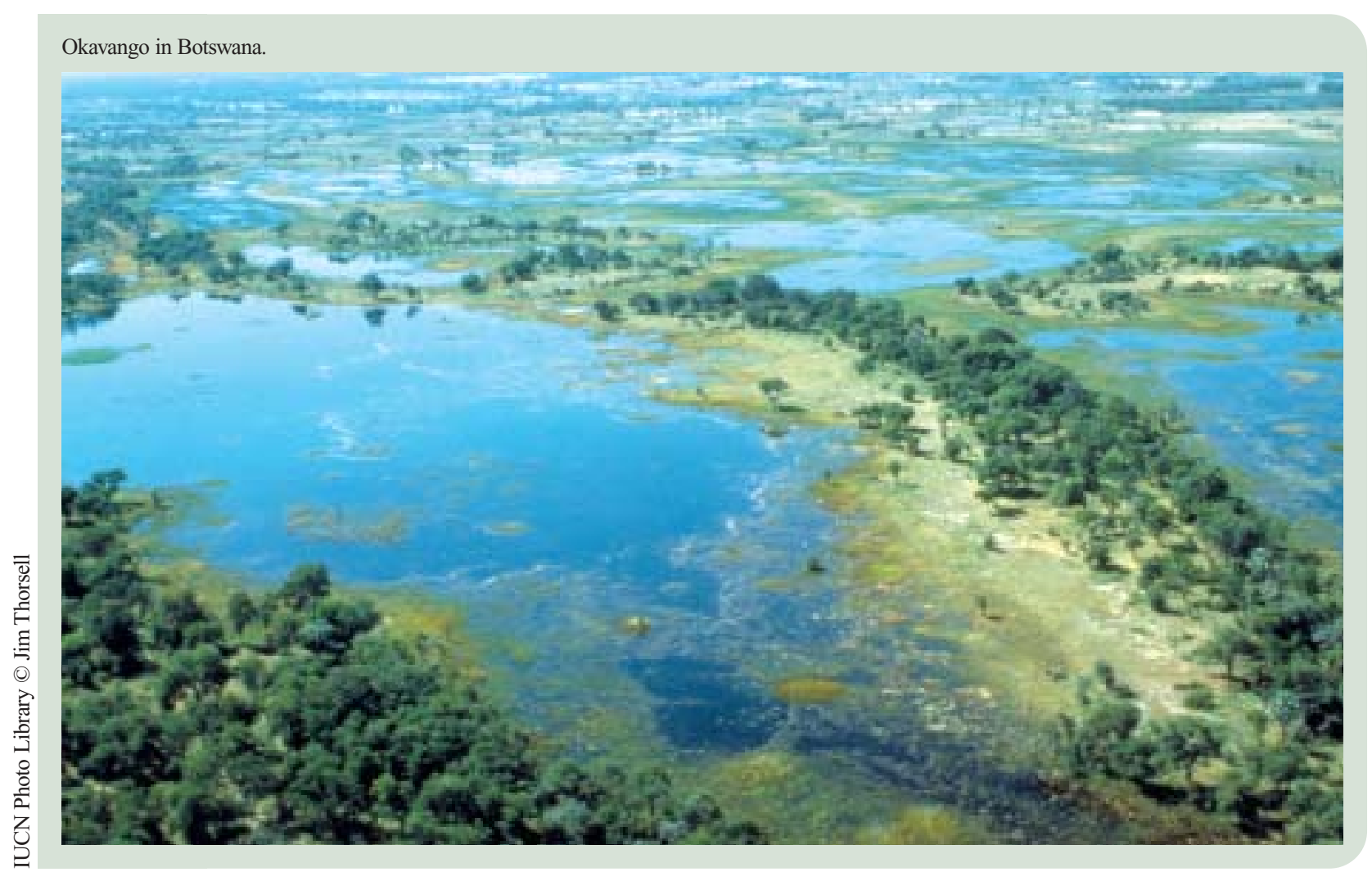

community-based marine protected areas, and the organization of about 134 community-based marine protected areas across the country into a national alliance called PAMANA Ka Sa Pilipinas. This makes it the country's premier national fisher folk organization advocating marine conservation and sustainability of near-shore fisheries (Lavides, 2003).

To achieve the Haribon Foundation's goals of protecting the marine environment, the process of building local government and community support for protected areas and building local and national alliances is estimated to consist of $70 \%$ communication and education activities. The remaining efforts consist of research and other functions. High value is put on the communication skills of protected area champions such as the project staff, particularly the community organizers, local government liaisons, the biologists and the people's organization leaders who are all on the frontline in support of protected areas and biodiversity conservation in general.

As well as working at the community level, Haribon generated support from the public through national campaigns which advocated policy measures for the sustainability of marine conservation efforts and near- shore fisheries. Haribon conducted a market survey in Manila to gauge the top environmental issues. It was not surprising to see that air pollution and waste management were the top two issues identified. This revealed multiple sources for creating awareness for environmental concerns with personal experience highest in importance. Television was the most important source of awareness for all issues for all age groups, followed by the newspaper and radio. Haribon embarked on a multi-media campaign in 2002 and reviewed the impact, achieving an increase in total awareness for biodiversity conservation from $11 \%$ in 2001 to $22 \%$ in 2002 .

At the Tingo Maria National Park, Peru, the benefits of the protected area (principally as a water resource) and further potential benefits (in terms of tourism and education) were emphasised by the Park management, attempting to obtain a favourable change of attitude towards the Park and begin integrating the population towards the co-management. Among other efforts, participatory workshops were developed in the surrounding hamlets and the town of Tingo Maria, building up a vision of the Park, the boundaries and the definition of buffer zones. A Management Committee was formed for the Park, made up of representatives of the distinct sectors, and an 
innovative pilot project was carried out with the local farmers to reduce encroachment on the borders of the park. The project was based on the installation of an agro-forestry system on degraded soils in areas adjacent to the Park, indicating the economic and social viability of improving living conditions for this population while improving the soil.

Results include an improved relationship between the Park administration and surrounding communities, better attitudes towards the Park, its conservation values, and its potential to contribute to the development of the region. The strategy now being used in Peru insists that "communication must be oriented towards demonstrating specific points to be affected, giving the population adequate information, showing them other similar examples and generating a space for dialogue and participation. The outcome is to generate understanding which values environmental quality, promotes a demand for this and generates abilities to act towards avoiding or correcting environmental damage" (Davila, 2003).

In the Djoudj National Park in Senegal, a Ramsar and World Heritage site, Diouf (2003) reported on the changing relations with people over time. In the 1970s a military approach was oriented to keeping people out of the area when the creation of the park disrupted people's pastoral activities and generated conflicts over water for rice production. Now the approach has changed to a more participatory one in which several committees have been set up for communication and decision making; these include an inter-village conservation committee, a scientific committee and an orientation committee. People from seven peripheral villages have been trained to form a corps of "eco-guards" to provide awareness and education activities in the villages and increase appreciation of the park's values and to support the park's managers. Theatre has proved a useful means to help develop understanding and stimulate discussion about how important the park is to the communities. School children in the surrounding villages have met scientists to talk about the future of the park and teaching aids on park management have been provided to secondary schools. Njagabaar magazine for schools, prepared by teachers, is widely read in the villages and has proved an effective strategy. Radio is used for the general public through a partnership to provide a weekly broadcast of thirty minutes. The indigenous people have changed from being hostile to supportive because of the more participatory approach and the efforts made to explain the park's values and show that the park does not take away rice fields. An important influence has been the development of tourism, stimulating more involvement in the park's affairs. To support the tourism industry an infrastructure consisting of an eco museum, artisanal shop and tent provide contact points for an annual visitation of 14,000 .

In the Sierra Gorda Biosphere Reserve in Mexico, conservation and environmental education are addressed in association with the development of

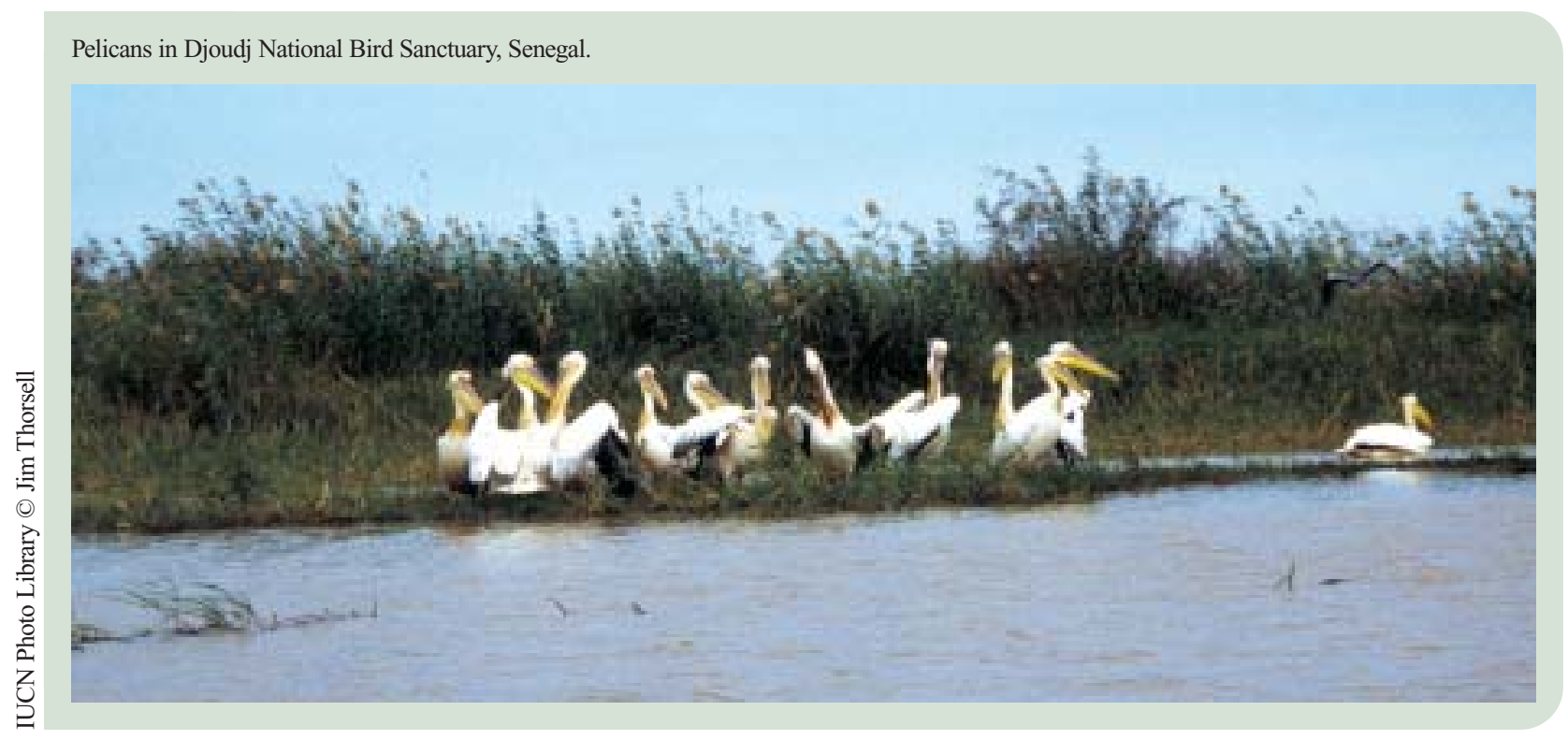


capacity of the community to develop more income and have a healthier lifestyle. In this mostly very poor area, conservation has been promoted as a means to support people's lives, now and in the future, while improving income generation through micro enterprises and diversification of production. The Sierra Gorda communication and education programme presents a graphic statistic about the level of interventions required to effect social change and to support poor communities while achieving conservation objectives. Over 360 training sessions for adults about sustainable alternatives have been held, over 25,000 environmental awareness sessions held with children, 120 teachers trained and 23 children's forests established. Some 500 organic vegetable gardens have been created and 1300 stoves have been introduced using trained community promoters. Over 1800 community meetings were held along with 300 consensus building workshops to adopt a management plan for the Reserve. Over 1300 clean up campaigns have been instigated in the Reserve and 59 recycling centres have been developed which provide income generation. An important part of the strategy to involve the community has been the use of radio and celebrations through "earth festivals" including music and singing. Murals with environmental messages decorate buildings in the Reserve (Ruiz, 2003).

Communication and conservation education have been integral parts of WWF Nepal Terai Arc - a multiple protected areas programme - activities since its inception in 1993. WWF runs many conservation awareness programmes for different target groups to help them understand how conserving the natural and cultural environment will benefit them in the long run. WWF Nepal also uses many communication tools to raise awareness among the people residing in and around the national park areas. Communication and education have played a significant role in creating a better understanding among the people living in the national parks and buffer zones about the needs to conserve the natural and cultural environment. Environmental awareness programmes like community mobile education and extension, audio/visual programmes, campaigns, boards with conservation messages and street theatre, are organized at local levels to create awareness on conservation issues among the local communities. Various capacity building programmes such as training, workshops and study tours, are organized for local staff, teachers and local leaders to develop their understanding and skills in order to make them more capable of working towards conservation and sustainable development (Gurung, 2003).

Of particular interest is the approach used to motivate cattle herders towards conservation. As cattle herders spend most of their time in the forest during which time they destroy plants, cutting off the branches of the trees, collecting the eggs of birds and killing birds for meat, education programmes for them are carried out in the field. At the Royal Bardia National Park a football was given to the group of cattle herders for every 15-20 catapults received. This was to counteract the tendency to kill birds to entertain themselves, as there was no other means of entertainment in the villages. After this programme was launched, the cattle herders would play football rather than kill birds in their spare time.

\section{Role of communication in the national system of protected areas}

At the national protected area system level, Bronson (2003) discusses the difficulties of Parks Canada from the 1980s to the mid-1990s, behind which were internal issues including "shortfalls in professional capacity and fundamental flaws in organizational structure...unclear accountability for overall communication, often no professional communication advice at the management table, no communication unit from which to build and implement comprehensive communication strategies and the erosion of funding support for communication programmes and products".

In Mexico national instruments for communicating the protected area system were needed once a national system had been put in place, helping to give the protected areas a common identity. A logo, norms and standards were developed for the corporate identity, and signposting in all protected areas was given a consistent look. A media campaign was launched with over 1000 events held to build public consciousness of protected areas (Sanchez, 2003). 
A national communication strategy is being prepared, with communication objectives including:

- integrating a biodiversity component into development planning and sector policies;

- increasing the status of protected areas within federal and state administration as well as within local policies and programmes;

- increasing the support of institutional stakeholders (directors of NGOs, decision makers in local government, researchers and social grassroots leaders);

- increasing the support and participation of local users and owners of natural resources in conservation efforts;

- involving participation in planning, changes in land-use patterns and understanding legal frameworks (Vidal, 2003).

As motivation, the Mexican communication strategy aims to communicate national sovereignty considerations and demonstrate economic values of protected areas to stakeholders through leaders of opinion, social groups and journalists. Populations will continue to be encouraged to learn that economic development is not against conservation and that sustainable resource management can increase the quality of life. The intermediate outcomes will be a shared vision of the role of protected areas in development, as well as establishment and operation of an inter-sectoral commission. In the longer term, communities are expected to adopt sustainable management practices and the practice of conservation actions facilitated by an increase of budget and support (Vidal, 2003).

\section{Need for capacity development in communication}

The need for capacity development is being recognised by national and international bodies, such as governments, institutions and conventions. Both the Ramsar Convention and the Convention on Biological Diversity have adopted decisions and work plans calling for integration of communication and interactive management approaches in policy development and site management (Van Boven, 2003). However much remains to be done to develop capacity in communication.
In the Communicating Nature Conservation project of PEBLDS (the Pan European Biological and Landscape Diversity Strategy) 1998-2003 in Hungary, Poland, Slovenia, Slovakia and the Czech Republic, "the team worked with, and at the same time targeted, conservation managers at Ministries and Nature Protection Agencies and protected areas, and their staff" (Van Boven, 2003), assisting them to interact with other sectors and to communicate internally. The project has undertaken four phases of initial common training, institutional development, exchange of experiences among participants at yearly international workshops and learning-on-the-job experiences in national and local pilot projects. This communication project has revealed the necessity for protected area agencies to adapt their management styles and increase engagement with stakeholders, leading to an improved reputation of the agency, reduced conflict and improved management effectiveness of protected areas.

\section{The state of strategic communication related to protected areas}

Whoever the stakeholders, communication and participation are necessary for a project to be valid and sustainable. They are not, however, sufficient unless they are strategic. A communication needs assessment carried out in 1994/5 in South Africa (Anyaegbunam et al., 1998) showed that the wide adoption of participatory approaches, through being based on a horizontal model of communication, seldom resulted in a specific systematic communication strategy. An approach that combined the people-based approach of participation with a systematic communication focus was required for success (Mefalopulos, 2003). Communication needs to be systematic and strategic, directed to achieving management objectives.

In the management of protected areas, neither in theory nor in practice is the concept of communication univocal. Several terms (such as education, interpretation, information and communication) are often used to make reference to the same, or at least overlapping, fields of activities and even when using the term "communication", a 
specific kind (or aspect) of communication may be intended and another understood (Mefalopulos, 2003).

The role of communication is understood in different ways and, consequently, variously incorporated in protected area management. Accordingly, while many "managers still think that communication is just about press releases, brochures, websites and publications" (Hesselink, 2003), others are turning to more comprehensive and participatory communication, and recognising the need for strategic approaches, as a tool contributing to the management objectives and mission of a protected area.

In contributing to a protected area's management objectives, many agencies emphasise interpretation as a means to build support from visitors, enhance their visit, gain their co-operation to protect the natural resources, and ensure their safety.

When used to relate to local communities, local governments, and other agencies, communication strengthens the reputation of protected areas and develops public relations. In this form a dialogue and exchange of information is used, trust is developed and problem solving undertaken jointly.

Table 14.1 presents the range of social instruments that are encompassed by communication and education. In each case the main purpose of the instrument is indicated, along with summaries of the processes that characterize its use, the settings in which it is used and the means used.

Strategic communication is gaining recognition and application, yet many interpretations of what is entailed are still being used. GreenCOM uses the term strategic participatory communication (SPC) as a process for addressing a problem or dispute, bringing people together to:

- Understand how their perspectives on a resource issue differ and appreciate the points on which they agree.

- Make decisions and solve problems in ways that involve and benefit as many people or groups of people affected by the issue as possible.

\section{Table 14.1}

\section{Communication instruments for protected areas}

\begin{tabular}{|c|c|c|c|c|c|c|c|}
\hline & Information & Publicity & $\begin{array}{c}\text { Stakeholder } \\
\text { dialogue }\end{array}$ & $\begin{array}{l}\text { Public } \\
\text { relations }\end{array}$ & $\begin{array}{c}\text { Social } \\
\text { marketing }\end{array}$ & Education & $\begin{array}{l}\text { Capacity } \\
\text { development }\end{array}$ \\
\hline Purpose & $\begin{array}{l}\text { Service } \\
\text { Public duty }\end{array}$ & $\begin{array}{l}\text { Put on agenda, } \\
\text { or position of } \\
\text { organisation } \\
\text { or issue }\end{array}$ & $\begin{array}{l}\text { Consensus } \\
\text { Acceptable } \\
\text { actions }\end{array}$ & Co-operation & $\begin{array}{l}\text { Change } \\
\text { behaviour } \\
\text { towards } \\
\text { conservation }\end{array}$ & $\begin{array}{l}\text { Skills, values, } \\
\text { knowledge }\end{array}$ & $\begin{array}{l}\text { Work with } \\
\text { and for } \\
\text { conservation }\end{array}$ \\
\hline Process & $\begin{array}{l}\text { One way } \\
\text { dissemination }\end{array}$ & One way & $\begin{array}{l}\text { Two way } \\
\text { dialogue }\end{array}$ & Two way & $\begin{array}{l}\text { Mostly one way } \\
\text { based on } \\
\text { research into } \\
\text { motivations }\end{array}$ & $\begin{array}{l}\text { Facilitate } \\
\text { learning }\end{array}$ & $\begin{array}{l}\text { Knowledge } \\
\text { and skill } \\
\text { enhancement } \\
\text { Institutional } \\
\text { frameworks or } \\
\text { settings }\end{array}$ \\
\hline Setting & $\begin{array}{l}\text { Informal } \\
\text { Visitors }\end{array}$ & $\begin{array}{l}\text { Informal } \\
\text { Mass media }\end{array}$ & $\begin{array}{l}\text { Informal and } \\
\text { non formal }\end{array}$ & Non formal & Campaigns & $\begin{array}{l}\text { Formal and } \\
\text { non formal }\end{array}$ & $\begin{array}{l}\text { Non formal } \\
\text { and Formal }\end{array}$ \\
\hline Means & $\begin{array}{l}\text { Website } \\
\text { Brochures } \\
\text { Handbooks } \\
\text { Visitor centres } \\
\text { Person to person } \\
\text { Interpretation }\end{array}$ & $\begin{array}{l}\text { Press releases } \\
\text { Launches } \\
\text { Events } \\
\text { Unpaid } \\
\text { promotion }\end{array}$ & $\begin{array}{l}\text { Interviews } \\
\text { Round tables } \\
\text { Workshops }\end{array}$ & $\begin{array}{l}\text { Telephone } \\
\text { Mail } \\
\text { Person to person } \\
\text { Data base } \\
\text { Informal events, } \\
\text { drinks, meals }\end{array}$ & $\begin{array}{l}\text { Messages via } \\
\text { mass media } \\
\text { Press releases } \\
\text { Events } \\
\text { Theatre }\end{array}$ & $\begin{array}{l}\text { Interpretation } \\
\text { Class visits } \\
\text { Teacher training } \\
\text { materials } \\
\text { Eco clubs } \\
\text { Adult courses } \\
\text { and workshops } \\
\text { Curriculum } \\
\text { influence }\end{array}$ & $\begin{array}{l}\text { Professional } \\
\text { training } \\
\text { Community } \\
\text { development } \\
\text { Mentoring } \\
\text { Policy review } \\
\text { Network } \\
\text { management }\end{array}$ \\
\hline Result & $\begin{array}{l}\text { Visitor } \\
\text { satisfaction } \\
\text { Agency position }\end{array}$ & $\begin{array}{l}\text { Protected area } \\
\text { more visible }\end{array}$ & $\begin{array}{l}\text { Relevant policy } \\
\text { Support to } \\
\text { co-manage }\end{array}$ & $\begin{array}{l}\text { Trust } \\
\text { Partnership }\end{array}$ & $\begin{array}{l}\text { Creating a } \\
\text { social } \\
\text { acceptance of } \\
\text { an action }\end{array}$ & $\begin{array}{l}\text { Attitude of } \\
\text { concern and } \\
\text { ability to act }\end{array}$ & $\begin{array}{l}\text { Competence } \\
\text { to act }\end{array}$ \\
\hline
\end{tabular}

Source: Adapted from Fien, J., Scott, W. and Tilbury, D. 1999. Education and Conservation: An evaluation of the contributions of educational programmes to conservation within the WWF network, pages 26-27. 
- Apply systems thinking concepts to generate a sustainable transformation of the way individuals, institutions, and societies view and manage resources (Hilbrunner, 2003).

For IUCN's Commission on Education and Communication (CEC), communication is defined as 'a 'listening and dialogue' intervention, using a wide range of media to help change an existing undesirable situation into a desired situation for biodiversity conservation. In this process the intent is to change actions, which may come with a change in attitudes, values, and perceptions, of the target group, with the ultimate effect that biodiversity is conserved or used sustainably" (Hesselink, 2003). Strategic communication provides appropriate interventions in different phases of the policy, management plan, or project that are oriented to crafting solutions together and supporting other instruments. Communication is strategic when it does not decide on means first, but rather seeks to define the communication problem, the appropriate groups to work with, the messages to attract them to work together and then the means. Strategic communication is focused on priority conservation or management issues and supports the objectives of these. It is targeted and designed to deliver a specific outcome: increase in support or awareness, new constituencies and partnerships, participation of key stakeholders, acceptable policy or management plans, development of local capacity for comanagement, and investment in social change (Hamú, 2003).

For others, "strategic communication is to... maintain a dialogue among the stakeholders to facilitate a platform of information, motivation and an enabling environment for decision making (choices) at the individual and social levels" (Vidal, 2003).

\section{Conservation International's conservation} awareness efforts aim to inform and inspire key audiences ultimately to change their behaviour in favor of biodiversity conservation. This behavioural change can take many forms and is specific to the targeted public involved, though it is recognised that in many cases, awareness alone cannot change behaviour. Instead, a portfolio of other conservation tools must come into play - such as economic incentives or effective policy changes - for the final behaviour change to be realized. Without conservation awareness playing a part in this portfolio, however, the stakeholders involved may lack the motivation or information necessary to make sound decisions and put conservation into practice (Castro, 2003).

Conservation International (CI) defines conservation awareness as incorporating two distinct but complementary approaches: communications and environmental education (EE). Communications often seek to reach a large number of people, quickly, on a broad regional scale via television, radio, print publications, and campaigns. Through research into identifying sources of information for key audiences and the use of carefully crafted messages, mass communication can be far-reaching, fast acting, and locally targeted. It is an especially efficient way to reach large numbers of people when an issue is urgent (Castro, 2003).

In order for a conservation message to be heard among the information "noise," a campaign must gather momentum and have well-timed "peaks and valleys" within its outreach. In the case of smaller communities, organizing events can reach large percentages of the population and ensure good participation among target publics. Campaigns create media opportunities, allowing journalists to find more fodder for stories and features and address specific challenges or threats. Campaigns can target multiple audiences, helping to "condition" audiences to receive more specific, tailored messages later. Since campaigns are organized within a time frame they help concentrate efforts and to rally partners and donors around a specific theme or need. The launching of documentaries may play an important role as the centre piece of campaigns, gathering hundreds of key stakeholders together. If a partnership can be created with a local television station, the documentary may be broadcast to a larger public, reaching, in large countries, millions of people (Castro, 2003).

Environmental education supplements this process by going beyond awareness, knowledge and concern for the environment and environmental issues, to also develop skills for target groups to participate in problem solving, decision making, and conservation 
action. Although environmental education yields results both now and in the future, an investment in EE reflects a long-term goal of developing an educated citizenry with the capacity to think critically about issues facing biodiversity. EE can either be broadscale (as in formal education reform to integrate biodiversity conservation into the curriculum) or locally targeted (as in training rural educators to teach students and community members about biodiversity) (Castro, 2003).

\section{Importance of research first}

As a strategic instrument of protected area management, communication functions as an indispensable analytical research tool for identifying, investigating and analysing needs, risks and problems that need to be addressed (Mefalopulos, 2003).

Yet problems of inadequate planning of communication and education strategies continue, perhaps because of inadequate communication research (Encalada, 2003). Communication research is crucial in:

- addressing the problems and the need for environmental strategic communication in protected area management (Vidal, 2003);

- defining target audiences/stakeholder groups and actors/publics (Bronson/Castro, 2003);

- examining the socio-economic and political structure, and cultural aspects of the area and people (Hilbrunner, 2003);

- assessing people's dependence on, and relationship with, the area and its natural resources (Molefi, 2003);

- evaluating awareness levels and attitudes of people towards environmental issues (Mahajan, 2003);

- analysing what is currently working well and where efforts need to be concentrated to achieve results (Bronson, 2003);

- identifying potential partners in the area (Molefi, 2003).

Greater research into the people towards whom protected area communication is to be directed enhances the likelihood of successful communication. Understanding the needs of the people, their perceptions regarding the protected area and their own communication structures and skills, enables

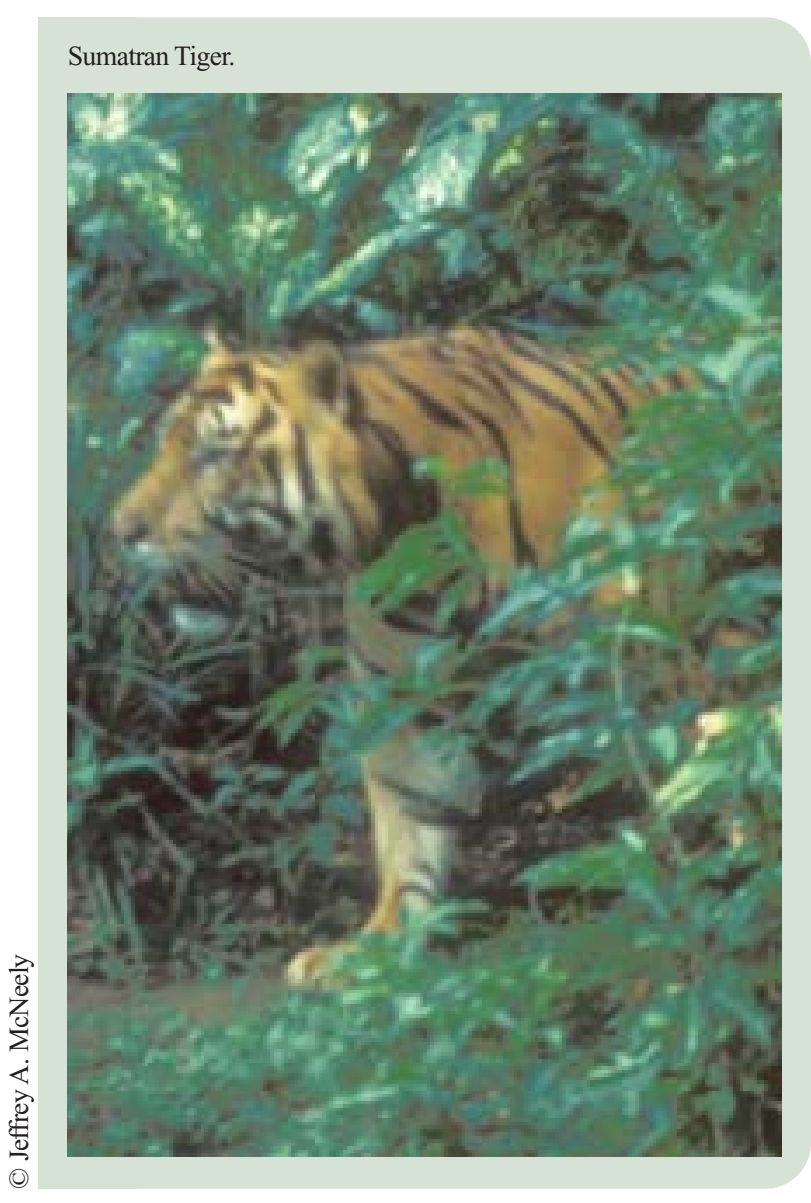

communication strategies to be designed which are specifically tailored to them (Encalada, 2003).

Encalada (2003) presents a model of communication research focusing on the basic conceptual knowledge and perceptions of audiences regarding: their influence on the protected area; potential to contribute to conservation of the protected area; potential to benefit from conservation of the protected area; the conservation needs of the protected area; and the adoption of practices contributing to conservation of the protected area. The audience's communication structures and skills also need to be analysed, including: exposure to external information (whether from other people, mass media or electronic information systems); ability to process external information; ability to express their views; ability to defend their rights; communication systems within the community (cultural expressions and communication media); opportunities for dialogue and practical demonstrations at all levels; and informal networks of social influence.

This information can be used to map the role and influence of different individuals and groups in 
relation to the natural resource, classifying people into groups with progressive influence - with the most being substantive, followed by supportive, factorial and general. Based on this classification, appropriate and effective communication can be designed.

\section{The process of communication planning}

Participatory practices should be maintained while defining objectives, planning further communication, implementing communication plans, and evaluating the communication strategy, as well as during constant step-by-step evaluation and revision of intermediate outcomes, in order to make any necessary strategic adjustments (Molefi, 2003; Vidal, 2003).

Once the audience-specific objectives are defined, objective-specific and appropriate communication actions are designed, with expected results, indicators and criteria for evaluation (Vidal, 2003). Accountability should also be determined, specifying where responsibility for the communication actions will rest, recognising geographic and organizational realities (Bronson, 2003).

CI uses the 4-P Creative Workshop, with the name derived from the four main sessions of the workshop; Problems, Publics, Products and Plan. The process of the workshop is to assess the Problems to be addressed in a particular geographical area; define the Publics that the message will target; identify the appropriate Products to reach these publics; and design an action Plan, including a clear timetable for a two-year period. It is a participatory exercise with about 30 to 40 people, which goes beyond formulas in order to create "custom-fit" communications strategies for specific regions, ecosystems or conservation outcomes. The approach was inspired by different methodologies, including innovative advertising and social-marketing techniques (Castro, 2003).

Workshop participants include communicators and educators from partner organizations, members of the national and local media, marketing specialists, government officials, protected area staff, and other appropriate representatives of selected stakeholders who are directly related to the theme of the workshop. Workshop organizers then refine the plan into a communications strategy during an internal session after the workshop, incorporating any funding, staffing, and scheduling realities. A final report is then made available to all those who participated so they can see how their contributions were used.

When it comes to the delivery, or 'carrying out', of the communication actions, different approaches are needed, beginning with positioning the concepts and ideas, followed by a reflexive phase and a

\section{Changing the way conservation organizations work}

Protected area management agencies may need to change their own attitudes to take full advantage of the benefits of communications for building broader support. In Central Europe the changes in attitudes and behaviour of the protected area managers for their new role in building relations and communicating include:

\section{Table 14.2}

\begin{tabular}{ll} 
From & To \\
\hline $\begin{array}{l}\text { Perceiving farmers as enemies } \\
\text { Focusing on science (conservation) as the most } \\
\text { important issue }\end{array}$ & $\begin{array}{l}\text { Focusing on people (socio-economic) as well asissue } \\
\text { science (conservation) }\end{array}$ \\
\hline Seeing farmers as a problems & Realizing everyone is part of the problem \\
\hline Sending messages & Listening and having an open mind \\
\hline Trying to press people to believe as they do & Changing attitudes from negative to neutral \\
\hline Behaving as experts & Behaving as partners \\
\hline Formal and authoritarian behaviour & Informal and more egalitarian behaviour \\
\hline Planning communication based on assumptions & Planning based on the goals of the stakeholders \\
\hline Push strategy & Pull strategy \\
\hline Conservation managers as initiators & Conservation managers as stakeholders \\
\hline
\end{tabular}


mobilization stage (Vidal, 2003). The communication messages, means and actions should be pre-tested in an experimental phase designed to identify effective approaches and improve the strategy before largerscale application (Hilbrunner, 2003; Mahajan, 2003).

As indicated above, monitoring and evaluation are not left as afterthoughts in strategic communication. With indicators and criteria for evaluation and monitoring defined early on in the process (with the definition of objectives and the design of communication actions), these are ongoing processes facilitating informed and strategic response.

The main challenge still faced is systematically mainstreaming communication in conservation and development interventions. To promote the valueadded of this discipline, communicators need to provide empirical evidence on the impact of communication in development initiatives, strengthening the likelihood of communicators being integrated within management (Mefalopulos, 2003).

\section{Professionalizing communication}

Besides these organizational change issues, which are associated with a suite of other organizational skill capacities, communication often has a low position within the organization. This limits both the resources allocated to communication and the influence of communicators in the work of the organization and the protected area. When communication is not seen as a fundamental part of the organization's relations, reputation and strategy, it is used simply to make publications and brochures attractive. Associated with these management issues is clarity on the responsibilities of the communication department/personnel, internal barriers and resources (Vidal, 2003), and the organization's capacity for enabling decision making (Molefi, 2003). Professionalizing communication is an internal challenge which must be faced by protected area management before communication can be used strategically to address external challenges effectively.

The Parks Canada national communication strategy, Engaging Canadians, went hand-in-hand with a new organizational model. Each Parks Canada field unit was to create a communication unit, headed by a communication manager, providing leadership and coordination of the full range of communications activities, including agency communications, programme/service communications and education communications (Bronson, 2003).

Implementation posed some significant challenges, such as building buy-in among managers and staff for the organizational change (managed within existing budgets), overcoming fatigue from successive reorganization, getting the right people in place, recruiting and/or training for the new skill sets of the future, and building the culture among staff that recognises and supports communications as one of the primary tools for achieving the mandate. Nevertheless, these organizations are now getting established with key positions being staffed with qualified professionals. Next steps in the process include the establishment and strengthening of internal and external networks to build synergy and cooperation, filling the skills gap through training and professional development, and ensuring the tools and processes are in place to enable communication professionals to succeed (Bronson, 2003).

Communication actions included implementing a consistent and professional identity for the Agency, improving and integrating the delivery of information services on the web, by telephone and in person, facilitating awareness, trip planning and reservations, and presenting Heritage awards of excellence to recognise and reward excellence and innovation in programmes, products and people nationwide.

Early results of Engaging Canadians include a stronger, more cohesive and professional national identity; improved relations with key stakeholder groups; better issue management; and recognition of the importance of education. Parks Canada is now seen as a trusted steward of heritage and a trusted source of information on the state of Canadian National Parks. The level of awareness and trust Canadians have for Parks Canada is a good starting point as we move down the continuum from "inform" to "influence" and "involve", but the trust of Canadians must continue to be earned through actions taken every day by Parks Canada. 


\section{Conclusions and recommendations for the next decade}

The added value of communication to protected areas is to achieve policy and management objectives and reduce conflict, by involving people in the early phases of policy and management planning. Communication plays a role in developing relations in partnerships, developing new constituencies, changing policy, supporting and facilitating participation, and developing local capacity. It contributes to the reputation of the organization and the sustainability of programmes by investing in social change and building social capital.

A significant percentage of the population does not know much about protected areas because communicating their values has been given a low priority. Even in government agencies charged with responsibility for biodiversity conservation, biodiversity is regarded as low priority compared to other environmental issues. This is compounded in developing countries with the low awareness among funding agencies about the importance of biodiversity information dissemination. Many of the available funding windows currently in place are for community development, governance and poverty alleviation (Lavides, 2003). Therefore, advocacy for the need for protected areas communication and public awareness raising campaigns should be directed to the governments and donors, academics and other influential organizations such as religious bodies.

The resource management efforts of local communities and local government must build support from the general public in urban areas where public opinion has direct impact on policy making. Policies that shape the nation, public opinion, and therefore public pressure are created in the urban centres (see Tryzna, this volume). The plight of the communities near the protected areas and that of the protected areas themselves will not be addressed if these matters are not brought to the attention of policy makers through public opinion, which is heavily influenced by the urban public.
Crafting messages to stimulate interest in protected areas requires connecting biodiversity issues to everyday life: for example, to link flooding with deforestation and biodiversity loss to economic losses. Protected area concepts, issues and solutions should be communicated in a language that the public can relate to by adapting messages to the information gleaned from market surveys. Messages that engender pride in protected areas as national symbols, and their economic values, can also be effective.

Because of the large task to build support for protected areas in many countries, forming and strengthening partnerships is essential for effective action. Partnerships are in evidence among organizations from government, civil society, the corporate sector, and academia. Also important is increasing membership of environmental organizations to add weight to their voice, provide funds and become a more effective constituency for protected areas. People are influenced by friends and relatives, so building a large cadre of people able to express support for protected areas provides an important conduit of influential information.

Actions for the next ten years should include:

- Protected areas should include strategic communication as part of training for PA managers, with a rationale for communication and for involving communication thinking (and professionals) from the beginning of planning.

- Conservation organizations should provide a means to give strong support to the HOW and WHY of communication, so that the value of the instrument might be better appreciated by protected area managers.

- In recognition of the conflicts and problems encountered in many development projects, often due to weak use of communication, communication capacity should be included as part of development programmes affecting protected areas.

- Prepare guidelines on communication which include tools and clarify standards of good communication (IUCN's Commission on Education and Communication), and develop a curriculum on protected areas for journalism colleges. 
This book has contained numerous examples of economic sectors and institutions that potentially have an interest in supporting protected areas, ensuring that they are managed effectively, and enabling them to contribute to the full range of ecosystem services. This chapter brings together some of the main lessons learned from the previous chapters, and thereby contributes to the Programme of Work on Protected Areas agreed under the Convention on Biological Diversity.

Because people have occupied virtually the entire land surface of the world for thousands of years, no "unoccupied" land is available, and the biodiversity that is found today is the result of a long history of interaction between people and the rest of nature. But modern society has brought expanding populations, global markets, and new pressures on land and resources. Protected areas are an essential element of the strategies of modern societies to ensure that resources are used sustainably and biodiversity is conserved for present and future generations. Protected areas provide a wide range of economic, social, cultural, recreational, scientific and spiritual services. These services provide very considerable economic benefits, ranging from tourism development to carbon sequestration to watershed protection. For example, for many protected areas, direct revenues from tourism far exceed the management budget, though revenue to protected areas themselves tends to be relatively modest because of low admission fees. The economic benefits from watershed protection often are even greater, though means of capturing such benefits by protected areas remain elusive. The configuration of the benefits from ecosystem services will vary with the distance from the site. For example, products harvested directly from the forest are likely to be of greatest interest to communities in or near the buffer zone, while recreational opportunities and water supplies may be of greatest interest to nearby towns and cities. The existence value of tropical rainforest species such as tigers or rhinos is often appreciated more in big cities or industrialized countries than in or near the forest itself (van Schaik and Kramer, 1997), so rural communities are unlikely to be as concerned about threatened species as scientists or nature advocates living in urban centres might be.

Inevitably, a protected area will enhance certain types of economic opportunities, such as tourism or recreational home building, while hampering others such as logging and mining. Some rural communities have been devastated by the closing of mining and timber operations and others have had to face social and infrastructural problems of rapid growth brought on by increased tourism and associated construction. Thus New York's Adirondack Biosphere Reserve, with several resort towns including Lake Placid, saw a dramatic increase in the proportion of service and retail trade jobs and a rapid decline in the number of manufacturing jobs during the same period. 
Converting the potential benefits of protected areas into real and perceived goods and services for society at large (and especially local people) requires a systems approach, as supported by the Convention on Biological Diversity (Article 8a). Elements of this approach include:

- At the national level, each country should have a protected area system plan that presents a coordinated strategy clarifying objectives and goals for individual protected areas and the protected area system, and identifies priorities for investment. A system plan enables protected areas to be integrated fully within all key planning frameworks, including land use and development plans, national biodiversity strategies and action plans, and strategic plans for all relevant sectors

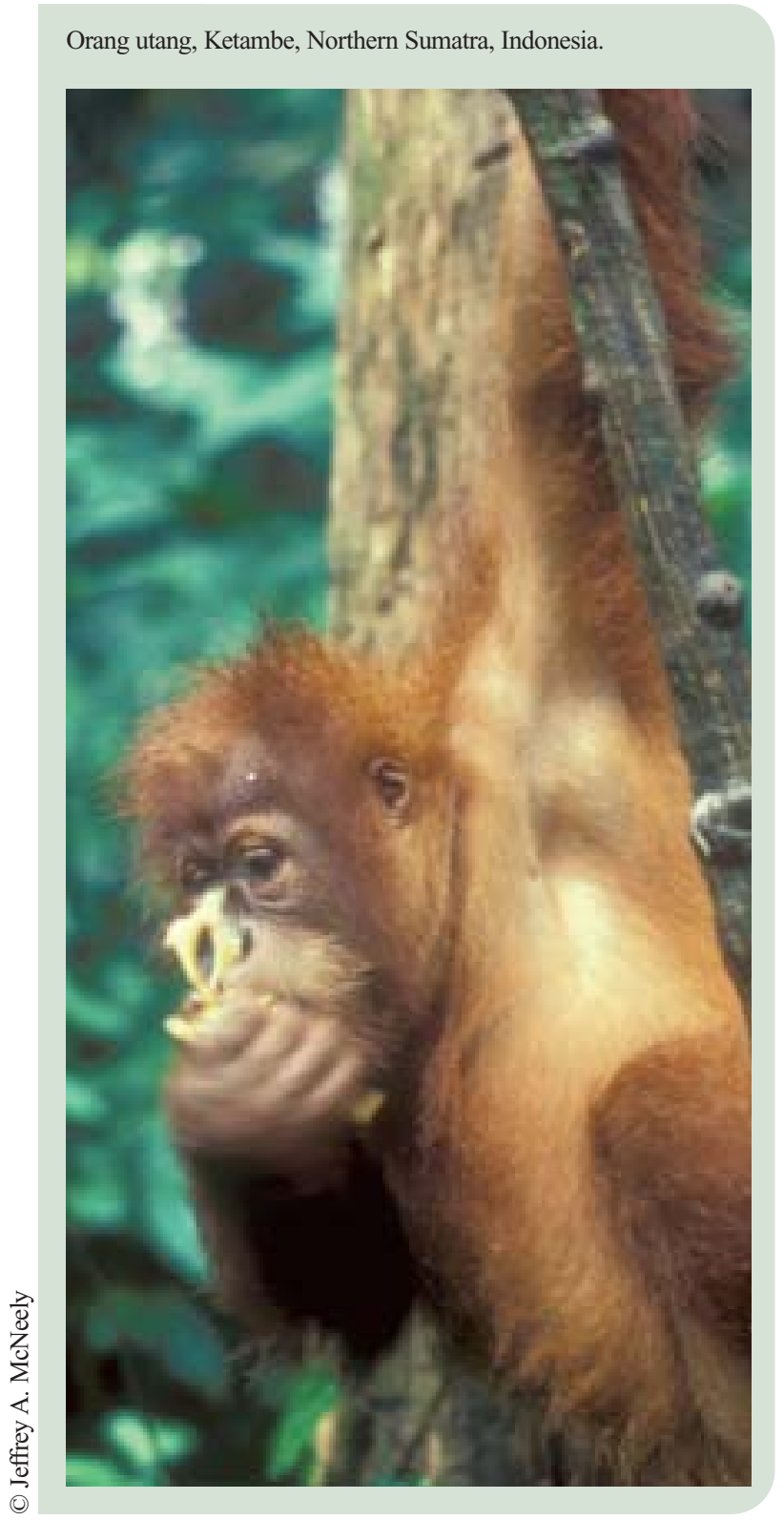

(including tourism, health, energy, transport, forestry, agriculture, and even the military). The protected area system needs to include examples of the full range of habitats, communities and other landscape features of the country as well as areas of particular biological significance, such as the habitat of rare species. A protected area system needs a strong legal component as well.

- Within each country, the approach to conservation should include core areas that include national parks and other categories of relatively strict protection located within larger landscapes comprising whole ecosystems that surround the core areas, where voluntary cooperative agreements can be established with stakeholders and other interested parties in a decentralized manner, and where various forms of land use (including agriculture, forestry, mining, and energy development) can be managed to support the continuing delivery of ecosystem services.

- At the site level, each protected area should have a management plan which specifies its management objectives, sets up effective mechanisms for reconciling any conflicts with neighbouring lands, and establishes a framework for partnerships with potential interest groups such as those identified in this book. Ideally, each management plan should be very specific about its relationship with any agricultural lands that may be found within the protected area, and forestry, resource extraction, and agricultural lands in the surrounding matrix.

- Effective links need to be established with the social, political, economic and ecological processes which affect the protected areas, helping to put into practice the Millennium Development Goals. Ultimately, solutions for many of the threats facing protected areas belong in the realm of national and international politics. Important influences on the demand for park resources, such as local land ownership patterns, credit and income inequities among agricultural producers, and indigenous peoples' rights to land and resources, are politically volatile and often beyond the power of park managers and 
conservationists to control. Often other government ministries may be directly at odds with the goals of conservation. Frontier settlement programmes, emergency refugee relief, planned colonization of protected areas for national security reasons, and commercial exploitation of natural resources to service national debts, result from government decisions that may be oblivious of protected area objectives.

- Within the framework of the market-based economic systems that are becoming increasingly widespread, greater participation by the civil society in economic development should extend to the management of protected areas, especially for tourism and the sustainable use of certain natural resources.

The implications of these measures for building broader support for the integrity and objectives of protected areas will require additional efforts to establish standards and enforce them. Thus the appropriate government institutions will need to continue strengthening their role in the creation, planning and management of protected areas, while inviting greater participation of NGOs, private business, universities and local communities.

One useful mechanism for putting this vision into practice is through "Integrated Conservation and Development Projects" that seek to reconcile conservation and community interests through promoting social and economic development among communities in and around protected areas. Past shortcomings have shown that such projects need to be carefully designed to ensure that the interests of the various stakeholders are well represented. It is critical that the effort involves a clear identification of the problems facing the protected area so that the proposed measures specifically address the problems identified at the level where the intervention can be effective.

While early efforts at establishing protected areas often excluded people, more recent approaches have sought to involve local communities in ways that are appropriate to the agreed objectives for the protected areas. This can be a considerable challenge, as local people often feel disenfranchised and would like to

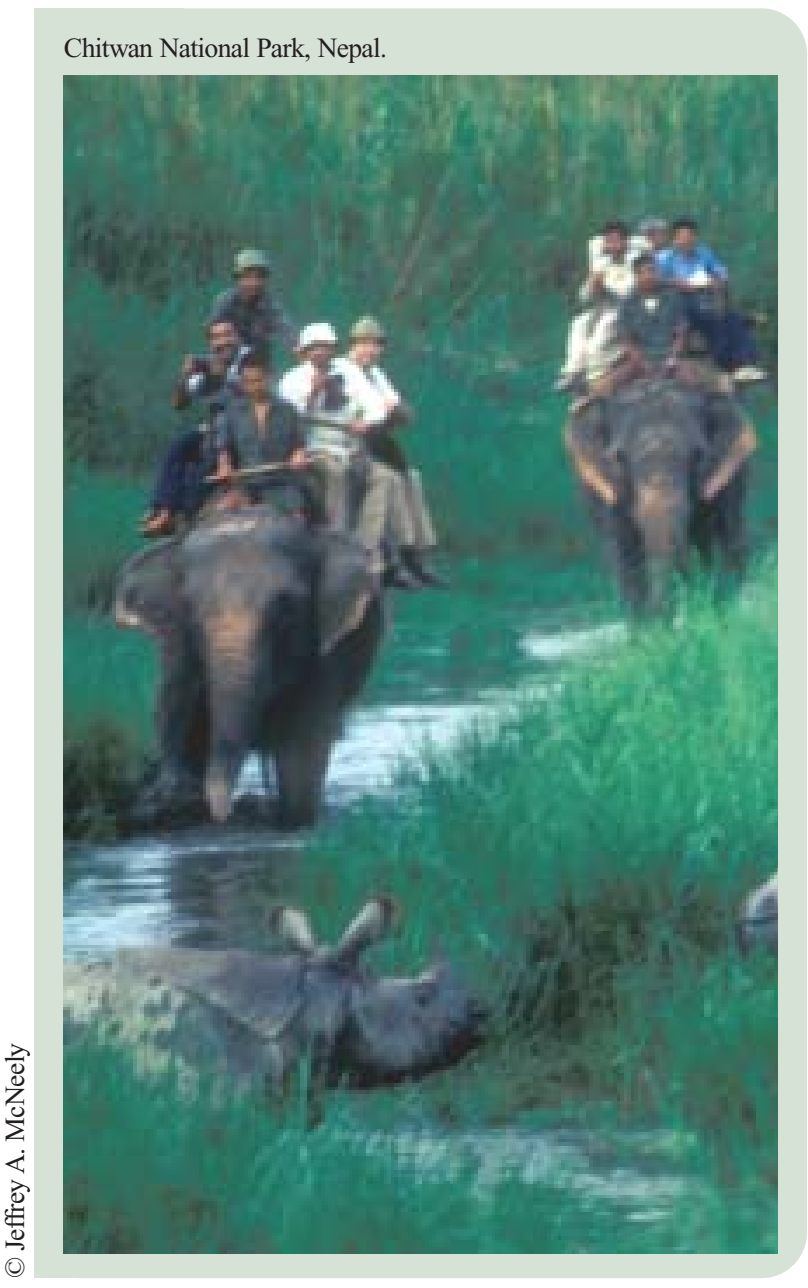

extract far more resources from a protected area than can be provided on a sustainable basis. Providing sustainable services to local communities from protected areas may require more effective controls to ensure that populations of plants and animals - and the services they support - are maintained at productive levels. The general approach to protected area management that is advocated in this book involves using a wide range of protected area categories managed as a system that involves national, provincial and local governments, non-governmental organizations, local communities and indigenous peoples, the private sector, researchers and other stakeholders. This does not remove the need for active protection by government, as some individuals will always be able to benefit from "beating the system", to earn individual benefits by breaking regulations that are designed to provide broad social benefits.

Joint management agreements with new partners may also be possible. The objective of a joint management agreement is to arrive at a series of accommodations of the goals and needs of both 
parties through mutual decision-making, with the intent for informal resolution wherever possible (Planning and Conservation Services, 1990). Involvement of all groups from the beginning promotes ownership in the process, which in turn channels energies towards constructive problemsolving rather than criticism. Joint management agreements must be clearly stated with no ambiguity that can lead to divergent interpretations and result in on-going conflict. Under a joint management agreement, the management of a protected area must be completely cooperative, with no decisions being made without consultation among the two groups. Where indigenous peoples are joint managers, their role must be as equal and effective partners on an ongoing basis, at the upper policy-making management levels as well as at the field level as rangers. An advisory committee, composed of native and government representatives. should reach decisions by consensus rather than by voting, and allow for freedom of exchange of experience and knowledge between the groups. The members of the committee should try to bring together the concepts of scientific and indigenous knowledge.

\section{Conclusions}

This book has built on the fundamental assumption that protected areas provide multiple benefits to many groups of people. Different benefits flow differently to different people, in different ways. Some of these benefits are easy to recognise and capture in an economic sense, such as tourism; others are easy to recognise but the economic benefits are more difficult to capture by the protected area, such as watershed protection; others may require new regulations to ensure a flow of benefits, such as carbon sequestration or conservation of genetic resources like wild relatives of domestic plants; and still others may require new ways of thinking, such as health, non-material, spiritual or cultural benefits.

Continuing to provide a stream of benefits may require some trade-offs, deciding whether to value long-term benefits over immediate ones, or whether to provide wide benefits to the general public rather than financial gain to a select few. This requires clearly identifying and measuring the multiple flows of protected area services, developing means to convert services into support for protected areas, and negotiating ways to ensure that the distribution of protected area services among the multiple interest groups is socially equitable.

It also requires a more complete assessment of the costs of protected areas, including the costs of managing the area effectively, renouncing alternative uses of the land, and controlling problem animals that may move out of the protected area and cause economic damage to local people. And perhaps most important is to address the opportunity costs paid by the people who live in and around the protected areas and who are no longer permitted certain forms of land and resource use. In short, the foundation of support for protected areas is a sound assessment of costs and benefits, and their distribution.

Building broader support for protected areas also faces some obstacles. These may involve conflicts over competing values, for example, choosing to harvest logs for construction or to maintain trees for providing habitat to wild species. The effects of globalization may pit local interests against international ones, while the effects of decentralization may distort the relative power of some interest groups. In some cases, governments may be reluctant to enable protected areas to collect payments for the ecosystem services they are providing, preferring that any income generated goes to the central treasury instead.

Protected areas are complex systems of land management, which involve complicated issues and numerous stakeholders who have different perspectives on the issues. This book has explored the principle that protected areas are more likely to prosper when they have a wide range of supporters in political terms, "a broad constituency". This means giving multiple stakeholders a real interest in protected areas.

Generating more support from politicians for protected areas requires convincing them of the political importance of protected area issues. This in turn requires that the public be provided with fuller information about the benefits, both tangible and intangible, that protected areas provide. Politicians also need to be provided with evidence to enable them 


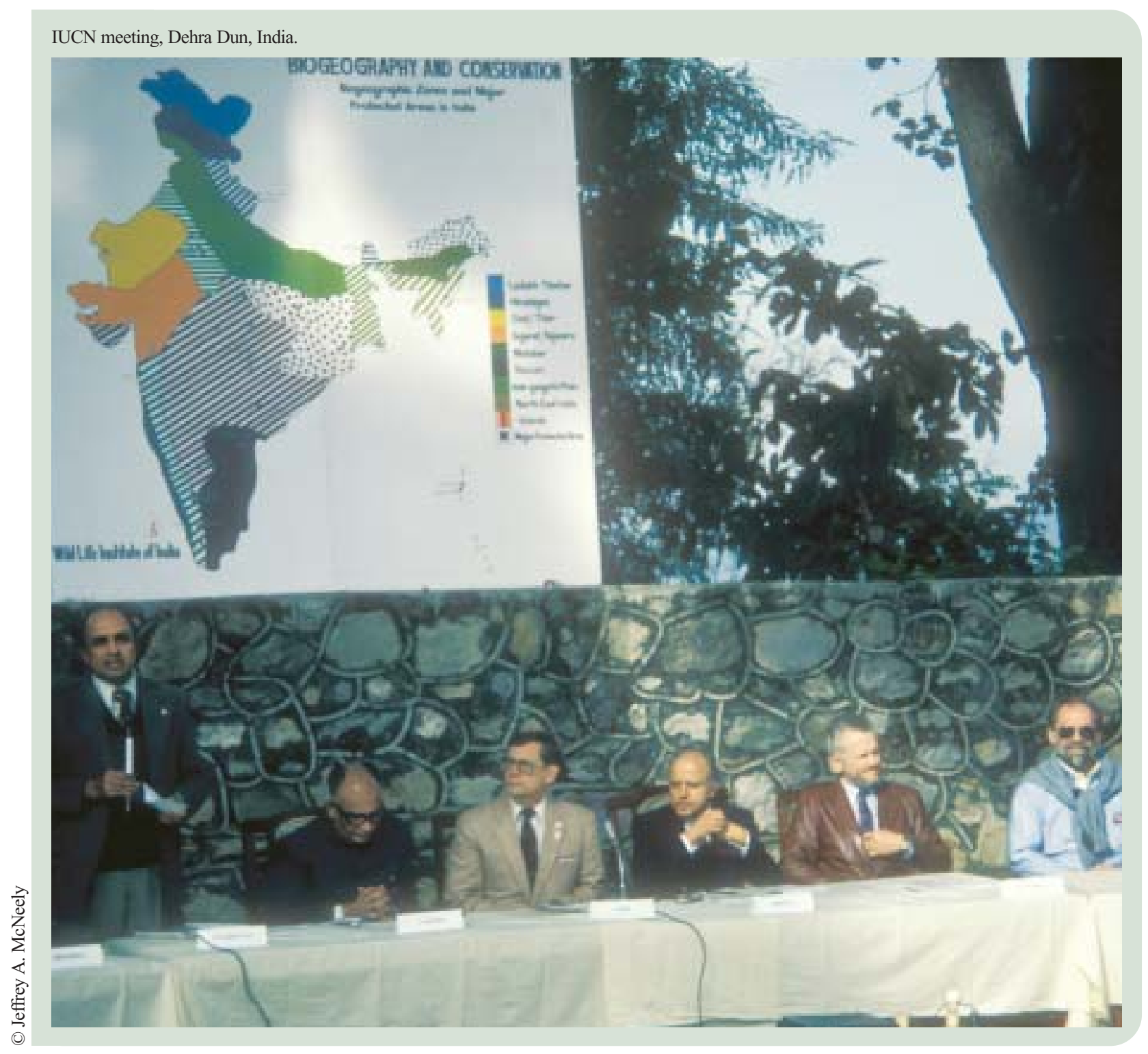

to state convincingly the case for support of protected area agencies. This book has provided an indication of the range of public and private sectors which benefit from protected areas. It has outlined both the nature and extent of benefits to both protected areas and those sectors, and indicated how such benefits can be improved or increased. Drawing from this summary, each sector now needs to be approached in each country, urging their support for the integrity of protected areas and providing adequate resources to manage them effectively.

This book also provides the basis for identifying sectors whose activities may impinge adversely on protected areas and seeks their cooperation in maintaining the integrity of protected areas, mitigating against adverse impacts, and finding ways of being supportive of protected areas.
A programme for national protected area systems needs to include both firm governmental action and alliances with the other stakeholders. National governments cannot delegate their role of guarantors of the conservation of a country's cultural and natural heritage, so the appropriate authorities need to build the capacity to fulfil their regulatory and management duties and responsibilities. But civil society can share certain rights and responsibilities regarding the management of protected areas after careful preparations and an adequate definition of roles and responsibilities. Given the interests of NGOs, veterinarians, business, indigenous peoples and local communities who live within or close to protected areas, alliances should be created among stakeholders enabling each to play an appropriate role according to clear government policies and laws. 


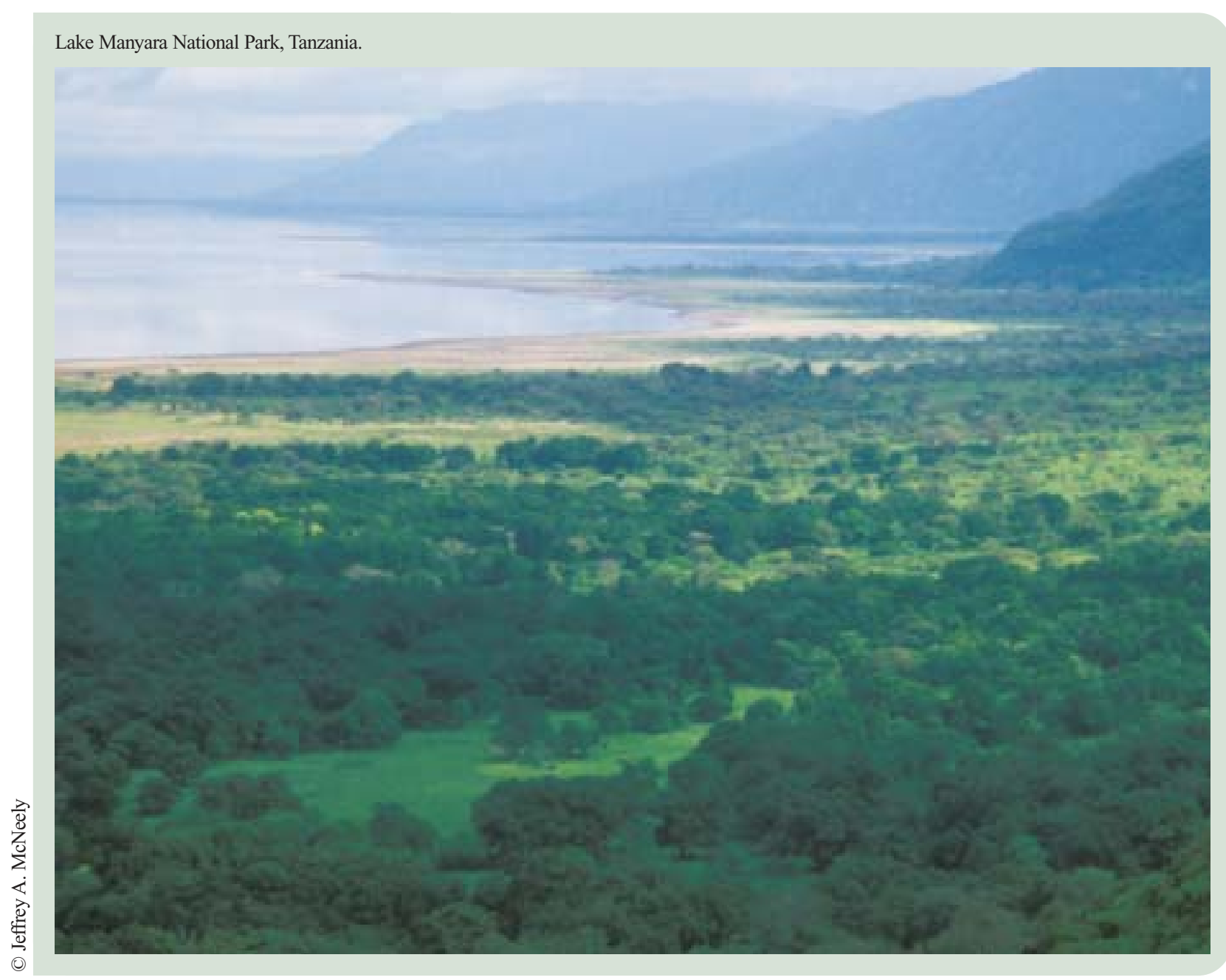

And finally, we need to recognise that new challenges require new knowledge. A vigorous research capacity is an essential element of building support for protected areas. In seeking to encourage universities, research institutions and others to carry out research that is essential and relevant to successful protected areas, the international community should promote the following kinds of actions:

- strengthen the institutional capacity of research institutions in each region, including universities, museums and field stations;

- support long-term ecological research sites located in protected areas;

- mobilize local indigenous and traditional knowledge about species, ecosystems, resource management systems, traditional laws and regulations, and so forth;

- incorporate research components in major development projects that affect protected areas;
- support cooperative research programmes, for example between animal and human health and protected areas; and

- support broader studies of the operation of economic systems as they affect protected areas and biodiversity, focusing on macro-economic policy and development strategies in attempting to provide more general conclusions about the relationship between development and natural resource management.

It is hoped that enlisting new partners will result in broader support for protected areas in all parts of the world. If civil society can become an active partner in the management of protected areas, then we could see a new era of conservation - an era in which civil societies have the will and the means to assume an effective stewardship role over their own resources, conserving biological diversity, using biological resources sustainably, and ensuring that the benefits of such use are distributed in a fair and equitable manner. 


\section{Acronyms}

\begin{tabular}{|c|c|}
\hline ADB & Asian Development Bank \\
\hline BEN & Black Environment Network \\
\hline CBD & Convention on Biological Diversity \\
\hline CGIAR & $\begin{array}{l}\text { Consultative Group on International } \\
\text { Agricultural Research }\end{array}$ \\
\hline CIDA & $\begin{array}{l}\text { Canadian International Development } \\
\text { Agency }\end{array}$ \\
\hline CITES & $\begin{array}{l}\text { Convention on International Trade in } \\
\text { Endangered Species of Wild Fauna } \\
\text { and Flora }\end{array}$ \\
\hline CNP & Council for National Parks \\
\hline CUBES & Cape Town Urban Biosphere Group \\
\hline EBI & Energy and Biodiversity Initiative \\
\hline EIA & Environmental Impact Assessment \\
\hline FAO & $\begin{array}{l}\text { Food and Agriculture Organization of } \\
\text { the United Nations }\end{array}$ \\
\hline GDP & Gross Domestic Product \\
\hline GEF & Global Environment Facility \\
\hline GTZ & $\begin{array}{l}\text { Deutsche Gesellschaft für Technische } \\
\text { Zusammenarbeit }\end{array}$ \\
\hline ICDP & $\begin{array}{l}\text { Integrated Conservation and } \\
\text { Development Projects }\end{array}$ \\
\hline IDP & Internally Displaced People \\
\hline IMF & International Monetary Fund \\
\hline IT & Informational Technology \\
\hline
\end{tabular}

\begin{tabular}{ll} 
NGO & Non-governmental organization \\
\hline ODA & Official Development Assistance \\
\hline OECD & $\begin{array}{l}\text { Organisation for Economic } \\
\text { Co-operation and Development }\end{array}$ \\
\hline PA & Protected area \\
\hline SIA & Social Impact Assessments \\
\hline SMMC & $\begin{array}{l}\text { Santa Monica Mountains } \\
\text { Conservancy }\end{array}$ \\
\hline TBPA & Transboundary protected area \\
\hline UNDP & $\begin{array}{l}\text { United Nations Development } \\
\text { Programme }\end{array}$ \\
\hline UNEP & $\begin{array}{l}\text { United Nations Environment } \\
\text { Programme }\end{array}$ \\
\hline UNESCO & $\begin{array}{l}\text { United Nations Educational, } \\
\text { Scientific and Cultural Organization }\end{array}$ \\
\hline WHCC & World Conservation Congress \\
\hline WCPA & $\begin{array}{l}\text { World Commission on Protected } \\
\text { Wreas }\end{array}$ \\
\hline WHC & World Heritage Convention \\
\hline World Health Organization \\
\hline World WSA)
\end{tabular}




\section{List of contributors}

\section{Elisabeth Auchincloss}

Intern, Environmental Education and

Communication

IUCN - The World Conservation Union

Rue Mauverney 28

CH-1196 Gland, Switzerland

E-mail: elisabeth.auchincloss@iucn.org

\section{Robyn Bushell}

Head, School of Environment and Agriculture

University of Western Sydney

Locked Bag 1797

Penrith South DC

New South Wales 1797, Australia

E-mail: r.bushell@uws.edu.au

\section{Wendy Goldstein}

Head, Environmental Education and

Communication

IUCN - The World Conservation Union

Rue Mauverney 28

CH-1196 Gland, Switzerland

E-mail: wendy.goldstein@iucn.org

\section{Richard Grahn}

Natural Resources and Conflict Adviser

Interafrican Bureau for Animal Resources

(OAU-IBAR)

UNEP/EAP

Nairobi, Kenya

E-mail: richard.grahn@oau-ibar.org

\section{Anne Hammill}

Project Manager

International Institute for Sustainable

Development

13 chemin des Anémones

CH-1219 Châtelaine, Switzerland

E-mail: ahammill@iisd.ca

\section{Gladys Kalema-Zikusoka}

Chief Executive Officer

Conservation Through Public Health

898 Wrenn Smith Road

Siler City, North Carolina 27344, USA

E-mail: gladys@ctph.org,

gkalemazikusoka@yahoo.com

\section{William Karesh}

Department Head, Field Veterinary Program

The Wildlife Conservation Society

2300 Southern Boulevard

Bronx, New York 10460-1099, USA

E-mail: wkaresh@wcs.org

\section{Richard A. Kock}

TA PACE Epidemiology Wildlife

Monrovia Street

30786 AU IBAR POBOX

Nairobi, Kenya

E-mail: richard.kock@au-ibar.org

\section{Peter Bille Larsen}

Project Coordinator, Capacity Building

\& Social Policy

IUCN - The World Conservation Union

Rue Mauverney 28

CH-1196 Gland, Switzerland

E-mail: peter.larsen@iucn.org

\section{Tim Leyland}

Head, CAPE Unit

AU/IBAR-PACE/CAPE

P.O. Box 30786

00100 Nairobi, Kenya

E-mail: tim.leyland@oau-ibar.org

\section{Jeffrey A. McNeely}

Chief Scientist

IUCN - The World Conservation Union

Rue Mauverney 28

CH-1196 Gland, Switzerland

E-mail: jeffrey.mcneely@iucn.org 


\section{Thomas O. McShane}

Senior Conservation Advisor

WWF International

Avenue du Mont Blanc

CH-1196 Gland, Switzerland

E-mail: tmcshane@wwfint.org

\section{Steven A. Osofsky}

Senior Policy Advisor, Wildlife Health

Field Veterinary Program

Wildlife Conservation Society

11697 Fox Glen Drive

Oakton, Virginia 22124, USA

E-mail: sosofsky@wcs.org

\section{David Ostergren, $\mathrm{PhD}$.}

Assistant Professor

School of Forestry

Center for Environmental Sciences and Education

Northern Arizona University

Box 5694

Flagstaff, AZ 86011, USA

E-mail: d.a.o@nau.edu

\section{Gonzalo Oviedo}

Senior Adviser - Social Policy

IUCN - The World Conservation Union

Rue Mauverney 28

CH-1196 Gland, Switzerland

E-mail: gonzalo.oviedo@iucn.org

\section{Allen Putney}

Leader, Task Force on Non-Material Values

IUCN - World Commission on Protected Areas

736 Allison Drive

PO Box 4046

Incline Village, Nevada 89450, USA

E-mail: Allen.Putney@att.net,

Allen.Putney@worldnet.att.net

\section{Kent H. Redford}

Director, Biodiversity Analysis \& Coordination The Wildlife Conservation Society

2300 Southern Boulevard

Bronx, New York 10460-1099, USA

E-mail: kredford@wcs.org

\section{Lea Scherl}

35 Mirimar Crescent

Arcadia

Magnetic Island 4819, Qld, Australia

E-mail: lea.scherl@bigpond.com

\section{Assheton Stewart Carter}

Director, Energy and Mining Programme

Conservation International

1919 M St. N.W., Suite 600

Washington, DC 20036, USA

E-mail: a.carter@celb.org

\section{Jim Thorsell}

Senior Advisor, World Heritage

PO Box 4482

Banff, Alberta T1L 1E8, Canada

E-mail: thorsell@telusplanet.net

\section{Ted Trzyna}

President, California Institute of Public Affairs PO Box 189040

Sacramento, California 95818, USA

E-mail:Ted_Trzyna@interenvironment.org 



\section{References}

Adams, Alexander B. 1962. First World Conference on National Parks. U.S. Government Printing Office, Washington, DC, USA.

African Union/Interafrican Bureau for Animal Resources (AU/IBAR). 2002. Fact sheet on livestock production in Africa. CAPE Unit Programme for the Control of Epizootics (PACE) Newsletter 2(1):8.

Aguilar, L., I. Castaneda, H. Salazar (with Giselle Rodrigues and Jackie Siles). 2002. In Search of the Lost Gender: Equity in Protected Areas. IUCN, San Jose, Costa Rica.

Aguirre, A.A., R.S. Ostfeld, G.M. Tabor, C. House and M.C. Pearl (Eds). 2002. Conservation Medicine: Ecological Health in Practice. Oxford University Press, New York, USA.

\section{Albertson, A. 1998. Northern Botswana Veterinary} Fences: Critical Ecological Impacts. Okavango Peoples Wildlife Trust, Maun, Botswana. Accessed March 2004 at www.stud.ntnu.no / skjetnep /owls/ fences/index.html\#impact

Alem, Alfonso, A. Robles and M. de la Cruz. 2003. New Ways of Involving Local, Indigenous, and Traditional Populations in Protecting and Managing Non-material Value. PowerPoint presented at the $\mathrm{V}^{\text {th }}$ World Parks Congress, Technical Sessions on Building Cultural Support for Protected Areas, September 12. Durban, South Africa.

Alexander, K.A., E. Pleydell, M.C. Williams, E.P. Lane, J.F.C. Nyange and A.L. Michel. 2002. Mycobacterium tuberculosis: an emerging disease of free-ranging wildlife. Emerg. Infect. Dis. 8:598-601.

Alvarez, J.M. 2003. Conservation of Natural Resources and Biodiversity in El Salvador: The SalvaNATURA-SHELL Alliance. $\mathrm{V}^{\text {th }}$ World Parks Congress, Workshop II.5, on Building Support from New Constituencies, Durban, South Africa, 11-13 September 2003.
Amaya, Maria Teresa. 2003. Exorcising Death in the Purace National Natural Park, Colombia. Paper presented at the $\mathrm{V}^{\text {th }}$ World Parks Congress, Technical Sessions on Building Cultural Support for Protected Areas, September 12, Durban, South Africa.

Amend, Stephan and Thora Amenda (Eds). 1995. National Parks Without People? The South American Experience. IUCN and Parques Nacionales y Conservacion Ambientale, Quito, Ecuador.

Andanje, S. 2002. Factors Limiting the Abundance and Distribution of Hirola (Beatragus hunteri) in Kenya. $\mathrm{PhD}$ dissertation, Evolution and Behaviour Research Group, Department of Psychology, University of Newcastle upon Tyne, Newcastle, UK.

Anderson, Mary B., L. Olson and K. Doughty. 2003. Confronting War: Critical Lessons for Peace Practitioners. The Collaborative for Development Action, Cambridge, USA.

Andrade, G.I. 2000. The Non-material Values of Machu Picchu World Heritage Site: from acknowledgement to action. Parks 10(2):49-62.

Argumedo, Alejandro. 2003. Indigenous Peoples and Sacred Landscapes: The Ausangate Spiritual Park. PowerPoint presented at the $\mathrm{V}^{\text {th }}$ World Parks Congress, Technical Sessions on Building Cultural Support for Protected Areas, September 13, Durban, South Africa.

Arntzen, J.W. 2002. An Economic View on Wildlife Management Areas in Botswana. CBNRM Support Programme, Gaborone, Botswana.

Austin, Duncan and A. Sauer. 2002. Changing Oil: Emerging Environmental Risks and Shareholder Value in the Oil and Gas Industry. World Resources Institute, Washington, DC, USA.

Austin, Jay E. and C.E. Bruch. 2003. Legal Mechanisms for Addressing Wartime Damage in Tropical Forests. In: Steven Price (Ed.). War and Tropical Forests: Conservation in Areas of Armed Conflict. The Haworth Press, New York, USA. 
Baillie, Barry. 2002. New Gummut Awards for Holiday Parks. Presentation at Ecotourism Australia, 11 ${ }^{\text {th }}$ National Conference, 10-14 November 2003.

Balmford, A. and T. Whitten. 2003. Who should pay for tropical conservation, and how could the costs be met? Oryx 37(2):238-250.

Barktus, B.R., S.A. Morris and B. Sierfert. 2002. Governance and Corporate Philanthropy: Restraining Robin Hood? Business and Society 41(3): 319-344.

Barnes, J.L. 1998. Wildlife Economics: A Study of Direct Use Values in Botswana's Wildlife Sector. $\mathrm{Ph}$.D. thesis. University College, London, UK.

Barnes, J.I. 2001. Economic returns and allocation of resources in the wildlife sector of Botswana. South African Journal of Wildlife Research 31:141-153.

Barnett, Jon. 2001. The Meaning of Environmental Security: Ecological Politics and Policy in the New Security Era. Zed Books, London, UK.

Barrow, Edmund. 2003. Our Culture, Our Spirituality and Nature: Understanding and Integrating the Importance of Sacred Trees and Forests into Our Lives. Paper presented at the $\mathrm{V}^{\text {th }}$ World Parks Congress, Technical Sessions on Building Cultural Support for Protected Areas, September 12, Durban, South Africa.

Barrow, E. 2003. IUCN's ICD Experiences thus far and the Evolution to a Landscape Approach. Presentation at the $V^{\text {th }}$ World Parks Congress, Durban.

Barzetti, Valerie. 1993. Parks and Progress: Protected Areas and Economic Development in Latin America and the Caribbean. IUCN, Gland, Switzerland and Inter-American Development Bank, Washington DC, USA.

Beasley, V. 1993. Ecotoxicology and ecosystem health: roles for veterinarians; goals of the Envirovet program. J. Am. Vet. Med. Assoc. 203:617-628.
Beazley, Olwen, Graeme Calma and Lynette Liddle. 2001. "Nganana Tatintaja Wiya", "We Never Climb": Uluru-Kata Tjuta National Park, Sustainable Management and Development. In: Final Report of the UNESCO Thematic Expert Meeting on Asia-Pacific Sacred Mountains. UNESCO, Tokyo, Japan.

Beltrán, J. (Ed.). 2000. Indigenous and Traditional Peoples and Protected Areas: Principles, Guidelines and Case Studies. IUCN, Gland, Switzerland and Cambridge, UK and WWF International, Gland, Switzerland.

BEN. 2004. Black Environment Network. BEN, Llanberis, Wales. www.ben-network.org.uk

Bendell, J. 2000. Civil regulation: a new form of democratic governance for the global economy? In: Bendell, J. (Ed.). Terms for Endearment: Business, NGOs and Sustainable Development. Greenleaf Publishing, Sheffield, UK.

Bengis, R.G. 2005. Transfrontier conservation area initiatives in sub-Saharan Africa: some animal health challenges. In: Osofsky, S.A., S. Cleaveland, W.B. Karesh, M.D. Kock, P.J. Nyhus, L. Starr and A. Yang (Eds). Conservation and Development Interventions at the Wildlife/Livestock Interface: Implications for Wildlife, Livestock and Human Health. IUCN, Gland, Switzerland and Cambridge, UK.

Bengis, R.G., R.A. Kock and J. Fischer. 2002. Infectious animal diseases: the wildlife/livestock interface. Rev. Sci. Tech. 21:53-65.

Berger, J., P.B. Stacey, L. Bellis and M.P. Johnson. 2001. A mammalian predator-prey imbalance: grizzly bear and wolf extinction affect avian neotropical migrants. Ecological Applications 11:947-960.

Bernbaum, Edwin. 2003. The Cultural and Spiritual Meaning of Mountains as a Basis for Interpretation and Conservation. Paper presented at the $\mathrm{V}^{\text {th }}$ World Parks Congress, Technical Sessions on Building Cultural Support for Protected Areas, September 12, Durban, South Africa. 
Bhutia, Pema. 2003. Demazong: The Sacred Landscape: A community managed conservation site in Khangchendzonga, India. PowerPoint presented at the $\mathrm{V}^{\text {th }}$ World Parks Congress, Technical Sessions on Building Cultural Support for Protected Areas, September 13, Durban, South Africa.

Bienen, L. 2002. Conservation corridors and the spread of infectious disease. Conservation in Practice 3:11-17.

Birckhead, Jim, Terry de Lacy and Laurajane Smith (Eds). 1992. Aboriginal Involvement in Parks and Protected Areas. Aboriginal Studies Press, Canberra, Australia.

Bishop, J. 2003. Pro Poor Markets for Ecosystem Services. Presentation at the $\mathrm{V}^{\text {th }}$ World Parks Congress, Durban.

Bodmer, R. E. 1994. Managing wildife with local communities in the Peruvian amazon: the case of the Reserva Comunal Tamshiyacu-Tahuayo. In: Western, D., R.M. Wright and S. Strum (Eds). Natural Connections: Perspectives in communitybased conservation. Island Press, Washington DC, USA.

Bodmer, R.E. and P.E. Puertas. 2000. Communitybased co-management of wildlife in the Peruvian Amazon. In: Robinson, J.G. and E.L. Bennett (Eds). Hunting for sustainability in tropical forests. Columbia University Press, New York, USA.

Borrini-Feyerabend, Grazia. 2003. Governance of protected areas - innovation in the air... Policy Matters 12: 92-101.

Borrini-Feyerabend, Grazia. 2003. Community conserved areas (CCAs) and co-managed protected areas (CMPAs) - towards equitable and effective conservation in the context of global change. Report of the IUCN joint CEESP/WCPA Theme on Indigenous and Local Communities, Equity and Protected Areas (TILCEPA) for the Ecosystem, Protected Areas and People (EPP) project, April 2004.
Bourn, D. and R. Blench (Eds). 1999. Can Livestock and Wildlife Co-Exist? An Interdisciplinary Approach. Overseas Development Institute (ODI) and The Environment Research Group Oxford (ERGO) Publishers, London, UK.

Boyce, W. 2003. Ecological Monitoring in the Anza Borrego/Cuyamaca Region. Report prepared for California State Parks. Wildlife Health Center, University of California, Davis, CA, USA.

Boyd, C., R. Blench, D. Bourn, L. Drake and P. Stevenson. 1999. Reconciling Interests Among Wildlife, Livestock and People in Eastern Africa. A Sustainable Livelihoods Approach. Overseas Development Institute (ODI) Natural Resource Perspectives. Accessed March 2004 at www.odi.org.uk/nrp/45.html

Boyd, S.W. 2000. Tourism, national parks and sustainability. In: Richard W. Butler and Stephen W. Boyd (Eds). Tourism and National Parks: Issues and Implications. John Wiley and Sons, Ltd., New York, USA.

Brandon, K., K. Redford and S. Sanderson (Eds). 1998. Parks in Peril: People, Politics and Protected Areas. Island Press, Washington, DC, USA.

Brechin, Steven R., P.R. Wilshusen, C.L. Fortwangler and P.C. West. 2002. Beyond the Square Wheel: Toward a More Comprehensive Understanding of Biodiversity Conservation as Social and Political Processes. Society and Natural Resources 15:41-64.

Brechin, S.R., P.R. Wilshusen, C.L. Fortwangler and P.C. West. 2003. Contested Nature: Promoting International Biodiversity with Social Justice in the 21 st Century. SUNY Press, Albany, NY, USA.

Bronson, D. 2004. Engaging Canadians: Building Professional Communications in Parks Canada. In: Auchincloss and Goldstein (Eds). 2004. Communicating Protected Areas. IUCN, Gland, Switzerland and Cambridge, UK. 
Brown, K. 2004. Trade-off Analysis for Integrated Conservation and Development. In: T.O. McShane and M.P. Wells (Eds). Getting Biodiversity Projects to Work: Towards More Effective Conservation and Development. Columbia University Press, New York, USA.

Buckley, R. and J. Pannell. 1990. Environmental Impacts of Tourism and Recreation in National Parks and Conservation Areas. Journal of Tourism Studies 1: 24-32.

Burton, R. (Ed.). 1991. Nature's Last Strongholds. Oxford University Press, New York, USA.

Bushell, R. and S. McCool. [In press.] Tourism as a Tool for Conservation and Support for Protected Areas: Setting the Agenda. In: Bushell and Eagles (Eds). Tourism and Protected Areas: Benefits Beyond Boundaries. Forthcoming CABI publication.

Butler, R.W. and S.W. Boyd (Eds). 2000. Tourism and National Parks: Issues and Implications. John Wiley and Sons, New York, USA.

CA. 2004. The urban challenge. Cities Alliance, Washington, DC, USA. www.citiesalliance.org

Calver, M.C. 2000. Lessons from preventive medicine for the precautionary principle and ecosystem health. Ecosystem Health 6:99-107.

CARE-WWF Social and Environmental Justice Initiative. 2002. www.care-international.org/wssd and www.panda.org/mpo/wssd

Carlisle, L. and S. Bagley. 2003. Tourism as a Tool for Conservation and Community Development. An African Private Sector Model: Conservation Corporation Africa. Paper presentation $\mathrm{V}^{\text {th }}$ World Parks Congress, Durban.

Castelo, M. and S. Schielmann. 2001. Information on United Nations Conferences, Bodies, and Instruments relating to Environmental Issues and Indigenous Peoples. WWF International People and Conservation Unit, Gland, Switzerland.
Castro, H., R. Abadia and S. Quesada. 2004. Strategic Intentions: Using Communications and Education to Support Biodiversity Conservation and Protected Areas. In: Hamù, Auchincloss and Goldstein (Eds). 2004. Communicating Protected Areas. IUCN, Gland, Switzerland and Cambridge, UK.

Castro, H. and J. Wyss. 2004. Mass Media and Engaging Journalists: Supporting Biodiversity Conservation. In: Hamù, Auchincloss and Goldstein (Eds). 2004. Communicating Protected Areas. IUCN, Gland, Switzerland and Cambridge, UK.

Castro, K.G. 1995. Tuberculosis as an opportunistic disease in persons infected with human immunodeficiency virus. Clin. Infect. Dis. 21(Suppl. 1): S66-S71.

Cavalcanti, H.C. 2004. The Projeto Doces Matas and Communication, Minas Gerais, Brazil. In: Hamù, Auchincloss and Goldstein (Eds). 2004. Communicating Protected Areas. IUCN, Gland, Switzerland and Cambridge, UK.

Ceballos-Lascurain, H. 1996. Tourism, Ecotourism and Protected Areas: The State of Nature Based Tourism Around the World and Guidelines for its Development. IUCN, Gland, Switzerland.

Central Intelligence Agency (CIA). 2003. Uganda. In: The World Fact Book. CIA Publications, Washington, DC, USA.

Cernea, Michael and K. Schmidt-Soltau. 2003. The End of Forced Displacements? Making conservation and impoverishment incompatible. In: Community Empowerment for Conservation, Policy Matters. IUCN Commission on Environmental, Economic and Social Policy.

Cernea, Michael and K. Schmidt-Soltau. 2003. National parks and poverty risks: Is population resettlement the solution? Presentation at the $\mathrm{V}^{\text {th }}$ World Parks Congress, Durban.

CFN. 2004. Cape Flats Nature: The project. Cape Flats Nature, Cape Town, South Africa. www.capeflatsnature.org 
Chape, S., S. Blyth, L. Fish and M. Spalding (Compilers). 2003. 2003 United Nations List of Protected Areas. IUCN, Gland, Switzerland and UNEP-WCMC, Cambridge, UK.

Chardonnet, P., B. des Clers, J. Fischer, F. Jori and F. Lamarque. 2002. The value of wildlife. Rev. Sci. Tech. 21:15-51.

Chatterjee, S., Y Gokhale, K.C. Malhotra, S. Srivastava. Undated. Sacred Groves of India. An Overview. Indira Gandi Rashtriya Manav Sangrahalaya, Bhopal, India.

Child, G. 1995. Wildlife and People: the Zimbabwean Success. Wisdom Foundation, Harare, Zimbabwe and New York, USA.

Child, G. and L. Chitsike. 2000. "Ownership" of wildlife. In: Prins, H.H.T., J.G. Grootenhuis and T.T. Dolam (Eds). Wildlife Conservation by Sustainable Use. Kluwer Academic Publishers, Boston.

Child, B. 2003. A comparison of the impact of top down versus bottom up CBNRM systems on incentives and accountability in the Luangwa Valley. Presentation at the $\mathrm{V}^{\text {th }}$ World Parks Congress, Durban.

Chilonda, P., J.D. Woodford, B. Ahmadu, K.L. Samui, M. Syakalima and J.E. Mlangwa. 1999. Foot and mouth disease in Zambia: a review of the aetiology and epidemiology and recommendations for possible control. Rev. Sci. Tech. 18(3):585-592.

Christ, C., O. Hillel, S. Matus and J. Sweeting. 2003. Tourism and Biodiversity: Mapping Tourism's Global Footprint. UNEP and Conservation International, Washington DC, USA.

Christensen, J. 2004. Win-Win Illusions: Facing the Rift between People and Protected Areas. Conservation in Practice 5.1:12-19.

CIPA. 2001. An ecosystem approach to natural resource conservation in California. California Institute of Public Affairs, Sacramento, USA. www.InterEnvironment.org/cipa
CIPA. 2004. An intercontinental program on cities and conservation in Mediterranean-type ecosystems. www.InterEnvironment.org/med-5

Cirelli, M.T. 2002. Legal Trends in Wildlife Management. FAO, Rome, Italy.

Clifton-Hadley, R.S., C.M. Sauter-Louis, I.W. Lugton, R. Jackson, P.A. Durr and J.W. Wilesmith. 2001. Mycobacterium bovis infections. In: Williams, E.S. and I.K. Barker (Eds). Infectious Diseases of Wild Mammals, $3^{\text {rd }}$ Ed. Manson Publishing/The Veterinary Press, London, UK.

CNP. 2004. Mosaic: Building links between ethnic communities and national parks. Council for National Parks, London, UK. www.cnp.org.uk /mosaic.htm

Cochrane, P. 2001. The Cultural Dimension to Nature-based Tourism: a case and future of jointly managed parks. The Fenner Research Conference Nature Tourism and the Environment, Australian Academy of Science, Australia.

Cock, J and D. Fig. 2000. From colonial to community based conservation: environmental justice and the national parks of South Africa. Society in Transition 31(1):22-36.

Colding, J. and C. Folke. 2001. Social taboos: "invisible" systems of local resource management and biological conservation. Ecological Applications 11:584-600.

Conca, Ken and G.D. Dabelko. 2002. Environmental Peacemaking. Woodrow Wilson Center Press, Washington, DC, USA.

Conner, Nicholas. 2005. Some benefits of protected areas for urban communities: A view from Sydney, Australia. In: Trzyna, 2005.

Conservation International and Tour Operators Initiative. 2002. A Practical Guide to Good Practice: Managing Environmental and Social Issues in the Accommodations Sector. Conservation International, Washington DC, USA.

Convention on Biological Diversity (CBD). 2004. Web site updated March 2004. www.biodiv.org/ default.aspx 
Convention of Biological Diversity. 2004. Conference of the Parties, Decision VII/28, Protected Areas (Articles 8(a) to (e)), www.biodiv.org/decisions/

Council, N.R. 2001. Marine Protected Areas: Tools for Sustaining Ocean Ecosystems. National Academy Press, Washington DC, USA.

Creasey R. and L. Fischer. 2004. Reduction of Footprint and Restoration of Function: An Approach to Cumulative Effects Management. In: The Seventh Society for Petroleum Engineers International Conference on Health, Safety and Environment in Exploration and Production. Calgary, Canada, 29-31 March 2004.

Creel, S. and N.M. Creel. 1997. Lion density and population structure in the Selous Game Reserve: evaluation of hunting quotas and offtake. African Journal of Ecology 35:83-93.

CUBES. 2003. Submission to the Conference on Urban Biosphere and Society: Partnership of Cities. CUBES Cape Town Urban Biosphere Group, Cape Town, South Africa.

CUBES. 2004. Cape Town Urban Biosphere Group; New York Urban Biosphere Group. Columbia University/UNESCO Joint Program on Biosphere and Society, New York, USA. www.earthinstitute .columbia.edu/cubes

Cumming, D.H.M. and I. Bond. 1991. Animal Production in Southern Africa: Present Practice and Opportunities for Peasant Farmers in Arid Lands. WWF Multispecies Project, No. 22, Harare, Zimbabwe.

Cumming, D.H.M. and the AHEAD GLTFCA Working Group. 2004. Sustaining animal health and ecosystem services in large landscapes: Concept for a program to address wildlife, livestock and related human and ecosystem health issues in the Greater Limpopo Transfrontier Conservation Area. Wildlife Conservation Society (WCS) AHEAD GLTFCA concept paper. $2^{\text {nd }}$ draft, 24 pp. Accessed October 2004 at www.wcsahead.org/workinggrps_limpopo.html
Cunha e Menezes, Pedro da. 2005. Raising the priority of urban areas in protected area systems in Brazil and beyond. In: Trzyna, Ted (Ed.). 2005. The Urban Imperative: Urban Outreach Strategies for Protected Area Agencies. InterEnvironment, California Institute of Public Affairs, Sacramento, USA.

Dahlstrom, Asa Nilsson. 2003. Negotiating Wilderness in a Cultural Landscape: Predators and Saami Reindeer Herding in the Laponian World Heritage Area. Ph.D Thesis. Uppsala University, Sweden.

Daszak, P. and A.A. Cunningham. 2002. Emerging infectious diseases: a key role for conservation medicine. In: Aguirre, A.A., R.S. Ostfeld, G.M. Tabor, C. House and M.C. Pearl (Eds). Conservation Medicine: Ecological Health in Practice. Oxford University Press, New York, USA.

Davey, A.G. 1998. National System Planning for Protected Areas. IUCN, Gland, Switzerland and Cambridge, UK.

Davis, George. 2005. Biodiversity conservation as a social bridge in the urban context: Cape Town's sense of "The Urban Imperative" to protect its biodiversity and empower its people. In: Trzyna, Ted (Ed.). 2005. The Urban Imperative: Urban Outreach Strategies for Protected Area Agencies. InterEnvironment, California Institute of Public Affairs, Sacramento, USA.

Davys, T.R., D.M. Forsyth and G.J. Hickling. 1999. Recreational Himalayan thar (Hemitragus jemlahicus) hunters in Canterbury, New Zealand: A profile and management implications. New Zealand Journal of Zoology 26(1):1-9.

Dawe, P.S., F.O. Flanagan, R.L. Madekurozwa, K.J. Sorensen, E.C. Anderson, C.M. Foggin, N.P. Ferris and N.J. Knowles. 1994. Natural transmission of foot-and-mouth disease virus from African buffalo (Syncerus caffer) to cattle in a wildlife area of Zimbabwe. Vet. Rec. 134(10): 230-232. 
Debonnet, Guy and K. Hillman-Smith. 2003. Supporting Protected Areas in a Time of Political Turmoil: The Case of World Heritage Sites in the Democratic Republic of Congo. Paper prepared for workshop on Building Support for Protected Areas. V ${ }^{\text {th }}$ World Parks Congress, Durban, September 2003.

Deem, S.L., W.B. Karesh and W. Weisman. 2001. Putting theory into practice: wildlife health in conservation. Conservation Biology 15:1224-1233.

De la Torre, Luz Maria. The Cayambe Sacred Mountain, Ecuador. PowerPoint presented at the $V^{\text {th }}$ World Parks Congress, Technical Sessions on Building Cultural Support for Protected Areas, September 12, Durban, South Africa.

de Lisle, G.W., R.G. Bengis, S.M. Schmitt and D.J. O'Brien. 2002. Tuberculosis in free-ranging wildlife: detection, diagnosis and management. Rev. Sci. Tech. 21:317-334.

Department for International Development (DFID). 2002. Wildlife and Poverty Study. DFID, London, UK.

De Vos, V., R.G. Bengis, N.P.J. Kriek, A. Michel, D.F. Keet, J.P. Raath and H.F.K.A. Huchzermeyer. 2001. The epidemiology of tuberculosis in freeranging African buffalo (Syncerus caffer) in the Kruger National Park, South Africa. Onderstepoort J. Vet. Res. 68:119-130.

Diamond, Jared. 2005. Collapse: How Societies Choose to Fail or Succeed. Viking, New York, USA.

Diouf, A.M. 2003. Education environnementale support pour une gestion participative du parc de Djoudj au Sénégal. PowerPoint Presentation at the $V^{\text {th }}$ World Parks Congress, Durban 2003.

Driml, S. and M. Common. 1995. Economic and financial benefits of tourism in major protected areas. Australian Journal of Environmental Management 2(2):19-39.
Driver J., R.M. Cowling and K. Maze. 2003. Planning for Living Landscapes: Perspectives and Lessons from South Africa. The Botanical Society of South Africa and the Center for Applied Biodiversity Science, Washington DC, USA.

Drumm, Andy and A. Moore. 2002. Ecotourism Development: A Manual for Conservation Planners and Managers. The Nature Conservancy, Washington DC, USA.

Ducks Unlimited accessed April 19, 2004. www.ducks.org/news/Sept2003NAWCAGrants.asp

Dudley, N., G. Biksham, B. Jackson, J.P. Jeanrenaud, G. Oviedo, A. Phillips, P. Rosabal, S. Stolton and S. Wells. 1999. Challenges for protected areas in the 21st century. In: Stolton, S. and N. Dudley (Eds). Partnerships for Protection: New Strategies for Planning and Management for Protected Areas. Earthscan, London, UK.

Dudley, N. and S. Stolton. 2003. Mining and Protected Areas: Draft Case Study, Speaking a Common Language research project, www.cf.ac.uk/cplan/sacl/cs-mining_pas.pdf

Dudley, Nigel, and S. Stolton. 2005. The role of forest protected areas in supplying drinking water to the world's biggest cities. In: Trzyna, Ted (Ed.). 2005. The Urban Imperative: Urban Outreach Strategies for Protected Area Agencies. InterEnvironment, California Institute of Public Affairs, Sacramento, USA.

Dutt, S. 2003. Ecodevelopment Effort in India. Presentation at the $\mathrm{V}^{\text {th }}$ World Parks Congress, Durban.

Eagles, P.F.J., M.E. Bowman and T. Chang-Hung Tao. 2001. Guidelines for Tourism in Parks and Protected Areas of East Asia. IUCN, Gland, Switzerland and Cambridge, UK in collaboration with University of Waterloo, Canada.

Eagles, P.F.J. and S. McCool. 2002. Tourism in National Parks and Protected Areas: Planning and Management. CAB International, New York, USA. 
Eagles, P., S. McCool and C. Haines. 2002. Sustainable Tourism in Protected Areas: Guidelines for Planning and Management. IUCN, Gland, Switzerland and Cambridge, UK.

Edgerton, Robert B. 1992. Sick Societies: Challenging the Myth of Primitive Harmony. Free Press, New York, USA.

Ellen, Roy, P. Parkes and A. Bicker (Eds). 2000. Indigenous Environmental Knowledge and its Transformations. Harwood, Amsterdam, Netherlands.

Elliott, Hugh. 1974. Second World Conference on National Parks. IUCN, Lausanne, Switzerland.

Else, J.G. and M.A. Pokras. 2002. Introduction. In: Aguirre, A.A., R.S. Ostfeld, G.M. Tabor, C. House and M.C. Pearl (Eds). Conservation Medicine: Ecological Health in Practice. Oxford University Press, New York, USA.

Emerton, L. 2001. The nature of benefits and the benefits of nature: why wildlife conservation has not economically benefited communities in Africa. In: Hulme, D. and M.W. Murphree (Eds). African Wildlife and Livelihoods: The Promise and Performance of Community Conservation. James Currey Ltd., Oxford, UK.

Encalada, M. 2004. Optimizing the use of research in order to consolidate communication planning and practice for protected areas. In: Hamù, Auchincloss and Goldstein (Eds). 2004. Communicating Protected Areas. IUCN, Gland, Switzerland and Cambridge, UK.

Energy and Biodiversity Initiative. 2003. Integrating Biodiversity Conservation into Oil and Gas Development. Energy and Biodiversity Initiative, www.theebi.org, Washington DC, USA.

English, Anthony J. 2000. An Emu in the Hole: Exploring the Link between Biodiversity and Aboriginal Cultural Heritage in New South Wales, Australia. Parks 10(2):13-25.
English, Anthony J. and Ellen Lee. 2003. Managing the Intangible. In: Harmon, D. and A. Putney (Eds). The Full Value of Parks: from Economics to the Intangible. Rowman and Littlefield Publishers, Lanham, MD, USA.

Ewel, K. 1997. Water quality improvement: evaluation of an ecosystem service. In: Daily, G. (Ed.). Nature's Services: Societal Dependence on Natural Ecosystems. Island Press, Washington DC, USA.

Extractive Industries Review. 2003. 'Striking a Better Balance': The Final Report of the Extractive Industries Review, December 2003. www.eireview.org

Fairley, A. 2004. Turtle Island, personal communication.

Farrell L., P. Sampat, R. Sarin and K. Slack. 2004. Dirty Metals: Mining, Community and the Environment. Earthworks and Oxfam America, Washington DC, USA.

Fernández Dávila, P. 2004. The process of local ownership of the Tingo Maria National Park (Huánuco, Perú). In: Hamù, Auchincloss and Goldstein (Eds). 2004. Communicating Protected Areas. IUCN, Gland, Switzerland and Cambridge, UK.

Ferraro, P.J. and A. Kiss. 2002. Direct Payments to Conserve Biodiversity. Science 298:1718-1719.

Ferraro, P.J. 2001. Global habitat protection: limitations of development interventions and a role for conservation performance payments. Conservation Biology 15:990-1000.

Figgis, P.J. 1999. Australia's National Parks and Protected Areas: Future Directions Discussion Paper. Australian Committee for IUCN Occasional paper No 8. Australian Committee for IUCN, Sydney. 
Financing Protected Areas Task Force (FPATF). 2000. Financing Protected Areas. IUCN, Gland, Switzerland and Cambridge, UK.

Finger, Matthias. 1994. From Knowledge to Action? Exploring the relationships between environmental experiences, learning, and behavior. Journal of Social Issues 50(3):141-160.

Fisher, B. 2003. Within Boundaries: the Implications of Pro-Poor Conservation for Protected Areas. Presentation at the $\mathrm{V}^{\text {th }}$ World Parks Congress, Durban.

Fischer, Frauke et al. 2003. Status of the Comoe National Park, Cote d'Ivoire and the Effects of War. Paper prepared for workshop on Building Support for Protected Areas. $\mathrm{V}^{\text {th }}$ World Parks Congress, Durban, September 2003.

Flintan, F. 2003. Engendering Eden Volume 1: Women, Gender and ICDPs: Lessons Learnt and Ways Forward. IIED Wildlife and Development Series No. 16.

Folke, C., L. Pritchard Jr., F. Berkes, J. Colding and U. Svedin. 1998. The problem of fit between ecosystems and institutions. International Human Dimensions Programme on Global Environmental Change. www.hdp.uni-bonn.de

Food and Agriculture Organization (FAO)/United Nations Environment Programme (UNEP)/ Consultative Group on International Agricultural Research (CGIAR). 2004. The poverty lines: population living with less than 2 dollars and less than 1 dollar a day. Accessed March 2004 at www.povertymap.net/mapsgraphics/index.cfm? data $\_$id $=23417 \&$ theme $=$

Food and Agriculture Organization (FAO). 2003. Accessed September 2003 at http://apps.fao.org/faostat/default.jsp

Formenty, P., C. Hatz, B.L. Guenno, A. Stoll, P. Rogenmoser and A. Widmer. 1999. Human infection due to Ebola virus, subtype Cote d'Ivoire: clinical and biologic presentation. $J$. Infect. Dis. 179(Suppl. 1):S48-S53.
Fossey, D. 1983. Gorillas in the Mist. Houghton Mifflin, Boston, USA.

Foxlee, J. 2003. Key Principles and Direction for Tourism in Protected Areas: a review of existing charters, guidelines and declarations. Unpublished report, University of Western Sydney, Australia.

Franks, P. 2003. New directions for Integrated Conservation and Development - a CARE/WWF perspective. Presentation at the $\mathrm{V}^{\text {th }}$ World Parks Congress, Durban.

Freeman, M.M.R. 2001. Culture, commerce, and international co-operation in the global recovery of Polar Bears. Pacific Conservation Biology 7:161-168.

Freese, C.H. 1998. Wild Species as Commodities: Managing Markets and Ecosystems for Sustainability. Island Press, Washington DC, USA.

Gao, F., E. Bailes, D.L. Robertson, Y. Chen, C.M. Rodenburg, S.F. Michael, L.B. Cummins, L.O. Arthur, M. Peeters, G.M. Shaw, P.M. Sharp and B.H. Hahn. 1999. Origin of HIV-1 in the chimpanzee Pan troglodytes troglodytes. Nature 397:436-441.

Gardner, J. 2001. Rehabilitating mines to meet land use objectives: bauxite mining in the Jarrah Forest of Western Australia. Unasylva 52:2001-4. www.fao.org/DOCREP/004/Y2795E/y2795e00.h tm\#TopOgPage

Gardner, J. and G. Stoneman. 2003. Bauxite Mining and Conservation of the Jarrah Forest in SouthWest Australia. Paper prepared for the IUCN ICMM Mining and Biodiversity Workshop, Gland, July 2003.

Gavva, I.A., V.V. Krinitsky and Y.P. Yazan. 1984. Development of nature preserves and national parks in the Soviet Union. In: McNeely, Jeffrey A. and Kenton R. Miller (Eds). National Parks, Conservation, and Development. Smithsonian Institution Press, Washington DC, USA. 
GEF. 2004. GEF and the Convention on Biological Diversity. Global Environment Facility, Washington DC, USA.

\section{Geisler, C. 2003a. A New Kind of Trouble: Evictions} in Eden. Blackwell, Oxford, UK.

Geisler, C. 2003b. Your Park, My Poverty: Using Impact Assessment to counter the displacement effects of environmental greenling. In: Brechin, S.R., P.R. Wilshusen, C.L. Fortwangler and P. West. Contested nature: Promoting International Biodiversity with Social Justice. SUNY Press, New York, USA.

Gelderblom, G., B.W. Van Wilgren and N. Rossouw. 1996. Proposed Transfrontier Conservation Areas: Maps and Preliminary Data Sheets. Council for Scientific and Industrial Research (CSIR), Division of Water, Environment and Forestry Technology, Stellenbosch, South Africa.

Gell, F.R. and C.M. Roberts. 2003. Benefits beyond boundaries: the fishery effects of marine reserves. Trends in Ecology and Evolution 18:448-455.

Gerber, L.R., P.M. Kareiva and J. Bascompte. 2002. The influence of life history attributes and fishing pressure on the efficacy of marine reserves. Biological Conservation 106:11-18.

Ghimire, K. and M. Pimbert. 1997. Social Change and Conservation. Earthscan, London, UK.

Gichere, S. 2003. Protected Areas and Poverty in Kenya - A Government Perspective. Presentation at the $\mathrm{V}^{\text {th }}$ World Parks Congress, Durban.

Gill, C. 2003. Biodiversity Conservation and USAID's Global Development Alliance. Presentation at $\mathrm{V}^{\text {th }}$ World Parks Congress, Workshop II.5, on Building Support from New Constituencies, Durban, South Africa, 11-13 September 2003.

Gilligan, B. and C. Allen. 2001. Resource and Visitor Management in NSW National Parks. The Fenner Conference on Nature Tourism and the Environment 3-6 Sept, Australian National University with CRC Sustainable Tourism, Canberra.
Gillin, C.M., G.M. Tabor and A.A. Aguirre. 2002. Ecological health and wildlife disease management in national parks. In: Aguirre, A.A., R.S. Ostfeld, G.M. Tabor, C. House and M.C. Pearl (Eds). 2002. Conservation Medicine: Ecological Health in Practice. Oxford University Press, New York, USA.

Gladu, Jean Paul, D. Brubacher and C. Meek. 2003. Aboriginal Experiences in Canada. Parks and Protected Areas. Boreal Footprint Project, Taiga Rescue Network.

Global Environmental Facility (GEF). 2004. Web site updated April 2004. www.gefweb.org/

Gokhale, Yogesh. 2003. Communicating the Importance of Sacred Groves to a Broader Audience for Conservation of Biocultural Heritage. Paper presented at the $\mathrm{V}^{\text {th }}$ World Parks Congress, Technical Sessions on Building Cultural Support for Protected Areas, September 12, Durban, South Africa.

Goode, David. 2005. Connecting with nature in a capital city: The London Biodiversity Strategy. In: Trzyna, Ted (Ed.). 2005. The Urban Imperative: Urban Outreach Strategies for Protected Area Agencies. InterEnvironment, California Institute of Public Affairs, Sacramento, USA.

Graczyk, T.K., A.B. Mudakikwa, M.R. Cranfield and U. Eilenberger. 2001. Hyperkeratotic mange caused by Sarcoptes scabiei (Acariform Sarcoptidae) in juvenile human-habituated mountain gorillas (Gorilla gorilla beringei). Parasitol. Res. 87:1024-1028.

Graczyk, T.K. 2002. Zoonotic infections and conservation. In: Aguirre, A.A., R.S. Ostfeld, G.M. Tabor, C. House and M.C. Pearl (Eds). 2002. Conservation Medicine: Ecological Health in Practice. Oxford University Press, New York, USA.

Grant, G. (Ed.). 2002. Guidelines for Sectoral ICT Policy and Planning: Regional Initiative for Informatics Strategies, Sectoral ICT Strategies Planning Templates. The Commonwealth Network of IT for Development (COMNET-IT) and The Commonwealth Secretariat. Ottawa, Canada. 
Groundwork. 2004. What is Groundwork? Groundwork UK, Birmingham, UK. www.groundwork.org.uk

Grove, Richard H. 1995. Green Imperialism: Colonial Expansion, Tropical Island Edens and the Origins of Environmentalism, 1600-1860. Cambridge University Press, Cambridge, UK.

Gurung, C. and N. Shrestha. 2004. Bringing Positive Changes in the Protected Areas of Nepal through Communication and Education. In: Hamù, Auchincloss and Goldstein (Eds). 2004. Communicating Protected Areas. IUCN, Gland, Switzerland and Cambridge, UK.

Hall, M.C. and A.A. Lew. 1998. Sustainable Tourism: A Geographic Perspective. Longman Publishing, New York, USA.

Halpern, B. 2003. The impact of marine reserves: do reserves work and does reserve size matter? Ecological Applications 13:S117-S137.

Hamù, Denise, Auchincloss, E. and W. Goldstein (Eds). 2004. Communicating Protected Areas. IUCN, Gland, Switzerland and Cambridge, UK.

Harmon, David. 1994. Coordinating Research and Management to Enhance Protected Areas. IV ${ }^{\text {th }}$ World Congress on National Parks and Protected Areas, Caracas, Venezuela. IUCN, Gland Switzerland, in collaboration with The George Wright Society, Science and Management of Protected Areas Association, and the Commission of the European Union.

Harmon, David. 2002. In Light of our Differences: How Diversity in Nature and Culture Makes Us Human. Smithsonian Institution Press, Washington DC, USA.

Harmon, David and Allen Putney (Eds). 2003. The Full Value of Parks: from Economics to the Intangible. Rowman and Littlefield, Lanham, MD, USA.
Hart, J.A. 2000. Impact and sustainability of indigenous hunting in the Ituri forest, CongoZaire: a comparison of hunted and unhunted duiker populations. In: Robinson, J. G. and E. L. Bennett (Eds). Hunting for Sustainability in Tropical Forests. Columbia University Press, New York, USA.

Herlugson, C. 2003. The Scottish Forest Alliance. $V^{\text {th }}$ World Parks Congress, Workshop II.5, on Building Support from New Constituencies, Durban, South Africa, 11-13 September 2003.

Hesselink, F. 2004. How to manage change? How to manage people? Skills and knowledge for effectiveness in communicating protected areas and biodiversity values. In: Hamù, Auchincloss and Goldstein (Eds). 2004. Communicating Protected Areas. IUCN, Gland, Switzerland and Cambridge, UK.

Hesselink, F., E. Idle and G. Van Boven. 2004. Beyond Training: Protected Area Institutions as Learning Organisations. Developing capacity to change towards management in partnership. Effective Communication for Nature Conservation. In: Hamù, Auchincloss and Goldstein (Eds). 2004. Communicating Protected Areas. IUCN, Gland, Switzerland and Cambridge, UK.

Hilbrunner, R.W. 2004. The GreenCOM Project: Using Strategic Participatory Communications for Protected Areas. In: Hamù, Auchincloss and Goldstein (Eds). 2004. Communicating Protected Areas. IUCN, Gland, Switzerland and Cambridge, UK.

Hill, K., G. McMillan and R. Farina. 2003. Huntingrelated Changes in Game Encounter Rates from 1994 to 2001 in the Mbaracayu Reserve, Paraguay. Conservation Biology 17:1312-1323.

Hockings, Mark, S. Stolton and N. Dudley. 2000. Evaluating Effectiveness: A Framework for Assessing the Management of Protected Areas. IUCN, Gland, Switzerland and Cambridge, UK.

Holling, C.S. (Ed.). 1978. Adaptive Environmental Assessment and Management. John Wiley, New York, USA. 
Homsey, J. 1999. Ape Tourism and Human Diseases: How Close Should We Get? A Critical Review of the Rules and Regulations Governing Park Management and Tourism for the Wild Mountain Gorilla, Gorilla gorilla beringei. Report. Consultancy for the International Gorilla Conservation Programme (IGCP) Regional Meeting, Rwanda, Uganda, February 1999.

Honey, M. 1999. Ecotourism and Sustainable Development: Who Owns Paradise? Island Press, Washington DC, USA.

Hornback, K. and P. Eagles. 1999. Guidelines for Public Use Measurement and Reporting at Parks and Protected Areas. IUCN, Gland, Switzerland and Cambridge, U.K, Parks Canada, CRC for Sustainable Tourism, Australia.

Hudson, P.J. and A.P. Dobson. 1989. Epidemiology and population dynamics of host parasite interactions. Parasitology Today 5:283-291.

Hulme, D. and M. Murphree. 1999. Communities, wildlife and 'the new conservation'. Africa J. Int. Dev. 11:277-286.

Humavindu, M.N. and J.I. Barnes. 2003. Trophy hunting in the Namibian economy: an assessment. South African Journal of Wildlife Research 33:65-70.

Hunter, C.G. 1996. Land uses on the Botswana/Zimbabwe border and their effects on buffalo. South African Journal of Wildlife Research 26:136-150.

Hurt, R. and P. Ravn. 2000. Hunting and its benefits: an overview of hunting in Africa with special reference to Tanzania. In: Prins, H.H.T., J.G. Grootenhuis and T.T. Dolam (Eds). Wildlife Conservation by Sustainable Use. Kluwer Academic Publishers, Boston.

Hutcherson, Lucy. 2005. Chicago Wilderness: A collaborative model for urban conservation. In: Trzyna, Ted (Ed.). 2005. The Urban Imperative: Urban Outreach Strategies for Protected Area Agencies. InterEnvironment, California Institute of Public Affairs, Sacramento, USA.
Hwang, Y.T. 2003. Dynamics of rabies and striped skunk (Mephitis mephitis) populations: an indication of disease population regulation mechanisms. In: Proc. $52^{\text {nd }}$ Wildlife Disease Association Conference. Saskatoon, Canada, 11-14 August.

International Council on Mining and Metals, August 20 2003, Press Release: "Landmark "no go" pledge from leading mining companies'. www.icmm.com/news/158ICMMPressRelasenogoareas-20August03.pdf

International Institute for Environment and Development (IIED). 1994. Whose Eden? An Overview of Community Approaches to Wildlife Management. IIED, London, UK.

IPIECA (i) (International Petroleum Industry Environmental and Conservation Assocation). Series of case studies: The Oil and Gas Industry Operating in Sensitive Environments:BP in Dorset, southern England. www.ipieca.org/ publications/biodiversity.html accessed on April 25 2004.

IPIECA (ii) (International Petroleum Industry Environmental and Conservation Assocation). Series of case studies: The Oil and Gas Industry - Operating in Sensitive Environments: Statoil in Norway. www.ipieca.org/publications/ biodiversity.html accessed on April 252004.

IUCN. 1994. Guidelines for Protected Area Management Categories. IUCN, Gland, Switzerland.

IUCN. 1998. Economic Values of Protected Areas: Guidelines for Protected Area Managers. IUCN, Gland, Switzerland and Cambridge, UK.

IUCN. 2001. Vision and Reality: The World Heritage Convention in action. World Conservation 2.

IUCN. 2003. $\mathrm{V}^{\mathrm{th}}$ World Parks Congress: Recommendation 5.24 on Indigenous Peoples and Protected Areas and Recommendation 5.29 on Protected Areas and Poverty. IUCN, Gland, Switzerland. 
IUCN(i). 2003. The Durban Accord, Output of the World Parks Congress, www.iucn.wpc2003

IUCN(ii). 2003. The Durban Action Plan, Output of the World Parks Congress, www.iucn.wpc2003

IUCN(iii). 2003. Message of the $\mathrm{V}^{\text {th }}$ World Parks Congress to the Convention on Biological Diversity, Output of the World Parks Congress, www.iucn.wpc2003

IUCN(iv). 2003. Recommendations of the $\mathrm{V}^{\text {th }}$ World Parks Congress, www.iucn.wpc2003

IUCN. 2003. Community Empowerment for Conservation. Policy Matters 12.

IUCN. 2004. IUCN ICMM workshop: Mining, Protected Areas and Biodiversity Conservation: Searching and Pursuing Best Practice and Reporting in the Mining Industry. www.iucn.org/themes/business/mining/index.htm

Jaffe A. and D. Victor. 2004. The Geopolitics of Natural Gas, Executive Summary, May 2004, Program on Energy and Sustainable Development at Stanford University and James A. Baker III Institute for Public Policy at Rice University. http://pesd.stanford.edu/docs/natural_gas/Exec_S um.pdf

Jaireth, H. and D. Smyth. 2003. Innovative Governance: Indigenous peoples, Local Communities and Protected Areas. Ane Books, New Delhi, India.

Jansen D., I. Bond and B. Child. 1992. Cattle, Wildlife, Both, or Neither. Results of a Financial and Economic Survey of Commercial Ranches in Southern Zimbabwe. WWF Multispecies Project, No. 27, Harare, Zimbabwe.

Jeanrenaud, Sally. 1999. People-oriented Approaches in Global Conservation: Is the Leopard Changing its Spots? IIED, London, UK.

Jeanrenaud, Sally. 2001. An International Initiative for the Protection of Sacred Natural Sites and Other Places of Indigenous and Traditional Peoples with Importance for Biodiversity Conservation: A Concept Paper. Unpublished paper: WWF International, Gland, Switzerland.
Jell, B. and J.S. Machado. 2002. Collaborative management in the region of Lobéké, Cameroon: the potentials and constraints in involving the local population in protected area management. Nomadic Peoples 6:180-203.

Jolles, A.E. 2003. Tuberculosis in African buffalo (Syncerus caffer): population effects of a chronic disease. In: Proc. $52^{\text {nd }}$ Wildlife Disease Association Conference. Saskatoon, Canada, 11-14 August.

Joly, D.O. 2003. Bovine tuberculosis and brucellosis as factors limiting population growth of bison in northern Canada. In: Proc. $52^{\text {nd }}$ Wildlife Disease Association Conference. Saskatoon, Canada, 11-14 August.

Jones, B. and M.W. Murphree. 2001. The evolution of policy on community conservation. In: Hulme, D. and M.W. Murphree (Eds). African Wildlife and Livelihoods: The Promise and Performance of Community Conservation. James Currey Ltd., Oxford, UK.

Joshi, N.V. and M. Gadgil. 1991. On the role of refugia in promoting prudent use of biological resources. Theoretical Population Biology 40:211-229.

Justiniano, H. 2003. The Chiquitano Forest Conservation and Sustainable Development Plan. $\mathrm{V}^{\text {th }}$ World Parks Congress, Workshop 8, on Sustainable Finance Stream, September 2003, Durban, South Africa.

Kahn, Peter H., Jr. and S.R. Kellert (Eds). 2002. Children and Nature: Psychological, Sociocultural, and Evolutionary Investigations. MIT Press, Cambridge, MA, USA.

Kalema-Zikusoka, G. 2005. Protected areas, human livelihoods and healthy animals: ideas for improvements in conservation and development interventions. In: Osofsky, S.A., S. Cleaveland, W.B. Karesh, M.D. Kock, P.J. Nyhus, L. Starr and A. Yang (Eds). Conservation and Development Interventions at the Wildlife/Livestock Interface: Implications for Wildlife, Livestock and Human Health. IUCN, Gland, Switzerland and Cambridge, UK. 
Kalema-Zikusoka, G., R.A. Kock and E.J. Macfie. 2002. Scabies in free-ranging mountain gorillas (Gorilla gorilla beringei) in Bwindi Impenetrable National Park, Uganda. Vet. Rec. 150:12-15.

Kalema-Zikusoka G., B. Mugerwa and S. Asuma. 2001. Health education workshops for local communities of Bwindi Impenetrable National Park, Uganda. In: Proc. American Association of Zoo Veterinarians (AAZV), the American Association of Wildlife Veterinarians (AAWV), the Association of Reptilian and Amphibian Veterinarians (ARAV), and the National Association of Zoo and Wildlife Veterinarians (NAZWV) Joint Conference. AAZV/AAWV/ ARAV/NAZWV, 18-23 September. Orlando, USA.

Kalpers, J. 2001. Overview of Armed Conflict and Biodiversity in Sub-Saharan Africa: Impacts, Mechanisms and Responses. Biodiversity Support Program, Washington, DC, USA.

Kamugisha, J.R., Z.A. Oguta and M. Stahl, 1997. Parks and People - Conservation and Livelihoods at the Crossroads: Four Case Histories. Technical Report 17. Regional Soil Conservation Unit/Swedish International Development Agency (SIDA), Nairobi, Kenya.

Karanth, K.U. and M.D. Madhusudan. 2002. Mitigating human-wildlife conflicts in southern Asia. In: Terborgh, J., C.P. van Schaik, L. Davenport and M. Rao (Eds). Making Parks Work: Strategies for Preserving Tropical Nature. Island Press, Washington, DC, USA.

Keene-Young, R. 1999. A thin line: Botswana's cattle fences. Africa Environment and Wildlife 7:71-79.

Kemf, Elizabeth (Ed.). 1993. The Law of the Mother: Protecting Indigenous Peoples in Protected Areas. Sierra Club Books, San Francisco, CA, USA.

Kennedy, P. 2001. Minnamurra Rainforest Centre Budderoo National Park: a case study of the link between National Parks and Tourism. A Resource for NSW Geography Teachers, CD produced by the University of Western Sydney, Australia.
Kibuga, D. 2001. Multi-sectoral approach to DOTS - the only hope. Scand. J. Infect. Dis. 33:725-727.

Kock, M.D. 1996. Wildlife, people and development: veterinary contributions to wildlife health and resource management in Africa. Trop. Anim. Health Prod. 28:68-80.

Kock, R.A., J.M. Wambua, J. Mwanzia, H. Wamwayi, E.K. Ndungu, T. Barrett, N.D. Kock and P.B. Rossiter. 1999. Rinderpest epidemic in wild ruminants in Kenya 1993-1997. Vet. Rec. 145(10):275-283.

Kock, M.D., G.R. Mullins and J.S. Perkins. 2002. Wildlife health, ecosystems, and rural livelihoods in Botswana. In: Aguirre, A.A., R.S. Ostfeld, G.M. Tabor, C. House and M.C. Pearl (Eds). Conservation Medicine: Ecological Health in Practice. Oxford University Press, New York, USA.

Kock, R.A., B. Kebkiba, R. Heinonen and B. Bedane. 2002. Wildlife and pastoral society shifting paradigms in disease control. Ann. N.Y. Acad. Sci. 969:24-33.

Kock, R.A. 2005a. The wildlife domestic animal disease interface - should Africa adopt a hard or soft edge? Transactions of the Royal Society of South Africa 59(I):10-15.

Kock, R.A. 2005b. What is this Infamous "Wildlife/Livestock Disease Interface?" A Review of Current Knowledge for the African Continent. In: Osofsky, S.A., S. Cleaveland, W.B. Karesh, M.D. Kock, P.J. Nyhus, L. Starr and A. Yang (Eds). Conservation and Development Interventions at the Wildlife/Livestock Interface: Implications for Wildlife, Livestock and Human Health. IUCN, Gland, Switzerland and Cambridge, UK.

Koutsouris A., E. Santi and A. Tare. 2004. Building Support for Protected Areas: the case of the Butrint National Park. In: Hamù, Auchincloss and Goldstein (Eds). 2004. Communicating Protected Areas. IUCN, Gland, Switzerland and Cambridge, UK. 
Kothari, A., N. Pathak and F. Vania. 2000. Where Communities Care: Community Based Wildlife and Ecosystem Management in south Asia. IIED, London, UK.

Kothari, Ashish. 2003. Cross-Cut Theme on Communities, Equity, and Protected Areas. Plenary presentation at the $\mathrm{V}^{\text {th }}$ World Parks Congress, Durban.

Koziell I. and E. Omosa. 2003. Room to Manoeuvre? Mining, biodiversity and protected areas. International Institute for Environment and Development and the World Business Council for Sustainable Development, London, UK.

Lafferty, K.D. and L.R. Gerber. 2002. Good medicine for conservation biology: the intersection of epidemiology and conservation theory. Conservation Biology 16:593-604.

Laine Powell, A. 2003. Pipeline Construction in Environmentally Sensitive Areas: Leveraging Partnerships with Oil and Gas Companies for Protected Areas. $V^{\text {th }}$ World Parks Congress, Workshop 8, on Sustainable Finance Stream, September 2003, Durban, South Africa.

Laird, Sarah (Ed.). 2002. Biodiversity and Traditional Knowledge: Equitable Partnerships in Practice. Earthscan, London, UK.

Lanjouw, Annette. Building Partnerships in the Face of Political and Armed Crisis. In: Steven Price (Ed.). War and Tropical Forests: Conservation in Areas of Armed Conflict. The Haworth Press, New York, USA.

Lankester, M. 2003. Parasites, barriers and consequences of breaching them. In: Proc. $52^{\text {nd }}$ Wildlife Disease Association Conference. Saskatoon, Canada, 11-14 August.

Lapham N. and R. Livermore. 2003. Striking a Balance, Ensuring Conservation's Place on the International Biodiversity Assistance Agenda. Conservation International, Washington DC, USA.

Lasswell, Harold D. 1958. Politics: Who Gets What, When, How. Merriam Books, New York, USA.
Last, J.M. 1983. A Dictionary of Epidemiology. Oxford University Press, New York, USA.

Laudré, J. and T.W. Clark. 2003. Managing puma hunting in the western United States: through a metapopulation approach. Animal Conservation 6:159-170.

Lavides, M., N.A. Mallari, A. Plantilla, B. Tabaranza Jr., B. de la Paz and C.M. Nozawa. 2004. Building Support For and Beyond Protected Areas in the Philippines: A Haribon's Journey of Transformations. In: Hamù, Auchincloss and Goldstein (Eds). 2004. Communicating Protected Areas. IUCN, Gland, Switzerland and Cambridge, UK.

Leach, M. 2000. New shapes to shift: war, parks, and the hunting person in modern West Africa. Royal Anthropological Institute 6:577-595.

Leader-Williams, N. 2000. The effects of a century of policy and legal change on wildlife conservation and utilisation in Tanzania. In: Prins, H.H.T., J.G. Grootenhuis and T.T. Dolam (Eds). Wildlife Conservation by Sustainable Use. Kluwer Academic Publishers, Boston.

LeBeau, Mark. 2003. Update on Protecting American Indian Sacred Places in California. Paper presented at the $\mathrm{V}^{\text {th }}$ World Parks Congress, Technical Sessions on Building Cultural Support for Protected Areas, September 12, Durban, South Africa.

Le Blanc, Stephen A. 1999. Prehistoric Warfare in the American Southwest. University of Utah Press, Salt Lake City, UT, USA.

Lee, Ellen. 2000. Cultural Connection to the Landa Canadian Example. Parks 10 (2):3-12.

Leopold, A. 1933. Game Management. Charles Scribner's Sons. Reprinted in 1986 by University of Wisconsin Press, Madison, USA.

Leroy, E.M., P. Rouquet, P. Formenty, S. Souquière, A. Kilbourne, J.-M. Froment, M. Bermejo, S. Smit, W. Karesh, R. Swanepoel, S.R. Zaki and P.E. Rollin. 2004. Multiple Ebola virus transmission events and rapid decline of central African wildlife. Science 303:387-390. 
Leung, Y.F., J.L. Marion and T.A. Farrell. 2001. The Role of Recreation Ecology in Sustainable Tourism and Ecotourism. In: McCool, S. and N. Moisey (Eds). Tourism, Recreation, and Sustainability. CABI, Wallingford, UK.

Leung, Y.F. and J.L. Marion. 2000. Recreation Impacts and Management in Wilderness. In: Cole, D.N. et al. (Compilers). Wilderness Science in a Time of Change. USDA Forest Service, Washington DC, USA.

Lewis, Connie. 1996. Managing Conflicts in Protected Areas. IUCN, Gland, Switzerland.

Lewis, D.M., G.B. Kaweche and A. Mwenya. 1990. Wildlife conservation outside protected areas lessons from an experiment in Zambia. Conservation Biology 4:171-180.

Lewis, D.M. and P. Alpert. 1997. Trophy hunting and wildlife conservation in Zambia. Conservation Biology 11:59-68.

Lewis, D.M. 2003. How Safari Hunting Can Build Partnerships: A Case Study from Zambia (Presentation). In: Building New Constituencies for Protected Areas. V Vh World Parks Congress, Durban, South Africa.

Lewis, D. 2005. Synergies between animal husbandry and wildlife conservation: perspectives from Zambia. In: Osofsky, S.A., S. Cleaveland, W.B. Karesh, M.D. Kock, P.J. Nyhus, L. Starr and A. Yang (Eds). Conservation and Development Interventions at the Wildlife/Livestock Interface: Implications for Wildlife, Livestock and Human Health. IUCN, Gland, Switzerland and Cambridge, UK.

London. 2002. Connecting with London's Nature: The Mayor's Biodiversity Strategy. Greater London Authority, London, UK. www.london.gov.uk/londonissues

Lougheed, L.W., G.J. Edgar and H.L. Snell (Eds). 2002. Biological Impacts of the Jessica Oil Spill on the Galapagos Environment: Final Report v.1.10. Charles Darwin Foundation, Puerto Ayora, Galapagos, Ecuador.
Lubow, B.C., F.J. Singer, T.L. Johnson and D.C. Bowden. 2002. Dynamics of interacting elk populations within and adjacent to Rocky Mountain National Park. Journal of Wildlife Management 66:757-775.

Mace, R. 1991. Overgrazing overstated. Nature 349:280-281.

Macfie, E.J. 1992. Gorilla tourism programme for Uganda: veterinary recommendations. In: Bwindi Impenetrable National Park: A Tourism Development Plan. International Gorilla Conservation Programme, Kampala, Uganda.

Mack, R. 1970. The great African cattle plague epidemic of the 1890's. Trop. Anim. Health Prod. 2:210-219.

MacKay, Fergus. 2002. Addressing Past Wrongs. Indigenous Peoples and Protected Areas: The Right to Restitution of Lands and Resources. Briefing Paper, Forest Peoples Program.

Mackenzie, John M. 1997. The Empire of Nature: Hunting, Conservation, and British Imperialism. Manchester University Press, Manchester, UK.

MacKinnon, John. 2002. ASEAN Experiences with World Heritage Parks. Paper presented for Workshop on Using World Heritage to build broader support for protected areas. IUCN HQ, Gland. 15-17 October, 2002.

Madden, F. 1998. The Problem Gorilla-A Report of the East and Central African Workshop on Problem Mountain Gorillas Using the Situation in Bwindi Impenetrable National Park as a Basis for Solution Development. International Gorilla Conservation Programme (IGCP) and Cooperative for Assistance and Relief Everywhere (CARE) - Development Through Conservation (DTC).

Mahajan, P. 2004. Developing Support for Protected Areas through a Conservation Education Centre India Case Study. In: Hamù, Auchincloss and Goldstein (Eds). 2004. Communicating Protected Areas. IUCN, Gland, Switzerland and Cambridge, UK. 
Mainka, S.A. 2001. The veterinarian's role in biodiversity conservation. J. Zoo Wildl. Med. 32:165-167.

Mair, J and J. Delafons. 2001. The Policy Origins of Britain's National Parks: The Addison Committee 1929-31. Planning Perspectives 16(3):293-309.

Makwaeba, I.M. 2004. The use of traditional knowledge in the South African National Parks' Imbewu Youth Programme: planting a seed of environmental awareness. In: Hamù, Auchincloss and Goldstein (Eds). 2004. Communicating Protected Areas. IUCN, Gland, Switzerland and Cambridge, UK.

Malhotra, K.C. 2003. Conservation and Culture in India. PowerPoint presented at the $\mathrm{V}^{\text {th }}$ World Parks Congress, Technical Sessions on Building Cultural Support for Protected Areas, September 11, Durban, South Africa.

Maller, Cecily et al. 2002. Healthy Parks, Healthy People: The Health Benefits of Contact with Nature in a Park Context. School of Health Sciences, Deakin University, Melbourne, Australia.

Maretti, Claudio. 2002. Protected Areas and Indigenous and Local Communities in Brazil. Report of the IUCN joint CEESP/WCPA Theme on Indigenous and Local Community, Equity and Protected Areas (TILCEPA).

Marfin, A.A., L.R. Petersen, M. Eidson, J. Miller, J. Hadler, C. Farello, B. Werner, G.L. Campbell, M. Layton, P. Smith, E. Bresnitz, M. Cartter, J. Scaletta, G. Obiri, M. Bunning, R.C. Craven, J.T. Roehrig, K.G. Julian, S.R. Hinten, D.J. Gubler, and ArboNET Cooperative Surveillance Group. 2001. Widespread West Nile virus activity, eastern United States, 2000. Emerging Infectious Diseases 7(4):730-735.

\section{Margoluis, R., S. Myers, J. Allen, J. Roca, M. Melnyk} and J. Swanson. 2001. An Ounce of Prevention: Making the Link Between Health and Conservation. World Wildlife Fund and Conservation International, Washington, DC, USA.
Marks, S.A. 1996. Local hunters and wildlife surveys: an assessment and comparison of counts for 1989, 1990, and 1993. African Journal of Ecology 34:237-257.

Martin, Paul S. and Richard G. Klein (Eds). 1984. Quaternary Extinctions: A Prehistoric Revolution. University of Arizona Press, Tucson, AZ, USA.

Martin, R.B. 1996. Sport hunting: the Zimbabwe government viewpoint. In: Williams, N., J.A. Kayera and G.L. Overton (Eds). Tourist Hunting in Tanzania. IUCN, Gland, Switzerland and Cambridge, UK.

Martin, R.B. 2005. The influence of veterinary control fences on certain wild large mammal species in the Caprivi, Namibia. In: Osofsky, S.A., S. Cleaveland, W.B. Karesh, M.D. Kock, P.J. Nyhus, L. Starr and A. Yang (Eds). Conservation and Development Interventions at the Wildlife/Livestock Interface: Implications for Wildlife, Livestock and Human Health. IUCN, Gland, Switzerland and Cambridge, UK.

Masoud, T. and R. Wild. 2003. Promoting Community-Based Management of Natural Resources in Zanzibar. Presentation at the $\mathrm{V}^{\mathrm{th}}$ World Parks Congress, Durban.

Mayaka, T.B. 2001. Wildlife co-management in the Bénoué National Park-complex, Cameroon: a bumpy road to institutional development. World Development 30:2001-2016.

Mayer, M. and C. Garbe. 2001. Compilation and analysis of existing international documents relating to sustainable tourism. Prepared for the Workshop on Biological Diversity and Tourism, Santo Domingo, 4-7 June.

Maze, K. 2003. AngloAmerican and the Bushmanland Conservation Initiative. $\mathrm{V}^{\mathrm{th}}$ World Parks Congress, Workshop II.5, on Building Support from New Constituencies, Durban, South Africa, 11-13 September 2003. PDAC. www.pdac.ca/pdac/land-use/pa-manitoba.html

McComb J. Research provides strategy to combat forest devastation www.comm.murdoch.edu.au/ webster/A74.html, accessed April 12th 2004. 
McCullough, D. 1996. Spatially structured populations and harvest theory. Journal of Wildlife Management 60:1-9.

McKerchar, N.D. and P.R. Dingwall. 1984. Identifying the essential scientific needs of protected area managers. In: McNeely, J.A. and D. Navid (Eds). Conservation, Science, and Society. UNESCO, Paris, France.

McNeely, J.A. and Paul Spencer Wachtel. 1988. Soul of the Tiger: Searching for Nature's Answers in Southeast Asia. Doubleday, New York, USA.

McNeely, J.A. 1994. Protected areas for the twenty first century: working to provide benefits to society. Unasylva 176(46):3-8.

McNeely, J.A. (Ed.). 1995. Expanding Partnerships in Conservation. Island Press, Washington, DC, USA.

McNeely, J.A. and L. Guruswamy. 1998. Conclusion: how to save the biodiversity of Planet Earth. In: Guruswamy, Lakshman and J.A. McNeely (Eds). Protection of Global Diversity: Converging Strategies. Duke University Press, Durham, NC, USA.

McNeely, J.A. 1999. Protected area institutions. In: Sue Stolton and Nigel Dudley (Eds). Partnerships for Protection: New Strategies for Planning and Management of Protected Areas. Earthscan Publications, London, UK.

McNeely, J.A. (Ed.). 1999. Imagine Tomorrow's World: 50 hin Aniversary Symposium Proceedings. IUCN, Gland, Switzerland and Cambridge, UK.

McNeely, J.A. 2002. Biodiversity, Conflict and Tropical Forests. In: Matthew, Richard, M. Halle and J. Switzer (Eds). Conserving the Peace: Resources, Livelihoods, and Security. IISD and IUCN, Winnipeg, Canada.

McNeely, J.A. (Ed.). 2001. Cities and Protected Areas: An oxymoron or a partnership. Parks 11(3):1-3.

McNeely, J.A. 2003. Conserving Forest Biodiversity in Times of Violent Conflict. Oryx 37(2): 142-152.
McNeely, J.A., K. Redford and A.L Stewart Carter. 2003. A Taxonomy Of Support: How And Why New Constituencies Are Supporting Protected Areas. Framework Paper for $\mathrm{V}^{\text {th }}$ World Parks Congress Workshop II.5, on Building Support from New Constituencies, Durban, South Africa, 11-13 September 2003.

McNeilage, A., A. Plumptre, A. Brock-Doyle and A. Vedder. 2001. Bwindi Impenetrable National Park, Uganda: gorilla census. Oryx 35:39-47.

McShane, T. 2003 Integrated Conservation and Development: Summary of Lessons learnt, most important issues to address in the next 10 years with approaches and methodologies. Presentation at the $\mathrm{V}^{\text {th }}$ World Parks Congress, Durban.

McShane, T.O. and M.P. Wells (Eds). 2004. Getting Biodiversity Projects to Work: Towards More Effective Conservation and Development. Columbia University Press, New York, USA.

McShane, T.O. and S.A. Newby. 2004. Expecting the Unattainable: The Assumptions Behind ICDPs. In: T.O. McShane and M.P. Wells (Eds). Getting Biodiversity Projects to Work: Towards More Effective Conservation and Development. Columbia University Press, New York, USA.

Maginnis, S., W. Jackson and N. Dudley. 2003. Conservation Landscapes. Whose landscapes? Whose trade-offs? In: McShane, T. and M. Wells (Eds). Getting Biodiversity Projects to Work: Towards more Effective Conservation and Development. Columbia University Press, New York, USA.

Medellin, R. 2003. Trophy Hunting, Local Communities, and Biosphere Reserves: A Case from Tiburon Island, Mexico. In: Building New Constituencies for Protected Areas. $\mathrm{V}^{\text {th }}$ World Parks Congress, Durban, South Africa.

Mefalopulos, P. and Grenna, L. 2004. Promoting Sustainable Development Through Strategic Communication. In: Hamù, Auchincloss and Goldstein (Eds). 2004. Communicating Protected Areas. IUCN, Gland, Switzerland and Cambridge, UK. 
Meffe, G.K. 1999. Conservation medicine. Conservation Biology 13:953-954.

Memon, Jessica. 2005. Mosaic: Building links between ethnic communities and national parks in the United Kingdom. In: Trzyna, Ted (Ed.). 2005. The Urban Imperative: Urban Outreach Strategies for Protected Area Agencies. InterEnvironment, California Institute of Public Affairs, Sacramento, USA.

Meyer, Carrie A. 1997. Public-non-profit partnerships and North-South green finance. Journal of Environment and Development 6(2):123-146.

Michel, A.L. 2005. Tuberculosis - what makes it a significant player at the wildlife/livestock/human interface? In: Osofsky, S.A., S. Cleaveland, W.B. Karesh, M.D. Kock, P.J. Nyhus, L. Starr and A. Yang (Eds). Conservation and Development Interventions at the Wildlife/Livestock Interface: Implications for Wildlife, Livestock and Human Health. IUCN, Gland, Switzerland and Cambridge, UK.

Millennium Ecosystem Assessment. 2003. Ecosystems and Human Well-being: A Framework for Assessment. Island Press, Washington DC, USA.

Miller, G. 2003. The Energy and Biodiversity Initiative Site Selection Framework. $\mathrm{V}^{\text {th }}$ World Parks Congress, Workshop II.5, on Building Support from New Constituencies, Durban, South Africa, 11-13 September 2003.

Ministry of Planning and Economic Development. 1997. Statistical Abstract. The Republic of Uganda, Kampala, Uganda.

Milner-Gulland, E.J., E.L. Bennett and the SCB 2002 Annual Meeting Wild Meat Group. 2003. Wild meat: the bigger picture. Trends in Ecology and Evolution 18:351-357.

Miranda M., P. Burris, J. Bingcang Froy, P. Shearman, J. Briones, A. La Vina and S. Menard. 2003. Mining and Critical Ecosystems: Mapping the Risks. World Resources Institute, Washington DC, USA.
Mittermeier, R. 2003. Foreword. In: Christ, C., O. Hillel, S. Matus and J. Sweeting. Tourism and Biodiversity: Mapping Tourism's Global Footprint. UNEP and Conservation International, Washington DC, USA.

MMSD (Mining, Minerals and Sustainable Development). 2002. Breaking New Ground. Earthscan, London, UK. Can be accessed www.iied.org/mmsd/mmsd_pdfs/finalreport_toc. pdf

Molefi, T. 2004. Protected Area Communication, Education and Public Awareness: Case of Every River Has Its People Project - Botswana. In: Hamù, Auchincloss and Goldstein (Eds). 2004. Communicating Protected Areas. IUCN, Gland, Switzerland and Cambridge, UK.

Morales, M. 2003. Indigenous Territories, Rights and Conservation of Protected Areas in Latin America. Presentation at the $\mathrm{V}^{\text {th }}$ World Parks Congress, Durban.

Morales, M and L.M. Scherl. 2003. Integrated Conservation and Development in Ecuador: Analysis of a Ten Year Project. Presentation at the $V^{\text {th }}$ World Parks Congress, Durban.

Moseley, Robert. 2003. Kawagebo Snow Mountains: Sacred Natural Sites Case Study. Paper presented at the $\mathrm{V}^{\text {th }}$ World Parks Congress, Technical Sessions on Building Cultural Support for Protected Areas, September 12, Durban, South Africa.

Moss, Jack, G. Wolff, G. Gladden and E. Guittierez. 2003. Valuing Water for Better Governance: How to Promote Dialogue to Balance Social, Environmental, and Economic Values. Sponsored by the CEO Panel, Business and Industry.

Mulongoy, Kalemani Jo and Stuart Chape. 2004. Protected Areas and Biodiversity: A Summary of Key Issues. UNEP and CBD, Montreal, Canada. 
Murphree, M.W. 2000. Community-based conservation: old ways, new myths and enduring challenges. Proceedings of the Conference on African Wildlife Management in the New Millennium, 13-15 Dec 2000. Mweka, Tanzania: College of African Wildlife Management.

Murphree, M.J. 2005. "Counting sheep": the comparative advantages of wildlife and livestock - a community perspective. In: Osofsky, S.A., S. Cleaveland, W.B. Karesh, M.D. Kock, P.J. Nyhus, L. Starr and A. Yang (Eds). Conservation and Development Interventions at the Wildlife/Livestock Interface: Implications for Wildlife, Livestock and Human Health. IUCN, Gland, Switzerland and Cambridge, UK.

Najam, Adil. 2003. Environment, Development and Human Security: Perspectives from South Asia. University Press of America, Lanham, MD, USA.

Namara, A., N. Agrippina et al. 2003. Bwindi and Mhahinga National Parks in Uganda: Has 15 Years of ICD Programming Succeeded in Increasing Support for Conservation among Local Communities? Paper prepared for workshop on Building Support for Protected Areas. $V^{\text {th }}$ World Parks Congress, Durban, September 2003.

Nash, R.F. 2001. Wilderness and the American Mind. Fourth Edition. Yale University Press, New Haven, USA.

Natori, Y. 1997. Shiretoko Logging Controversy: a case study in Japanese environmentalism and nature conservation system. Society and Natural Resources 10(6).

Ndolanga, M.A. 1996. The Department of Wildlife's perspective on tourist hunting in Tanzania. In: Williams, N., J.A. Kayera and G.L. Overton (Eds). Tourist Hunting in Tanzania. IUCN, Gland, Switzerland and Cambridge, UK.

Nelson, J. and L. Hossack (Eds). 2003. From Principles to Practice: Indigenous Peoples and Protected Areas in Africa. Forest Peoples Programme, Moreton-in-Marsh, UK.
Noss, A.J. 1999. Censusing rainforest game species with communal net hunts. African Journal of Ecology 37(1):1-11.

Noss, AJ. and R.L. Cuellar. 2001. Community attitudes towards wildlife management in the Bolivian Chaco. Oryx 35:292-300.

Novaro, A.J., K.H. Redford and R.E. Bodmer. 2000. Effect of hunting in source-sink systems in the neotropics. Conservation Biology 14:713-721.

NSW National Parks and Wildlife Service. 2003. Project Brief: Research into Kinship with the Natural World: Influencing the role and function of field staff within the NSW National Parks and Wildlife Service.

OECD. 1996. Shaping the 21st Century: The Role of Development Co-operation. OECD, Paris, France.

Office International des Epizooties (OIE). 2003. Terrestrial Animal Health Code 2003. Office International des Epizooties, Paris, France. Accessed December 2003 at www.oie.int/eng/normes/MCode/A_summry.htm

O'Neill, Brian and G. Moore. 2005. Building urban constituencies for nature conservation: The Golden Gate Experience. In: Trzyna, Ted (Ed.). 2005. The Urban Imperative: Urban Outreach Strategies for Protected Area Agencies. InterEnvironment, California Institute of Public Affairs, Sacramento, USA.

Osofsky, S.A. 1997. Think link: critically evaluating linkages between conservation projects and development. J. Zoo Wildl. Med. 28:141-143.

Osofsky, S.A., W.B. Karesh and S.L. Deem. 2000. Conservation medicine: a veterinary perspective. Conservation Biology 14:336-337.

Osofsky, S.A., S. Cleaveland, W.B. Karesh, M.D. Kock, P.J. Nyhus, L. Starr and A. Yang (Eds). 2005. Conservation and Development Interventions at the Wildlife/Livestock Interface: Implications for Wildlife, Livestock and Human Health. IUCN, Gland, Switzerland and Cambridge, UK. 
Ostergren, D.M. and S.J. Hollenhorst. 1999. Convergence in protected area policy: a comparison of the Russian zapovednik and American wilderness systems. Society and Natural Resources 12(4):293-313.

Ostrom, Elinor. 1998. Scales, policentricity, and incentives: designing complexity to govern complexity. In: Guruswamy, Lakshman and J.A. McNeely (Eds). Protection of Global Diversity: Converging Strategies. Duke University Press, Durham, NC, USA.

Otegui Acha, Mercedes. Wirikuta: The Wixarika/Huichol Sacred Natural Site in the Chihuahuan Desert, San Luis Potosi, Mexico. In: Harmon, D. and A. Putney (Eds). The Full Value of Parks: from Economics to the Intangible. Rowman and Littlefield Publishers, Lanham, MD, USA.

Otegui Acha, Mercedes. 2003. Wirikuta, the Huichol Sacred Space in the Chihuhuan Desert of San Luis Potosi. Paper prepared for the $\mathrm{V}^{\text {th }}$ World Parks Congress, Technical Sessions on Building Cultural Support for Protected Areas, September 11-13, Durban, South Africa.

Otegui Acha and Diana Luque. 2003. Taheojc: The Comcaac Sacred Space, Tiburón Island, Sonora, Mexico. Paper prepared for the $V^{\text {th }}$ World Parks Congress, Technical Sessions on Building Cultural Support for Protected Areas, September 11-13, Durban, South Africa.

Otegui Acha and Gilberto Torres. 2003. The Sacred Caves of the Wind and Fertility, "Tam Bokom Mim". Huehuetlan, San Luis Potosi, Mexico. Paper prepared for the $\mathrm{V}^{\text {th }}$ World Parks Congress, Technical Sessions on Building Cultural Support for Protected Areas, September 11-13, Durban, South Africa.

Ott-Joslin, J.E. 1993. Zoonotic diseases of nonhuman primates. In: Fowler, M.E. (Ed.). Zoo and Wild Animal Medicine, Current Therapy 3. W.B. Saunders Company, Philadelphia, USA.
Oviedo, Gonzalo. 2002. Protected Areas and Indigenous and Traditional Peoples' Lands and Territories: Options and Opportunities. April 2002 draft.

Oviedo, Gonzalo. 2003a. Trabajo con Comunidades Indigenas en las Areas Protegidas. CIAT, Cali, Colombia.

Oviedo, Gonzalo. 2003b. Lessons Learned in the Establishment and Management of Protected Areas by Indigenous and Local Communities, South America. In: Enhancing equity in the relationship between protected areas and indigenous and local communities in the context of global change. www.iucn.org/themes/ceesp/ Publications/TILCEPA/CCA-GOviedo.pdf

Oviedo, Gonzalo, Luisa Maffi and Peter Bille Larsen. 2000. Indigenous and Traditional Peoples of the World and Ecoregion Conservation: An Integrated Approach to Conserving the World's Biological and Cultural Diversity. WWF International and Terralingua.

Oviedo, Gonzalo. 2004. Conservation of Biodiversity Rich Sacred Natural Sites. Draft Project Proposal. IUCN, Gland, Switzerland.

Pagiola, S., J. Bishop and N. Landell-Mills. 2002. Selling Forest Environmental Services: Marketbased Mechanisms for Conservation and Development. Earthscan, London, UK.

Pagiola S. 2003. Pro-poor Markets for Water Catchment Services. Presentation at the $\mathrm{V}^{\text {th }}$ World Parks Congress, Durban.

Pasanisi, G. 1996. The outfitter's perspective of tourist hunting in Tanzania. In: Williams, N., J.A. Kayera and G.L. Overton (Eds). Tourist Hunting in Tanzania. IUCN, Gland, Switzerland and Cambridge, UK.

Paul, Seema. 2003. The Appeal of World Heritage Designation to Funding Agencies: Case of the UN Foundation. Paper prepared for workshop on Building Support for Protected Areas. $\mathrm{V}^{\text {th }}$ World Parks Congress, Durban, September 2003. 
Pedersen, Arthur. 2002. Managing Tourism at World Heritage Sites: A Practical Manual for World Heritage Site Managers. World Heritage Centre, Paris, France.

Pedersen, Arthur and Alfredo Arellano. 2003. Using Tourism to Foster a Sense of Commitment at World Heritage Sites: A Case Study in Sian Ka'an. Paper prepared for workshop on Building Support for Protected Areas. $V^{\text {th }}$ World Parks Congress, Durban, September 2003.

Pei, Shengji. 2003. Workshop on the Importance of Sacred Natural Sites for Biodiversity Conservation: Kunming (17-18 Feb., 2003) and Xishuangbanna (19-20 Feb., 2003), Yunnan, China. PowerPoint presented at the $\mathrm{V}^{\text {th }}$ World Parks Congress, Technical Sessions on Building Cultural Support for Protected Areas, September 12, Durban, South Africa.

Pei, Shengji. 2003. Laojunshan: A Sacred Mountain in Northwestern Yunnan,China. PowerPoint presented at the $\mathrm{V}^{\text {th }}$ World Parks Congress, Technical Sessions on Building Cultural Support for Protected Areas, September 12, Durban, South Africa.

Perry, B.D., T.F. Randolph, J.J. McDermott, K.R. Sones and P.K. Thornton. 2002. Investing in Animal Health Research to Alleviate Poverty. International Livestock Research Institute (ILRI), Nairobi, Kenya.

Phillips, Adrian. 2002. World Heritage Sites: Foundations or Pinnacles? Paper presented for Workshop on Using World Heritage to build broader support for protected areas. IUCN HQ, Gland. 15-17 October 2002.

Phillips, Adrian. 2003. Turning Ideas on their Head - the New Paradigm for Protected Areas. The George Wright Forum 20(2):8-32.

Pimbert, M. and J.N Pretty. 1995. Parks, People and Professionals: Putting Participation into Protected Area Management. United Nations Research Institute for Social Development Discussion paper 57.
Pimentel, D. et al. 1995. Environmental and Economic Costs of Soil Erosion and Conservation Benefits. Science 267:1117-1123.

Plowright, W. 1968. Inter-relationships between virus infections of game and domestic animals. East African Agricultural and Forestry Journal Special Issue:260-263.

Plowright, W. 1982. The effect of rinderpest and rinderpest control on wildlife in Africa. In: Animal Diseases in Relation to Animal Conservation. Symposium of the Zoological Society of London 50:1-28.

Poirier R. and D. Ostergren. 2002. Evicting people from nature: indigenous land rights and national parks in Australia, Russia and the US. Natural Resources Journal 42(2):331-352.

Porter, G., A. Stewart Carter, M. Bakarr and C. Kormos. 2001. Review of an Ilmenite Mining Project in South East Madagascar. Conservation International, Washington DC, USA.

Posey, D.A. (Ed.). 1999. Cultural and Spiritual Values of Biodiversity: A Complementary Contribution to the Global Biodiversity Assessment. Intermediate Technology Publication, London, UK.

Prescott-Allen, Robert and Christine Prescott-Allen. 1984. Park your Genes: Protected areas as in situ genebanks for the maintenance of wild genetic resources. In: McNeely, Jeffrey A. and Kenton R. Miller (Eds). National Parks, Conservation, and Development: The Role of Protected Areas in Sustaining Society. Smithsonian Institution Press, Washington DC, USA.

Price, Steven V. (Ed.). 2003. War and Tropical Forests: Conservation in Areas of Armed Conflict. The Haworth Press, New York, USA.

Price Waterhouse. 1996. A comparison between hunting systems in some Southern African countries. In Williams, N., J.A. Kayera and G.L. Overton (Eds). Tourist Hunting in Tanzania. IUCN, Gland, Switzerland and Cambridge, UK. 
Pritchard, L. Jr., C. Folke and L. Gunderson. 2000. Valuation of ecosystem services in institutional context. Ecosystems 3:36-40.

Pulliam, R.H. 1988. Sources, sinks, and population regulation. The American Naturalist 132:652-661.

Putney, A. 2003. Introduction: Perspective on the Values of Protected Areas. In: Harmon, D. and A. Putney (Eds). The Full Value of Parks: from Economics to the Intangible. Rowman and Littlefield Publishers, Lanham, MD, USA.

Putney, A. and T. Schaaf. 2003. Guidelines for the Management of Sacred Natural Sites. Paper presented at the $\mathrm{V}^{\text {th }}$ World Parks Congress, Technical Sessions on Building Cultural Support for Protected Areas, September 13, Durban, South Africa.

Putz, F.E., K.H. Redford, J.G. Robinson, R. Fimbel and G.M. Blate. 2000. Biodiversity Conservation in the Context of Tropical Forest Management. The World Bank Environment Paper No. 75.

Pyle, R.M. 2002. Eden in a vacant lot: Special places, species, and kids in the neighborhood of life. In: Kahn and Kellert (Eds). Children and Nature: Psychological, Sociological, and Evolutionary Investigations. MIT Press, Cambridge, MA, USA.

Raipon and Caff. 2004. The Conservation Value of Sacred Sites of Indigenous Peoples of the Arctic: A Case Study in Northern Russia - Report on the State of Sacred Sites and Sanctuaries. The CAFF Technical Report 11. www.caff.is

Ramakrishnan, P.S. 2001. Ecology and Sustainable Development. National Book Trust, New Delhi, India.

Ramakrishnan, P.S. 2003. Conserving the Sacred: The Protective Impulse and the Origins of Modern Protected Areas. In Harmon, D. and A. Putney (Eds). The Full Value of Parks: from Economics to the Intangible. Rowman and Littlefield Publishers, Lanham, MD, USA.
Rametsteiner, E. and M. Simula. 2001. Forging Novel Incentives for Environment and Sustainable Forest Management: Background Paper. For Workshop on Forest Certification, Brussels, 6-7 September. European Commission DG Environment. October.

Rapport, D. 1998. Defining ecosystem health. In: Rapport, D., R. Costanza, P.R. Epstein, C. Gaudet and R. Levins (Eds). Ecosystem Health. Blackwell Science, Oxford, UK.

Rapport, D., R. Costanza, P.R. Epstein, C. Gaudet and R. Levins. (Eds). 1998. Ecosystem Health. Blackwell Science, Oxford, UK.

Ratter, A. 1997. Participatory Evaluation. Evaluation report: Community Conservation, for Uganda Wildlife Authority Project. Kampala, Uganda.

Redford, Kent and Jane A. Mansour (Eds). 1996. Traditional Peoples and Biodiversity Conversation in Large Tropical Landscapes. America Verde Publications, Arlington, VA, USA.

Redford, K.H., K. Brandon and S. Sanderson. 1998. Holding ground. In: K. Brandon, K.H. Redford and S.E. Sanderson (Eds). Parks in Peril: People, Politics, and Protected Areas. Island Press, Washington DC, USA.

Redford, K.H., P. Coppolillo, E.W. Sanderson, G.A.B. Fonseca, C. Groves, G. Mace, S. Maginnis, R. Mittermeier, R. Noss, D. Olson, J.G. Robinson, A. Vedder and M. Wright. 2003. Mapping the Conservation Landscape. Conservation Biology 17(1):116-132.

Richards, D., J. Hall and P. Roberts. 2003. RioTinto Biodiversity Partnership Programme. $\mathrm{V}^{\text {th }}$ World Parks Congress, Workshop II.5, on Building Support from New Constituencies, Durban, South Africa, 11-13 September 2003.

Roberts, Debra et al. 2005. Resource economics as a tool for open space planning in Durban, South Africa. In: Trzyna, Ted (Ed.). 2005. The Urban Imperative: Urban Outreach Strategies for Protected Area Agencies. InterEnvironment, California Institute of Public Affairs, Sacramento, USA. 
Rodrigues A.S., S.J. Andelman, M.I. Bakarr, L. Boitan, T.M. Brooks, R.M. Cowling, L.D. Fishpool, G.A. Fonseca, K. Gaston, M. Hoffman, J.S. Long, P.A. Marquet, J.D. Pilgrim, R.L. Pressey, J. Schipper, W. Sechrest, S.N. Stuart, L.G. Underhill, R.W. Waller, M.J. Watts and X. Yan. 2004. Effectiveness of the Global Protected Area Network in Representing Species Diversity. Nature 428:640-643.

Rodriguez-Navarro, Guillermo E., 2003. Spiritual Significance and Environmental Effects of Offerings Amongst the Indigenous People of the Sierra Nevada of Santa Marta. Paper presented at the $\mathrm{V}^{\text {th }}$ World Parks Congress, Technical Sessions on Building Cultural Support for Protected Areas, September 11-13. Durban, South Africa.

Rodwell, T.C., I.J. Whyte and W.M. Boyce. 2001. Evaluation of population effects of bovine tuberculosis in free-ranging African buffalo (Syncerus caffer). J. Mammal. 82:231-238.

Roe, D. and J. Elliot. 2003. Pro-poor conservation: The elusive win-win for conservation and poverty reduction? Presentation at the $\mathrm{V}^{\text {th }}$ World Parks Congress, Durban.

Roe, D. and J. Elliott. 2004. Poverty reduction and biodiversity conservation: rebuilding the bridges. Oryx 38:137-139.

Rondinelli, D.A. 2002. Transnational Corporation: International Citizens or New Sovereigns? Business and Society Review 107(4):391-413.

Rosabal, P. 1997. IUCN guidelines for protected area management categories: a framework for actions. Gibier Faune Sauvage 14:125-140.

Rosenberg, A.A. 2001. Marine reserves and population recovery or how do closed areas affect exploited population dynamics. Reviews in Fish Biology and Fisheries 10:519-520.

Rosenfeld A., D. Gordon and M. Guerin-McManus. 1997. Reinventing the Well: Approaches to Minimizing the Environmental Impact and Social Impact of Oil Development in the Tropics. Conservation International, Washington DC, USA.
Rosenfeld Sweeting A. and A. Clark. 2000. Lightening the Lode: A Guide to Responsible Large-Scale Mining. Conservation International, Washington DC, USA.

Rosenzweig, M.L. 2003. Reconciliation ecology and the future of species diversity. Oryx 37:194-205.

Ross, A. 1994. Traditional hunting in national parks and the cultural heritage paradigm. Ngulaig 11:1-19.

Rössler, Mechtild. 2000. World Heritage Convention: Goals, Objectives, Criteria, Issues and Challenges with Respect to World Heritage and Mining. In: IUCN, UNESCO World Heritage Centre and ICME. Proceedings of a Technical Workshop on World Heritage and Mining. Gland, Switzerland.

Rössler, Mechtild. 2003. Using World Heritage to Link Nature and Culture. Paper prepared for workshop on Building Support for Protected Areas. $\mathrm{V}^{\text {th }}$ World Parks Congress, Durban, September 2003.

Roth, E.A. 1996. Traditional pastoral strategies in a modern world: an example from northern Kenya. Human Organisation 55:219-224.

Rozemeijer, N. 2003. CBNRM in Botswana: Revisiting the assumptions after 10 years of implementation. IUCN/SNV CBNRM Support Programme in Botswana, Gabarone.

Ruiz Corzo, M.I. 2004. Education and Communication for Conservation: Comanagement of the Sierra Gorda Biosphere Reserve, Mexico. In: Hamù, Auchincloss and Goldstein (Eds). 2004. Communicating Protected Areas. IUCN, Gland, Switzerland and Cambridge, UK.

Ruddle, Kenneth and R.E. Johannes. 1985. The Traditional Knowledge and Management of Coastal Systems in Asia and the Pacific. UNESCO, Jakarta, Indonesia.

Ruppert, D. 2003. Building partnerships between Native Americans and the National Park Service. Ecological Restoration 21(4):261-263. 
Russ, G.R. and A.C. Alcala. 2003. Marine reserves: rates and patterns of recovery and decline of predatory fish, 1983-2000. Ecological Applications 13:1553-1565.

Ruzicka, J. 1995. Legal framework of game management in the Czech Republic. In: How Hunting and Fishing Can Contribute to Nature Conservation and Rural Development. Council of Europe Publishing, Strasbourg, France.

Sahgal, Bittu. 2005. Kids for Tigers: The Sanctuary Asia Tiger Program: A globally replicable school contact program to win support for wildlife and protected areas. In: Trzyna, Ted (Ed.). 2005. The Urban Imperative: Urban Outreach Strategies for Protected Area Agencies. InterEnvironment, California Institute of Public Affairs, Sacramento, USA.

Saiia D.H., A.B. Carroll and A.K. Bucholtz. 2003. Philanthropy as Strategy: When Corporate Charity "Begins at Home". Business and Society 42(2):169-201.

Salafsky, N. 2003. A Systematic Test of an Enterprise Based Approach to Conservation: The Experience of the Biodiversity Conservation network in Asia and the Pacific. Presentation at the $\mathrm{V}^{\text {th }}$ World Parks Congress, Durban.

Salvatori, V., H. Okarma, O. Ionescu, Y. Dovhanyeh, S. Findo and L. Boitani. 2002. Hunting legislation in the Carpathian Mountains: implications for the conservation and management of large carnivores. Wildlife Biology 8:3-10.

Sanchez Lira, M. 2004. Case study: Strategic Communication and Identity in the National Commission for Natural Protected Areas. In: Hamù, Auchincloss and Goldstein (Eds). 2004. Communicating Protected Areas. IUCN, Gland, Switzerland and Cambridge, UK.

Saunier, Richard E. and R.A. Meganck. 1995. Conservation of Biodiversity and the New Regional Planning. Organization of American States and IUCN, Gland, Switzerland.
Sayer, J. and M.P. Wells. 2004. The Pathology of Projects. In: T.O. McShane and M.P. Wells (Eds). Getting Biodiversity Projects to Work: Towards More Effective Conservation and Development. Columbia University Press, New York, USA.

Sayre, R., E. Roca, G. Sedaghatkish, B. Young, S. Keel, R. Roca and S. Sheppard. 2000. Nature in Focus: Rapid Ecological Assessment. Island Press, Washington, DC, USA.

Scherl, L.M. 2003. Working the Links between Protected Areas and Poverty. Presentation at the $\mathrm{V}^{\text {th }}$ World Parks Congress, Durban.

Scherl, L.M., A. Wilson, R. Wild, J. Blockhus, P. Franks, J.A. McNeely and T.O. McShane. 2004. Can Protected Areas Contribute to Poverty Reduction? Opportunities and Limitations. IUCN, Gland, Switzerland, and Cambridge, UK.

Schnitger, F.M. 1964. Forgotten Kingdoms in Sumatra. E.J. Brill, Leiden, Netherlands.

Schultz, P. Wesley. 2000. Empathizing with Nature: The effects of perspective taking on concern for environmental issues. Journal of Social Issues 56(3):391-406.

Schultz, P. Wesley. 2002. Inclusion with Nature: The psychology of human-nature relations. In: Peter Schmuck and P. Wesley Schultz (Eds). Psychology of Sustainable Development. Kluwer, Boston.

Schwabe, C.W. 1974. Veterinary Medicine and Human Health. Williams \& Wilkins, Baltimore, MD, USA.

Schwenk, S. 1991. History of hunting and conservation of Ungulates by hunters in Germany and Austria. In: Spitz, F., G. Janeau, G. Gonzalez and S. Aulagnier (Eds). Proceedings of the international symposium Ongulés/Ungulates.

Scoones, I. (Ed.). 1994. Living with Uncertainty: New Directions in Pastoral Development in Africa. Intermediate Technology Development Group, London, UK. 
Scott Wilson Resource Consultants/Environment and Development Group. 2000. Final Report: Environmental Assessment of Veterinary Fences in Ngamiland. Volumes 1-5. UK Department for International Development (DFID) and the Government of Botswana, Edinburgh and Oxford, UK.

Secaira, Estuardo. 2003. A Fruitful Dialogue between Local Protected Area Managers and Spiritual Guides: the Case of Chicabal Volcano and Lagoon in the Western Highlands of Guatemala. Paper presented at the $\mathrm{V}^{\mathrm{th}}$ World Parks Congress, Technical Sessions on Building Cultural Support for Protected Areas, September 12, Durban, South Africa.

Sellers, R.W. 1997. Preserving Nature in the National Parks: A History. Yale University Press, New Haven, USA.

Senior, John and Mardie Townsend. 2005. "Healthy Parks, Healthy People" and other social capital initiatives of Parks Victoria, Australia. In: Trzyna, Ted (Ed.). 2005. The Urban Imperative: Urban Outreach Strategies for Protected Area Agencies. InterEnvironment, California Institute of Public Affairs, Sacramento, USA.

Seymour M. 2003. Partnerships to support sustainable development and conservation: WestEast Pipeline Project, China. V ${ }^{\text {th }}$ World Parks Congress, Workshop 8, on Learning from concrete successes of sustainably financing protected areas. Durban, South Africa, 11-13 September 2003.

Shafer, C.L. 2000. The Northern Yellowstone Elk debate: policy, hypothesis, and implications. Natural Areas Journal 20:342-359.

Shambaugh, James, J. Oglethorpe and R. Ham. 2001. The Trampled Grass: Mitigating the Impacts of Armed Conflict on the Environment. Biodiversity Support Program, Washington, DC, USA.

Shell. 27 August 2003. Press Release: Shell commits not to operate in World Heritage Sites. www.shell.com/home/
Shorten, P., I. Harper and R. Loon. 2003. Sabi Sabi - a model for effective ecotourism, conservation and community involvement in southern Africa. Paper presentation $\mathrm{V}^{\text {th }}$ World Parks Congress, Durban.

Sinclair, A.R.E. 1970. Studies of the Ecology of the East African Buffalo. D.Phil. thesis. Oxford University, Oxford, UK.

Sinclair, A.R.E. 1995. Serengeti Past and Present. In: Sinclair, A.R.E. and P. Arcese (Eds). Serengeti II: Dynamics, management, and conservation of an ecosystem. University of Chicago Press, Chicago, USA.

Singh, S., V. Sankaran, H. Mander and S. Worah. 2000. Strengthening Conservation Cultures: Local Communities and Biodiversity Conservation. UNESCO, Paris, France.

Singh, Shekhar. 2002. Relating Cultural and Religious Heritage to Biodiversity Conservation: The Indian Experience. Paper prepared for the Workshop on Using World Heritage to build broader support for protected areas. IUCN HQ, Gland. 15-17 October, 2002.

Sitanon, Jasdapipat and Matthew D. Markopoulos. 1996. Promoting private investment in biodiversity conservation. In: McNeely, J.A. and Sunthad Somchevita (Eds). Biodiversity in Asia: Challenges and Opportunities for the Scientific Committee. Office of Environmental Policy and Planning, Ministry of Science, Technology and Environment, Bangkok, Thailand.

Skeat, A. and H. Skeat. 2003. Systems to make tourism and others contribute to protected areas the Great Barrier Reef. Paper presentation $V^{\text {th }}$ World Parks Congress, Durban.

Sladek Nowlis, J. and C.M. Roberts. 1999. Fisheries benefits and optimal design of marine reserves. Fisheries Bulletin 97:604-616.

Smietana, W. and J. Wajda, 1997. Wolf number changes in Bieszczady National Park, Poland. Acta Theriologica 43:241-252. 
Smyth, D. 2001. Joint Management of National Parks in Australia. In: Baker, R.J., J. Davies and E. Young (Eds). Working on Country Contemporary Indigenous Management of Australia's Lands and Coastal Regions. Oxford Press, Oxford, UK.

Sorvig, Kim. 2002. The Wilds of South Central. Landscape Architecture 92(4):66-75.

Soutter, Rob, Yaa Ntiamoa-Baidu, John Smith and Devendra Rana. 2003. Recognising the Contribution of Sacred Natural Sites for Biodiversity Conservation. Paper presented at the $\mathrm{V}^{\text {th }}$ World Parks Congress, Technical Sessions on Building Cultural Support for Protected Areas, September 11, Durban, South Africa.

Spergel, B. 2002. Raising Revenues for Protected Areas: A Menu of Options. WWF, Washington, DC, USA.

Staiff, R., R. Bushell and P. Kennedy. 2002. Interpretation in national parks: some critical questions. Journal of Sustainable Tourism 10(2):97-113.

Staiff, R. and R. Bushell. 2004. Minnamurra Rainforest Centre: Interpretation and Education Strategic Plan. Report to NSW National Parks and Wildlife Services. University of Western Sydney, Australia.

Stanvliet, R. et al. 2004. Applicability of the biosphere reserve concept to an urban context: An overview evaluation of the CUBES Cape Town Study. Annals of the New York Academy of Sciences, 1023:80-104.

Stewart Carter, A.L. 1999. Mining Companies as Agents of Development? Corporate Social Responsibility, Participation and Local Community at Mining Projects. Ph.D Thesis. University of Bath, UK.

Stewart Carter, A.L. 2003a. Partners in Funding Strategies for Protected Areas: The Efficacy of Corporate Philanthropy. $\mathrm{V}^{\text {th }}$ World Parks Congress, Workshop II.5, on Building Support from New Constituencies, Durban, South Africa, 11-13 September, 2003.
Stewart Carter, A.L. 2003b. The Initial Biodiversity Assessment and Planning Methodology: a tool for land use planning at energy and mining projects. $V^{\text {th }}$ World Parks Congress, Workshop I, on Linkages in the Landscape/Seascape, Durban, South Africa, 11-13 September, 2003.

Stolton, Sue and Nigel Dudley (Eds). 1999. Partnerships for Protection: New Strategies for Planning and Management of Protected Areas. Earthscan Publications, London, UK.

Stone, C. 2003. The Global Conservation Fund. $V^{\text {th }}$ World Parks Congress, Workshop II.5, on Building Support from New Constituencies, Durban, South Africa, 11-13 September, 2003.

Sumaila, U.R., S. Guénette, J. Alder and R. Chuenpagdee. 2000. Addressing ecosystem effects of fishing using marine protected areas. ICES Journal of Marine Science 57.

Sutmoller, P., G.R. Thomson, S.K. Hargreaves, C.M. Foggin and E.C. Anderson. 2000. The foot-andmouth disease risk posed by African buffalo within wildlife conservancies to the cattle industry of Zimbabwe. Prev. Vet. Med. 44(1-2):43-60.

Suzuki, David and P. Knudtson. 1992. Wisdom of the Elders: Sacred Native Stories of Nature. Bantam, New York, USA.

Sweeting, James and Wayne, Scott. 2003. A Shifting Tide: Environmental Challenges and Cruise Industry Responses. Conservation International, Washington, DC, USA.

Sykes, R. 2003. Shell Working Together for Conservation. $\mathrm{V}^{\text {th }}$ World Parks Congress, Workshop II.5, on Building Support from New Constituencies, Durban, South Africa, 11-13 September, 2003.

Szabo, S. et al. 1996. Indigenous Protected Areas: A New Concept in Biodiversity Conservation. In: Biodiversity - Broadening the Debate. Australian Nature Conservation Agency, Canberra, Australia. 
Taber, A., G. Novarro and M.A. Arribas. 1997. A new park in the Bolivian Gran Chaco - an advance in tropical dry forest conservation and community based management. Oryx 31:189-198.

Tabor, G.M. 2002. Defining conservation medicine. In: Aguirre, A.A., R.S. Ostfeld, G.M. Tabor, C. House and M.C. Pearl (Eds). Conservation Medicine: Ecological Health in Practice. Oxford University Press, New York, USA.

Tanzania Game Tracker Safaris and Robin Hurt Safaris. 1996. The Cullman rewards and benefits scheme. In: Leader-Williams, N., J.A. Kayera and G.L. Overton (Eds). Tourist Hunting in Tanzania. IUCN, Gland, Switzerland and Cambridge, UK.

Taskforce on Economic Benefits of Protected Areas. 1998. Economic Values of Protected Areas: Guidelines for Protected Area Managers. IUCN, Gland, Switzerland and Cambridge, UK.

Taylor, R. 2001. Participatory natural resource monitoring and management. In: Hulme, D. and M.W. Murphree (Eds). African Wildlife and Livelihoods: The Promise and Performance of Community Conservation. James Currey Ltd., Oxford, UK.

Ten Kate, K. 2003. Sensitive Sites - Sensitive Issues: An Investors' Perspective on Extractive Companies and Biodiversity. $\mathrm{V}^{\text {th }}$ World Parks Congress, Workshop II.5, on Building Support from New Constituencies, Durban, South Africa, 11-13 September, 2003.

Thambi, E. 2003. Promoting Livestock Marketing and Trade for Sustainable Livestock Development. Internal publication, African Union/Interafrican Bureau for Animal Resources, Nairobi, Kenya.

Thibauls, M. and S. Blaney. 2003. The Oil Industry as an Underlying Factor in the Bushmeat Crisis in Central Africa. Conservation Biology 17(6):1807-1813.

Thomson, G.R., W. Vosloo and A.D.S. Bastos. 2003. Foot and mouth disease in wildlife. Virus Res. 91:145-161.
Thomson, G.R., E.N. Tambi, S.K. Hargreaves, T.J. Leyland, A.P. Catley, G.G.M. van't Klooster and M.-L. Penrith. 2004. Shifting paradigms in international animal health standards: the need for comprehensive standards to enable commodity-based trade. CAPE Unit, Pan African Programme for the Control of Epizootics (PACE), African Union/Interafrican Bureau for Animal Resources (AU/IBAR) Discussion Paper. Nairobi, Kenya. Accessed October 2004 at www.eldis.org/static/DOC15066.htm

Thorsell, Jim. 1992. World Heritage Twenty Years Later. IUCN, Gland, Switzerland.

Thorsell, Jim. 2003. World Heritage Convention: Effectiveness 1992-2002 and Lessons for Governance. Governance Workshop. $\mathrm{V}^{\text {th }}$ World Parks Congress. Durban.

Thrupp, L.A. and N. Megateli. 1999. Critical Links: Food Security and the Environment in the Greater Horn of Africa. WRI Project Report. World Resources Institute (WRI), International Livestock Research Institute (ILRI), Nairobi, Kenya.

Thulstrup Hans. 1999. World Natural Heritage and the Local Community: Case Studies from AsiaPacific, Australia and New Zealand. World Heritage Centre, Paris, France.

Todishev, Mikhail. 2003. The Conservation Value of Sacred Sites of Indigenous Peoples of the Arctic: A Case Study in Northern Russia. Paper presented at the $\mathrm{V}^{\text {th }}$ World Parks Congress, Technical Sessions on Building Cultural Support for Protected Areas, September 11. Durban, South Africa.

Tongson, E. 2003. Securing Tenure for Biodiversity Protection: The Case of Sibuyan Mangyan Tagabukid, Philippines. Presentation at the $\mathrm{V}^{\text {th }}$ World Parks Congress, Durban.

Torres, Miriam and Ricardo Espinosa. 2003. Building Cultural Support through development of a network of PAs Associated to the Great Inca Route. PowerPoint presented at the $\mathrm{V}^{\text {th }}$ World Parks Congress, Technical Sessions on Building Cultural Support for Protected Areas, September 11. Durban, South Africa. 
Tranel, Michael J. and Adrienne Hall, 2003. Parks as Battlegrounds: Managing Conflicting Values. In: Harmon, D. and A. Putney (Eds). The Full Value of Parks: from Economics to the Intangible. Rowman and Littlefield Publishers, Lanham, MD, USA.

Trouvilliez, J. 1997. Twenty years of hunting reserves and refuges in France: conclusions and recommendations. Gibier Faune Sauvage 14:227-235.

Trzyna, Ted. 2001a. California's Urban Protected Areas: Progress despite daunting pressures. Parks 11(3):4-15.

Trzyna, Ted. 2001b. The Groundwork Approach to Urban Renewal: What California can learn from an innovative British environmental partnership organization. California Institute of Public Affairs, Sacramento, USA. www.Inter Environment.org/ cipa/groundwork.htm

Trzyna, Ted (Ed.). 2005. The Urban Imperative: Urban Outreach Strategies for Protected Area Agencies. InterEnvironment, California Institute of Public Affairs, Sacramento, USA.

Tryzna, T. 2005. Urban Dwellers and Protected Areas: Natural Allies. (This volume).

Uganda Wildlife Authority (UWA). 2001. Bwindi Impenetrable National Park/Mgahinga Gorilla National Park (Bwindi/Mgahinga Conservation Area) General Management Plan (July 2001-June 2011). UWA Planning Unit, Kampala, Uganda.

UN (United Nations Population Division). 2004. UN report says world urban population of 3 billion today expected to reach 5 billion by 2030. Press release, 24 March, 2004. United Nations, New York. www.unpopulation.org

UNEP and WTO. 2002. The Quebec Declaration on Ecotourism. World Tourism Organization, Madrid, Spain.

UNESCO. 1996. Biosphere Reserves: The Seville Strategy and the Statutory Framework of the World Network. UNESCO, Paris, France.
UNESCO. 2004. MAB Urban Group. UNESCO,

Paris, France. www.unesco.org/mab

United Nations Educational, Scientific, and Cultural Organization (UNESCO). 2004. World Heritage List. UNESCO, Paris, France. Online at: http://whc.unesco.org/heritage.htm (April 22nd 2004).

U.S. Department of the Interior, Fish and Wildlife Service and U.S. Department of Commerce (Census Bureau). 2002. 2001 National Survey of Fishing, Hunting, and Wildlife-Associated Recreation. Washington DC, USA.

USFWS. Viewed February 20, 2004. http:// refuges.fws.gov/faqs/acquisition.html\#hunters

Van Boven, G. and F. Hesselink. 2003. Conservation results by Managing Change: The Role of Communication, Education and Public Awareness, Experiences in Central Europe. IUCN, Gland, Switzerland.

Van Weerd, M., G. Van Boven and J. Van der Ploeg. 2004. Using Communication to involve Local Communities and Local Governments in Protected Area Management: Two Related Cases from Northeast Luzon, Philippines. In: Hamù, Auchincloss and Goldstein (Eds). 2004. Communicating Protected Areas. IUCN, Gland, Switzerland and Cambridge, UK.

Various recommendations arising from the Congress available from IUCN (2003). www.iucn.org/themes/wcpa/wpc2003/pdfs/Proce edings/recommendations.pdf

Vidal, R.M., G. Grenna, E. Santi and D. Calabrese. 2004. Strategic Communication Planning for a National System of Protected Areas: The Mexican Case. In: Hamù, Auchincloss and Goldstein (Eds). 2004. Communicating Protected Areas. IUCN, Gland, Switzerland and Cambridge, UK.

Vincelette, M. Environmental Program Manager, QIT Madagascar Minerals. Personal communication by email on April 22, 2004. 
Von Droste, Berndt and N. Ishwaran. 2003. World Heritage in Danger: How it can Build Political Support. Paper prepared for workshop on Building Support for Protected Areas. $V^{\text {th }}$ World Parks Congress, Durban, September, 2003.

Wadley, R.L., C.J. Pierce Colfer and I.G. Hood. 1997. Hunting Primates and Managing Forests: The Case of Iban Forest Farmers in Indonesian Borneo. Human Ecology 25:243-271.

Wallace, David Rains. 1992. The Quetzal and the Macaw: The Story of Costa Rica's National Parks. Sierra Club Books, San Francisco, USA.

Wallis, J. and L.D. Rick. 1999. Primate conservation: the prevention of disease transmission. Int. J. Primatol. 20:803-825.

Warhurst, A. 1992. Environmental management in mining and mineral processing in developing countries. Natural Resources Forum 16:39-48.

Warhurst, A., A.L. Stewart Carter and A. Mohan. 2001. Corporate Foundations as Agents of Development. Mining Policy Research Initiative of the International Development Research Centre, Canada.

WCPA. 2000. Definition of the Non-Material Values of Protected Areas. Unpublished report. IUCN World Commission on Protected Areas, Task Force on the Non-Material Values of Protected Areas, Gland, Switzerland.

WCPA. 2003. Cities and Protected Areas (Recommendation 5.14 of the $\mathrm{V}^{\text {th }}$ World Parks Congress). www.iucn.org/themes/wcpa

WCPA. 2004. Task Force on Cities and Protected Areas. www.InterEnvironment.org/pa
Weaver, L.C. and P. Skyer. 2005. Conservancies: integrating wildlife land-use options into the livelihood, development and conservation strategies of Namibian communities. In: Osofsky, S.A., S. Cleaveland, W.B. Karesh, M.D. Kock, P.J. Nyhus, L. Starr and A. Yang (Eds). Conservation and Development Interventions at the Wildlife/Livestock Interface: Implications for Wildife, Livestock and Human Health. IUCN, Gland, Switzerland and Cambridge, UK.

Welcomme, R.L. 2001. Inland Fisheries: Ecology and Management. Food and Agriculture Organization of the United Nations. Blackwell, Oxford, UK.

Wells, M. and K. Brandon. 1992. People and parks: Linking Protected Area Management with Local Communities. The World Bank, Washington, DC, USA.

Wells, M., S. Guggenheim, A. Khan, W. Wardojo and P. Jepson. 1999. Investing in Biodiversity: A Review of Indonesia's Integrated Conservation and Development Projects. World Bank, Washington, DC, USA.

Wells, M. 2003. The Evolution of the ICD Approach: An Overview. Presentation at the $\mathrm{V}^{\text {th }}$ World Parks Congress, Durban.

Werikhe, S., L. Macfie, N. Rosen and P. Miller (Eds). 1998. Can the mountain gorilla survive? Proc. Population and Habitat Viability Assessment Workshop for Gorilla gorilla beringei. Conservation Breeding Specialist Group (CBSG), Apple Valley, MN, USA.

West, P.C. and S.R. Brechin (Eds). 1991. Resident Peoples and National Parks. University of Arizona Press, Tucson, USA.

Western, D. 1994. Ecosystem conservation and rural development - the case of Amboseli. In: Western, D., R.M. Wright and S.C. Strum (Eds). Natural Connections: Perspectives in Community-based Conservation. Island Press, Washington, DC, USA. 
Western, D., R.M. Wright and S.C. Strum (Eds). 1994. Natural Connections: Perspectives in Community-based Conservation. Island Press, Washington, DC, USA.

Wildlife Conservation Society (WCS), The Field Veterinary Program (FVP). 2003a. Animal Health Matters: Improving the Health of Wild and Domestic Animals to Enhance Long-Term Development Success in USAID-Assisted Countries. RFA USAID/G/ENV/ENR 99-01 Technical Application Report. Wildlife Conservation Society, Bronx, New York, USA. Accessed October 2004 at http://wcs.org/swhigh_tech_tools/wildlifehealthscience/fvp/16857 0/168612/animalhealthmatters

Wildlife Conservation Society (WCS), The Field Veterinary Program (FVP). 2003b. Livestock and Wildlife Health. Wildlife Health: Disease - A Growing Threat to Wildlife Conservation. Accessed October 2004 at http://wcs.org/swhigh_tech_tools/wildlifehealthscience/fvp/167670

Wildlife Conservation Society (WCS), The Field Veterinary Program (FVP). 2003c. Gorilla and Human Health. Wildlife Health: Disease - A Growing Threat to Wildlife Conservation. Accessed October 2004 at http://wcs.org/swhigh_tech_tools/wildlifehealthscience/fvp/167670

Wilkie, D.S. and J.F. Carpenter. 1999a. Can nature tourism help finance protected areas in the Congo Basin? Oryx 33:332-338.

Wilkie, D.S. and J.F. Carpenter. 1999b. The potential role of safari hunting as a source of revenue for protected areas in the Congo Basin. Oryx 33:339-345.

Wilkie, D., K.H. Redford and T.O. McShane. [In press]. Taking of rights for natural resource conservation: a discussion about compensation. Oryx.

Williams, Michael. 2003. Deforesting the Earth: From Prehistory to Global Crisis. University of Chicago Press, Chicago, IL, USA.
Williams, Nancy and G. Baines (Eds). 1988. Traditional Ecological Knowledge: Wisdom for a Sustainable Development. Australian National University, Canberra, Australia.

Wilshusen, Peter R., S.R. Brechin, C.L. Fortwangler and P.C. West. 2002. Reinventing a Square Wheel: Critique of a Resurgent "Protection Paradigm" in International Biodiversity Conservation. Society and Natural Resources 15:17-40.

Wily, L. 2003. Emerging Legal Opportunities for Community Ownership of Valuable Resources. Presentation at the $\mathrm{V}^{\text {th }}$ World Parks Congress, Durban.

Woodford, M.H. 1982. Tuberculosis in wildlife in the Ruwenzori National Park, Uganda (Part I). Trop. Anim. Health Prod. 14:81-88.

Woodford, M.H., T.M. Butynski and W.B. Karesh. 2002. Habituating the great apes: the disease risks. Oryx 36:153-160.

World Bank. 2001. World Development Report 2000/2001: Attacking Poverty. The World Bank, Washington DC, USA.

World Bank. 2002. World Development Indicators 2002. World Bank, Washington DC, USA.

World Commission on Protected Areas. 1999. WCPA Position Statement on Mining and Protected Areas. Paper endorsed by the IUCN Council, April.

World Health Organization (WHO). 2002. Global Tuberculosis Control: WHO Report, 2002. World Health Organization, Geneva, Switzerland.

World Heritage Centre. 1999. Operational Guidelines for the Implementation of the World Heritage Convention. World Heritage Centre, Paris, France.

World Heritage Centre. 2001. UNESCO Thematic Expert Meeting on Asia-Pacific Sacred Mountains. World Heritage Centre, Paris, France. 
World Parks Congress Outputs. 2003. $V^{\text {hh }}$ World Parks Congress Emerging Issues. Accessed March 2004 at www.iucn.org/themes/wcpa/ wpc2003

WWF. 2004. How Effective are Protected Areas? A Preliminary Analysis of Forest Protected Areas. Report prepared for the Seventh Conference of Parties of the Convention on Biological Diversity. WWF, Gland, Switzerland.
Yunis, E. 2003. Sustainable Tourism: World Trends and Challenges Ahead. In: Buckley, R., C. Pickering and D. Weaver (Eds). Nature-based Tourism, Environment and Land Management. CABI Press.

Zimmerman, B., C.A. Peres, J.R. Malcolm and T. Turner. 2001. Conservation and development alliances with the Kayapó of south-eastern Amazonia, a tropical forest indigenous people. Environmental Conservation 28:10-22. 


\section{Front Cover Photographs}

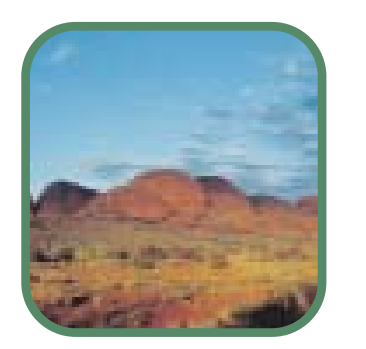

Olga group of rock domes in Uluru National Park, Australia.

IUCN Photo Library @ Jim Thorsell

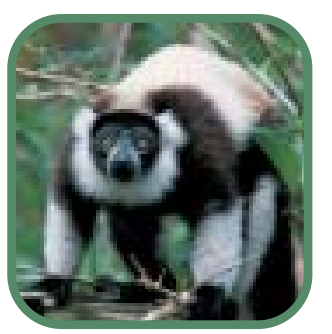

The endangered black-and-white ruffed lemur (Varecia variegata) is found in the rainforest of eastern Madagascar, and is threatened by habitat destruction and hunting. Recent information indicated that it might be divided into three distinct subspecies. Madagascar and Indian Ocean Islands Hotspot.

c) Russell A. Mittermeier/Conservation International

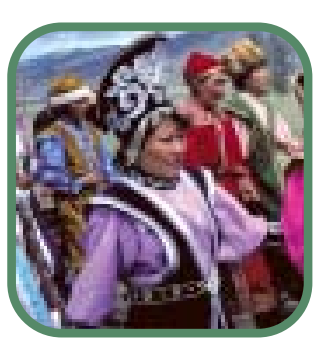

Men and women in Golden Mountains of Altai, Mongolia. IUCN Photo Library @ Jim Thorsell

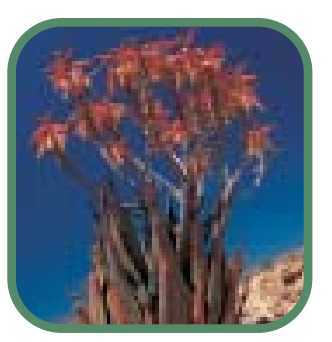

Aloes are very diverse in the Succulent Karoo, and are often very restricted in range by small differences in altitude and soil condition. South Africa's Succulent Karoo Hotspot.

(c) Haroldo Castro/Conservation International

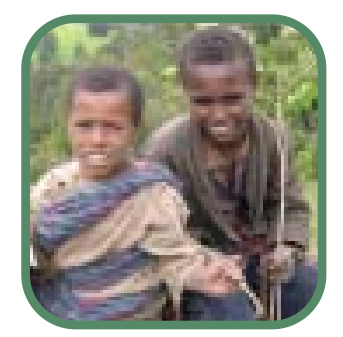

Mosaic of natural forest and agricultural land in Ethiopia.

The future of this landscape rests with a new generation.

(c) Thomas O. McShane 


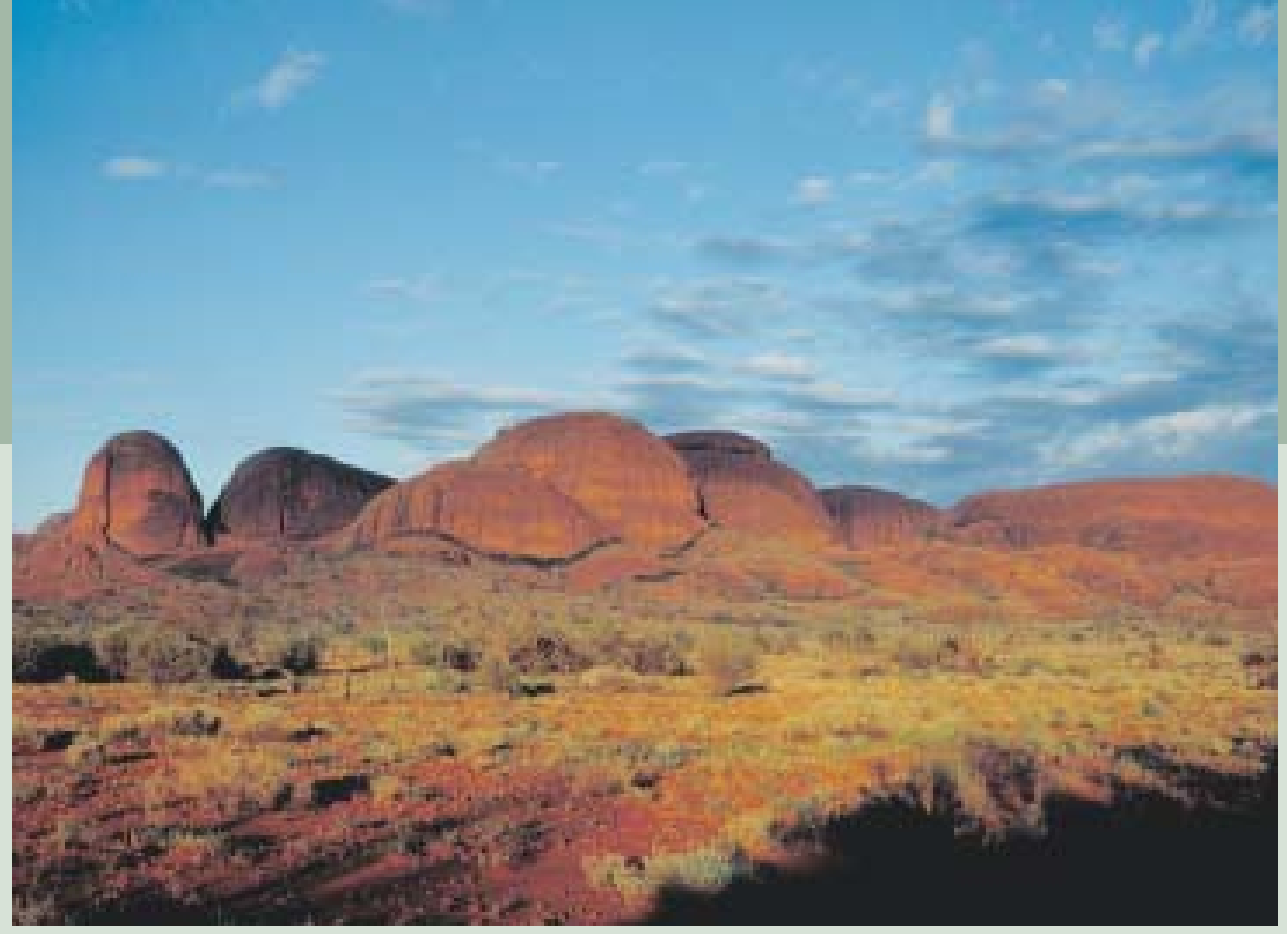

\section{IUCN - The World Conservation Union}

Founded in 1948, The World Conservation Union brings together States, government agencies and a diverse range of non-governmental organizations in a unique world partnership: over 1000 members in all, spread across some 150 countries.

As a Union, IUCN seeks to influence, encourage and assist societies throughout the world to conserve the integrity and diversity of nature and to ensure that any use of natural resources is equitable and ecologically sustainable.

The World Conservation Union builds on the strengths of its members, networks and partners to enhance their capacity and to support global alliances to safeguard natural resources at local, regional and global levels.

\section{Chief Scientist's Office}

IUCN - The World Conservation Union

Rue Mauverney 28

$\mathrm{CH}-1196$ Gland

Switzerland

Tel: $\quad+41229990000$

Fax: +41229990002

www.iucn.org

\section{IUCN Publications Services Unit}

219c Huntingdon Road

Cambridge CB3 ODL, UK

Tel: +44 1223277894

Fax: +44 1223277175

www.iucn.org/bookstore 